
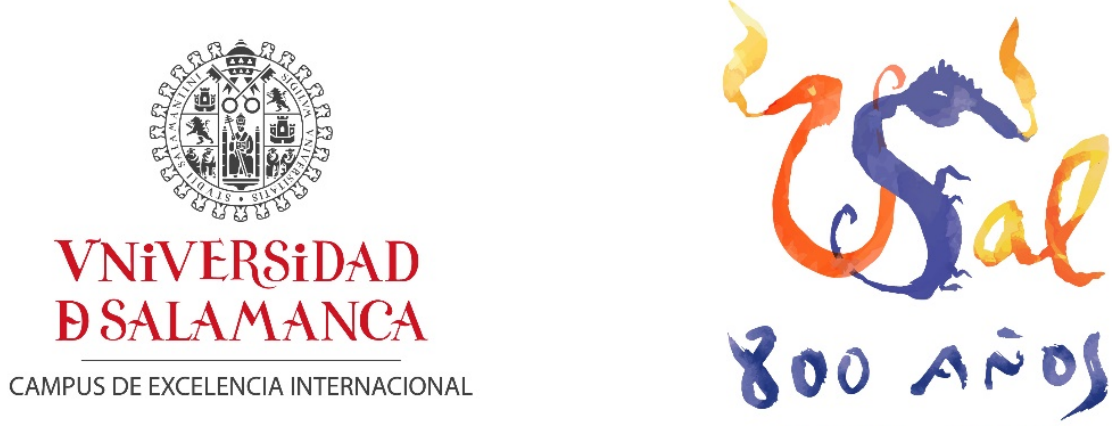

$1218 \sim 2018$

\author{
ESCUELA DE DOCTORADO 'STUDII SALAMANTINI' \\ PROGRAMA DE DOCTORADO \\ ESTADO DE DERECHO Y GOBERNANZA GLOBAL
}

\author{
T E S I S D O C T O R A L
}

\title{
Transparencia e integridad en grandes eventos deportivos \\ Lecciones aprendidas en Río 2016
}

\section{CLAUDIO DE CASTRO PANOEIRO}

\section{Director:}

PEDRO T. NEVADO-BATALLA MORENO

Prof. Titular de Derecho Administrativo

Universidad de Salamanca 


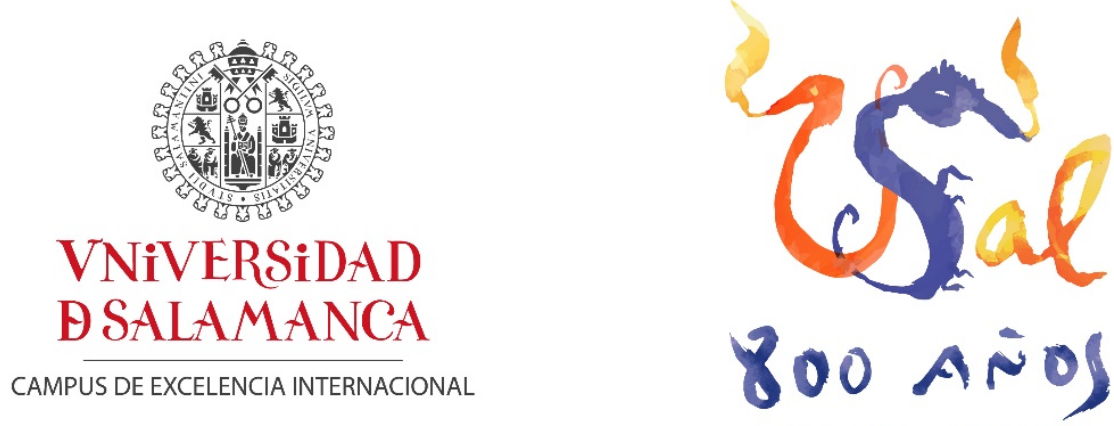

$1218 \sim 2018$

\author{
ESCUELA DE DOCTORADO 'STUDII SALAMANTINI' \\ PROGRAMA DE DOCTORADO \\ ESTADO DE DERECHO Y GOBERNANZA GLOBAL
}

\author{
T E S I S D OCTORA L
}

\title{
Transparencia e integridad en grandes eventos deportivos \\ Lecciones aprendidas en Río 2016
}

\section{CLAUDIO DE CASTRO PANOEIRO}

Tesis Doctoral presentada para obtener el grado de Doctor por la Universidad de Salamanca (España), dirigida por PEDRo T. Nevado-Batalla Moreno (Prof. Titular de Derecho Administrativo Universidad de Salamanca). 



\section{DEDICATORIA}

Inicialmente, ofrezco esta tesis doctoral a Dios, razón y principio de toda creación, quien me ha bendecido con innumerables oportunidades a lo largo de mi vida personal y profesional, más allá de lo que podría imaginar o creer en su momento, las cuales, además de hacerme más grande como persona, me permiten comprender cada vez más el sentido de la existencia y la belleza de cada una de sus criaturas. Asimismo, dedico esta investigación a la Santísima Virgen María, cuyo amor maternal me ha servido de apoyo y me ha dado el sostén necesario para superar las dificultades enfrentadas a lo largo de esta jornada.

También dedico el escrito a mis padres, Elson y Celina, ejemplos vivos de amor incondicional, que no han medido esfuerzos para que yo pudiera seguir estudiando, aunque las circunstancias de la vida hubiesen recomendado todo lo contrario.

Bajo esa misma premisa, lo dedico también a María Lucia y a Cleide Queiroz, quienes trabajaron en su momento y en silencio para que todo esto fuera posible, prestándome parte considerable de su precioso tiempo para que yo pudiera convertirme en lo que soy.

Asimismo, lo ofrezco a mi familia, amigos y compañeros de trabajo quienes han creído en este proyecto, en especial a todos aquellos que un día actuaron y actúan como miembros del Grupo Permanente de Actuación Proactiva de la Abogacía-General de la Unión de Brasil, dedicándose a la defensa de la probidad administrativa y del patrimonio público.

Finalmente, dedico este esfuerzo a Jeane Esteves, mi amada esposa y compañera, quien siempre ha estado a mi lado durante esta odisea española, compartiendo momentos de alegría y tristeza, satisfacción y ansiedad, preocupaciones y regocijo, bien sea en cuanto al objeto de la tesis doctoral, bien sea en cuanto a la educación de nuestro Luca, un niño que llegó a Salamanca con tan solo dos años y que, ahora mismo, regresa a Brasil dos años mayor, tras conquistar grandes e inolvidables conocimientos en estas tierras.

Seguramente, no solo Luca se ha transformado durante este periodo al objeto de incorporar nuevos e importantes conocimientos a su pequeña existencia. También nosotros hemos cambiado y crecido como personas y como pareja mientras que vivimos 
en España, en tanto que, juntos, conquistamos la madurez necesaria para enfrentarnos a nuevos desafíos. Independientemente del lugar en donde ellos pasen, ojalá tú estés a mi lado para que, juntos, podamos superarlos y, así como en Salamanca, escribir otro dichoso capítulo de nuestra historia.

Como ya lo he dicho tantas veces a lo largo de estos años, desde que nos convertimos en una familia, ya no conjugamos los verbos en la primera persona del singular (yo), sino en la primera persona del plural (nosotros), con lo cual este no es "mi doctorado", sino "nuestro doctorado", exactamente porque así lo siento en mi corazón.

Por último, dedico esta investigación a mi amado Luca, hijo querido quien ha estado a mi lado durante toda esta jornada, brindándome en todo momento con su sonrisa y fantásticas historias de toros, dinosaurios y monstros que hicieron con que me olvidara de las preocupaciones de cada día.

Es cierto que, hoy por hoy, con tan solo cuatro años, no puedes comprender el verdadero significado de estas palabras. Sin embargo, cuando seas mayor, seguramente podrás entender que su presencia entre nosotros va más allá de meros juegos entre padre e hijo, sirviendo, en realidad, como verdadero alimento para que yo pudiera seguir adelante día tras día, superando las dificultades debido al amor que nos une a nosotros desde que estuviste en el vientre de mamá.

\section{AGRADECIMIENTOS}

Ineludiblemente, una tesis doctoral no nace de la nada, sino a partir de las inquietudes intelectuales de alguien que, movido por sus propias dudas, busca encontrar respuestas para los problemas con que se enfrenta a diario en el normal ejercicio de su labor y que, sinceramente, espera responderlos a través de una investigación seria y responsable en torno al tema objeto de estudio.

En este sentido, la tesis doctoral, más allá de constituir el resultado de la investigación, también representa un instrumento destinado a proponer cambios para la sociedad, lo que únicamente es posible tras un largo periodo de investigación y un análisis crítico de los asuntos objeto de estudio. 
Seguramente, no es una tarea sencilla, toda vez que, más allá del objeto de la investigación en sí misma, para que uno pueda cumplir con eses objetivos, debe estar consciente de que, primero, necesita renunciar al convivio con la familia, los amigos y a los compañeros de jornada, además de las comodidades con que suele disfrutar habitualmente, en especial cuando los estudios realizados a este título asan a miles de kilómetros de su país de origen, como sucedió con nosotros y sucede a diario con varios de los alumnos del programa de doctorado en Estado de derecho y gobernanza global de la universidad de salamanca.

Aunque estos es un hecho indiscutible y que la participación en el doctorado resulta de una decisión personal del investigador, también es verdad que a lo largo de toda la jornada siempre contamos con ayuda de personas que, directa o indirectamente, acaban con contribuir para que el producto de la investigación, la tesis doctoral, llegue a su final. En este sentido, agradezco a todas las personas que de alguna manera contribuyeron para que ello pasara en su momento como los profesores y funcionarios de la universidad de salamanca, además de los doctorandos que conocimos durante este largo periodo de investigación y que, de alguna manera, fueron participes de esta aventura.

A este propósito, me refiero, inicialmente, al profesor Pedro Tomás Nevado Batalla Moreno, director de la tesis doctoral, quien siempre tuvo la paciencia necesaria para convivir con mis dificultades a lo largo de la investigación y siempre buscó animarme para que pudiera conquistar mis objetivos. En este sentido, agradezco su permanente disposición en ayudarme a lo largo de esta etapa y por contribuir de manera valiosa para que este esfuerzo pudiera alcanzar un resultado satisfactorio.

Asimismo, agradezco al profesor Nicolás Rodríguez-García, ejemplo de profesional dedicado a la lucha contra la corrupción y cuyas virtudes ya lo han reconocido diversas instituciones nacionales e internacionales, más allá de los miles de alumnos que frecuentaron los programas de máster y doctorado de la Universidad de Salamanca. De mi parte, avanzo aún más en el reconocimiento de estas virtudes para destacar una de las calidades de dicho profesor que, a lo mejor, pocos se han dado cuenta a lo largo de su trayectoria académica. Me refiero, en este caso, a las condiciones materiales que aludido profesor me ha facilitado para el normal desarrollo de esta tesis doctoral. 
Considerando mi condición de persona con discapacidad, el profesor Nicolás me ha facilitado un despacho exclusivo en el centro de gobernanza global de la Universidad de Salamanca, un verdadero oasis académico, donde utilicé cómodamente las múltiples aplicaciones de voz que facilitan la interacción entre personas invidentes como yo y el ordenador, el internet y los libros electrónicos utilizados a lo largo de la investigación

Agradezco, además, a las editoras que se ocuparon de producir libros electrónicos entre sus publicaciones, los cuales acaban permitiendo a las personas invidentes acceder a su contenido directamente, sin las limitaciones de otros tiempos. Hace poco más de veinte años, cuando aún frecuentaba la carrera de derecho en la Universidad Federal de Rio de Janeiro, no había libros con estas características que pudieran ser utilizados por personas con discapacidad. La falta de obras de este tipo dificultaba en mucho el estudio de las ciencias jurídicas, demandando de cada uno un esfuerzo añadido para alcanzar el conocimiento. Debido a las nuevas tecnologías todo esto ha pasado y, aunque no todas las obras estén publicadas en estas plataformas digitales, seguramente ha habido un incremento de la producción académica en ese sentido, con lo cual me gustaría agradecerlos cambios realizados en esta materia.

Desde otra perspectiva, también agradezco al André Luiz de Almeida Mendonça, actual abogado general de la unión, quien igualmente ha jugado un papel fundamental en la consecución de este objetivo. Pese a mi condición de persona con discapacidad, André siempre mi ha animado a seguir adelante y a superar nuevos desafíos, bien sea en Brasil, bien sea en España, pasando por encima de prejuicios o resistencias que, infelizmente, aún existen en nuestro entorno.

Asimismo, ha revelado a Brasil y al mundo la política institucional que vigora en nuestra Abogacía-General de la Unión en cuanto al tema de la inclusión de las personas con discapacidad. Independientemente de la unidad donde desarrollamos nuestras actividades, todos somos considerados verdaderos protagonistas y no meros espectadores en la construcción de un Brasil mejor, en tanto que somos llamados a manifestarnos respecto a las principales decisiones de nuestra institución.

En el momento en que esta tesis doctoral llega a su final, también considero relevante señalar las virtudes de nuestra institución en esta materia y, a través de André, 
extender a todos mis compañeros de la Abogacía-General de la Unión de Brasil mis agradecimientos por colaborar para que pudiera cumplir con esta tarea.

Asimismo, agradezco a Cristina Fernández González, Magaly Lanze, Estela Willeman, Lourdes y Clara Brum, quienes dedicaron parte de su tiempo para subsanar los errores cometidos a lo largo de esta investigación, bien sea organizándome las citaciones bibliográficas, o reparando errores cometidos durante la escritura de la tesis, con lo cual viabilizaron su presentación a la Escuela de Doctorado de la Universidad de Salamanca.

Agradezco, además, a la propia Universidad de Salamanca, quien me acogió amablemente durante estuve vinculados a esta institución desde septiembre del 2013, cuando llegué a estas tierras españolas para participar del programa de máster en derecho.

En este sentido, agradezco a los funcionarios de la biblioteca Francisco de Vitoria por su disposición en ayudarme durante la elaboración de este trabajo, facilitándome libros y recursos tecnológicos que han sido de gran utilidad en mi labor investigadora. También agradezco a los funcionarios de la cafetería de la facultad de derecho, quienes me brindaron con su amabilidad mientras que participé de este programa de investigación.

Finalmente, agradezco especialmente a la Abogacía General de la Unión de Brasil, institución que ha comprendido la necesidad de capacitación del Abogado Público brasileño y que ha creado las condiciones para que este proyecto se haga realidad. 



\section{INDICE}

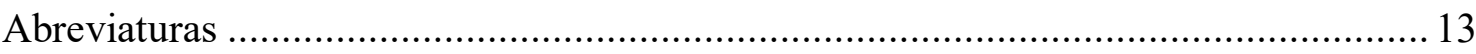

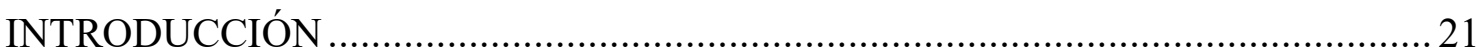

CAPITULO I - MARCO TEÓRICO Y NORMATIVO DE LA TRANSPARENCIA GUBERNAMENTAL EN LA REGENERACIÓN DE LA DEMOCRACIA Y EN LA

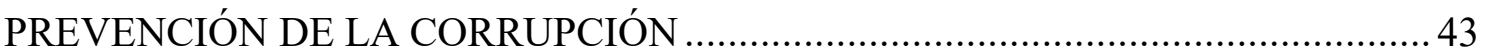

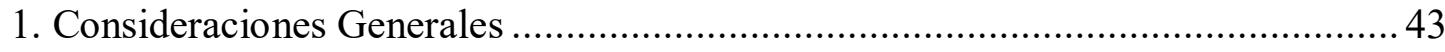

1.1. La producción de los juegos olímpicos como ambiente favorable a los actos

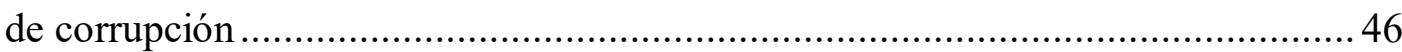

1.2. Los antecedentes de la restauración de los juegos olímpicos modernos ......60 60

1.3. Los antecedentes de la transparencia gubernamental................................. 80

1.4. La transparencia gubernamental como estrategia para la regeneración de la democracia y la prevención de la corrupción ...................................................... 91

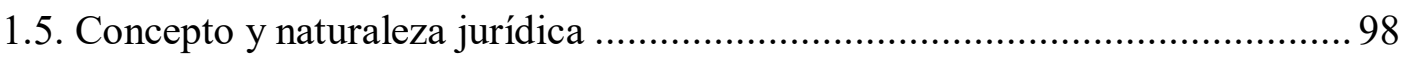

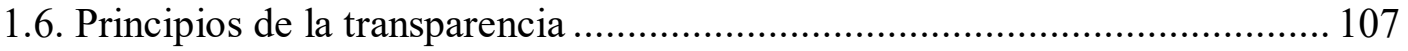

1.7. Los límites a la transparencia gubernamental.......................................... 142

1.8. Órganos de control y responsabilidad de los funcionarios ........................... 152

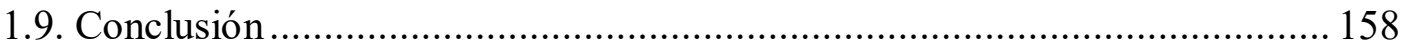

CAPÍTULO II - LAS DEBILIDADES DEL SISTEMA BRASILEÑO DE TRANSPARENCIA GUBERNAMENTAL PARA PREVENIR LA CORRUPCION ASOCIADA A LOS JUEGOS OLÍMPICOS RIO 2016 ............................................... 169

2. CONSIDERACIONES GENERALES........................................................... 169

2.1. Los pactos perfeccionados para que Rio fuera elegida ciudad anfitriona de las olimpiadas de 2016

2.2. El origen de los recursos que financiaron la elección de rio como ciudad olímpica y el problema de las agendas de los altos directivos de la administración pública

2.3. La falta de transparencia en cuanto a las exigencias técnicas constantes de los pliegos concernientes a las obras de preparación de los juegos olímpicos rio 2016

2.4. Los contratos ficticios como instrumentos a servicio de la oscuridad y la corrupción asociada a los juegos olímpicos Rio 2016

2.5. Oscuridad y sigilo en la construcción de equipamientos olímpicos. ............. 252

2.6. Conclusión 


\section{CAPÍTULO III - RUMBO A LA CONSTRUCCIÓN DE UNA CULTURA DE}

TRANSPARENCIA EN LA ADMINISTRACIÓN PÚBLICA ................................... 263

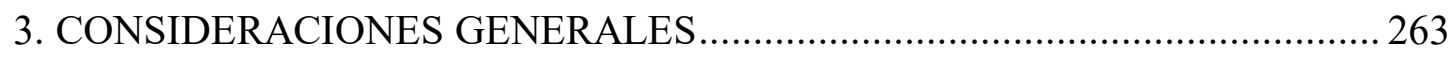

3.1. La publicidad de las agendas de los altos directivos y funcionarios de la

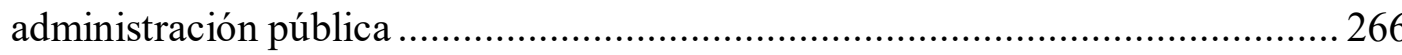

3.2. La transparencia de las exigencias técnicas y demás informes concernientes a la contratación pública

3.3. La publicidad de los contratos firmados entre los contratistas del sector público y terceros ajenos a la administración

3.4. La valorización de la labor de las mesas (o comisiones) responsables de

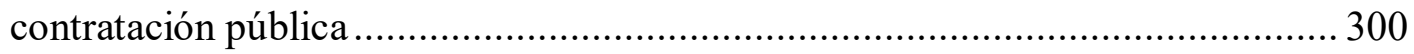

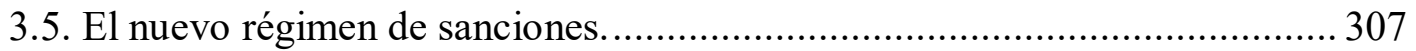

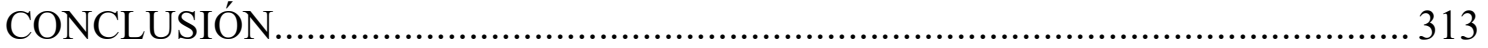

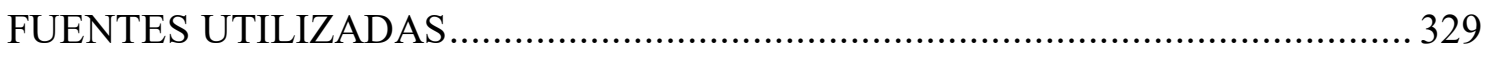

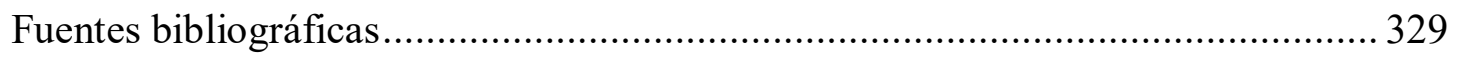

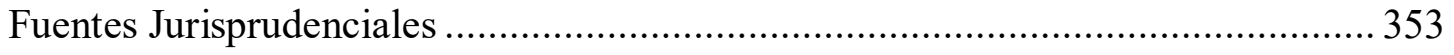

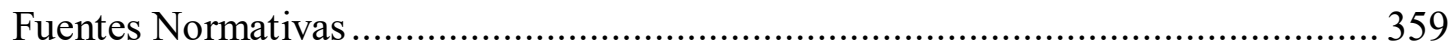




\section{Abreviaturas}

ADB Banco Asiático de Desarrollo

AgR - Agravo

AGRG - Agravo Regimental

AI - Agravo de Instrumento

BM Banco Mundial

CNUCCConvención de las Naciones Unidas contra la Corrupción

COB - Comité Olímpico Brasileiro

COE Council of Europe

COI - Comité Olímpico Internacional

COJO - Comité Organizador dos Jogos Olímpcos

CO-Rio - Comité Organizador dos Jogos Olímpicos do Rio

CPLT Consejo para la Transparencia

DUDH Declaración Universal de los Derechos del Hombre y del Ciudadano

EREsp - Embargos em Recurso Especial

EU European Union

FMI y del Fondo Monetario Internacional

MS - Mandado de Segurança

OAS Organization of American States

OCDE Organización para la Cooperación y el Desarrollo Económico

OEA Organización de los Estados Americanos

OLAF Oficina Europea de Lucha contra el Fraude

OSCE Organización para la Seguridad y la Cooperación en Europa

RAE Real Academia Española

REsp - Recurso Especial

RMS - Recurso em Mandado de Segurança

STC -n Sentencia

STF - Supremo Tribunal Federal

STJ Superior Tribunal de Justiça

TEDH Tribunal Europeo de Derechos Humanos

TI Transparencia Internacional 



\section{Resumen}

La transparencia gubernamental es un poderoso instrumento de regeneración democrática y prevención de la corrupción. Con ella, da a los ciudadanos la posibilidad de participar en la toma de decisiones y permite el control efectivo de las acciones del Estado, verificando su compatibilidad con la ley y con los principios jurídicos. La transparencia abarca además a todos los responsables de la gestión pública, en particular a los altos cargos de la Administración, quienes están obligados a divulgar todos sus actos y decisiones para conocimiento de los ciudadanos. En este sentido, la transparencia impone la publicación de informaciones relativas a la agenda profesional de compromisos de estas personas, demanda una efectiva claridad y exactitud de las informaciones oficiales y un acompañamiento eficaz de las actuaciones de los contratistas que se relacionan con la Administración Pública. A pesar de la relevancia de esas materias, la ley de transparencia de Brasil no obliga a que los altos cargos del Estado publiquen sus agendas profesionales mientras que desempeñan como titulares de cargo, empleo o mandato en cualquier órgano o entidad pública. Tampoco considera a los adjudicatarios del sector público sujetos obligados al deber de transparencia, pese a la naturaleza pública de las actividades que desarrollan o a la naturaleza oficial de los recursos invertidos. Esa lamentable omisión acaba creando ambientes de oscuridad en determinados sectores del poder público que favorecen la comisión de actos de corrupción, especialmente durante la preparación de grandes eventos deportivos como los Juegos Olímpicos. Desde esa perspectiva, es fundamental cambiar la ley de transparencia de Brasil, con objetivo de incorporar al ordenamiento jurídico de este país la obligatoriedad de divulgar la agenda de los altos cargos del Estado en todas esferas de gobierno, aparte de incorporar a los adjudicatarios del sector público como sujetos obligados a la transparencia activa.

\section{Palabras clave:}

Transparencia gubernamental. Prevención de la corrupción. Juegos olímpicos Rio 2016. Debilidades del régimen legal en vigor. Necesidad de cambios. 



\section{Resumo}

A transparência governamental é um poderoso instrumento de regeneração democrática e prevenção da corrupção. Ela possibilita a participação dos cidadãos na toma de decisões e permite o controle efetivo das ações do Estado, verificando a compatibilidade de suas condutas com a lei e com os princípios jurídicos. Além disso, a transparência abarca todos os responsáveis pela gestão pública, em particular os titulares de altos cargos, empregos ou mandatos na estrutura do Estado, os quais estão obrigados a divulgar todos os seus atos e decisões para conhecimento dos cidadãos. Neste sentido, a transparência impõe a publicação de informações relativas à agenda profissional de compromissos destas pessoas, demanda uma efetiva claridade e exatidão das informações oficiais e um acompanhamento eficaz das atuações dos licitantes que se relacionam com a Administração Pública. Apesar da relevância dessas matérias, a lei de transparência do Brasil não obriga a que os titulares de altos cargos, empregos o mandatos publiquem as suas agendas profissionais enquanto atuem como altos dirigentes de qualquer órgão ou entidade pública. Essa lamentável omissão acaba por criar um ambiente de obscuridade em determinados setores do poder público, o que favorece o cometimento de atos de corrupção, especialmente durante a preparação de grandes eventos esportivos como os Jogos Olímpicos. Desde essa perspectiva, é fundamental alterar a lei de transparência do Brasil, com objetivo de incorporar al ordenamento jurídico deste país a obrigatoriedade de divulgar a agenda dos titulares de altos cargos, empregos ou mandatos em qualquer órgão ou entidade do poder público, além de incorporar os adjudicatários de contratos com o setor público como sujeitos obrigados à transparência ativa.

\section{Palavras chave:}

Transparência governamental. Prevenção da corrupção. Jogos olímpicos Rio 2016. Debilidades do regime legal em vigor. Necessidade de alterações. 



\begin{abstract}
Governmental transparency is a powerful instrument of democratic regeneration and corruption prevention. It enables the citizen's participation in decision-making and allows effective control of state actions, verifying their compatibility with law and the legal principles. Transparency encompasses all those in charge of public management, specially the senior management positions, who are obliged to disclose all their actions and decisions, in order to inform the citizens. Therefore, transparency impels the publication of information about professional commitments agenda of these persons, demands an effective clarity and accuracy official information and effective monitoring of the actions of contractors who related to the Public Administration. In spite of the relevance of these subjects, Brazil's law of transparency does not demands that the senior management positions publish their professional agendas while they hold as office holders or employee in any organism or public entity. It also does not consider the public sector contractors to be obliged to disseminate their information despite the public nature of the activities that develop or the official nature of the inverted resources. This unfortunate omission ends up creating darkness environments in certain sectors of the Public Administration that facilitates the reporting of acts of corruption, especially during the preparation of major sporting events such as the Olympic Games. From this perspective, it is essential to change the transparency law of Brazil to incorporate the professional commitments agenda of the senior management positions in Public Administration among the matters that must be disclosed for society knowledge, apart from incorporating the public sector contractors as subjects obliged to active transparency.
\end{abstract}

\title{
Key words:
}

Governmental transparency. Corruption prevention. Olympic games Rio 2016. Weaknesses of current legal regime. Need for change. 



\section{INTRODUCCIÓN}

La corrupción como fenómeno social es una enfermedad muy antigua que aflige a todos los países desde hace muchos años, ${ }^{1}$ desde la antigüedad hasta nuestros días, hallándose presente en todas partes y en todos periodos históricos. ${ }^{2}$

No es un acto exclusivo de países subdesarrollados o de personas sin estudios, sino que abarca a todos indistintamente, ${ }^{3}$ ricos y pobres, judíos y cristianos, católicos y protestantes, a menudo manifestándose de diferentes e ingeniosas maneras, ${ }^{4}$ con lo cual es difícil establecer un concepto de corrupción, así como un catálogo cerrado de todos los actos y prácticas corruptas que cualquiera podrá realizar en el ejercicio de sus tareas.

Esta es una dificultad que Bustos Gisbert ${ }^{5}$ atribuye al hecho de que la propia idea sobre este fenómeno no es precisa en la historia, ya que hay conductas que son consideradas corruptas en determinados lugares y no lo son en otros, al igual que hay comportamientos que son reputados lícitos en cierto momento y dejan de serlo en otro, desde ahí se verifica la gran dificultad que tienen los expertos para establecer un concepto universal e indiscutible de este fenómeno.

La identificación de ese aspecto cambiante alrededor de la definición de corrupción ya lo reconoció Fernández Ríos, ${ }^{6}$ quien señala que cada contexto sociocultural puede establecer unos criterios específicos para decir lo que puede o no considerarse como corrupción y que, además, pueden no vigorar en otros sitios. ${ }^{7}$

Así es que, hasta hace poco tiempo, el soborno por empresas europeas a gobiernos extranjeros era considerado como gasto deducible para fines tributarios en el país de

\footnotetext{
${ }^{1}$ GIL VILLA, Fernando. La Cultura de la Corrupción. Madrid: Maia Ediciones, 2008. p. 19.

${ }^{2}$ VIANA, Ruth Araújo. Poder Discricionário e Atos de Corrupção: uma análise de casos concretos. In AZAMBUJA, E.; BALLAÁN JUNIOR, O.; OLIVEIRA E SILVA, V.; MIZUNO, J. H. Combate à Corrupção na Visão do Ministério Público. Belo Horizonte: 2018, p. 124-125.
}

${ }^{3}$ GIL VILLA, op. cit.., p. 61-72.

${ }^{4}$ GARCIA, Emerson. A Cultura da Sociedade Enquanto Fator de Contenção ou de Estímulo à Corrupção. In AZAMBUJA, E.; BALLAÁN JUNIOR, O.; OLIVEIRA E SILVA, V.; MIZUNO, J. H. Combate à Corrupção na Visão do Ministério Público. Belo Horizonte: 2018, p. 50.

${ }^{5}$ BUSTOS GISBERT, Rafael, Corrupción de los gobernantes, responsabilidad política y control parlamentario, en Teoría y realidad constitucional, n. 19, 2007, p. 135-161. ISSN 1139-5583.

${ }^{6}$ RÍOS, Luis Fernández. Psicología de la corrupción y de los corruptos. Santiago de Compostela: Grupo Editorial Universitario, 1999, p. 21.

${ }^{7}$ Ibidem. 
origen de la empresa, ${ }^{8}$ no siendo sancionado como corrupción, aunque desde la perspectiva del país del funcionario corrompido sí que se trataba como un acto de esa naturaleza.

Con todo, la dificultad no resulta tan solo de cuestiones de naturaleza temporal o geográfica, sino que también deriva de la propia complejidad del fenómeno y de la habilidad intelectual del agente que practica dichos actos. Este aspecto se puso de manifiesto en una entrevista publicada en los periódicos El País y The New York Times el 16 de noviembre de 2006, cuando un político corrupto italiano declaró a estos medios de comunicación que: ${ }^{9}$

"normalmente la gente cree que la corrupción es sólo una cuestión de dinero que pasa de un bolsillo a otro, una cosa fácil... En la práctica no es así. Es realmente difícil explicar cómo funciona el mundo de la corrupción. Se necesita mucha paciencia para comprender sus diferentes (y casi siempre complejos) mecanismos. No es una cadena de robos: existen reglas y relaciones, convenciones fijas; todo un lenguaje de matices y entonaciones que revisten toda la solemnidad de un contrato escrito."

Así la duda alrededor del concepto de corrupción todavía persiste hasta nuestros días. Desde una perspectiva semántica, el término "corrupción", proviene del latín rumpere, que significa romper, dividir, quebrar, violar, anular; que a su vez se deriva de corrumpere, cuyo significado es alteración, desunión, descomposición. Corrumpere, entonces, debería significar: "romper con", "romper en unión de", pero en realidad quiere decir "echar a perder, pudrir" 10.

Este es un concepto de naturaleza gramatical, pero que refleja con fidelidad el sentimiento del hombre de a pie sobre lo que se entiende por corrupción, una clase de actos inmorales cuyo sentido se asemeja al concepto de putrefacción. ${ }^{11}$

\footnotetext{
${ }^{8}$ LOPES SILVA, Lucilia; TORRES, Alcidio. O Combate contra a Corrupção e pela Promoção da Ética em Portugal e no Brasil. Portugal: Chiado; Bookess, 2013, p. 54.

${ }^{9}$ GIL VILLA, Fernando. La Cultura de la Corrupción. Madrid: Maia Ediciones 2008, p. 61-62.

${ }^{10} \mathrm{El}$ diccionario de la Real Academia Española, define a la corrupción como la "acción y efecto de corromper o corromperse. Alteración, soborno o vicio en las cosas materiales". Diccionario de la lengua española. Disponible en: http://www.rae.es/recursos/diccionarios/drae. Acceso en: 8 mar. 2014.

${ }^{11}$ ROSE-ACKERMAN, Susan, "Economía política de las raíces de la corrupción: investigación y políticas públicas". En SANDOVAL, Irma Eréndira (org.). Corrupción y transparencia: debatiendo las fronteras
} 
Otro término que también refleja el sentimiento del hombre de a pie en cuanto a la definición de lo que debe entenderse por corrupción es la palabra "robo", entendida en este caso como toda sustracción patrimonial indebida llevada a cabo por una persona deshonesta e inescrupulosa. Como ya ha observado Gil Villa: ${ }^{12}$

\begin{abstract}
"Los ciudadanos entrevistados que han sido objeto de extorsión por funcionarios públicos dicen sentirse "robados". En efecto, el robo se nos aparece como la figura general con la que el hombre de la calle asocia la corrupción, robo también en su acepción vulgar, no afinada jurídicamente, porque no distingue entre las distintas categorías que se dan dentro de él. Lo único que se deduce al respecto es la identificación del acto de corrupción con un acto de sustracción indebida y en general sin violencia, ni contra las personas ni contra las cosas."
\end{abstract}

Ese acercamiento entre los términos "corrupción" y "robo" se puso de manifiesto en España el 2 de agosto de 2006, fecha en la que el diario La Vanguardia creó en internet un foro titulado: "Isabel Pantoja ante la operación Malaya", con el objetivo de medir las reacciones de los ciudadanos ante casos de corrupción ocurridos en el país.

Dos meses después de inaugurarse dicho espacio virtual, había 172 comentarios publicados por los lectores, siendo las observaciones más frecuentes las siguientes: ${ }^{13}$ "Madrid (robo), Marbella (robo), Valencia (robo que te robo), otros que intuimos, otros que sabemos y los que vendrán. La corrupción está de moda como la pasarela Cibeles".

El acercamiento de los términos "corrupción", "putrefacción" y "robo" no satisface a los expertos en general a la hora de definir a la corrupción. Preocupados con las consecuencias que suelen advenir de la definición de un fenómeno tan grave como el que

\footnotetext{
entre estado, mercado $\mathbf{y}$ sociedad. [S.1.]: Siglo XXI, 2009. Disponible en: http://books.google.es/books?id=gW7hUGWttzAC\&pg=PA12\&lpg=PA12\&dq=\%22economia + politica + $\mathrm{de}+$ las + raices + de + la + corrupcion $\% 22+$ susan\&source=bl\&ots=hZpOA5t_DG\&sig=Be30VEy5ePujB_Y7e JI2S06n YA\&hl=pt-

BR\&sa $=$ X\&ei=QLiNU7_uGqX00gXL5YGQDw\&ved=0CF8Q6AEwBg\#v=onepage\&q=\%22economia $\%$ 20politica $\% 20 \mathrm{de} \% 201 \mathrm{as} \% 20$ raices $\% 20 \mathrm{de} \% 201 \mathrm{a} \% 20$ corrupcion $\% 22 \% 20$ susan $\& \mathrm{f}=$ false. Acceso en: 3 jun. 2014.

${ }^{12}$ GIL VILLA, Fernando. La Cultura de la Corrupción. Madrid: Maia Ediciones, 2008. p. 55-59

${ }^{13}$ Ibidem.
} 
ahora se analiza, dichos estudiosos buscan un concepto más preciso que aquel contenido en el diccionario. Esta es una tarea que no es fácil en absoluto, por ahí observándose una serie de definiciones ora más amplias, ora más restringidas, dependiendo de la perspectiva específica de quienes propone el concepto. ${ }^{14}$

Aunque exista esa divergencia de carácter dogmático, todos coinciden en que la corrupción siempre se asocia a la idea de abuso de poder, desvío de finalidad, uso de potestades públicas para fines privados y despilfarro de fondos, ${ }^{15}$ conductas que, en definitiva, producen resultados desastrosos en lo político, en lo económico y en lo social. $^{16}$

Políticamente hablando, la corrupción genera pérdida de confianza en las instituciones públicas y consecuente alejamiento de los ciudadanos, ${ }^{17}$ quienes ya no se consideran representados por los altos directivos del Estado y buscan otros núcleos de poder en el tejido social. Económicamente, la corrupción impide el ingreso de recursos en las arcas públicas ${ }^{18}$ e inviabiliza la ejecución de programas y políticas a cargo del poder ejecutivo.

En el ámbito social, la enfermedad fomenta la creación de códigos paralelos de conducta que no están reglamentados en el orden jurídico, ${ }^{19}$ pero que, poco a poco, se diseminan en el tejido social, por ahí convirtiéndose en una práctica común entre los ciudadanos, quienes pasan a considerarla legítima, lo que acompaña al género humano desde hace muchos años.

Conforme enseña Zavala, ${ }^{20}$ la doctrina no está de acuerdo respecto al origen del primer acto de corrupción de la historia. Mientras que algunos sostienen que tal acto

\footnotetext{
${ }^{14}$ ARGANDOÑA, Antonio. MOREL, Ricardo. La lucha contra la corrupción. Una perspectiva empresarial | Biblioteca Virtual RS. [S.1: s.n.]. Disponible en: http://www.bibliotecavirtual.info/2012/03/lalucha-contra-la-corrupcion-una-perspectiva-empresarial/. Acceso en: 6 mar. 2014. , [S.d.] p. 8.

${ }^{15}$ FURTADO, Lucas Rocha. As Raízes da Corrupção no Brasil: Estudo de Casos e Lições para o Futuro. Belo Horizonte: Fórum, 2015, p. 27.

${ }^{16}$ GARCIA, op. cit., p. 52.

${ }^{17}$ PESCHARD, Jacqueline. Transparencia: Promesas y Desafíos (Grandes Problemas). Electrónica, Ciudad de México: El Colegio de México, 2018, L. 1016.

${ }^{18}$ GARCIA, op. cit., p. 53.

${ }^{19}$ GARCIA, op. cit., p. 39.

${ }^{20}$ ZAVALA, Juan Roberto. Revista Conocimiento 123. Disponible en: http://issuu.com/revistaconocimiento/docs/123/7. Acceso en: 8 mar. 2014, p. 5.
} 
sucedió cuando Eva ofreció a Adán el fruto del árbol del conocimiento, otros defienden que este hecho pasó en el antiguo Egipto, durante el reinado de Ramsés IX (1142-1123 a de C).

En definitiva, había en el Egipto Antiguo dos funcionarios que se dedicaban a vigilar las tumbas en los cementerios, con el objetivo de evitar que ladrones profanaran las sepulturas y sacaran de ahí los tesoros que las familias solían enterrar con los muertos. $^{21}$

Aprovechándose de su posición, uno de los funcionarios negoció con dichos ladrones un soborno a cambio del cual les permitía profanar las tumbas y sacar de ellas todo que fose de su agrado. Pero el mal uso de sus funciones no agradó a su compañero que pronto lo denunció a las autoridades egipcias, sufriendo toda suerte de persecuciones así como los profanadores. ${ }^{22}$

La corrupción también era frecuente entre los romanos. Pero ahí era cometida a menudo por los jueces, agentes públicos que estaban obligados a desarrollar sus actividades de forma gratuita, pero que, en general, cobraban por su trabajo, luego apropiándose de la cuantía recibida.

Para cohibir estos comportamientos, el legislador aprobó leyes que sancionaban con más rigor la corrupción judicial. Entre esas medidas merece la pena señalar, entre otras, la Lex Cincia, propuesta por Marcus Cíncio Alimento ${ }^{23}$ que obligaba al corrupto a restituir al interesado la cuantía que indebidamente le cobró. Si acaso el corrupto no restituía el valor cobrado de forma espontánea, el perjudicado podría utilizar una acción civil para pedir la devolución (la actio repetundarum), creada entre 123-122 A.C.

Esa norma no produjo el resultado esperado ya que los jueces continuaron cobrando indebidamente por el ejercicio de sus funciones. La conducta indebida llevó a la aprobación de la ley de las 12 tablas (lex duodecim tabularum), que sancionó con más rigor esas malas prácticas, por ahí previendo que los jueces corruptos podrían ser condenados a muerte si cobraran indebidamente por su trabajo. ${ }^{24}$

\footnotetext{
${ }^{21}$ Ibidem.

${ }^{22}$ Ibidem.

${ }^{23}$ OLIVEIRA, Edmundo. Crimes de corrupção. Rio de Janeiro: Forense, 1991, p. 21.

${ }^{24}$ COSTA JUNIOR, Paulo José Da. Comentários ao Código Penal: Parte Especial. São Paulo: Saraiva, 1988. v. 2, p. 468.
} 
La pena capital también fue utilizada entre los griegos y los hebreos. En la Grecia antigua, ${ }^{25}$ la pena de muerte alcanzaba límites extremos, habiendo casos en que la piel del juez corrupto era utilizada para cubrir la silla donde se iba a sentar su sustituto.

Así, la gravedad de la sanción funcionaba como advertencia para que el nuevo titular del cargo no procediera como su antecesor, pena de sufrir la misma punición. Entre los hebreos, la ley mosaica decía que el juez corrupto debería sufrir una pena de flagelación, luego pudiendo aplicársele la pena de muerte. ${ }^{26}$

En la Edad Media, la corrupción traspasó los límites del Estado y alcanzó a la Iglesia Católica, donde era común la venta de indulgencias, obispados y curados de todos tipos. ${ }^{27}$ Este comportamiento se sumó a otros factores de naturaleza política y económica de interés de la nobleza y de banqueros, de ahí llevando a la reforma protestante comandada por Martín Lutero. ${ }^{28}$

Con la llegada de la revolución industrial, hubo un incremento de las transacciones comerciales y el surgimiento de la burguesía. Se trataba de una nueva clase social que accedió al poder y trajo consigo la esperanza de nuevos tiempos de transparencia y honestidad en el seno de la política. Se creía que los abusos anteriores cometidos por la nobleza iban a terminar y que iba a surgir un nuevo periodo de prosperidad. Pero esto no sucedió. Las prácticas ilegales del pasado se mantuvieron y fueron registradas por escritores de la época como Émile Zola. ${ }^{29}$

A través de su conocida obra El Dinero, el escritor denunció las principales irregularidades acontecidas en Francia a fines del siglo XIX, utilizándose para ello de su famoso personaje Madame Caroline, quien dijo: "En París el dinero corría a ríos y

\footnotetext{
${ }^{25}$ "conta a História que o rei Cambises mandou esfolar vivo um juiz venal, cuja pele foi guarnecer a cadeira onde devia sentar o seu substituto". Cf. HUNGRIA, Nélson. Comentários ao Código penal (Dec.-lei n. 2.848, de 7 de dezembro de 1940). Rio de Janeiro: Forense, 1958. v. 9, p. 365.

${ }^{26}$ Biblia.com. Disponible en: http://biblia.com/. Acceso en: 6 mar. 2014. Exodus 21:12. Disponible en: http://biblia.com/bible/nvi/Éxodo 21.12?culture=es. Acceso en: 6 mar. 2014. Leviticus 20:10. Disponible en: http://biblia.com/bible/nvi/Levítico 20.10?culture=es. Acceso en: 6 mar. 2014. Deuteronomy: 21. Disponible en: http://biblia.com/bible/nvi/Deuteronomio 22.4?culture=es. Acceso en: 6 mar. 2014. Las modalidades de la pena capital según la Ley Mosaica eran muerte por la espada (Éxodo 21:12), estrangulamiento, fuego (Lev. 20), y lapidación (Deut. 21).
}

${ }^{27}$ ZAVALA, op.cit, p. 6.

${ }^{28}$ SALGADO, Max. A reforma protestante-Reforma, Tratado e o pacto cristão. [S.1.]: Rubidelfon, [S.d.], p. 6.

${ }^{29}$ LA VANGUARDIA. Historia de la corrupción. Disponible en: http://www.lavanguardia.com/estilosde-vida/20120803/54331562523/historia-de-la-corrupcion.html. Acceso en: 8 mar. 2014. 
corrompía todo, en la fiebre del juego y de la especulación. El dinero es el abono necesario para las grandes obras, aproxima a los pueblos y pacifica la tierra". ${ }^{30}$

Con la llegada del siglo XX, el planeta conoció dos guerras mundiales y el surgimiento de regímenes totalitarios como el nazismo y el comunismo, en el seno de los cuales también hubo mucha corrupción. Desafortunadamente, esa realidad también se verificó en los regímenes democráticos, como lo vigente en Inglaterra, sobre todo cuando el tema se relacionaba a sus colonias. ${ }^{31}$

En este sentido, el primer ministro inglés Sir Winston Churchill, tuvo oportunidad de decir que: "un mínimo de corrupción sirve como un lubricante benéfico para el funcionamiento de la máquina de la democracia",, 32 por ahí reflejando una cierta tolerancia con el fenómeno de la corrupción y de las malas prácticas administrativas.

A pesar de ser pronunciada en la mitad del siglo XX, la frase de Winston Churchill se mantuvo actual hasta el siglo XXI, a menudo incorporándose al discurso de muchas autoridades a lo largo del planeta, quienes consideran que la corrupción no solo es beneficiosa económicamente, sino que es atractiva social y políticamente, toda vez que permite la superación de obstáculos con mayor celeridad y menor dispendio de energía, ${ }^{33}$ aunque para ello se tenga que practicar más de un acto corrupto.

En definitiva, una mirada retrospectiva hacia la historia pone de manifiesto que la corrupción abarca no solo relaciones sencillas, por ejemplo, la entrega de dinero al funcionario para que practique o deje de practicar determinado acto, sino que también engloba relaciones complejas, tal como la entrega de una ventaja personal al funcionario, quien luego la entrega a otro funcionario, quien también la entrega a un tercero a pretexto de que practique o deje de practicar cierto acto, hasta que, al final, la ventaja regresa al primero. $^{34}$

\footnotetext{
${ }^{30}$ Ibidem.

${ }^{31}$ Ibidem.

${ }^{32}$ Ibidem.

${ }^{33}$ GARCIA, op. cit.., p. 52.

${ }^{34}$ Ibidem.
} 
Es más, la corrupción no está restringida a un exclusivo sector de la sociedad, sino que se ha esparcido por todas partes, con lo cual abarca actividades relacionadas con la adjudicación de obras públicas, con la exportación e importación de mercaderías, con las oposiciones públicas y, porque no decirlo, con los mega eventos internacionales, deportivos o no.

Los mega eventos son una realidad muy propia del género humano. ${ }^{35}$ Todos los días gobiernos, corporaciones, universidades, entidades deportivas e iglesias realizan encuentros de grandes proporciones para tratar asuntos relativos a sus actividades principales, a menudo sacando de estos seminarios y congresos conclusiones que, directa o indirectamente, podrán afectar a la vida de muchas personas. Todos estos encuentros constituyen, en realidad, una forma muy especial de compartir información, transmitir valores y dar robustez a las instituciones. ${ }^{36}$

Pese a su importancia en el escenario político, económico, deportivo y cultural, la literatura especializada no suele dedicar muchas líneas a la búsqueda de un concepto de mega evento, a lo mejor porque considera que la idea fundamental respecto a esos encuentros ya está suficientemente arraigada en el seno de la población. ${ }^{37}$ En otras palabras, todos ya saben que es un mega evento y por ello no hace falta destinar mucho tiempo a la investigación de un concepto que le aparte de otros fenómenos sociales.

A pesar de este entendimiento casi uniforme, consideramos relevante dedicarle unas pocas líneas a la indagación del concepto de mega evento deportivo, sobre todo para diferenciarlo de otros encuentros que no constituyen objeto de este estudio, como la realización de unas bodas reales, una reunión de jefes de Estado, un fórum económico internacional, el carnaval, las ferias internacionales y las grandes fiestas religiosas.

En este cometido, registramos que la expresión "mega evento" se constituye en dos partes, el adjetivo "mega" y el sustantivo "evento", las cuales unidas traducen la idea de un gran acontecimiento, sobre todo relacionado con el área del entretenimiento, que involucra grandes medios de producción e interesa a un considerable número de personas. Dicho de otra manera, se tratan más bien de grandes encuentros que reúnen a personas de

\footnotetext{
${ }^{35}$ CIERVA, Yago de la et al. Mega eventos de la Iglesia Católica: Derrotero Para Organizadores y Comunicadores. Méjico; DF: Variopinto Comunicación Insurgentes, 2018, L. 341.

${ }^{36}$ Ibidem, L. 490.

${ }^{37}$ DORA, Octavio Tavares. Megaeventos Esportivos: Temas Polêmicos. Porto Alegre, v. 17, n. 03, p. 1135, jul/set de 2011. Disponible en: http://www.pgedf.ufpr.br/OtavioTavares. Acceso em 28 set. 2018.
} 
diferentes lugares en un mismo sitio, en un corto espacio de tiempo, para que puedan participar de congresos, seminarios, conferencias, simposios, torneos deportivos o manifestaciones culturales y religiosas de todos tipos, con grande simbolismo para toda la gente y extraordinario potencial de impacto en innumerables sectores de la sociedad. ${ }^{38}$

El término "deporte", por su parte, deriva de la palabra inglesa "sport", que, originalmente en Inglaterra, era empleada con la versión más antigua "disport", para referirse a un variado número de pasatiempos entretenidos, que eran practicados por toda la gente alrededor del país, incluso por los miembros de la Casa Real. De acuerdo con unos escritos del siglo XVI, por ejemplo, esos pasatiempos divertidos han constituido objeto de las actividades del joven Rey Ricardo de Inglaterra, que a menudo participaba de encuentros entretenidos organizados por los ciudadanos del reino. Los propios ciudadanos, incluso, con frecuencia tomaban parte en estos juegos deportivos en determinadas épocas del año, como los juegos de Navidad, periodo en el que la gente solía dejar las actividades laborales para relajarse y confraternizar en estos encuentros. ${ }^{39}$

Con el paso del tiempo, la palabra "sport" se ha consagrado como término propio para señalar formas de recreación en las que los ejercicios físicos tenían un papel fundamental, puesto que se habían convertido en un pasatiempo divertido y placentero de toda la gente, ${ }^{40}$ que no posee, en principio, carácter competitivo. ${ }^{41}$

Restringiendo el análisis al ámbito meramente deportivo y competitivo, Lamartine Pereira da Costa y Ana Miragaya consideran que un mega evento puede ser definido, fundamentalmente, mediante el número de personas que acuden al encuentro y mediante el tiempo necesario para su efectiva preparación por parte de los responsables. Con base en estos elementos, conceptúan al mega evento deportivo como el gran encuentro de atletas de diferentes lugares en un mismo sitio, para que puedan participar de una o más

\footnotetext{
${ }^{38}$ Ibidem.

${ }^{39}$ ELIAS, Norbert; DUNNING, Eric. Deporte y Ocio en el Proceso de la Civilización. Traducción de Purificación Jiménez. Méjico DF: Fondo de Cultura Económica, 2015, L. 4199. [Electrónica]

${ }^{40}$ Ibidem, L. 3631 y 3645.

${ }^{41}$ En efectiva, muchos deportes que se practican hoy tuvieron origen en Inglaterra, como el fútbol, las carreras de caballos, la lucha libre, el tenis, la caza de zorros, el boxeo moderno y el remo. A lo mejor por el gran desarrollo económico de aquel país, todas esas actividades traspasaron a otros sitios, principalmente entre la segunda mitad del siglo XIX y la primera mitad del siglo XX, llevando a estos lugares el término “sport”. Cf. ELIAS; DUNNING, op.cit., L. 3619. [Electrónica]
} 
competencias deportivas de diferentes modalidades, en un corto espacio de tiempo, tras un largo periodo de preparación. ${ }^{42}$

Horne y Manzenreiter consideran que los mega eventos deportivos deben ser entendidos como grandiosos encuentros de naturaleza cultural, que reúnen a personas de diferentes lugares en un único sitio, más allá de presentar carácter dramático, fuerte apelo popular y significado internacional. ${ }^{43}$

A raíz de todos los elementos presentados, es posible decir que los mega eventos deportivos, ineludiblemente, resultan del encuentro de atletas profesionales y aficionados de diferentes lugares en un mismo sitio, para que, en un corto espacio de tiempo, puedan confraternizarse y participar de competiciones deportivas de una o más modalidades, tras un largo periodo de preparación, con marcado carácter emocional y extraordinario potencial de impacto sobre los participantes y sobre determinados sectores de la sociedad. ${ }^{44}$

La presentación de todas esas características permite concluir que los Juegos Olímpicos constituyen el típico ejemplo de un mega evento deportivo internacional que, en poco más de dos semanas, reúnen en un mismo sitio a miles de atletas, aficionados y periodistas de diferentes países, quienes no solo participan y acuden a varias competencias de distintas modalidades, sino que celebran la confraternización universal a través del deporte y exaltan los principios olímpicos edificados por los antiguos griegos desde hace 2800 años. ${ }^{45}$

Además de resaltar las nobles virtudes de los juegos del pasado, con el paso del tiempo, los Juegos Olímpicos modernos todavía se han convertido en un poderoso instrumento de crecimiento económico y regeneración urbana de las ciudades

\footnotetext{
${ }^{42}$ DA COSTA, Lamartine Pereira; MIRAGAYA, Ana. Estado da Arte do Conhecimento sobre Legados de Megaeventos Esportivos no Exterior e no Brasil. In: esportivos. Brasília: Ministério do Esporte, 2008. p. 33-45. . et al. (ed.). Legados de megaeventos

${ }^{43}$ HORNE, J; MANZENREITER, W. An introduction to the sociology of sports mega- events. In: HORNE, J;MANZENREITER, W. (ed.). Sports Mega-Events: Social Scientific Analyses of a Global Phenomenon. (Special Issue: The Sociological Review Monograph Series) v. 54, Issue Supplement s2, December 2006. p. 1-24.

${ }^{44}$ CIERVA, op. cit., pos. 471.

${ }^{45}$ RIBEIRO, Tiago; CORREIA, Abel; BISCAIA, Rui; FIGUEIREDO, Carlos. Perspectiva Social e Organizacional dos Jogos Olímpicos: Estado da Arte. In: MARQUES, J. C.; ROCCO, A. J. (coord.). Leituras e Reflexões sobre os Jogos Olímpicos Rio-2016. São Paulo: Cultura Acadêmica, 2018, p. 22.
} 
anfitrionas, ${ }^{46}$ sirviendo como factor responsable de grandes inversiones públicas y privadas en diferentes sectores de la economía local que terminan impactando positivamente en la imagen de la ciudad en el escenario global. ${ }^{47}$

Aparte de los beneficios económicos, la celebración de los juegos también genera aumento del espíritu comunitario, el incremento del orgullo cívico y el fortalecimiento de una cultura del deporte, fomentando que jóvenes y adultos se dediquen a actividades con esas características, lo que en resumen termina beneficiando a toda la sociedad. ${ }^{48}$

Todos estos factores, económicos o no, acaban contribuyendo directamente a la popularidad de los mega eventos deportivos, ${ }^{49}$ a menudo desviando la atención de los ciudadanos de otros problemas relacionados con la preparación y la ejecución de estos grandes espectáculos, como el fracaso financiero de algunas ediciones, ${ }^{50}$ el aumento de la criminalidad, los perjuicios para la movilidad urbana durante el mega evento, los costes ambientales y sociales que derivan de ello y, principalmente, la práctica de actos de corrupción. ${ }^{51}$

La relación entre la corrupción y Juegos Olímpicos no es un fenómeno reciente, sino que acompaña al mega evento desde los festivales deportivos y religiosos de la antigua Grecia, donde atletas deshonestos ya buscaban sobornar a los árbitros y a los demás competidores con objeto de sacar ventajas deportivas personales, mirando más bien hacia los beneficios que resultaban de la conquista. ${ }^{52}$ Diversas referencias históricas contrastadas avalan esta afirmación:

\footnotetext{
46 JONES, Magie; STOKES, Terry. The Commonwealth Games and urban regeneration: an investigation into training initiatives and partnerships and their effects on disadvantaged groups in East Manchester. In Managing Leisure, v. 8, n. 4, 2003, p. 198-211.
}

${ }^{47}$ ALLEN, J. et al. Festival and special event management. Milton, Australia: John Wiley \& Sons Australia, 2002.

${ }^{48}$ KAPLANIDOU, Kiki; KARADAKIS, Kostas. Understanding the legacies of a host Olympic city: the case of the 2010 Vancouver Olympic Games. In Sport Marketing Quarterly, v. 19, p. 110-117, 2010.

${ }^{49}$ PREUSS, Holger; SOLBERG, Harry. Attracting Major Sporting Events: The Role of Local Residents. In European Sport Management Quarterly, v. 6, n. 4, p. 391-411, 2006.

${ }^{50}$ BILLINGS, Stephen; HOLLADAY, Scott. Should Cities Go For The Gold? The Long- Term Impacts of Hosting The Olympics In Economic Inquiry, v. 50, n.3, p. 754-772.

${ }^{51}$ HUANG, Hai-Yan; et. al. Social exchange process in collectivistic countries: an examination of sporting events in China. In European Sport Management Quarterly, v. 16, n. 2, p. 172-189, 2016.

${ }^{52}$ Según la mitología, el primer caso de corrupción en los juegos ha ocurrido en una carrera de la que participó Pelopes, rey de Frigia, que ha logrado vencer a todos sus oponentes a causa de un soborno que les pagó antes que comenzara la competencia, con ello conquistando el derecho de casarse con Hipodamia. 
Por un lado, en el año 388 a.c. Tessalio Eupolo, corredor griego, intentó sobornar a sus oponentes para lograr vencer la principal carrera de los juegos. Con ello se convirtió en el principal atleta de aquella edición del mega evento, pero el soborno fue descubierto $\mathrm{y}$ todos los involucrados en la trama fueron sancionados, con lo cual el deseo de gloria y reconocimiento rápidamente se convirtió en vergüenza y castigo. ${ }^{53}$

Por otro lado, en el año 332 a.c. Calipo, pentatleta de Atenas, también intentó sobornar a sus oponentes con monedas de oro, mirando más a los beneficios sociales y económicos que la victoria olímpica podría traerle. Esta corrupción fue descubierta y Calipo fue condenado, aunque los atenienses posteriormente le enviaron un abogado para defenderlo en el Senado Olímpico, ${ }^{54}$ órgano considerado la principal autoridad de los Juegos Olímpicos y que tenía competencia para decidir los conflictos nacidos durante las disputas.

En efecto, la victoria en los Juegos de la antigüedad le daba al campeón no solo el reconocimiento público de sus calidades físicas y morales, sino que también le proporcionaba otros beneficios, tales como la construcción de una estatua en el lugar de la conquista, el recibimiento de donaciones de los vecinos, caballos, mujeres, cien ánforas de aceite, una casa nueva o incluso quedarse eximido en cuanto al pago de tributos. ${ }^{55}$ Además, le concedería el acceso a las clases más abastadas de la sociedad y le otorgaría un puesto en la élite gubernamental. ${ }^{56}$

Claro que el Barón Pierre de Coubertin no se refirió a ninguna de esas malas prácticas cuando, en $1892^{57}$ y $1894,{ }^{58}$ organizó dos Congresos en la Universidad de Sorbona, en París, enfocando la recreación de los Juegos Olímpicos y la constitución del Comité Olímpico Internacional.

Cf. PÉREZ, Iván Mera. Los Juegos Olímpicos de la Era Antigua en Grecia. La Carrera de Filípedes en el año 490 a.C. y la Batalla de Maratón. Estados Unidos: José Millariega Editor, 2014, L. 610.

${ }^{53}$ PÉREZ, op. cit., L. 610.

${ }^{54}$ PÉREZ, op. cit., L. 610.

${ }^{55}$ Ibidem, L. 173 y 697.

${ }^{56}$ ELIAS, op.cit., L. 4032.

${ }^{57}$ GOLDBLATT, David. The Games: A Global History of The Olympics. London: Pan Macmillan, 2016, p. 41.

${ }^{58}$ Ibidem. 
En ambos encuentros, Coubertin concentró su discurso casi exclusivamente en las nobles virtudes que los Juegos del pasado lejano buscaban resaltar y que, rápidamente, trató de convertir en los principios fundamentales del Movimiento Olímpico. ${ }^{59}$ Esos principios, resaltó el Barón, deberían gobernar las acciones del Comité Olímpico Internacional a lo largo de su existencia, una vez que le impusieran a la entidad el firme compromiso de: ${ }^{60}$ promover el desarrollo físico y moral del individuo, educar los más jóvenes a través del deporte, difundir los principios olímpicos por todo el planeta y reunir a los atletas del mundo cada cuatro años, para celebrar los Juegos Olímpicos y la confraternización universal de las naciones.

Pese a todo el esfuerzo que hizo para apartar la corrupción de los Juegos, omitiéndola deliberadamente de los discursos que hizo en los Congresos de París de 1892 y 1894, Coubertin no logró extirpar esa enfermedad del mega evento deportivo más importante del planeta.

Las malas prácticas acompañan a los Juegos Olímpicos modernos no solo desde su recreación en Atenas 1896, sino que han ultrapasado las fronteras meramente deportivas para alojarse en otras actividades asociadas, tanto a la organización del espectáculo, como a las obras necesarias para la preparación de la ciudad anfitriona con objeto de acoger al mega evento.

Efectivamente, la experiencia ha demostrado que siempre ha existido la asociación entre obras públicas, contratos administrativos, licitaciones, corrupción y Juegos Olímpicos, aunque también es cierto que ese fenómeno se ha incrementado considerablemente a partir de la segunda mitad del siglo XX, principalmente tras la entrada de la televisión en los Juegos. A partir de ese periodo, existió la necesidad de mayores inversiones públicas en infraestructura ${ }^{61}$ con motivo de la celebración del

\footnotetext{
${ }^{59} \mathrm{El} \mathrm{Movimiento} \mathrm{Olímpico} \mathrm{se} \mathrm{constituye,} \mathrm{fundamentalmente,} \mathrm{en} \mathrm{tres} \mathrm{niveles} \mathrm{jerárquicos.} \mathrm{El} \mathrm{Comité}$ Olímpico Internacional ocupa la cabeza de esa estructura y trata de establecer las directrices generales con respecto a los juegos olímpicos. Por debajo del Comité Olímpico Internacional están los Comités Olímpicos Nacionales, que administran el Movimiento Olímpico en su propio territorio y envían a los juegos los atletas de su país. El último nivel es ocupado por las Federaciones Internacionales de Deportes, como la Federación Internacional de Atletismo, la Federación Internacional de Natación y la Federación Internacional de Baloncesto, encargadas de establecer reglas para el desarrollo de cada modalidad deportiva. Cf. PAYNE, Michael. A Virada Olímpica: Como os Jogos Olímpicos Tornaram-se a Marca Mais Valorizada no Mundo. Rio de Janeiro: Casa da Palavra, 2006, p. 18.
}

${ }^{60}$ Ibidem, p. 17.

${ }^{61}$ OLIVEIRA, Nelma Gusmão de. O Poder dos Jogos e os Jogos de Poder: os interesses em campo na produção de uma cidade para o espetáculo esportivo. 2012 Tese ( Doutorado do Programa de Pós- 
encuentro $^{62}$ y muchas de estas obras constituyeron un ambiente favorable a las malas prácticas administrativas.

A partir de finales de los años setenta y principio de los ochenta, la relación de los gobiernos con los Juegos Olímpicos fue utilizada con objeto de fomentar la recuperación económica de los Estados, con lo cual la realización de las obras necesarias a la preparación de la ciudad anfitriona se incorporó completamente al discurso económico de los países desarrollados. ${ }^{63}$

Las décadas de los setenta y ochenta estuvieron marcadas por la llamada crisis de la restructuración productiva, fenómeno que impuso a los países ricos la obligatoria disminución de las inversiones públicas y a la reducción de las políticas sociales asociadas al Estado de bienestar. ${ }^{64}$

Con objeto de superar estos problemas, políticos famosos como la Primera Ministra de Inglaterra Margaret Thatcher, y el Presidente de Estados Unidos Ronald Reagan, trataron de poner en marcha el nuevo modelo económico que se había desarrollado pocos años antes, el capitalismo neoliberal, que recomendaba la concentración de las inversiones públicas en los sectores más ricos de la sociedad, sacando a partir de ahí la recuperación económica del país. ${ }^{65}$

La disminución de los recursos ha fomentado feroces disputas entre varios sectores de la sociedad, que a diario buscaban convencer al gobierno de que ellos deberían recibir las inversiones públicas, ya que a partir de su actividad empresarial ayudarían a la recuperación económica del país.

La victoria de esa gigantesca disputa le tocó al sector de la construcción civil. Más bien con el apoyo del presidente francés François Mitterrand, los empresarios de ese

Graduação em Planejamento Urbano e Regional), Universidade Federal do Rio de Janeiro, Rio de Janeiro, Rio de Janeiro: 2012, p. 53-57. [Orientador: Carlos Bernardo Vainer]

${ }^{62}$ RITCHIE, J. R. Brent; Smith, Brian. The impact of a mega-event on host region awareness: A longitudinal study. In Journal of Travel Research, v. 30, n.1, 1991, p. 310.

${ }^{63}$ FERREIRA, João Sette Whitaker. Brasil em Jogo: o que fica da Copa e das Olimpíadas? Um Teatro Milionário. São Paulo: Boitempo Editorial, 2014, p. 9-10.

${ }^{64}$ Ibidem.

${ }^{65}$ Ibidem. 
sector lograron convencer a muchos gobiernos de que la salida de la crisis estaba en la recuperación de los equipamientos urbanos de las grandes ciudades, como museos, plazas, parques y estaciones de trenes, ineludiblemente degradados a raíz del paso del tiempo. ${ }^{66}$

El discurso oficial se orientó en el sentido de que la realización de grandes obras de restauración de dichos monumentos resolvería el problema del desempleo en las grandes ciudades europeas y asimismo sería beneficioso para el político de turno, quien sería visto como un gobernante moderno, con coraje e inteligencia, ya que había logrado presentar nuevas ideas para antiguos problemas. ${ }^{67}$

Así mismo se decía que la recuperación de los monumentos incrementaría el turismo y la mercadotecnia de la ciudad, aparte de que generaría miles de empleos directos e indirectos, ya fuera a causa de las obras realizadas o en consecuencia de otras actividades desarrolladas a partir de la llegada de capital internacional. ${ }^{68}$

Las ideas de François Mitterrand no tardaron en conquistar seguidores en otros sitios. A principios de los noventa, estas ideas llegaron a otros países como Inglaterra y España, viabilizando la realización de grandes inversiones públicas para la recuperación de equipamientos urbanos, tales como las docas de Londres o el museo Guggenheim en Bilbao. ${ }^{69}$

A pesar de su amplia aceptación entre los sectores más abastados de la sociedad, la recuperación de equipamientos públicos no siempre fue bien aceptada por la población, aunque estaba respaldada por un discurso de defensa del arte y de la cultura. La falta de inversiones en programas sociales recibió críticas de los sectores más humildes, que rápidamente empezaron a manifestarse en contra de estas obras.

Con objeto de vencer tal resistencia, tanto gobiernos como empresarios, coincidieron en que lo mejor sería asociar las grandes obras públicas a los mega eventos deportivos, como el campeonato Mundial de fútbol y los Juegos Olímpicos, ya que ambos eventos afectaban directamente a las emociones de los ciudadanos y claramente

\footnotetext{
${ }^{66}$ Ibidem, p. 10-11.

${ }^{67}$ VAINER, Carlos. A Cidade do Pensamento Único: Desmanchando Consensos. Os Liberais Também Fazem Planejamento. Petrópolis: Vozes, 2000, p. 117-119.

${ }^{68}$ FERREIRA, op.cit., p. 11-12.

${ }^{69}$ Ibidem, p. 11.
} 
desviaban su atención de otras cuestiones fundamentales relacionadas con la inversión de los fondos públicos.

En definitiva, además de permitir la construcción de grandes estadios y modernas arenas, los grandes eventos deportivos también fomentarían la construcción de otros emprendimientos, como grandes centros de negocios, aeropuertos, hoteles de lujo y viviendas, que transformarían la ciudad y, por tanto, demandarían muchas inversiones. ${ }^{70}$

La posibilidad de gastar grandes cantidades de dinero en un corto periodo de tiempo ha llamado la atención de políticos y empresarios alrededor del planeta, corruptos o no, quienes rápidamente trataron de presentar la candidatura de las ciudades ubicadas en su área de influencia, queriendo acoger los Juegos Olímpicos y disfrutar de todos los beneficios que su realización podría proporcionar. ${ }^{71}$

Entre tantas ciudades interesadas merece particular referencia la situación de Río de Janeiro, cuatro veces candidata en acoger los Juegos Olímpicos, pero que tan solo ha conquistado el derecho de hacerlo en una oportunidad, el 02 de octubre de 2009, fecha en la que fue elegida la ciudad anfitriona de los Juegos Olímpicos de verano de $2016 .{ }^{72}$ Claro que la elección de Río fue responsable de una ola de manifestaciones en Brasil, favorables y contrarias a la realización de las Olimpiadas, dependiendo del punto de vista que uno busca enfatizar en su análisis.

Por un lado, había quienes reprodujeron el discurso oficial y dijeron que los Juegos serían responsables del crecimiento económico y de la regeneración urbana de la ciudad anfitriona, ${ }^{73}$ que sería beneficioso para la autoestima de los brasileños, que fomentaría una cultura deportiva de carácter nacional y mejorarían la imagen de la ciudad en el escenario global. ${ }^{74}$ Por otro lado, había una gran preocupación por el enfrentamiento a la corrupción, bien por la trayectoria de los Juegos Olímpicos a lo largo del siglo XX, bien

\footnotetext{
${ }^{70}$ MARICATO, Ermínia. Brasil em Jogo: o que fica da Copa e das Olimpíadas? A Copa do Mundo no Brasil: tsunami de capitais aprofunda a desigualdade urbana. São Paulo: Boitempo Editorial, 2014, p. 36.

${ }^{71}$ JENNINGS, Andrew. Brasil em Jogo: o que fica da Copa e das Olimpíadas? A Máfia dos Esportes e o Capitalismo Global. São Paulo: Boitempo Editorial, 2014, p. 112.

${ }^{72}$ Antes que fuera elegida ciudad anfitriona de los juegos olímpicos de 2016, Río de Janeiro había
presentado su candidatura a los juegos de 1936, 2004 y 2012, siendo superada por Berlín, Atenas y Londres,
respectivamente. ${ }^{73}$ JONES; STOKES, op. cit, p. 198-211.

${ }^{74}$ ALLEN, J. et al. Festival and special event management. Milton, Australia: John Wiley \& Sons Australia, 2002.
} 
por la historia política de Brasil, país marcado por varios casos de despilfarro de fondos, desviación de recursos públicos, tráfico de influencia y sobrefacturación de contratos de obras y servicios desde el periodo colonial. ${ }^{75}$

Cuatro años antes que Río de Janeiro fuera elegida ciudad anfitriona de los Juegos Olímpicos de 2016, ya en 2005 el país se enfrentó a uno de los mayores escándalos de corrupción de la república, el caso de "mensalão". Diputados y Senadores de varios partidos políticos aprobaron proyectos de interés del gobierno a cambio de recibir una cantidad de dinero al mes, como si cobraran un sueldo mensual del poder ejecutivo a causa de sus servicios. ${ }^{76}$

Las investigaciones también revelaron que la práctica delictiva no se restringió únicamente a los altos directivos del poder ejecutivo, sino que terminó contaminando a toda la Administración Pública brasileña, asociándose, en este caso, a la financiación ilegal de partidos políticos. ${ }^{77}$

Muchos de los empleados en órganos o entidades vinculadas al poder ejecutivo fueron obligados a entregar al partido político responsable de su nombramiento una cantidad de dinero al mes a cambio de mantener su puesto de trabajo, con lo cual los funcionarios actuaban como verdaderos recaudadores de fondos para su agremiación política. $^{78}$

Los recursos utilizados vinieron más bien de los contratos perfeccionados por suministradores de productos y servicios a órganos y entidades públicas, quienes entregaban parte del valor recibido durante la ejecución del negocio a miembros de la banda criminal, para que financiaran todo el sistema. ${ }^{79}$

Aunque todo el esquema fue descubierto y que muchos políticos, funcionarios y empresarios fueron condenados, ${ }^{80}$ hubo gran recelo de que los contratos perfeccionados

\footnotetext{
${ }^{75}$ ROMEIRO, Adriana. Corrupção e Poder no Brasil: uma história, séculos XVI a XVIII. Belo Horizonte: Autêntica, 2017.

${ }^{76}$ VILLA, Marco Antônio. Mensalão: O Julgamento do Maior Caso de Corrupção da História Política Brasileira. São Paulo: Leya, 2012, L. 46.

${ }^{77}$ Ibidem, L. 240.

${ }^{78}$ Ibidem.

${ }^{79}$ Ibidem, L. 99.

${ }^{80}$ Los crímenes referentes al "mensalão" fueron apurados en la acción penal n. ${ }^{\circ}$ 470/2007 juzgada por el Supremo Tribunal Federal.
} 
con motivo de la preparación de la ciudad de Río de Janeiro pudieran utilizarse como instrumento para la práctica de actos de corrupción de todo tipo, repitiéndose lo que ya pasó en la historia reciente de Brasil y, por qué no decirlo, en la propia trayectoria de los Juegos Olímpicos modernos.

Con objeto de cohibir conductas de esa naturaleza, cinco años antes de que los juegos arrancaran, en 2011, Brasil aprobó la ley de transparencia y acceso a la información (ley n. ${ }^{\circ}$ 12.527/2011, permitiendo el control ciudadano de los gastos realizados con la preparación de los Juegos, además de la prevención de posibles actos de corrupción asociados a la construcción de equipamientos olímpicos y a las obras de infraestructura de la ciudad anfitriona.

A lo largo de esta tesis, buscamos analizar los desafíos de la transparencia gubernamental a la hora de afrontarse al fenómeno de la corrupción en los Juegos Olímpicos, en particular en los juegos de Río 2016, cuando todos esperaban que la normativa brasileña fuese capaz de impedir la comisión de actos de esa naturaleza.

En efecto, la ley brasileña ha sido de las últimas leyes de transparencia y acceso a la información en América Latina, con lo cual ha podido aprovecharse de los logros y fracasos de otras leyes de igual naturaleza. Ello le permitió al Parlamento dibujar una normativa que exaltara las virtudes y corrigiera los errores cometidos por otros países en esa materia. En otras palabras, la ley de Brasil ha buscado crear un régimen eficiente de control ciudadano y lucha contra la corrupción, cohibiendo las malas prácticas a menudo asociadas a la preparación de los Juegos Olímpicos.

Teniendo en cuenta esa realidad es que, durante esta investigación, buscamos identificar las fortalezas y debilidades de la Ley de Transparencia y Acceso a la Información de Brasil en cuanto a la prevención de la corrupción asociada a los Juegos Olímpicos Río 2016.

Para alcanzar este objetivo, adoptamos por metodología, en primer lugar, realizar un análisis de los dispositivos de la Ley de Transparencia y Acceso a la Información de Brasil, confrontándola con los enseñamientos de la doctrina y con otras leyes de igual naturaleza, como la Ley n. ${ }^{\circ}$ 19, de 09 de diciembre de 2013, de Transparencia y Buen Gobierno de España, y algunas normas autonómicas que tratan de este asunto en aquel país.

Aun en el continente europeo, se examinó el régimen de la transparencia en el Convenio n. ${ }^{\circ} 205$ del Consejo de Europa sobre el acceso a los documentos públicos; 
normativa que permite la presentación de pedido de acceso a la información de forma anónima, diferentemente del que prevén las leyes de España y Brasil en esa materia.

Asimismo, en el territorio americano, buscamos examinar cómo el derecho de acceso a la información pública ha sido reglado en la Ley Modelo Interamericana y cómo esa norma ha influenciado en la ley brasileña a la hora de definir la información que deberá publicarse en páginas web u otros sitios para satisfacer el deber de transparencia activa.

A partir de estas comparaciones, buscamos identificar los principios que inspiraron cada uno de los derechos y deberes previstos en la Ley, el modelo de órgano de control adoptado, sus atribuciones y prerrogativas en lo relativo a la defensa de la transparencia gubernamental, el régimen de sanciones y los límites a la divulgación de los actos y decisiones oficiales.

El estudio inicia con un capítulo donde se analizó los elementos fundamentales de la transparencia activa, tales como origen, concepto, naturaleza jurídica, principios fundamentales y límites de la divulgación de la información.

También enfrentamos cuestiones como la naturaleza jurídica del derecho de acceso a la información desde la perspectiva del derecho supraestatal, momento en que presentamos las principales decisiones sobre esa materia dictadas por la Corte Interamericana de Derechos Humanos y el tribunal europeo de Derechos Humanos, organismos que consideran el derecho de acceso como derecho fundamental.

En esta oportunidad, registramos las discusiones doctrinales existentes en el derecho español, país donde no todos los expertos consideran el derecho de acceso como derecho fundamental, sacando la conclusión de que su violación no autoriza la presentación de recurso de amparo, limitación que uno suele considerar el primer desafío de la transparencia gubernamental en la lucha contra la corrupción.

Luego, analizamos los elementos de la transparencia gubernamental en Brasil inaugurados a partir de la Ley n. ${ }^{\circ}$ 12.527/2011, tales como los sujetos obligados a publicar la información, los asuntos que deberán divulgarse y el lugar y la forma de publicación.

En ese mismo capítulo, se discutió el contenido de las informaciones que deben ser publicadas como consecuencia del deber de transparencia gubernamental. Desde esa perspectiva, observamos que la ley brasileña determina la publicación de informaciones referentes a los contratos administrativos, pero no prevé el acceso electrónico a los procesos de licitación pública, medida expresamente referida en la recién aprobada ley de Colombia y que consideramos interesante desde la perspectiva de las medidas 
anticorrupción, sobre todo cuando buscamos cohibir las malas prácticas asociadas a los mega eventos deportivos.

Aun respecto al objeto, verificamos que las leyes de transparencia en Brasil y España no establecen la obligatoriedad de divulgación de la agenda de los responsables políticos del Estado, tema de gran importancia para la lucha contra la corrupción, sobre todo a raíz del papel que dichas autoridades juegan en el proceso de preparación y realización de los Juegos Olímpicos.

Finalmente, examinamos el órgano responsable de la transparencia en el contexto de los diferentes modelos en vigor de otros países y el régimen de sanciones para el caso de incumplimiento de la ley, señalando su debilidad en cuanto al efectivo control de los actos practicados en la oscuridad.

Pasando de la teoría a la práctica, buscamos identificar las principales irregularidades en la preparación de otras ediciones de las Olimpíadas, desde principios del siglo XX hasta los Juegos de Río 2016, confrontando cada una de estas malas prácticas con la Ley de Transparencia y Acceso a la Información de Brasil. En este caso, analizamos la literatura en torno al tema de los Juegos Olímpicos concentrando nuestra atención en las obras de preparación del torneo y en las medidas adoptadas para la gestión de los equipamientos olímpicos tras el mega evento. La idea ha sido probar la hipótesis objeto de la investigación, o sea, si la Ley brasileña estaba preparada para cohibir la corrupción y todas las malas prácticas a menudo asociadas con la organización de las Olimpíadas.

El capítulo II comienza con los antecedentes de la promulgación de la Ley de Transparencia y Acceso a la Información de Brasil y, además enfatiza su relación con las reglas establecidas para la contratación pública de los Juegos Olímpicos Río 2016.

En este capítulo también nos ocupamos de presentar diferentes casos de corrupción asociados a la preparación de los Juegos Olímpicos Río 2016, con lo cual tratamos de evidenciar las debilidades de la Ley de Transparencia y Acceso a la Información en Brasil, concerniente a la prevención de estas malas prácticas.

La presentación de todos estos casos pretende demostrar a partir de datos empíricos, que la corrupción no es una enfermedad exclusiva de países ricos o pobres, católicos o protestantes, a menudo manifestándose en todas las actividades desarrolladas por el hombre, incluso aquellas de naturaleza recreativa o mimética.

Por otro lado, los ejemplos procuran evidenciar que el tradicional discurso en favor de la pureza del deporte no se ha reflejado totalmente en los Juegos Olímpicos, sirviendo 
más bien como pretexto para la ejecución de grandes obras de ingeniería en un corto periodo de tiempo, que terminaron viabilizando el cometimiento de innumerables actos de corrupción.

El capítulo III, finalmente, concluye con la presentación de una justificación para la constitución de un nuevo modelo de transparencia activa que pasa, necesariamente, por la adopción de técnicas que realicen un mayor acercamiento del poder público al ciudadano.

Concluimos que la transparencia gubernamental constituye una importante medida de lucha contra la corrupción, pero que afronta innumerables desafíos a la hora de perseguir sus objetivos, teniendo en cuenta los obstáculos criados a partir de una restringida interpretación de los principios de responsabilidad y máxima divulgación.

Referidos principios demandan de la Administración no solo la publicación de la información por todos medios disponibles, sino que la adopción de un lenguaje claro y directo a la hora de redactarla, con objeto de permitirle el amplio entendimiento al ciudadano, poco importando su formación profesional.

Asimismo, justificamos la elección de este tema por la importancia que la contratación pública y los Juegos Olímpicos poseen para la sociedad moderna, lo que es evidente a partir del gran volumen de recursos invertidos para su preparación. En efecto, la contratación pública ha constituido, en los últimos años, un importante instrumento para el desarrollo de las ciudades, más bien debido a la realización de grandes obras de infraestructura y recuperación ambiental, lo que se pone en evidencia durante la preparación de los mega eventos deportivos internacionales como las Olimpíadas.

En este sentido, la corrupción asociada a cualquier de estos proyectos no solo impide que sean ejecutados correctamente, como demandan más recursos de lo necesario para su realización, lo que acaba con disminuir las inversiones públicas en otros sectores de la sociedad, además de avalar la confianza de los ciudadanos en las instituciones.

En otras palabras, la corrupción concerniente a la contratación pública en los Juegos Olímpicos evidencia una cicatriz del propio sistema de contratación pública en general, tanto que organismos como la Unión Europea trataron de reconocerlo en diferentes documentos. Merece referencia al respecto el informe de la Comisión, del Consejo y del Parlamento europeo del año 2014, el cual puso de manifiesto la necesidad de adoptarse medidas para proteger el sector de la contratación pública en general, debido a que es de los más susceptibles a las malas prácticas administrativas. 
Si bien, en teoría, todo el sistema de contratación pública está dibujado con objetivo de asegurar una buena gestión de los fondos públicos, en la práctica no siempre ello sucede, más bien en lo que concierne a los mega eventos deportivos como los Juegos Olímpicos. La literatura especializada evidencia que los Juegos constituyen un ambiente favorable a los actos de corrupción, con lo cual consideramos importante estudiar el tema de la transparencia asociada a la contratación pública en las Olimpíadas.

Buscamos con esta investigación ofrecer alternativas para eliminar los espacios de oscuridad que existen en esa materia y, asimismo, crear instrumentos que posibiliten una mayor claridad de la información facilitada a los ciudadanos.

En otras palabras, pretendemos que las alteraciones sugeridas contribuyan a una mayor integridad en la contratación pública y a una efectiva rendición de cuentas de los gestores públicos en esta materia. Asimismo, buscamos fortalecer el papel de los órganos responsables de la transparencia gubernamental y mejorar el régimen de sanciones aplicables a los actos practicados con oscuridad, lo que consideramos fundamental para fomentar una cultura de transparencia en el seno de las Administraciones Públicas. 


\section{CAPITULO I - MARCO TEÓRICO Y NORMATIVO DE LA TRANSPARENCIA GUBERNAMENTAL EN LA REGENERACIÓN DE LA DEMOCRACIA Y EN LA PREVENCIÓN DE LA CORRUPCIÓN}

\section{Consideraciones Generales}

La corrupción es un fenómeno que suele desarrollarse en la oscuridad, distante de los ojos de todos, exactamente para que los responsables de esa conducta puedan ejecutarla sin cualquier tipo de coacción o control social. Para cohibir esas malas prácticas, los Estados democráticos tratan de crear medios que permitan a los ciudadanos fiscalizar permanentemente el contenido de los actos y decisiones estatales ${ }^{81}$, a partir de ahí demandando los cambios políticos e institucionales que consideran necesarios a modo de perfeccionar el ordenamiento jurídico.

Uno de estos medios es la transparencia gubernamental, importantísima herramienta en la lucha contra la corrupción que fue incorporada mediante órdenes jurídicas nacionales desde hace más de 250 años, con la aprobación de la Real Ordenanza sobre la Libertad de Prensa de Suecia del año 1766. ${ }^{82}$ A partir de la segunda mitad del siglo XX, el control ciudadano se generalizó y fueron aprobadas leyes de transparencia en países de Europa ${ }^{83}$, América, Asia, África y Oceanía. En el mundo árabe, la aprobación de leyes de transparencia coincide con las manifestaciones de la primavera árabe en el $2010 .^{84}$

Más allá de prevenir la corrupción, la transparencia también actúa como un factor relevante para la regeneración la democracia ${ }^{85}$, en tanto que permite un diálogo efectivo

\footnotetext{
${ }^{81}$ BRASIL. Supremo Tribunal Federal (2. Turma). AI n. 239.874. AgR. Rel. Min. Celso de Mello. Julgado em: 10.08.1999. DJ, p. 13,10 set. 1999.

82 POMED SÁNCHEZ, Luis Alberto. El derecho de acceso de los ciudadanos a los archivos y registros administrativos. Madrid: Ministerio de Administraciones Públicas, 1989, p. 9.

${ }^{83}$ GUICHOT, Emilio et al. Transparencia, Acceso a la Información Pública y Buen Gobierno. Madrid: Tecnos, 2014, p. 18.

${ }^{84}$ MENDEL, Toby. Right to Transparency Index, Rating Data Analysis Series: Overview of Results and Trends Centre for Law and Democracy Access Info Europe, Halifax y Madrid: 2013, p. 8.

85 PESCHARD, Jacqueline. Transparencia: Promesas y Desafíos (Grandes Problemas). Ciudad de México: El Colegio de México, 2018, L. 187.
} 
entre gobernantes y gobernados ${ }^{86}$, que no queda restringido exclusivamente al proceso electoral. En este punto, la transparencia permite a los ciudadanos influenciar directamente en la toma de decisiones ${ }^{87}$, participar de los negocios públicos y demandar la rendición de cuentas de los responsables de los fondos públicos. ${ }^{88}$

Para que cumpla con su papel, la transparencia cuenta con principios fundamentales que condicionan la interpretación de las normas y encaminan la actuación del poder público $^{89}$, como el principio de responsabilidad, el de máxima divulgación, el de buena $\mathrm{fe}^{90}$, el de participación y el de universalidad.

A causa de estos principios, el Estado queda obligado a divulgar las informaciones directamente (transparencia activa) o mediante previa solicitud de los interesados (transparencia pasiva), ${ }^{91}$ mirando a una mayor visibilidad de los actos y decisiones oficiales, lo que permitirá a los ciudadanos fiscalizar y controlar la destinación, la utilización y la rendición de cuentas de los fondos públicos. ${ }^{92}$

En efecto, en los regímenes democráticos, el ejercicio de los poderes estatales se condiciona al control social permanente y a la fiscalización de orden jurídico

\footnotetext{
${ }^{86}$ HEALD, David. Varieties of Transparency. In: HOOD, Christopher Hood y HEALD, David (ed.). Transparency: The Key to Better Governance? Oxford: Oxford University Press, 2006, p. 26.

${ }^{87}$ PESCHARD. op.cit., L. 1063.

${ }^{88}$ CANOTILHO, José Joaquim Gomes; MOREIRA, Vital. Constituição da República portuguesa anotada. São Paulo: Revista dos Tribunais, 2007. v.1, p. 655-656.

${ }^{89}$ GORDILlO, 1988, apud MELlO, Celso Antônio Bandeira de. Curso de Direito Administrativo. 21. ed., São Paulo: Malheiros Editores, 2006, p. 912-914.

${ }^{90}$ PÉREZ, Jesús González. El Principio General de Buena Fe en el Derecho Administrativo. 3. ed., , Madrid: Civitas, 1999, p. 69-70.

${ }^{91}$ BRASIL. Controladoria-Geral da União. Transparência ativa e passiva. In: Rumo a uma cultura de acesso à informação: Lei 12.527. Disponible en: https://www.cgu.gov.br/noticias/2013/10/cgu-promove-cursovirtual-sobre-lei-de-acesso-a-informacao, Acceso en: 30 nov. 2019.
}

${ }^{92}$ BRASIL. Supremo Tribunal Federal. MS n. 24.725/MC. Decisão monocrática proferida pelo Rel. Min. Celso de Mello. Julgado em 28 de novembro de 2003. DJ, p. 47, 27, fev. 2004. (STF, Informativo 33) 
constitucional realizada por jueces y tribunales, ${ }^{93}$ con lo que se pretende fortalecer la democracia y enfrentarse a la corrupción. ${ }^{94}$

Pese a su importancia, la transparencia gubernamental no es absoluta y sufre con restricciones que impiden su incidencia en todos $\operatorname{casos}^{95}$. Tales límites resultan de la necesidad de protección de otros bienes jurídicos, por ahí autorizando la constitución de espacios en donde la transparencia gubernamental no producirá sus efectos.

Si bien existen diferencias puntuales de uno a otro régimen legal, lo que resulta de las características de cada Estado o grupo de Estados, los ordenamientos jurídicos nacionales e internacionales coinciden con que la transparencia gubernamental encuentra límites en la intimidad y la privacidad, la estabilidad financiera, la seguridad nacional y las investigaciones ministeriales ${ }^{96}$.

Desde luego que esas situaciones, aunque excepcionales, condicionan la actuación de los poderes públicos, impidiendo que, por ejemplo, sea revelado al público información de carácter personal de determinados individuos, exponiéndoles a la curiosidad, al escarnio, a la maledicencia o a la piedad de todos ${ }^{97}$.

Pese a esas restricciones, el intérprete siempre deberá tener en cuenta que, en las democracias participativas, la publicidad es la regla y el secreto la excepción. Así, la publicidad y el derecho a la información no podrán ser restringidos con fundamento en acto discrecional, salvo cuando este justificado el objeto de proteger la intimidad, la privacidad o el honor, o cuando fuese esencial a la defensa del interes público, ${ }^{98} \mathrm{o}$ a la seguridad de la sociedad o del Estado.

\footnotetext{
${ }^{93}$ BRASIL. Supremo Tribunal Federal (2. Turma). AI n. 239.874. AgR. Rel. Min. Celso de Mello. Julgado em: 10.08.1999. DJ, p. 13,10 set. 1999. No mesmo sentido BRASIL. Supremo Tribunal Federal (2. turma). AI núm. 241.397 AgR. Rel. Min. Celso de Mello. Julgado em 10 de agosto de 1999. DJ, p. 47,17 set. 1999.

${ }^{94}$ La divulgación de información requiere grandes inversiones públicas para su implementación. Países como Estados Unidos e Inglaterra llegan a gastar 380 millones de dólares y 35 millones de libras para mantener el sistema de transparencia en funcionamiento. Los costes son elevados, aunque necesarios, siempre que contribuyen para disminuir el despilfarro de fondos. (Transparência é necessária, mas sai cara. Congresso em Foco - Jornalismo para mudar). Disponible en: http://congressoemfoco.uol.com.br Acceso en: 8 en. 2019.

${ }^{95}$ PESCHARD, op.cit., L. 1173

${ }^{96}$ Ibidem.

${ }^{97}$ ZANCANER, Weida. Lineamentos Sobre a Lei de Acesso à Informação. In: VALIM, R.; MALHEIROS, A. C.;BACARIA, J. (coord.). Acesso à Informação Pública. Belo Horizonte: Fórum Editora, 2015, p. 26.

98 BRASIL. Supremo Tribunal Federal (2.Turma). RMS 23036, Rel. Min. Mauricio Correa. Rel. para o Acórdão: Min. Nelson Jobim. Julgado em 28 de março de 2006. DJ, 25 ago. 2006.
} 
Durante este capítulo, será analizado el origen de la transparencia, su papel en lo relativo a la regeneración de la democracia y la lucha contra la corrupción, como trató de establecerse como derecho fundamental en muchos ordenamientos jurídicos, los principios que encaminan las acciones del poder público en esa materia y las restricciones que impiden la divulgación de determinadas informaciones a la sociedad

Asimismo, será analizado como los principios de la transparencia gubernamental (responsabilidad, máxima divulgación, buena fe, participación y universalidad), así como mandamientos dirigidos a los altos funcionarios del Estado, trataron de relacionarse con la preparación de los Juegos Olímpicos a lo largo de los últimos ciento veinte años, desde su restauración en Atenas 1896 hasta nuestros días, buscando prevenir las malas prácticas a menudo asociadas a estos mega eventos.

El enredo de este capítulo será, por tanto, la historia de estas dos realidades. De un lado, la trayectoria de las malas prácticas que han acompañado a muchas de las ediciones de los Juegos Olímpicos desde su restauración en Atenas 1896; de otro, el papel que los principios de la transparencia gubernamental han jugado en este mismo periodo, con particular destaque para la manera como ellos fueron sistemáticamente violados.

El estudio de estas realidades nos va a permitir entender como Brasil se preparó para afrontar al desafío de acoger a los Juegos Olímpicos Río 2016 y como, también ahí, los principios fueron sistemáticamente violados, asunto que será objeto del según capítulo.

Conviene señalar la manera en que la corrupción se asocia a los Juegos Olímpicos y como la principal entidad responsable de su organización, el Comité Olímpico Internacional (COI), busca apartar estas dos realidades a través de un discurso que exalta la pureza del deporte por encima de las malas prácticas, lo que es fundamental para que el teatro millonario pueda moverse de uno a otro sitio a cada cuatro años, ingresando cada vez más ganancias en las arcas de la entidad.

\subsection{La producción de los juegos olímpicos como ambiente favorable a los actos de corrupción}


Los Juegos Olímpicos, así como la Copa del Mundo de Fútbol, forman parte de los llamados mega eventos deportivos internacionales, los cuales dominaron el siglo XX y revolucionaron la industria de entretenimiento en todo el planeta. Ciento veinte años tras su restauración en Atenas 1896, los Juegos Olímpicos siguen siendo considerados la franquicia más importante del mundo, según los expertos en economía y marketing deportivo de todo el planeta. ${ }^{99}$

Esta transformación sucedió, fundamentalmente, a partir de finales del siglo XX, a causa de la labor del inglés Michael Payne y de la creación del nuevo programa de patrocinio del COI conocido como Top Olympic Partnership.

A principios de los años 1980, las arcas del COI registraban ingresos de 200.000,00 de dólares y activos financieros que no sobrepasaban 2,0 millones de dólares. ${ }^{100}$ La única fuente de recursos resultaba de la compraventa de los derechos de transmisión para Estados Unidos, principales socios comerciales de la entidad. En este sentido, los Juegos Olímpicos de verano de Moscú 1980 y de invierno de Lake Placid 1980 incorporarían a las arcas del COI 122 millones de dólares, 83\% de los cuales derivaban de la compraventa para Estados Unidos. ${ }^{101}$

Aun así, el COI tampoco estaba seguro de que estos valores ingresarían en las cajas de la entidad. A causa del boicoteo norteamericano a los Juegos olímpicos de 1980, la cadena de televisión NBC fue prohibida por el Departamento de Comercio de Estados Unidos de ejecutar cualquier pago en favor de los responsables de la organización de las Olimpíadas de Moscú. Además, con arreglo en una decisión personal del presidente Jimmy Carter, la prohibición también abarcó cualquier pagamento realizado en favor del COI. ${ }^{102}$

Las restricciones políticas y económicas tuvieron, además, consecuencias en lo jurídico. Las tres principales cadenas de televisión de Estados unidos (ABC, CBS y NBC) estaban dispuestas a cambiar las reglas para la compraventa de los derechos de transmisión de futuras ediciones de los Juegos. Los directivos de las tres emisoras llegaron a reunirse en Nueva York con objetivo de establecer una propuesta única que en

\footnotetext{
${ }^{99}$ PAYNE, Michael. A Virada Olímpica: como os Jogos Olímpicos tornaram-se a marca mais valorizada no mundo. Rio de Janeiro: Casa da Palavra, 2006, p. 9.

${ }^{100}$ Ibidem, p. 24.

${ }^{101}$ Ibidem., p. 25.

${ }^{102}$ Ibidem, p. 24.
} 
seguida sería presentada al COI. La iniciativa buscaba reducir los costes con la compraventa de los derechos de transmisión de los Juegos y, Asimismo, poner fin a años de disputas comerciales.

Para esto, llegaron a solicitar al Departamento de justicia de Estados Unidos que cambiara las reglas antitrust, con objetivo de que pudieran presentar la propuesta al COI, sin que violaran las leyes de Estados Unidos. ${ }^{103}$ El español Juan Antonio Samaranch, presidente del COI, estaba al tanto de lo que iba pasar y de sus consecuencias para el Movimiento Olímpico. Por consiguiente, trató de adoptar medidas que aseguraran el empoderamiento económico del COI frente a los gobiernos, a las cadenas de televisión y a los patrocinadores.

Inicialmente, creó una comisión destinada a buscar nuevas fuentes de recursos que beneficiaran la institución. En seguida, se acercó a Host Dassler, presidente de Adidas, con objetivo de establecer una estrategia de marketing para el COI. Dassler conocía bien el funcionamiento de grandes organizaciones deportivas mundiales, en tanto que ya estaba involucrado con los contratos de patrocinio de la FIFA tras la elección de João Avelange para la presidencia de la entidad. Así las cosas, no le ha sido difícil crear un programa de igual naturaleza para el COI. ${ }^{104}$

En lo político, Samaranch viajó a la práctica totalidad de los países del planeta y se reunió con los principales líderes mundiales, con objetivo de convencerles de que el Movimiento Olímpico juega un importante papel en la búsqueda de la paz universal y, consecuentemente, no puede someterse a disputas políticas internacionales, como pasó en Moscú 1980 y Los Ángeles 1984. ${ }^{105}$

Por último, concentró su labor en la unión de los miembros de la familia olímpica (Federaciones Internacionales, Comités Olímpicos Nacionales y Entidades de atletas), con el objetivo de dar valor a la marca olímpica y exaltar los principios creados por el Barón Pierre de Coubertin, los cuales representaban la pureza del Movimiento Olímpico. ${ }^{106}$

\footnotetext{
103 Ibidem.

${ }^{104}$ Ibidem, p. 31.

105 Ibidem.

106 Ibidem.
} 
El trabajo de Samaranch produjo resultados casi inmediatos. La estrategia de marketing creada por Michael Payne, además de aumentar las ganancias del COI, también le otorgó a la entidad mayor poder en lo relativo a los COJOS, los CONS y las cadenas de televisión. ${ }^{107}$

Hasta los años 1990, las negociaciones relativas a la compraventa de los derechos de transmisión de los Juegos contaban con la participación de, como mínimo, cuatro entidades: el COI, el COJO, el CON y las cadenas de televisión. Sin embargo, la experiencia ha demostrado que la participación de las entidades locales no siempre produjo buenos resultados en lo económico. Los COJOS veían en los contratos una oportunidad para que ganaran mucho dinero en un corto espacio de tiempo. Por tanto, no siempre estaban preocupados con valorizar la marca olímpica. Así, los contratos abarcaban únicamente la transmisión de las principales competencias deportivas, quedando fuera del acuerdo las modalidades de menor popularidad, lo que acababa con perjudicar la marca olímpica. ${ }^{108}$

A partir de la labor de Michael Payne, el COI adoptó la estrategia de negociar los derechos de transmisión no más para cada edición de los Juegos en específico, sino para más de una edición, con lo cual los Comités locales ya no más tendrían el control de todo el proceso. Además, ha decidido negociar estos derechos antes que fuera elegida la ciudad anfitriona, con lo cual eliminaba la presencia de los COJOS y de los CONS en cualquier acuerdo. ${ }^{109}$

Los resultados no tardaron en aparecer. Los ingresos referentes a la compraventa de los derechos de transmisión relativos a las Olimpíadas de invierno aumentaron desde 21,0 millones de dólares en Lake Placid 1980 hasta 738 millones de dólares en Salt Lake City 2002. Igual incremento se verificó en cuanto a los Juegos Olímpicos de verano. Los ingresos saltaron, en este caso, desde 101 millones de dólares en Moscú 1980 hasta 1,497 mil millones en Atenas 2004. ${ }^{110}$

El ingreso de recursos le posibilitó al COI ayudar de manera financiera a las Federaciones Internacionales y a los Comités Olímpicos Nacionales, en particular los de

\footnotetext{
${ }^{107}$ Ibidem, p. 65.

${ }^{108}$ Ibidem, p. 64-65.

${ }^{109}$ OLIVEIRA, Nelma Gusmão de. Jogo Espetáculo, Jogo Negócio. In Boitempo Editorial y Carta Maior. Brasil em Jogo: o que fica da Copa e das Olimpíadas? São Paulo: Boitempo Editorial, 2014, p. 56.

${ }^{110}$ PAYNE, op.cit., p. 37.
} 
países en desarrollo, transfiriéndoles los fondos de que necesitaban para el desempeño de sus tareas. Los recursos saltaron desde 8,0 millones de dólares en los años 1980 para 210 millones de dólares en los años 2000. ${ }^{111}$

Asimismo, con objeto de aumentar aún más las ganancias, Payne decidió comercializar los valores asociados al deporte, como son el honor, la integridad, la determinación, la competencia y la excelencia. ${ }^{112}$ Rápidamente se percató de que a las empresas en general les encantaría vincular su imagen a estos valores y que pagarían caro por hacerlo. Así, trató de negociarlos por un alto precio y, como consecuencia, recuperó las finanzas del COI. ${ }^{113}$

La búsqueda por nuevas fuentes de recursos hizo que el COI también cambiara las reglas de patrocinio de los Juegos. Para tanto, la entidad se asoció a una gran empresa de marketing deportivo, la International Sport Leisure (ISL), quien creó el llamado Top Olympic Partnership en 1982.

El programa ha posibilitado a los patrocinadores exhibir sus marcas con exclusividad en productos ofrecidos por el COI. Igual que en los contratos de transmisión, también podrían adquirir el derecho de exhibición para más de una edición de los Juegos, lo que le ha dado al COI la posibilidad de aumentar sus ingresos con la compraventa de los activos asociados a las Olimpíadas. La iniciativa, además, ha buscado eliminar la participación de los COJOS y CONS en el proceso de negociación de tales contratos. ${ }^{114}$

La alteración no le terminó de gustar a los COJOS y a los CONS, en tanto que consideraban que el TOP les quitaba poder político y económico en lo relativo a la preparación de las Olimpíadas. El COI argumentó, en respuesta, que la negociación de los contratos bajo el nuevo régimen le posibilitaría a la entidad sacar más recursos de los patrocinadores. Asimismo, señaló que las ganancias conquistadas igual serían compartidas con las entidades locales, quienes recibirían un valor fijo para cada mega evento, además de una gratificación por atleta que acudiese a los Juegos.

Las expectativas se habían confirmado. Cuando fue inaugurado en el 1982 mirando a las Olimpíadas de verano de Seúl 1988 y a las Olimpíadas de invierno de Calgary 1988,

\footnotetext{
111 Ibidem, p. 37.

112 OLIVEIRA, op. cit., p. 56.

${ }^{113}$ PAYNE, op. cit., p. 29.

${ }^{114}$ OLIVEIRA, op. cit., p. 56-57.
} 
el programa TOP logró reunir a nueve empresas patrocinadoras, quienes ingresaron 175 millones de dólares en las arcas de la entidad apenas en el cuadrienio 1988 a 1991. Catorce años después, en el cuadrienio 2005 a 2008, correspondiente a los Juegos Olímpicos de invierno de Torino 2006 y a los Juegos Olímpicos de verano de Pequín 2008, las ganancias se acercaron a 1,0 mil millones de dólares.

A modo de incrementar las ganancias del COI, Michael Payne se lanzó a un nuevo desafío. Buscó descubrir que aspectos de la marca olímpica interesaban a las empresas, es decir, que atributos llevarían las compañías a perfeccionar contratos de patrocinio con la institución. La investigación ha revelado que cuatro expresiones despertaban el interés de las grandes corporaciones: ${ }^{115}$

a) Esperanza;

b) Sueño e inspiración;

c) Amistad; y

d) Lisura y placer por el esfuerzo.

La investigación ha revelado, además, que las empresas no querían asociar sus marcas a productos considerados políticamente incorrectos, como el tabaco y las bebidas alcohólicas.

Con arreglo en los resultados, Payne inició una campaña publicitaria que conectaba las mencionadas expresiones a escenas de los Juegos Olímpicos cargadas de emociones y con gran valor simbólico. La idea fue clara, pues Payne quería exaltar los valores olímpicos y despertar el interés de las empresas en lo relativo a posibles contratos perfeccionados con el COI.

Con fundamento a la investigación, creó un riguroso protocolo que ha buscado seleccionar las entidades que podrían ser patrocinadoras de la institución. Desde esta perspectiva, no todos podrían asociar su marca a las enseñas olímpicas. Únicamente las entidades que pudieran valorizar la imagen del COI podrían perfeccionar contratos con la entidad.

Finalmente, a modo de atraer grandes corporaciones, también fijó reglas que prohibieran el llamado marketing de emboscada, o sea, el uso indebido de la marca

115 PAYNE, op.cit., p. 31-32. 
olímpica por personas no autorizadas. La restricción ha buscado asegurar la exclusividad otorgada en favor de los patrocinadores del COI.

Las alteraciones realizadas impactaron en la visibilidad de los Juegos. A finales del siglo XX, la audiencia del mega evento se acercó a 4,0 mil millones de personas en 200 países en todo el planeta, lo que ha convertido a los Juegos en el principal evento televisivo del mundo, ${ }^{116}$ lo que igual los convierte en objeto de deseo de muchas ciudades alrededor del planeta. Así, cada nueva edición de los Juegos significa una singular oportunidad para la realización de grandes inversiones en ámbito local, además de promover la imagen de la ciudad anfitriona internacionalmente. ${ }^{117}$

En efecto, tras el invento de la televisión, la imagen ha adquirido un papel fundamental en lo relativo al desarrollo urbano de la ciudad y, consecuentemente, su supervivencia económica depende, cada vez más, de su capacidad para atraer nuevas inversiones ${ }^{118}$. A causa de ello, los responsables políticos de la ciudad se ven obligados a adoptar estrategias de gestión que buscan promoverla cada vez más en el escenario nacional e internacional, con objeto de atraer todos tipos de inversiones. ${ }^{119}$ Así, la ciudad se presenta al mundo como un dichoso ambiente capaz de recibir todos tipos de creencias, ideas y negocios, con lo cual, se convierte en un verdadero mercado de oportunidades abierto a todos tipos de inversiones.

Aunque este fenómeno sea más evidente a partir de la segunda mitad del siglo XX, lo correcto es que las estrategias de valorización de la imagen de la ciudad acompañan al hombre desde hace muchos años. Históricamente, siempre ha habido iniciativas en el sentido de dar valor a la imagen de la ciudad en el ámbito nacional e internacional, como ha pasado, por ejemplo, con las Ciudades-Estado italianas de Firenze y Venecia, cuya imagen ha estado asociada a grandes transacciones comerciales. Lo mismo ha pasado con las ciudades de la Costa Oeste de Estados Unidos a partir del siglo XIX, por entonces consideradas adecuadas para la realización de excelentes negocios, principalmente en lo

\footnotetext{
${ }^{116}$ Ibidem, p. 31-32.

${ }^{117}$ Ibidem, p. 15.

118 RICHARDS, Greg; PALMER, Robert. Why cities need to be eventful. Eventful Cities: Cultural Management and Urban Revitalization. London: Routledge, 2012, p. 37.

119 BROUDEHOUX, Anne-Marie. Mega-events and Urban Image Construction. Oxford: Routledge, 2017, p. 5.
} 
relativo al descubrimiento del oro, metal precioso que había sido encontrado en California tras la independencia. ${ }^{120}$

A partir de la segunda mitad del siglo XIX, el proceso de valorización de la imagen de la ciudad estuvo directamente asociado a los mega eventos internacionales, como las grandes ferias y exposiciones organizadas por algunas de las principales metrópolis del planeta. Así, en 1850, Londres ha recibido una gran exposición internacional que, más allá de exhibir las últimas novedades tecnológicas, también ha buscado demostrar el protagonismo y la importancia de la capital inglesa en el escenario económico mundial. En este sentido, Londres se ha presentado a los asistentes como una ciudad propicia a la realización de excelentes negocios y, por ende, lista para recibir capitales de todas partes del planeta.

Cuarenta años después, en 1893, Chicago también organizó una gran exposición internacional con las mismas características, con objeto de presentarla al mundo como otro importante centro de negocios. Semejante estrategia adoptó la ciudad de San Francisco, California, tras la gran feria internacional de 1906. Nueve años tras el encuentro, en 1915, la ciudad acogió a la exposición internacional de Panamá y Pacífico, con objeto de demostrar al mundo su desarrollo y, asimismo, su nueva realidad económica. San Francisco ha sido, por tanto, desde principios del siglo XX, una de las ciudades más importantes de Estados Unidos y utilizó el mega evento para divulgar esta realidad al mundo. ${ }^{121}$

A partir del siglo $\mathrm{XX}$, con la gran industrialización, la disputa por nuevas inversiones ha aumentado aún más y las ciudades trataron de adoptar estrategias para valorizar su imagen cada vez más. La alternativa fue realizar mega eventos de todos tipos, tales como conferencias, congresos, seminarios y conciertos, que mantendrían su nombre en el escenario internacional. Actualmente, ciudades como Londres, Paris y Ámsterdam poseen programas específicos que miran hacia la promoción de la imagen de la ciudad internacionalmente y que buscan presentarlas como ambientes favorables a la realización de grandes negocios. ${ }^{122}$

En este sentido, los mega eventos deportivos internacionales como los Juegos Olímpicos y la Copa del Mundo de Fútbol cumplen con un papel fundamental en esta

\footnotetext{
120 Ibidem.

${ }^{121}$ BENEDICT, Burton. The Anthropology of World's Fairs: San Francisco's Panama Pacific International Exposition of 1915. Berkeley, CA, Lowie Museum of Anthropology, 1983.

${ }^{122}$ BROUDEHOUX, op.cit., p. 6.
} 
materia. Además de permitir la construcción de grandes estadios y modernas arenas, los grandes eventos deportivos también fomentan la construcción de otros emprendimientos, como grandes centros de negocios, aeropuertos, hoteles de lujo y viviendas, que, en definitiva, acaban con promover la imagen de la ciudad en el escenario mundial.

De ahí la razón por la que, recientemente, ciudades de países en desarrollo buscan atraer a los mega eventos deportivos a su territorio. Por lo general, confían en que con la realización del espectáculo le aportará a la metrópoli beneficios económicos inmediatos, además de promoverla en el escenario internacional. Al respecto, merecen particular referencia la realización de los Juegos de la Commonwealth de 2010, disputados en Nueva Deli; los Juegos Olímpicos de 2008, pasados en Pequín; los Juegos Olímpicos de Invierno de 2014, disputados en Sochi; y los Juegos Olímpicos de 2016, realizados en Río de Janeiro. Además, merecen ser destacadas la Copa del Mundo de Fútbol de 2010, disputada en Sudáfrica; la Copa del Mundo de Fútbol de 2014, realizada en Brasil; y, finalmente, la Copa del Mundo de 2018, pasada en Rusia. ${ }^{123}$

Aparte del elemento económico, los Juegos también exaltan los llamados principios olímpicos, cuidadosamente fijados por el Barón Pierre de Coubertin, en 1894, apenas creó el Comité Olímpico Internacional (COI). Con arreglo a estos principios, los Juegos Olímpicos deberán: promover el desarrollo de las calidades físicas y morales de los atletas; educar los jóvenes a través del deporte, incentivando la amistad y el entendimiento universal; difundir los principios olímpicos alrededor del planeta y la buena voluntad mundial; y reunir a los atletas del planeta a cada cuatro años para que participen de los Juegos Olímpicos. Los principios olímpicos constituyen, además, el fundamento de los llamados ideales olímpicos: fraternidad, amistad, paz y entendimiento universal. ${ }^{124}$

Así las cosas, la pregunta que inaugura este apartado y que, asimismo, podría titular el siguiente capítulo es la siguiente: ¿Existe corrupción en los Juegos Olímpicos? La respuesta es afirmativa.

La corrupción es un fenómeno de ámbito global que afecta a todas las formas de organización humana conocidas y que logra diseminarse a la vez por las estructuras de poder más sencillas y por las más refinadas y complejas. En nuestros días, gracias a la

\footnotetext{
${ }^{123}$ Ibidem, p. 12.

${ }^{124}$ PAYNE, op. cit., p. 15.
} 
sofisticación de la sociedad, los comportamientos corruptos adoptan formas tan variadas que el Derecho - como herramienta de control social - trata de seguir sus huellas, con el objetivo de desvelar sus estratagemas y artimañas, sobre todo cuando ellos le posibilitan esconderse por detrás de los principios e ideales olímpicos.

La estrategia consiste, en este caso, en utilizar el discurso típico de otras ciencias sociales que buscan exaltar la pureza del deporte frente a otras actividades y, por consiguiente, colocarlo a salvo de cualquier forma de control social. Así las cosas, a partir de los conceptos afines a la sociología, se creó el discurso de que las actividades deportivas se caracterizan como actividades recreativas o miméticas y, como tal, no se someten a los influjos de la corrupción.

En otras palabras, el deporte sería un mundo aparte que exaltaría principios e ideales no económicos por encima de todo, los principios e ideales olímpicos, y, por ello, no sería un ambiente favorable a las malas prácticas administrativas. Se insiere, como ya lo hemos dicho, en el universo de las actividades recreativas o miméticas, que valorizan el placer y el deleite de los individuos por encima de todo.

Desde la perspectiva de la sociología, las actividades humanas suelen clasificarse en recreativas o miméticas y no recreativas o laborales, según la extensión del control que la sociedad ejerce sobre el comportamiento de sus miembros. ${ }^{125}$

Las actividades no recreativas o laborales se caracterizan por el acentuado control social de las emociones y sentimientos de las personas, con objetivo de mantener el equilibrio y la paz social. ${ }^{126}$ Tal control invade todas las esferas de la vida y trata de impedir que las emociones de uno se vayan de las manos y favorezcan a la formación de una atmosfera de intranquilidad que podría perjudicar la vida en comunidad. ${ }^{127}$

Ello no significa que estas personas no tengan sentimientos. Es evidente que lo tienen, pero, desde jóvenes son educados a controlarlos y a concentrar toda su energía en tareas profesionales, académicas o de otra naturaleza, que no dependen de manifestaciones de carácter emocional para su ejecución. No hay espacio para sentimientos, toda vez que ellos podrían dañar el equilibrio de las relaciones sociales. ${ }^{128}$

\footnotetext{
${ }^{125}$ ELIAS, Norbert; DUNNING, Eric. Deporte y Ocio en el Proceso de la Civilización. Traducción de Purificación Jiménez. México/DF: Fondo de Cultura Económica, 2015, L. 2121.

${ }^{126}$ Ibidem, L 2118.

127 Ibidem, L. 3447-3451.

${ }^{128}$ Ibidem, L. 3256.
} 
En el universo de las actividades no recreativas o laborales, uno jamás podrá decirle al superior jerárquico, al empleado o al cliente lo tanto que le detesta, le odia o le gustaría alejarse de él. Asimismo, tampoco podría revelarle a su compañera de trabajo lo tanto que la quiere y como le encantaría acostarse con ella. En ambos casos, si lo hace, la revelación de estos sentimientos podría tener consecuencias devastadoras en lo social y en lo jurídico, siempre que estas actividades se someten a un riguroso control de la sociedad. ${ }^{129}$

Las actividades recreativas o miméticas, en sentido contrario, son aquellas en donde los controles sociales no inciden con tanto rigor. Las personas pueden manifestar sus emociones y sentimientos libremente, sin preocuparse con las consecuencias sociales o jurídicas de sus actos. Entran en esta categoría actividades como el deporte, la danza, la música y el teatro. ${ }^{130}$

Así, cuando uno acude al teatro, a un concierto o a un partido de fútbol, sabe que en tales ambientes podrá expresar sus sentimientos con libertad y animar a su equipo, ofender al árbitro o discutir con su compañero y, en ningún caso, sufrirá con reproches sociales a causa de sus manifestaciones. ${ }^{131}$

La diferencia de tratamiento de una y otra actividad se explica a causa del relevante papel que las actividades recreativas o miméticas juegan en la sociedad. Estudios sociológicos comprueban que el ablandamiento de las reglas de autocontrol favorece al relajamiento de las tensiones y a la recuperación física y psicológica de los individuos. ${ }^{132}$

Ello explica porque, en Inglaterra, el desarrollo de actividades recreativas conectadas al deporte ha tomado mayor relevancia a partir de la Revolución Industrial del siglo XVIII, exactamente cuando los operarios empeñaban largas jornadas de trabajo en las fábricas. Las actividades miméticas han funcionado como antídotos para las preocupaciones normales y corrientes de los individuos, ofreciéndoles dichosos momentos de placer y alegría que no siempre disfrutaban en las actividades no recreativas o laborales. ${ }^{133}$

\footnotetext{
${ }^{129}$ Ibidem, L. 3256.

${ }^{130}$ Ibidem, L. 3211.

${ }^{131}$ Ibidem, L. 2154.

132 Ibidem, L. 2764.

${ }^{133}$ Ibidem, L. 4222.
} 
Los fundamentos sociológicos son reforzados, además, por elementos históricos. Los Juegos de la antigua Grecia se realizaban bajo un ambiente de harmonía y confraternización universal, acudiendo a cada mega evento atletas de todas partes de la península balcánica y otros territorios, con objetivo de rendir homenaje a la divinidad y participar de las festividades deportivas que se realizaban a cada cuatro años.

El carácter religioso de las fiestas pone de manifiesto otro aspecto de los Juegos. El atleta olímpico debería ser, en principio, un hombre virtuoso en lo deportivo y en lo moral, acercando su conducta al comportamiento comúnmente esperado de los héroes. Con arreglo en estas características, se firmó el discurso de que, al menos en principio, la corrupción y el deporte constituyen fenómenos que no andan juntos. La corrupción es una enfermedad que ataña a la violación de la ley y al despilfarro de fondos públicos, mientras que el deporte pertenece al universo de las actividades lúdicas y placenteras. Sería un mundo sano y limpio y, además, nada tenía que ver con las malas prácticas comunes en otros sectores de la sociedad. ${ }^{134}$ Hasta el día de hoy, el COI insiste con que los principios olímpicos de la antigua Grecia son la base y el fundamento del Movimiento Olímpico moderno. ${ }^{135}$

Pese al discurso en favor de la absoluta pureza del deporte en cuanto a otras actividades, la experiencia ha demostrado que el recurso a definiciones y conceptos afines a la sociología no se ha confirmado en el mundo de los hechos. Las malas prácticas acompañan a los Juegos Olímpicos desde la Grecia antigua, ${ }^{136}$ en donde estuvo asociada con diferentes tipos de irregularidades.

Además de los ejemplos ya expuestos, podemos recordar en este momento que en el 388 A.C., el corredor griego Tessalio Eupolo había sobornado a sus rivales a cambio de que ellos le facilitaran la victoria en la principal carrera de los Juegos Olímpicos. Igual en 332 A.C., el pentatleta ateniense Calipo había sobornado a sus adversarios con

\footnotetext{
${ }^{134}$ BONOLI, Paolo Bertucci. Análisis de la Correlación entre Corrupción y Deporte desde la Perspectiva Transdisciplinar. Revista Encuentros Multidisciplinares, v. 13, n. 39, 2011, p. 47-56. Disponible en: https://dialnet.unirioja.es/servlet/articulo? $\operatorname{codigo}=3778571$ Acceso en: 02 jul 2019.

${ }^{135}$ HEATHER. L. Reid, Afterword: "Olympic Philosophy between East and West", en BROWNELL, Susan (comp.). From Athens to Beijing. West Meets East In the Olympic Games, v. 1, Sport, the Body and Humanism in Ancient Greece and China. Nueva York: Greekworks, 2013, p. 199-222.

${ }^{136}$ Según la mitología, el primer caso de corrupción en los juegos ha ocurrido en una carrera de la que participó Pelopes, rey de Frigia, que ha logrado vencer a todos sus oponentes a causa de un soborno que les pagó antes que comenzara la competencia, con ello conquistando el derecho de casarse con Hipodamia. PÉREZ, op.cit, L. 610.
} 
monedas de oro a cambio de que le permitiesen convertirse en un campeón olímpico. ${ }^{137}$ Asimismo, Gayo Plinio II, escritor, científico, naturalista, botánico y militar romano, había relatado que algunos competidores solían prepararse infusiones a base de determinados hongos especiales, con objeto de que la sustancia les aumentase la resistencia durante las carreras más largas de los Juegos. ${ }^{138}$

En todos casos, las irregularidades se explican a causa de los beneficios sociales y económicos que la victoria le otorgaba al atleta campeón. El vencedor disfrutaba del reconocimiento público de sus virtudes físicas y morales, y la organización del mega evento le construía una estatua en el lugar de la conquista, como para que fuese un ejemplo a los demás ciudadanos. Asimismo, los poetas y músicos de su propia ciudad les alababan el triunfo como si fuese un verdadero héroe. A veces, solía recibir donaciones, caballos, mujeres, cien ánforas de aceite, una casa nueva o, incluso, quedaba exento en cuanto al pago de tributos. ${ }^{139}$ La victoria también les facilitaría el acceso a las clases más altas de la sociedad y le otorgaría un puesto en la elite gubernamental. ${ }^{140}$

Pero, si la victoria en los Juegos podría traerle al campeón tantos beneficios, la infracción de las reglas también le sometía a un riguroso régimen de sanciones. Los atletas deshonestos eran deshonrados en público y, además, condenados a pagar una multa que prácticamente les quitaba cualquier beneficio económico obtenido con la victoria. El valor de la sanción se utilizaba, asimismo, para la construcción de una estatua en honor a la divinidad que gobernaba cada edición de los Juegos. Las faltas pasadas en Olímpia, por ejemplo, autorizaban la edificación de una estatua en alabanza a Zeus, como para pedirle perdón por el error cometido.

La estatua, además, debía quedarse a lo largo del camino hacia Olímpia y contendría el nombre del atleta corrupto, como para que todos conocieran el motivo de su condena. Así, en 388 A.C., Tessalio Eupolo y sus rivales fueron condenados a pagar una multa que habría financiado la construcción de cinco estatuas de bronce ubicadas a lo largo del camino hacia Olímpia. En 332 A.C., Calipo y sus adversaros fueron considerados

\footnotetext{
${ }^{137}$ Ibidem, L. 610.

${ }^{138}$ Ibidem, L. 843.

${ }^{139}$ Ibidem, L. 173 y 697.

${ }^{140}$ ELIAS; DUNNING, op.cit., op.cit., L. 4032.
} 
responsables de corrupción y pagaron una multa que costearía una estatua en tributo a Zeus. ${ }^{141}$

La deshonra pública del atleta y la aplicación de sanciones no ha agotado el universo de sanciones aplicables a los atletas corruptos. El soborno de un árbitro le sometía el malhechor al apaleamiento público o autorizaba que le fuera aplicada una violenta ración de azotes. ${ }^{142}$

La existencia de un régimen de sanciones indica que la corrupción no ha sido un hecho aislado de una u otra edición de los Juegos de la Grecia antigua, sino una enfermedad que ha acompañado al mega evento a lo largo de muchos festivales. Es más. Estudios recientes han demostrado que las malas prácticas del pasado han atravesado los siglos y llegado a los Juegos Olímpicos Modernos, a los cuales afectaron en cuatro aspectos, tales como: ${ }^{143}$

a) La corrupción relacionada con la gestión económica de los mega eventos deportivos y las licitaciones públicas;

b) La corrupción referente a las apuestas clandestinas;

c) La corrupción asociada al doping; y

d) La corrupción conectada al soborno de atletas y árbitros.

A pesar de la variedad de asuntos conectados al estudio de la corrupción en el deporte, interesa en este capítulo, únicamente, el análisis de las malas prácticas que atañan a la preparación de los Juegos Olímpicos y su relación con la transparencia gubernamental.

En este sentido, las investigaciones desarrolladas a causa de esta tesis doctoral demuestran que la desestimación a la transparencia no ocurre de igual manera en todas ediciones de las Olimpíadas. Hasta el 1992, época de los Juegos de Barcelona, las infracciones se daban en lo relativo a la falta de divulgación de informaciones esenciales respecto a la preparación de la ciudad anfitriona.

Desde Atlanta 1996, mucho antes al invento de internet y de la aprobación de leyes de transparencia en varios países, ya se nota una preocupación de los gobiernos con publicar informaciones relativas a la divulgación de los preparativos realizados con

\footnotetext{
${ }^{141}$ PÉREZ, op.cit., L. 610.

142 Ibidem, L. 216 e 217.

${ }^{143}$ BONOLI, op.cit., p. 47-56.
} 
motivo de los Juegos, si bien no siempre la forma de divulgación puede favorecer el control ciudadano de los actos oficiales. Todavía se nota algunos espacios de oscuridad en determinados ordenamientos que acaban con favorecer la comisión de actos de corrupción.

Para entender esta peligrosa asociación entre Juegos Olímpicos, transparencia y corrupción, será necesario, primero, retroceder al siglo XIX y estudiar los movimientos olímpicos que antecedieron a la restauración de los Juegos Olímpicos Modernos a partir de 1896. Cada uno de estos movimientos, comenzando con los Juegos Escandinavos de 1834, han incorporado a los Juegos Olímpicos elementos que fueron importantes para su crecimiento en ámbito internacional a partir del siglo XX. En resumen, los movimientos del siglo XIX lanzaron las bases sobre las que el COI ha edificado todo su empoderamiento político, económico y científico en cuanto a los Juegos Olímpicos.

Paralelamente a ese crecimiento, es posible observar la comisión de actos contrarios a la ley y al derecho que, técnicamente, se clasifican como corrupción. Desde esta perspectiva, por tanto, la corrupción ha acompañado a los Juegos desde las primeras ediciones del mega evento, aunque el COI se esforzara en el sentido de esconderla atrás de rituales y de un discurso especialmente creado para fortalecer la marca olímpica.

Además, la experiencia ha demostrado que los mega eventos deportivos suelen ser responsables de ahondar las desigualdades sociales, aumentar la inflación, promover una valorización artificial del precio de los inmuebles y comprometer la implementación de programas sociales a cargo del Estado, ${ }^{144}$ con lo cual, en los últimos años, sufren con la resistencia de los vecinos de grandes ciudades del planeta, quienes, gracias a la transparencia, conocen las irregularidades a menudo asociadas a estos grandes espectáculos y se manifiestan en contra su realización.

\subsection{Los antecedentes de la restauración de los juegos olímpicos modernos}

Históricamente, debe tenerse en cuenta el dato de que Teodosio I en 380 d. C., declarase extintos los juegos olímpicos tal y como los concibieron los griegos antiguos, provocando que no se realizasen nunca hasta que un rico comerciante ateniense del siglo XIX trató de poner en marcha la idea de su restauración. En 1856, Evangelios Zappas le

${ }^{144}$ HAYES, Graeme. and Horne, John. Sustainable Development: Shock and Awe. London 2012 Civil Society', Sociology. v. 45, n. 5, p. 749-764., 2011. 
escribió al Rey Oto de Grecia ofreciéndole recursos para que restaurara los juegos olímpicos de la antigüedad.

La idea había complacido al monarca. El Rey veía en los Juegos Helénicos no solo un excelente motivo para exaltar los juegos del pasado, como también una extraordinaria oportunidad de divulgar al mundo la recién conquistada independencia de Grecia frente al Imperio Otomano en el año 1821 . $^{145}$ Tras una sangrienta guerra que se extendió por casi once años, ${ }^{146}$ desde el 1821 hasta el $1832,{ }^{147}$ proporcionó as griegos la posibilidad de sentirse señores de su destino y, en este contexto, la realización de los Juegos podría darles el protagonismo que buscaban a mediados del siglo XIX. ${ }^{148}$

Zappas también veía en los juegos ventajas que iban más allá de lo deportivo. La restauración sería una excelente ocasión para apalancar sus negocios, ya que le daba la posibilidad de involucrarse en cada una de las obras de preparación del encuentro. Se empeñó en particular con la restauración del estadio Panathenaicos. La majestuosa edificación acogió las competencias de atletismo en la Atenas antigua ${ }^{149}$ y, por tanto, tenía un inestimable valor histórico para los griegos.

Así las cosas, Zappas no midió esfuerzos para que la edificación reprodujera la arquitectura de la construcción original. El estadio tenía una escalera en mármol blanco igual a de los Juegos de la antigüedad y toda la atmosfera de la edificación invitaba a los asistentes a que se sintiesen como si regresaran al pasado. ${ }^{150}$

Desde esta perspectiva, los Juegos Helénicos presentaron, además, tres elementos que iban a acompañar los Juegos Olímpicos y Paralímpicos a lo largo de los años

${ }^{145}$ LAFORGE, François. Los Juegos Olímpicos. Paris: De Vecchi Ediciones, 2012, L. 266.

146 VIVES, Eduard. La Independencia de Grecia. Disponible en: https://evives3.files.wordpress.com/2014/10-independencia-grecia.pdf. Acceso en 13 jul 2018.

${ }^{147}$ Los griegos consideran que el día 25 de marzo del 1821 es la fecha oficial de la independencia de Grecia frente al Imperio Otomano. Celebran el hecho histórico de que en aquel día en específico, el monasterio de Agia Labra, en el Peloponeso, hizo un llamamiento de toda la gente a la guerra contra los turcos. Aunque los griegos fueran derrotados, se trata de una fecha de gran significado para ellos. Ibidem.

${ }^{148}$ MEDEIROS, Carolina. Trégua Olímpica: Da Antiguidade Aos Dias de Hoje. Revista Pré-Univesp, n. 61, UNIVERSO, dezembro 2016, janeiro 2017, p. 1-14. Disponible en http://pre.univesp.br/treguaolimpica\#.WzO27haHvYU

\footnotetext{
_Acceso en: 06 jun 2018.

${ }^{149}$ MEDEIROS, op.cit. p. 9.

${ }^{150}$ Ibidem.
} 
siguientes. En todo momento habría, siempre una estrecha relación entre inversiones estatales, obras públicas y emociones de los espectadores. Los tres factores serían esenciales para que los mega eventos fosen exitosos y que, además, pudiesen superar las críticas de sus principales adversarios.

Ajenos a esta realidad, los griegos de mediados del siglo XIX habían trabajado duro para poner en marcha los Juegos Helénicos. Las obras de preparación del encuentro tardaron tres años para terminar. Al final, habían dado la posibilidad de la realización de cuatro ediciones del mega evento en un periodo de treinta años: 1859, 1870, 1875 y 1889. La edición de 1870 fue de las más relevantes. Atrajo a 30.000 espectadores a Atenas. Los asistentes, además de animar a los atletas griegos, querían conocer al histórico estadio Panathenaicos, ${ }^{151}$ cuna de tantas victorias de los atletas griegos en el pasado tan lejano.

A pesar de su relevancia, los Juegos Helénicos fueron bastante inferiores a los primeros Juegos Olímpicos de la Era Moderna. La competencia idealizada por Evangelios Zappas ha contado únicamente con atletas griegos y del imperio Otomano. ${ }^{152}$ Ello ha dificultado su consolidación en el escenario internacional, ya que el encuentro no contaba con el apoyo de otros países.

Sin embargo, aunque no se firmasen, los Juegos Helénicos demostraron que, en el siglo XIX, ya había el deseo de restaurar los Juegos Olímpicos de la Grecia antigua. Son numerosos los ejemplos. Así, en 1834 y 1836, el educador sueco Gustav Johan Schartau realizó los juegos escandinavos, ${ }^{153}$ en 1844 , la comunidad de lengua inglesa en Montreal organizó los juegos anglófonos; ${ }^{154}$ en 1850, William Penny Brookes organizó los primeros juegos olímpicos de Gran Bretaña; ${ }^{155}$ en 1862, Charles Melly y John Hulley organizaron el festival olímpico de Liverpool; ${ }^{156}$ y, en 1865, John Hulley, William Brookes y Ernst Ravenstein organizaron los Juegos de Londres; ${ }^{157}$ De todos ellos,

\footnotetext{
${ }^{151}$ GOLD, John R. Gold, Margaret M. Olympic Cities: City Agendas, Planning and the World's Games, 1896-2020. Routledge, Oxford: 2016, p. 26.

${ }^{152}$ MEDEIROS, op.cit..

${ }^{153}$ LAFORGE, op.cit., L. 274.

${ }^{154}$ GOLD, John R. Gold, Margaret M. op. cit., p.25.

${ }^{155}$ GOLDBLATT, David. The Games: A Global History of The Olympics. London: Pan Macmillan, 2016, p. 21.

${ }^{156}$ Ibidem, p. 22.

${ }^{157}$ Ibidem, p. 23.
} 
merecen particular referencia los tres últimos a causa de los elementos que incorporaron a los futuros Juegos Olímpicos Modernos, recreados por el Barón Pierre de Coubertin.

Los Juegos de Much Wenlock fueron ideados por el cirujano inglés William Penny Brookes en 1850. Brookes se aprovechó del prestigio que tenía como miembro de la sociedad de Agricultores de Much Wenlock, Inglaterra, para crear las llamadas clases olímpicas. Esas clases consistían en una serie de ponencias que buscaban perfeccionar el desarrollo moral, físico e intelectual de los vecinos. ${ }^{158}$ A las enseñanzas teóricas les seguían entretenidos torneos de cricket, fútbol, arco y fleja y atletismo. ${ }^{159}$

En principio, los Juegos de Much Wenlock no utilizaban recursos oficiales, así como tampoco construían grandes estructuras para el encuentro. Por lo que no tenían el glamur de los Juegos Helénicos de Evangelios Zappas o de la Grecia antigua. Sin embargo, acudían comúnmente al encuentro atletas amateurs y profesionales, hombres y mujeres de todas las edades y clases sociales, lo que era suficiente para demostrar su exitosa fórmula de preparación. No había, en ese entonces despilfarro de fondos públicos en estos encuentros. Los recursos eran limitados y, por ello, había mucho cuidado con su utilización.

La popularidad de la primera edición animó a que Brookes organizase ediciones anuales del evento. ${ }^{160}$ Así, la segunda edición contó con modalidades como el ciclismo y el tiro, además de torneos de poesía, canto y baile. ${ }^{161}$ La directriz de preparación del torneo se mantuvo en relación al primer encuentro, así como la no inclusión de inversiones públicas y, por tanto, la no existencia de registros de casos de corrupcion.

Pero, el acercamiento de los juegos de Much Wenlock a los poderes públicos no tardó en realizarse. En 1860, Brookes escribió a los alcaldes de cinco ciudades vecinas y les propuso organizar los primeros juegos olímpicos de la región de Shropshre. ${ }^{162}$ Esa iniciativa agradó a los prefectos. Juntas, las máximas autoridades organizaron cuatro

\footnotetext{
${ }^{158}$ Ibidem, p. 21.

159 Ibidem.

${ }^{160}$ GOLD, John R. Gold, Margaret M. op. cit., p.25.

161 Ibidem, p. 21.

${ }^{162}$ Ibidem.
} 
ediciones de los juegos en los cuatro años siguientes, llegando a realizar un mega evento que contó con la asistencia de 15.000 personas. ${ }^{163}$

Con arreglo al triunfo de los Juegos de Much Wenlock, en 1862, Charles Melly y John Hully organizaron el festival olímpico de Liverpool. El evento fue ampliamente divulgado por la prensa británica, y el periódico Liverpool Daily Post describió al encuentro como una extraordinaria fiesta del deporte. ${ }^{164}$ El Festival había reunido a los mejores atletas amateurs de la región. Al contrario de los Juegos de Much Wenlock, el Festival de Liverpool no premiaba a los campeones olímpicos con dinero. Los vencedores recibían únicamente una medalla de plata o bronce, de conformidad con el resultado de la competencia. ${ }^{165}$ A pesar de las restricciones, en cuanto a la participación de atletas profesionales, los Festivales de Liverpool fueron de los más populares de Inglaterra, realizadas tres ediciones del mega evento, destacando el evento de 1863 que reunió a 12.000 personas. ${ }^{166}$

El gran número de asistentes no fue el único aspecto que llamó la atención en estos encuentros. Con el paso del tiempo, los Juegos evolucionaron e incorporaron nuevos elementos que fijaron las bases sobre las que el COI estructuró los Juegos Olímpicos Modernos.

Los juegos de Suecia e Inglaterra de 1834 y 1850, respectivamente, revelaron la importancia del factor humano para el desarrollo de los mega eventos deportivos. Sin la labor de hombres como Gustav Schartau y William Brookes, los festivales escandinavos y los encuentros de Much Wenlock no se podrían haber realizado. Nadie habría reunido a los ciudadanos en su conjunto alrededor de esa idea fundamental y los animaría a participar de entretenidos torneos deportivos. En resumen, sin la labor y la dedicación de estos hombres, los Juegos no llegarían a realizarse.

Los Juegos Helénicos, por otro lado, involucraron al Estado y a los empresarios en los preparativos de los torneos olímpicos. La intervención estatal habría contribuido directamente para el crecimiento del evento y, además, facilitando e indicado el camino

\footnotetext{
${ }^{163}$ Ibidem.

${ }^{164}$ Ibidem, p. 22.

${ }^{165}$ Ibidem.

166 Ibidem.
} 
que torneos de esta naturaleza iban a seguir a partir de finales del siglo XIX. Con rarísimas excepciones, la producción exitosa de espectáculos de esta magnitud dependería cada vez más de grandes inversiones públicas y de la participación de empresas privadas para su realización.

Asimismo, los festivales de Liverpool habrían incorporado a los juegos la participación de los medios, poderosos vehículos que fueron responsables de la divulgación del mega evento en los primeros años tras la restauración de los Juegos Olímpicos y que, posteriormente, convirtieron el encuentro en la principal plataforma publicitaria del planeta.

En 1865, los Juegos de Londres se incorporaron otros elementos al universo de los mega eventos deportivos. Se propuso, por primera vez, la creación de una entidad que reuniría bajo su liderazgo las asociaciones y clubes deportivos de Inglaterra. La institución era considerada el embrión del futuro COI. ${ }^{167}$ La idea era que la Asociación Olímpica Nacional organizase los Juegos Olímpicos del Reino Unido, que dictara las reglas de la participación de atletas amateurs y eligiera la ciudad anfitriona de cada encuentro. El monopolio de los Juegos Olímpico, recaía en Reino Unido. Esa iniciativa no les complació a las demás asociaciones y clubes de Inglaterra. Así, en febrero de 1866, trataron de constituir la Asociación de Clubes Amateurs y pasaron a ser los rivales de la Asociación Olímpica Nacional en cuanto al monopolio de los Juegos Olímpicos. ${ }^{168}$

Las disputas políticas habrían impedido que los ingleses fuesen los responsables de la recreación de los Juegos Olímpicos Modernos, ${ }^{169}$ influenciando a que otros lo intentaran a finales del siglo XIX. ${ }^{170}$

Viendo todo este protagonismo, en 1890, el príncipe Constantino de Grecia dictó un Real Decreto donde se establecía que, desde el 1892, se iniciaba un nuevo periodo olímpico de cuatro años. ${ }^{171}$ Con arreglo a esta normativa, en 1891 y 1893 , los griegos realizaron dos ediciones de los juegos panhelénicos de Evangelios Zappas. ${ }^{172}$ A pesar de

\footnotetext{
${ }^{167}$ Ibidem, p. 23.

${ }^{168}$ Ibidem.

${ }^{169}$ Ibidem , p. 24.

${ }^{170}$ MEDEIROS, op. cit.

${ }^{171}$ GOLDBLATT, op. cit., p. 26.

${ }^{172}$ Ibidem.
} 
la tentativa, no lograron restaurar los Juegos Olímpicos. A finales del siglo XIX, los Helénicos ya no tenían el protagonismo del pasado y no habían convencido a los demás países de Europa al respecto de la importancia de recrear los Juegos. Asimismo, las experiencias anteriores ya habían demostrado que la restauración dependería de la conjugación de diferentes factores, como el elemento político, el económico, el institucional y el personal. No todos estos elementos estaban presentes en el Real Decreto de $1890 \mathrm{y}$, por ello, la tentativa había fracasado.

Así las cosas, la labor del Barón Pierre de Coubertin fue, antes todo, de naturaleza diplomática, en tanto en cuanto tuvo que reunir a todos estos elementos bajo una sola bandera para, desde ahí, obtener la autorización para restaurar los Juegos Olímpicos. ${ }^{173}$ Por tanto, el 25 de noviembre de 1892, Coubertin reunió a las principales entidades deportivas de Europa y Estados Unidos en Paris, en la Universidad de Sorbona, con motivo de un Congreso que celebraba el aniversario de la Unión de las Sociedades Francesas de Deportes Atléticos. ${ }^{174}$ A lo largo del encuentro, se planteó la discusión al respecto de la restauración de los Juegos Olímpicos de la antigua Grecia, además de proponerles a los asistentes la creación de una asociación de carácter internacional que sería la responsable de organizar al mega evento. ${ }^{175}$

La idea no gustó a todos los asistentes del encuentro. Igual que ya había ocurrido en Inglaterra en 1865, no todas las entidades estaban de acuerdo con que una sola institución tuviese el monopolio de los Juegos. A causa de ello, a lo largo de los dos años siguientes, Coubertin tuvo que esforzarse para convencer a los críticos respecto de los beneficios que resultarían de la aprobación de la propuesta. Finalmente, en 16 de junio de

\footnotetext{
173 Al explicar las razones que le han motivado a restaurar los juegos olímpicos, el Barón Pierre de Coubertin ha dicho que: “¿Por qué restauré los Juegos Olímpicos? Para ennoblecer y reforzar los deportes, para garantizar su independencia y duración y, por tanto, permitirles cumplir la gran labor educacional que les cabe en el mundo moderno. Para a glorificación del atleta individual, cuya actividad muscular es necesaria para la comunidad y cuya bravura es necesaria para el mantenimiento del espirito de competición. Cf. PAYNE, op.cit., p. 17.

${ }^{174}$ GOLDBLATT, op. cit., p. 41.

175 RÚBEO, Kátia. Jogos Olímpicos da Era Moderna: uma proposta de periodização. Artigo publicado na Revista Brasileira de Educação Física e Esporte, São Paulo, v. 24, n. 1, janeiro-março de 2010, p. 55-68. Disponible en http://www.scielo.br/pdf/rbefe/v2n14., Acceso en: 07 jun 2018.
} 
1894, también durante un Congreso en la Universidad de Sorbona, ${ }^{176}$ el Barón obtuvo la autorización para restaurar los Juegos Olímpicos y crear el COI. ${ }^{177}$

En esta fecha fue elegido el primer presidente del Comité, el escritor griego Demetrius Vikelas, y el secretario general, el francés Pierre de Coubertin, el principal responsable de la gestión de la asociación. ${ }^{178}$ Por tanto, el COI fue la primera asociación internacional que reclamó jurisdicción sobre múltiples deportes y, como consecuencia, acabó en convertirse en la principal organización con estas características en todo el planeta. ${ }^{179}$ Así, el COI es, jurídicamente, una asociación privada y organización no gubernamental, con sede en Lausana, Suiza, quienes, desde el 1894, tiene el monopolio y el control absoluto de la realización de los Juegos Olímpicos. ${ }^{180}$

Sin embargo, a pesar de su liderazgo al frente del Movimiento Olímpico, a lo largo del siglo XX, el COI siempre había reconocido la existencia de otras instituciones que habrían contribuido igual para que los Juegos se perpetuasen y acabasen en convertirse en la principal franquicia del planeta. Entre tales entidades se destacan las Federaciones Internacionales de Deportes, las Federaciones Nacionales de Deportes, las Asociaciones y Clubes Deportivos, los Comités Olímpicos Nacionales (CON) y los Comités Organizadores de los Juegos (COJO), si bien que no todos surgieron al mismo tiempo. ${ }^{181}$

Con la colaboración de estos socios, principalmente en la primera mitad del siglo $\mathrm{XX}$, el COI pudo crear diversas enseñas que identificasen los Juegos, como el símbolo olímpico, la bandera olímpica, el lema del olimpismo y la antorcha olímpica. Asimismo, ha creado varios rituales que han buscado fortalecer la marca olímpica y establecer una diferencia fundamental entre los eventos organizados por la entidad y aquellos gobernados por otras instituciones. A partir de 1908, fueron creados rituales, tales como la ceremonia de apertura y el cierro de las Olimpíadas, el desfile de delegaciones, el

\footnotetext{
${ }^{176}$ GOLDBLATT, op. cit., p. 41.

${ }^{177}$ LAFORGE, op. cit., L. 274.

${ }^{178}$ RÚBEO, op.cit. p. 55-68.

179 BESNIER, Niko; BROWNELL Susan; CARTER, Thomas F. Antropología del deporte: Emociones, poder y negocios en el mundo contemporáneo. Traducción de Teresa Arijón, . Buenos Aires: Siglo Veintiuno Editores, 2018, L. 1201.

${ }^{180}$ CHAPPLET, Jean-Loup. KUBLER-MABBOTT, Brenda. The International Olympic Committee and the Olympic System: The Governance of World Sport Global institutions. New York: Routledge Editor, 2008 , p. 13.

${ }^{181}$ Ibidem, p. 5.
} 
juramento olímpico, la ceremonia de premiación y la entrega de medallas a los tres primeros clasificados en las competencias.

En lo político, todos los socios reconocieron como suprema autoridad del COI al frente del Movimiento Olímpico y, además, su prerrogativa como para dictar reglas que gobernaran el funcionamiento de la institución, sus relaciones con otras entidades deportivas y, principalmente, relativas a la preparación y realización de las Olimpíadas. Por lo general, estas reglas figuraron en la Carta Olímpica, una especie de estatuto, promulgado por primera vez en 1908 con motivo de los Juegos de Londres, conocido en su momento como “Annuaire du Comité Internacional Olympique”. ${ }^{182}$

La Carta fijó los principios fundamentales de las olimpiadas y reconoció la autoridad del Comité sobre todo el Movimiento Olímpico. También se fijaron las reglas que iban a gobernar la gestión de la entidad, el régimen de reuniones y la elección de sus miembros. ${ }^{183}$ De acuerdo a estas reglas, las personas estaban reclutadas por el Comité y estaban obligadas a defender los intereses de la entidad en sus países, como verdaderos embajadores de la institución. Los elegidos no ocuparían cargos políticos en su país y tampoco recibirían instrucciones, recomendaciones o consejos de entidades gubernamentales o deportivas, como Federaciones, Asociaciones o Clubes de atletas. La restricción habría pensado el mantener la independencia de sus manifestaciones y votos, en tanto que los intereses del COI y de cualquier de estas instituciones estuviese en conflicto. $^{184}$

La Carta Olímpica de 1908, además de su relevancia histórica, también habría inaugurado el llamado orden jurídico olímpico. Tal ordenamiento fue constituido desde un conjunto de principios y reglas que controlaban el funcionamiento del Comité y sus relaciones con los Estados, las ciudades anfitrionas, las Federaciones Internacionales, las Asociaciones y Clubes y los patrocinadores. ${ }^{185}$

Con el paso del tiempo, las Cartas Olímpicas fueron responsables de grandes transformaciones en cuanto a la forma, las ciudades anfitrionas prepararon los Juegos Olímpicos. A partir de los años 1950, a modo de dar cada vez más valor al torneo, el COI

\footnotetext{
182 OLYMPIC CHARTER 1908. Disponible en: https://www.olympic.org/olympic-studiescentre/collections/official-publications/olympic-charters, Acceso en 25 de jul 2018.

183 Ibidem, p. 9.

${ }^{184}$ Ibidem, p. 8.

${ }^{185}$ OLIVEIRA, Nelma Gusmão de. op.cit. p. 123-125.
} 
estableció que las ciudades interesadas en acoger al mega evento deberían comprometerse con no realizar cualquier otro festival durante las Olimpíadas, como las grandes ferias y exposiciones internacionales y los campeonatos de diferentes modalidades. ${ }^{186}$

Asimismo, en 1949, considerando las bajas inversiones públicas realizadas con motivo de los Juegos de Londres 1948, el COI estableció que, a partir de las Olimpíadas de 1952, las autoridades de la ciudad sede del mega evento deberían invertir recursos lo suficiente como para preparar los Juegos de la mejor manera posible. ${ }^{187}$

Los Juegos Olímpicos han experimentado una enorme transformación a partir de la Segunda Guerra Mundial. En lo tecnológico, las Olimpíadas de Londres 1948 confirmaron la expectativa de que la televisión iba a incorporarse al mega evento por todo siempre, lo que igual iba a posibilitar su divulgación para varios países alrededor del planeta. La BBC, conocida cadena pública de televisión del Reino Unido, por primera vez en la historia, pagó al COI 1.000 libras por la compraventa de los derechos de transmisión de los Juegos ${ }^{188}$ y dando viabilidad a su exhibición para 500.000 personas en Estados Unidos y Europa. ${ }^{189} \mathrm{La}$ novedad tecnológica no se habría reflejado en otros sectores. En consecuencia, los juegos de Londres entraron para la historia como los Juegos de la Austeridad a causa de las pequeñas inversiones realizadas con motivo de su preparación. ${ }^{190}$

La restricción presupuestaria no llegaba a ser una sorpresa, toda vez que, en 1948, Inglaterra aún sufría las consecuencias económicas de la Segunda Guerra Mundial y, en consecuencia, las grandes inversiones que marcaron los juegos de Los Ángeles 1932 y Berlín 1936 ya no existían, así como tampoco las grandes obras de arquitectura que fueron edificadas en las dos ediciones anteriores al conflicto. ${ }^{191}$

186 OLYMPIC CHARTER 1955. Disponible en: https://www.olympic.org/olympic-studiescentre/collections/official-publications/olympic-charters., Acceso en 23 jul 2018, p. 8.

187 OLYMPIC CHARTER 1949. Disponible en: https://www.olympic.org/olympic-studiescentre/collections/official-publications/olympic-chartersAcceso en 22 jul del 2018, p. 7.

${ }^{188}$ GOLDBLATT, op. cit., p. 197.

189 PRONI, Marcelo Weishaupt. A Reinvenção dos Jogos Olímpicos: um projeto de marketing. Revista Esporte e Sociedade da Universidade Estadual de Campinas, Ano 3, n. 9, julho a outubro de 2008. Disponible em: http://www.cev.org.br/biblioteca/a-reinvencao-dos-jogos-olimpicos-um-projetomarketing., Acesso em 10 jul 2018.

${ }^{190}$ HOLT, Richard; MASON, Tony. Sport in Britain, 1945-2000. Oxford: Blackwell 2000, p. 27-29.

${ }^{191}$ GOLDBLATT, op. cit., p. 196. 
Desde esta perspectiva, el gobierno inglés invirtió tan solo 3,0 millones de libras en el evento y la principal obra de infraestructura fue la construcción de una pasarela peatonal de 800 metros de largo que ha conectado el estadio olímpico a la estación de tren de Wimbledon Park. ${ }^{192}$ Por lo demás, los ingleses han aprovechado equipamientos que ya existían, como el estadio de Wembley y la piscina imperial, oportunamente transformada en parque acuático. Asimismo, el Finichley Lido, a menudo utilizado para picnics, excursiones y actividades recreativas, fue adaptado para acoger a las competencias de polo acuático, ${ }^{193}$ mientras que la arena de baloncesto y el gimnasio de lucha fueron vendidos tras el evento a modo de disminuir los costes de la ciudad. ${ }^{194}$

Londres 1948 tampoco brindó a los atletas con la construcción de una villa olímpica como en Los Ángeles 1932 y Berlín 1936. Los deportistas fueron alojados en instalaciones quizás demasiado sencillas para los estándares olímpicos, como el cuartel de la armada en UXbridge, un colegio en Wimbledon y otras escuelas primarias a lo largo de la ciudad. ${ }^{195}$

Las restricciones presupuestarias no le agradaron al COI, pues la entidad temía que la disminución de las inversiones públicas afectase al desarrollo y la importancia de las Olimpíadas. Con arreglo en su poder para dictar reglas que gobiernan la realización de los Juegos, la institución trató de establecer nuevas exigencias para la financiación del mega evento a partir de Helsinki 1952 y Melbourne 1956. Según los nuevos criterios, la presentación de la candidatura de una ciudad a sede de las Olimpiadas ya no iba a resultar únicamente de una solicitud del CON de cada país, sino que también iba a depender de la previa manifestación favorable de las autoridades de la ciudad, quienes iban a comprometerse con realizarlo de manera "satisfactoria y adecuada", de acuerdo con las exigencias del COI. ${ }^{196}$

La Carta Olímpica de 1955 extendió el compromiso a las demás autoridades del país y, asimismo, aclaró el objeto de las inversiones necesarias a la preparación de las Olimpíadas. De acuerdo con la Carta, las diferentes esferas de gobierno están obligadas

\footnotetext{
192 Ibidem, p. 38.

${ }^{193}$ Ibidem, p. 204.

${ }^{194}$ Ibidem, p. 197.

${ }^{195}$ GOLD, John R; GOLD, Margaret M. op. cit., p. 38.

${ }^{196}$ OLYMPIC CHARTER 1949. op.cit.
} 
a realizar gastos que den la posibilidad de edificar estadios, gimnasios, restaurantes, villa olímpica y otros servicios complementarios, ${ }^{197}$ los cuales deberán ser ofrecidos a bajo precio, con objeto de viabilizar la participación de un mayor número de atletas. Las instalaciones deberán, además, estar ubicadas en un mismo sitio, para evitar los problemas de desplazamiento pasados en Paris 1924. ${ }^{198}$

También, en 1955, el COI le exigió al poder ejecutivo local para que hiciera inversiones mirando hacia al incremento del número de alojamientos que pudieran acoger a los visitantes que acudiesen a los Juegos, lo que implicaba la realización de gastos con la ampliación de la red de hoteles y otros establecimientos congéneres en la ciudad. ${ }^{199}$

Asimismo, en 1955, preocupada con la divulgación de las olimpíadas, la entidad estableció que el poder ejecutivo tendría que proporcionar toda infraestructura necesaria al trabajo de los medios, lo que igual significaba realizar inversiones en tecnología y la contratación de empresas especializadas en ese tema. ${ }^{200}$

La preocupación con la labor de la prensa hizo que el Comité aumentara aún más el nivel de las exigencias. Así, a partir de 1974, el poder ejecutivo se comprometió con asegurar que habría alojamientos lo suficiente en los hoteles para acoger a los periodistas y a los equipos de transmisión cómodamente, lo que implicaba realizar nuevas inversiones en este sector. ${ }^{201}$

Cuatro años más tarde, en 1978, el Comité cambió su orientación en ese tema y exigió de las ciudades anfitrionas que edificaran una villa olímpica para la prensa, con todas facilidades necesarias al buen funcionamiento de su labor. La villa olímpica de la

\footnotetext{
${ }^{197}$ OLYMPIC CHARTER 1950. The conditions required for a town or a city to obtain the organization of the Games. The I. O. C. decides at least three years beforehand in which town or city the Olympic Games are to be held. Any city applying for the celebration of the Games must be ready to bear all the expenses incurred in the construction of the stadia and other installations necessary for the Games. Disponible en: https://www.olympic.org/olympic-studies-centre/collections/official-publications/olympic-charters
}

Acceso en: 22 jul 2018.

${ }^{198}$ OLYMPIC CHARTER 1955. op. cit.

${ }^{199}$ Ibidem

${ }^{200}$ Ibidem.

${ }^{201}$ Olympic Charter 1974. Disponible en: https://www.olympic.org/olympic-studiescentre/collections/official-publications/olympic-charters Acceso en: 6 ab. 2019. 
prensa también debería ofrecerles equipamientos de alta tecnología a los periodistas, lo que claramente elevaba los costes con la preparación del mega evento. ${ }^{202}$

Los cambios verificados a partir de 1949 no significan que antes que fuera aprobada la Carta Olímpica no hubiese inversiones públicas con motivo de la preparación de los Juegos. Efectivamente, las había, pero, la normativa buscó establecer el compromiso permanente de los Estados en lo relativo a la financiación de los Juegos, evitando que alteraciones de las circunstancias políticas o económicas internas pudieran afectar la preparación del mega evento.

Ahora bien, el aumento de los compromisos estatales en lo relativo a la preparación de los Juegos y la falta de transparencia en cuanto a los proyectos arquitectónicos asociados al mega evento hicieron que los gobiernos malgastaran los fondos públicos $\mathrm{y}$, al final, las Olimpíadas acabaran convirtiéndose en una fuente de despilfarro de caudales públicos.

Con arreglo en las nuevas exigencias del COI, Helsinki buscó repetir el modelo de grandes construcciones que hubo en los Juegos de Los Ángeles 1932 y Berlín 1936. Para ello, el gobierno finlandés edificó un estadio olímpico y un parque acuático para los Juegos, además de reformar varias instalaciones con igual objetivo. ${ }^{203}$ También construyó una villa olímpica, considerada por los expertos como la principal fuente de despilfarro de fondos públicos de todo el encuentro. La razón es sencilla: la villa de Käpylä quedaba alrededor de seis kilómetros de la ciudad anfitriona de los juegos y, por esa ello, no les permitía a los atletas que se desplazaran desde ella hacia al centro de Helsinki de forma más rápida. Por ende, gran parte de los deportistas dejaron de alojarse en la misma buscaron otro sitio donde acomodarse. El error en la planificación había obligado al gobierno local a ofrecerles hospedaje en otro sitio, con lo cual se han incrementado os costes del mega evento. ${ }^{204}$

Asimismo, a causa de las disputas de la guerra fría, los soviéticos también se manifestaron contrariamente a la utilización de la villa olímpica de Käpylä. Por lo general,

\footnotetext{
202 OLYMPIC CHARTER 1978. Do you plan the construction or adaptation of a main press center? How do you propose to accommodate the press? In a specially constructed press village similar to those built in Mexico City and Munich? Where? In what form? What tariffs do you propose? If not, what accommodation is planned? Disponible en: https://www.olympic.org/olympic-studies-centre/collections/officialpublications/olympic-chartersAcceso en: 6 ab. 2019.
}

${ }^{203}$ GOLD, John R; GOLD, Margaret M. op.cit., p. 39.

${ }^{204}$ Ibidem. 
señalaban que los atletas del bloque comunista no podrían alojarse en el mismo sitio de los atletas de Estados Unidos y sus aliados. Ello obligó al gobierno finlandés a ofrecerles hospedaje en otro lugar, ${ }^{205}$ lo que también provocó el incremento de los costes con la preparación del encuentro.

Llama la atención en este episodio la omisión del COI en cuanto a la actitud de los soviéticos. La autoridad olímpica no obligó a que los comunistas se alojaran en la villa junto a los demás atletas, con el objetivo de fomentar la convivencia harmónica de todos ellos por encima de divergencias políticas internacionales, aunque esto fuese uno de los principios olímpicos fijados por Pierre de Coubertin. ${ }^{206}$ Al contrario, la institución únicamente demandó de las autoridades finlandesas que respetaran las reglas establecidas en la Carta Olímpica de 1949 y que adoptaran todas las providencias para que los Juegos se produjeran de manera "adecuada y satisfactoria". 207

Las disposiciones de la Carta Olímpica de 1949 fueron utilizadas, además, para los Juegos Olímpicos de Melbourne 1956. A pesar de las exigencias en cuanto a la realización de grandes inversiones públicas, los australianos buscaron ser responsables en lo relativo a los gastos con la preparación del mega evento. Los únicos equipamientos olímpicos construidos para las olimpíadas fueron el parque acuático y el velódromo. ${ }^{208}$ Para todo lo demás, ellos buscaron aprovechar la infraestructura de la ciudad, como The Exhibition Hall y The St. Quilda Town Hall, ${ }^{209}$ los cuales habían sido adaptados para acoger al encuentro.

Pero, igual que en Helsinki cuatro años antes, el despilfarro de fondos públicos se verificó a partir de la construcción de la villa olímpica. En realidad, los recursos utilizados para el proyecto fueron obtenidos desde un préstamo concedido por el gobierno central, que tenía la ambición de utilizar las casas construidas para los juegos en un programa de viviendas populares en el suburbio de Heidelberg para un futuro. La iniciativa no se

\footnotetext{
${ }^{205}$ HORNBUCKLE, A. R. Helsinki. 1952: the Games of the 15th Olympiad, in FINDLING, J.E; PELLE, K.D. (ed.). Historical Dictionary of the Modern Olympic Movement. Westport, CN: Greenwood Press, 1996, p. 109-118.

${ }^{206}$ OLYMPIC CHARTER 1949. op.cit.

${ }^{207}$ Ibidem.
}

${ }^{208}$ GOLD, John R. GOLD, Margaret M. op.cit, p. 40.

${ }^{209}$ GOLDBLATT, David. op.cit., p.197. 
implementó totalmente. La baja calidad del proyecto conllevó a la edificación de casas de pésima calidad, con lo cual hubo necesidad de nuevas inversiones para corregir los errores cometidos. ${ }^{210}$

Cuatro años más tarde, en Roma 1960, los Juegos estuvieron marcados por sospechas de corrupción en lo relativo a la adjudicación de los contratos para la construcción de muchos de los equipamientos olímpicos. Un reducido grupo de empresarios y arquitectos que tenían buenas relaciones con políticos y directivos del Comité Olímpico Local lograron estar al frente de las obras para la edificación del parque acuático y de la villa olímpica, ${ }^{211}$ transformando el mega evento en un ambiente favorable a las malas prácticas administrativas.

La Iglesia Católica también fue beneficiada con algunas de las obras asociadas a los Juegos. La Villa Olímpica de Campo Priolo, por ejemplo, fue construida cerca de las propiedades de la Santa Sede, exactamente para que los inmuebles sacerdotales se valorizaran tras el evento y la Iglesia pudiera obtener ganancias a partir de ello. ${ }^{212}$

A partir de Tokio 1964, las malas prácticas a menudo asociadas a las Olimpíadas no solo se restringieron a la construcción de los equipamientos olímpicos, sino que también abarcaba grandes obras de infraestructura conectadas al propio desarrollo urbano de la ciudad. La capital japonesa utilizó los juegos como pretexto para realizar grandes obras públicas de todos tipos. La idea era promover cambios significativos en el ambiente urbano y preparar la ciudad para que acogiera a una población de 15,0 millones de habitantes a finales de los años 1960 y principio de los años $1970 .^{213}$

Así, el gobierno japonés utilizó los Juegos para construir más de 100 kilómetros de carreteras de alta velocidad, dos líneas de metro, un monorrail que conectaba el aeropuerto a los hoteles cinco estrellas de la capital, además de un tren de alta velocidad que ha conectado las ciudades de Tokio y Osaka. ${ }^{214}$ Las obras le costaron al gobierno japonés alrededor de $\$ 2,8$ mil millones. ${ }^{215}$

\footnotetext{
${ }^{210}$ GOLD, John R. GOLD, Margaret M.op.cit.,p. 41.

${ }^{211}$ GOLDBLATT, David. op.cit., P. 243.

${ }^{212}$ Ibidem, p. 244.

${ }^{213}$ Ibidem, p. 233.

${ }^{214}$ Ibidem

${ }^{215}$ Ibidem, p. 235.
} 
Las grandes inversiones no solo le trajeron desarrollo deportivo y urbanístico a Japón. Durante los preparativos de los Juegos, la especulación inmobiliaria y las malas prácticas estuvieron por todas partes, identificándose varias relaciones espurias entre políticos, agencias estatales y grandes corporaciones empresariales. Los sobornos fueron pagados a altos directivos del Estado para que se conquistase el derecho de construir y operar los trenes de alta velocidad puestos en funcionamiento con motivo de las Olimpíadas, con lo cual las grandes obras de infraestructura fueron alcanzadas por el fenómeno de la corrupción. La gravedad de las malas prácticas y el rechazo social a tales comportamientos conllevó a la dimisión del presidente de la Agencia Nacional de Trenes de Japón, algo nunca visto en la historia de los Juegos. ${ }^{216}$

México, en el año 1968, también se enfrentó a las malas prácticas asociadas a las obras ejecutadas a causa de las Olimpíadas. Entre las irregularidades se destaca la relativa a la manutención de la "Vía de la Amistad", una avenida con diecisiete kilómetros de largo, que conectaba los principales equipamientos olímpicos. La avenida fue adornada, además, con dieciocho esculturas construidas por artistas de diferentes países, con lo cual México había buscado exaltar el carácter cosmopolita de los primeros Juegos Olímpicos en América Latina. ${ }^{217}$

Pese a su inestimable valor artístico y cultural, las referidas esculturas no recibieron cualquier atención de las autoridades apenas terminaran las Olimpíadas. Las piezas fueron totalmente abandonadas y rápidamente dominadas por la vegetación, más allá de manchas con tintas que, en realidad, terminaban con quitarles sus características originales, ${ }^{218}$

El estado de abandono se mantuvo durante veinte años, hasta que las autoridades finalmente realizaran un programa para su completa restauración. En 2012, la Vía de la Amistad también fue incluida en un programa de recuperación del patrimonio histórico y cultural (THE WORLD MONUMENT WATCH), con objeto de preservarla para las futuras generaciones. La idea, en principio, fue excelente, pero las esculturas que adornaban la ruta iban a ser trasladadas a dos parques municipales, lo que le quitaba a la

\footnotetext{
${ }^{216}$ Ibidem, p. 254-255.
}

217 WENDL, Karel. The route of friendship: a cultural/artistic event of the Games of the XIX Olympiad in Mexico City, 1968. Olympika, 7, 1998, p. 113-134.

${ }^{218}$ FERNÁNDEZ CONTRERAS, R. A. The route of friendship: a testimony to Mexico City's aesthetic modernity. Voices of Mexico, 82, 2008, p. 34-43. 
vía su verdadero significado. ${ }^{219}$ Asimismo, la escultura edificada por el australiano Clement Meadmore's, además de retirada de su lugar original a lo largo de la vía, fue trasladada a una escuela privada y su imagen utilizada como logotipo de la institución. ${ }^{220}$

Estudios más recientes revelaron, además, que muchas de las obras realizadas con motivo de los Juegos de México en 1968 tuvieron carácter cosmético y no buscaron resolver los problemas de la ciudad. Las intervenciones realizadas miraban únicamente transmitir al mundo la imagen de un país moderno y desarrollado, pero no se ocuparon de solucionar las verdaderas necesidades de los ciudadanos, ${ }^{221}$ con lo cual se convirtió nuevamente en una fuente de despilfarro de fondos públicos.

Ocho años después, en Montreal 1976, las irregularidades abarcaron no solo la edificación de algunas instalaciones olímpicas, sino también grandes obras de infraestructura asociadas a la realización de los Juegos.

Apenas fue elegida ciudad anfitriona de las Olimpíadas de 1976, el alcalde de Montreal, Jean Depreau, afirmó en un discurso que la realización del mega evento posibilitaría aumentar la modernización de la ciudad y su consecuente incorporación al circuito de las principales metrópolis del planeta, como Londres, Paris y Nueva York. Al describir el proyecto, señaló que, consecuencia de las Olimpíadas habría grandes inversiones públicas en una región en expansión del municipio, la cual abarcaría estadios, arenas deportivas, villa olímpica, centro de prensa, hoteles, restaurantes, etc.

Al final del encuentro, insistía con que la región se incorporaría a la ciudad y sus expectativas de valorización de la imagen de la ciudad se confirmarían. Asimismo, al contestar las preguntas respecto a su viabilidad, siempre se insistió en la posibilidad de que los juegos fracasaran, y de que sería semejante al ejemplo de que un hombre pudiese dar a luz a un bebé. ${ }^{222}$

Arrojadas las ideas de Jean Depreau, estas no coincidían con la realidad económica internacional. A mediados de los años 1970, con motivo de la crisis internacional del

\footnotetext{
${ }^{219}$ GOLD, John R. GOLD, Margaret M. op.cit., p. 299.

${ }^{220}$ Ibidem.

${ }^{221}$ BREWSTER, Claire; BREWSTER, Keith. Representing the Nation: Sport and Spectacle in Postrevolutionary Mexico. Newcastle: Routledge, 2013, p. 795.

${ }^{222}$ PAYNE, op.cit., p. 24.
} 
petróleo, muchos de los países se enfrentaban con periodos de recesión y la prudencia recomendaba que no se realizaran grandes inversiones hasta que todo se normalizara. ${ }^{223}$ Pese a las recomendaciones, Depreau llevó adelante su proyecto y realizó varias obras faraónicas a causa de los Juegos, que acabaron con convertirse en enormes fuentes de despilfarro de fondos públicos, ${ }^{224}$ con deudas que, en el 2006, llegaran a más de \$2,0 mil millones. $^{225}$

El estrepitoso desastre financiero vino de diferentes factores, tales como errores en los proyectos arquitectónicos de algunas de las instalaciones olímpicas, el retraso en las obras de algunos de los equipamientos y, principalmente, la corrupción asociada a la adjudicación de contratos destinados a la edificación de estructuras necesarias al normal desarrollo de los Juegos.

El principal error en lo relativo a las instalaciones se refería a la construcción del estadio olímpico. La gigantesca estructura fue proyectada para que tuviera un techo retráctil que posibilitaría su utilización como arena multiuso tras las Olimpíadas, ${ }^{226} \sin$ embargo los equívocos en cuanto al proyecto hicieron que la novedad arquitectónica no funcionara con motivo de los Juegos, así como tampoco en los años siguientes al mega evento. En 1987, tras nuevas inversiones públicas, los defectos del proyecto original fueron corregidos y el equipamiento pudo finalmente funcionar, aunque no para las Olimpíadas. $^{227}$

Así como el estadio, otras instalaciones también presentaron problemas estructurales como el velódromo. A modo de atender a las exigencias del COI, la construcción del equipamiento fue adjudicada a arquitectos extranjeros quienes no conocían la geología local $\mathrm{y}$, por tanto, acabaron con equivocarse en cuanto a las fundaciones del mismo. Los errores cometidos, además de retrasar la obra, le obligaron

\footnotetext{
${ }^{223}$ GOLD, John R. GOLD, Margaret M. op.cit., p. 44.

${ }^{224}$ SANDERS, Barry A. The Los Angeles Olympic Games. Charleston, South Carolina Library of Congress: Arcadia Publishing, 2013, p. 13.

${ }^{225}$ PAYNE, op.cit., p. 17.
}

${ }^{226}$ KILLANIN, Lord. My Olympic Years. London: Martin Secker and Warburg, 1983, p. 123.

${ }^{227}$ GOLD, John R. GOLD, Margaret M. op.cit., p. 44-45. 
al gobierno a realizar nuevas inversiones para que el equipamiento estuviera listo a la fecha, por lo que los costes estuvieron muy por encima de lo originalmente previsto.

Igual que el estadio y el velódromo, muchas otras instalaciones olímpicas tuvieron problemas durante el periodo de preparación y no lograron estar preparadas al tiempo. En mayo de 1976, por ejemplo, pocos días antes que comenzaran los Juegos, el gobierno se vio obligado a construir instalaciones temporales para el mega evento, en lugar de concluir las obras ya iniciadas para este. ${ }^{228}$

Además de los problemas arquitectónicos y el retraso de las obras, los Juegos también estuvieron marcados por sospechas de corrupción en lo relativo a la adjudicación de contratos para la construcción de la infraestructura necesaria al mega evento. En este sentido, el contrato para la edificación de la Villa Olímpica fue perfeccionado con una entidad aliada política del alcalde, quienes no tardaron en elevar los costes con la construcción de la infraestructura antes que estuviera lista.

Inicialmente, los gastos con la construcción de la villa que habían sido previstos en 22 millones de dólares se elevaron a 43 millones y, finalmente, tres semanas antes que arrancaran los juegos, llegaron a 80 millones de dólares. Asimismo, la construcción de una fuente en el parque acuático les costó a los canadienses ocho millones de dólares, lo que estaba muy por encima del precio a menudo exigido para semejante estructura. La última construcción que llama la atención en lo relativo a las Olimpíadas de Montreal es el aeropuerto de Mirabel. La faraónica estructura, además de distante y cara, jamás ha logrado cumplir con su objetivo y, finalmente, terminó clausurado tres décadas tras su inauguración. ${ }^{229}$

Algunos años tras el cierre de los Juegos, las investigaciones a cargo del juez Malouf pusieron de manifiesto que, ineludiblemente, las Olimpíadas de Montreal 1976 conllevaron al despilfarro de fondos públicos. La conclusión fue contundente. No bastaría todo el esfuerzo de las autoridades hacia la promoción de la imagen de la ciudad en el ámbito internacional, los Juegos Olímpicos de verano del 1976 revelaron al mundo una estrecha y peligrosa conexión entre la construcción de los equipamientos olímpicos y vergonzosos casos de corrupción. ${ }^{230}$ Estas malas prácticas asociadas a las Olimpíadas de

\footnotetext{
${ }^{228}$ GOLD, John R. GOLD, Margaret M. op.cit., p. 45

${ }^{229}$ Ibidem., p. 44-45.

${ }^{230}$ PAYNE, op.cit., p. 24.
} 
1976 no les agradó a los vecinos de Montreal, quienes reivindicaron a las autoridades que dinamitaran el estadio olímpico tras el cierre del encuentro, puesto que no querían que permaneciera entre ellos aquel vergonzoso símbolo de corrupción. ${ }^{231}$

La protesta de los canadienses puso de manifiesto dos aspectos que consideramos relevante señalar en cuanto a la preparación de los mega eventos deportivos internacionales, como la Copa del Mundo de Fútbol y, principalmente, los Juegos Olímpicos. Inicialmente, la manifestación de los canadienses en contra de las Olimpíadas corroboró la asertividad de que, en raras ocasiones, los Juegos constituyen un ambiente favorable a la comisión de malas prácticas administrativas de diferentes modalidades, las cuales, recientemente, sufren con el rechazo y la oposición de vecinos de varias ciudades y países en todo el mundo.

En efecto, tras el fracaso financiero de las Olimpíadas y los escándalos de corrupcion en Montreal 1976, pocas ciudades alrededor del planeta manifestaron interés en acoger las siguientes ediciones del mega evento. Así, mientras que Moscú y Los Ángeles presentaron su candidatura para los Juegos de 1980, la ciudad estadounidense fue la única interesada en organizar las Olimpíadas de $1984 .{ }^{232}$ Aun así, los norteamericanos impusieron algunas condiciones para que el mega evento tuviese lugar en su territorio. No habría inversiones públicas y los recursos para la financiación de los Juegos serían obtenidos en la iniciativa privada. ${ }^{233}$ La exigencia hizo que el COI, por primera vez en la historia de las Olimpíadas, tuviese que renunciar a la regla que les imponía a las ciudades anfitrionas el compromiso de realizar todos los dispendios necesarios al normal desarrollo de los Juegos. ${ }^{234}$

Diecinueve años después, en 2013, tras un referéndum que les preguntó a los ciudadanos de Múnich al respecto de la posibilidad de que la ciudad acogiese a los Juegos Olímpicos de Invierno de 2018 o 2022, los bávaros se manifestaron totalmente en contra a la idea. ${ }^{235}$ Los principales motivos para el rechazo fueron los altos costes en la

\footnotetext{
${ }^{231}$ Ibidem.

${ }^{232}$ PAYNE, op.cit., p. 27.

${ }^{233}$ Ibidem.

${ }^{234}$ OLYMPIC CHARTER 1978. op.cit.

${ }^{235}$ GROHMANN, K. Hamburg beats Berlin to become Germany's 2024 Games bid. Disponible en: https://www.reuters.com/article/us-olympics-2024-germany/hamburg-beats-berlin-to-become-germanys2024-games-bid-idUSKBN0MC23E20150316, Acceso en 23 ago 2019.
} 
preparación del torneo, las exigencias impuestas por el COI para su organización y el riesgo de que se practicaran actos de corrupción.

El recelo en cuanto a la comisión de actos de esta naturaleza revela la importancia de estrategias de prevención de la corrupción como la transparencia gubernamental tienen en lo relativo a la preparación de tales torneos. Desde la Real Ordenanza sobre la Libertad de Prensa del año $1766^{236}$, la transparencia busca desvelar para los ciudadanos las intimidades del Estado, con lo cual podrán conocer toda la información resguardada en manos de los poderes públicos. ${ }^{237}$. Pese a su origen a partir de la segunda mitad del siglo XVIII, la transparencia ganó mayor importancia en el escenario internacional desde los años 1990, cuando varios países incorporaron Leyes de Transparencia y Acceso a la Información a los propios ordenamientos jurídicos.

A modo de entender la manera en la que la transparencia gubernamental podría actuar para prevenir la corrupción con frecuencia asociada a los Juegos Olímpicos, analizamos en los apartados siguientes los elementos que le dan conformidad jurídica, como el concepto, la naturaleza jurídica, los principios y límites de actuación, aparte del régimen de sanciones que a menudo se establece para el caso de su incumplimiento. Realizamos, siempre que sea posible, la debida comparación con las malas prácticas identificadas en las diferentes ediciones de las Olimpíadas, exactamente para que se pueda demostrar, en concreto, la relevancia de esta estrategia de prevención de la corrupción.

\subsection{Los antecedentes de la transparencia gubernamental}

La historia de la humanidad ha estado marcada durante años por una cultura de secreto y oscuridad. Desde la antigüedad hasta la edad moderna, la concepción predominante fue la de que la información generada por los poderes públicos tan solo debería estar disponible para individuos con características especiales, quienes concentrarían bajo su autoridad todo el conocimiento necesario a la toma de decisiones. ${ }^{238}$

En la antigüedad, el control de la información estuvo bajo el comando de un restringido grupo de individuos con capacidad y conocimiento técnico para ello, una

\footnotetext{
${ }^{236}$ POMED SÁNCHEZ, op.cit, p. 9.

${ }^{237}$ ZANCANER, op.cit, p. 35-36.

${ }^{238}$ PESCHARD, op.cit., L. 187.
} 
verdadera aristocracia intelectual, que tendría el conocimiento exclusivo de los problemas de la colectividad y que, por tanto, sería apta para indicar a los demás el camino a seguir. A los demás ciudadanos no se les ha permitido conocer dicha información, así como tampoco interferir en las decisiones gubernamentales de esa minoría cualificada, ya que no estarían preparados intelectualmente para ello. ${ }^{239}$

El secreto de las informaciones ha constituido, por tanto, la herramienta necesaria para que la aristocracia intelectual pudiera actuar libremente hacia la búsqueda de sus intereses $^{240}$, sin que tuvieran que contestar a preguntas incómodas de los ciudadanos. ${ }^{241}$

Ese régimen de secreto y opacidad quedó consagrado en la expresión latina arcanas imperii (o secretos del poder), a principio utilizada para referirse a los misterios de la guerra y a las estrategias adoptadas por los ejércitos para enfrentarse al enemigo. Posteriormente, la expresión también fue utilizada en el ámbito político para referirse al control de la información necesaria al ejercicio y conservación del poder. ${ }^{242}$

En Roma, la idea de los arcanas imperii fue utilizada para apartar del Senado el conocimiento de asuntos de interés de los gobernantes, como el contenido de la política imperial y la conquista de nuevas tierras, lo cual sería patrimonio exclusivo de quienes estarían al frente de la gestión del Estado. ${ }^{243}$

La idea de los arcanas imperii se mantuvo a lo largo de la Edad Media (siglos V al $\mathrm{XV})$, pero, el titular de la información no sería el gobernante, sino la institución política más poderosa en su momento, la iglesia católica. La Santa Sede tenía el absoluto control sobre los arcanas ecclesiae o secretos divinos. Los sacerdotes serían, por tanto, los únicos capaces de desvelar los misterios trascendentales establecidos por Dios y transmitirlos a los hombres ${ }^{244}$ y los clérigos les indicaban la conducta a seguir y ellos no podrían cuestionarles las verdades celestiales.

\footnotetext{
${ }^{239}$ Ibidem, L. 282.

${ }^{240}$ CANETTI, Elías. Masa y Poder. Madrid: Alianza, 199, p. 288.

${ }^{241}$ PESCHARD, op.cit., L. 198.

${ }^{242}$ ZEPEDA, Jesús Rodríguez. Estado y transparência: un paseo por la filosofia política, Instituto Federal de Acceso a la Información Pública, cuaderno de transparencia 4, 2004, p.10.

${ }^{243}$ Ibidem, p. 15.

${ }^{244}$ BOK, Sissela. Secrets on the Ethics of Concealment and Revelation., Nueva York: Vintage Books, 2011, p. 172.
} 
Con el absolutismo del siglo XVI, el control de la información se trasladó de las manos de la iglesia hacia las del monarca, quien debería adoptar todas las medidas necesarias para la protección de los súbditos del reino. Por esa época nació el concepto de razón de Estado, con el significado de que los intereses del Estado estarían siempre por encima de los de los ciudadanos, como forma para permitirle al monarca defender la seguridad y la propiedad de los súbditos.

En ese cometido, toda vez que los intereses del Estado estuvieran en peligro, sería legítimo al rey intervenir eficazmente con objeto de mantener el orden público, lo que haría a través del conocimiento de informaciones secretas que le permitirían enfrentarse a los enemigos del reino. Además, no estaría obligado a rendir cuentas de cualquiera de los actos que practicara bajo esas condiciones, ya que el sigilo oficial sería un instrumento al servicio de la existencia y preservación del Estado.

El secreto de los actos del rey ha contado con el fundamento teórico de pensadores como Juan Bodino, quien defendió que el gobierno absoluto tendría que evitar a todo coste intromisiones inoportunas en los asuntos oficiales. Ello tan solo sería posible toda vez que se reservara a los directivos del país el conocimiento exclusivo de determinadas informaciones. Las ideas de Bodino ofrecieron el fundamento necesario para los llamados secretos de la política, que tendría como principal característica retirar del conocimiento de los ciudadanos asuntos considerados necesarios para la supervivencia del gobierno. ${ }^{245}$

La Revolución inglesa del 1688 y la Revolución francesa del 1789 cambiaron esa realidad. Ambos movimientos inauguraron un régimen que reconoció a los ciudadanos derechos fundamentales frente al Estado, el cual ya no podría actuar con libertad hacia la consecución de sus objetivos. La máxima autoridad actuaría con absoluto respeto a las libertades de pensamiento, de consciencia, de creencia y de expresión de los súbditos, además de pautar todos sus actos en un régimen de normas previamente establecidas. ${ }^{246}$

Las nuevas ideas conllevaron a que el Parlamento inglés, en el 1688, aprobara leyes que fijaban criterios objetivos para la recaudación de impuestos y el control de los gastos públicos, lo que fue fundamental para que los ciudadanos conocieran por adelantado cómo se realizarían dichos actos. Además, a principios del siglo XIX, se autorizó a que

\footnotetext{
${ }^{245}$ ALASDARI, Roberts. Blacked Out: Government Secrecy in the Information Age. Cambridge: Cambridge University Press, 2006, p. 9.

${ }^{246}$ PESCHARD, op.cit, L. 346.
} 
la prensa acompañara los debates relativos a la aprobación de las leyes en el Parlamento. Posteriormente, en el 1829, les reconoció la igualdad de derecho a los ciudadanos. ${ }^{247}$

La idea de acercar los ciudadanos a los gobernantes también estuvo presente en los principios de la Revolución francesa. La Declaración Universal de los Derechos del Hombre y del Ciudadano (DUDH) reconoció al individuo la calidad de sujeto de derechos y libertades políticas frente al Estado, independientemente de su origen o clase social ${ }^{248}$. A partir de ahí a los ciudadanos se les permitió conocer el carácter, la conducta y los actos de los gobernantes directamente. ${ }^{249}$ Así que la autoridad tan solo sería legítima si permitía al individuo acompañar desde cerca el ejercicio de las potestades públicas. ${ }^{250}$

En ese cometido, la publicidad de los actos oficiales contó con el respaldo de teóricos como Immanuel Kant, quien consideró injustas todas las acciones de los hombres públicos cuyos actos no sean verdaderamente publicados, con motivo de permitirles el efectivo y democrático control de los ciudadanos. ${ }^{251}$

A pesar de todos los avances conquistados desde finales del siglo XVI, las primeras reglas de transparencia se referían con exclusividad a la libertad de prensa y al derecho de acompañar los debates parlamentarios ${ }^{252}$, todavía no hallándose consagrado el derecho de acceso a los archivos y documentos públicos.

La primera ley de transparencia de la historia fue publicada en Suecia en la segunda mitad del siglo XVIII, con la aprobación de la Real Ordenanza sobre la Libertad de Prensa del año $1766^{253}$, la cual representó un avance respecto al modelo adoptado en Inglaterra. La ley sueca tenía previsto no solo la libertad de prensa como prerrogativa de los

\footnotetext{
${ }^{247}$ ALASDARI, op.cit., p. 10.

${ }^{248}$ FIORAVANTI, Maurizio. Los Derechos Fundamentales. Apuntes de la Historia de las Constituciones. Madrid: Trotta, 1996.

${ }^{249}$ SANDOVAL, Irma E. (coord.). Corrupción y Transparencia: debatiendo las fronteras entre Estado, mercado y sociedad. México: Siglo XXI Editores, 2009, p. 272.

${ }^{250}$ ZEPEDA, op.cit., p. 26.

251 "Son injustas todas las acciones que se refieren al derecho de los hombres cuyos principios no soportan ser publicados". KANT, Immanuel. Sobre La Paz Perpetua. Madrid: AKAl, 2012, p. L 2944

${ }^{252}$ RIVERA, José Antonio Aguilar. Transparencia y Democracia: claves para un concierto, Cuadernos de Transparencia, IFAI, México, 2008, p. 14.

${ }^{253}$ POMED SÁNCHEZ, op. cit., p. 9.
} 
ciudadanos, sino también el derecho de acceso a los archivos y documentos públicos producidos por el Estado. ${ }^{254}$

El Artículo $1^{\circ}$ del capítulo segundo de la Real Ordenanza sueca de 1766 establecía que: "Para fomentar el libre intercambio de opinión y la ilustración del público, cada súbdito sueco tendrá libre acceso a los documentos oficiales". ${ }^{255}$

Ello hizo posible que los ciudadanos conocieran la historia y el funcionamiento de las instituciones y que pudieran opinar sobre los asuntos oficiales. La libertad de prensa buscó asegurar no solo la libertad de opinión y expresión de los medios en la sociedad sueca de finales del siglo XVIII, sino también pretendía evitar que el Estado censurara la divulgación de diferentes ideas y corrientes de pensamiento sobre los actos del gobierno, que, en efecto, podrían contribuir en el debate público alrededor de los asuntos oficiales.

En este sentido, en Suecia ya existía el entendimiento de que el acceso de la prensa y de los ciudadanos a los archivos y documentos del Estado podría profundizar la discusión respeto a los actos del gobierno, con lo cual toda la sociedad podría evaluar y controlar las acciones de los políticos desde diferentes perspectivas, lo que al final contribuiría para una verdadera participación ciudadana en los asuntos públicos. ${ }^{256}$

Por otro lado, la apertura de los archivos y documentos oficiales a la sociedad les permitiría a los ciudadanos acompañar la gestión pública directamente, evitando que políticos y funcionarios se dedicaran a malas prácticas administrativas.

Ese fue uno de los principales objetivos de la Real Ordenanza sobre la Libertad de Prensa del año 1766. Según el Diputado y Sacerdote sueco Anders Chydenius, uno de los principales defensores de la aprobación de la nueva ley, la directiva buscaba revelar a la sociedad las ineficiencias y la corrupción de los funcionarios públicos suecos a la hora de gestionar los intereses de la colectividad.

Chydenius se inspiró en una costumbre china muy antigua a la hora de presentar la propuesta de la creación de la primera ley de transparencia de la historia. Había en la China antigua un órgano del gobierno llamado Buró de Censura Imperial, cuyo principal objetivo era dar publicidad a los actos del gobierno y de los funcionarios a los ciudadanos,

\footnotetext{
${ }^{254}$ MICHENER, Greg. FOIA: Laws around the World. In: JOURNAL OF DEMOCRACY, p. 145-159, 2011.

${ }^{255}$ HERRERA, Manuel Palomares. Transparencia y acceso a la información en el sector público. Madrid: Wolters Kluwer Editora, 2018, p. 108.

${ }^{256}$ PESCHARD, op.cit., L. 446.
} 
con lo cual era posible realizar el control de la Administración Pública. ${ }^{257}$ Los resultados positivos de ese control social llevaron a que el Diputado trabajase hacia la aprobación de la ley, con el objetivo de resolver los problemas de ineficiencia y corrupción de la Administración pública sueca.

A pesar de su importancia, la ley sueca no tuvo aplicación efectiva en su país de origen, hasta que fue reformada por otra Ley del año 1812 y por otras normas de igual naturaleza, pero en todos los casos siempre mantuvo el acceso a la información como un derecho de los ciudadanos. Además, fijó como principio la obligatoriedad de que los gobiernos debían documentar todos los actos y decisiones oficiales. Desde ese momento, se creó una memoria institucional de la nación. ${ }^{258}$ Actualmente, ese texto en vigor fue aprobado en el año 1974 y goza de rango constitucional por previsión expresa de la Ley Fundamental de aquel país. ${ }^{259}$

Pese a sus debilidades, la Real Ordenanza de Libertad de Prensa de Suecia de 1766 también fue aplicada en Finlandia a finales del siglo XVIII, en tanto que ella integraba el largo reino sueco como gran ducado por esa fecha. ${ }^{260}$

La iniciativa sueca tuvo influencia directa en el espíritu de los revolucionarios franceses del 1789, en tanto que la Asamblea Constituyente del 1790 aprobó la creación de archivos históricos nacionales en Francia, con objeto de reunir en un solo sitio los documentos producidos por el gobierno. La Asamblea además estableció los principios fundamentales que regirían la organización de esos archivos en todo el territorio, muchos de los cuales subsisten en la actualidad. Así que compite a los archivos históricos nacionales franceses: 261
a) Reunir los archivos de la nación;
b) Asegurar el acceso a los ciudadanos;

\footnotetext{
${ }^{257}$ ACKERMAN, John M. Sandoval, Irma, Leyes de acceso a la información en el mundo. Cuadernos de Transparencia, 7, IFAI, México, 2005.

${ }^{258}$ BLANTON, Thomas S. The Global Openness Movement in 2006. 240 Years after the First Freedon of Information Law, Access to Government Information Now Seen as A Human Right. MUSTONEN, Juhan (ed.). The worls's First Freedon of information act: Anders Chydenius Legacy Today. Kokkola: Anders Chydenius Foundation, 2006.

${ }^{259}$ POMED SÁNCHEZ, op.cit., p. 9.

${ }^{260}$ Ibidem, p, 40.

${ }^{261}$ PESCHARD, op.cit., L. 592.
} 
c) Crear una red nacional de archivos; y

d) Organizar un servicio de archivos en cada Departamento del país.

La institución de los archivos nacionales franceses significó un cambio importante con respecto a la colección y tratamiento de la información producida por el gobierno. Durante el antiguo régimen, no había en Francia un órgano que estuviera a cargo de organizar todo el conocimiento producido por el Estado, identificándose más bien iniciativas aisladas de unos pocos órganos oficiales en este sentido, como el Ministerio de Defensa, el Ministerio de Asuntos Exteriores y el Tribunal de Cuentas. ${ }^{262}$

Los archivos nacionales franceses comenzaron a funcionar a principios del siglo XIX, pronto dedicándose a coleccionar y organizar los documentos de los Ministerios que formaban parte del gobierno, además de confeccionar inventarios de esos escritos, con objeto de facilitar la consulta de la información para todos aquellos interesados. Así fueron reunidos en los archivos franceses fotografías, cartas, escritos, datos y otras evidencias que se refieren a los principales acontecimientos políticos y administrativos de la historia nacional. ${ }^{263}$

Desde el 1867, los archivos franceses se convirtieron en museos y se transformaron en un lugar abierto al público, en el cual se podía acudir con motivo de conocer y estudiar los principales documentos de la historia del país, de las tradiciones y experiencias comunes de las diferentes generaciones que contribuyeron a la formación de la identidad nacional. ${ }^{264}$

La iniciativa sueca acabo influenciando a otros países de Escandinavia para aprobar leyes de acceso a la información ${ }^{265}$, tendencia que también fue seguida por Estados Unidos y los países de su área de influencia anglófona.

Históricamente, conviene señalar que la aprobación de la ley norteamericana estuvo directamente relacionada con el contexto geopolítico de la Guerra fría entre Estados Unidos y la Unión Soviética en los años 1960. Con la idea de protegerse de su principal enemigo externo, el gobierno norteamericano restringió drásticamente el acceso de los periodistas y de la oposición a los archivos y documentos oficiales por razones de

\footnotetext{
${ }^{262}$ PESCHARD, op.cit., L. 592.

${ }^{263}$ Ibidem, L. 603.

${ }^{264}$ FUGUERAS, Ramón Alberch. Archivos: entender el pasado y construir el futuro. Barcelona: Editorial UOC, 2014.

${ }^{265}$ POMED SÁNCHEZ, op.cit., p. 9.
} 
seguridad nacional. ${ }^{266}$ Esa medida provocó reacciones de los políticos de la oposición, en particular en el diputado demócrata John Moss, quien denunció dichas restricciones ante el Parlamento. ${ }^{267}$

Refiriéndose a la existencia de una verdadera "cortina de papel" que impedía a la sociedad conocer los actos y decisiones gubernamentales, Moss defendió un cambio en el orden jurídico de Estados Unidos, con la aprobación de una ley de transparencia que regularía esa materia y que le permitía a la prensa y a la oposición consultar los archivos y documentos resguardados por el Estado. ${ }^{268}$

Así como ya había pasado en Francia a principios del siglo XIX, la aprobación de la ley de transparencia en Estados Unidos también fue precedida a la creación de archivos nacionales que coleccionaban y organizaban documentos y materiales producidos por el gobierno. En el 1934, el Congreso norteamericano autorizó la creación del archivo nacional en el territorio estadounidense (The National Archives and Records Administration), que reunía los principales documentos del gobierno federal que tenían valor histórico, como forma de constituir la memoria institucional del país.

En la actualidad, la gestión del archivo nacional estadounidense está a cargo de una agencia independiente federal que guarda los documentos y materiales compilados a lo largo de los años, además de permitirles el acceso a quienes manifiesten interés en consultarlos. La constitución de ese archivo y de la agencia federal que lo gestiona han sido fundamentales para la aprobación y el éxito de la ley de transparencia y acceso a la información norteamericana. Merece la pena señalar que la ley estadounidense del año 1966 es considerada por muchos expertos como la principal ley de transparencia de la actualidad $^{269}$, aunque también es cierto que no alcanzó su efectividad hasta la reforma llevada a cabo en el año 1974, tras el escándalo del caso Watergate.

Entre finales de los setenta y principios de los noventa, esa tendencia llegó a los países latinos de Europa occidental, ampliándose el debate alrededor de este tema. Merece

\footnotetext{
${ }^{266}$ SHAUDSON, Michael. Origins of Freedom of Information Act in United States. In: BOWLES, Nigel. HAMILTON, James y LEVY, David (ed). Transparency in Politics and Media. Accountability and Open Government. Londres: Ib Tauris-Reuters Institute of the Study of Journalism, 2014, p. 16

267 Ibidem.

${ }^{268}$ Ibidem.

269 FERNÁNDEZ RAMOS, Severiano; PÉREZ MONGUIÓ, José Maria. Transparencia, Acceso a la Información Pública y Buen Gobierno- Ley 19/2013 de 9 de diciembre. 1. Navarra: Thomson Reuters - Arazandi, 2014, p. 25.
} 
la pena destacar en este periodo la ley francesa del año 1978, que mantuvo el derecho de acceso a los documentos administrativos, fomentando la cultura de transparencia en aquel país. ${ }^{270}$

A finales de los noventa y principios del siglo XXI, hubo una verdadera expansión de esas ideas y se generalizó la aprobación de leyes de transparencia y acceso a la información pública en países como Reino Unido, Alemania y Suiza ${ }^{271}$, además de países de Europa que estaban integrados en la Unión Soviética hasta la caída del muro de Berlín, incluida la propia Rusia. También fueron aprobadas leyes con esas características en países de América Central y del Sur, Asia, África y Oceanía. En el mundo árabe, la aprobación de leyes de transparencia y acceso a la información coincide con las manifestaciones de la primavera árabe en el $2010 .^{272}$

Todos estos hechos sirven para comprobar que la transparencia gubernamental se ha convertido en una realidad universal que va más allá del límite territorial de cada Estado. En este sentido, conviene destacar que la Declaración Universal de los Derechos Humanos de 1948 afirmó la libertad de expresión y la libertad de prensa como derechos íntimamente asociados al derecho a la información, ${ }^{273}$ tendencia que fue seguida por otras convenciones y leyes, como la Ley Modelo Interamericana sobre Derecho de Acceso a la Información Pública, ${ }^{274}$ aprobada por la Asamblea General de la Organización de los Estados Americanos (OEA) en 2010 y del Convenio núm. $205^{275}$ del Consejo de Europa sobre acceso a los documentos públicos.

\footnotetext{
${ }^{270}$ FERNÁNDEZ RAMOS; PÉREZ MONGUIÓ, op.cit., p. 25.

${ }^{271}$ GUICHOT et al, op.cit., p. 18.

${ }^{272}$ MENDEL, op.cit., p. 8.

273 "Todo individuo tiene derecho a la libertad de opinión y de expresión; este derecho incluye el de no ser molestado a causa de sus opiniones, el de investigar y recibir informaciones y opiniones, y el de difundirlas, sin limitación de fronteras, por cualquier medio de expresión." NACIONES UNIDAS La Declaración Universal de Derechos Humanos. Disponible en https://www.un.org/es/universal-declaration-humanrights/.Acceso en: 15 enero 2019.
}

274 OEA. Organización de los Estados Americanos: Democracia para la paz, la seguridad y el desarrollo. Disponible en: http://www.oas.org/es/sla/ddi/acceso_informacion_ley_modelo.asp.Acesso en 10 enero 2019.

${ }^{275}$ OAS. Convenio del Consejo de Europa sobre el Acceso a los Documentos Públicos. Disponible en: http://www.oas.org/es/sla/ddi/docs/acceso_informacion_desarrollos convenio consejo_europeo.pdf.

Acceso en: Acceso en: 8 mayo 2014. 
Por último, conviene observar que el tratado de funcionamiento de la Unión Europea (UE) del año $2007{ }^{276}$ reconoce a todo ciudadano de la Unión, así como toda persona física o jurídica que resida o tenga su domicilio social en un Estado miembro, el derecho a acceder a los documentos de las instituciones y órganos de la Unión, cualquiera que sea su soporte, lo que corrobora esa tendencia de universalización de la transparencia gubernamental $^{277}$.

Llevados por esa ola de universalización del derecho de acceso y participación ciudadana, otros países como Brasil ${ }^{278}$ y España ${ }^{279}$ también probaron sus leyes de transparencia gubernamental, incorporando en su ordenamiento jurídico esa importante herramienta de regeneración democrática y prevención de la corrupción.

Sin embargo, la expansión de la transparencia no se ha dado tan solo a nivel geográfico, pues se puede apreciar un cambio significativo en la forma como los Estados han empezado a regular internamente el ejercicio de ese derecho. ${ }^{280}$ Es entonces donde se ha pasado de un modelo donde la transparencia era considerada como un derecho público subjetivo del ciudadano frente a la Administración, hacia un modelo que reconoce la naturaleza de un derecho fundamental o de un derecho humano.

De forma subjetiva, mientras que las leyes más antiguas consideraban sujetos obligados a la transparencia tan solo a las Administraciones Públicas en sentido estricto, término que abarca exclusivamente los órganos y entidades que forman parte del poder ejecutivo, las leyes más recientes también consideran como tales a los otros poderes del Estado e incluso a sujetos privados que colaboran con los mismos, como las entidades privadas que reciben recursos públicos. 276 UE. Tratado de funcionamiento de la Unión Europea. 13 diciembre 2007. Disponible en:
https://www.boe.es/doue/2010/083/Z00047-00199.pdf. Acceso en: 8 mayo 2014.

\section{${ }^{277}$ Ibidem}

278 BRASIL. LEI N N $^{0}$ 12.527, DE 18 DE NOVEMBRO DE 2011. Regula o acesso a informações previsto no inciso XXXIII do art. 5o , no inciso II do § 3o do art. 37 e no § 2o do art. 216 da Constituição Federal; altera a Lei no 8.112, de 11 de dezembro de 1990; revoga a Lei no 11.111, de 5 de maio de 2005, e dispositivos da Lei no 8.159, de 8 de janeiro de 1991; e dá outras providências. Disponible en: http://legislacao.planalto.gov.br/legisla/legislacao.nsf/Viw Identificacao/lei\%2012.527-

2011? OpenDocument. Acceso en: 8 mayo 2014.

${ }^{279}$ ESPANA. Ley $\mathbf{n}^{\mathbf{0}} \mathbf{1 9} / \mathbf{2 0 1 3}$. Ley de transparencia, acceso a la información pública y buen gobierno. Disponible en: https:/www.boe.es/boe/dias/2013/12/10/pdfs/BOE-A-2013-12887.pdf . Acceso en: 6 mayo 2014.

${ }^{280}$ FERNÁNDEZ RAMOS; PÉREZ MONGUIÓ, op.cit., p. 19-25. 
En cambio, en materia objetiva, a su vez, si durante muchos años el derecho a la transparencia tuvo como objeto exclusivamente los documentos administrativos, término que restringe demasiado el ámbito de incidencia de la ley, las normativas más modernas caminan en el sentido de establecer que el objeto de ese derecho es la información en poder de los sujetos obligados.

Este es un concepto mucho más amplio que el anterior, una vez que abarca todos los datos, procesados o no, que pueden ser utilizados para producir o transmitir conocimiento, independientemente del medio, soporte o formato utilizado para guardarlos ${ }^{281}$. Respecto al papel de la llamada publicidad activa, mientras que las primeras leyes consideraban que ella jugaba un papel secundario en materia de transparencia gubernamental, las normativas recién aprobadas fomentan su utilización por la Administración Pública, lo que también ha resultado del desarrollo de nuevas tecnologías que permiten una mayor divulgación de la información.

Como señala Fernández Ramos:

Una de las diferencias más claras entre las Leyes de acceso a la información de los años 70 a 90 y las posteriores, es el escaso peso que en las primeras presentaban los deberes de publicidad activa de información de interés público a cargo de las autoridades, prácticamente limitados a la publicación de circulares e instrucciones de interpretación y aplicación de las normas, como sucedía con el artículo 37 LRJPAC. ${ }^{282}$

En cambio, el salto extraordinario que han supuesto desde entonces las nuevas tecnologías de la información determina que la publicidad proactiva presente hoy en día una dimisión hasta hace no mucho inimaginable, y que tiene su correspondiente reflejo en las Leyes comparadas más modernas, lo que ha llevado a incorporar en muchos casos la voz "transparencia" al propio título de la Ley (como Ley Federal de México de Transparencia y Acceso a la Información Pública Gubernamental de 2002). ${ }^{283}$

Desde otra perspectiva, también observamos que las leyes más modernas procuran simplificar el procedimiento administrativo de acceso a la información, con la reducción

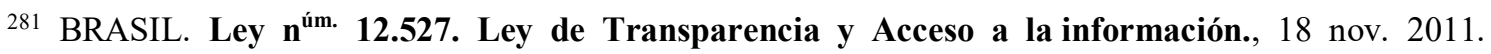
Disponible en: http://www.planalto.gov.br/ccivil 03/ ato2011-2014/2011/lei/112527.htm . Acceso em: 8 mayo 2014.

${ }^{282}$ FERNÁNDEZ RAMOS, Severiano. La Transparencia Pública: Pasado, Presente y Futuro. In: Revista Aragonesa de Administración Pública, ISSN 2341-2135, n. ${ }^{\circ}$ 51, Zaragoza, 2018, p. 213-243.

${ }^{283}$ FERNÁNDEZ RAMOS; PÉREZ MONGUIÓ, op.cit., p.101-102.
} 
del plazo de respuesta y la ampliación de los canales de contacto entre el titular del derecho y la Administración Pública, lo que también es posible gracias a las nuevas tecnologías.

Por último, también observamos que las leyes más avanzadas prevén la creación de órganos independientes, dotados de personalidad jurídica propia y con competencia para emitir decisiones en esta materia, funcionando como verdaderas agencias independientes, lo que es imprescindible para cualquier ley que tenga como objetivo la lucha contra la corrupción.

\subsection{La transparencia gubernamental como estrategia para la regeneración de la democracia y la prevención de la corrupción}

Históricamente, las primeras leyes de transparencia y acceso a la información tuvieron como característica asegurar la libertad de prensa, el derecho de petición y la prohibición de la censura ${ }^{284}$, sin preocuparse por fomentar el diálogo entre los poderes públicos y la sociedad, la estabilidad económica del país o la lucha contra la corrupción.

La comprensión de que la transparencia constituye un derecho de los ciudadanos se consolidó a partir de la segunda mitad del siglo XX, asociándose a la expansión de la democracia y de las nuevas exigencias que se le han añadido como forma de gobierno. ${ }^{285}$

A lo largo del siglo XX, la demanda principal de la democracia estuvo relacionada directamente con la ampliación de los derechos políticos y la coexistencia de elecciones justas, libres y competitivas, en donde los ciudadanos manifestarían su voluntad por medio del voto. ${ }^{286}$

En resumen, se creía sinceramente que ese proceso de elección y nombramiento de los altos directivos de la nación frenaría autoritarismos y abusos de otros tiempos, además de fomentar mayor identidad entre las decisiones gubernamentales y el enfrentamiento de los grandes problemas de la sociedad. ${ }^{287}$

\footnotetext{
${ }^{284}$ PESCHARD, op.cit., L. 2043.

${ }^{285}$ Ibidem, L. 2054

${ }^{286}$ SCHUMPETER, op.cit., p. 269.

${ }^{287}$ PESCHARD, op.cit., L. 980.
} 
Pero, justo después de que ese modelo se fijara como alternativa política, también comenzó a demostrar sus debilidades, una vez que el político había sido elegido se aprovechaba de sus cargos y se apartaba de los vecinos que lo habían elegido, con lo cual hubo una verdadera crisis de la democracia que no tardó en aparecer.

Apenas se dieron cuenta de las malas prácticas administrativas, los ciudadanos empezaron a abstenerse de participar en las elecciones y a alejarse de los partidos políticos e instituciones públicas, además de cuestionar la legitimidad de la propia democracia. ${ }^{288}$ Los ciudadanos ya no se conformaban con un sistema que les permitiera participar en elecciones libres y nombrar representantes ${ }^{289}$ sino que demandaban una democracia que, verdaderamente, pusiera de manifiesto la confianza entre gobernantes y gobernados. ${ }^{290}$

La comprensión de que la confianza constituye elemento fundamental para la nueva democracia obligó al Estado a adoptar instrumentos que permitiera a los ciudadanos conocer con detalle las razones que llevaron a los poderes públicos a tomar una decisión. Cualquier persona tiene derecho a saber cómo actúa el Estado, el porqué de las acciones de los funcionarios y cuanto del presupuesto se ha invertido en dicho programa o proyecto

Desde esa perspectiva, el canal utilizado con objeto de fomentar la participación ciudadana en los asuntos oficiales ha sido la transparencia gubernamental, principal instrumento que viabiliza el dialogo entre la Administración Pública y los ciudadanos. La transparencia les permite interferir directamente en la gestión de los intereses colectivos $^{291}$ y les convierte en verdaderos protagonistas en el proceso de toma de decisiones. $^{292}$

La capacidad de la transparencia hacia promover el dialogo entre el poder público y la sociedad se reconoció por vez primera en la declaración sobre el medioambiente y el desarrollo de Rio 1992. En ese momento todos coincidieron en la necesidad de divulgar información medioambiental a los ciudadanos, así como informarles de los riesgos que resultarían de una mala calidad del medio ambiente para la salud de todos. Desde esa

\footnotetext{
${ }^{288}$ PESCHARD, op.cit., L. 1016.

${ }^{289}$ SCHUMPETER, op.cit., p. 269.

${ }^{290}$ ROSANVALLON, Pierre. La Contra democracia: la política em la era de la desconfianza, Manantial, Buenos Aires: 2008.

${ }^{291}$ HEALD, op.cit., p. 26.

292 PESCHARD, op.cit., L. 1063.
} 
perspectiva, el principio 10 de la Cumbre de la Tierra, como quedó conocida la conferencia en Río $1992^{293}$, señala que:

"El mejor modo de tratar las cuestiones ambientales es con la participación de todos los ciudadanos interesados, en el nivel que corresponda. En el plano nacional, toda persona deberá tener acceso adecuado a la información sobre el medio ambiente de que dispongan las autoridades públicas, incluida la información sobre los materiales y las actividades que encierran peligro en sus comunidades, así como la oportunidad de participar en los procesos de adopción de decisiones. Los Estados deberán facilitar y fomentar la sensibilización y la participación de la población poniendo la información a disposición de todos. Deberá proporcionarse acceso efectivo a los procedimientos judiciales y administrativos, entre, estos el resarcimiento de daños y los recursos pertinentes. " (Principio 10)

Este principio de la declaración de Rio 1992 constituye, por tanto, un ejemplo vivo del rol que la transparencia gubernamental ha jugado en la sociedad desde los años 1990, actuando más bien en el sentido de fomentar la rendición de cuentas y la participación ciudadana en la toma de decisiones en asuntos medioambientales.

La nueva concepción de la democracia rápidamente se trasladó a otros sectores de la vida social, como la economía y la lucha contra la corrupción. En lo económico, desde los años 1990, los países latinoamericanos se vieron obligados a dar mayor publicidad a sus políticas económicas, como medida para atraer inversiones internacionales que mirasen hacia la recuperación de los mercados internos. ${ }^{294}$ De hecho, hasta los años 1980 , la política económica de los países latinoamericanos estuvo marcada por un gran proteccionismo de mercado, altos niveles de endeudamiento público e inflación incontrolada, fruto de una serie de decisiones políticas y económicas equivocadas, pero, sobre todo, de una cultura de secreto y opacidad que siempre ha caracterizado a los regímenes autoritarios que dominaron el continente entre los años 1960 y $1980 .{ }^{295}$

Cuando los altos niveles de endeudamiento y la hiperinflación practicados por estos regímenes tuvieron como resultado una crisis financiera sin precedentes, surgió la

\footnotetext{
${ }^{293}$ NACIONES UNIDAS. Disponible en https://www.un.org/Acceso en 15 En. 2019.

${ }^{294}$ MICHENER, op.cit., p. 145-159.

295 Ibidem.
} 
necesidad de adoptarse medidas efectivas que devolvieran la confianza a los inversores internacionales, siendo esto posible, entre otras razones, tras la aprobación de leyes de transparencia y acceso a la información del sector público. ${ }^{296}$

Todos coincidieron en que el conocimiento de informaciones gubernamentales sería imprescindible para sanear las finanzas públicas, promover buenas prácticas administrativas y enfrentarse a la corrupción. Desde los años 1990, la demanda de transparencia ha constado de las recomendaciones de Naciones Unidas, de la OCDE, del Banco Mundial (BM) y del Fondo Monetario Internacional (FMI) hacia los países latinoamericanos ${ }^{297}$, siendo considerada imprescindible para atraer inversiones internacionales.

Investigaciones a cargo de la OCDE han revelado que hay una estrecha relación entre la atracción de nuevas inversiones económicas y la transparencia gubernamental, en el sentido de que la apertura de la información desvela el comportamiento de las instituciones, disminuye riesgos en la toma de decisiones y cohíbe actos de corrupción. ${ }^{298}$

Como bien ha señalado Mauricio Merino: "Los promotores principales de las mejores prácticas han sido, al menos en un principio, los grandes organismos internacionales, con la OCDE y el Banco Mundial a la cabeza". 299

En el mismo sentido, Joseph Stiglitz, vicepresidente del Banco Mundial entre el 1997 y 2000, señaló que: “El secreto no sólo contribuye a la inestabilidad generalizada, sino que constituye una importante fuente de corrupción, dañando la confianza en el gobierno en su conjunto". ${ }^{300}$ Por tanto, los organismos internacionales pusieron de manifiesto que asegurar la transparencia y el acceso a la información constituye un factor determinante hacia el crecimiento económico del país ${ }^{301}$, con lo cual, necesariamente,

\footnotetext{
${ }^{296}$ MICHENER, op.cit. p. , 145-159.

${ }^{297}$ Ibidem.

298 ORGANIZACIÓN PARA LA COOPERACIÓN Y EL DESARROLLO ECONÓMICOS, Foreign Direct Investment for Development. Maximizing Benefits, Minimizing Costs, OCDE, Paris, 2002. Disponible en: https://www.oecd.org/investment/investmentfordevelopment/1959795.pdf Acceso en en.2019.
}

${ }^{299}$ MERINO, Mauricio. El Desafío de la Transparencia. Una Revisión de las Normas de Acceso a la Información Pública en las Entidades Federativas de México. In: ELIZONDO, Carlos et al. Democracia y Transparencia. IEDF, México, 2005, p. 3.

300 STIGLITZ, Joseph E. On Liberty, the Right to Know and Public Discourse: The Role of Transparency in Public Life. Banco Mundial. Oxford: Oxford Amnesty Lecture, 1999, p. 20.

${ }^{301}$ ACKERMAN, op. cit., p. 46. 
debería ser implementada por los gobiernos de todo el mundo. A raíz de la labor de esas instituciones, los países latinoamericanos comenzaron a abrir sus cuentas a los observadores internacionales, que desde ahí pudieron identificar áreas que merecerían inversiones, fijar estrategias comerciales y acotar riesgos. ${ }^{302}$

Finalmente, la transparencia gubernamental también fue y sigue siendo impulsada por diferentes organismos internacionales, como OCDE, OEA, el Consejo de Europa y Naciones Unidas, que aprobaron los primeros Convenios internacionales de lucha contra la corrupción, tales como:

a) Convención Interamericana contra la Corrupción; ${ }^{303}$

b) Convenio de lucha contra la Corrupción de la OCDE; 304

c) Convenio Penal y el Convenio Civil sobre la Corrupción del Consejo de Europa; ${ }^{305} \mathrm{y}$

d) la convención de las Naciones Unidas contra la Corrupción (CNUCC). ${ }^{306}$

En Europa también ha sido creado el Grupo de Represión contra la Corrupción $(\text { GRECO })^{307}$, órgano que integra el Consejo de Europa ${ }^{308}$ y que actúa directamente en la lucha contra la corrupción.

\footnotetext{
${ }^{302}$ ESTAVILLO, María Elena; MARTINEZ, Leonardo; ESCOBAR, Rebeca. Evaluación del Impacto Económico de la Ley Federal de Transparencia y Acceso a la Información Pública Gubernamental. IFAI, México, 2006.
}

303 OEA. Convención Interamericana Contra La Corrupción (B-58). Disponible en: http://www.oas.org/es/sla/ddi/tratados multilaterales interamericanos B-58 contra Corrupcion.asp Acceso en: 16 mar. 2014.

304 OCDE. Convenio de lucha contra la corrupción de agentes públicos extranjeros en las transacciones comerciales. Disponible en: https:/www.boe.es/diario boe/txt.php?id=BOE-A-2002-3593 pdf. Acceso en 16 mar. 2014.

305 ESPAÑA. Instrumento de Ratificación del Convenio penal sobre la corrupción BOLETÍN OFICIAL DEL ESTADO. Miércoles 28 de julio de 2010. Disponible en: https://www.boe.es/diario boe/txt.php?id=BOE-A-2011-4192 Acceso en:16 mar. 2019.

${ }^{306}$ EU. Convención de las Naciones Unidas contra la corrupción. Decisión del Consejo 2008 /801/CE, de 25 de septiembre de 2008, sobre la celebración, en nombre de la Comunidad Europea, de la Convención de las Naciones Unidas contra la opción (DO L 287 de 29.10.2008). Disponible en: https://eurlex.europa.eu/legal-content/ES/TXT/HTML/?uri=LEGISSUM:133300\&from=BGAcceso en: 15 abr. 2019

307 COE. Group of States against corruption (GRECO) Website. Disponible en: https://www.coe.int/en/web/greco. Acceso en: 16 mar. 2019.

${ }^{308}$ Según sus directrices, GRECCO tiene como uno de sus objetivos fortalecer a la democracia y el respecto a los derechos humanos, con ello evitando el surgimiento de regímenes contrarios a ella, como el nazismo y el fascismo. 
Entre las innumerables iniciativas nacionales ${ }^{309}$ merece la pena destacar la aprobación del Código de Comportamiento de los empleados de las Administraciones Públicas de Italia (1993), la aprobación de la Ley para combatir la corrupción en Alemania (1997), la aprobación de la Ley que creó la Fiscalía Especial para la represión de los delitos económicos relacionados con la Corrupción en España (1995) y la aprobación de las Leyes de improbidad administrativa (1992) y de anticorrupción de empresas (2013) en Brasil.

Esas nuevas ideas también llegaron al mundo académico a finales de los años setenta, pues en 1978, Rose Ackerman publicó su famoso libro sobre el tema, pero que comenzó a tener relevancia a partir de los años ochenta. ${ }^{310}$ Esto no quiere decir que antes de ese periodo no hubiera estudios sobre la corrupción, pues aunque los había, se analizaba el fenómeno desde el punto de vista de la antropología, concentrándose la investigación en el continente africano y no en otros sitios, aunque la corrupción fuera un fenómeno mundial.

El trabajo de Rose Ackerman destacó ya que examinaba la corrupción bajo una mirada económica y política que no se había hecho hasta entonces. Desde esa iniciativa, la autora permitió que organismos internacionales como el Banco Mundial y el Fondo Monetario Internacional pudieran diseñar políticas anticorrupción, teniendo en cuenta el análisis de sus causas y efectos más comunes, así como los involucrados en casos de esa naturaleza, como los gobernantes de muchos países.

En este sentido, es importante decir que hasta el 1996, el Banco Mundial no utilizaba la palabra "corrupción" en sus documentos, tendencia que se ha cambiado gracias al trabajo de personas como Peter Eigen, ${ }^{311}$ el fundador de Transparencia Internacional. ${ }^{312}$

\footnotetext{
309 ALFARO, Luis Humberto Contreras. Corrupción y principio de oportunidad: alternativas en materia de prevención y castigo a la respuesta penal tradicional. Salamanca: Ratio Legis, 2005, p.134.

${ }^{310}$ ROSE-ACKERMAN, op.cit. p. 23-43.

311 Transparencia Internacional (TI) es una organización no-gubernamental que tiene como objetivo principal luchar contra la corrupción. Fue fundada el 1993 bajo el liderazgo de Peter Eigen, exfuncionario del Banco Mundial, que tenía gran experiencia en proyectos de desarrollo en América Latina y África. Actualmente, la entidad está ubicada en Berlín, siendo responsable por la elaboración de un informe anual sobre la percepción de la corrupción alrededor del mundo, con representaciones en diferentes países.

312 TRANSPARENCIA INTERNACIONAL ESPAÑA. Disponible en: https://transparencia.org.es/Acceso en: 05 mar. 2019.
} 
Esa institución efectúa varios estudios respecto a la situación de la corrupción alrededor del planeta y los divulga por medio de tres informes mundialmente conocidos:

a) El índice de percepción de la corrupción (Corruption Perception Índex);

b) El índice de pagamiento de Sobornos (Bríhe Payers Index); y

c) El barómetro Global de la Corrupción (Global Corruption Barometer).

Por tanto, a partir de los últimos años del siglo $\mathrm{XX}$, la corrupción entró definitivamente en la agenda política internacional, mereciendo la atención de entidades como Naciones Unidas, Transparencia Internacional, Organización de los Estados Americanos y Unión Europea, que pasaron a trabajar concretamente en el sentido de erradicar a través de innumerables medidas de naturaleza legal y administrativa.

Algunas de esas medidas fueron expresamente mencionadas por el Banco Mundial en el año 1992, cuando la entidad buscó establecer criterios mínimos para la formación del llamado buen gobierno. Según ese documento, para que el Estado pudiera cumplir con su papel en la sociedad, debería fomentar medidas como la responsabilidad, la transparencia gubernamental, el Estado de derecho y la pluralidad de actores participando del proceso de decisiones. ${ }^{313}$

Efectivamente, como señala Emilio Guichot ${ }^{314}$, la transparencia fomenta el desarrollo económico y social, fortalece la democracia y disminuye la corrupción, mereciendo una mayor atención de los gobiernos, los cuales deben crear condiciones para que todas las personas puedan utilizarla. En este sentido, la $\mathrm{CNUCC}^{315}$ recomienda a los estados fomentar la transparencia de las instituciones públicas, medida que varios países han implementado desde los años noventa del siglo XX, pero que Brasil y España han adoptado recientemente tras la aprobación de las leyes $n^{\circ} 12.527$, del 18/11/2011, y 19, del 9 de diciembre de 2013, respectivamente. Queda claro, que el incremento de la transparencia gubernamental como política pública no se produjo a raíz de un factor en específico, sino que resultó más bien de la asociación de causas políticas, económicas y sociales que determinaron un cambio de comportamiento de las instituciones oficiales, en

\footnotetext{
${ }^{313}$ LOPES, José Mouraz. O espectro da corrupção. Coimbra: Almedina, 2011, p. 10.

${ }^{314}$ GUICHOT, op.cit., p. 17.

315 NACIONES UNIDAS. Convención de las Naciones Unidas contra la corrupción. 9 dez. 2003. Disponible En: https://eur-lex.europa.eu/legal-content/ES/TXT/?uri=LEGISSUM\%3Al33300. Acceso en: 06 mar. 2019.
} 
el sentido de que deberían revitalizar la democracia, fomentar el crecimiento económico y cohibir las malas prácticas de los directivos y funcionarios del Estado.

Respecto al enfrentamiento de las malas prácticas políticas y administrativas, conviene señalar que la transparencia gubernamental juega un papel importante en lo que se refiere a los mega eventos deportivos internacionales como los Juegos Olímpicos y paralímpicos y la Copa del Mundo de fútbol. Una vez que en estos espectáculos suelen realizarse grandes inversiones públicas en un corto espacio de tiempo, se perfeccionan muchos contratos para la construcción de los equipamientos deportivos, la realización de grandes obras de infraestructura y recuperación ambiental e, históricamente, se han practicado actos de corrupción de todo tipo.

En ese contexto, la aprobación de una ley de transparencia y acceso a la información constituye una importante herramienta para acompañar la ejecución de los gastos públicos y cohibir las malas prácticas políticas y administrativas, lo que, al final, le permitirá a la sociedad no tener que enfrentarse con uno de los grandes problemas de la lucha contra la corrupción: la efectiva recuperación de los recursos oficiales desviados. ${ }^{316}$

Por tanto, cobra especial importancia el estudio de los temas relativos a la naturaleza de la transparencia gubernamental, a los principios que encaminan la actuación de los poderes públicos, a las limitaciones legales al ejercicio del derecho de acceso, a los órganos responsables de analizar las decisiones que deniegan el acceso y a los sujetos obligados, los cuales interfieren directamente en la fiscalización y en el control ciudadano de los actos oficiales, en particular cuando relativos a la preparación de los Juegos Olímpicos.

\subsection{Concepto y naturaleza jurídica}

Desde una perspectiva semántica, el término "transparencia"317, se refiere a la cualidad de ser transparente ${ }^{318}$, que deja pasar la luz, que permite ver con claridad a través

\footnotetext{
${ }^{316}$ RUFATO, Pedro Evandro de Vicente. A Tutela Preventiva da Corrupção e dos Atos de Improbidade. In: AZAMBUJA, Edson; BALLAN JUNIOR, Octahydes; e OLIVEIRA E SILVA, Vinicius de. Combate à Corrupção na Visão do Ministério Público. Belo Horizonte: J. H. Mizuno, 2018, p. 344-5.

317 El diccionario de la Real Academia Española define a la Transparencia como: "Cualidad de transparente". RAE. Diccionario de la lengua española. Disponible en: https://dle.rae.es/. Acceso en: 6 mar. 2019.

318 El diccionario de la Real Academia Española, define transparente como: "Claro, evidente, que se comprende sin duda ni ambigüedad." Ibidem.
} 
de él y que es fácil de comprender. En este sentido, la palabra mantiene su significado desde el latín medieval "transparens" y "transparere", que daba la idea de "aparecer a través de". 319

Por otro lado, el término "publicidad" contiene la idea de difusión, divulgación, con lo cual toda la gente puede conocer los actos practicados por terceros, en particular por los responsables de la gestión pública, es decir, por los encargados de gobernar, guiar o dirigir un país o colectividad política. ${ }^{320}$

Al menos en lo relativo a las estrategias anticorrupción, los términos de transparencia y publicidad tienen carácter complementario. $\mathrm{Si}$, por un lado, los actos y decisiones oficiales deben ser llevados al conocimiento de los ciudadanos, lo que resulta del principio de publicidad, por otro, con arreglo a la transparencia, deben facilitar que los interesados accedan a su contenido y que conozcan los motivos y finalidades que enmarcaron la actuación de la Administración, lo que será fundamental para el control social de la gestión pública. ${ }^{321}$

La transparencia se refiere, en este caso, a la apertura de las informaciones producidas por el gobierno en el ejercicio de sus competencias y permite a los ciudadanos el control efectivo de los actos y decisiones oficiales. ${ }^{322}$ Con otras palabras, la transparencia tiene como principal objetivo levantar el velo de todas las administraciones públicas y busca desvelar a la sociedad, con claridad y objetividad, todo lo que pasa en el seno de los órganos y entidades que forman parte del Estado.

Así, no basta con conocer las decisiones de los responsables de la gestión de los intereses colectivos, lo que resulta de la publicidad, sino que es fundamental estar al tanto de las reglas que gobiernan cada acto y decisión de las autoridades. ${ }^{323}$ El gobierno no solo debe hacer públicas sus decisiones a través de medios adecuados, sino que también debe informar a la sociedad de los elementos, cálculos y consideraciones en los cuales se basó

\footnotetext{
${ }^{319}$ HERRERA, op.cit., p. 180.

${ }^{320} \mathrm{RAE}$. Diccionario de la lengua española. Disponible enhttps://www.rae.es/?val=gobierno. Acceso en: 4 mayo 2019.

${ }^{321}$ MOTTA, Fabricio. Notas Sobre Publicidade e Transparência na Lei de Responsabilidade Fiscal. Revista Eletrônica de Direito do Estado, Salvador, Bahia, n. 14, p. 2-3, abril-junho de 2008. Disponible en: http://www.revistaaec.com/index.php/revistaaec/article/view/638

322 DAVIS, J. Access to and Transmission of Information: Position of Media. In: DECKMYN, Veerle; THOMSON, Ian (eds.). Openness and Transparency in the European Union. Maastricht: European Institute of Public Administration, 1997, p. 121.

${ }^{323}$ PESCHARD, op.cit., L. 653.
} 
para tomarlas en cada caso, lo que permitirá a los ciudadanos estar al tanto de todo el proceso político o administrativo precedente y no solo del acto final manifestado por el Estado. ${ }^{324}$

La transparencia da la posibilidad de que quienes son afectados por ciertas decisiones logren conocer no solo el acto final de la Administración Pública, como también los mecanismos y procesos que han contribuido a la adopción de determinada política pública. ${ }^{325}$ En este sentido, el Banco Asiático de Desarrollo ya tuvo oportunidad de señalar que la transparencia debe ser considerada como: "la información que está accesible a la población en general y que ofrece claridad sobre las reglas y las decisiones del gobierno". 326

El Consejo de Transparencia de Chile, uno de los más desarrollados del mundo, clarifica que: ${ }^{327}$

"la Transparencia Activa es la obligación que tienen los organismos públicos de entregar cierta información relevante y actualizada cada mes de cómo están organizados sus contratos y contrataciones, así como distintos modos de relación con la ciudadanía (transferencias, beneficios, mecanismos de participación) entre otros. Esta obligación se fundamenta en la entrega de información pública relevante a la ciudadanía y al público en general; entrega que debe ser permanente, actualizada y de forma accesible y comprensible." 328

Como se puede observar, se trata de una definición muy sencilla, pero que atiende al objetivo que se propone, que es definir con claridad el objeto y el sentido de la transparencia activa, con todos sus elementos fundamentales, es decir, la existencia de información compilada y organizada en archivos oficiales, de forma clara y sencilla, con

\footnotetext{
${ }^{324}$ ODONNELL, Guillermo. Horizontal Accountability: The Legal institutionalization of mistrust. In: MAINWARING, Scott; WELNA, Christopher (coords.). Democratic Accountability in Latin America. Oxford: Oxford University Press, 2003, p. 34-54.

${ }^{325}$ HERRERA, op.cit., p. 180.

${ }^{326}$ Banco Asiático de Desarrollo, Governance: Sound Development Management, ADB, Manila, 1995, p. 256. Disponible en : https://www.adb.org/documents/governance-sound-development-management Acceso en mar.2019

327 CTPL. Consejo de Transparencia Chile. ¿Que es la transparencia activa? Disponible en: http://www.consejotransparencia.cl/que-es-la-transparencia-activa/consejo/2012-12-19/230022.html. https://www.consejotransparencia.cl/ Acceso en: 06 jun 2019.

${ }^{328}$ Ibidem.
} 
lenguaje de fácil comprensión, además de la colocación de esa información a servicio de los ciudadanos por medios adecuados.

Pero, esa misma claridad respecto al concepto no se verifica en cuanto a la naturaleza jurídica del derecho de acceso a la información, principalmente en el derecho español, donde el tema genera discusiones entre los expertos. ${ }^{329}$

Inicialmente, hay quienes sostienen que el derecho de acceso es un derecho fundamental ${ }^{330}$ cuya base legal es el artículo 20.1.d de la Constitución de España, precepto que consagra la libertad a la información como derecho fundamental, insertado en el capítulo segundo, Sección $1^{\text {a }}$ del Título I. ${ }^{331}$

En este sentido, el derecho de acceso es una manifestación concreta del derecho a recibir información, plasmado en el artículo 20.1.d de la Constitución de España, de tal forma que de este precepto deriva el correspondiente deber de la Administración de permitir el libre acceso a la información administrativa, como consecuencia de los principios de publicidad, transparencia y democracia. ${ }^{332}$ Se trata de un derecho de tercera generación, caracterizado como "un elemento moderno de calidad democrática.",333

Esa interpretación permite a los ciudadanos presentar del Recurso de Amparo en el caso de que el Estado no les facilite la información demandada y que el objeto de su pedido tenga especial transcendencia constitucional ${ }^{334}$, como prevé el artículo 53.2 de la Constitución de España. ${ }^{335}$

Otros autores defienden que el derecho de acceso se caracteriza como un derecho constitucional autónomo de configuración legal, cuyo fundamento de validez es el

\footnotetext{
${ }^{329}$ GUICHOT et al, op. cit., p. 17.

${ }^{330}$ Ibidem.

331 Artículo 20. Libertad de expresión 1. Se reconocen y protegen los derechos: d) A comunicar o recibir libremente información veraz por cualquier medio La Constitución española de 1978. Disponible en: https://app.congreso.es/consti/constitucion/indice/titulos/articulos.jsp?ini=15\&fin=29\&tipo=2Acceso en: 11 mayo 2019.

332 FERNÁNDEZ RAMOS, op.cit., 350-358.

${ }^{333}$ FERNÁNDEZ RAMOS; PÉREZ MONGUIÓ, op.cit., p. 19-25.

${ }^{334}$ ZAMORA, Miguel Agudo et al. Manual de Derecho Constitucional. 2. ed. Madrid: Tecnos, 2013, p. 394.
}

${ }^{335}$ ESPAÑA. La Constitución española de 1978. Disponible en: http://www.congreso.es/consti/constitucion/indice/titulos/articulos.jsp?ini=53\&fin $=54 \&$ tipo $=2$

Acceso en: 15 mayo 2019. 
artículo 105.B, precepto que asegura a los ciudadanos el derecho de acceso a los archivos y registros administrativos ${ }^{336}$, diferente de la libertad de información.

Efectivamente, cuando fue aprobada la Constitución de España, en el año 1978, la libertad de información de la que trata el artículo 20.1.d fue concebida como una limitación impuesta al Estado en el sentido de no interferir en el proceso de comunicación entre particulares ${ }^{337}$, garantizándoles condiciones para que pudieran disfrutar del derecho a la libre difusión de ideas, sin tener nada que ver con el derecho de acceso a la información.

Esta también ha sido la conclusión a la que llegó el Tribunal Constitucional de España, ${ }^{338}$ cuando rechazó el recurso de amparo de un ciudadano que quería ver asegurado su derecho de acceso a determinados documentos que le fueron negados por la Administración. El Tribunal señaló en su fallo que el derecho de acceso a documentos y archivos deriva del artículo 105.b de la Constitución y no del artículo 20, razón por la que no es considerado un derecho fundamental en España. Así las cosas, no autorizó la sustanciación del Recurso de Amparo, conforme establece el artículo 53.2 de la Constitución.

También en este sentido se ha manifestado la Sala tercera del Tribunal Supremo del país a estudio, al dictar una sentencia el 19 de mayo de $2003^{339}$ en la que el juez don Manuel Goded Miranda señaló que el derecho de acceso constituye un derecho de configuración legal, como determina el artículo 105.b de la Constitución, con lo cual no se caracteriza como derecho fundamental.

Con objeto de solucionar ese problema, en noviembre de 2015, el Partido Ciudadanos presentó en el Parlamento propuesta de enmienda a la Constitución que reconociera a la transparencia gubernamental y al derecho de acceso la naturaleza de derecho fundamental. ${ }^{340}$ La propuesta incorporaba la transparencia y el derecho de acceso

\footnotetext{
${ }^{336}$ Ibidem.

${ }^{337}$ POMED SÁNCHEZ, op.cit., p. 116.

${ }^{338}$ ESPAÑA. Tribunal Constitucional, STC n. 161. SENTENCIA 161/1988. 20 set. 1988. Disponible en http:/hj.tribunalconstitucional.es/cs-CZ/Resolucion/Show/1102
}

\footnotetext{
. Acceso en: 03 mayo 2019.

${ }^{339}$ GUICHOT, op.cit., 40.

${ }^{340}$ HERRERA, op.cit., p. 47-48.
} 
en el Artículo 23 de la Constitución de 1978, colocándoles al lado de otros derechos como el derecho de participación y el derecho de acceder a los cargos públicos. ${ }^{341}$ Al justificar la propuesta, Ciudadanos argumentó que el cambio constitucional sería esencial a la regeneración democrática e institucional del país y permitiría su aplicación a todas las Administraciones locales y autonómicas del territorio español para dotarles de una máxima protección. ${ }^{342}$

Pero, pese a los argumentos, el cambio no se produjo y, por tanto, la transparencia y el derecho de acceso no son considerados un derecho fundamental en España.

A pesar de esa controversia en el seno del derecho español, desde la perspectiva de la comunidad internacional queda evidente que el derecho de acceso a la información pública tiene la naturaleza de derecho fundamental. En este sentido, el Comité de Derechos Humanos de las Naciones Unidas reconoce que el derecho de acceso a la información es esencial para la libertad de expresión, conclusión que extrae del artículo 19 de la Declaración Universal de Derechos del Hombre, ${ }^{343}$ aprobada por la Asamblea General de las Naciones Unidas el 30 de diciembre del año 1948.

Se trata de la misma conclusión a la que ha llegado el Tribunal Europeo de Derechos Humanos (TEDH), que se ha manifestado a tal respecto en las sentencias dictadas en los casos Társaság a Szabadságjogokért vs Hungría y Kenedi vs Hungría. ${ }^{344}$

En estos dos supuestos, la Corte explicó que el derecho de acceso deriva del hecho ineludible de que la Administración Pública mantiene un monopolio respecto a la titularidad de muchas informaciones, por ello resulta imprescindible divulgarla como forma de reequilibrar el juego de poder que hay entre el Estado y los particulares.

Efectivamente, la Administración Pública posee mucha más información si la comparamos con la de los ciudadanos y que obtiene a través de diferentes canales, muchos de ellos alimentados por los propios particulares. Se trata de información que es única por

\footnotetext{
${ }^{341}$ Ibidem.

${ }^{342}$ Ibidem.

${ }^{343}$ Artículo 19. Todo individuo tiene derecho a la libertad de opinión y de expresión; este derecho incluye el de no ser molestado a causa de sus opiniones, el de investigar y recibir informaciones y opiniones, y el de difundirlas, sin limitación de fronteras, por cualquier medio de expresión. NACIONES UNIDAS. Declaración Universal de Derechos Humanos. Disponible en: http://www.un.org/es/documents/udhr/
}

Acceso en: 4 mayo 2014.

${ }^{344}$ GUICHOT, op.cit., p. 37. 
su diversidad y universalidad ${ }^{345}$, convirtiéndose en instrumento de poder en manos del Estado que pasa a detener conocimientos que el ciudadano no posee ordinariamente.

Esta es la razón por la que el derecho de acceso a la información pública es esencial en el Estado democrático, pues, si por un lado él permite a los ciudadanos conocer y controlar todos los actos de la Administración Pública, por otro reequilibra las fuerzas de poder en la sociedad.

Esa comprensión quedó evidente en el citado caso Társaság a Szabadságjogokért v. Hungría, del 14 de abril del año 2009 (App. núm. 37374/05), ${ }^{346}$ el cual fue responsable por un cambio en la jurisprudencia del TEDH.

El caso arrancó cuando la Unión de Libertades Civiles Húngara, una organización no gubernamental cuyo objetivo es promover los derechos fundamentales, solicitó información sobre un recurso planteado ante el Tribunal Constitucional Húngaro y el mencionado acceso le fue denegado por la Corte Suprema.

Disconformes con la respuesta, la entidad presentó un recurso al $\mathrm{TEDH}^{347}$, que reformó la sentencia del Tribunal Constitucional y le reconoció el derecho de acceso a los documentos, para ello apoyándose en la naturaleza jurídica del derecho de acceso a la información. Se trató de una decisión que produjo un cambio en la jurisprudencia del TEDH, permitiéndole avanzar hacia una interpretación más amplia del concepto de derecho de acceso y de libertad de recibir información.

A su vez, la sentencia Kenedi v. Hungría, del 26 de mayo del año $2009{ }^{348}$ arranca a partir de una decisión que niega al señor Kenedi el derecho de acceder a ciertos documentos oficiales, incluso después de haber obtenido una sentencia favorable de los tribunales húngaros. El interesado quería acceder a esos documentos porque deseaba

\footnotetext{
${ }^{345}$ VEIGA, Alexandre Brandao da. Acceso à Informação da Administração Pública pelos Particulares. Coimbra: Almedina, 2007, p. 17.

346 CASE OF TÁRSASÁG A SZABADSÁGJOGOKÉRT v. HUNGARY. 37374/05. 14 jul. 2009. Disponible en: https://hudoc.echr.coe.int/eng\#\{\%22itemid\%22:[\%22001-92171\%22]\}. Acceso en: 5 dic 2019

${ }^{347}$ DIEGO, Manuel Sanchez De. El principio de transparencia y el derecho de acceso a la información pública. A vueltas con el Estado. [S.l: s.n.]. Ponencia presentada en el XII Congreso de Constitucionalistas de España "Participación, representación y Democracia", celebrado en la vieja Universidad de Salamanca el 3 y 4 de abril de 2014, p. 1-36. Disponible enhttps://sanchezdediego.blogspot.com// . Acceso en: 4 mayo 2014. , 28 abr. 2014.

348 GUICHOT, Emilio. Op.cit. p. 37.
} 
escribir un estudio sobre el funcionamiento del Servicio de Seguridad del Estado húngaro en la década de 1960, período en que el país estuvo bajo el régimen comunista.

En este caso, de forma emblemática, el TEDH resaltó que el acceso a las fuentes documentales originales para la investigación histórica legítima constituía un elemento esencial del ejercicio del derecho del demandante a la libertad de expresión, desde ahí sacando su naturaleza de derecho fundamental.

La sentencia más reciente se encuentra en el caso Youth Initiative for Human Rights v. Serbia, del 25 de junio del año 2013 (Appl. núm. 48135/06) ${ }^{349}$. En este caso, se trataba de la reiterada negativa de la agencia de inteligencia serbia (Bezbednosno-informativna agencija) de proporcionar información relacionada con la vigilancia electrónica, concretamente $^{350}$ sobre cuántas personas habían sido objeto de la vigilancia electrónica por ese organismo en el año 2005.

Al fallar el caso, el TEDH concluyó de la siguiente forma:

La reticencia obstinada de la agencia de inteligencia de Serbia para cumplir con la orden del Comisionado de Información fue un desafío del derecho interno y equivale a la arbitrariedad. Por lo que en consecuencia se ha acordado considerar que ha existido una violación del artículo 10 de la Convención. ${ }^{351}$

Ese reconocimiento del derecho de acceso como derecho fundamental fue también manifestado en el fallo de la Corte Interamericana de derechos humanos cuando se decidió el Caso Claude Reyes vs Chile. ${ }^{352}$

Precisamente, se trataba de un hecho ocurrido entre mayo y agosto de 1998 que guardaba relación con la negativa del Estado de facilitar a los señores Marcel Claude Reyes, Sebastián Cox Urrejola y Arturo Longton Guerrero toda la información que

${ }^{349}$ CASE OF YOUTH INITIATIVE FOR HUMAN RIGHTS v. SERBIA. 25 jun. 2013. Disponible en: http://hudoc.echr.coe.int/sites/eng/Pages/search.aspx\# $\{\% 22$ fulltext $\% 22:[\% 22$ Youth $\% 20$ Initiative $\% 20$ for \%20Human $\% 20$ Rights $\% 20 \mathrm{v} . \% 20$ Serbia\%22],\%22sort\%22:[\%22appnoyear\%20Descending,appnocode $\%$ 20Descending $\% 22], \% 22$ documentcollectionid $2 \% 22:[\% 22$ GRANDCHAMBER $\% 22, \% 22$ CHAMBER $\% 2$ 2],\%22itemid\%22:[\%22001-120955\%22]\}

. Acceso en: 03 dic 2019.

${ }^{350}$ DIEGO, op. cit. P. 1-36.

${ }^{351}$ Ibidem.

${ }^{352}$ CORTE INTERAMERICANA DE DERECHOS HUMANOS. Caso Claude Reyes y otros Vs. Chile. 19 set. 2006. Disponible en: http://www.corteidh.or.cr/docs/casos/articulos/seriec_151_esp.pdf 
requerían del Comité de Inversiones Extranjeras sobre la empresa forestal Trillium y el Proyecto Río Condor.

En resumen, se trataba de un proyecto de deforestación que sería ejecutado en la $12^{\mathrm{a}}$ región de Chile y que podría ser perjudicial para el medio ambiente, además de impedir el desarrollo sostenible del país.

Al decidir el conflicto, la Corte reconoció que la restricción impuesta a los interesados viola el artículo 13 de la Convención Interamericana de Derechos Humanos. ${ }^{353}$ Ese precepto asegura a todos el derecho a la libertad de pensamiento y de expresión y comprehende el derecho de buscar, recibir y divulgar informaciones e ideas, verbalmente o por escrito, sin restricciones de fronteras, salvo en los casos en que se aplique una legítima restricción.

En este sentido, confiérase el párrafo 77 de la sentencia de la Corte Interamericana de Derechos Humanos:

77. En lo que respecta a los hechos del presente caso, la Corte estima que el artículo 13 de la Convención, al estipular expresamente los derechos a "buscar" y a "recibir" "informaciones", protege el derecho que tiene toda persona a solicitar el acceso a la información bajo el control del Estado, con las salvedades permitidas bajo el régimen de restricciones de la Convención. Consecuentemente, dicho artículo ampara el derecho de las personas a recibir dicha información y la obligación positiva del Estado de suministrarla, de forma tal que la persona pueda tener acceso a conocer esa información o reciba una respuesta fundamentada cuando por algún motivo permitido por la Convención el Estado pueda limitar el acceso a la misma para el caso concreto. Dicha información debe ser entregada sin necesidad de acreditar un interés directo para su obtención o una afectación personal, salvo en los casos en que se aplique una legítima restricción. Su entrega a una persona puede permitir a su vez que ésta circule en la sociedad de manera que pueda conocerla, acceder a ella y valorarla. De esta forma, el derecho a la libertad de pensamiento y de expresión contempla la protección del derecho de acceso a la

\footnotetext{
353 “Artículo 13. Libertad de Pensamiento y de Expresión 1. Toda persona tiene derecho a la libertad de pensamiento y de expresión. Este derecho comprende la libertad de buscar, recibir y difundir informaciones e ideas de toda índole, sin consideración de fronteras, ya sea oralmente, por escrito o en forma impresa o artística, o por cualquier otro procedimiento de su elección." OEA. Convencion Americana Sobre Derechos Humanos (Pacto de San José). Nov, 1969. Disponible en: https://www.oas.org/dil/esp/tratados b-32 convencion americana sobre derechos humanos.htm.htm. Acceso en:03 dic 2019.
} 
información bajo el control del Estado, el cual también contiene de manera clara las dos dimensiones, individual y social, del derecho a la libertad de pensamiento y de expresión, las cuales deben ser garantizadas por el Estado de forma simultánea.

La Ley Modelo Interamericana también reconoce el carácter fundamental del derecho de acceso a la información pública, ${ }^{354}$ considerándolo imprescindible para fomentar la transparencia de las instituciones e incentivar la participación ciudadana en la toma de decisiones.

Así es que, desde la perspectiva de la comunidad internacional, la transparencia gubernamental y el derecho de acceso a la información son considerados derechos fundamentales, cuya base para su reconocimiento es la naturaleza representativa de los gobiernos democráticos y los principios de igualdad y libre manifestación.

Coincidiendo con todos estos precedentes, la ley de transparencia de Brasil reconoce al derecho de acceso a la información la naturaleza de derecho fundamental ${ }^{355}$, reproduciendo en este aspecto la idea consagrada en la Constitución del año 1988, que incorporó ese derecho en el título de los derechos fundamentales. También el Tribunal Constitucional ya reconoció la naturaleza fundamental de la transparencia y del derecho de acceso a la información en el orden jurídico brasileño. ${ }^{356}$

\subsection{Principios de la transparencia}

Así como todos los ramos de la ciencia jurídica, la transparencia gubernamental también sufre con la influencia de principios generales que orientan la actuación de los

\footnotetext{
${ }^{354}$ OAS. Ley Modelo Interamericana sobre Acceso a la Información: El acceso a la información es un derecho humano fundamental del hombre y una condición esencial para todas las sociedades democráticas. Disponible en: https://www.oas.org/dil/esp/CP-CAJP-2840-10_Corr1_esp.pdf Acceso en 18.01.2019.
}

355 “Art. 3o Os procedimentos previstos nesta Lei destinam-se a assegurar o direito fundamental de acesso à informação e devem ser executados em conformidade com os princípios básicos da administração pública e com as seguintes diretrizes.(..)" BRASIL. LEI N. 12.527, DE 18 DE NOVEMBRO DE 2011. Regula o acesso a informações previsto no inciso XXXIII do art. $5^{\circ}$, no inciso II do $\S 30$ do art. 37 e no $\S 20$ do art. 216 da Constituição Federal; altera a Lei no 8.112, de 11 de dezembro de 1990; revoga a Lei no 11.111, de 5 de maio de 2005, e dispositivos da Lei no 8.159, de 8 de janeiro de 1991; e dá outras providências. Disponible em: http://www.planalto.gov.br/ccivil 03/ ato2011-2014/2011/lei/112527.htm Acceso en: 3 dic 2019.

356 BRASIL. Supremo Tribunal Federal. MS núm. 24.725 MC. Decisão monocrática proferida pelo Rel. Min. Celso de Mello. Julgado em: 28.11.2003; DJ, p. 47, 27 fev. 2004 (Informativo núm. 331 do STF).

Disponible em: www.stf.jus.br/arquivo/informativo/documento/informativo331.htm Acceso en 03 dic 2019. 
órganos y entidades públicas en lo relativo al ejercicio de sus competencias. De acuerdo con el diccionario de la Real Academia Española, la palabra "principio" proviene del latín "principium" y significa base, origen, razón fundamental sobre la cual se procede en cualquier materia. Se trata de la primera proposición o verdad fundamental por donde se empieza a estudiar las ciencias o las artes.

Jurídicamente, los principios constituyen mandamientos generales que sirven de fundamento axiológico a todo el orden jurídico, condicionan la interpretación de las normas y encaminan la actuación del poder público, fijándole una dirección a seguir. Los principios son, desde ese punto de vista, la norma o idea fundamental que rige el pensamiento y la conducta del Estado. Como señala Agustín Gordillo ${ }^{357}$

Diremos entonces que los principios de Derecho Público contenidos en la Constitución son normas jurídicas, pero no sólo eso; mientras que la norma es un marco dentro del cual existe una cierta libertad, el principio tiene substancia integral. (...) La norma es límite, el principio es límite y contenido. La norma da a la ley facultad de interpretarla o aplicarla en más de un sentido, y el acto administrativo la facultad de interpretar la ley en más de un sentido; pero el principio establece una dirección estimativa, un sentido axiológico, de valoración, de espíritu.

En efecto, la importancia de los principios ha cambiado muchísimo a lo largo de la historia. La doctrina tradicional, sobre todo la relativa al derecho civil, veía a los principios exclusivamente como medios de integración del derecho positivo, siempre que la ley no reglamentase determinado asunto. Los principios se aplicaban, por tanto, en defecto de la ley, así como otras fuentes supletivas, como la analogía, la equidad y la jurisprudencia. ${ }^{358}$

Sin embargo, con el paso del tiempo, la literatura especializada comenzó a dar mayor valor a los principios y a reconocerles como verdaderos instrumentos que posibilitan la aplicación de las normas jurídicas y que, además, condicionan la

\footnotetext{
357 GORDILLO, op.cit., p. 912-914.

${ }^{358}$ SOUZA, Cláudio Pereira de.; SARMENTO, Daniel. Direito Constitucional: Teoria, História e Métodos de Trabalho, 2. ed. Belo Horizonte: Editora Fórum, 2014, L. 1079.
} 
interpretación de las leyes, decretos y otros actos normativos ${ }^{359}$, teniendo en cuenta los principios consagrados en la Constitución y en los tratados internacionales.

Resulta de esa nueva visión que, tanto los principios, como las reglas dan la posibilidad de aplicación de normas jurídicas $\mathrm{y}$, por consiguiente, se aplican a los supuestos de hecho, si bien es cierto que de manera diferente en uno y otro caso. ${ }^{360}$

Los principios encaminan la aplicación de normas jurídicas que constituyen verdaderos mandamientos superiores, que permiten su cumplimiento en diferentes niveles de intensidad, según las circunstancias fácticas y jurídicas de cada caso. Ello implica decir que el hecho de que cierto principio tenga menor importancia en determinada situación no significa que no podrá aplicarse en otros casos. La aplicación de los principios es siempre modulable, a raíz de las circunstancias y de la incidencia de otros principios. ${ }^{361}$

Las reglas, por otro lado, si bien encaminan normas jurídicas, inciden en el caso concreto de manera distinta a los principios, siempre que sigan una lógica binaria para su aplicación, pues son normas que ordenan algo en carácter definitivo. Por lo general, ordenan algo para el caso que se satisfagan ciertas condiciones, aunque también puedan revestir una forma categórica. Un ejemplo de ello sería una prohibición absoluta de tortura. ${ }^{362}$

En este caso, el intérprete no tiene ningún margen de actuación. Si una regla es válida según el orden jurídico estatal, deberá aplicarse totalmente al supuesto de hecho, no permitiendo al intérprete restringir o ampliar su intensidad, ya que las reglas no admiten modulación en ningún caso. ${ }^{363}$

El conflicto entre reglas se resuelve fundamentalmente por medio de la declaración de invalidez de una de ellas por la previsión de una cláusula de excepción en cualquiera de las reglas en confrontación (lo que apartaría la incidencia de cualquier de ellas) ${ }^{364}$ a

\footnotetext{
359 Ibidem.

${ }^{360}$ ALEXY, Robert. Teoria dos Direitos Fundamentais. Tradução de Virgílio Afonso da Silva. São Paulo: Malheiros, 2008, L. 87.

361 ALEXY, op. cit., 90.

${ }^{362}$ ALEXY, op.cit., L. 99.

${ }^{363}$ ALEXY, op. cit., L. 104.

${ }^{364}$ Ibidem, L. 92.
} 
través de los criterios tradicionales de solución de antinomias: cronológico, jerárquico o de especialidad. ${ }^{365}$

La aplicación de los principios obedece a otro tipo de razonamiento. Como se trata de mandatos de optimización, los principios pueden ser cumplidos en diferentes grados o niveles, de acuerdo con las posibilidades fácticas y jurídicas de cada caso, teniendo en cuenta la incidencia de otros principios que actúan en sentido contrario. ${ }^{366}$

La tensión entre principios se resuelve por medio de la técnica de la ponderación, con la utilización de la llamada "Fórmula del Peso". 367

Ese proceso se desarrolla en tres momentos o etapas que el intérprete deberá vencer antes que pueda afirmar la preponderancia de un principio sobre otro. En un primer momento, tendrá que definir el grado de no satisfacción de uno de los principios en conflicto. En el segundo, identificará el grado de satisfacción del principio que juega en sentido contrario. Luego, deberá definir si el grado de satisfacción del principio contrario justifica la restricción del primero. ${ }^{368}$ Por tanto, la diferencia entre principios y reglas es siempre cualitativa y no de grado, pues los principios admiten la modulación de su intensidad por medio de la técnica de la ponderación, mientras que las reglas utilizan otros criterios para la resolución de conflictos, como el cronológico, el jerárquico y el de especialidad.

Esa diferencia al respecto de los métodos de interpretación pone de manifiesto la importancia que los principios han conquistado en los últimos años, tanto que, actualmente, la doctrina reconoce que violar un principio constituye una infracción más grave que infringir a una ley, ya que la transgresión al principio significa ofender al orden jurídico y sus valores. ${ }^{369}$

Si bien la transparencia no aparezca expresamente entre los principios que deben regir las Administraciones Públicas, lo cierto es que ella es un principio implícito en los Estados democráticos de derecho y condiciona las acciones de los poderes públicos. Por un lado, inspira la labor del Parlamento en cuanto a la producción de las leyes que

\footnotetext{
${ }^{365}$ BOBBIO, op. cit., L. 92/97.

${ }^{366}$ ALEXY, op.cit., L. 110.

${ }^{367}$ Ibidem, L. 72.

${ }^{368}$ Ibidem, L. 106.

${ }^{369}$ GORDILLO, op.cit., L. 912-914
} 
disciplinan la forma como pasará la divulgación de la información resguardada en manos de los órganos y entidades públicas. Establecen criterios para la divulgación de la información, canales de participación ciudadana en la gestión pública y límites al derecho de acceso, lo que resulta, además, de la ponderación de los intereses en conflicto.

Por otro lado, la transparencia condiciona la actuación de los responsables de la gestión pública, animándoles a rendir cuentas de sus actos, a divulgar informaciones de intereses de la comunidad, reproducir con fidelidad las informaciones a su cargo, dialogar con la sociedad a modo de mejorar la gestión pública y asegurar a todos el derecho de acceso a archivos y documentos oficiales.

Finalmente, la transparencia favorece la seguridad jurídica, viabiliza la tutela judicial de derechos y posibilita el seguimiento de las acciones administrativas en diferentes sectores, más bien en lo relativo a la preparación de los mega eventos deportivos como los Juegos Olímpicos.

Teniendo en cuenta estos aspectos, la doctrina suele identificar cinco principios que derivan de la transparencia, conforme con el rasgo que predomina en cada uno de ellos. Así, se consideran principios de la transparencia: responsabilidad, máxima divulgación, buena fe, participación y universalidad. ${ }^{370}$

Pese a la diferencia, en realidad, los principios de la transparencia imponen a los responsables de la gestión pública la realización de acciones concretas que favorezcan la visibilidad, el conocimiento y el control social de los actos y decisiones oficiales. ${ }^{371}$ Buscan fomentar la integridad de los gestores públicos e invitarles a orientar sus acciones en el sentido de prevenir los actos de corrupción, entendiéndose como integridad el uso correcto que uno hace de los poderes legalmente recibidos.

A lo largo de los apartados siguientes, tratamos de examinar cada uno de los principios que enmarcan las acciones de los poderes públicos en lo relativo a la transparencia gubernamental, identificando su contenido, sus manifestaciones en la legislación y en la jurisprudencia, lo que es fundamental para entender su papel en lo relativo al control ciudadano y a la prevención de la corrupción, en particular cuando asociada a los mega eventos deportivos como los Juegos Olímpicos.

\footnotetext{
370 PESCHARD, op.cit., L. 1092.

${ }^{371}$ MOTTA, op.cit., p. 2-3.
} 


\subsubsection{Principio de responsabilidad}

El principio de responsabilidad es inspirado en el pensamiento de los filósofos iluministas del siglo XVIII, como Voltaire, John Locke y Montesquieu ${ }^{372}$, con lo cual establece que los responsables de la gestión de recursos públicos estarán obligados a rendir cuentas de sus actos a la sociedad. ${ }^{373}$

Históricamente, durante los siglos XVI y XVII, fue predominante en las monarquías europeas la idea de que el poder del príncipe era absoluto, que su voluntad era la ley y que todos habrían que cumplirla sin restricciones. ${ }^{374}$ La propiedad de todos los bienes ubicados en el territorio, además, le tocaba únicamente al soberano ${ }^{375} \mathrm{y}$, para mantener su autoridad, el Rey estaba autorizado a omitir del conocimiento público los asuntos de la monarquía. ${ }^{376}$ A raíz de tales ideas, el Rey absoluto no se sometía al principio de responsabilidad y no estaba obligado a rendir cuentas de sus actos.

Las ideas iluministas han cambiado esa realidad y han permitido que surja el Estado de derecho. Desde ese momento, ya no es la voluntad absoluta del Rey la que importa. El patrimonio del soberano no se confunde con el patrimonio público y la ley enmarca los límites de la actuación del Estado ${ }^{377}$ así como también impone el deber de informar a los ciudadanos de los actos y decisiones a su cargo. ${ }^{378}$

Con arreglo en las enseñanzas de tales filósofos, en el siglo XIX, Ludwig Feuerbach comparó la publicidad y la transparencia de los poderes públicos a la "luz", al "bien" y a la "razón", asociando la opacidad y el secreto a las "tinieblas", al "mal" y a la

\footnotetext{
${ }^{372}$ FERNÁNDEZ RAMOS, op. cit., p. 213.

${ }^{373}$ PAU I VALL, Francesc. La transparencia desde el Parlamento. XXI Jornadas de la Asociación Española de Letrados de Parlamentos. Madrid: Tecnos, 2015.

${ }^{374}$ DI PIETRO, Maria Sylvia Zanella. Direito Administrativo. 24. ed. São Paulo: Atlas, 2011, p. 1.

${ }^{375}$ ROCHA, Carmen Lúcia Antunes. Princípios constitucionais da administração pública. Belo Horizonte: Del Rey, 1994, p. 240.

376 BOBBIO, Norberto. Stato, Governo, Società: Per una teoria generale de la politica. ., Giulio Einaudi editore s. p. a., Torino: 1985, p. 18.

${ }^{377}$ DIAS, Joelson; Campos, Sarah. Lineamentos Sobre a Lei de Acesso à Informação. In: Acesso à Informação Pública. VALIM, Rafael; MALHEIROS, Antônio Carlos; BACARIA, Josephina (coord.). Belo Horizonte: Fórum Editora 2015, p. 48.
}

${ }^{378}$ BOBBIO, op.cit., p. 70. 
"arbitrariedad". Por ahí, dejó claro que la publicidad y la transparencia se conectaban a valores positivos, mientras que la opacidad y el secreto tenían un significado negativo. ${ }^{379}$

Las concepciones iluministas acabaron de incorporarse a la Constitución brasileña en 1988, la cual estableció que todos tienen derecho a recibir de los órganos públicos informaciones de sus intereses particulares o relativas al interés colectivo o general, las cuales serán facilitadas en el plazo de la Ley, pena de responsabilidad, salvo que subsistan motivos que justifiquen la restricción, cuando su divulgación pusiera en riesgo la seguridad del Estado y de la sociedad. ${ }^{380}$

En este sentido, las informaciones que obran en manos de los órganos y entidades públicas se clasifican, doctrinariamente, en informaciones de interés colectivo en sentido amplio e informaciones de interés colectivo en sentido estricto. ${ }^{381}$

Las primeras conciernen a toda información producida por la Administración Pública y por quienes actúan en nombre del interés colectivo como las entidades privadas que reciben fondos públicos para desarrollar determinadas actividades, como sucede, en el caso brasileño, con el Comité Olímpico. Las segundas se refieren a informaciones resguardadas por el Estado, pero que conciernen a cuestiones particulares que son irrelevantes para el conocimiento público, como los datos bancarios o la dirección de un funcionario público. ${ }^{382}$ Aparte de estas informaciones de interés colectivo, la Administración Pública también resguarda informaciones de interés privado, que, obviamente, no será publicada para conocimiento de todos.

En este sentido, tratándose de información de interés particular, como un certificado médico o los resultados de análisis clínicos, es razonable entender que su divulgación depende, en principio, de una petición por parte del interesado. Sin embargo, tratándose de información de interés colectivo o general, como los resultados de las oposiciones para alguno cargo público o los acuerdos perfeccionados con motivo de una

\footnotetext{
${ }^{379}$ RAMOS, Severiano Fernández. La Transparencia Pública: Pasado, Presente y Futuro. In: Revista Aragonesa de Administración Pública, 2018, p. 213.

380 Ver al respecto el Artículo 5º, XXXIII de la Constitución brasileña de 1988. Disponible en: http://www.planalto.gov.br/ccivil 03/constituicao/constituicao.htm. Acceso en: 8 jun. 2019.

381 POLÍZIO JÚNIOR, Wladimir. Lei de Acesso à Informação, Manual Teórico e Prático. Curitiba: Juruá, 2015, p. 12.

382 Ibidem.
} 
licitación, las informaciones deberán ser difundidas, previa solicitud de los vecinos, a modo de permitir el control social de los actos y decisiones estatales. ${ }^{383}$

Como ya lo hemos dicho en otra oportunidad, en los regímenes democráticos, la legitimidad de los gobernantes no resulta únicamente de la victoria en las urnas. Depende, también, de la existencia de instrumentos que permitiera a los ciudadanos conocer con detalle las razones que llevaron a los poderes públicos a tomar una decisión. Cualquier persona tiene derecho a saber cómo actúa el Estado, el porqué de las acciones de los funcionarios y cuál es la cantidad del presupuesto que se ha invertido en dicho programa o proyecto. ${ }^{384}$

A causa del principio de responsabilidad, por tanto, los altos directivos del Estado, los funcionarios y todos los que ejercen potestades públicas tienen que rendir cuentas de sus actos y decisiones a la sociedad, explicándole como gestionan los recursos recibidos y como desarrollan las actividades a su cargo. ${ }^{385}$ Interesan, en este caso, principalmente, los actos y decisiones a cargo del Poder Ejecutivo, siempre que se trata del responsable de la gestión de los programas y políticas públicas. ${ }^{386}$

Desde esta perspectiva, el principio se manifiesta de diferentes maneras. Inicialmente, demanda de las autoridades y funcionarios la divulgación de las agendas de reuniones, los asuntos objeto del encuentro, los asistentes al mismo y la ata producida a causa de su realización. La publicidad de tales informaciones le posibilitará a la sociedad conocer no solo el acto final dictado por la Administración, como también los debates

\footnotetext{
383 PÉREZ GUEVARA, Martín. Bases Normativas del Control Jurisdiccional de los Poderes Públicos en Venezuela. Instituto de Derecho Público, Facultad de Ciencias Jurídicas y Políticas, Universidad Central de Venezuela, Caracas: Imprenta Universitaria, 1979, p. 15.

${ }^{384}$ CHÁIREZ, Cristian Jafet Montenegro. Progreso y Fortalecimiento de Derechos Fundamentales de Nueva Generación en el Estado de Durango: Transparencia y Protección de Datos Personales. Revista Científica de la Universidad Autónoma de Sinaloa. 2018. Disponible en https://www.amazon.es . Acceso en: 8 mayo 2014.

385 Sentencia n. 46/2017, de 22 de junio de 2017, del Juzgado Central de lo Contencioso-Administrativo núm. 2 de Madrid. Disponible en: http://consejodetransparencia.es/dam/jcr:792a560e-0e80-4bcd-bade$\underline{134 \mathrm{~b} 801 \mathrm{~b} 769 \mathrm{f} / \mathrm{r} 16 \text { sentencia } 462017 \text { particular7 tributos.pdf }}$
}

Acceso en: 8 jun. 2019.

${ }^{386}$ PESCHARD, op.cit., L. 1259. 
que antecedieron a tal manifestación, aspecto fundamental para el control y la rendición de cuentas de los funcionarios públicos. ${ }^{387}$

El conocimiento previo de todos los actos que encaminan las decisiones de la Administración tiene especial relevancia en cuanto a la preparación de los Juegos Olímpicos. De acuerdo con las investigaciones a cargo del Departamento de Justicia de Estados Unidos, con motivo de la elección de South Lake City como ciudad anfitriona de los Juegos Olímpicos de invierno de 2002, directivos norteamericanos sobornaron a miembros del COI a modo de que apoyaran la candidatura de la ciudad como sede de las Olimpíadas.

Las investigaciones revelaron, además, que el soborno practicado con motivo de la elección de South Lake City no se trataba de un hecho aislado. Veinte años antes, los miembros del COI solían recibir, directa o indirectamente, alguna ventaja económica con objeto de que apoyaran determinadas candidaturas y que los pagos se escondían por detrás de gastos con hospedaje, donaciones de carácter filantrópico o comodidades en viajes internacionales. ${ }^{388}$

Los acuerdos perfeccionados a ese título y la forma en la que se pagaba la ventaja fueron estipulados a lo largo de reuniones previamente agendadas entre las partes, directamente o por medio de testaferros, las cuales pasaron dentro o fuera del territorio nacional. En todos casos, no ha habido cualquier registro en las diferentes Administraciones Públicas en cuanto a tales encuentros o, cuando se ha registrado algo, las informaciones no fueron lo suficientemente claras como para que uno pudiera acompañar los actos que antecedieron la elección de la ciudad como sede de las Olimpíadas.

Desde esta perspectiva, las reuniones entre autoridades nacionales o sus representantes y miembros del COI no fueron documentadas por medio de actas, así como tampoco se ha informado al respecto de la naturaleza de los acuerdos perfeccionados con motivo de estos encuentros, o, finalmente, se ha suministrado cualquier otra información que permitiera un juicio crítico en cuanto a los actos practicados.

\footnotetext{
387 DIAS, Joelson; CAMPOS, Sarah. Lineamentos Sobre a Lei de Acesso à Informação. In: VALIM, Rafael., MALHEIROS, Antônio Carlos.; BACARIA, Josephina. (coord.). Acesso à Informação Pública. Belo Horizonte: Fórum Editora, 2015, p. 49.
}

${ }^{388}$ GOLDBLATT, op. cit., p. 372. 
Por lo general, los vecinos suelen tomar conocimiento únicamente de la decisión final del COI en esta materia, quedando ajenos a cualquier intercambio de favores entre ellos.

A modo de prevenir estas malas prácticas, el principio de responsabilidad les impone a los funcionarios que no acepten regalos que sobrepasen los usos y costumbres de cortesía, que tampoco reciban favores o servicios en condiciones ventajosas que puedan condicionar el ejercicio de sus funciones. Además, no deben ofrecer cualquier ventaja a terceros a cambio de que practiquen, retrasen o dejen de practicar determinados actos, en particular cuando ello pueda traer consecuencias para la Administración Pública de que participen.

Asimismo, con arreglo al principio de responsabilidad, los altos directivos del Estado, los funcionarios y todos aquellos que ejercen potestades públicas tienen el deber de comunicar a los órganos competentes cualquier irregularidad de la que tomen conocimiento, para que sean adoptadas las debidas providencias. En otras palabras, el principio convierte a los funcionarios en verdaderos defensores de la integridad y la ética en la Administración.

Para esto, las autoridades deberán divulgar, previa solicitud de los ciudadanos, informaciones relativas a los nombres de los interesados en hacerse cargo de las obras de construcción de los equipamientos olímpicos y demás obras de infraestructura, los lugares elegidos para tales instalaciones y los nombres de los potenciales beneficiados con las edificaciones.

En este caso, el principio se destina a cohibir que entidades cercanas al gobierno sean injustamente beneficiadas a causa de acuerdos perfeccionados con las autoridades, que tengan como objeto las obras de preparación del mega evento. Asimismo, busca evitar que determinadas personas o grupos reciban informaciones privilegiadas al respecto de los lugares destinados a los equipamientos olímpicos, como pasó en Amberes 1920 y Los Ángeles 1932.

En Bélgica, a causa de informaciones privilegiadas que obtuvieron junto a las autoridades, los miembros de la familia Grisar se enteraron que el Beerschot Estadio sería el principal equipamiento olímpico. A partir de ello, trataron de adquirir inmuebles alrededor del estadio a bajo precio con la expectativa de que, futuramente, pudiesen 
venderlos a precios elevados. Así, las informaciones privilegiadas de antes de los Juegos acabaron con convertirse en ganancias nada más terminar el mega evento. ${ }^{389}$

Asimismo, en Estados Unidos, el norteamericano William May Garland, aprovechándose de su posición como presidente del Comité responsable de la organización de los Juegos, trató de influenciar en las decisiones de las autoridades respecto a la elección de los lugares destinados a la construcción de los principales equipamientos olímpicos. ${ }^{390}$

Tratándose de un famoso corrector de inmuebles en California, Garland conocía como pocos el mercado de compraventa de inmuebles en Los Ángeles en los años 1920 y 1930. En este sentido, antes que las autoridades eligieran los lugares destinados a la edificación de los equipamientos olímpicos, él trató de adquirir inmuebles a bajo precio en determinadas regiones de la ciudad y, nada más perfeccionar estos negocios, logró influenciar con las decisiones de la Administración Pública a modo de que los edificaran directamente en sus propiedades o, como mínimo, cerca de ellas.

Consecuentemente, al final de los Juegos, los inmuebles de Garland acabaron con valorizarse extraordinariamente y él terminó con convertirse en uno de los hombres más ricos de California. Aunque no destinada específicamente a la prevención de las malas prácticas asociadas a los Juegos Olímpicos, la Ley de Transparencia y Acceso a la Información de Brasil trató de incorporar el principio de responsabilidad entre sus dispositivos. Así, todos los órganos y entidades que forman parte de la Administración Pública directa (o centralizada) e indirecta (o descentralizada) deberán rendir cuentas de sus actos a la sociedad.

El compromiso abarca a todos los órganos y entidades de los Poderes Ejecutivo, Legislativo y Judicial, así como el Ministerio Público y el Tribunal de Cuentas, órgano que, en el régimen constitucional brasileño, integra el Poder Legislativo. Como consecuencia, en términos olímpicos, el principio de responsabilidad impone que todos los Ministerios que forman parte del Poder Ejecutivo Federal deben transparentar todos los actos y decisiones concernientes a la preparación del mega evento. Tal compromiso también se extiende a las Secretarías o Consejerías estatales y municipales, como la

\footnotetext{
${ }^{389}$ GOLDBLATT, op. cit., p. 108.

${ }^{390}$ Ibidem, p. 151.
} 
Secretaría de Obras Públicas, órgano que juega un papel fundamental en la preparación de las Olimpíadas.

Finalmente, también se someten al principio de responsabilidad las entidades privadas sin fines lucrativos que reciben recursos públicos directamente del presupuesto, o a través de subvenciones sociales, por contrato de gestión, alianza, convenio, acuerdo, ajustes o a través de otros instrumentos similares.

Este compromiso abarca, en el caso brasileño, a los actos practicados por el Comité Olímpico Brasileño al que les había tocado preparar los Juegos Olímpicos, siempre que la aludida entidad reciba fondos públicos para fomentar y desarrollar actividades deportivas de todo tipo, en especial las destinadas a la preparación del mega evento.

\subsubsection{Principio de máxima divulgación}

El principio de máxima divulgación se conecta directamente al objeto de la transparencia gubernamental. Significa que toda información en manos de los Poderes Públicos es accesible a los ciudadanos, salvo que haya motivos excepcionales que restrinjan el acceso, lo que resulta de las hipótesis previamente establecidas en Ley. ${ }^{391}$ Con arreglo a referido principio, en los regímenes democráticos, la transparencia activa de la información constituye la regla general y la solicitud de los ciudadanos la excepción. $^{392}$

A causa de referido principio, los Poderes Públicos deberán colocar a la disposición de los ciudadanos toda información asociada a la intimidad del Estado y de las organizaciones que gestionan fondos públicos. ${ }^{393}$ Desde esta perspectiva, el principio abarca toda la información guardada en manos de los poderes públicos, entendida la

${ }^{391}$ LEY MODELO INTERAMERICANA SOBRE ACCESO A LA INFORMACIÓN. Disponible en: https://www.oas.org/dil/esp/CP-CAJP-2840-10 Corr1 esp.pdf Acceso en: 18 en. 2019.

392 MARTINS, Ricardo Marcondes. Restrições ao Acesso à Informação. In: Acesso à Informação Pública. In: VALIM, Rafael., MALHEIROS, Antônio Carlos.; BACARIA, Josephina. (coord.). Acesso à Informação Pública. Belo Horizonte: Fórum Editora, 2015, p. 111-114.

393 ZANCANER, Weida. Lineamentos Sobre a Lei de Acesso à Informação. In: Acesso à Informação Pública. . In: VALIM, Rafael., MALHEIROS, Antônio Carlos.; BACARIA, Josephina. (coord.). Acesso à Informação Pública. Belo Horizonte: Fórum Editora, 2015, p. 35-36. 
información como todo aquello que sirve para reducir o eliminar incerteza de los ciudadanos respecto de determinado asunto. ${ }^{394}$

Así las cosas, el principio de máxima divulgación posibilita a los ciudadanos levantar el manto que cubre las Administraciones Públicas y, además, les permite conocer los actos y decisiones practicados en el ejercicio de sus competencias, lo que es fundamental para el efectivo control social de la gestión pública. ${ }^{395}$

El principio de máxima divulgación difiere del principio de publicidad en cuanto a la forma que cada uno traslada la información en manos de los órganos y entidades del Estado. De acuerdo con el principio de publicidad, todos los actos y decisiones de los poderes públicos deberán ser divulgados a través del Diario Oficial o del Boletín Oficial del Estado, con lo cual no se considera como publicado el acto o decisión cuya divulgación se dio únicamente a través de la prensa escrita, hablada o televisiva, aunque en programa exclusivamente destinado a noticiar los hechos de la Administración Pública. Así ya lo decidió, por ejemplo, la Corte Constitucional de Brasil cuando dictó sentencia en el RE núm. 71.652. ${ }^{396}$

Sin embargo, tratándose de actos y decisiones publicados con fundamento en el principio de máxima divulgación, se admite que los poderes públicos divulguen información por todos los medios de comunicación posibles: televisión, radio, periódicos e internet, independientemente de cualquier solicitud de los interesados, con objeto de dar a los ciudadanos un amplio conocimiento de sus acciones.

La relevancia del principio ya se ha puesto de manifiesto en diferentes ocasiones. La Sala Plena de la Corte Constitucional de Colombia ${ }^{397}$ destacó la estrecha relación entre la transparencia de la gestión pública, el régimen constitucional y la lucha contra la corrupción. ${ }^{398}$

\footnotetext{
${ }^{394}$ RUBINO, LEONARDO. INFORMAZIONE, ACCESSO E TRASPARENZA A 800 ANNI DALLA MAGNA CARTA (DALL'HABEAS CORPUS ALL'HABEAS DATA),., LEONARDO RUBINO EDITORE, ROMA: 2016, L. 463.

${ }^{395}$ DAVIS, J. Access to and Transmission of Information: Position of Media. In: DECKMYN, Veerle y THOMSON, Ian (eds.). Openness and Transparency in the European Union. Maastricht: European Institute of Public Administration, 1997, p. 121.

${ }^{396}$ GASPARINI, Diógenes. DIREITO ADMINISTRATIVO. 15ª ed. . Sao Paulo: Saraiva, 2011. p.66.

397 SALA PLENA DE LA CORTE CONSTITUCIONAL DE COLOMBIA. Sentencia C-491/07. 27 de junio de 2007, p. 1 Disponible en: https://www.corteconstitucional.gov.co/relatoria/2007/C-491-07.htm Acceso en: 8 jun. 2019.

${ }^{398}$ Ibidem.
} 
Al fallar el caso, el Tribunal decidió que el principio de máxima divulgación impone que las autoridades y funcionarios deberán rendir cuentas a los ciudadanos y a los órganos de fiscalización y control al respecto del uso que hacen de los poderes recibidos y de los fondos públicos, lo que es fundamental para cohibir las malas prácticas políticas y administrativas.

Hay que tener en cuenta que el acompañamiento de los actos y decisiones gubernamentales no depende exclusivamente de la divulgación de la información pública directamente a los ciudadanos y a los órganos de control interno y externo del propio Estado, como la Controlaría, el Ministerio Público y el Tribunal de Cuentas.

La aplicación del principio también exige que los archivos y documentos públicos sean organizados sistemáticamente, teniendo en cuenta la necesidad de facilitar de cualquier manera la investigación y la consulta de los interesados. Así que uno siempre deberá adoptar criterios objetivos y sencillos a la hora de organizar la información, por ahí permitiéndole al interesado encontrar rápidamente todas las respuestas a sus demandas.

El principio también impone que los funcionarios deberán adoptar un lenguaje claro y directo al redactar la información, que deberá ser cierta, completa, exacta, oportuna y actualizada, con objeto de permitirle el amplio entendimiento al interesado, importante poco su formación profesional ${ }^{399}$. Además, deberá proceder de documentos auténticos, fiables e íntegros que permiten su reutilización. Por ende, la claridad, integralidad, oportunidad y actualidad de la información no solo resultan de la aplicación del principio de máxima divulgación, sino que asimismo constituyen deberes de los poderes públicos, ${ }^{400}$ pues de esa forma lo decidió la Sala Plena de la Corte Constitucional de Colombia ${ }^{401}$.

El principio también incide en el ámbito de la carga de la prueba, exigiendo que la autoridad no solo fundamente la decisión que limita el acceso a los archivos y documentos públicos, sino que demuestre la compatibilidad de la restricción con la Constitución y con las medidas anticorrupción. ${ }^{402}$

\footnotetext{
${ }^{399}$ PESCHARD, op. cit., L. 1111

${ }^{400}$ SALA PLENA DE LA CORTE CONSTITUCIONAL DE COLOMBIA. op. cit.

${ }^{401}$ Ibidem.

${ }^{402}$ PRINCIPIOS SOBRE EL DERECHO DE ACCESO A LA INFORMACIÓN DEL COMITÉ JURÍDICO INTERAMERICANO: 7. La carga de la prueba para justificar cualquier negativa de acceso a la información
} 
No basta con que el funcionario o autoridad responsable de la información se refiera, de manera abstracta, a cualquiera de las hipótesis legales de secreto con objeto de limitar la incidencia del principio. El régimen democrático le demanda aún más, exigiéndole que también indique claramente los motivos que fundamentaron su decisión, lo que posibilidad el control disciplinario, administrativo o jurisdiccional de los actos practicados. $^{403}$

La Corte Interamericana de Derechos Humanos también ha decidido en este sentido en el caso Claude Reyes v. Chile, cuando estableció claramente que la autoridad del Estado está obligada a motivar la decisión que niega el acceso a los archivos y documentos oficiales, como forma de restringir arbitrariedades y permitir el control ciudadano de las acciones gubernamentales. ${ }^{404}$

Finalmente, el principio establece que la transparencia y el derecho de acceso a los archivos y documentos públicos prevalecerá, siempre que las condiciones de su ejercicio no estén fijadas expresamente en ley. ${ }^{405}$ La omisión legislativa o reglamentar no pueden servir de excusa para obstaculizar el control ciudadano de los actos y decisiones oficiales.

En otras palabras, considerando el nuevo papel atribuido a los principios, ellos deben actuar de forma directa, toda vez que las leyes no logran ofrecer una respuesta en concreto para las demandas presentadas a la Administración Pública. Los principios actúan, por tanto, no solo en el proceso de interpretación de las reglas, como también lo hacen como normas en sí mismas, de tal manera que deberán cumplirse y ser aplicados, aunque no existan reglas al respecto de determinados asuntos. ${ }^{406}$ Los principios se han

debe recaer en el órgano al cual la información fue solicitada. Disponible en: http://www.oas.org/es/default.asp, Acceso en 18 en. 2019.

${ }^{403}$ SALA PLENA DE LA CORTE CONSTITUCIONAL DE COLOMBIA. op.cit.

${ }^{404}$ CORTE INTERAMERICANA DE DERECHOS HUMANOS. Caso Claude Reyes y otros. Sentencia de 19 de septiembre de 2006. Serie C, No. 151, p. 122. Disponible en : http://www.corteidh.or.cr/docs/casos/articulos/seriec_151_esp.pdf Acceso en 03 dic 2019

${ }^{405}$ Ese entendimiento fue consagrado en la decisión de la Corte Interamericana de Derechos Humanos en el caso Claude Reyes y otros v. Chile del 19 de septiembre de 2006, en la que se decidió que el derecho a la libertad de expresión consagrado en el Artículo 13 de la Convención Americana sobre Derechos Humanos incluye el derecho de acceso a la información. Disponible en: http://www.oas.org

, Acceso en 18 en.2019.

406 GIMENO FELIÓ, José María. "Reglas para la prevención de la corrupción en la contratación pública". In: Observatorio de Contratación Pública, V Seminario de contratación pública, Formigal (Huesca), septiembre de 2014, p. 37-38. Disponible en: https://contratodeobras.com/2014/09/bibliografiadocumentacion-del-v-seminario-de-contratos-publicos-formigal-2014/, Acceso en: 28 nov 2019. 
convertido, en esta nueva concepción, en verdaderos ejes vertebradores del ordenamiento jurídico. ${ }^{407}$

A raíz del principio de máxima divulgación, por tanto, el derecho de recibir información de interés colectivo o general de los órganos integrantes de la estructura del Estado se califica como una prerrogativa de los ciudadanos, que únicamente podrá ser restringida en las hipótesis fijadas en la Constitución. ${ }^{408}$

A pesar de su importancia, no siempre el principio es respetado por las instituciones públicas locales, regionales, nacionales o internacionales. Hay casos en que dichas instituciones buscan obstaculizar su incidencia a través de medidas de naturaleza legislativa o administrativa, lo que impone la presentación de acciones en el poder judicial cuestionando estos límites.

Sirve como ejemplo de todo lo dicho la acción presentada por la Organización No Gubernamental (ONG) Access Info Europa contra España y el Consejo Europeo, que cuestionaba la forma como se desarrollaba el procedimiento para la toma de decisiones en el seno de las instituciones europeas.

De acuerdo con el Artículo 4, apartado 3, párrafo primero del Reglamento núm. 1049/2001, el Consejo podría mantener bajo secreto la identidad de los Estados que presentaban propuestas de enmiendas durante los debates legislativos en ese órgano. Aparte del propio Consejo, la restricción contaba además con el apoyo de países como España, Francia, Grecia, Reino Unido y República Checa. ${ }^{409}$

En definitiva, ellos abogaban con que el anonimato de los responsables evitaría presiones sociales en el Estado que propusiera cada enmienda. Asimismo, decían que el principio de máxima divulgación solo es aplicable en lo relativo a los documentos completos y no en lo relativo a los que todavía están en su fase inicial de elaboración. ${ }^{410}$

\footnotetext{
${ }^{407}$ RODRÍGUEZ ARANA, Jaime. "Los principios generales del derecho global de la contratación pública". In: RODRÍGUEZ ARANA, Jaime. Contrataciones públicas en el ámbito de los derechos sociales fundamentales. Madrid: INAP, 2017, p. 13-40.

${ }^{408}$ BRASIL. Supremo Tribunal Federal. MS n. 24.725 MC. Decisão monocrática proferida pelo Rel. Min. Celso de Mello. Julgado em: 28.11.2003; DJ, p. 47, 27 fev. 2004 (Informativo núm. 331 do STF). Disponible em : http://www.stf.jus.br/arquivo/informativo/documento/informativo331.htm Acceso en 04 dic 2019.

${ }^{409}$ HERRERA, op.cit., p. 96

${ }^{410}$ Ibidem.
} 
El Parlamento Europeo también se unió al caso, aunque para apoyar a la ONG, exactamente porque entendía que habría que dar mayor visibilidad a los actos de las instituciones de la Unión a causa del principio de máxima divulgación, mientras que el Tribunal de Justicia Europeo, al dictar sentencia, entendió que la mera circunstancia de que la solicitud de información se presentara en una fase muy temprana del procedimiento legislativo no es suficiente para que se aplicara la cláusula de secreto. ${ }^{411}$

La sentencia, además de su importancia para el caso en concreto, reforzó la legitimación ante los ciudadanos de las leyes y directivas europeas, aumentando aún más el rol del ciudadano en las instituciones ${ }^{412}$, reconociendo la preponderancia del principio de máxima divulgación sobre la cultura de secreto y opacidad de las instituciones.

En conclusión, el Tribunal puso de manifiesto la idea predominante en la propia literatura jurídica española en el sentido de que, mientras que en un Estado autocrático la regla es por naturaleza es la opacidad y el secreto, en un Estado Democrático, la regla debe ser la Transparencia de la acción de los poderes públicos, y el secreto la excepción. $^{413}$

Con arreglo al principio de máxima divulgación, la divulgación de la información resguardada en manos de los órganos y entidades públicas obedece a tres criterios principales:

a) el criterio de la frecuencia de las solicitudes;

b) el criterio de los esquemas de publicación; y

c) el criterio de la relevancia de la información.

Inicialmente, el criterio de la frecuencia de la solicitud se basa en el número o cantidad de pedidos sobre asuntos que reflejan las principales preocupaciones de la sociedad en su momento. ${ }^{414} \mathrm{Si}$ los habitantes de cierto municipio a menudo piden informaciones sobre los gastos con salud y educación en determinado año, entonces el ayuntamiento debe publicar dichas informaciones en su página web, como forma de permitirles el conocimiento de estos datos directamente.

\footnotetext{
411 SALA PRIMERA DEL TRIBUNAL DE JUSTICIA DE LA UNIÓN EUROPEA. STC C-280/11 P, de 17 de octubre de 2013. Disponible en: https://eur-lex.europa.eu/ Acceso en: 6 en. 2019.

${ }^{412}$ HERRERA, op.cit., p. 96.

${ }^{413}$ FERNÁNDEZ RAMOS, op.cit. p. 213-214.

${ }^{414}$ GUICHOT, et al. op. cit., p. 153-155.
} 
La medida, más allá de fomentar el control ciudadano de los actos oficiales, también demuestra una buena gestión administrativa por parte del gobernante de turno, en tanto que evita que el funcionario conteste pedidos de igual naturaleza repetidas veces, lo que caracteriza, como mínimo, un ejemplo de ineficiencia administrativa.

ASIMISMO, el criterio de la frecuencia de la solicitud revela que la transparencia activa y el derecho de acceso se complementan en lo relativo a la publicidad de la información. Se, de un lado, el derecho de acceso está basado en un pedido que refleja el interés de uno solo ciudadano, lo que implica un enfoque muy limitado, de otro, la reiteración de la solicitud obliga a que la administración publique la información de forma proactiva y, por tanto, permita su conocimiento por cualquiera. ${ }^{415}$

La relevancia de este criterio fue reconocida por organismos internacionales como la OEA, institución que recomendó a los Estados que divulgasen de forma proactiva la información que fuese solicitada más de una vez por cualquier interesado, garantizando a todos el acceso igualitario a la información. ${ }^{416}$

Por otro lado, el criterio de los esquemas de publicación contempla las clases de documentos que deben ser divulgados por la administración pública, previa solicitud de los ciudadanos, como la información presupuestaria, los salarios de los servidores, las licitaciones, los contratos perfeccionados por el estado, las subvenciones otorgadas a entidades privadas y la ejecución de proyectos y políticas públicas. ${ }^{417}$

Por último, el criterio de la relevancia de la información tiene en cuenta el protagonismo que determinados asuntos presentan en la sociedad en dado periodo histórico- De acuerdo con ese modelo, la administración pública está obligada a divulgar toda la información considerada importante para la comunidad en su momento y que, en principio, no sería publicada con arreglo a los criterios de la frecuencia de la solicitud o de los esquemas de publicación.

El contenido de la información publicada bajo ese criterio varía de tiempo en tiempo y de un sitio para otro, lo que también explica la expresión genérica a menudo utilizada para elegir las materias que deberán ser divulgadas por la administración. Comúnmente, uno se refiere a la "relevancia social de la información" o "información de

\footnotetext{
${ }^{415}$ FERNÁNDEZ RAMOS; PÉREZ MONGUIÓ, op.cit., p. 102-103.

${ }^{416}$ LEY MODELO INTERAMERICANA SOBRE ACCESO A LA INFORMACIÓN. Disponible en https://www.oas.org acceso en 18 en. 2019.

${ }^{417}$ Ibidem.
} 
gran interés social" cuando trata de explicar el fundamento que legitima la divulgación de tales asuntos.

La generalidad de las expresiones busca, en realidad, hacer que la transparencia activa permanezca siempre en contacto con la sociedad, lo que, además, viabiliza la divulgación de la información que mejor refleja el interés de los ciudadanos.

Independientemente del criterio adoptado (frecuencia de la solicitud, esquema de publicación o relevancia de la información), lo cierto es que el principio de máxima divulgación impone a las autoridades publicar, como mínimo, la información relativa a los costes con la preparación de los Juegos Olímpicos, los proyectos arquitectónicos asociados al mega evento, las obras de infraestructura que serán realizadas y el plan de gestión del patrimonio olímpico tras el encuentro.

El previo conocimiento de estas informaciones da posibilidad para que los vecinos cuestionen las autoridades en cuanto a la conveniencia y oportunidad de realización del torneo, los beneficios y sacrificios que resultarán de su organización y las medidas adoptadas como para prevenir las malas prácticas administrativas.

En efecto, los costes con la preparación de las Olimpíadas siempre fueron un problema para las ciudades anfitrionas. De acuerdo con un estudio comandado por los economistas Bent Flyvbjerg y Allison Stewart de la universidad de Oxford, Inglaterra, entre el 1960 y el 2010, los costes de la preparación de las Olimpíadas siempre estuvieron por encima del presupuesto inicialmente previsto por las autoridades. Ese incremento llega a 135 veces en el caso de los Juegos Olímpicos de invierno y a 257 veces en las Olimpíadas de verano. ${ }^{418}$

Tales costes quedaron evidentes con motivo de las Olimpíadas de Londres 2012. En principio, el gobierno inglés se creía que iba a gastar 3,1 millones de euros para preparar el torneo. Pero, al final de los Juegos, las inversiones públicas llegaron a 12 millones de euros, aunque estos valores estuviesen muy por debajo de los costes totales del mega evento. ${ }^{419}$

En definitiva, la factura presentada por las autoridades británicas no llevó en consideración las inversiones realizadas con el desplazamiento de la antorcha olímpica, la preparación del equipo olímpico de Gran Bretaña, los gasto con medidas antidopaje,

\footnotetext{
${ }^{418}$ BOSIO. Roberto. Roma 2024. Un Affare per Pochi., Roma: Amazon, 2016, L. 97.

${ }^{419}$ Ibidem.
} 
los costes con dispositivos de seguridad y prevención del terrorismo, más allá de la compraventa de terrenos y la construcción de instalaciones olímpicas.

La consideración de todas estas variables hizo que el coste final de los Juegos llegara a 31 millones de euros ${ }^{420}$, muy por encima de lo originalmente previsto. Así, la disparidad entre el presupuesto inicial y los costes finales del mega evento justifica la divulgación de toda la información a este respecto, la cual se considera socialmente relevante para fines del principio de máxima divulgación.

Más allá de los costes, el principio también encamina la acción de las autoridades en el sentido de divulgar los proyectos arquitectónicos presentados con motivo de los Juegos, con indicación expresa de las estructuras que serán edificadas y los materiales utilizados en cada caso. La medida busca, en este caso, viabilizar el control ciudadano en cuanto a la ejecución de tales proyectos, aspecto fundamental como para prevenir las irregularidades verificadas en las Olimpíadas de Melbourne 1956 y Montreal 1976.

En Australia, los recursos utilizados para la construcción de la Villa Olímpica fueron obtenidos desde un préstamo concedido por el gobierno, que ambicionaba utilizar las casas construidas para los juegos en un futuro programa de viviendas populares en el suburbio de Heidelberg. La iniciativa no se ha implementado totalmente. La baja calidad del proyecto ha conllevado a la edificación de casas de pésima calidad, con lo cual ha habido la necesidad de nuevas inversiones para corregir los errores cometidos. ${ }^{421}$

Veinte años después, en Montreal 1976, los errores en cuanto al proyecto del estadio olímpico y del velódromo hicieron que el gobierno malgastara los fondos públicos y tuviera que realizar nuevas inversiones para que las estructuras estuviesen acabadas, lo que apenas pasó en 1987, exactamente once años tras el encierre de los Juegos.

En ambos casos, una vez que la información estuviese disponible a los ciudadanos con base al principio de máxima divulgación, sería posible establecerse un dialogo entre los responsables del proyecto y la sociedad en cuanto a la calidad de los materiales empleados y la viabilidad técnica de las novedades presentadas. El debate podría contribuir, por ejemplo, con alteraciones en el proyecto o su total sustitución, a modo de prevenir un posible despilfarro de fondos públicos.

\footnotetext{
${ }^{420}$ Ibidem.

${ }^{421}$ GOLD, John R. GOLD, Margaret M. op.cit., p. 41.
} 
En cuanto a las obras de infraestructura, el principio de máxima divulgación requiere de las autoridades amplia publicidad de las licitaciones destinadas a su ejecución, todo ello en interés de los principios de concurrencia o libre competencia.

Se destaca, en este caso, el conocimiento de los criterios utilizados por las autoridades con motivo de la elaboración de los contratos, con objeto de verificar si las cláusulas del instrumento fueron redactadas con objeto de eliminar la participación de interesados y orientar la contratación pública hacia determinadas sociedades.

En este caso, el principio busca prevenir los problemas pasados en los Juegos de Roma 1960, Tokio 1964 y Montreal 1976, cuando muchas de las obras para la construcción de los equipamientos olímpicos fueron dirigidas a sociedades que tenían buenas relaciones con el partido del gobierno.

Finalmente, el principio da viabilidad al control ciudadano en cuanto a la gestión del llamado legado olímpico, formado a partir de las obras de infraestructura y de los equipamientos deportivos incorporados a la ciudad tras el mega evento. Desde esta perspectiva, el principio busca evitar la creación de elefantes blancos a menudo asociados a algunas ediciones de las Olimpíadas, como pasó en Londres 1908 y Atenas 2004.

En Inglaterra, por primera vez en la historia de las Olimpíadas, se construyó un estadio para los Juegos, el Sheperd's Bush, también conocido como White City, con 93.000 lugares y 63.000 asientos, además de un complejo olímpico que acogió a varias modalidades deportivas. ${ }^{422}$ La estructura también tenía restaurantes, centros de ocio y servicios de urgencia. La edificación se hizo posible a causa de una alianza entre los responsables de la preparación de los Juegos y los encargados de la organización de una exposición franco-anglófona de ciencias, artes e industria que pasó en Londres en el verano de $1908 .^{423}$

A pesar de su importancia, el estadio de White City se ha convertido en un problema tras el mega evento. La gigantesca estructura se ha utilizado escasamente por casi dos décadas en seguida a las Olimpíadas, con lo cual se ha convertido en el primer elefante blanco de los Juegos Olímpicos. ${ }^{424}$

\footnotetext{
${ }^{422}$ Disponible en: https://www.olympic.org/greatbritain Acceso en 02 abr. 2019.

${ }^{423}$ GOLD, John R. GOLD, Margaret M. op. cit., p. 32.

${ }^{424}$ MANGAN, J.A. Prologue guarantees of global goodwill: post-Olympic legacies - too many limping white elephants, International Journal of the History of Sport, 25(14), 2008. p. 1869-83.
} 
Para resolver este problema, em 1926, el estadio fue enteramente reformado y su capacidad fue reducida de los 93.000 para 80.000 lugares. También fue construida una pista para acoger a eventos no olímpicos, como carreras de Galgos, deporte que disfrutaba de gran popularidad en el Reino Unido a principios del siglo XX. ${ }^{425}$ En 1932, se construyó una pista de atletismo con 400 metros de largo que se ha utilizado para competencias nacionales e internacionales, con destaque para los Juegos del Imperio Británico de 1934 y los Juegos Mundiales de las Personas Sordas de $1936 .{ }^{426}$

Sin embargo, cuando las competencias de atletismo fueron trasladadas al nuevo estadio de Crystal Palace en 1971, el estadio de White City fue completamente abandonado por largos catorce años, hasta que, en 1985, la histórica edificación fue completamente derrumbada, para que se construyera en su lugar una nueva sede administrativa de BBC. ${ }^{427}$

Casi cien años después, en Atenas 2004, la historia se repitió. Terminados los Juegos, varios elefantes blancos surgieron por todas partes, fruto de una preparación inadecuada y de la falta de un plan de gestión de los equipamientos olímpicos.

Así como en Helsinki 1952, la Villa Olímpica fue construida en una región muy distante de las principales instalaciones deportivas utilizadas durante el mega evento, lo que no solo ha dificultado el desplazamiento de atletas durante los Juegos, sino que también ha inviabilizado la implementación de futuros programas de viviendas populares. Las casas y apartamentos utilizados durante las Olimpíadas fueron edificadas en una región que no contaba con una adecuada infraestructura de transporte que conectase la región con el centro de la ciudad. ${ }^{428}$

Además, la promesa de que muchos equipamientos olímpicos serían convertidos en escuelas tras los Juegos tampoco se ha confirmado. ${ }^{429}$ El Galatsi Olympic Complex, que acogió las competencias de tenis de mesa y gimnástica rítmica, debería transformarse

\footnotetext{
${ }^{425}$ HAWTHORNE, F.H.; PRICE, R. The Soulless Stadium: A Memoir of London's White City, 3-2 Books, Upminster: 2001, p. 7.

${ }^{426}$ GOLD, John R; GOLD, Margaret M. op. cit., p. 33.

${ }^{427}$ Ibidem.

${ }^{428}$ GOLDBLATT, op.cit., p. 386.

${ }^{429}$ Ibidem.
} 
en un centro comercial apenas acabasen las Olimpíadas, sin embargo, este hecho no llegó a ocurrir.

Dos años después de los Juegos, en 2006, un grupo de empresarios portugueses perfeccionó un contrato de arrendamiento del inmueble y comenzó a realizar inversiones a modo de transformarlo en un centro de negocios. Sin embargo, las dificultades enfrentadas con la burocracia griega hicieron con que abandonasen la idea, permaneciendo este inmueble sin cualquier utilización desde entonces. ${ }^{430}$

A raíz de todo lo sucedido, surgía el sentimiento general de que, en Atenas 2004, el legado olímpico se había compuesto de elefantes blancos que se habían incorporado al paisaje de la ciudad. Irónicamente, los griegos decían que esto no era exactamente un problema. Poco a poco, los equipamientos olímpicos se habían convertido en ruinas y los griegos ya estaban acostumbrados a convivir con ellas desde hace muchos años. ${ }^{431}$ En 2015, con motivo de la guerra de Siria, los equipamientos abandonados fueron utilizados como campos de refugiados ${ }^{432}$, una realidad muy distante de lo que los griegos habían imaginado cuando la ciudad de Atenas fue elegida sede de las Olimpíadas.

A modo de prevenir irregularidades de esta naturaleza, la Ley de Transparencia y Acceso a la Información de Brasil también ha incorporado al principio de máxima divulgación entre sus dispositivos. En este sentido, la Ley n. ${ }^{\circ}$ 12.527/2011 establece que la Administración Pública deberá divulgar información para conocimiento de los ciudadanos, independientemente de su previa solicitud, con lo cual se busca asegurar el control social de todos sus actos y decisiones.

\subsubsection{Principio de buena fe}

La buena fe como principio general del derecho también encamina la actuación de los poderes públicos en el ámbito de la transparencia gubernamental. Si bien es cierto que la expresión buena fe presenta una variedad de significados y contenidos, en el que

\footnotetext{
${ }^{430}$ GOLDBLATT, op.cit., p. 388.

${ }^{431}$ Ibidem.

${ }^{432}$ Ibidem.
} 
predomina, en derecho, más bien la idea de buena fe subjetiva y buena fe objetiva, según el aspecto que uno considere más relevante en cada caso. ${ }^{433}$

Así que obrar de buena fe significa, por un lado, instalarse en la difícil relación entre la bondad y la fe que, con respecto al protagonista, suele llevar al predominio subjetivo de la fe y a la creencia de que actúa en conformidad con lo jurídicamente permitido. En cuanto a los terceros, implica el cumplimiento de la promesa y de la palabra dada, respondiendo a las expectativas de todos con quienes se relacionan. ${ }^{434}$

De forma objetiva, el principio implica la necesidad de que uno siempre mantenga una conducta leal y honesta toda vez que establezca una relación con otra persona ${ }^{435}$ abarcando la idea de confianza, honradez y rectitud de carácter, teniendo en cuenta el comportamiento a menudo esperado del hombre común y medio. ${ }^{436}$

En lo relativo a la transparencia, el principio significa que los funcionarios públicos deberán interpretar la ley fomentando el acceso a los archivos y documentos oficiales, sabiendo que ello implica fortalecer la democracia y la prevención de la corrupción.

De esta forma, deberán informar a los ciudadanos del verdadero contenido de los actos y decisiones oficiales que están bajo su responsabilidad, ya sea directamente (transparencia activa), o indirectamente (derecho de acceso). Se les prohibirá omitir informaciones con el pretexto de proteger la Administración Pública o satisfacer los intereses personales o de terceros, salvo que la ley lo establezca expresamente.

La Ley núm. 2/2015, de 2 de abril, de Transparencia, Buen Gobierno y Participación Ciudadana de la Comunidad Valenciana hizo especial referencia al principio de buena fe, por ahí imponiéndoles a los altos directivos y a los funcionarios regionales y locales el compromiso de actuar mirando hacia la calidad de los servicios y a la buena administración, siempre que ello es el comportamiento esperado por la sociedad. ${ }^{437}$

\footnotetext{
${ }^{433}$ SILVESTRI, op.cit. p. 44-45.

${ }^{434}$ CALDAMI, op.cit. p. 05.

${ }^{435}$ PÉREZ, op.cit., p. 69-70

${ }^{436}$ PÉREZ, op.cit., p.74.

${ }^{437}$ ESPAÑA. Ley 2/2015, de 2 de abril, de Transparencia, Buen Gobierno y Participación Ciudadana de la Comunitat Valenciana. Disponible en :https://www.boe.es/buscar/pdf/2015/BOE-A-2015-4547consolidado.pdf Acceso en 30 nov. 2019.
} 
Además, deberán observar estrictamente el régimen de incompatibilidades previsto en el orden jurídico, así como dejar de intervenir en los asuntos en que concurra alguna causa que pueda afectar a su imparcialidad. Esto es, en esencia, el comportamiento que los ciudadanos esperan de los altos directivos y funcionarios públicos. ${ }^{438}$

Asimismo, los altos directivos y demás funcionarios formularan, al principio y al final del mandato, declaración sobre causas de posible incompatibilidad y sobre cualquier actividad que les proporcione o pueda proporcionar ingresos económicos ajenos al ejercicio de la función pública.

Aunque prevista únicamente para los titulares de mandato por elección y similares, la regla que obliga informar los ingresos ajenos al ejercicio de la función pública también debería extenderse a todos los responsables de potestades públicas, porque la corrupción bien podrá realizarse teniendo en cuenta esas actividades.

Finalmente, el principio de buena fe impone que los reconocimientos honoríficos o conmemorativos se destinen, exclusivamente, a personas que demuestren un compromiso público relevante. También deberán mirar a quienes no hayan sido condenados penalmente mediante sentencia firme, teniendo en cuenta el efecto social de estas circunstancias sobre los demás ciudadanos.

El principio de buena fe también fue incorporado a la Ley de Transparencia y Acceso a la Información de Brasil, siempre que la información facilitada a los ciudadanos deberá reflejar, obligatoriamente, hechos pasados en el seno de la Administración Pública. Esta es, en esencia, la conducta que los ciudadanos esperan de la Administración toda vez que buscan una información resguardada por cualquier órgano o entidad que forma parte de su estructura.

En términos olímpicos, el principio impone que toda información concerniente a los Juegos deberá ser divulgada sin distorsiones. Los escritos y otros documentos que obran en manos de la Administración Pública deberán reflejar exactamente lo que ha pasado en el mundo de los hechos a modo de que los ciudadanos puedan manifestarse críticamente en cuanto a lo sucedido.

Tomando como ejemplo las obras de infraestructura realizadas con motivo del mega evento, el principio impone que los informes elaborados por los funcionarios responsables de su fiscalización registren fielmente todos los hechos sucedidos durante su ejecución y que conciernen al cumplimiento del contrato administrativo. Así,

${ }^{438}$ Ibidem. 
consideramos que el principio prohíbe a los fiscales de las obras declarar en sus informes que una parcela de la construcción fue ejecutada cuando, en realidad, tal hecho no ha pasado.

En otras palabras, el principio de buena fe prohíbe a los funcionarios responsables a hacer que las obras olímpicas falten en la lealtad del desarrollo de sus tareas. En consecuencia, les prohíbe declarar, en sus escritos, cualquier hecho que no coincida con la realidad, ya que lo anterior compromete la confianza de los ciudadanos en la Administración Pública.

\subsubsection{Principio de participación}

El principio de participación significa que los poderes públicos deberán adoptar todas medidas necesarias para incentivar el dialogo permanente entre el gobierno y la sociedad, como forma para permitir la regeneración de la democracia liberal tradicional.

Desde mediados del siglo XX, la democracia sufre con serios cuestionamientos que colocan en duda la legitimidad de los sistemas presidencialista y parlamentarista de gobierno, ${ }^{439}$ siempre que limitan la intervención de los ciudadanos exclusivamente al proceso electoral, a la selección de los representantes que están al frente de la gestión pública y, por tanto, a un momento en específico de la vida política del Estado. ${ }^{440}$

Como forma de corregir estas deformidades, los críticos comenzaron a requerir de una verdadera participación de la sociedad en los asuntos estatales, con la creación de canales de comunicación entre el Estado y los ciudadanos que permitieran una mayor intervención en las actividades públicas, un mayor acercamiento entre la Administración y los individuos, ajeno al comúnmente realizado por los partidos políticos. ${ }^{441}$

\footnotetext{
${ }^{439}$ Disponible en en $\quad$ https://eur-lex.europa.eu/legalcontent/PT/TXT/HTML/?uri=LEGISSUM:310401_3\&from=EN Acceso en: 18 jun. 2019.

440 DE LA FUENTE, Carlos et al. Las TIC en el Gobierno Abierto: Transparencia, Participación y Colaboración. Electrónica, Madrid: Fundación Telefónica y editorial Planeta, 2013, p. 3.

${ }^{441}$ BENALCÁZAR GUERRÓN, Juan Carlos. Participación ciudadana y control de la corrupción. 2011, p. 7-8. Disponible en: http://derecho.posgrado.unam.mx/congresos/congreibero/ponencias/juancarlosbenalcazar.pdf Acceso en: 17 jun. 2019.
} 
Como también señala Fernando Flores Giménez, ${ }^{442}$ por participación ciudadana también se entiende a la:

“[...] intervención más o menos directa de la ciudadanía en las actividades públicas, en los distintos ámbitos territoriales estatal o municipal, pero una participación ajena a la mediada por los partidos políticos y a la ejercida a través del derecho al voto para la elección de cargos públicos. Es decir, los mecanismos de democracia directa constituyen formas de participación política en ocasiones ejercida mediante el voto directo y universal, sin embargo, su objetivo no es la elección de los miembros de los órganos democrático-representativos (Legislativo o Ejecutivo), sino involucrar al conjunto de la ciudadanía en el proceso de toma de decisiones."

En definitiva, hoy por hoy, uno ya no puede concebir una democracia sin transparencia y participación y, por tanto, sin el más mínimo control de los ciudadanos sobre la acción de sus gobernantes, más allá de las elecciones. ${ }^{443}$

Ahora bien, el surgimiento de las nuevas tecnologías de la información y de la comunicación (Tics), como Facebook, Twitter, WhatsApp e Instagram, acabaron comprometiendo al cambio tan esperado en esta materia, ya que trataron de dar la posibilidad a la permanente interacción entre gestores públicos y sociedad. ${ }^{444}$

Esas plataformas digitales reproducen, en cierta medida, la función que desempeñaban las antiguas plazas de los pueblos en el pasado, o sea, un lugar de encuentro y confraternización, donde la gente acudía para informarse u opinar en las asambleas populares. $^{445}$

442 FLORES GIMÉNEZ, Fernando. "La Participación Democrática: Partidos Políticos, Sistemas Electorales y Participación Ciudadana". In: FLORES GIMÉNEZ, Fernando. La Participación Política en Ecuador. (coord.). Tribunal Constitucional de la República del Ecuador. Instituto de Derecho Público Comparado de la Universidad Carlos III de Madrid, Comisión Europea, Quito, Corporación Editora Nacional, 2004, p. 21.

${ }^{443}$ ZEPEDA, op.cit.p. 26.

${ }^{444}$ DE LA FUENTE. op.cit., p. 7.

${ }^{445}$ Ibidem. 
En ese aspecto, el principio se conecta con la propia idea de democracia, de que el poder estatal pertenece al pueblo, único titular de la soberanía, y que constituye el cimiento desde el que se construye el propio orden jurídico en los Estados modernos. ${ }^{446}$

En efecto, es justamente en los regímenes democráticos en donde el principio de participación cobra su importancia. En una democracia verdaderamente madura, las autoridades no temen en abrir las puertas de la Administración a los ciudadanos y permitirles colaborar en la gestión de los asuntos públicos y en la determinación de los intereses generales. $^{447}$

Además, el principio da posibilidad a que las administraciones públicas tengan acceso a conocimientos técnicos al respecto de asuntos que están en manos de la sociedad y que el Estado ignora totalmente, aunque relevantes para el desarrollo de sus tareas. En este aspecto, la participación ciudadana da vías a la utilización racional de los recursos públicos y previne las malas prácticas administrativas, siempre que ofrezca alternativas eficientes de aplicación de los fondos públicos. ${ }^{448}$

El principio actúa, por tanto, en una doble dirección. De un lado, los ciudadanos podrán intervenir en la planificación y la ejecución de las políticas públicas a través del llamado gobierno abierto y, de otro, la Administración tendrá la posibilidad de obtener en la sociedad los conocimientos de que necesita para gobernar sus acciones. ${ }^{449}$

Internacionalmente, el principio de participación fue reconocido en el seno del llamado Plan de Integridad para el buen gobierno en América Latina y el Caribe, aprobado el 19 de octubre de 2018 por el Consejo Directivo del Programa Regional de la OCDE. ${ }^{450}$ La organización recomienda a que los Estados latinoamericanos y caribeños adopten todas las medidas a su cargo para incentivar la participación de las partes en procesos regulatorios y de toma de decisiones.

\footnotetext{
${ }^{446}$ HERRERA, Manuel Palomares. op.cit., p. 140.

447 CASTEllà ANDREU, Josep Ma., Los Derechos Constitucionales de Participación Política en la Administración Pública. Barcelona: Cedecs Editorial, 2001, p. 39-40.

${ }^{448}$ DE LA FUENTE, op.cit., p. 22.

${ }^{449}$ Idem, p. 15.

450 Disponible en: http://www.oecd.org/about/sge/integridad-para-el-buen-gobierno-en-america-latina-yel-caribe-9789264307339-es.htmAcceso en: 18 jun. 2019.
} 
En esencia, la iniciativa busca acortar distancias entre la autoridad y la sociedad, favorecer el dialogo entre ellos y posibilitar el efectivo control social de las decisiones de la Administración Pública, ${ }^{451}$ lo que es fundamental para la prevención de las malas prácticas administrativas y de la corrupción.

De forma interna, el principio de participación figura como directriz de la Administración Pública en la Ley núm. 2/2015, de 2 de abril, de Transparencia, Buen Gobierno y Participación Ciudadana de la Comunidad Valenciana. La aplicación de dicho principio les impone a los órganos regionales y locales el deber de fomentar la integración entre los poderes públicos y la sociedad, en particular en cuanto a la elaboración de las políticas públicas, lo que será posible únicamente a través de canales de comunicación entre ellos.

El principio de participación, por tanto, más allá de viabilizar la transparencia de la Administración Pública, fomenta la cultura del llamado gobierno abierto, siempre que sea capaz de convertir al ciudadano en protagonista en la gestión de los intereses colectivos y aumenta la confianza en las instituciones. ${ }^{452}$

En lo relativo a los Juegos Olímpicos, el principio de participación demanda de las autoridades el establecimiento de canales permanentes de comunicación con la sociedad, como para verificar si los vecinos consideran interesante realizar las Olimpíadas y, si afirmativa la respuesta, bajo cuales condiciones ello deberá pasar.

La manifestación positiva, en el primer caso, busca exactamente identificar el nivel de interés de los ciudadanos en cuanto a la celebración de los Juegos y, desde ahí, evitar la realización de gastos públicos innecesarios con su preparación, como pasó en Amberes 1920, cuando las disputas locales impactaron directamente en la baja asistencia de personas a los eventos olímpicos.

A principios de los años 1920, las más ciudades más importantes de Bélgica estuvieron divididas a causa de divergencias de esta naturaleza y, a menudo, estos conflictos se han reflejado en otros sectores de la sociedad. En lo deportivo, existía en el país, tres federaciones que reunían la mayoría de las asociaciones, clubes y atletas entorno a su ideología: la Federación Francófona, la Federación de los Trabajadores y la Federación Católica.

\footnotetext{
${ }^{451}$ BENALCÁZAR GUERRÓN, op.cit., p. 8.

${ }^{452}$ DE LA FUENTE, op.cit., p. 20.
} 
Las tres federaciones, igual que en otras actividades, rivalizaban en cuanto a todas competencias deportivas. Cada una de ellas trataba de realizar sus eventos con independencia en cuanto a las demás. En este sentido, con motivo de los Juegos de Amberes 1920, dos diferentes torneos deportivos pasaron en Bélgica a la vez: los juegos olímpicos francófonos o juegos olímpicos de bourgeois, concentrados en el Beerschot stadium; y los juegos olímpicos populares o Juegos Olímpicos de los Trabajadores, que abarcaban únicamente las modalidades de boxeo y futbol. ${ }^{453}$

La dualidad de eventos ha afectado la asistencia a los Juegos. Mientras que la elite ha preferido acudir a las competencias organizadas por el COI, los operarios y demás ciudadanos se han reunido alrededor de las disputas realizadas por el Movimiento de los Trabajadores en el Deporte, ${ }^{454}$ con lo cual se puso de manifiesto que el mega evento a cargo del Comité no ha logrado conectarse con la realidad social de Bélgica. ${ }^{455}$

El fracaso de Amberes 1920 fue responsable de un cambio en las reglas que disciplinaron la preparación de los Juegos Olímpicos desde la segunda mitad del siglo XX. A partir de los años 1950, el COI estableció que las ciudades interesadas en acoger las Olimpíadas deberían comprometerse a no realizar cualquier otro mega evento en su territorio durante los Juegos, como las grandes ferias y exposiciones internacionales y los campeonatos de diferentes modalidades. ${ }^{456}$

Pero, la ruina de los Juegos de Amberes no se restringió a la baja asistencia de personas al encuentro. En lo económico, los Juegos registraron, además, un déficit de 625 millones de francos belgas a causa de una mala preparación y planificación del encuentro. ${ }^{457}$ Desde esta perspectiva, por tanto, los Juegos de 1920 se califican como un vergonzoso caso de despilfarro de fondos públicos, ${ }^{458}$ que podría haber sido evitado si

\footnotetext{
${ }^{453}$ GOLDBLATT, op.cit., p. 105.

${ }^{454}$ RENSON, Roland. The Games Reborn: The VIIth Olympiad. London: Pandora, 1996, p. 33.

${ }^{455}$ RENSON, op.cit., p. 87-88. ${ }^{456}$ OLYMPIC CHARTER 1955. Disponible en: https://www.olympic.org/olympic-studies-
centre/collections/official-publications/olympic-charters Acceso en 23 jul 2018.
}

${ }^{457}$ RENSON, op.cit., p. 54-60.
${ }^{458}$ GOLDBLATT. op.cit., p. 104. 
hubiese existido un dialogo entre el gobierno belga y la sociedad al respecto de la realización de los Juegos.

Sin embargo, no todos tuvieron motivos para quejarse de la manera en cómo Amberes había preparado el encuentro. El Beerschot Tenis Club, una asociación privada frecuentada por la aristocracia francófila, tuvo su estadio totalmente reformado con fondos públicos con motivo de las Olimpíadas de 1920, aunque no se obligara a ofrecer cualquier contrapartida en favor de la sociedad. ${ }^{459}$

El principio de participación da la posibilidad, además, del dialogo entre los responsables de la organización de las Olimpíadas y las Federaciones Deportivas Internacionales y atletas quienes acudirán al mega evento. El debate, en este caso, da la posibilidad de que no se repitan en cuanto a la preparación de los Juegos los errores cometidos en Helsinki 1952, cuando la Villa Olímpica de Käpylä quedaba alrededor de seis kilómetros de la ciudad anfitriona.

La larga distancia entre uno y otro sitio no les ha permitido a los atletas que se desplazaran desde ella hacia al centro de Helsinki rápidamente. Por consiguiente, gran parte de los deportistas dejaron de alojarse en la misma y buscaron otro sitio donde acomodarse. El error en la planificación obligó al gobierno local a ofrecerles hospedaje en otro sitio, con lo cual se incrementaron los costes del mega evento. ${ }^{460}$

Finalmente, el dialogo es importante para que los ciudadanos se manifiesten al respecto de la forma como los Juegos deberán ser financiados, como sucedió en Los Ángeles 1984. Tras el fracaso financiero de las Olimpíadas de Montreal y causa de los escándalos de corrupción asociados a la construcción de muchos equipamientos, los norteamericanos impusieron algunas condiciones para que el mega evento pasara en su territorio. No habría inversiones públicas y los recursos para la financiación de los Juegos serían obtenidos en la iniciativa privada. La exigencia hizo que el COI, por primera vez en la historia de las Olimpíadas, tuviese que renunciar a la regla que se les imponía a las ciudades anfitrionas con el compromiso de realizar todos los gastos necesarios para el desarrollo de los Juegos. ${ }^{461}$

\footnotetext{
${ }^{459}$ GOLDBLATT. op.cit., p. 108.

${ }^{460}$ GOLD, John R; GOLD, Margaret M. op.cit., p. 39.

${ }^{461}$ OLYMPIC CHARTER 1978. Disponible en: https://www.olympic.org/olympic-studiescentre/collections/official-publications/olympic-charters Acceso en: 22 jul. 2018.
} 
A causa del principio de participación, por tanto, la tarea de preparar los Juegos no resulta únicamente de los actos y decisiones de las autoridades. Depende, también, de la previa audiencia de los vecinos y demás personas involucradas en todo el proceso, con lo cual será posible prevenir las malas prácticas a menudo asociadas a tales mega eventos.

La Ley de Transparencia y Acceso a la Información de Brasil también ha incorporado el principio de participación entre sus dispositivos, sobre todo cuando trata de fomentar la realización de audiencias y consultas públicas respecto a determinados asuntos y prevé la creación de canales de comunicación entre los ciudadanos y la Administración. ${ }^{462}$

La idea es fomentar el diálogo permanente entre el Estado y la sociedad a modo de mejorar la calidad de las actividades a cargo del Ente Público. Con arreglo al principio, la Administración Pública brasileña podría consultar a la población en cuanto a su interés en la realización de los Juegos Olímpicos y la manera de financiarlos, fomentando el debate en torno a este asunto.

En efecto, desde que fueron recreados en Atenas 1896, los Juegos han registrado varios casos de corrupción y despilfarro de fondos públicos con motivo de su preparación. Además, siempre han demandado grandes inversiones públicas en un corto periodo de tiempo, a veces retirando caudales de otros sectores socialmente relevantes, como pasó en México 1968. También es cierto que los Juegos fueron responsables de importantes obras de infraestructura en las ciudades anfitrionas, lo que acabó con mejorar la vida de los vecinos tras el mega evento.

Considerando todas estas variables, opinamos que el principio de participación juega un papel importante en cuanto a la realización de las Olimpíadas, toda vez que permite a la Administración Pública encaminar sus decisiones con arreglo a los verdaderos intereses de los ciudadanos.

${ }^{462}$ POLÍZIO JÚNIOR, Wladimir. op.cit., p. 164. 


\subsubsection{Principio de universalidad}

El principio de universalidad implica que toda persona tiene derecho a acceder a los archivos y documentos públicos ${ }^{463}$ y no estará obligada a revelar los motivos que justifican la investigación. ${ }^{464}$ Ello supera la visión tradicional de que la otra cara de la transparencia, el derecho de acceso se caracteriza como instrumento que mira exclusivamente hacia la tutela de derechos o intereses individuales. ${ }^{465}$

Esta es la razón por la que el principio otorga facultades a la persona de no contratar abogado o defensor público con motivo de la presentación de pedido de información, siempre que ello significa una limitación en el control de los actos y decisiones oficiales.

Evidentemente, no siempre las leyes de transparencia reflejan esta tendencia. Con frecuencia, las normativas aprobadas en esta materia utilizan términos que restringen el ejercicio del derecho, refiriéndose, por ejemplo, a "cualquier interesado" como siendo el titular del derecho de acceso a los archivos y documentos públicos. ${ }^{466}$

La expresión "cualquier interesado" recibe muchas críticas de la doctrina, una vez que el término "interesado" suele referirse a uno que tiene interés legítimo a la información, es decir, uno que tiene necesidad y utilidad de la información requerida. Los elementos "necesidad" y "utilidad" suelen ser considerados requisitos propios del derecho procesal, pero aquí podrían ser invocados para restringir el derecho de acceso, siempre que el ciudadano tuviera que demostrar la "utilidad y necesidad" de la solicitud para pedir cualquier información a la Administración Pública.

\footnotetext{
${ }^{463}$ SALA CONSTITUCIONAL DE LA CORTE SUPREMA DE JUSTICIA DE COSTA RICA. Exp. 05001007-0007-CO, Res. 2005-04005, San José, Costa Rica. 15 de abril de 2005. Considerando IV. Disponible https://www.oas.org/es/cidh/expresion/docs/informes/acceso/4.\%20Jurisprudencia\%20nacional\%20y\%20 buenas\%20pr\%C3\%A1cticas\%20de\%20derecho\%20interno\%20en.doc. Acceso en: 6 en. 2019.

${ }^{464}$ SALA DE REVISIÓN DE LA CORTE CONSTITUCIONAL DE COLOMBIA. Sentencia T-437/04. Expediente T-832492. 6 de mayo de 2004. Fundamento jurídico 6 . Disponible en: http://www.corteconstitucional.gov.co/relatoria/2004/T-437-04.htm Acceso en: 8 jun. 2019.

${ }^{465}$ GUICHOT, op.cit., p. 217-218.

${ }^{466}$ Ley de Transparencia de Brasil, Artículo 10. BRASIL. Ley de Transparencia de Brasil, Disponible en: http://www.planalto.gov.br/ccivil 03/ ato2011-2014/2011/lei/112527.htm
}

. Acceso en: 18 jun. 2019. 
Se trata de una exigencia que, en contexto semejante, ya había sido rechazada por la Oficina Antifraude de Cataluña, cuando dijo no considerar razonable exigir la concurrencia de un interés legítimo para facilitarse el acceso a los documentos contenidos en procedimientos archivados. ${ }^{467}$

En este mismo sentido, la Corte Interamericana de Derechos Humanos también rechazó comprobar el interés como requisito del derecho de acceso a la información pública, cuando decidió el Caso Claude Reyes vs Chile. En ese caso concreto, la Corte dijo que: "La información debe ser proporcionada sin necesidad de comprobar interés directo ni relación personal para obtenerla, exceptuándose los casos en los cuales sea aplicable una restricción legítima" (apartado 77). ${ }^{468}$

En el caso brasileño, el equívoco fue corregido seis meses después de la aprobación de la ley, cuando fue aprobado el decreto que regula su aplicación a la Administración Pública federal. En ese momento, el Poder Ejecutivo clarificó que el término "interesado" se refiere a cualquier persona física o jurídica, ${ }^{469}$ pero no mira exclusivamente hacia la tutela de derechos o intereses individuales.

Esa alteración buscó compatibilizar el modelo brasileño con el diseño legal establecido en otras leyes de igual naturaleza, como la española ${ }^{470}$, la chilena ${ }^{471}$, la argentina ${ }^{472}$ y la colombiana, ${ }^{473}$ que no condicionan el derecho de acceso a la tutela de derechos o intereses individuales.

${ }^{467}$ FERNÁNDEZ RAMOS; PÉREZ MONGUIÓ, op. cit. p. 75-83

${ }^{468}$ CORTE INTERAMERICANA DE DERECHOS HUMANOS. Disponible en: http://www.corteidh.or.cr/docs/casos/articulos/seriec 151 esp.pdf Acceso en: 29 nov. 2019.

${ }^{469}$ BRASIL. Decreto no. 7.724. Regulamenta a lei de acesso à informação de 16 maio 2014. Disponíble en: http://www.planalto.gov.br/ccivil 03/_ato2011-2014/2012/decreto/D7724.htm., Acceso en: 8 jun. 2019.

${ }^{470}$ ESPAÑA. Ley n. 19/2013. Art. 12. Disponible en https://www.boe.es/boe/dias/2013/12/10/pdfs/BOEA-2013-12887.pdf Acceso en: 6 mayo 2014.

471 CHILE. Ley n. $\mathbf{2 0 . 2 8 5}$ de 11-AGO-2008. Disponible em: http://www.leychile.cl/Navegar?idNorma=276363\&idVersion=2008-08-20., Acceso en: 06 mayo 2019.

472 ARGENTINA. Decreto n. $\mathbf{1 1 7 2 / 2 0 0 3}$ y Ley n. 27.275/2015. Disponible en: http://infoleg.gov.ar/infolegInternet/anexos/90000-94999/90763/norma.htm., Acesso em: 5 jun. 2014.

${ }^{473}$ COLOMBIA. Lei n. 1712. Ley de Transparencia y del derecho de acceso a la información de 06 mar. 2014. Disponible en: http://www.anticorrupcion.gov.co/SiteAssets/Paginas/Publicaciones/ley1712.pdf Acceso en: 8 jun. 2019. 
Desde la perspectiva del derecho supranacional, la ley modelo interamericana también se refiere a la "persona" cuando identifica al titular del derecho de acceso. ${ }^{474}$ Podemos observar una decisión similar en el Convenio núm. 205 del Consejo de Europa sobre acceso a los documentos públicos.

Esa fórmula ampliada a la hora de definir el sujeto activo del derecho de acceso evidencia la preponderancia del principio de universalidad sobre las reglas que buscan restringir la transparencia y el derecho de acceso a la información pública, siempre que dispense al ciudadano de comprobar su condición de interesado en el momento de solicitar información al órgano o entidad gubernamental, lo que podría limitar el ejercicio del derecho en casos de corrupción. ${ }^{475}$

Pero, el principio de universalidad no está restringido únicamente a las relaciones entre la Administración Pública y los ciudadanos. También se aplica a las relaciones institucionales entabladas entre los poderes del Estado ${ }^{476}$, sobre todo para permitirle a cualquier Diputado o Senador, Partido Político, Comisión o grupo Parlamentario demandarle al Poder Ejecutivo información que se estime oportuna en cada caso. En este aspecto, el principio de universalidad viabiliza el control parlamentario de la Administración Pública y del gobierno, ${ }^{477}$ con lo cual también contribuye a la prevención de la corrupción.

Finalmente, a causa del principio de universalidad, la información facilitada a los ciudadanos también deberá ser gratuita, identificable, localizable y que funcione en varios

474 Ley Modelo Interamericana sobre Acceso a la Información Pública. "Derecho de acceso a la
información: 5. Toda persona que solicite información a cualquier autoridad pública que esté comprendida
por la presente ley tendrá los siguientes derechos, sujetos únicamente a las disposiciones del capítulo IV de
esta ley: (...)". OEA - ORGANIZACIÓN DE LOS ESTADOS AMERICANOS. Democracia para la paz,
la seguridad
la y http://www.oas.org/es/sla/ddi/acceso_informacion_ley_modelo.aspAcceso en: 8 jun. 2019.

475 Convención de Naciones Unidas contra la Corrupción: “Artículo 10. Información pública. Habida cuenta de la necesidad de combatir la corrupción, cada Estado Parte, de conformidad con los principios fundamentales de su derecho interno, adoptará las medidas que sean necesarias para aumentar la transparencia en su administración pública, incluso en lo relativo a su organización, funcionamiento y procesos de adopción de decisiones, cuando proceda. Esas medidas podrán incluir, entre otras cosas: (..) b) La simplificación de los procedimientos administrativos, cuando proceda, a fin de facilitar el acceso del público a las autoridades encargadas de la adopción de decisiones; (..)" NACIONES UNIDAS. Convención de las Naciones Unidas contra la corrupción de 9 dic. 2003. Disponible en: https://www.boe.es/diario boe/txt.php?id=BOE-A-2006-13012 Acceso en: 16 mar. 2019.

476 STC 161/1988, De 20 sep. 1988 De la Sala Primera del Tribunal Constitucional de España. Publicada en el BOE n. ${ }^{\circ}$ 247, de 14 oct. 1988. Disponible en: http://hj.tribunalconstitucional.es/caES/Resolucion/Show/1102, Acceso en: 30 nov. 2019.

${ }^{477}$ HERRERA, op.cit., p. 157. 
sistemas o formatos. Asimismo, deberá ser reutilizable, de tal manera que uno pueda realizar búsquedas, seleccionar fragmentos o elaborar obras derivadas a partir de ella. ${ }^{478}$

Sin embargo, la gratuidad de la solicitud no es absoluta y las leyes de transparencia suelen establecer que los interesados deberán pagar, como mínimo, los costes de reproducción de la información, siempre que ello sea necesario y que el suplicante no sea pobre. $^{479}$

En conclusión, con arreglo en el principio de universalidad, toda persona, física o jurídica, nacional o extrajera, tiene derecho a acceder a la información resguardada en manos del Estado, independientemente de cualquier derecho subjetivo asociado a la solicitud, ${ }^{480}$ lo que tiene particular relevancia en cuanto a la preparación de los Juegos Olímpicos, toda vez que viabiliza el control social de los actos practicados a tal respecto.

\subsection{Los límites a la transparencia gubernamental}

La transparencia gubernamental, pese a su importancia para el fortalecer la democracia y al enfrentamiento de la corrupción, no es absoluta. También ha sufrido restricciones que impiden su incidencia en todos los casos y que resultan más bien de la necesidad de proteger a otros bienes jurídicos fundamentales para la sociedad. ${ }^{481}$

Sintéticamente, dichos bienes jurídicos representan los valores de la vida humana y social que merecen protección del derecho en dado momento histórico, anterior a la propia norma jurídica, con ello autorizando la constitución de espacios en donde la transparencia gubernamental no producirá sus efectos.

Aunque existan diferencias puntuales de uno a otro régimen legal, lo que resulta de las características de cada Estado o grupo de Estados, los ordenamientos jurídicos nacionales e internacionales coinciden con que la transparencia gubernamental encuentra

\footnotetext{
${ }^{478}$ HERRERA, op. cit. p. 21.

479 Véase al respecto el Artículo 12 de la Ley n. 12.527/2011, de Transparencia y Acceso a la Información de Brasil. Disponible en: http://www.planalto.gov.br/ccivil_03/_ato2011-2014/2011/lei/112527 Acceso en: 18 jun. 2019.

${ }^{480}$ HERRERA, op. cit., p. 138.

${ }^{481}$ PESCHARD, op.cit. L. 1173.
} 
límites en la intimidad y la privacidad, la estabilidad financiera, la seguridad nacional, el secreto comercial e industrial y las investigaciones ministeriales. ${ }^{482}$

El reglamento $1049 / 2001$ de la Comunidad Europea ${ }^{483}$, la ley modelo interamericana sobre acceso a la información pública ${ }^{484}$ y la Convención sobre Acceso a Documentos Oficiales del Consejo de Europa ${ }^{485}$ han seguido esa tendencia y han excluido del ámbito de incidencia de la transparencia gubernamental asuntos que puedan perjudicar la seguridad pública, la defensa y los asuntos militares, las relaciones internacionales y la política financiera, monetaria y económica. ${ }^{486}$

También quedan fuera del ámbito de incidencia de la transparencia y del derecho de acceso las informaciones que puedan perjudicar la integridad, la intimidad y la privacidad de la persona. ${ }^{487}$

Internamente, las leyes de transparencia de España ${ }^{488}$ y Brasil ${ }^{489}$ fijan como límites a la transparencia la privacidad y la intimidad, la defensa y la soberanía nacional, la integridad del territorio, la vida, la seguridad o la salud de la población, la estabilidad financiera, económica o monetaria del país y los secretos comerciales e industriales.

\footnotetext{
${ }^{482}$ Ibidem, L. 1173

${ }^{483}$ Principios de la Unión Europea sobre acceso a documentos del Parlamento, Consejo y Comisión. Disponible en: https://www.access-info.org/wpcontent/uploads/ES_ONLINE_Guide_on_access to_EU_Documents.pdf Acceso en: 3 dic. 2019.

484 OEA. Ley Modelo Interamericana sobre Acceso a la Información Pública. Disponible en: https://www.oas.org/dil/esp/CP-CAJP-2840-10 Corr1 esp.pdf Acceso en: 05 jun. 2019.
}

\footnotetext{
${ }^{485}$ MONTERO CARO, María Dolores. LA REGULACIÓN DEL ACCESO A LA INFORMACIÓN EN LA UNIÓN EUROPEA1. Universidad de Córdoba, 2018, p. 1-12. Disponible en: www.europarl.europa.eu Acceso en 30 nov. 2019.

${ }^{486}$ Disponible en: https://www.europarl.europa.eu/RegData/PDF/r1049 es.pdfAcesso em: 04 dic . 2019

${ }^{487}$ Ley Modelo Interamericana sobre Acceso a la Información Pública. Excepciones a la divulgación: OEA. OEA - Organización de los Estados Americanos: Democracia para la paz, la seguridad y el desarrollo. Disponible en: http://www.oas.org/es/sla/ddi/acceso informacion ley modelo.asp. Acesso em: 8 abril . 2019.
}

${ }^{488}$ ESPAÑA. Ley n. 19/2013. Ley de transparencia, acceso a la información pública y buen gobierno. Disponible en: https:/www.boe.es/boe/dias/2013/12/10/pdfs/BOE-A-2013-12887.pdf. Acceso en: 6 mayo 2019.

489 BRASIL. Lei n. 12.527, de $\mathbf{1 8}$ de novembro de 2011. Disponible em: http://www.planalto.gov.br/ccivil_03/_Ato2011-2014/2011/Lei/L12527.htm. Acceso en: 07 mayo 2019. 
Estas restricciones han sufrido críticas de organizaciones españolas ${ }^{490}$ como la Organización para la Seguridad y la Cooperación en Europa (OSCE) y la Asociación Española de Archivos de la Función Pública. Las entidades han señalado que las limitaciones establecidas en la ley han utilizado términos demasiado amplios para restringir la transparencia. Esto permite colocar bajo sus paraguas innumerables supuestos de hecho que bien podrían frustrar los objetivos de la ley.

Con el objetivo de limitar la discrecionalidad de los responsables de la gestión pública, defienden la sustitución de los conceptos jurídicos indeterminados adoptados en la normativa por otros vocablos más específicos, con lo cual entienden que habrá una verdadera participación ciudadana y la prevención de la corrupción.

Aunque se trate de una crítica dirigida en su momento al proyecto de ley de transparencia de España, las consideraciones también podrían plantearse respecto a la normativa brasileña, que igual utiliza términos generalistas para fijar límites al derecho de acceso.

Así, por ejemplo, el empleo de expresiones tales como "riesgos a seguridad de las instituciones o de autoridades nacionales" ${ }^{491}$ puede justificar una decisión administrativa en el sentido de dejar de publicar determinada información o de negar el derecho de acceso de los ciudadanos, aunque el pedido del interesado esté relacionado con un caso de corrupción.

Afrontando esa crítica, otros expertos ${ }^{492}$ ponderan que el empleo de cláusulas generales en las leyes de transparencia refleja una tendencia universal que se pone de manifiesto incluso en documentos internacionales sobre el tema, como el Reglamento 1049/2001 de la Comunidad Europea y la ley modelo interamericana sobre el acceso a la información pública.

Desde otra perspectiva, subsanar de cada supuesto de hecho a las hipótesis de secreto siempre deberá realizarse en concreto y teniendo en cuenta las particularidades del caso, de tal forma que estará en manos de las autoridades y de los tribunales decidir si están o no delante de un caso de secreto.

\footnotetext{
${ }^{490}$ GUICHOT et al, op. cit., p. 97-102.

${ }^{491}$ BRASIL. Lei n. 12.527, de 18 de novembro de 2011. Disponible em: http://www.planalto.gov.br/ccivil_03/_Ato2011-2014/2011/Lei/L12527.htm. Acceso en: 8 junio 2019.

${ }^{492}$ GUICHOT, op. cit., p. 136-188.
} 
"La ley consagra pues la prevalencia del derecho subjetivo a obtener la información y correlativamente el deber de entregarla, salvo que concurran causas justificadas que limiten tal derecho, a las que se refiere el art. 14, causas que constituyen conceptos jurídicos indeterminados cuya relevancia y trascendencia han de ser concretadas en cada caso, ponderando los intereses en conflicto (...)"493

El número de situaciones de ese tipo es variado. Se identifican ejemplos en el ámbito de las Administraciones locales, regionales, nacionales e internacionales que a menudo colocan en confrontación, de un lado, los principios de la transparencia y, de otro, las restricciones a su aplicación.

Sirva como ejemplo, en Europa, la Sentencia del Tribunal de Justicia Europeo T93/11, de 13 de julio de 2013, que anuló una decisión de la Comisión Europea, de 6 de diciembre de $2010 .^{494}$

El acto impugnado denegó el acceso de la ONG Stichting Corporate Europe Observatory (Observatorio Corporativo de Europa) a documentos relativos a un acuerdo de libre comercio entre la Unión Europea y la India. Por consiguiente, la entidad no obtuvo cualquier información al respecto de las actas de grupos de trabajo, posturas de los Estados e identificación de intervinientes en ese acuerdo, en tanto que el secreto y la opacidad acabaron con prevalecer por encima de la transparencia.

En lo jurídico, la solicitud fue desestimada con base en el artículo 4.1.A-Tercer del Reglamento núm. 1049/2001 del Parlamento y del Consejo Europeos, apartado que prevé las hipótesis de secreto de los documentos de las principales instituciones europeas, como la Comisión, el Consejo y el Parlamento. Así, el artículo mencionado fija que las instituciones quedan autorizadas a denegar el acceso a un documento siempre que ello suponga un perjuicio para la protección del interés público en lo relativo a:

a) La seguridad pública;

b) La defensa y los asuntos militares;

c) Las relaciones internacionales; y

\footnotetext{
${ }^{493}$ HERRERA, op. cit., p. $167-168$.

${ }^{494}$ Disponible en: https://www.eur-lex.europa.eu. Acceso en: 8 jun. 2019.
} 
d) La política financiera, monetaria o económica de la Comunidad o de un Estado miembro.

Inconformada, la ONG presentó una acción ante el Tribunal de Justicia Europeo y afirmó que el artículo 4.1.A-tercer no se aplicaba a su pedido de información, siempre que los documentos solicitados habrían entrado en el dominio público a causa de las acciones y omisiones de la propia Comisión.

También señaló que, en teoría, no habría cualquier diferencia entre ella y los empresarios consultados por la Comisión antes que perfeccionara el acuerdo y que tuvieron acceso a los documentos. Por último, argumentó que no habría motivo para entender que ella sería menos fiable de los gobiernos destinatarios del acuerdo de libre comercio, con lo cual la restricción implicaba una ofensa al principio de igualdad.

Aparte de ello, el pedido de información también tuvo en consideración otros precedentes del Tribunal en casos semejantes, como la STC C-344/04 ${ }^{495}$ y la STC C250/11. ${ }^{496}$ En concreto, ambas decisiones exigen que situaciones semejantes habrá que recibir igual tratamiento y que en situaciones diferentes habrá que tener soluciones distintas, lo que resulta del principio de igualdad.

A pesar de que no obtuvo una victoria en el Tribunal, la ONG logró que la Comisión cambiara su entendimiento al respecto del acceso a documentos en el seno de las instituciones europeas. A partir de la discusión planteada en el proceso, la Comisión puso fin a su práctica de conceder acceso privilegiado a las grandes empresas a las políticas comerciales de la Unión a expensas del interés general. ${ }^{497}$

De ahí en adelante, las restricciones a la transparencia deberán estar clara y específicamente fijadas en la ley, ya que la regla en los regímenes democráticos es la publicidad y la excepción es el secreto. ${ }^{498}$ La recomendación consta de documentos internacionales sobre el asunto, como la Ley Modelo Interamericana de Acceso a la

\footnotetext{
${ }^{495}$ STC C-344/04, de 10 de enero de 2006, IATA y ELFAA, Rec. p. 1-403, apartado 95. Disponible en: https://eur-lex.europa.eu., Accesso en: 09 en. 2019.

${ }^{496}$ STC C-250/11, de 19 de julio de 2012, Lietuvos gelezinkeliai, apartado 44. Disponible en https://eurlex.europa.eu... Accesso en: 09 en. 2019.

${ }^{497}$ HERRERA, op. cit., p. 92.

${ }^{498}$ GUICHOT, op. cit., p. 97-102.
} 
Información Pública ${ }^{499}$ y el Convenio 205 del Consejo de Europa, ${ }^{500}$ aparte de repetirse en otras normativas nacionales e internacionales sobre el asunto.

La restricción a la transparencia no prevalece cuando la información solicitada se destina a la tutela judicial de derechos fundamentales, o tenga como objeto la descripción de conductas que conlleven a la violación de los derechos humanos, practicada por agentes públicos o por orden de autoridades. ${ }^{501}$

Resulta de todo lo dicho que las limitaciones a la transparencia deberán siempre interpretarse de forma estricta o restrictiva, ${ }^{502}$ teniendo en cuenta que la transparencia de la información resguardada en manos del Estado es la regla en los regímenes democráticos y el secreto la excepción.

La transparencia posibilita el conocimiento de las instituciones públicas y la participación ciudadana en la toma de decisiones ${ }^{503} \mathrm{y}$, por ello, solamente se verá limitada en aquellos casos en que así sea necesario por la naturaleza de la información o cuando su divulgación entrase en conflicto con otros intereses protegidos. ${ }^{504}$

Entre tantas limitaciones a la transparencia gubernamental, merece ser destacada relativa a la protección de la intimidad y la privacidad de las autoridades involucradas con la preparación de los Juegos Olímpicos, a causa del obstáculo que pueden representar a la prevención de los actos de corrupción comúnmente asociados a estos mega eventos.

La protección de la intimidad y de la privacidad resultan de la comprensión universal de que todo ser humano debe disponer de una esfera de actuación que lo mantenga a salvo de la curiosidad de terceros, lo que se considera fundamental para el normal desarrollo de su personalidad. ${ }^{505}$

\footnotetext{
${ }^{499}$ Ley Modelo Interamericana sobre Acceso a la Información Pública. OEA, op. cit.

${ }^{500}$ Convenio n. 205 del Consejo de Europa. Disponible en: https://eur-lex.europa.eu/legalcontent/ES/TXT/?uri=LEGISSUM:114546. Acceso en: 8 jun. 2019.

${ }^{501}$ Artículo 44. ley modelo interamericana sobre derecho a la información pública. OEA, op. cit.

${ }^{502}$ HERRERA, op. cit., p. 167-168.

${ }^{503}$ ESPAÑA. Sentencia n. 46/2017, de 22 de junio de 2017, del Juzgado Central de lo ContenciosoAdministrativo núm. 2 de Madrid, dictada en el PO 38/2016. Disponible en: https://eur-lex.europa.eu . Accesso en: 09 enero, 2019.

${ }^{504}$ ESPAÑA. Sentencia n. 85/2016, de 14 de junio de 2016, del Juzgado Central de lo ContenciosoAdministrativo núm. 5 de Madrid, dictada en el PO 43/2015. Disponible en: https://eur-lex.europa.eu . Accesso en: 09 enero, 2019.

${ }^{505}$ LAFER, op.cit., p. 239-240.
} 
Investigaciones realizadas por doctrina alemana ponen de manifiesto que la personalidad de los seres humanos suele desarrollarse sobre tres esferas de actuación ${ }^{506}$, el ambiente donde uno realiza sus actividades normales y corrientes, la que abarca la esfera de la intimidad, la esfera de la privacidad y la esfera de lo público. ${ }^{507}$

La esfera de la intimidad es la más restrictiva de todas ${ }^{508}$ ya que se refiere a los actos, a las informaciones, a los asuntos o a las características particulares de la persona que uno quiere mantener a salvo de la crítica y de la curiosidad de terceros a todo coste. Así se habla de los amigos íntimos, de las relaciones íntimas y de los pensamientos íntimos. ${ }^{509}$ Se trata de informaciones que, llevadas a conocimiento público, podrían causarle daños irreparables en lo personal o en lo profesional ${ }^{510}$, con lo cual se recomienda su protección por encima de otros derechos.

A menudo los órganos y entidades públicas guardan informaciones relativas a la identificación, la salud, el estado civil, la profesión, la situación financiera o fiscal de las personas, que pertenecen a su exclusiva esfera de intereses personal o profesional, y que, por tanto, deberán estar totalmente a salvo del conocimiento de todos.

Así, las informaciones relativas a las preferencias sexuales, a las enfermedades, a los problemas financieros o a los periodos sin trabajo, si están legalmente archivados en órganos o entidades públicas, no podrán ser revelados a terceros o al público en general, bajo el riesgo de que se vulnere la intimidad de la persona. ${ }^{511}$

La privacidad, por otro lado, abarca informaciones o asuntos de naturaleza familiar o profesional de la persona que le gustaría mantener en secreto a toda costa, pero que no siempre es posible, debido a la mayor o menor exposición pública de la persona en los medios, o bien a raíz de la preponderancia de otros intereses más relevantes, como, por

\footnotetext{
${ }^{506}$ COSTA ANDRADE, Manuel da. Liberdade de Imprensa e Inviolabilidade Pessoal: Uma Perspectiva Jurídico-Criminal. Coimbra: Coimbra Editora, 1996, p. 88.

${ }^{507}$ Ibidem, p. 92.

${ }^{508}$ Ibidem, p. 95-6.

509 ESCALANTE GONZALBO, Fernando. El Derecho a la privacidad, 6 a ed., México: Cuadernos de transparencia. 2008, p. 21.

${ }^{510}$ MENDES, Gilmar Ferreira. MÁRTIRES COELHO, Inocêncio. GONET BRANCO, Paulo Gustavo. Curso de Direito Constitucional. São Paulo: Saraiva, 2007, p. 367-371.

${ }^{511}$ ESCALANTE, op. cit., p. 11.
} 
ejemplo, la necesidad de depurar ilícitos de corrupción. ${ }^{512}$ En comparación, lo íntimo se coloca dentro de lo privado, aunque es más restringido y personal. ${ }^{513}$

Finalmente, la esfera de lo público alcanza a todos los actos, informaciones o asuntos de la persona que no se someten al secreto, una vez que se practican en el ámbito de la colectividad y que, por tanto, son del conocimiento de todos.

Pese la diferencia que la doctrina alemana suele establecer entre la intimidad y la privacidad de la persona ${ }^{514}$ lo que también podría interferir con la publicidad de la información archivada en los órganos y entidades del Estado, a menudo las leyes de transparencia y acceso a la información no fijan cualquier distinción entre ellas, colocando ambas figuras bajo la misma protección legal. Así, ya sea un acto relativo a la intimidad, o un acto referente a la privacidad, su contenido no podrá revelarse al público en general (transparencia activa) o a terceros (transparencia pasiva). En este caso, la doctrina y la jurisprudencia coinciden con que existe una esfera de actuación de la persona humana que no puede ser traspasada. ${ }^{515}$

Esta esfera de actuación es la dignidad de la persona humana, un espacio donde uno podrá moverse con libertad y sin el control y la vigilancia de los demás. En efecto, se ha formado un consenso universal de que no es digna la vida de la persona que, constantemente, se somete a instrucciones y al control de la sociedad. ${ }^{516}$

La dignidad supone, por tanto, no solo el derecho de actuar con libertad, sino el derecho de mantener en secreto el resultado de sus acciones. En otras palabras, la dignidad no estaría protegida si uno tuviese que divulgar sus actos, aunque los hubiese practicado en secreto. ${ }^{517}$

Además de los casos de restricciones generales, las leyes de transparencia suelen prever limitaciones parciales a este respecto, casos en los que el interesado solo podrá acceder a una parte del documento que esté archivado en el órgano o entidad público. En

\footnotetext{
${ }^{512}$ COSTA ANDRADE, op. cit., p. 98-100.

${ }^{513}$ ESCALANTE GONZALBO, Fernando. op.cit., p. 21.

${ }^{514}$ COSTA ANDRADE, op. cit., p. 88

${ }^{515}$ STJ. Recurso Especial n. 709.769. Disponible en: https://www.stj.jus.br. Acceso en 09 en. 2019.

${ }^{516}$ ESCALANTE GONZALBO, Fernando. op.cit., p. 11.

${ }^{517}$ Ibidem, p. 35.
} 
este caso, el acceso parcial podrá concretarse a través de una copia de las partes públicas del documento, o por medio de un certificado que reproduzca su contenido publicable. ${ }^{518}$

Pero, puede suceder que el acceso parcial asegurado al interesado conlleve a una información distorsionada o que carezca de sentido, caso en que el derecho de acceso no atiende a su papel en la sociedad. Con vistas a solucionar problemas de esa naturaleza, la ley de España determina que la Administración Pública deberá indicar al solicitante que una parte de la información es omitida por los motivos legalmente establecidos, de tal forma que pueda analizar críticamente los documentos recibidos. ${ }^{519}$

En cualquier caso, con todo, conviene señalar que las restricciones a la transparencia son excepcionales y que solo pueden aplicarse en casos extremos, tomando en cuenta su objeto y finalidad de protección. ${ }^{520}$

Así, la autoridad pública debe siempre ponderar los intereses público y privado en conflicto a la hora de conceder el acceso a los documentos públicos, ponderación que se hace de forma motivada y teniendo en cuenta las circunstancias de cada caso. Por tanto, la decisión que deniega el derecho de acceso no es discrecional, sino que se fundamenta a la luz de los supuestos de hecho de cada caso ${ }^{521}$, con lo cual cobra gran importancia el papel que desarrolla la abogacía pública del Estado, órgano encargado de asesorar la administración pública en cuanto a la aplicación de la ley.

Los límites a la transparencia con base a la protección de la intimidad y la privacidad no inciden de igual forma en lo relativo a los funcionarios públicos y las autoridades responsables de la gestión de los intereses colectivos. ${ }^{522}$ La naturaleza de las tareas que tienen a su cargo y los poderes que reciben como para realizarlas someten a tales personas a una mayor fiscalización de la sociedad a modo de prevenir las malas prácticas administrativas y los actos de corrupción.

\footnotetext{
${ }^{518}$ Ley de Transparencia de Brasil. "Art. $7^{\circ} \mathrm{O}$ acesso à informação de que trata esta Lei compreende, entre outros, os direitos de obter: $\S 2^{\circ}$ Quando não for autorizado acesso integral à informação por ser ela parcialmente sigilosa, é assegurado o acesso à parte não sigilosa por meio de certidão, extrato ou cópia com ocultação da parte sob sigilo." BRASIL, op. cit.

${ }^{519}$ Ley de Transparencia de España. Artículo 16. ESPAÑA, op. cit.

${ }^{520}$ Artículo 14. Ibidem.

${ }^{521}$ Ley Modelo Interamericana sobre Acceso a la Información. OEA, op.cit.

522 DWORKIN, Ronald. O direito da liberdade: a leitura moral da Constituição norte-americana. São Paulo: Martins Fontes, 2006, p. 261-416.
} 
Así ya se ha manifestado la Comisión Interamericana de Derechos Humanos cuando decidió en el caso Eduardo Kilme vs. Argentina, sentencia del 2 de mayo del 2008. Al fallar dicho caso, la Corte evidenció que los funcionarios públicos se someten a un nivel más amplio de crítica por la sociedad, pues "el control democrático a través de la opinión publica fomenta la transparencia de las actividades estatales y promueve la responsabilidad de los funcionarios sobre su gestión pública”, lo que tan solo es posible por medio de una mayor circulación de informes y opiniones sobre asuntos de interés público. ${ }^{523}$

Por consiguiente, la fuerza normativa de los principios de moralidad y publicidad impide que el funcionario invoque la protección a la intimidad y a la privacidad como para esconder posibles irregularidades, como la corrupción, el tráfico de influencia y la improbidad administrativa. ${ }^{524}$ En otras palabras, la gestión de los negocios públicos no se somete, como regla, al secreto, sino que es orientada con arreglo a la publicidad, lo que impone a los funcionarios el deber de divulgarlos a modo de permitir el control social de la Administración. ${ }^{525}$

Las manifestaciones de la doctrina y de la jurisprudencia entorno a los límites de la transparencia y su relación con la intimidad y la privacidad tiene particular relevancia en cuanto a la preparación de los Juegos Olímpicos. A causa de los compromisos perfeccionados con el COI, más bien tras la Carta Olímpica de 1949, los Estados suelen realizar grandes inversiones a modo de organizar al mega evento.

En este sentido, apenas conquista el derecho de acoger a las Olimpíadas, la ciudad trata de ejecutar obras de todos tipos, más bien deportivas y de infraestructura, las cuales acabarían en convertirse en un ambiente favorable a las malas prácticas administrativas.

A modo de prevenir estas irregularidades, los diferentes ordenamientos jurídicos imponen a los altos directivos del Estado el deber de publicar sus actos y decisiones para conocimiento de la sociedad, lo que resulta más bien de los principios de responsabilidad, máxima divulgación y participación.

\footnotetext{
523 OEA, op.cit., p. 17.

${ }^{524}$ MORAES, op. cit, p. 137-138

${ }^{525}$ Fragmento del voto del Juez Sepúlveda Pertence. Cf. BRASIL. SUPREMO TRIBUNAL FEDERAL (1 turma). HC n ${ }^{\circ}$ 87.341-3/PR. Rel. Min. Eros Grau, decisão: 7 de fevereiro de 2006. Disponible en: http://portal.stf.jus.br/
} 
Con arreglo a estos principios, consideramos insuficiente la reglamentación fijada en la Ley de Transparencia y Acceso a la Información de Brasil, que no prevé la obligatoriedad de divulgación de las agendas de los altos directivos de la Administración Pública. Tal omisión impide que los ciudadanos sean informados al respecto de las reuniones de que ellos participan, los asuntos objeto de cada encuentro y las influencias a que se someten con motivo de la preparación de los Juegos, lo que es importante para la prevención de la corrupción.

Asimismo, el incumplimiento de este deber, de acuerdo con la realidad de cada ordenamiento, somete a los infractores, por un lado, a la fiscalización de los órganos responsables de la tutela de la transparencia y, por otro, confirmada la omisión en cuanto al deber de divulgar, autoriza la aplicación de sanciones a los responsables.

\section{8. Órganos de control y responsabilidad de los funcionarios}

La aprobación de una ley de transparencia y acceso a la información no siempre es suficiente para asegurar el control ciudadanos de los actos y decisiones gubernamentales, tampoco enfrentarse al fenómeno de la corrupción. Además de poner en marcha normativas con esas características, los Estados todavía establecen órganos responsables de la fiscalización y el cumplimiento de sus principios y reglas, quienes deberán tener poderes efectivos para resolver los conflictos originados desde su aplicación.

En la doctrina, algunos especialistas suelen identificar tres modelos de autoridades responsables de controlar los actos y decisiones de los órganos y entidades públicas en materia de transparencia gubernamental: ${ }^{526}$

a) El modelo judicial ;

b) El modelo de comisiones especializadas;

c) El modelo de ombudsman.

El modelo judicial confía a los tribunales judiciales o administrativos la competencia para resolver todas cuestiones relativas al incumplimiento de la ley de

\footnotetext{
${ }^{526}$ NEUMAN, Laura. Enforcement Models content and Context. Banco Mundial, 2009. Disponible em: http://siteresources.worldbank.org/PSGLP/Resources/LNEuman.pdf. Acceso em: 8 jun. 2019.
} 
transparencia y acceso a la información, toda vez que la negativa del órgano o entidad pública no esté fundamentada o de conformidad con los principios constitucionales. ${ }^{527}$

Dicho modelo es adoptado en países como Bulgaria, Estados Unidos y Sudáfrica. Así que toda vez que una solicitud de acceso a la información sea denegada, el interesado podrá presentar su solicitud a un Tribunal administrativo de Bulgaria, a la Corte Federal de Estados Unidos o a la Suprema Corte de Sudáfrica que deberá analizar la solicitud y dictar una sentencia. ${ }^{528}$

La principal ventaja de ese modelo es resultado de que los tribunales suelen tener autoridad suficiente para ordenar la entrega de la información, incluso con la aplicación de sanciones a la persona jurídica que resguarda los archivos y documentos, o directamente al funcionario responsable de la negativa, con lo cual, al menos en principio, sería un modelo con mucha efectividad. ${ }^{529}$

Sin embargo, la principal desventaja de ese modelo proviene de que los órganos del poder judicial se ocupan de cuestiones de todos tipos (ambientales, civiles, penales o laborales), con lo cual el análisis de las demandas relativas a la transparencia suele tardar mucho, lo que acaba con generar una sensación de inefectividad. Además, el análisis de esas demandas a cargo del poder judicial con frecuencia obliga a que los interesados se vean obligados a contratar abogados para lograr el acceso a la información, lo que todavía incrementa los costes con el ejercicio del derecho, gastos que no siempre podrán ser afrontados por los ciudadanos. ${ }^{530}$

El modelo de comisión se caracteriza por entregar a una comisión independiente de acceso a la información la tarea de analizar con exclusividad la impugnación contra la decisión que no permite el acceso a la información en manos de los órganos o entidades públicos. ${ }^{531}$ Ese modelo ha sido adoptado más bien en Canadá, Chile, Escocia, India y México, si bien con características distintas en cada uno de ellos.

En Chile, India y México las decisiones de la comisión son definitivas y obligatorias y no podrán ser impugnadas ante el poder judicial. En Canadá, por otro lado,

\footnotetext{
${ }^{527}$ Ibidem, p. 15-17.

528 Ibidem.

${ }^{529}$ Ibidem.

${ }^{530}$ Ibidem.

${ }^{531}$ NEUMAN, op. cit., p. 17-21.
} 
las decisiones de la comisión sí que podrán ser acatadas ante el poder judicial y tan solo serán definitivas tras una sentencia firme dictada por un juez o tribunal. ${ }^{532}$

La principal ventaja de ese modelo frente al modelo judicial resulta de que inicialmente, la comisión actúe con exclusividad en materia de transparencia y acceso a la información y, además, constituye órgano independiente con respecto a los poderes públicos. La exclusividad le permite a la comisión decidir las demandas relativas a la transparencia con mayor rapidez en comparación al modelo judicial, toda vez que no esté obligada a analizar cuestiones de naturaleza civil, penal o laboral, como si suele suceder en los tribunales.

La independencia, por otro lado, le asegura a la comisión mantenerse a salvo de influencias de los partidos políticos, lo que es relevante en el tema del control ciudadano y de la lucha contra la corrupción.

Históricamente, el modelo de comisión de India nació justamente a raíz de la lucha contra las malas prácticas administrativas y la corrupción. En principio, una pequeña organización de base de obreros y campesinos llamada La Mazdoor Kisan Shakdi Sanga Than (MKSST), ubicada en la zona rural de Rajasdán, demandó de las autoridades informaciones sobre la ejecución del presupuesto a cargo del gobierno local, considerado incapaz de resolver los problemas de los vecinos de la región con tales recursos. En definitiva, la entidad se quejaba de que los responsables de la ejecución del presupuesto eran agentes corruptos y no empleaban los fondos públicos para solucionar los problemas de la colectividad, sino que se apropiaban de todo el dinero, aprovechándose más bien de su posición.

Las protestas de la asociación produjeron resultados rápidamente, y otras entidades presentaron solicitudes de igual naturaleza por todo el país, en el entendido de que las autoridades locales deberían ser transparentes en el contenido de la ejecución del presupuesto, sobre todo, con el objeto de cohibir y prevenir actos de corrupción.

Las autoridades no tardaron en contestar a las demandas, creando un sistema de transparencia donde cada estado o comunidad del país tendría una comisión de carácter administrativo que les obligaría a los gobiernos locales a divulgar las informaciones que resguardaran. ${ }^{533}$

\footnotetext{
532 Ibidem.

${ }^{533}$ PESCHARD, op.cit., L. 2399.
} 
Así como en otros países que adoptan el modelo de comisiones especializadas, en la India uno no estará obligado a contratar abogados o pagar cualquier tributo para que pueda presentar solicitudes de acceso a los archivos y documentos oficiales, ${ }^{534}$ lo que claramente facilita el control ciudadano y la lucha contra la corrupción.

Finalmente, el modelo de ombudsman se caracteriza por reconocer en el orden jurídico estatal la existencia de un órgano autorizado a dar recomendaciones a otros órganos y entidades del Estado, pero sin carácter vinculante. Se trata más bien de un modelo que se adapta mejor a las tradiciones y principios del derecho anglosajón, en donde se da el privilegio del dialogo, la mediación y la conciliación por encima del conflicto. ${ }^{535}$

El modelo de ombudsman se adopta en países como Suecia, Noruega, Nueva Zelanda y Hungría, y, ha presentado excelentes resultados, a pesar de no aplicar sanciones a los responsables de transgresiones a los principios y reglas de las leyes de transparencia. ${ }^{536}$

En países como Suecia y Noruega, una recomendación del ombudsman a cualquier órgano o entidad del Estado suena como una verdadera instrucción a que deberán atender inevitablemente, con lo cual no hace falta la previsión de sanciones legales en el caso de incumplimiento. ${ }^{537}$

Actualmente, los países de Europa del Este caminan hacia un modelo de ombudsman, con énfasis principalmente en las recomendaciones y el dialogo, mientras que los países de América se vuelven más bien hacia un modelo de comisiones especializadas, dotadas de poderes para resolver los conflictos definitivamente. ${ }^{538}$

Ninguno de los modelos presentados puede considerarse, en teoría, superior a los demás, ya que el éxito de cualquier modelo depende directamente del entramado

\footnotetext{
${ }^{534}$ En países como Irlanda, sí que hay que pagar por presentar una solicitud de acceso a ciertos archivos y documentos oficiales, variando el coste de $\$ 50,00$ a $\$ 150,00$, según la naturaleza del pedido. Disponible en http://www.courts.ie/Home.nsf/LookupPageLink/home Acceso en: 8 jun. 2019.

${ }^{535}$ NEUMAN, Laura. op.cit., p. 22-25.

${ }^{536}$ Ibidem.

${ }^{537}$ Ibidem.

${ }^{538}$ PESCHARD, op.cit., L. 2411.
} 
institucional y de la tradición jurídica de cada Estado. ${ }^{539}$ Lo importante es que cualquier régimen, ya sea el judicial, el de comisiones, o el de ombudsman, debe preocuparse con asegurar la accesibilidad de los canales de comunicación, la independencia política de los órganos de transparencia, la promoción del acceso directo de los interesados y la eliminación de formalidades que dificulten el acceso. ${ }^{540}$

En Brasil, el principal órgano responsable de controlar la transparencia y el acceso a la información es la Contraloría General de la Unión, quien es el órgano del Gobierno Federal responsable de dar asistencia directa e inmediata al Presidente de la República en los asuntos que, en el ámbito del Poder Ejecutivo, sean relativos a la defensa del patrimonio público y al aumento de la transparencia de la gestión por medio de las actividades de control interno, auditoría pública, corrección, prevención y combate a la corrupción y mediación.

La Contraloría también debe ejercer, como órgano central, la supervisión técnica de los órganos que componen el sistema de Control Interno, el Sistema de Corrección, de las oficinas de Defensor del Pueblo del Poder Ejecutivo Federal, prestando la orientación normativa necesaria para tanto. ${ }^{541}$

A diferencia de lo que comúnmente pasa en otros países, la Contraloría General de la Unión de Brasil no es una comisión independiente, sino forma parte del Poder Ejecutivo federal, con lo cual se somete a las directrices y a la autoridad del presidente de la República. De ahí que, desde la promulgación de la Ley núm. 13.341, de 29 de septiembre de 2016, la Contraloría es considerada un ministerio y, como tal, deberá, cada año, rendir cuentas al presidente en cuanto a las actividades desarrolladas en lo relativo al control interno, auditoría pública, corrección, prevención y combate a la corrupción.

Finalmente, las tareas legalmente encomendadas a la Contraloría no impiden el control interno realizado directamente por cada órgano o entidad pública encargada de su aplicación en su ámbito de competencia. Desde esta perspectiva, todos las entidades y órganos públicos brasileños están obligados a divulgar sus actos y decisiones para

\footnotetext{
${ }^{539}$ Neuman, Laura. op.cit. p. 25.

${ }^{540}$ Ibidem, p. 1-5.

${ }^{541}$ CGU - CONTROLADORIA-GERAL DA UNIÃO. Disponible en: http://www.cgu.gov.br. Acceso en: 17 mar. 2019.
} 
conocimiento de los ciudadanos, como consecuencia de los principios de responsabilidad, máxima divulgación y participación.

En España, la tarea de fiscalizar el correcto cumplimiento de la ley está a cargo del Consejo de Transparencia y Buen Gobierno, que "podrá dictar resoluciones en las que se establezcan las medidas que sea necesario adoptar para el cese del incumplimiento y el inicio de las actuaciones disciplinarias que procedan" 542

Respecto a las sanciones, la ley brasileña considera ilícita la conducta del funcionario público, civil o militar, que deliberadamente recusarse a suministrar información requerida, o que, intencionalmente, facilitase información incorrecta, incompleta o imprecisa. ${ }^{543}$ También considera susceptible de ser punible la conducta del funcionario que impone secreto a la información para sacar provecho personal o para un tercero, o cuando la ocultación tiene como objetivo eludir la práctica de acto ilegal cometido por sí mismo o por otra persona. ${ }^{544}$

El castigo de estos comportamientos pone de manifiesto el objetivo del legislador de cohibir la práctica de actos de corrupción cometidos con fundamento en la propia ley, cuando el funcionario solicita una ventaja indebida para facilitar el acceso a la información que ha colocado bajo secreto, o cuando dichas faltas tienen origen en otras normas y la ley de transparencia es utilizada para encubrir las irregularidades.

En cualquier caso, el incumplimiento intencionado a las obligaciones fijadas en la ley puede caracterizar transgresión mínima, mediana o grave, o infracción $\operatorname{administrativa~}^{545}$, que podrán ser sancionadas con las sanciones de suspensión, destitución de función, demisión o casación de jubilación. ${ }^{546}$

En otra medida, el autor de las conductas tipificadas como ilícitas en la ley brasileña también podrá ser responsable por la práctica de acto de improbidad

\footnotetext{
${ }^{542}$ ESPAÑA. LEY DE ACCESO A LA INFORMACIÓN Y BUEN GOBIERNO. Disponible en:. https://www.boe.es/buscar/pdf/2013/BOE-A-2013-12887-consolidado.pdfAcceso en: 6 mayo 2019.

${ }^{543}$ BRASIL. Lei $\mathbf{n}^{0}$ 12.527. Ley de Transparencia y Acesso a la información. 18 nov. 2011. Disponible en: http://www.planalto.gov.br/ccivil_03/ato2011-2014/2011/lei/112527.htm Acceso en: 8 junio 2019.

544 BRASIL. op. cit.

545 BRASIL. op. cit.

546 BRASIL. Lei n 8.112/1990. Disponible en http://www.planalto.gov.br/ccivil_03/leis/18112cons.htm Acceso en: 6 jun. 2019.
} 
administrativa ${ }^{547}$ y en este caso, podrá sufrir las sanciones de pérdida del cargo, empleo o función pública, suspensión de los derechos políticos, multa civil, entre otras ${ }^{548}$, observándose, desde luego, un abanico de penas más rigurosas que las establecidas en otras leyes de igual naturaleza.

La ley de Chile, por ejemplo, prevé que la autoridad del órgano o servicio de la Administración del Estado requerido que deniegue infundadamente el acceso a la información será penalizado con multa de $20 \%$ a $50 \%$ de su remuneración ${ }^{549} \mathrm{y}$, si persiste en su actitud, se le impondrá el doble de la sanción indicada y la suspensión en el cargo por un lapso de cinco días. 550

Como forma de ablandar el rigor de las sanciones, la ley brasileña establece que, en todos casos, la aplicación de la sanción será fijada tomando en cuenta la naturaleza y la gravedad de la infracción, los danos que ha producido para la Administración Pública, las circunstancias agravantes $\mathrm{y}$ atenuantes relacionadas al caso concreto y los antecedentes del imputado. ${ }^{551}$

\subsection{Conclusión}

Tras más de veinte años de la promulgación de la Constitución democrática (1988) la sociedad brasileña tiene un instrumento jurídico que es la Ley de Transparencia y Acceso a la Información, la cual permite acompañar a los gestores públicos en actos y

\footnotetext{
${ }^{547}$ BRASIL. op.cit.

548 BRASIL. Lei $\mathbf{n}^{\mathbf{0}} \mathbf{8 . 4 2 9} / 1992$. Disponible en: http://www.planalto.gov.br/ccivil_03/Leis/L8429.htm Acceso en: 19 mar. 2019.

${ }^{549}$ CHILE. Ley de Transparencia. Artículo 45. La autoridad o jefatura o jefe superior del órgano o servicio de la Administración del Estado requerido, que hubiere denegado infundadamente el acceso a la información, contraviniendo, así, lo dispuesto en el artículo 16, será sancionado con multa de $20 \%$ a $50 \%$ de su remuneración. Cf. CHILE. Ley $\mathbf{n}^{\mathbf{0}}$ 20.285. Acceso a la información pública. Disponible en: https://www.leychile.cl/Navegar?idNorma=276363 Acceso en: 19 mar. 2019.
}

${ }^{550}$ CHILE. Ley de Transparencia. Artículo 46. La no entrega oportuna de la información en la forma decretada, una vez que ha sido ordenada por resolución a firme, será sancionada con multa de $20 \%$ a $50 \%$ de la remuneración correspondiente. Si la autoridad o jefatura o jefe superior del órgano o servicio de la Administración del Estado, requerido, persistiere en su actitud, se le aplicará el duplo de la sanción indicada y la suspensión en el cargo por un lapso de cinco días. Cf. CHILE. Ley $\mathbf{n}^{0}$ 20.285. op. cit.

${ }^{551}$ BRASIL. Lei n 8.112/1990. Art. 128. op. cit. 
decisiones administrativas. Esto implica una gran conquista en la prevención de la corrupción.

La ley antes indicada establece canales de comunicación entre los ciudadanos y el Estado, encargando a un órgano específico la tarea de velar por el respeto a la transparencia gubernamental y, además, contempla un régimen de sanciones para el caso de que no fuesen observadas sus disposiciones.

Asimismo, Brasil creyó en la posibilidad de prevenir la corrupción asociada a la preparación de los Juegos Olímpicos con la aprobación de la Ley de Transparencia y Acceso a la Información. Se imaginó que, debido a la normativa, los errores comunes a otras ediciones de las Olimpíadas no se repetirían en Río, además de todos los instrumentos de prevención de malas prácticas existentes, el país tiene una ley que impone a los altos directivos de la Administración Pública el deber de hacer transparentes todos sus actos relativos a la preparación de los juegos.

En las primeras Olimpíadas brasileñas no permitirían irregularidades, nada de acuerdos sigilosos entre políticos, altos funcionarios públicos y empresarios, sin licitaciones preparadas, así como tampoco el pago por ventajas indebidas, todo iba a ser diferente. Los Juegos de Río no darían a los brasileños los beneficios que, efectivamente, todos esperaban.

En este sentido, terminado el mega evento, Río sería una mejor ciudad con más infraestructura, mejores servicios y una mejor calidad de vida para los vecinos. En definitiva, en Río, los juegos iban a cumplir con su promesa para la ciudad anfitriona, así como un legado más allá de lo deportivo tras su realización. La ciudad tendría una mejor infraestructura, existiendo un mejor sistema de transporte, y con favelas urbanizadas. El tráfico de drogas sería debelado. Al final, todos ganarían con el sueño olímpico.

Muchos factores justificaban que pasara esto, porque fue aprobada en el Congreso Nacional la Ley de Transparencia y Acceso a la Información, aplicada a todas las esferas del gobierno. Los órganos y entidades de la Administración Pública Federal, estatal y municipal fueron obligados como regla, a publicar sus actos y decisiones para la sociedad. 
Se ha considerado irrelevante, en este caso, el hecho de que Brasil es un Estado compuesto $^{552}$, como son los federales o autonómicos. Estas organizaciones presentan una descentralización política que genera diferentes niveles de gobierno. ${ }^{553}$ Todos ellos tienen autonomía para aprobar leyes que entraran en vigor dentro de su propio territorio, con lo cual cada uno tienen capacidad para gestionar los intereses públicos de los ciudadanos en su esfera de actuación ${ }^{554}$.

Esta idea es compatible con los conceptos de soberanía y autonomía dentro de un mismo espacio político, entendiéndose la autonomía como el atributo reconocido a cada uno de los miembros de la federación para organizar sus propios servicios administrativos y aprobar leyes que van a vigorar en su territorio ${ }^{555}$. En comparación, sucede lo mismo en el Estado autonómico, cuyo principal representante es España, país donde el Estado y las comunidades autónomas tienen competencia para aprobar leyes sobre determinadas materias.

A pesar de existir varios centros de producción legislativa en esta materia, la ley brasileña opta por considerar la normativa aprobada por el Estado Nacional que establece patrones mínimos sobre este tema ${ }^{556}$. Los estados miembros, el Distrito Federal y los municipios no están autorizados a restringir el ámbito de incidencia de la ley, permitiendo tan solo desarrollar su contenido o ampliar su objetivo, como forma de garantizar una mayor participación ciudadana.

Como consecuencia, la Ley de Transparencia aprobada en cierto estado miembro, comunidad autónoma o municipio no puede reducir el catálogo de sujetos obligados a la transparencia gubernamental, tampoco puede ampliar los casos de secreto fijados en la ley nacional, pena de disminuir la efectividad de las medidas anticorrupción.

Respecto al tema, conviene señalar que la Convención de Naciones Unidas contra la corrupción del año 2003, recomienda a todos los Estados que adopten medidas para facilitar la transparencia gubernamental y la rendición de cuentas. Considerando estas

\footnotetext{
${ }^{552}$ VERRILLI, Antonio; SOLENNE, Diego. op. cit., p. 5.

${ }^{553}$ CARVALHO FILHO, José dos Santos. op. cit., p. 5-6.

${ }^{554}$ VERRILLI, Antonio; SOLENNE, Diego. op. cit., p. 8.

${ }^{555}$ MENDES, Gilmar Ferreira. MÁRTIRES COELHO, Inocêncio. GONET BRANCO, Paulo Gustavo. $o p$. cit., p. 848.

${ }^{556}$ GUICHOT, Emilio. op. cit., p. 18.
} 
ideas, la Ley de Transparencia de Brasil dispone que orientara todas las entidades políticas de la federación al fijar sus reglas de transparencia y acceso a la información ${ }^{557}$.

Además, establece que todas las Administraciones Públicas (centralizadas o no) se someten al deber de transparencia activa, independientemente del régimen legal en vigor en cada ente político de la federación. Aunque tengan competencia para aprobar leyes de transparencia en su propio territorio, los estados, los municipios y el distrito federal no pueden restringir el ámbito de incidencia de la Ley de Transparencia aprobada por el parlamento, si lo hacen, afrontan la constitución y la Convención de Naciones Unidas de lucha contra la corrupción.

También esta fue la solución planteada en la Ley de Transparencia de España. La citada normativa establece un contenido mínimo sobre la materia de acuerdo a las reglas internacionales, permitiendo a las comunidades autónomas desarrollar dichas cuestiones en su propio ordenamiento para garantizar una mayor publicidad en los actos del poder público $^{558}$.

Las leyes de las comunidades autónomas pueden ampliar el contenido de la Ley núm. 19 de fecha 9 de diciembre de 2013, incorporando otros elementos que fortalezcan la democracia, al prevenir la corrupción.

En España, la Ley de Transparencia del Principado de Asturias, Ley núm. 8, de 14 de septiembre de 2018, además, de reglamentar la transparencia y el derecho de acceso, trató de reglamentar la actividad de los grupos de intereses, grupos de presión o lobby. En este sentido, creó un registro público para tenerlos controlados, legalizados, fiscalizados e imponerles un régimen de transparencia ${ }^{559}$.

Igual ocurre con la Ley núm. 2/2015, de 2 de abril, de Transparencia, Buen Gobierno y Participación Ciudadana de la Comunidad Valenciana que enuncia varios principios que tendrán que encaminar la labor de quienes ocupan los altos cargos del gobierno y del alto funcionariado de la comunidad. Entre los principios se destacan los de transparencia, responsabilidad, buena fe y participación. La ley también prevé la

\footnotetext{
557 BRASIL, Ley núm. 12.527/2011, Artículo $1^{\circ}$. Disponible em: http://www.planalto.gov.br/ccivil 03/ ato2011-2014/2011/lei/112527.htm, Acceso en: 27 de junio de 2019. Op.cit.

${ }^{558}$ ESPAÑA, Ley núm. 19/2013. Artículo 5. Disponible en: https://www.boe.es. Acceso en: 11 mayo 2019.

559 ESPAÑA. Ley núm. 8/2018. Ley de Transparencia, Buen Gobierno y Grupos de Interés del Principado de Asturias, Arts. 51 y 52. Disponible en: https://www.boe.es/buscar/pdf/2018/BOE-A-201814293-consolidado.pdf
} 
aprobación de un código de buen gobierno que tendrá en cuenta dichos principios y con lo cual se busca incorporar la dimensión ética en la gestión pública ${ }^{560}$.

La Comunidad Valenciana posee, además, normas complementarias en la materia, como el Decreto núm. 56/2016, de 6 de mayo, que aprobó el Código de Buen Gobierno y la Ley núm. 8/2016, de 28 de octubre, que creó el régimen de Incompatibilidades y Conflictos de Intereses de Personas con Cargos Públicos no Electos.

La Ley núm. 12/2014, de 26 de diciembre, de Transparencia y Acceso a la Información Pública de la Comunidad Canaria, también incorporó otra novedad al régimen de transparencia y prevención de la corrupción. La normativa da la posibilidad de que el ciudadano solicite información a los poderes públicos de forma oral, utilizando canales de comunicación telefónicos facilitados por la Administración, además, previó la creación de un "Buzón de consulta de la Oficina Canaria de Información", el cual consiste en un formulario que le permite al ciudadano pedir información a la Administración por escrito, presentando una solicitud con hasta trescientos caracteres ${ }^{561}$.

La capacidad de los entes locales para incorporar nuevos elementos a la transparencia gubernamental contribuye en el permanente dialogo entre el Estado y los ciudadanos, permite a los poderes públicos conocer las preocupaciones de la sociedad ${ }^{562}$, aparte de que previene actos de corrupción ${ }^{563}$.

Aunque tuviesen autonomía para aprobar leyes de Transparencia y Acceso a la Información en el ámbito de sus respectivas Administraciones Públicas, ni el Estado de Rio de Janeiro ${ }^{564}$, ni el Municipio de Río de Janeiro ${ }^{565}$ lo hicieron con motivo de los

560 ESPAÑA. Ley núm. 2/2015.Ley de Transparencia, Buen Gobierno y Participación de la Comunidad Valenciana, Arts. 26 y 27. Disponible en: https://www.boe.es/buscar/pdf/2015/BOE-A2015-4547-consolidado.pdf. Acceso en: 6 enero 2019.

${ }^{561}$ ESPAÑA. Ley núm. 12/2014, de 26 de diciembre, de Transparencia y Acceso a la Información Pública de la Comunidad Canaria. Disponible en: https:/www.boe.es/diario boe/txt.php?id=BOE-A2015-1114. Acceso en 27/05/2019. Acceso en: 6 enero 2019.

${ }^{562}$ ESPAÑA. TRIBUNAL CONSTITUCIONAL. 161. SENTENCIA 161/1988. 20 set. 1988. Disponible en http://hj.tribunalconstitucional.es/cs-CZ/Resolucion/Show/1102

. Acceso en: 03 mayo 2019.

${ }^{563}$ HERRERA, Manuel Palomares. op. cit., p. 60.

564 BRASIL. Decreto n. 46.475/2018 do Estado do Rio de Janeiro. Disponible em: www.governoaberto.rj.gov.br, Acceso en 12 out 2019.

565 BRASIL. Lei núm. 13.460/2017 Disponible em: http://www.planalto.gov.br/ccivil 03/ Ato20152018/2017/Lei/L13460.htmAcceso en 12 out 2019. 
Juegos Olímpicos de 2016. En consecuencia, las normas federales sobre la materia se aplicaron en su plenitud para prevenir las malas prácticas asociadas al mega evento, lo que, sin embargo, no ha sido suficiente.

Incluso, la Ley de Transparencia aprobada por el Congreso Nacional se enfrentó con un problema en cuanto a su aplicación. A pesar de que Río de Janeiro fue elegida ciudad anfitriona de las Olimpíadas en 2009, la Ley de Transparencia brasileña fue aprobada el 18 de noviembre de 2011, dos años tras la decisión del Comité Olímpico Internacional (COI).

Este intervalo entre la decisión de la entidad y la aprobación de la normativa de hecho podría representar un problema en lo relativo a la prevención de la corrupción a menudo asociada al mega evento. Con base al principio tempus regit actum, la Ley de Transparencia únicamente producirá efectos futuros. En consecuencia, los órganos y entidades públicas no estarían obligados a divulgar informaciones generadas antes de que entrara en vigor.

Esta aparente restricción en cuanto a los límites temporales de la ley no llegó a convertirse en un obstáculo al control ciudadano de los actos de la Administración Pública. Antes que la ley fuese sancionada, Brasil contaba con otras leyes que demandaban de las autoridades la necesidad de publicar sus actos para conocimiento de los ciudadanos. Se destacan, en este caso, la Ley núm. 8.666, de 21 de junio de 1993, de Licitaciones y Contratos Administrativos ${ }^{566}$, y la Ley núm. 8.429, de 02 de junio de 1992, de Improbidad Administrativa ${ }^{567}$.

Ambas leyes, con base en el principio democrático, demandan de quienes ocupan cargo, empleo o función en el sector público el deber de hacer transparentes sus actos y decisiones para la sociedad, sometido al permanente juicio crítico de los ciudadanos. Este compromiso abarca, como regla, todos los actos y decisiones practicados por las autoridades y funcionarios públicos, en especial los relativos a la contratación pública, siendo este un ambiente propicio para las malas prácticas administrativas.

Según la Ley de Licitaciones y Contratos Administrativos de Brasil, todas las licitaciones a cargo de la Administración Pública deberán observar los principios de

\footnotetext{
566 BRASIL. Lei núm. 8.666/1993. Disponible em: http://www.planalto.gov.br/ccivil_03/leis/18666.htm, Acceso en 12 out 2019.

${ }^{567}$ BRASIL. Lei núm. 8.429/1992. Disponible em: http://www.planalto.gov.br/ccivil 03/leis/L8429.htm, Acceso en 12 out 2019.
} 
legalidad, moralidad, probidad, igualdad, motivación, publicidad, vinculación al instrumento convocatorio y juzgamiento objetivo, además, de otros que con ellos se relacionan ${ }^{568}$. Cada uno de estos principios, en mayor o menor extensión, reproduce aspectos de los principios de la transparencia, como el de responsabilidad, máxima divulgación y participación.

Con arreglo al principio de legalidad, los actos y decisiones de las autoridades no pueden practicarse con base en la voluntad del gestor, como solía pasar en las monarquías absolutas de los siglos XV y XVI ${ }^{569}$. Las decisiones de la Administración deberán atañer a la ley, siempre que sea la expresión de la voluntad del pueblo.

En cuanto a las licitaciones, actuar con legalidad significa cumplir con las reglas previamente establecidas, elegir una de las modalidades fijadas para el procedimiento, adoptar criterios claros y objetivos para el juzgamiento de las propuestas, cumplir con las determinaciones que constan en los pliegos, examinar con cuidado los documentos presentados por los interesados, juzgar las propuestas según los criterios previamente establecidos y finalmente realizar la contratación directa en los casos autorizados en ley ${ }^{570}$.

A su vez, el principio de moralidad demanda que el gestor actúe con base en la integridad y la ética al frente de la Administración Pública, es decir, con responsabilidad, mirando el interés público ${ }^{571}$. La moralidad condiciona no solo la acción del gestor, sino la de los particulares que participan de la licitación, incentivándolos a no establecer acuerdos previos a la disputa para frustrar su carácter competitivo ${ }^{572}$.

Además, el principio de igualdad requiere en la Administración Pública tratamiento idéntico a quienes manifiesten predilección en contratar con el Estado, salvo que existan motivos de naturaleza técnica que justifican la discriminación. Así, es

\footnotetext{
568 BRASIL. Lei núm. 8.666/1993, Art. $3^{\circ}$. Disponible em: http://www.planalto.gov.br/ccivil_03/leis/18666cons.htm, Acceso en 12 out 2019.

${ }^{569}$ Di Pietro, Maria Sylvia Zanella. op. cit., p. 1.

${ }^{570}$ CARVALHO FILHO, José dos Santos. op. cit., p. 251.

${ }^{571}$ JUSTEN FILHO, Marçal. Comentários à Lei de Licitações e Contratos Administrativos, Rio de Janeiro: AIDE: 1993, p. 31.

${ }^{572}$ Furtado, Lucas Rocha. Curso de Direito Administrativo. 4a ed., Belo Horizonte, Editora Fórum, 2013, L. 10.879 .
} 
totalmente prohibido que los órganos y entidades públicas concedan privilegios o ventajas a quienes estén más cerca de la Administración, independientemente del motivo.

Esta prohibición no abarca los requisitos de calificación técnica fijados por los órganos y entidades públicas para la compraventa de determinados productos o servicios con características especiales. Cuando sucede, algunos interesados no cumplirán con los requisitos. Consecuentemente, serán inhabilitados y perderán el derecho de contratar con la Administración ${ }^{573}$. La igualdad para contratar con el Estado es de mera expectativa, ya que todos en principio podrán hacerlo ${ }^{574}$.

Con base en estas exigencias de naturaleza técnica, el gestor no podrá direccionar la licitación para que favorezca a la sociedad en la que participa el funcionario o alto directivo del órgano o entidad responsable de la misma ${ }^{575}$, si el funcionario o alto directivo ya no tiene vínculo con la Administración Pública ${ }^{576}$.

Así, con arreglo al principio de igualdad, los actos de la Administración Pública no se basan en los lazos de naturaleza personal o comercial que conectan el gestor a terceros, sino que resultan de la aplicación de la ley, como consecuencia del principio de responsabilidad.

En cuanto al principio de motivación, resulta que la Administración Pública deberá hacer explicitas las razones que impulsaron su actuación en cada caso.

Finalmente, el principio de publicidad le impone al gestor la acción de divulgar todos los actos y decisiones que atañan a la realización de la licitación, lo que posibilita su conocimiento por un mayor número de interesados ${ }^{577}$.

\footnotetext{
${ }^{573}$ Furtado, Lucas Rocha. op. cit., L. 10.866.

${ }^{574}$ RIGOLIN, Ivan. Manual Prático das Licitações, São Paulo, Saraiva: 1991, p. 38.

${ }^{575}$ BRASIL. STJ, Resp. n. 254.115-SP, 1a T., Rel. Min. GARCIA VIEIRA, J. 20/06/2000. Disponible en: http://www.stj.jus.br, Acceso en 09 de octubre de 2019.

${ }^{576}$ BRASIL, TCU, Acórdão núm. 1448/2011-Plenario. Disponible en https://portal.tcu.gov.br/inicio/index.htm Acceso en 09 de octubre de 2019.

577 NIEBOHR, Joel de Menezes, Licitações e Contratos Administrativos, $3^{\mathrm{a}}$ ed., Belo Horizonte, Fórum, 2013, p. 57.
} 
Con base en el principio, los pliegos relativos a la licitación deberán ser divulgados a través de la prensa oficial ${ }^{578}$, además, deberá realizarse audiencia pública cuando se trate de licitaciones para adquirir productos o servicios de gran valor ${ }^{579}$.

Por otro lado, la Ley de Improbidad Administrativa prevé que los actos de la Administración serán públicos, resultado de que el Estado, como ente político, no tiene intimidad, siempre que sus fines se atañen a la satisfacción del interés público. De acuerdo con la ley, por tanto, administrar presupone actuar con transparencia de criterios y procedimientos, así, la opacidad es incompatible con el propio régimen democrático ${ }^{580}$.

Aunque, la Ley de Transparencia y Acceso a la Información de Brasil fue promulgada dos años tras la elección de Río como ciudad anfitriona de las Olimpíadas de 2016, o sea, el 18 de noviembre de 2011, antes de su aprobación, el ordenamiento brasileño ya contaba con medios para prevenir la corrupción, a menudo, asociada a los Juegos Olímpicos.

Sin embargo, terminados los juegos, nada de esto ocurrió. El análisis retrospectivo de todo el período olímpico reveló justamente lo contrario. Las Olimpíadas no cumplieron con sus promesas. Así como en otras ediciones, los Juegos de Río sirvieron de palco para una serie de malas prácticas. La transparencia no logró prevenir las irregularidades y los Juegos Olímpicos Río 2016, no observaron los principios de responsabilidad, máxima divulgación, participación, buena fe y universalidad.

Incluso antes de ser elegida como ciudad olímpica, Río sufrió con las acciones de políticos y empresarios sin escrúpulos, que utilizaron las licitaciones y contratos públicos únicamente con el objetivo de obtener provecho personal en perjuicio de la Administración Pública. Estas malas prácticas acabaron contaminando todo el período de preparación, ya que los mismos políticos, funcionarios y empresarios trataron de utilizar el mega evento únicamente para aumentar sus ganancias.

\footnotetext{
${ }^{578}$ BRASIL. Lei núm. 8.666/1993, Art. 21. Disponible en: http://planalto.gov.br/ccivil 03/LEIS/L8666compilado.htm, Acceso en 09 de octubre de 2019.

${ }^{579}$ BRASIL. Lei núm. 8.666/1993, Art. 39. Disponible en: http://planalto.gov.br/ccivil 03/LEIS/L8666compilado.htm, Acceso en 09 de octubre de 2019.
}

${ }^{580}$ FAZZIO JÚNIOR, Waldo. Atos de Improbidade Administrativa: Doutrina, Legislação e Jurisprudência, $2^{\mathrm{a}}$ ed., São Paulo, Atlas, 2008, p. 16. 
A modo de entender lo que ha pasado, consideramos importante entender el contexto político que antecedió la elección de Río como ciudad olímpica. Comprender la realidad política del Estado de Río de Janeiro antes de la decisión del COI el 02 de octubre de 2009, analizar el papel desempeñado por el Gobernador Sergio Cabral en todo el proceso, además, de su comportamiento frente de la Administración Pública durante de este período.

Asimismo, consideramos relevante analizar el procedimiento de las principales constructoras brasileñas respecto a las licitaciones públicas, en especial las asociadas a los preparativos de mega eventos deportivos internacionales. Al final de este estudio, será posible verificar, que las empresas y sus directivos, siempre han dirigido sus conductas a partir de una cultura de secreto y opacidad, a fin de aumentar sus ganancias debido a los contratos perfeccionados con entes públicos.

Las investigaciones revelaron que las malas prácticas administrativas no se restringieron únicamente a las licitaciones responsabilidad del Estado de Río de Janeiro, y, asimismo, contaminaron los procedimientos de la Secretaría de Obras Públicas del Municipio, verificando alguna similitud entre unas y otras irregularidades. Los responsables de ilícitos trataron de aprovecharse de las debilidades de la Ley de Transparencia en Brasil para incurrir en actos de corrupción. 



\section{CAPÍTULO II - LAS DEBILIDADES DEL SISTEMA BRASILEÑO DE TRANSPARENCIA GUBERNAMENTAL PARA PREVENIR LA CORRUPCION ASOCIADA A LOS JUEGOS OLÍMPICOS RIO 2016}

\section{CONSIDERACIONES GENERALES}

Río de Janeiro fue elegida ciudad sede de las Olimpiadas de 2016, el 2 de octubre de 2009, en Copenhague, Dinamarca ${ }^{581}$, dos años tras acoger una edición de los Juegos Panamericanos provocando con esta victoria mucha ilusión entre los brasileños. En un intervalo de tan solo dos años, la ciudad recibiría dos de los principales mega eventos deportivos internacionales, la Copa del Mundo de Fútbol FIFA 2014 y las Olimpíadas de $2016^{582}$.

Esto no llegó a ser una novedad. Casi cincuenta años antes, entre 1968 y 1970, otra ciudad ubicada en un país subdesarrollado había conquistado este derecho. La ciudad de México acogió ambos mega eventos en un intervalo de sólo dos años, convirtiéndose en la primera ciudad latinoamericana que logró realizarlo.

Así como en México, las Olimpíadas en Rio estaban copadas de expectativas que fueron más allá de lo deportivo. Se experimentó el sentimiento de que los juegos aportarían grandes beneficios para el país y para la ciudad anfitriona. Por primera vez en la historia, tras 120 años desde que se restauraron en Atenas (1896), los Juegos Olímpicos llegaron a un país de Sudamérica y la ciudad elegida fue Rio de Janeiro ${ }^{583}$.

Además, el triunfo en Copenhague puso fin a una trayectoria de fracaso en cuanto al deseo de Brasil en acoger una edición de los Juegos Olímpicos. Históricamente, Rio de Janeiro ya había presentado su "candidatura" como anfitriona de las Olimpíadas en tres

581 PAZZI Jr, M. Rio é escolhido como cidade-sede de Olimpíada de 2016. Estadão. Disponible en: https://esportes.estadao.com.br/noticias/geral,rio-e-escolhido-como-cidade-sede-da-olimpiada-de2016,444804 Acceso en: 24 jun. 2019.

582 CAPELO, Rodrigo. Os bilhões de Dólares das Olimpíadas e das Copas. Revista Época. Disponible en: https://epoca.globo.com/vida/esporte/noticia/2016/06/os-bilhoes-de-dolares-das-olimpiadas-e-dascopas.html. Acceso en: 12 oct. 2019.

583 PRIMEROS Juegos Olímpicos Modernos: de Grecia a Rio. El País. Disponible en: https://elpais.com/deportes/2016/04/06/actualidad/1459929798_239239.html Acceso en: 24 jun. 2019. 
ocasiones, 1936, 2004 y 2012. En cada oportunidad, fue superada por Berlín, Atenas y Londres, respectivamente ${ }^{584}$.

Así, la victoria en 2009 tuvo un sabor especial. En las tres tentativas anteriores, la "candidatura" de Rio ni siquiera superó la primera etapa de calificación. Técnicamente, la ciudad jamás fue considerada para acoger una edición de los Juegos Olímpicos, identificándose más bien como una mera aspirante en hacerlo.

La elección de la ciudad anfitriona sucede en varias etapas. Todas son rigurosas y se realizan de conformidad con los criterios fijados por el COI. A lo largo de la disputa, las interesadas deberán comprobar que cumplen con todos los requisitos fijados por la entidad olímpica.

En síntesis, el proceso comienza desde una solicitud de la ciudad interesada al Comité Olímpico de su país, declarando su ambición de organizar una edición de los Juegos Olímpicos y presenta las condiciones que ofrece ${ }^{585}$.

Esa solicitud estará acompañada de cartas firmadas por las máximas autoridades de las diferentes esferas gubernamentales, involucradas directamente con la preparación de las Olimpíadas ${ }^{586}$. Las autoridades se comprometerán en realizar todas las inversiones necesarias a la preparación de los juegos ${ }^{587}$, lo que es fundamental para tramitar la solicitud $^{588}$.

En cuanto dicho requerimiento es recibido por el Comité Olímpico Nacional, lo remite al COI para evaluar y opinar al respecto. En cuanto examina los documentos, el COI envía a las ciudades aspirantes un cuestionario. Indagando sobre el apoyo de autoridades y vecinos, infraestructura disponible, posibilidad de construirse una villa olímpica, alojamientos, transportes y seguridad ciudadana ${ }^{589}$. También requiere de la

\footnotetext{
${ }^{584}$ BUARQUE DE HOLLANDA, Bernardo Borges; MEDEIROS, Jimmy; FONSECA, Vivian. Políticas Públicas Esportivas no Brasil do Século XXI: da Candidatura Olímpica à Construção de um "Legado" para os Jogos Olímpicos Rio 2016. In: MARQUES, José Carlos; ROCCO JÚNIOR, Ary José. Leituras e Reflexões sobre os Jogos Olímpicos Rio-2016. São Paulo: Cultura Acadêmica, 2018, p. 44.

585 OLYMPIC Charter 1949. Disponible en: https://www.olympic.org/olympic-studiescentre/collections/official-publications/olympic-charters. Acceso en: 22 jul 2018.

${ }^{586}$ Ibidem.

${ }^{587}$ BUARQUE DE HOLLANDA, Bernardo Borges; MEDEIROS, Jimmy; FONSECA, Vivian. op. cit, p. 44.

588 CAPELO, Rodrigo. op. cit.

589 OLYMPIC Charter 1950, p. 9-10. Disponible en: https://www.olympic.org/olympic-studiescentre/collections/official-publications/olympic-chartersAcceso en: 22 julio 2018.
} 
información en cuanto al impacto ambiental, experiencias anteriores relativas a la organización de mega eventos y sobre el legado olímpico ${ }^{590}$.

Las respuestas se analizan con base en una herramienta desarrollada para las etapas de candidatura olímpica (el software olymplogic). La aplicación evalúa y clasifica las ciudades aspirantes de acuerdo con las respuestas presentadas al cuestionario. En cuanto se verifican los resultados, el COI es el encargado de anunciar las ciudades candidatas en acoger los Juegos Olímpicos. ${ }^{591}$

Hasta los juegos de 2016, Rio no había superado jamás esta primera etapa de calificación. En términos olímpicos, no se consideraba una ciudad candidata para acoger al mega evento ${ }^{592}$, pero esto cambio totalmente con motivo de la disputa para los Juegos Olímpicos de 2016. En Copenhague, Rio no solo logró el título de "ciudad candidata", también superó a metrópolis con la envergadura de Chicago, Madrid y Tokio. Finalmente, tras casi ochenta años, conquistó el derecho de acoger los Juegos Olímpicos ${ }^{593}$.

Llamados a explicar lo sucedido, los expertos señalaron que algunos factores contribuyeron directamente en esa decisión. En 2009, Brasil ya era la octava economía mundial ${ }^{594}$. Contaba con la estabilidad política necesaria como para acoger al mega evento $^{595}$. Tenía la experiencia de haber organizado los Juegos Panamericanos de 2007, de estar representado por el presidente de la República Lula da Silva ${ }^{596}$, considerado uno de los políticos más carismáticos del planeta en ese momento ${ }^{597}$.

\footnotetext{
${ }^{590}$ BUARQUE DE HOLLANDA, Bernardo Borges; MEDEIROS, Jimmy; FONSECA, Vivian. op. cit., p. 45 .

591 Ibidem, p. 44.

592 Ibidem, p. 44-45.

593 Ibidem, p. 45.

594 PISANI, Silvia. Brasil ya es la octava economía mundial. La Nación. Disponible en : https://www.lanacion.com.ar/el-mundo/brasil-ya-es-la-octava-economia-mundial-nid1312483 Acceso en: 24 jun 2019.

595 SANTANDREU, Alba. Brasil inicia Ano Olímpico Cercado Por Crises. Exame. Disponible em: https://exame.abril.com.br/brasil/brasil-inicia-ano-olimpico-cercado-por-crises/Acceso en: 24 jun. 2019.

${ }^{596}$ BUARQUE DE HOLLANDA, Bernardo Borges; MEDEIROS, Jimmy; FONSECA, Vivian. op. cit., p. 50.

597 LULA é o cara diz Obama em reunião do G-20 em Londres. O Globo. Disponible em: http://g1.globo.com/Noticias/Economia Negocios/0, MUL1070378-9356,00-

LULA+E+O+CARA+DIZ+OBAMA+DURANTE+REUNIAO+DO+G+EM+LONDRES.html. Acceso en: 24 jun. 2019.
} 
La victoria en Copenhague fue conmemorada con mucha ilusión en la playa de Copacabana ${ }^{598}$. Artistas, literatos, exatletas, autoridades y la gente de a pie esperaban que los juegos pudieran ser responsables de grandes transformaciones en la ciudad. No sería un evento restringido únicamente a lo deportivo ${ }^{599}$, también creían que pudiera resolver los problemas de transporte ${ }^{600}$, falta de infraestructura ${ }^{601}$ y seguridad ciudadana que castigaban a sus vecinos a diario ${ }^{602}$. Al final del torneo, Rio se convertiría en una de las principales metrópolis del planeta ${ }^{603}$.

La expectativa ciudadana reflejó el discurso de las autoridades en esa materia. Todos insistían en que Rio recibiría grandes inversiones públicas y privadas a causa de las Olimpíadas. Los juegos serían responsables de grandes obras de infraestructura, movilidad urbana y recuperación ambiental, también permitiría la construcción de estadios, arenas y gimnasios olímpicos, que fomentarían una cultura en favor del deporte para las presentes y futuras generaciones.

Según las autoridades brasileñas, con motivo de los juegos, Brasil realizaría una serie de acciones destinadas a fomentar la práctica del deporte entre los jóvenes. La meta establecida fue de las más optimistas. Hasta el 2016, año de las Olimpíadas, tres millones (3.000.000) de niños y adolescentes en todo el país debieron practicar actividades deportivas con regularidad en las escuelas ${ }^{604}$.

\footnotetext{
${ }^{598}$ RIO 2016 - festa na Praia de Copacabana - Escolha do Rio como cidade sede dos jogos olímpicos 2016. Disponible em: https://www.youtube.com/watch?v=Y4fbFl6gc0M. Acceso en: 24 jun. 2016.

599 BARBASSA, Juliana. Brazil's Rollercoaster. In: ZIMBALIST, Andrew (ed.). Rio 2016: Olympic Myths, Hard Realities. Washington: Brookings Institution Press, 2017, p. 37-39.

${ }^{600}$ RUIZ, Rebecca: BELSON, Ken. El trafico de rio empeora a niveles olímpicos. New York Times. 2016. Disponible en: https:/www.nytimes.com/es/2016/08/19/nadie-puede-escapar-a-la-congestion-vehicularen-rio-de-janeiro-durante-las-olimpiadas/Acceso en: 25 jun. 2019.
}

${ }^{601}$ JACOBS, Andrew. After olympics, rio is altered if not reborn. New York Times. 2016. Disponible en: https://www.nytimes.com/2016/08/22/world/americas/rio-olympics.html Acceso en: 25 jun. 2019.

${ }^{602}$ BETIM, Felipe. La rutina de la violencia en rio perfora la burbuja olímpica. EI País. 2016. Disponible en: https://elpais.com/internacional/2016/08/08/actualidad/1470685327 182344.html Acceso en: 25 jun. 2019.

${ }^{603}$ MAZZEI, Leandro Carlos. E para o Esporte Brasileiro, Existe Luz no Fim do Túnel? Reflexões pós Jogos Olímpicos do Rio de Janeiro 2016. In: MARQUES, José Carlos; ROCCO JÚNIOR, Ary José. Leituras e Reflexões sobre os Jogos Olímpicos Rio-2016. São Paulo: Cultura Acadêmica, 2018, p. 204.

${ }^{604}$ BRASIL. Ministério dos Esportes. Cadernos de legado Rio 2016 reafirmam compromisso olímpico do Brasil. Brasília, DF: Ministério dos Esportes. Disponible en: http://www2.esporte.gov.br/snear/rio2016/. Acceso en: 06 nov. 2019. 
En lo urbanístico, el mega evento sería responsable de la regeneración de áreas degradadas y la implantación de nuevos sistemas de transporte (Bus Rapid Transtit). Se expandieron y mejoraron tanto el metro como los ferrocarriles municipales. A su vez, en lo ambiental, permitirían la recuperación de Rios, lagunas, cuencas hidrográficas, parques y bosques ${ }^{605}$.

El discurso optimista se inspiraba en las experiencias exitosas de ciudades como Roma (1960), Tokio (1964), Múnich (1972), Barcelona (1992) y Sídney (2000). Todas estas metrópolis, en mayor o menor extensión, lograron asociar los Juegos Olímpicos al desarrollo urbano de la ciudad y de hecho sacaron beneficios para la ciudadanía en su conjunto.

Estas no fueron las únicas preocupaciones de los brasileños. La elección de Rio como ciudad olímpica llamó la atención de la sociedad por el tema de las malas prácticas asociadas a los juegos. Hubo recelo de que las obras ejecutadas a causa del mega evento favorecieran la desviación de recursos públicos, lo que tenía sentido debido al largo historial de corrupción que siempre caracterizó la trayectoria política de Brasil ${ }^{606}$.

Esta preocupación tenía sentido, pues dos años antes que fuera elegida ciudad olímpica, Rio acogió los Juegos Panamericanos de 2007. Así como las Olimpíadas, el evento prometió grandes transformaciones tras su realización ${ }^{607}$. Debido a los juegos, todos creían que existiría una revolución en la política pública asociada al deporte y se realizarían grandes obras de infraestructura en la ciudad e inversiones en sanidad y educación, que constituiría el legado social del mega evento ${ }^{608}$. El torneo no trajo los beneficios que prometió, y al contrario de lo esperado, los juegos fueron responsables de un gran despilfarro de fondos públicos, provocando que los gastos estuvieran muy por encima del presupuesto original.

En comparación, el presupuesto facilitado a la Organización Deportiva Panamericana reveló que los juegos costarían a las arcas públicas doscientos cincuenta

\footnotetext{
${ }^{605}$ Ibidem.

${ }^{606}$ ROMEIRO, Adriana. Corrupção e Poder no Brasil: uma história, séculos XVI a XVIII. Belo Horizonte: Autêntica Editora, 2017, L. 76.

${ }^{607}$ DONHA, E. L.; BONIN, A. P. C.; MOSKI, D. Pan-americano 2007 e Olimpíadas 2016: legados compatíveis, complementares ou divergentes? EFDeportes.com. Disponible em: https://www.efdeportes.com/efd154/pan-americano-2007-e-olimpiadas-2016-legados.htm. Acceso en: 12 oct. 2007.

${ }^{608}$ Ibidem
} 
millones (250.000.000) de dólares ${ }^{609}$. Terminado el mega evento, los costes alcanzaron la extraordinaria cifra de dos mil millones (2.000.000.000) de dólares, ocho veces más de lo previsto por las autoridades brasileñas.

Asimismo, los gastos realizados convirtieron al evento en los juegos más caros de la historia hasta la fecha ${ }^{610}$. En este sentido, los Juegos Panamericanos Rio 2007 costaron a los brasileños más de las cinco ediciones anteriores del torneo. En otras palabras, los gastos con la preparación de los Juegos de Santo Domingo (2003), Winnipeg (1999), Mar del Plata (1995), la Habana (1991) e Indianápolis (1987), sumados, fueron inferiores a los dispendios en el torneo de Rio ${ }^{611}$.

Además, el estadio olímpico João Avelange, principal equipamiento de los juegos debería haber costado a las arcas públicas ciento noventa y dos (192.000.000) millones de dólares. Al final del mega evento, los gastos llegaron a un mil doscientos (1.200.000.000) millones de dólares, más de seis veces el presupuesto inicialmente establecido $^{612}$.

A pesar de los elevados costes, pasados siete años de las obras, la cobertura del estadio presentó serios problemas estructurales, según laudo técnico elaborado por el Consorcio Engenhão, formado por las constructoras Norberto Odebrecht y OAS, las mismas responsables de las obras para su edificación. El documento estableció que la cobertura del estadio se movía más allá de lo normal en períodos de fuertes rachas de viento. Debido a problemas en la ejecución de las obras, se corría el riesgo que la estructura cayera sobre los aficionados, presentes en el complejo olímpico para ver cualquier tipo de competencia ${ }^{613}$.

Asimismo, el estadio de Maracaná, pese a que también fue reformado para el torneo, presentó también problemas tras el mega evento y tuvo que ser completamente reconstruido con la finalidad de ser usado en la Copa del Mundo de Fútbol FIFA 2014.

\footnotetext{
${ }^{609}$ BOYKOFF, Jules. Power Games: A Political History of the Olympics. New York: Verso Editor, 2016, p. 213.

${ }^{610}$ BOYKOFF, Jules. op. cit., p. 213.

611 CARDOSO. Tom. Se Não Fosse o Cabral: A máfia que destruiu o Rio e assalta o país. São Paulo: Tordesilhas, 2018, L. 1784.

${ }^{612}$ BOYKOFF, Jules. op. cit., p. 213.

${ }^{613}$ CORRÊAS, Douglas. Prefeitura do Rio interdita Engenhão por problemas estruturais na cobertura. EBC. Disponible em: http://www.ebc.com.br/noticias/brasil/2013/03/prefeitura-do-rio-interdita-engenhao-porproblemas-estruturais-na-cobertura Acceso en: 12 oct. 2017.
} 
Las inversiones públicas, en este caso, llegaron a doscientos sesenta y dos millones quinientos mil (262.500.000) euros, aunque hubiese sospechas de sobrefacturación de precios por parte de las constructoras encargadas ${ }^{614}$.

Finalmente, la Villa Panamericana, constituida por diecisiete (17) edificios con un mil cuatrocientos (1.400) apartamentos, igual presentó serios problemas desde su construcción, la cual se erigió en un terreno con alta cobertura vegetal. La Villa demandaba de los responsables de las obras la adecuada preparación del suelo para que no presentara problemas estructurales en el futuro, en cuanto a los edificios, calles y avenidas.

Sin embargo, cuatro años después de la entrega de los apartamentos, a partir de 2011, los casi cinco mil (5.000) moradores se enfrentaron con enormes dificultades para seguir habitando la villa. Debido a errores en la ejecución de los proyectos arquitectónicos y de ingeniería, a diario muchas de las calles y avenidas se estaban hundiendo, lo que hizo que la vida en este lugar se convirtiera en un verdadero sufrimiento ${ }^{615}$.

Las obras de reparación son responsabilidad del Municipio de Rio de Janeiro y en principio, les costarían a las arcas públicas alrededor de cuatrocientos treinta y siete mil seiscientos (437.600) $\operatorname{euros}^{616}$, de no existir otros problemas ocultos que acaben con demandar nuevas inversiones.

Más allá de los problemas relativos a los Juegos Panamericanos, otros asuntos también preocupaban a los brasileños de cara a la realización de las Olimpíadas. Un día antes que Rio resultara elegida ciudad olímpica, el Parlamento brasileño aprobó la Ley núm. 12.035, de 01 de octubre de 2009, de institución del "Acto Olímpico"617, que trató de ofrecer garantías y estableció reglas especiales para la realización de las Olimpíadas.

\footnotetext{
${ }^{614}$ REFORMA do Maracanã teve aditivos suspeitos e gastos em duplicidade, diz TCE-RJ. Disponible em: https://g1.globo.com/rio-de-janeiro/noticia/reforma-do-maracana-teve-aditivos-suspeitos-e-gastos-emduplicidade-diz-tce-rj.ghtml, Acceso en: 12 oct. 2019.
}

${ }^{615}$ DOLZAN, Marcio. Jogos Pan-americanos do Rio deixam legado de problemas dez anos depois. 2017. Disponible em: https://esportes.estadao.com.br/noticias/jogos-olimpicos,jogos-pan-americanos-do-riodeixam-legado-de-problemas-10-anos-depois, 70001888108 Acceso en: 12 oct. 2019.

\section{Ibidem.}

617 BRASIL. Lei n. 12.035/2009, de $\mathbf{1}^{\mathbf{0}}$ de outubro de 2009. Institui o Ato Olímpico, no âmbito da administração pública federal, com a finalidade de assegurar garantias à candidatura da cidade do Rio de Janeiro a sede dos Jogos Olímpicos e Paraolímpicos de 2016 e de estabelecer regras especiais para a sua realização, condicionada a aplicação desta Lei à confirmação da escolha da referida cidade pelo Comitê Olímpico Internacional. Disponible en: http://www.planalto.gov.br/ccivil_03/_Ato20072011/2009/Lei/L12035.htm. Acceso en: 12 out 2019. 
Con arreglo a la esta ley, el gobierno se comprometió a destinar recursos públicos suficientes para soportar eventual gasto operacional por parte del Comité Organizador de los Juegos (CO-RIO), previa manifestación de los Ministerios de Deporte, Hacienda y Planificación. Las inversiones se destinaban a ofrecer las condiciones económicas para que las olimpíadas sucedieran de manera "satisfactoria y adecuada".

En otras palabras, con el objetivo de cumplir las exigencias fijadas por el COI, se incorporó al ordenamiento jurídico brasileño el compromiso de que el país diera soporte político y financiero al torneo ${ }^{618}$. En lo jurídico, este soporte se materializó por medio de una cláusula general: "eventual dispendio operacional de responsabilidad del Comité Organizador del Torneo".

La amplitud de la autorización rápidamente despertó el interés de órganos controladores como el Ministerio Público y el Tribunal de Cuentas ${ }^{619}$, los cuales temían que la autorización posibilitara el despilfarro de fondos públicos, siempre que no existiera un límite legal para los gastos operacionales del CO-RÍO de cara a la preparación de las Olimpíadas.

En comparación, siete años después, en 2016, con base en las mismas exigencias, el Primer Ministro Italiano Mario Monti, retiró la candidatura de Roma como ciudad sede de las olimpíadas de 2024, aunque hubiese estudios que indicasen los beneficios de estos juegos para la ciudad ${ }^{620}$. Según una investigación a cargo de la Universidad Tor Vergata de Roma, la realización de las olimpíadas de 2024 sería responsable de un aumento del Producto Interno Bruto (PIB) de Italia en cero con cuatro décimas porcentuales $(0,4 \%)$, además, de crear más de ciento setenta mil (170.000) nuevos puestos de trabajo, directos e indirectos ${ }^{621}$.

Sin embargo, tras examinar con cuidado las exigencias fijadas por el COI, el gobierno consideró que no sería conveniente ni oportuno realizar el mega evento. Los altos costes con la preparación de la ciudad, la posibilidad de que los dispendios

\footnotetext{
${ }^{618}$ CARTA OLÍMPICA, 2007, p. 73-74. Disponible en: http://www.olympic.org/olympic-studies-centercollections-official-publications-olympic-charters Acceso en: 25 jul. 2018.

${ }^{619}$ PUFF, Jefferson. TCU e MPF cobram acesso a contratos olímpicos e a orçamento do Comitê Rio 2016. BBC News. Disponible em: https://www.bbc.com/portuguese/noticias/2015/09/150904 rio legado questionado ip Acceso en: 28 jun. 2019.

${ }^{620}$ BOSIO, Roberto. Roma 2024: Un Affare per Pochi. Roma: Amazon, 2016, L. 21.

${ }^{621}$ Ibidem.
} 
ultrapasaran el presupuesto establecido y las graves consecuencias para los vecinos después de su realización no justificaban la aventura de organizarlo en su momento ${ }^{622}$.

Según un estudio dirigido por el profesor Wladimir Andreff de la Universidad de Sorbona, París, en 2012, los costes en la preparación de los Juegos Olímpicos suelen sobrepasar el período destinado para ello. La decisión de realizarlos no es de las más sencillas y tendría que ser claramente discutida con la ciudadanía, toda vez que podrá afectar una o más generaciones de ciudadanos ${ }^{623}$.

Esto ocurrió, por ejemplo, con motivo de los Juegos Olímpicos de invierno de 1968, disputados en Grenoble, Francia. A causa de los altos costes en la preparación del torneo, los vecinos tuvieron que pagarle al Municipio una tasa adicional por largos veinticuatro años, hasta 1992, destinada a cubrir los costes para la organización del mega evento ${ }^{624}$.

Ocho años después, los vecinos de Montreal y Quebec, fueron obligados a pagar tributos adicionales para cubrir los costes de las Olimpíadas de verano e invierno de 1976. En Montreal, las autoridades crearon una tasa especial que les costó a los vecinos ciento setenta y seis millones (176.000.000) de dólares. En Quebec, a su vez, hubo un aumento significativo de los impuestos relativos a la compraventa del tabaco, que les costó a los canadienses cuatrocientos ochenta millones (480.000.000) de dólares ${ }^{625}$.

De acuerdo con el profesor Wladimir Andreff, en Albert Ville 1992, los perjuicios con la preparación del mega evento costaron sesenta millones (60.000.000) de dólares y fueron pagados por medio de un aumento de cuatro (4\%) por ciento del impuesto sobre la propiedad de inmuebles ${ }^{626}$.

A pesar de todos los riesgos, Brasil sacó adelante su proyecto olímpico. Se comprometió en realizar todos los gastos necesarios a la preparación de los juegos para que sucedieran de manera "satisfactoria y adecuada", según las exigencias del COI ${ }^{627}$.

\footnotetext{
${ }^{622}$ Ibidem, L. 83.

${ }^{623}$ Ibidem, L 83.

${ }^{624}$ Ibidem, L. 140.

${ }^{625}$ Ibidem, L. 85.

${ }^{626}$ Ibidem, L. 153.

${ }^{627}$ OLYMPIC CHARTER 1949. op. cit.
} 
Las inversiones realizadas fueron divididas en tres partes: ${ }^{628}$

a)El presupuesto destinado a la realización de los Juegos;

b)Las relativas a la matriz de responsabilidades convenida con el COI; y

c)Las asociadas con políticas públicas desarrolladas con base al mega evento.

El presupuesto olímpico englobó los recursos directamente asociados con la organización de las Olimpíadas; la matriz de responsabilidades abarcó proyectos financiados con recursos públicos y privados asociados al mega evento (como la construcción del parque olímpico); mientras que las inversiones asociadas a políticas públicas comprendieron grandes obras de infraestructura (como la construcción del Bus Rapid Transit System, la urbanización de favelas y la construcción del arco vial metropolitano).

Asimismo, los Juegos fueron realizados en cuatro regiones de la ciudad de Rio de Janeiro (Deodoro, Copacabana, Maracanã y Barra de la Tijuca), repitiéndose el modelo adoptado en otras ciudades olímpicas como Barcelona. La idea fue, en este caso, utilizar las Olimpíadas como instrumento para promover el desarrollo de diferentes regiones de Rio de Janeiro. ${ }^{629}$

En el ámbito jurídico, con la intención de que los Juegos se produjesen de forma "satisfactoria y adecuada", el COI solicitó al gobierno brasileño que aprobara Leyes que facilitaran la contratación pública y limitaran la presentación de recursos en los Tribunales en el caso de una compañía quedase eliminada en las licitaciones realizadas con motivo de las Olimpíadas. ${ }^{630}$

Apenas Rio de Janeiro conquistó el derecho de acoger las Olimpíadas, el Parlamento brasileño realizó varias alteraciones en las reglas de contratación pública con la excusa de crear condiciones jurídicas y económicas favorables a la realización del torneo. Se creó un régimen diferenciado de contratación para las obras de la Copa del

\footnotetext{
${ }^{628}$ SÁNCHEZ, Renata Latuf de Oliveira; ESSEX, Stephen. Architecture and Urban Design: The Shaping of Rio 2016 Olympic Legacies. In: ZIMBALIST, Andrew. Rio 2016: Olympic Myths, hard realities, Washington D.C.: Brounkings Institution Press, 2017, p. 100-101.

${ }^{629}$ Ibidem. p. 100-101.

${ }^{630}$ CHADE, Jamil Strictly Confidential: Access to Information and the Media in Rio. In: ZIMBALIST, Andrew. Rio 2016: Olympic Myths, hard realities, Washington D.C.: Brounkings Institution Press, 2017, p. 126.
} 
Mundo de Fútbol FIFA 2014 y las Olimpíadas Rio 2016 ${ }^{631}$. Además, se planteó un nuevo objetivo para las licitaciones brasileñas, que consistió en promover el desarrollo nacional.

Cuatro años antes que comenzara la Copa del Mundo de Fútbol FIFA 2014, el Poder Ejecutivo Brasileño dictó las Medidas Provisorias núm. 488/2010 ${ }^{632}$ y núm. 489/2010 ${ }^{633}$, creando un régimen diferenciado de contratación pública para las obras necesarias en la preparación del campeonato mundial de fútbol y los Juegos Olímpicos y paralímpicos Rio 2016. En líneas generales, ambas medidas presentaron exigencias y controles más flexibles de los previstos para las contrataciones normales y corrientes del poder público.

Hasta que fueron dictadas estas medidas provisorias, como norma general, las licitaciones públicas brasileñas se reglaban por medio de la Ley núm. $8.666,{ }^{634}$ de 21 de junio de 1993, de Licitaciones y Contratos Administrativos, establece que, por lo general, las contrataciones públicas brasileñas poseen dos momentos fundamentales relativos a su realización. Se trata de la elaboración tanto del proyecto básico como del proyecto ejecutivo de la obra o servicio ${ }^{635}$.

El proyecto básico contiene los elementos necesarios y suficientes que caracterizan la obra o servicio objeto de la licitación. El referido proyecto es elaborado con apego a los estudios preliminares realizados por la Administración en esa materia y que demuestran la viabilidad técnica, financiera y ambiental del emprendimiento. Por ello, el proyecto básico indicará los costes para la realización de la obra o servicio, con expresa

${ }^{631}$ BICALHO, Alécia Paolucci Nogueira. MOTTA, Carlos Pinto Coelho. RDC - Comentários ao Regime Diferenciado de Contratações: lei n. 12.462/2011; Decreto n. 7.581/2011. 2. ed., Belo Horizonte, Fórum: 2014, L. 438.

${ }^{632}$ BRASIL. Medida Provisória n. 488, de 12 de maio de 2010. Autoriza a criação da Empresa Brasileira de Legado Esportivo S.A. Brasil 2016 e dá outras providências. Disponible em: http://www.planalto.gov.br/ccivil 03/ Ato2007-2010/2010/Mpv/488.htm Acceso en: 27 jun. 2019..

${ }^{633}$ BRASIL. Medida Provisória n. 489, de 12 de maio de 2010. Autoriza a União a integrar, na forma de consórcio público de regime especial, a Autoridade Pública Olímpica - APO, e dá outras providências. Disponible em: http://www.planalto.gov.br/ccivil 03/ Ato2007-2010/2010/Mpv/489.htm Acceso en: 27 jun. 2019.

634 BRASIL. Lei n. 8.666/1993, de 21 de junho de 1993. Regulamenta o art. 37, inciso XXI, da Constituição Federal, institui normas para licitações e contratos da Administração Pública e dá outras providências. Disponible en: http://www.planalto.gov.br/ccivil_03/leis/18666cons.htm Acceso en: 27 jun. de 2019.

${ }^{635}$ CARVAlho Filho, José dos Santos. Manual de Direito Administrativo. 33. ed. São Paulo, Atlas: 2019, p. 187. 
referencia al presupuesto y sus partidas, asociado a cada material o servicio utilizado en el emprendimiento. ${ }^{636}$

Al aprobar el proyecto básico, la Administración Pública será apta para realizar la licitación y contratar la empresa responsable de la ejecución de la obra o prestación del servicio $^{637}$, lo que deberá acontecer de conformidad con los parámetros establecidos. El autor del proyecto básico no podrá, por tanto, participar de la ejecución del proyecto ejecutivo $^{638}$.

Ahora bien, el régimen de licitaciones que separa tanto la responsabilidad de la elaboración del proyecto básico como del proyecto ejecutivo recibió muchas críticas de algunos sectores de la comunidad jurídica brasileña, en particular, aquellos que se dedican a la lucha contra la corrupción. Señalando que los errores técnicos de muchos proyectos básicos en materia de licitación favorecían la mala elección de contratos perfeccionados de obras públicas, con la consecuente sobrefacturación de los precios y el despilfarro de fondos.

Con el objetivo de resolver estos problemas, las Medidas Provisorias núm. 488/2010 y núm. 489/2010, trataron de modificar este régimen y establecer que el contratista sería responsable de la elaboración del proyecto básico y del proyecto ejecutivo a la vez. La idea sería que, como ejecutor del proyecto básico, la empresa no podría imputar a la Administración Pública los errores técnicos de la propuesta. Por consiguiente, tampoco podría reivindicar los vicios en los contratos de obra o servicio. En teoría, por tanto, ya no habría sobrefacturación de precios ni despilfarro de fondos.

Apenas fueron publicadas las dos medidas provisorias la crítica no tardó en aparecer y los expertos señalaron que, a partir del nuevo régimen, la sobrefacturación de precios ya no se presentaría como vicio en los contratos de obra o servicio, sino que se incorporaría al propio proyecto básico elaborado por la empresa. En otras palabras, quien elaboraría el proyecto básico ya debía conocer la sobrefacturación de precios e impondría esta circunstancia en la Administración Pública.

\footnotetext{
${ }^{636}$ Art. $6^{\circ}$, IX cf. BRASIL. Lei n. 8.666/1993, de 21 de junho de 1993. Regulamenta o art. 37, inciso XXI, da Constituição Federal, institui normas para licitações e contratos da Administração Pública e dá outras providências. Disponible en: http://www.planalto.gov.br/ccivil 03/leis/18666cons.htm Acceso en: 27 jun. de 2019.

${ }^{637}$ Art. $1^{\circ}$, parágrafo $2^{\circ}$, I. Ibidem.

${ }^{638}$ Art. $9^{\circ}$. Ibidem.
} 
La censura generalizada acabó con influenciar la decisión del Parlamento. Las medidas provisorias no fueron aprobadas como se esperaba, quizás porque en el 2010, hubo elecciones generales en Brasil y ningún Diputado o Senador quería enfrentarse con a responsabilidad de aceptar un proyecto que, en teoría, disminuía el control de las contrataciones públicas.

Al año siguiente al tomar posesión de sus cargos los nuevos Senadores y Diputados en el Parlamento aprobaron la Medida Provisoria núm. 527/2011, convertida en la Ley núm. 12.462, de 04 de agosto de 2011, responsable de instituir el Régimen Diferenciado de Contratación Pública ${ }^{639}$.

Si bien con algunas diferencias, la ley trató de reproducir el régimen que figuraba en las Medidas Provisorias núm. 488/2010 y núm. 489/2010, más bien en lo relativo a la transferencia de responsabilidad a las empresas, de elaborar el proyecto básico y el proyecto ejecutivo. La normativa tenía como objeto la construcción de estadios de fútbol y equipamientos que serían usados en la Copa del Mundo FIFA 2014 y también para los Juegos Olímpicos y Paralímpicos Rio 2016.

La repetición del modelo recibió duras críticas de la comunidad jurídica y demás colectivos dedicados a la lucha contra la corrupción. En líneas generales, todos insistieron en la transferencia de la responsabilidad a contratistas, en cuanto a la producción del proyecto básico, lo cual terminó en favorecer la realización de malas prácticas ${ }^{640}$.

Otro aspecto que recibió críticas fue la falta de transparencia de costes estimados en la ejecución del proyecto. La ley admite, en este caso, que el presupuesto para la contratación sea publicado inmediatamente tras el cierre de la licitación, es decir, cuando

\footnotetext{
${ }^{639}$ BRASIL. Lei n. 12.462/2011, de 4 de agosto de 2011. Institui o Regime Diferenciado de Contratações Públicas - RDC; altera a Lei $\mathrm{n}^{\circ} 10.683$, de 28 de maio de 2003, que dispõe sobre a organização da Presidência da República e dos Ministérios, a legislação da Agência Nacional de Aviação Civil (Anac) e a legislação da Empresa Brasileira de Infraestrutura Aeroportuária (Infraero); cria a Secretaria de Aviação Civil, cargos de Ministro de Estado, cargos em comissão e cargos de Controlador de Tráfego Aéreo; autoriza a contratação de controladores de tráfego aéreo temporários; altera as Leis $\mathrm{n}^{\mathrm{o}} \mathrm{s} 11.182$, de 27 de setembro de 2005, 5.862, de 12 de dezembro de 1972, 8.399, de 7 de janeiro de 1992, 11.526, de 4 de outubro de 2007, 11.458, de 19 de março de 2007, e 12.350, de 20 de dezembro de 2010, e a Medida Provisória $\mathrm{n}^{\circ}$ 2.185-35, de 24 de agosto de 2001; e revoga dispositivos da Lei $\mathrm{n}^{\circ} 9.649$, de 27 de maio de 1998. Disponible en: http://www.planalto.gov.br/ccivil_03/_Ato2011-2014/2011/Lei/L12462.htm Acceso en: 30 nov. 2019.

${ }^{640}$ CONSELHO DE ARQUITETURA E URBANISMO DE SÃO PAULO. Autor da Lei de Licitações: "RDC propicia a corrupção e a injustiça". Disponible em: https://www.causp.gov.br/autor-da-lei-delicitacoes-rdc-propicia-a-corrupcao-e-a-injustica/. Acceso en: 26 jun. 2019.
} 
todo el procedimiento ya hubiese concluido ${ }^{641}$, aunque los órganos de control y fiscalización podrán acceder al presupuesto antes de su divulgación.

Considerando estas debilidades, los expertos trataron de defender un cambio en las reglas, exactamente para que no sucedieran irregularidades en las olimpíadas como las identificadas en los Juegos Panamericanos Rio 2007, cuando los fondos públicos acabaron convertidos en ganancias privadas ${ }^{642}$.

Otra alteración que no agradó a la comunidad jurídica fueron los cambios promovidos por la Ley núm. 12.439 , de 15 de diciembre de $2010^{643}$. La normativa prevé una nueva finalidad para las licitaciones públicas brasileñas. Con base en la aludida ley, más allá de buscar las condiciones más ventajosas para el interés público, las licitaciones también deberán preocuparse en promover el desarrollo nacional.

Hasta que se promulgara la aludida ley, las licitaciones a cargo de las Administraciones Públicas brasileñas siempre se destinaron a satisfacer alguna necesidad de los órganos y entidades que forman parte del Estado. La licitación tuvo desde esta perspectiva, carácter instrumental, toda vez que posibilita atender las necesidades de la Administración Pública ${ }^{644}$.

La alteración realizada con base en la Ley núm. 12.439/2010, cambió esta realidad, la previsión de la licitación igual se destina a promover el desarrollo nacional, aunque es

\footnotetext{
${ }^{641}$ Art. $6^{\circ}$. Cf. BRASIL. Lei n. 12.462/2011, de 4 de agosto de 2011. Institui o Regime Diferenciado de Contratações Públicas - RDC; altera a Lei n ${ }^{\circ} 10.683$, de 28 de maio de 2003, que dispõe sobre a organização da Presidência da República e dos Ministérios, a legislação da Agência Nacional de Aviação Civil (Anac) e a legislação da Empresa Brasileira de Infraestrutura Aeroportuária (Infraero); cria a Secretaria de Aviação Civil, cargos de Ministro de Estado, cargos em comissão e cargos de Controlador de Tráfego Aéreo; autoriza a contratação de controladores de tráfego aéreo temporários; altera as Leis $n^{\circ} \mathrm{s} 11.182$, de 27 de setembro de 2005, 5.862, de 12 de dezembro de 1972, 8.399, de 7 de janeiro de 1992, 11.526, de 4 de outubro de 2007, 11.458, de 19 de março de 2007, e 12.350, de 20 de dezembro de 2010, e a Medida Provisória $\mathrm{n}^{\circ}$ 2.185-35, de 24 de agosto de 2001; e revoga dispositivos da Lei $\mathrm{n}^{\circ}$ 9.649, de 27 de maio de 1998. Disponible en: http://www.planalto.gov.br/ccivil 03/_Ato2011-2014/2011/Lei/L12462.htm Acceso en: 30 nov. 2019.
}

${ }^{642}$ BOYKOFF, Jules. op. cit., p. 214.

${ }^{643}$ BRASIL. Lei n. 12.439/2010, de 15 de dezembro de 2010. Altera as Leis nos 8.666 , de 21 de junho de 1993, 8.958, de 20 de dezembro de 1994, e 10.973, de 2 de dezembro de 2004; e revoga o $§ 1^{10}$ do art. $2^{\circ}$ da Lei no 11.273, de 6 de fevereiro de 2006. Disponible en: http://www.planalto.gov.br/ccivil_03/_Ato20072010/2010/Lei/L12349.htm. Acceso en: 08 oct. 2019.

${ }^{644}$ FURTADO, Lucas Rocha. Curso de Direito Administrativo. 4 ed., Belo Horizonte, Fórum: 2013, L. 10.713 . 
uno de los objetivos de la República Federativa de Brasil ${ }^{645}$, ha dado al instituto una finalidad sustantiva que nunca ha existido ${ }^{646}$. En este sentido, una interpretación literal del dispositivo da la posibilidad de que las Administraciones Públicas realicen licitaciones, sin el objetivo de satisfacer las necesidades de los órganos y entidades públicas, sino para fomentar el desarrollo nacional ${ }^{647}$.

Asimismo, en cuanto a la prevención de la corrupción, los expertos temían que los nuevos objetivos de la licitación, o sea, la búsqueda del desarrollo nacional pudiera implicar una reserva de mercado en favor de las grandes constructoras brasileñas, que en principio, serían ellas las grandes responsables de generar empleo y fomentar la actividad económica en todo el país.

Aclarando las dudas en torno a los nuevos objetivos de la licitación, el Tribunal de Cuentas de la Unión (TCU) de Brasil, con motivo del juzgamiento del proceso TC002.481/2011-1 ${ }^{648}$, creó un grupo de expertos para estudiar los impactos de la Ley núm. 12.439, de 15 de diciembre de 2010, sobre las contrataciones públicas. En definitiva, la Corte buscó dilucidar si, a partir de la promulgación de la ley, las Administraciones Públicas deberían preferir adquirir productos o servicios suministrados por sociedades brasileñas $^{649}$.

Infelizmente, no se llegó a una conclusión antes que comenzaran muchas de las obras de preparación de los Juegos Olímpicos Rio 2016. En consecuencia, la Ley núm. 12.439, de 15 de diciembre de 2010, se mantuvo en vigor con motivo de la ejecución de grandes construcciones asociadas al mega evento, así como la Ley núm. 12.035, de 01 de octubre de 2009, y la Ley núm. 12.462, de 04 de agosto de 2011, aunque existían manifestaciones de varios órganos y entidades en cuanto a los riesgos que representaban para la prevención de las malas prácticas administrativas.

\footnotetext{
${ }^{645}$ Art. $1^{\circ}$, inciso III. Cf. BRASIL. [Constituição (1988)].Constituição da república Federativa do Brasil de 1988. Brasília, DF: Presidência da República. Disponible en: http://www.planalto.gov.br/ccivil_03/Constituicao/Constituicao.htm. Acceso en: 08 oct. 2019.

${ }^{646}$ FURTADO, Lucas Rocha. op. cit., L. 10.713.

${ }^{647}$ Ibidem, L. 10.713.

${ }^{648}$ BRASIL. Tribunal de Contas da União. Ata n. 35 de 24 de agosto de 2011. Brasília, DF: Tribunal de Contas da União [2011]. Disponible em: http://www.tcu.gov.br/Consultas/Juris/Docs/CONSES/TCU_ATA_0_N_2011_35.pdf Acceso en: 12 out. 2019.

${ }^{649}$ FURTADO, Lucas Rocha. op. cit., L. 10.740.
} 
Co la finalidad de calmar a los críticos, tres meses posteriores a la sanción de la Ley núm. 12.462, de 04 de agosto de 2011, el Parlamento brasileño aprobó la Ley núm. 12.527, de 18 de noviembre de 2011, de Transparencia y Acceso a la Información ${ }^{650}$. Como cualquier otra normativa de esta naturaleza, la ley brasileña impuso la publicidad de los actos de la Administración Pública como regla y el secreto como excepción, buscando divulgar todos los gastos realizados con motivo de las olimpíadas y prevenir las malas prácticas con frecuencia asociadas a los juegos. Fortalecería, en este caso, los principios de responsabilidad, máxima divulgación, participación, buena fe y universalidad.

Asimismo, las normas que impone el deber de transparencia no actúan solas. Se conjugan a otras normas jurídicas para que puedan cumplir con su labor de prevenir la corrupción. Se destacan, en este caso, las relativas a la contratación pública, directamente vinculadas a la preparación de los juegos olímpicos y las relativas a la probidad administrativa, que demandan de los administradores públicos transparencia de criterios y procedimientos al frente de la gestión de los intereses públicos.

A pesar de toda reglamentación entorno al control de la contratación pública en la preparación de las Olimpíadas Rio 2016, la Ley núm. 12.527/2011, de Transparencia y Acceso a la Información y la Ley núm. 8.666/1993, de Licitaciones y Contratos Administrativos, no incorporaron entre sus dispositivos herramientas necesarias para enfrentar la corrupción asociada a los juegos.

Entre otros asuntos, las normativas no previeron la divulgación de agendas de los altos directivos de la Administración Pública, las retribuciones que cobraban fuera del cargo público y lo referente a los debates que antecedieron a la elaboración de los pliegos destinados a contratar entidades encargadas de las obras asociadas a su realización.

Tampoco incorporaron a los contratistas de la Administración Pública como sujetos obligados al deber de transparencia activa, lo que ha permitido que muchos empresarios deshonestos utilizaran contratos ficticios para sacar recursos de las compañías que comandaban y pudieran entregarlos a políticos y altos funcionarios de la Administración Pública, de conformidad con lo previamente pactado. Durante estos encuentros, políticos

\footnotetext{
${ }^{650}$ BRASIL. Lei n. 12.527, de 18 de novembro de 2011. Regula o acesso a informações previsto no inciso XXXIII do art. 5o , no inciso II do § 3o do art. 37 e no § 20 do art. 216 da Constituição Federal; altera a Lei no 8.112, de 11 de dezembro de 1990; revoga a Lei no 11.111, de 5 de maio de 2005, e dispositivos da Lei no 8.159, de 8 de janeiro de 1991; e dá outras providências. Disponible en: http://www.planalto.gov.br/ccivil 03/ ato2011-2014/2011/lei/112527.htm Acceso en: 8 mayo 2014.
} 
y empresarios establecieron criterios especiales para la licitación de obras vinculadas a las olimpíadas, fijando el precio de la ventaja indebida y la forma como ocurrió su pago.

Esta omisión legislativa creó espacios de oscuridad, sirviendo de abrigo para personas deshonestas y que a menudo buscaban esconder sus malas prácticas detrás de conductas que, en apariencia, se presentan conforme al derecho.

Las irregularidades comenzaron, en este caso, desde la elección de la ciudad como sede olímpica y se extendieron a las principales obras de infraestructura y de recuperación ambiental asociadas a los juegos, con lo cual se puso de manifiesto las fragilidades del régimen de transparencia y acceso a la información en Brasil.

\subsection{Los pactos perfeccionados para que Rio fuera elegida ciudad anfitriona de las olimpiadas de 2016}

Los juegos olímpicos siempre despiertan el interés de las grandes ciudades alrededor del planeta. Desde que fueron restaurados en Atenas (1896), muchas de las principales metrópolis presentaron su candidatura con el objetivo de acoger al mega evento. Por lo general, todas buscaron con el torneo alcanzar una mayor visibilidad en el escenario global y atraer inversiones a sus países.

Este movimiento se acentuó a partir de los años sesenta del siglo XX, exactamente tras incorporarse la televisión a las olimpíadas. Desde este momento, los juegos olímpicos se convierten en una importantísima herramienta de transformación de las ciudades, utilizándolos para viabilizar la nueva gestión de los espacios urbanos ${ }^{651}$.

Este creciente protagonismo de la ciudad acabó en consagrar un modelo de gestión neoliberal que los expertos califican como emprendedor o empresarial y que es responsable de un cambio en la manera como se administra la ciudad ${ }^{652}$, la cual no es gestionada con arreglo a criterios meramente administrativos y sociales, sino bajo un régimen empresarial, debido a que las autoridades deberán incentivar la realización de grandes obras que promuevan la actividad económica en los centros urbanos ${ }^{653}$.

\footnotetext{
${ }^{651}$ MASCARENHAS, Gilmar. Cidade mercadoria, cidade-vitrine, cidade turística: a espetacularização do urbano nos megaeventos esportivos. Caderno Virtual de Turismo, v. 14, n. 1, nov. 2014, p. 52-53. Disponible en: http://www.redalyc.org/articulo.oa?id=115437784005 Acceso en: 13 mayo 2018.

${ }^{652}$ HARVEY, David. A produção capitalista do espaço. 2. ed. São Paulo: Annablume, 2005, p. 164.

${ }^{653}$ MASCARENHAS, Gilmar. op. cit., p. 54.
} 
Tal régimen se inició en los años sesenta y logró especial importancia a partir de los años ochenta del siglo XX, cuando la gestión empresarial de la ciudad fue considerada la solución para la llamada crisis de la restructuración productiva ${ }^{654}$. Con base en estas ideas, el desarrollo de la ciudad estuvo directamente conectado a la construcción de centros comerciales, museos, complejos turísticos y de ocio, además, la regeneración de lugares históricos ${ }^{655}$.

El régimen de gestión empresarial también buscó acercarse a la realización de los mega eventos deportivos internacionales, como la Copa del Mundo de Fútbol y los juegos olímpicos, entendidos como un ambiente favorable a la edificación de grandes construcciones, tales como modernos estadios y futuristas arenas, además, serían responsables de erigir grandes centros de negocios, aeropuertos, hoteles de lujo y viviendas, que transformarían la imagen de la ciudad, demandando muchas inversiones públicas para su realización ${ }^{656}$.

La posibilidad de invertir grandes cantidades de dinero en un corto período de tiempo llamó la atención de políticos y empresarios alrededor del planeta. Todos ellos rápidamente trataron de presentar la candidatura de las ciudades ubicadas en su área de influencia a modo de acoger los juegos olímpicos y disfrutar de los beneficios que su realización podría proporcionar ${ }^{657}$. En otras palabras, las transformaciones urbanas de la ciudad se convirtieron en una oportunidad para impulsar sus carreras y realizar excelentes negocios ${ }^{658}$, con lo cual no habría límites para lograr el derecho de acoger a estos mega eventos.

De acuerdo con esta premisa, políticos y empresarios de diferentes lugares alrededor del planeta acabaron involucrándose en grandes escándalos de corrupción. En definitiva, las malas prácticas se materializaron a través del ofrecimiento de ventajas indebidas a miembros del COI para que votaran a favor de la ciudad que representaban.

\footnotetext{
${ }^{654}$ FERREIRA, João Sette Whitaker. op. cit., p. 9-10.

${ }^{655}$ MASCARENHAS, Gilmar. op. cit., p. 54.

${ }^{656}$ MARICATO, Ermínia. op. cit., p. 36.

${ }^{657}$ JACOBS, Andrew. op. cit., p. 112.

${ }^{658}$ HORNE, John. Whannel, Garry. Understanding the Olympics. 2. ed. New York: Routledge, 2016, L. 425.
} 
Las conductas ilícitas se hicieron públicas por primera vez con motivo de la elección de South Lake City como ciudad sede de las Olimpíadas de invierno de 2002. De acuerdo con las investigaciones a cargo del Departamento de Justicia de Estados Unidos, Thomas Welch y David Johnson, presidente y vicepresidente del COI, respectivamente, autorizaron recursos de una cuenta secreta de la entidad para que se ofrecieran "regalos" a miembros del COI, a modo de que votaran a favor de la ciudad como sede de los juegos olímpicos de invierno de 2002.

En este sentido, el chileno Sergio Santander cobró diez mil (10.000) dólares para la financiación de su campaña como alcalde de Santiago, mientras que el ministro de deportes de Sudán, Abdel Gadir, recibió veinticinco mil (25.000) dólares por su voto. A su vez, Lamine Keitan, representante de Maldivas, fue beneficiado con cien mil (100.000) dólares y el ecuatoriano Agustín Arroyo, más allá de recibir igual ventaja, también solicitó un empleo para su hermana en el Utah Departament of Economic Development y en el Comité Olímpico local. Finalmente, Jean Claude Ganga, representante de la República del Congo, cobró ciento quince mil (115.000) dólares por su apoyo ${ }^{659}$.

Asimismo, las investigaciones revelaron que el soborno practicado con motivo de la elección de South Lake City no se trataba de un hecho aislado. Veinte años antes, miembros del COI solían recibir, directa o indirectamente, alguna ventaja económica para apoyar determinadas candidaturas, además de que los pagos se encubrían como gastos de hospedaje, donaciones de carácter filantrópico y comodidades en viajes internacionales ${ }^{660}$.

Además, Atlanta (1996), gastó siete millones trescientos mil (7.300.000) dólares en hospedaje, con lo cual se sospechó que los recursos fueron utilizados para sobornar a miembros del COI y asegurar la elección de la ciudad como sede de las olimpíadas del centenario, sin embargo, las dudas nunca se confirmaron a causa de una decisión de la Corte de Cuentas de Georgia, que decidió que los archivos relativos a tales gastos no se someterían a la Open Record Act, una especie de ley de transparencia local ${ }^{661}$.

Además, las investigaciones revelaron, que Nagoya (1998), gastó veintitrés (23.000.000\$) millones de dólares en hospedaje y ofreció comodidades atípicas a

\footnotetext{
${ }^{659}$ GOLDBLATT, David. op. cit., p. 374-375.

${ }^{660}$ Ibidem, p. 372.

${ }^{661}$ Ibidem.
} 
miembros del COI por su visita a la ciudad, como el traslado del presidente del COI y toda su comitiva desde el aeropuerto de Tokio hasta Nagoya en un tren exclusivo, ventaja que jamás disfrutó ninguna de las ediciones anteriores.

Las sospechas de corrupción se hicieron más evidentes cuando un empresario local, Yoshiaki Tsutsumi, donó un millón (1.000.000) de dólares a los proyectos personales del presidente del COI relativos al cuidado de pequeños animales, más allá de otros diecinueve (19.000.000) millones de dólares donados al museo olímpico en Lausana ${ }^{662}$.

Cuando el escándalo de South Lake City fue revelado, las autoridades japonesas pidieron al Comité Olímpico de Japón que presentara los archivos correspondientes a las Olimpíadas de Nagoya, con objeto de aclarar las sospechas de corrupción en lo relativo a la elección de la ciudad como sede de los juegos olímpicos. Sin embargo, pese a la solicitud, los archivos no fueron presentados, una vez que todos los documentos relativos a la candidatura de la ciudad fueron quemados durante un incendio tras el mega evento ${ }^{663}$.

Finalmente, las investigaciones estadounidenses revelaron que la compraventa de votos se realizó con motivo de las Olimpíadas de Sídney 2000. En este caso, la hija del presidente de la FIFA, el suizo Joseph Blatter, miembro del COI, logró un empleo en Australia poco tiempo antes que comenzaran los juegos. Asimismo, el cuñado del rumano Alexandro Spicro, otro miembro del COI, consiguió un empleo por la elección de la ciudad. Posteriormente se reveló que, por escoger la ciudad australiana como sede de las olimpíadas, fueron pagados cincuenta mil (50.000) dólares a los Comités Olímpicos de Kenia y Uganda, para que apoyaran la candidatura de Sídney ${ }^{664}$.

Las irregularidades cometidas en la elección de otras ciudades anfitrionas se repitieron en las Olimpíadas de Rio. En febrero de 2017, el Ministerio Público Financiero francés envió al Ministerio de Justicia brasileño un pedido de cooperación internacional en materia criminal (pedido núm. 16.133.000.600) ${ }^{665}$. Con la solicitud, el Ministerio Público buscó informaciones con respecto a un gran esquema de corrupción, en el cual

\footnotetext{
${ }^{662}$ Ibidem.

${ }^{663}$ Ibidem.

${ }^{664}$ Ibidem, p. 374.

${ }^{665}$ BRASIL. Tribunal Regional Federal (2 Região). Processo n. 0196181-09.2017.4.02.5101 Disponible en: https://www.jfrj.jus.br Acceso en: 12 oct. 2019
} 
resultaron involucrados miembros de la Federación Internacional de Atletismo y de la Agencia Mundial Antidopaje.

Según el Ministerio Público francés, altos directivos de ambas entidades aceptaron sobornos para encubrir casos por dopaje en atletas rusos dedicados al atletismo, lo que caracteriza una infracción penal para fines del derecho francés ${ }^{666}$. Entre los implicados estuvo el senegalés Papa Massata Diack, hijo de Lamine Diack, presidente de la Federación Internacional de Atletismo. Al declarar junto a las autoridades francesas, Lamine Diack reveló que hubo un esquema destinado a ocultar los casos de doping de atletas rusos vinculados al atletismo, asimismo, esclareció que, por causa del encubrimiento, la Federación Internacional de Atletismo, logró la renovación del contrato de patrocinio con el banco ruso $\mathrm{VTN}^{667}$.

Además, las autoridades francesas descubrieron que Lamine Diack no solo cobraba sobornos a cambio de ocultar casos de dopaje relativos al atletismo. El africano también aceptaba ventajas indebidas, a modo de apoyar la candidatura de determinadas ciudades, como sede de grandes eventos deportivos internacionales.

Lamine Diack recibió pagos indebidos de su hijo Papa Massata Diack para que apoyara la elección de las ciudades sedes de la Copa del Mundo de las Naciones de Atletismo de 2006, finales del Campeonato Mundial de Atletismo de 2006 y 2008, Campeonatos Mundiales de Atletismo de 2015, 2017, 2019, 2021, finalmente de las ciudades anfitrionas de las Olimpíadas de 2016 y 2020 (Oficio núm. 818/2017/ACRIM/SCI/PGR, PP. 14-15 y 34-35) $)^{668}$.

Asimismo, el Ministerio Público francés analizó las operaciones financieras vinculadas a las cuentas corrientes de Papa Massata Diack e identificó que el 23 de septiembre de 2009, la sociedad Matlock Capital Group Limited, con sede en las Islas Vírgenes Británicas, realizó por medio de la cuenta UBSWUS33, una transferencia de dos millones de (2.000.000) dólares para una cuenta de su titularidad en la Société Générale en Fontenay Sous Bois, Francia ${ }^{669}$.

\footnotetext{
666 Ibidem.

667 Ibidem.

${ }^{668}$ Ibidem.

669 la transferencia fue realizada, en este caso, en favor de la cuenta corriente FR7630003030020005262876644 AG CLIENTELA PRIVADA ITL- REF-MOTIT DESPESAS DE CONSULTORIA VTB. Cf. Ibidem.
} 
Cinco días después, el 28 de septiembre de 2009, siguiendo las reglas de prevención del blanqueo de capitales vigentes en Francia, la Société Générale, tras verificar el monto de la transferencia, rechazó el dinero y restituyó a la cuenta de la sociedad Matlock Capital Group Limited en las Islas Vírgenes Británicas el importe de un millón novecientos mil (1.900.000) dólares. Una vez que recibió el dinero, el 29 de septiembre de 2009, con el objetivo de asegurar que los recursos llegaran a Papa Massata Diack lo más breve posible, la sociedad Matlock Capital Group Limited realizó, entonces, desde una cuenta en Miami, dos transferencias a favor de la Société Générale, ubicadas en Rusia y Senegal ${ }^{670}$.

La primera transferencia por quinientos mil (500.000) dólares fue realizada a favor de la Société Générale Vostok en Moscú ${ }^{671}$. A su vez, la segunda, de un millón quinientos mil (1.500.000) dólares, fue destinada a la Société Générale Branques Au, en Senegal, para una cuenta con titularidad de la sociedad Pamodzi Consulting, ${ }^{672}$ gestionada por Papa Massata Diack.

La magnitud de los ingresos y el hecho de que tan solo tres días después, el 02 de octubre de 2009, sería la elección de la ciudad anfitriona de los juegos olímpicos de 2016, hizo que el Ministerio Público francés solicitara la cooperación internacional al Ministerio de Justicia brasileño y al Ministerio Público brasileño a modo de identificar si autoridades locales estaban involucradas en el soborno de miembros del COI, al ser nombrado Rio de Janeiro como sede de las olimpíadas.

Con tales informaciones, el Ministerio Público brasileño inició su propia investigación a modo de aclarar los hechos. A partir de documentos suministrados por autoridades de Antigua y Barbuda, verificó que la sociedad Matlock Capital Group Limited no solo tenía sede administrativa en las Islas Vírgenes Británicas, sino también que su principal socio fue el empresario brasileño Arthur Soares, quien de hecho hizo la transferencia de dos millones (2.000.000) de dólares a favor de Papa Massata Diack.

\footnotetext{
${ }^{670}$ Ambas transferencias partieron de la cuenta suite 720 Miami FL 33131-3354 - Estados Unidos. BRASIL. _. Tribunal Regional Federal (2 Região). Processo n. 0196181-09.2017.4.02.5101 Disponible en: https://www.jfrj.jus.br Acceso en: 12 oct. 2019.

${ }^{671}$ Los 500.000 dólares fueron ingresados en la cuenta n. 00173152 de la Société Générale Vostok en Moscú, cuya dirección es 2 Yakimanskaya, 6th Floor, Moscovo 109180. Cf. Ibidem.

${ }^{672}$ En este caso, el dinero ingresó en la cuenta IBAN SN00110700061007949901 de la Société Générale de Branques Au, Senegal, cuya dirección es 19 avenue du président L. Senghor BP 323, Dakar. Cf. Ibidem.
} 
El pago se destinó a superar dificultades técnicas con las que se enfrentó Rio en el cumplimiento de los requisitos con el objetivo de acoger una edición de las olimpíadas. Un año y medio antes que ocurriera la elección de la ciudad sede de los juegos, en marzo de 2008, el COI divulgó el ranking de las ciudades candidatas a ser anfitrionas de las Olimpíadas de 2016. De acuerdo con la entidad, Tokio ocupó el primer lugar en la clasificación con 8,3 puntos, seguida de Madrid con 8,1 puntos. A su vez, Chicago tuvo 7,0 puntos, mientras que Doha logró 6,9 puntos. Finalmente, Rio de Janeiro ocupó la última posición con 6,4 puntos.

Considerando lo que a menudo ocurría en otras elecciones, la comunidad internacional dio por cierto que la disputa final sucedería entre Tokio y Madrid, justamente las dos ciudades mejor clasificadas, asimismo, Rio de Janeiro estuvo virtualmente eliminada de la disputa por que faltó tiempo para subsanar todas las dificultades técnicas.

Con el objetivo de resolver el problema, entre marzo de 2008 y septiembre de 2009, el Gobernador Sergio Cabral viajó repetidas veces a Paris a reunirse con Carlos Nuzman, Leonardo Gryner, Lamine Diack y Papa Massata Diack. Al finalizar tales encuentros, los asistentes acordaron el pago de dos millones (2.000.000) de dólares a Lamine Diack para que sobornara a miembros africanos del COI. Además, establecieron la forma de realizar la entrega de los beneficios. Los recursos serían transferidos por Arthur Soares a Papa Massata Diack directamente porque Lamine Diack estuvo sometido a mayores controles a raíz de su labor como miembro del $\mathrm{COI}^{673}$.

Llama la atención en lo relativo a la transparencia, que las reuniones entre brasileños y senegaleses no fueron debidamente registradas en la agenda de los directivos brasileños, pese a la naturaleza pública de sus actividades.

Como principal autoridad del Estado de Rio de Janeiro, el Gobernador Sergio Cabral debió rendir cuentas de sus actos a la sociedad, publicando, como mínimo, la agenda de reuniones con directivos del COI, el contenido de cada encuentro y los

\footnotetext{
${ }^{673}$ OTÁVIO, Chico; BIASETTO, Daniel. Rei Arthur confirma compra de votos para escolha do Rio nos Jogos Olímpicos de 2016. O Globo. Disponible em: https://oglobo.globo.com/brasil/rei-arthur-confirmacompra-de-votos-para-escolha-do-rio-nos-jogos-olimpicos-de-2016-124046494? utm source=aplicativoOGloboutm medium=aplicativoutm campaign=compartilhar. Acceso en: 31 out 2019 .
} 
acuerdos perfeccionados entre las partes al terminar la cita, lo que naturalmente se espera de un Estado verdaderamente democrático. ${ }^{674}$

En efecto, la transparencia es un principio elemental de los Estados democráticos de derecho que encamina la actuación de la Administración Pública y sus gestores, quienes deben demostrar a los ciudadanos, permanentemente, la conformidad de sus actos y decisiones con la legalidad, la moralidad y la probidad.

Asimismo, según la Ley núm. 9.615, de 24 de marzo de 1998, que establece normas generales sobre el deporte, los altos directivos del Comité Olímpico brasileño tienen la prerrogativa de representar al país en grandes eventos deportivos internacionales y en las entidades responsables de su organización, con lo cual se equiparan a las autoridades del Estado en esta materia ${ }^{675}$.

Ahora bien, para que pueda desarrollar sus tareas, la ley le concede al presidente del comité pasaporte diplomático, lo que también evidencia la naturaleza pública de sus responsabilidades. En consecuencia, así como cualquier autoridad de la Administración Pública, el presidente del Comité Olímpico brasileño se somete al deber de rendir cuentas de sus actos a la sociedad, que es resultado de la aplicación del principio de responsabilidad.

Tal compromiso deriva de la naturaleza pública de los recursos destinados al Comité para cumplir con sus objetivos. Según el orden jurídico brasileño, compete al Estado incentivar el desarrollo de actividades deportivas formales y no formales, lo que demanda el empleo de recursos oficiales. ${ }^{676}$ Tales recursos son transferidos al Comité Olímpico brasileño y a otras entidades con arreglo a las Leyes núm. 9.615/1998 ${ }^{677}$ y $10.264 / 2001^{678}$, los cuales provienen de fondos deportivos, loterías oficiales, donaciones, patrocinios, legados, incentivos fiscales y otros ingresos.

\footnotetext{
${ }^{674}$ ZEPEDA, Jesús Rodríguez. op. cit., p. 6-9.

${ }^{675}$ Art. 15. BRASIL. Lei n. 9.615/1998, de 24 de março de 1998. Institui normas gerais sobre desporto e dá outras providências. Disponible en: http://www.planalto.gov.br/ccivil 03/LEYS/L9615consol.htm, Acceso en: 18 de sep. de 2019.
}

${ }^{676}$ Art. 217. BRASIL. [Constituição (1988)].Constituição da república Federativa do Brasil de 1988.

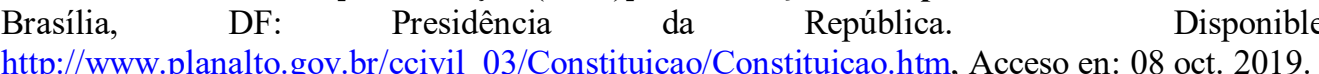

${ }^{677}$ Art. 56. Cf. BRASIL. Lei n. 9.615/1998, op. cit.

${ }^{678}$ Art. $1^{\circ}$ Cf. BRASIL. Lei n. 10.264/2001, de 16 de julho de 2001. Acrescenta inciso e parágrafos ao art. 56 da Lei no 9.615, de 24 de março de 1998, que institui normas gerais sobre desporto. Disponible en: http://www.planalto.gov.br/ccivil_03/LEIS/LEIS_2001/L10264.htm Acceso en: 18 de sep. de 2019. 
La naturaleza pública de los recursos impone el control y la fiscalización por el Tribunal de Cuentas de la Unión ${ }^{679}$ y somete a los responsables de su gestión a los principios de transparencia. Sin embargo, pese a estas exigencias, los directivos del Comité Olímpico brasileño no publicaron su agenda de reuniones con los senegaleses Lamine Diack y Papa Massata Diack. Con frecuencia, las reuniones sucedieron en cuartos de hoteles y otros ambientes privados, exactamente para no someterse al control ciudadano propio de los regímenes democráticos. Prevaleció, en este caso, una cultura de secreto y oscuridad, ${ }^{680}$ que favorece a la comisión de malas prácticas administrativas.

Una vez comprobado el pago, los investigadores brasileños trataron de esforzarse mejor en el sentido de identificar el origen de los recursos utilizados para sobornar a directivos africanos del COI, porqué estos valores estaban ingresados en una cuenta corriente de una institución financiera fuera de Brasil y, finalmente, qué papel jugaba Arthur Soares de Menezes en Rio de Janeiro para que fuese utilizada una cuenta vinculada a su empresa para pagarle el soborno a Papa Massata Diack.

La respuesta a estas preguntas depende de un breve análisis del escenario político de Brasil a principios del siglo XXI, cuando varias instituciones públicas y privadas acabaron involucrándose en enormes escándalos de corrupción debido al comportamiento deshonesto de políticos, empresarios y altos funcionarios y empleados públicos, quienes trataron de aprovecharse de sus prerrogativas para obtener ventajas personales ilícitas.

\subsection{El origen de los recursos que financiaron la elección de rio como ciudad olímpica y el problema de las agendas de los altos directivos de la administración pública}

Antes de que Rio de Janeiro fuera elegido ciudad olímpica el 2 de octubre de 2009, Brasil se enfrentó a un gran escándalo de corrupción de ámbito federal, el caso de las mensualidades (mensalão), que acabó llevando a la cárcel a varios políticos y empresarios

\footnotetext{
679 BRASIL. Tribunal de Contas da União. Acórdão n. 3162/2016-Pl. Disponible en: https://www.lexml.gov.br/urn/urn:lex:br:tribunal.contas.uniao;plenario:acordao:2016-12-07;3162 Acceso en: 18 sep. 2019.

${ }^{680}$ PESCHARD, . op.cit., L. 187.
} 
directamente involucrados en el partido del gobierno ${ }^{681}$.Estas irregularidades en el ámbito federal no constituyeron un hecho aislado, pues se trató de un problema de todas las Administraciones Públicas brasileñas, con especial énfasis en el Estado de Rio de Janeiro, comandado por el Gobernador Sergio Cabral.

Dicho Gobernador fue elegido en octubre de 2006, con cinco millones ciento veintinueve mil sesenta y cuatro (5.129.064) votos, un sesenta y ocho (68) por ciento de los votos válidos en su momento, superando a la juez Denise Frossard, quien obtuvo un treinta y dos por ciento de los votos válidos. ${ }^{682}$ La gigantesca diferencia entre un candidato y otro puso de manifiesto el gran apoyo popular que el Gobernador consiguió al tomar posesión del cargo.

El gran número de votos conquistados le dio a Sergio Cabral, poder suficiente para realizar transformaciones significativas en la gestión estatal y porque no decirlo, para inaugurar una serie de relaciones promiscuas con los proveedores de bienes y servicios para la Administración Pública. Consciente de la confianza que recibió de los vecinos, al conocer el resultado de las urnas, Cabral declaró que trabajaría a favor de reformas beneficiosas al país y a los brasileños. Su gestión en la Administración Pública se caracterizaría por la defensa, tanto del interés público como de los más pobres ${ }^{683}$, con medidas que revolucionarían la prestación de los servicios públicos.

Y en apariencia, así lo hizo. En los primeros meses de gobierno, Cabral inauguró varias unidades de salud por todo el Estado (las llamadas Unidades de Pronto Atendimiento UPAs24H), responsables de ofrecer cuidados médicos de urgencias a la población durante las veinticuatro horas ${ }^{684}$. Asimismo, creó las Unidades de Policía

\footnotetext{
681 BRASIL. Supremo Tribunal Federal. Ação Penal n. 470. Disponible em: http://www.stf.jus.br/portal/cms/verNoticiaDetalhe.asp?idConteudo=236494. Acceso en: 12 oct. 2019.

682 CABRAL é eleito no Rio de Janeiro com maioria absoluta dos votos. Disponible en http://g1.globo.com/Noticias/Eleicoes/0,AA1330709-6302-775,00.html Acceso en: 16 oct. 2019.

PUEDES CITAR EL LIBRO DE GERSON FONTELES O Estado Mínimo e a Corrupção

683 Ibidem.

684 CABRAL inaugura em Campo Grande a $18^{\text {a }}$ UPA do Rio. Disponible em: https://govri.jusbrasil.com.br/noticias/148145/cabral-inaugura-em-campo-grande-a-18-upa-do-rio Acceso en: 12 oct. 2019.
} 
Pacificadora (las UPPs), que ofrecieron seguridad ciudadana a los vecinos que vivían en las favelas de Rio de Janeiro ${ }^{685}$.

Las buenas prácticas del Gobernador no representaron la totalidad de sus acciones frente de la Administración Pública. Además de inaugurar unidades de servicio en salud y seguridad policial, también se aprovechó del cargo para lograr ventajas económicas indebidas a través de un gigantesco esquema de desviación de fondos públicos. Las irregularidades fueron cometidas por medio de contratos perfeccionados entre empresarios deshonestos y la Administración Pública ${ }^{686}$.

El esquema inició cuando Sergio Cabral actuó como Diputado en la Asamblea Legislativa del Estado de Rio de Janeiro, a finales de los años 1990, cuando ocupó la silla de presidente del Poder Legislativo Estatal. En este período, Cabral abrió una cuenta corriente secreta en un banco de Nueva York llamada "eficiencia" que le permitió ingresar la cifra de dos (2.000.000) millones de dólares ${ }^{687}$.

El dinero obtenido de comisiones pagadas por los altos directivos de las principales empresas de autobuses de Rio de Janeiro fue destinado para que el diputado aprobara los proyectos de ley de este sector ${ }^{688}$. Al tomar posesión como Gobernador, el esquema de corrupción se trasladó de la Asamblea Legislativa al palacio de gobierno y las cifras fueron superiores a las cobradas durante el ejercicio de diputado.

Antes de resultar electo Cabral como Gobernador solía cobrar a los empresarios alrededor de cuarenta y tres mil setecientos (43.700) euros al mes a título de comisión. Tras convertirse en la principal autoridad de la Administración Pública, pasó a cobrar doscientos dieciocho mil ochocientos (218.800) euros al mes, cinco veces más de lo que cobraba hasta entonces ${ }^{689}$.

El gobierno paralelo creado por Sergio Cabral demandó a los empresarios el pago de ventajas indebidas como si se tratarán de impuestos. Cada compañía que quisiera

\footnotetext{
685 CABRAL inaugura $14^{\mathrm{a}}$ UPP do RJ no Engenho Novo. Disponible em: https://www.estadao.com.br/noticias/geral,sergio-cabral-inaugura-14-upp-do-rj-no-engenhonovo,673355. Acceso en: 12 oct. 2019.

${ }^{686}$ CORREAA, Hudson. Sergio Cabral: o homem que queria ser rei. Rio de Janeiro: Primeira Pessoa, 2018, L. 91.

${ }^{687}$ BRASIL. Tribunal Regional Federal (2 Região). Processo n.0501024-41.2017.4.02.5101. Disponible en: http://www.jfri.jus.br. Acceso en: 12 oct. 2019.

${ }^{688}$ Ibidem.

${ }^{689}$ CORRÊA, Hudson. op. cit., L. 79.
} 
realizar contratos perfeccionados con la Administración Pública debería entregarle al Gobernador cinco (5) por ciento del valor correspondiente al negocio, adicional a un pago mensual que varió de setenta y seis mil quinientos (76.500) euros a ciento nueve mil cuatrocientos (109.400) euros. A cambio, Cabral le dio a la entidad contratos rentables de obras y servicios con la Administración Pública ${ }^{690}$. Así las cosas, se descubre como dirigió una trama corrupta para conceder a ciertas compañías contratos con la Administración Pública. No obstante, Cabral siempre fue cuidadoso para esconder malas prácticas detrás de buenas acciones administrativas. De esta forma, los vecinos no se daban cuenta de las irregularidades cometidas. En otras palabras, los actos del Gobernador fueron todos conforme al derecho, y tras cada nueva medida su carisma no dejo de aumentar hacia los ciudadanos.

Las malas prácticas del Gobernador comenzaron en el sector de la salud. Dos días después de la toma de posesión del cargo, el 3 de enero de 2007, Cabral y el Secretario Estatal de Salud, el médico Sergio Cortes, visitaron el hospital Albert Schweitzer, en el barrio de Realengo, considerado uno de los principales hospitales de la región oeste de la ciudad de Rio de Janeiro. Con esa visita, tenían la ambición de mostrar a la población los problemas asociados con la gestión de la sanidad durante los gobiernos anteriores a su llegada al poder. La publicidad sería fundamental para justificar las medidas extraordinarias que se adoptarían en el sector a partir de entonces. Al Terminar la visita, Sergio Cabral constató lo que todos ya sabían. Los hospitales gobernados por el Estado de Rio de Janeiro no ofrecían condiciones dignas a los enfermos. Faltaba de todo. Carecían de médicos, medicinas, equipos administrativos, alimentos, seguridad y tecnología.

Ante tantos problemas, el Gobernador no hizo más que afirmar que los hospitales públicos de Rio de Janeiro se convirtieron en máquinas "genocidas" a manos de la Administración Pública ${ }^{691}$. Con la intención de solucionar los problemas, se comprometió para adoptar las medidas necesarias y, así, superar la crisis, lo que le llevó a utilizar todos los recursos políticos y jurídicos para enfrentarse a las dificultades.

\footnotetext{
${ }^{690}$ Ibidem, L. 91.

691 ESTADO Comete Genocídio com Descaso na Saúde. Estadão. Disponible en: https://brasil.estadao.com.br/noticias/geral,estado-comete-genocidio-com-descaso-na-saude-dizcabral,20070103p14605 . Acceso en: 16 oct. 2019.
} 
En realidad, Cabral ya había adoptado tales medidas. Dos días antes que visitara el hospital, se aprovechó de una prerrogativa concedida por la Ley núm. 8.666, de 21 de junio de 1993, de Licitaciones y Contratos Administrativos ${ }^{692}$, y firmó el Decreto núm. 40.496, de 1 de enero de 2007, donde reconoció la situación de calamidad en la gestión pública de la salud. Con base en el decreto pudo realizar contrataciones directas para el sector y subsanar las faltas que identificó con motivo de la visita.

En efecto, la legislación brasileña prevé como regla, que la Administración Pública deberá realizar licitaciones para la compraventa de productos o servicios ${ }^{693}$. En todos los casos, excepto en situaciones previamente definidas en ley, se admite la contratación directa, lo que sucede a través de dos modalidades: la dispensa de licitación y la inexigibilidad de licitación ${ }^{694}$.

La diferencia básica entre las dos modalidades resulta que en el primer caso (dispensa de licitación), la competencia entre particulares es, en principio, posible y, en teoría, la licitación será viable ${ }^{695}$. En el segundo caso (inexigibilidad de licitación), la competencia no es posible, en tanto que apenas una persona u objeto en particular atienda las necesidades de la Administración Pública ${ }^{696}$. La licitación es, en este caso, inviable ${ }^{697}$.

Entre las situaciones de dispensa de licitación está, justamente, aquella calificada como de urgencia o calamidad, cuando la demora en realizar el contrato causara grave daño a la Administración Pública o a la sociedad ${ }^{698}$, como sucedió en el sector de la salud a principios de 2007. La falta de médicos, medicinas, equipos, alimentos, seguridad y tecnología fue lo suficientemente grave como para caracterizar la situación de calamidad prevista en ley. Con base a esta situación y al Decreto núm. 40.496, de 1 de enero de

${ }^{692}$ BRASIL. Lei n. 8.666/1993, de 21 de junho de 1993. Regulamenta o art. 37, inciso XXI, da Constituição Federal, institui normas para licitações e contratos da Administração Pública e dá outras providências. Disponible en: http://www.planalto.gov.br/ccivil 03/leis/18666cons.htm Acceso en: 27 jun. de 2019.

${ }^{693}$ Art. 37, XXI. BRASIL. Constituição de 1988. op. cit.

${ }^{694}$ Arts. 24 y 25. BRASIL. Lei n. 8.666, de 21 de junho de 1993. op. cit.

${ }^{695}$ FURTADO, Lucas Rocha. op. cit., L. 11.003.

${ }^{696}$ Ibidem, L. 11.020.

697 BRASIL. Tribunal de Contas da União. Acórdão n. 1.064/2005-Plenário. Disponible em: www.tcu.gov.br Acceso en: 17 oct. 2019.

${ }^{698}$ BRASIL. Tribunal de Contas da União. Decisão n. 347/1994-Plenário. Disponible em: www.tcu.gov.br Acceso en: 17 oct. 2019. 
2007, el Gobernador pudo contratar directamente, previa licitación, entidades que prestaran servicios a los hospitales gestionados por el Estado de Rio de Janeiro.

En las semanas siguientes, el Estado perfeccionó directamente contratos con proveedores de alimentación, limpieza, mantenimiento predial, seguridad, refrigeración, servicios administrativos y eliminación de basuras. Cabral cumplió el compromiso de adoptar medidas necesarias para superar la crisis en el sector de la sanidad. Asimismo, los actos de hecho se destinaron a beneficiar a los más pobres, siempre que ellos se considerasen los principales usuarios de los servicios sanitarios gestionados por el Estado.

En el ámbito jurídico, el contrato de derecho público también cumplió su papel. Sin que tuviese que realizar grandes alteraciones en la estructura administrativa del Estado, a partir de esta figura, el Gobernador logró responder a las necesidades concretas de los ciudadanos con rapidez ${ }^{699}$. Con fundamentos en el contrato, el Gobernador pudo utilizar los recursos disponibles en el mercado para subsanar las deficiencias de la Administración, lo que ha permitido una adecuada prestación de los servicios públicos ${ }^{700}$.

Estas contrataciones estuvieron a cargo del Secretario Estatal de Sanidad, Sergio Cortes, un afamado médico brasileño, el cual actuó como director del Instituto Nacional de Traumatología y Ortopedia en Rio de Janeiro (INTO) y que aceptó la invitación de Sergio Cabral para comandar la Secretaría Estatal de Salud durante su gestión como Gobernador. Al contrario de lo esperado, Sergio Cortes no marcó su gestión al frente de la Secretaría por los principios de transparencia y buen gobierno. El afamado médico aprovechó los poderes recibidos para repetir un gran esquema de corrupción y oscuridad que anteriormente había utilizado como director del INTO.

En base a la Constitución brasileña de 1988, los órganos públicos de las tres esferas del gobierno siempre disfrutaron de inmunidad tributaria en cuanto al pago de impuestos causados por la compraventa de productos o la adquisición de servicios de cualquier naturaleza ${ }^{701}$. Como consecuencia, cada contratación realizada por los hospitales públicos brasileños, independientemente del objeto del contrato, no se sometió al pago de impuestos, con lo cual, el valor del tributo no se incluyó en la factura presentada por el contratista.

\footnotetext{
${ }^{699}$ MIRANZO DÍAZ, Javier. La Prevención de la Corrupción en la Contratación Pública. Madrid: Wolterskluver, 2019, L. 189.

${ }^{700}$ Ibidem, L. 194.

701 Art. 150, VI. BRASIL. Constituição de 1988. op. cit.
} 
Con el objeto de establecer límites a la discrecionalidad de los gestores en cuanto a estas contrataciones, desde el 2005, el Tribunal de Cuentas de la Unión ya había fijado un criterio en las contrataciones directas de la Administración Pública. Aunque en las situaciones de calamidad, ellas tienen que observar la compatibilidad del precio contratado con el comúnmente practicado en el mercado ${ }^{702}$. Se trató de una interpretación que, ineludiblemente, buscó evitar la sobrefacturación de precios asociada a estas contrataciones excepcionales. En otras palabras, la situación de calamidad no permitiría a la Administración contratar bienes o servicios a cualquier precio, sino que debería buscar valores compatibles con los practicados en el mercado.

A pesar de que conocía estas reglas de las contrataciones públicas en Brasil, exactamente porque las licitaciones siempre están acompañadas de un informe firmado por un abogado del Estado ${ }^{703}$, Sergio Cortes solía pagar a las sociedades contratadas el valor relativo a los impuestos debidos a causa del negocio, aunque respetaba la decisión del Tribunal de Cuentas en lo relativo al precio comúnmente transado en el mercado.

En otras palabras, el elevado valor de algunos contratos perfeccionados por la Secretaría no vino de una probable incompatibilidad entre el precio de la contratación y los precios comúnmente pactados en el mercado. La mayor diferencia se produjo por la necesidad de que la sociedad contratada no disfrutaba de la inmunidad tributaria y tenía que pagar los impuestos debidos a otros entes de la federación, como el municipio y la Unión.

Las irregularidades, en ambos casos, abarcaron contratos que habían sido perfeccionados con entidades brasileñas y extranjeras. Asimismo, tuvieron como objeto la compraventa de equipos médicos de alta complejidad, tales como camillas eléctricas, máquinas de resonancia magnética, aparatos quirúrgicos y ambulancias. Aunque el departamento jurídico del contratista conocía la regla (la Administración Pública no incluía en la factura el valor de los impuestos), su pago, en este caso, se convirtió en requisito para que los órganos comandados por Sergio Cortes realizaran el contrato con la entidad ${ }^{704}$. Durante reuniones previas realizadas con directivos de las compañías, el secretario trató de explicarles las reglas que gobernarían cada contratación. Asimismo, se

\footnotetext{
${ }^{702}$ BRASIL. Tribunal de Contas da União. Acórdão n. 819/2005-Plenário. Disponible en: www.tcu.gov.br Acceso en: 17 oct. 2019.

${ }^{703}$ Art. 38, parágrafo único. BRASIL. Lei n. 8.666, de 21 de junho de 1993. op. cit.

${ }^{704}$ CARDOSO. Tom. op. cit., L. 1826.
} 
les informó que quienes no coincidieran en lo establecido, no ejecutarían contratos con el Estado.

En cualquier caso, y por ende, el pago del impuesto no se trató de una mera confusión en la interpretación de la Constitución. Al recibir el tributo, la sociedad debería restituir su valor directamente al secretario a título de comisión, que variaba de cuarenta (40) por ciento a sesenta (60) por ciento de lo informado en la factura.

Con base en este esquema, Sergio Cortes desvió del sector de la sanidad, entre el 2003 y el 2014, la impresionante cifra de sesenta y cinco millones seiscientos mil (65.600.000) euros. La desviación representó, en su momento, el doble del presupuesto anual del hospital Souza Aguiar, situado en la región central de Rio de Janeiro y administrado por el municipio, el cual tiene el servicio de urgencias más grande de Sudamérica $^{705}$.

Esas malas prácticas del Gobernador Sergio Cabral no se restringieron a la Secretaría de Sanidad, sino que a su vez, también contaminó otros órganos y entidades públicas a través de la contratación de sociedades prestadoras de servicios para la Administración. Al contrario de lo que comúnmente pasó en el sector de la sanidad, las irregularidades no se cometieron directamente a través del secretario responsable del área. Dicha tarea le tocó, en este caso, al empresario Arthur César Soares de Menezes Filho, también conocido como Rey Arthur, una especial deferencia que todos le hacían a raíz del gran poder que tenía en la Administración Pública.

Las entidades gestionadas por Arthur Soares tenían la mayoría de los contratos de prestación de servicios perfeccionados con el Estado de Rio de Janeiro desde 1999. Sus empresas controlaban las actividades de suministro de comida, recogida de basura, limpieza, seguridad y sanidad, entre otras actividades.

En 2003, durante el primer año de gestión de la Gobernadora Rosinha Garotinho, antecesora de Sergio Cabral, Arthur Soares perfeccionó con el Estado de Rio de Janeiro contratos equivalentes a doce millones ochocientos mil (12.800.000) euros. Apenas Sergio Cabral se convirtió en Gobernador, el empresario tuvo un extraordinario incremento patrimonial. Según un informe del Ministerio de Hacienda ${ }^{706}$, entre el 2006 y el 2007, su patrimonio había variado de tres millones seiscientos ochenta y tres mil

\footnotetext{
${ }^{705}$ Ibidem, L. 1826.

706 Informe RJ n. 20170019. BRASIL. Tribunal Regional Federal (2 Região). Processo n. 050752426.2017.4.02.5101. Disponible em: http://www.jfrj.jus.br Acceso en: 12 oct. 2019.
} 
trescientos veintinueve euros con veintidós céntimos $(3.683 .329,22 €)$ para treinta y cuatro millones doscientos diecinueve mil cuatrocientos treinta y cuatro euros con veinticinco céntimos $(34.219 .434,25 €)$ lo que corresponde a un incremento neto de 92,9 por ciento.

Muchas de las sociedades que habían estado gestionadas por Arthur Soares perfeccionaron excelentes contratos con el Estado de Rio de Janeiro durante este período. A título de ejemplo, la sociedad Facility Seguridad Ltda, cerró contratos por un valor que alcanzó la impresionante cifra de cincuenta y cuatro millones cuatrocientos veinte mil cincuenta y dos euros con ochenta y nueve céntimos $(54.420 .052,89 €)^{707}$.

Dos años más tarde, en 2009, las entidades gestionadas por el Rey Arthur firmaron contratos con el Departamento de Tránsito que ascendieron a ciento cincuenta y tres millones doscientos mil (153.200.000) euros, lo que demostró su poder junto a la Administración Pública Estatal. Con el paso del tiempo Arthur Soares conquistó la confianza del Gobernador y controló directamente toda la contratación pública relativa al suministro de bienes y servicios del Estado de Rio de Janeiro. Actuando como verdadero gestor, tuvo poderes suficientes para decidir quién contrataría o no con la Administración Pública.

Según César Romero ${ }^{708}$, Arthur Soares llegó a reunirse con varias entidades proveedoras de bienes y servicios en su propio despacho con el objetivo de establecer las reglas para la contratación con la Administración Pública. Cada sociedad tuvo que entregarle al Gobernador y sus socios un diez (10) por ciento correspondiente al valor del negocio. El pago de la comisión, más allá de permitir el cierre del contrato, garantizaba que la entidad calificara en futuros acuerdos con el ente público.

En estas reuniones, se estableció que el pago de los valores no se destinaba con exclusividad a Sergio Cabral, por lo que se dividían entre los miembros de la organización, de conformidad con criterios previamente establecidos ${ }^{709}$.

a) Un uno (1) por ciento se destinaba al empresario colaborador;

\footnotetext{
707 Disponible en: http://www.transparencia.rj.gov.br/transparencia/faces/capaTransparencia. Acceso en: 23 sept. 2019.

${ }^{708}$ BRASIL. Tribunal Regional Federal (2 Região). Processo n. 0507524-26.2017.4.02.5101. Disponible em: http://www.jfrj.jus.br Acceso en: 12 oct. 2019.

${ }^{709}$ Ibidem.
} 
b) El dos (2) por ciento se destinaba al secretario responsable del área en donde se daba la contratación;

c) El Cinco (5) por ciento se destinaba al Gobernador Sergio Cabral;

d) El uno (1) por ciento se destinaba a miembros del Tribunal de Cuentas del Estado de Rio de Janeiro; y

e) Un uno (1) por ciento se destinaba a mantener el sistema en funcionamiento.

En todos los casos, el pago de las comisiones pasaba a través de Arthur Soares. El mismo se encarga de enviar a sus empleados directamente a la entidad beneficiada con el contrato, o esperaba que la misma le entregara la comisión en su despacho. En este sentido, Arthur Soares controlaba todas las fases de la contratación pública, desde la licitación hasta el pago, más allá de ocuparse en ocultar los recursos ilegalmente recibidos $^{710}$.

Al recibir el dinero, el empresario trataba de enviarlo a una cuenta corriente en el banco EVG Bank LTD en Antigua y Barbuda, identificada con el nombre Matlock Capital Group LTD (reconocida a través del núm. 01145) ${ }^{711}$. Apenas llegaban los recursos a la referida institución, se transferían rápidamente a otra cuenta registrada en el EVG Bank LTD, perteneciente a los hermanos Renato y Marcelo Hasson Chebar, que a su vez eran los operadores financieros de Sergio Cabral.

El Gobernador conoció a los hermanos Chebar en 2003, cuando aún actuaba como Diputado en la Asamblea Legislativa del Estado de Rio de Janeiro. En esta época, contrató los servicios de ambos para enviar al exterior recursos que recibió durante la campaña para ser diputado y que no utilizó a lo largo de la disputa. A partir de entonces la idea fue mantener estos recursos en paraísos fiscales, para que las autoridades brasileñas no pudieran identificarlos ${ }^{712}$. Los hermanos Chebar utilizaron técnicas de seguridad informática para impedir que las operaciones de blanqueo de capitales fueran descubiertas por la Policía Federal. De hecho, crearon una cuenta colectiva en Google para comunicarse con Sergio Cabral y Carlos Miranda, hombre de confianza del Gobernador, con respecto a nuevas operaciones de remesa de dinero fuera del país.

\footnotetext{
${ }^{710}$ CARDOSO. Tom. op. cit., L. 1871.

${ }^{711}$ BRASIL. Tribunal Regional Federal (2 Região). Processo n. 0196181-09.2017.4.02.5101. Disponible en: http://www.jfrj.jus.br Acceso en: 12 oct. 2019.

${ }^{712}$ CARDOSO. Tom. op. cit., L. 1382.
} 
De acuerdo con la estrategia, quienes tuviesen la contraseña de la aludida cuenta podrían acceder a los mensajes registrados en ella, sin la necesidad de enviarlos a otro email. En este sentido, los hermanos Chebar sabían que las aplicaciones utilizadas por la Policía Federal no lograban identificar los mensajes escritos en la carpeta "borrador" de la cuenta de e-mail, en tanto que ellos no transitaban por el servidor de Google. Como consecuencia, los mensajes relativos a nuevas operaciones, órdenes de pago y facturas eran registrados en esta cuenta ${ }^{713}$.

Asimismo, los operadores tenían el debido cuidado de borrar del ordenador todos los registros que pudiesen ser identificados por las autoridades tras cada operación. Además, los archivos guardados en USB tenían códigos criptográficos creados por una aplicación llamada "Steganos", con lo cual no sería posible que terceros accedieran a su contenido. La aplicación creaba un falso disco duro en el ordenador, que tampoco podría ser identificado por las autoridades ${ }^{714}$.

Cuando Cabral se convirtió en Gobernador, siguió utilizando los servicios de los hermanos Chebar para esconder el dinero que cobraba de los contratistas de la Administración Pública Estatal. Por esta razón los recursos ingresados en la cuenta Matlock Capital Group LTD fueron transferidos a una cuenta perteneciente a los hermanos Renato y Marcelo Chebar. Para realizar esa transferencia, Renato utilizó un poder notarial otorgado por Arthur Soares que le dio amplia autorización para traspasar los recursos depositados en la cuenta Matlock a otras cuentas ${ }^{715}$. Según Renato Chebar, la elección de una institución financiera única para acoger las dos cuentas no fue una mera casualidad. Tratándose de cuentas vinculadas al mismo banco, los controles a cargo de las autoridades de Antigua y Barbuda fueron menos rigurosos. Como consecuencia, él podría transferirlos con mayor libertad.

Una vez realizadas las transferencias, Renato Chebar traspasó inmediatamente el dinero para la cuenta de blue stream investments LLC, perteneciente a Sergio Cabral. Los valores transferidos alcanzaron seis millones trescientos cincuenta y siete mil cuatrocientos cincuenta y nueve dólares con cincuenta y cuatro céntimos $(6.357 .459,54$ $€)$. Posteriormente, y con arreglo a los poderes recibidos de Arthur Soares, transfirió otros

\footnotetext{
${ }^{713}$ Ibidem, L. 1393.

${ }^{714}$ Ibidem.

${ }^{715}$ BRASIL. Tribunal Regional Federal (2 Região). Processo n. 0507524-26.2017.4.02.5101. Disponible em: http://www.jfrj.jus.br Acceso en: 12 oct. 2019.
} 
tres millones trescientos sesenta y ocho mil quinientos sesenta y seis (3.368.566) dólares directamente de la cuenta Matlock Capital Group LTD para las cuentas que tenía en el EVG Bank LTD y desde esta para cuentas del Gobernador Sergio Cabral ubicadas en paraísos fiscales $^{716}$.

Con la ayuda de Renato y Marcelo Chebar, por ende, el Gobernador Sergio Cabral logró enviar a paraísos fiscales la cifra de cien millones (100.000.000) de dólares, sacados de las arcas públicas del Estado de Rio de Janeiro a partir del pago de comisiones por los contratistas que realizaron algún negocio con el ente público.

Asimismo, Renato clarificó a la Justicia Federal de Rio de Janeiro que las cuentas que tenía en el EVG Bank LTD en Antigua y Barbuda no eran de su titularidad, sino del Gobernador Sergio Cabral y de sus comparsas Carlos Miranda y Wilson Carlos. En otras palabras, Renato Chebar fue, en realidad, testaferro del político y de otros miembros de la banda criminal.

Finalmente, también explicó que los recursos ingresados en la cuenta Matlock Capital fueron utilizados para sobornar a miembros africanos del COI, con lo cual se estableció la conexión entre las malas prácticas administrativas pasadas en el Estado de Rio de Janeiro y la elección de la ciudad brasileña como anfitriona de los Juegos Olímpicos. Las revelaciones de los hermanos Chebar y otros testigos pusieron de manifiesto otro aspecto relevante en cuanto a la preparación de los Juegos Olímpicos Rio 2016. Debido a la falta de reglas que impusieran la divulgación de las agendas de los altos directivos de la Administración Pública, funcionarios inescrupulosos lograron participar de reuniones sigilosas con empresarios igualmente deshonestos a modo de establecer reglas destinadas a asegurar el cobro de ventajas indebidas, sin que estos encuentros pudieran ser controlados por los ciudadanos.

\subsection{La falta de transparencia en cuanto a las exigencias técnicas constantes de los pliegos concernientes a las obras de preparación de los juegos olímpicos rio 2016}

Las desviaciones ocurridas en la Secretaría de Salud y en los contratos de prestación de servicios contaminaron rápidamente otros órganos de la Administración. En este caso,

\footnotetext{
${ }^{716}$ Ibidem
} 
la principal afectada fue la Secretaría Estatal de Obras Públicas, responsable de los contratos con mayor valor económico en la administración.

El 2007, primer año de mandato del Gobernador Sergio Cabral, el sector de la construcción civil estuvo dominado, básicamente, por cinco grandes compañías (OAS, Odebrecht, Andrade Gutierrez, Camargo Corrêa y Queiroz Galvão), quienes conquistaron los principales contratos con el Estado. Durante este periodo, las aludidas sociedades lograron un treinta y ocho (38) por ciento de las inversiones brasileñas relativas a las cincuenta principales obras públicas de todo el país, ${ }^{717}$ lo que ha incrementado aún más en los años siguientes.

E1 2009, año de la elección de Rio como ciudad olímpica, las inversiones públicas a cargo de la Unión, los Estados, los Municipios y demás entidades controladas por cada uno de estos entes políticos llegaron a un sesenta y dos (62) por ciento de los ingresos de Odebrecht, un treinta y cinco (35) por ciento de Camargo Corrêa, un setenta y dos (72) por ciento de Andrade Gutierrez y un cien (100) por ciento de Queiroz Galvão. ${ }^{718}$ Asimismo, a lo largo de este periodo, las cuatro hermanas (OAS, Odebrecht, Andrade Gutierrez y Camargo Corrêa $)^{719}$ fueron beneficiadas con préstamos baratos junto al Banco Nacional de Desarrollo Económico y Social (BNDES), una importante agencia de fomento en Brasil, lo que pone de manifiesto sus cercanas relaciones con la Administración Pública y sus altos directivos. Esta proximidad quedó particularmente evidente en el caso de Rio de Janeiro, donde las aludidas compañías controlaron, directamente o a través de subsidiarias, las veinte principales obras públicas en mencionado Estado y Municipio. ${ }^{720}$

Se destacan, en este caso, las obras para la construcción del arco vial metropolitano, ${ }^{721}$ la construcción del Bus Rapid Transit System de las Avenidas Transolímpica y

\footnotetext{
${ }^{717}$ BARBASSA, Juliana. op. cit., p. 42.

${ }^{718}$ SCOFIELD Jr, G.: D’ERCOLE, R.; NOGUEIRA, D. Quatro empreiteiras concentram R\$ 138 bilhões em obras no país. O Globo, 7 may. 2011. Disponible en: https://oglobo.globo.com/economia/quatroempreiteiras-concentram-138-bilhoes-em-obras-no-pais-2773130 Acceso en: 11 sept 2019
}

719 BELISARIO, Adriano. "As quatro irmãs", Pública, 30 de jun. 2014. Disponible en: http://apublica.org/2014/06/as-quatro-irmas/ . Acceso en: 11 sept 2019

${ }^{720}$ BARBASSA, Juliana. op. cit., p. 43.

721 BRASIL. Ministério Público Federal. Ministério Público Federal Denuncia Operação Calicute. Procuradoria da República no estado do Rio de Janeiro. Disponible em : http://www.mpf.mp.br/rj/sala-deimprensa/docs/pr-rj/Denuncia_ALEX\%20SARDINHA_Redigido.pdf/ Acceso en: 23 sept. 2019. 
Transcarioca, la construcción de un trolebús en la región central y la reurbanización de la región portuaria de la ciudad de Rio de Janeiro, más allá de la edificación de equipamientos olímpicos como el Parque Olímpico de Barra de la Tijuca y la reforma de los estadios João Avelange y Maracanã. ${ }^{722}$

Históricamente, las relaciones entre estas compañías y el Estado comenzaron aún en los años 1970, durante el régimen militar, y se mantuvieron en los años subsecuentes tras la redemocratización del país. A mediados de los años 1980, las constructoras trataron de financiar las campañas políticas de presidentes, Gobernadores, alcaldes y Parlamentarios a modo de garantizar la perfección de contratos con los entes públicos y las instituciones que ellos controlaban. ${ }^{723}$

Asimismo, una vez habían concluido los negocios (o incluso antes que ello pasara), solían pagar comisiones a los altos directivos y funcionarios de la Administración Pública con objeto de mantener sus buenas relaciones con las autoridades y asegurar la conclusión de futuros contratos con el Estado y sus empresas. Las comisiones pagadas a causa de cada negocio fueron muy elevadas en el caso del Estado de Rio de Janeiro, debido al gran volumen de las inversiones públicas realizadas con motivo de los Juegos Olímpicos.

A modo de evitar que otras sociedades lograran el derecho de perfeccionar contratos con la Administración Pública, estas compañías trataron de formar carteles con el objetivo de participar en las licitaciones. ${ }^{724}$ En este sentido, se comprometieron en fijar precios, condiciones, ventajas y abstenciones. Asimismo, se dispusieron a dividir el mercado, reunir proyectos de ingeniería bajo una única propuesta, organizarse en consorcios y subcontratar el objeto de la licitación para que todos ganaran con las obras ${ }^{725}$.

Antes que comenzaran las licitaciones, formaron un grupo de trabajo que, en secreto, busco interferir en la elaboración de las condiciones. Las compañías sabían que los pliegos constituyen uno de los elementos más importantes de la licitación. Con base en sus elementos, la Administración podía fomentar o restringir la participación de los

\footnotetext{
${ }^{722}$ BARBASSA, Juliana. op. cit., p. 43.

${ }^{723}$ Ibidem.

${ }^{724}$ NETTO, Vladimir; Parreira, Marcelo. Em Acordo de Leniência Empreiteira Revela Cartel Para Fraudar Obras no Rio. O Globo, nov. 30, 2016. Disponible emhttp:/g1.globo.com/economia/noticia/2016/11/emacordo-de-leniencia-empreiteira-revela-cartel-para-fraudar-obras-no-rio.html Acceso en: 30 nov. 2019.

${ }^{725}$ BRASIL. Tribunal Regional Federal (2 Região). Processo n. 0509503-57.2016.4.02.5101, p. 8.2128.213. Disponible en: http://jfrj.jus.br Acceso en: 12 oct. 2019.
} 
interesados, por lo que controlar su elaboración significaba, por tanto, controlar la propia licitación ${ }^{726}$.

Con la finalidad de que esto pasara, las constructoras trataron de reunirse para establecer exigencias técnicas que dificultaran la participación de sociedades que no formaban parte del esquema, incluso antes que las licitaciones iniciaran, todos sabían con antelación quienes vencerían las disputas y qué obras estarían a cargo de cada una de las empresas participantes ${ }^{727}$. El sigilo de esas actuaciones, en este caso, fue fundamental para que los altos directivos del Estado y las constructoras realizaran los acuerdos, y además, pudieran llevar en adelante el modelo de gestión implementado en los contratos del sector de la sanidad.

En el ámbito jurídico, llama la atención la conducta de los responsables de las malas prácticas en cada uno de estos casos. Considerando la magnitud de los proyectos, los implicados trataron de dividir el objeto del contrato en parcelas, realizar varias licitaciones y permitir la formación de consorcios privados para la ejecución de cada obra. Técnicamente, los pliegos estaban realizados conforme a derecho y a las normas de la buena gestión pública ${ }^{728}$. El fraccionamiento del objeto y la participación de consorcios privados fomentaron la presencia de un mayor número de interesados, y asimismo, estaba en armonía con la jurisprudencia del Tribunal de Cuentas de la Unión ${ }^{729}$ y del Tribunal Superior de Justicia ${ }^{730}$.

Las restricciones incorporadas a los pliegos contravinieron este hecho. Pese a que en la teoría se defendía que cualquier entidad podía participar de las licitaciones, en realidad, no todas lograron hacerlo, ya que fueron eliminadas de las disputas a causa de las exigencias fijadas en los pliegos. Con base en estas exigencias, las grandes constructoras conquistaron el derecho a realizar las principales obras de infraestructura

\footnotetext{
${ }^{726}$ FURTADO, Lucas Rocha. op. cit., L. 12.063.

${ }^{727}$ BRASIL. Tribunal Regional Federal (2 Região). Processo n. 0509503-57.2016.4.02.5101, p. 8.213. Disponible en: http://jfrj.jus.br Acceso en: 12 oct. 2019.

${ }^{728}$ Art. 23, $\S 1^{\text {o }}$. BRASIL. Lei n. 8.666/1993, op. cit.

${ }^{729}$ BRASIL. Tribunal de Contas da União. Acórdão n. 1.521/2003-TCU-Plenário e Decisão n. 186/1999TCU-Plenário, Decisão n. 811/2002-TCU-Plenário. $\quad$ Disponible en: https://portal.tcu.gov.br/inicio/index.htm Acceso en: 11 dic 2019.

${ }^{730}$ BRASIL. Superior Tribunal de Justiça ( 2 Turma). Processo RMS n. 6.597/MS. Rel. Min. Antonio de Padoa Ribeiro. jul. 16.12.1996. Disponible em http://www.stj.jus.br/sites/portalp/Inicio Acceso en: 12 oct. 2019.
} 
asociadas a las Olimpíadas Rio 2016. Entre las que se destacan la construcción del arco vial metropolitano, la modernización del estadio de Maracaná y la urbanización de tres grandes conjuntos de favelas ubicadas en la ciudad de Rio de Janeiro, ${ }^{731}$ las cuales serán examinadas en los apartados siguientes.

2.3.1. Las cláusulas que restringieron la participación de entidades en la licitación concerniente a las obras de reforma del estadio de maracaná

Teniendo en cuenta la división de mercado previamente establecida, las obras de reforma del estadio de Maracaná serían, en principio, responsabilidad de un consorcio formado por las compañías Norberto Odebrecht y Andrade Gutierrez ${ }^{732}$. Las entidades a las que hacemos alusión fueron comandadas en Rio de Janeiro por Benedicto Junior ${ }^{733}$ y Rogerio Nora, respectivamente, ${ }^{734}$ dos de los empresarios más influyentes en el Estado de Rio de Janeiro.

Benedicto conoció a Sergio Cabral en 2006, durante su campaña electoral para Gobernador. En esa oportunidad, Odebrecht le donó a Cabral seiscientos sesenta mil (660.000) euros para la disputa, aunque los recursos no fueron declarados a la justicia electoral en su momento, como lo establecía la legislación brasileña ${ }^{735}$. A solicitud del candidato, la contribución ingresó directamente en la caja B de la campaña, lo que indicó el tipo de vínculo que se establecería entre el político y el empresario en el futuro.

Al ser elegido Gobernador, Sergio Cabral trató de negociar directamente con Benedicto Junior, siempre a escondidas, las obras que le interesaban a Odebrecht en Rio de Janeiro. En cambio, le solicitó el pago de una comisión de cinco (5) por ciento sobre

\footnotetext{
${ }^{731}$ BRASIL. Tribunal Regional Federal (2 Região). Processo n. 0509503-57.2016.4.02.5101, p. 8.213. Disponible en: http://jfrj.jus.br Acceso en: 12 oct. 2019.

${ }^{732}$ Ibidem, p. 5.448-5.449.

${ }^{733}$ CORRÊA, Hudson. op. cit., L. 1217.

${ }^{734}$ BRASIL. Tribunal Regional Federal (2 Região). Processo n. 0017513-21.2014.4.02.5101, p. 5.4485.449. Disponible em: http://www.jfrj.jus.br. Acceso en: 06 nov. 2019.

${ }^{735}$ Art. 23. BRASIL. Lei n. 9.504/1997, de 30 de setembro de 1997. Estabelece normas para as eleições. Disponible em: http://www.planalto.gov.br/ccivil 03/leis/19504.htm . Acceso en: 12 oct. 2019.
} 
el valor de cada contrato, o sea, una contribución debida al Gobernador a causa de las medidas que adoptó para favorecer a la constructora en las licitaciones ${ }^{736}$.

Con base en estos acuerdos, apenas en el primer año de gestión, Odebrecht le entregó a Cabral doscientos veinte mil (220.000) euros. A cambio, logró el derecho a ejecutar diversas obras de infraestructura en el Estado, como la relativa a la reforma del estadio de Maracaná. Además, conquistó el derecho a realizar otras obras de infraestructura en el aludido Estado, aunque calificadas como proyectos menores. Entre comisiones y caja B para campañas, Odebrecht le entregó a Sergio Cabral la extraordinaria cifra de veintiséis millones doscientos mil (26.200.000) euros $^{737}$.

A pesar de lo acordado con Benedicto Junior, Sergio Cabral no siempre cumplió lo pactado con el empresario. Apenas regresó de un viaje a Paris, el Gobernador les comunicó a Odebrecht y Andrade Gutiérrez que Delta Construcciones, una sociedad administrada por Fernando Cavendish, compadre y amigo íntimo de Sergio Cabral también participaría de las obras de reforma del estadio de Maracaná ${ }^{738}$.

Las relaciones entre Cavendish y el Gobernador, de hecho, eran muy cercanas. Amantes del lujo y de las comodidades, ambos viajaron juntos a Paris en julio de 2009, acompañados del secretario de sanidad, Sergio Cortes, del asesor, Luiz Carlos de Bezerra, además de sus respectivas mujeres. El viaje se destinó a celebrar el cumpleaños de Adriana Anselmo, mujer de Sergio Cabral, quien cumpliría 39 años el 18 de julio de $2009^{739}$.

Se trató, por tanto, de un viaje de ocio, aunque no constó en la agenda oficial del Gobernador. Para los vecinos de Rio de Janeiro, desde principios de julio, se dijo que Sergio Cabral se quedaría toda la semana trabajando en el Palacio Guanabara, sede del gobierno estatal, dedicándose exclusivamente a funciones administrativas ${ }^{740}$. La realidad de los hechos desmintió esta afirmación. Durante las dos últimas semanas de julio de 2009, Cabral y sus amigos estaban en Francia para asistir a un concierto de música de la

\footnotetext{
${ }^{736}$ BRASIL. Tribunal Regional Federal (2 Região). Processo n. 0017513-21.2014.4.02.5101, p. 5.4525.453. Disponible em: http://www.jfrj.jus.br. Acceso en: 06 nov. 2019.

${ }^{737}$ Ibidem, p. 5.451-5.452.

${ }^{738}$ Ibidem, p. 5.452-5.453.

${ }^{739}$ CARDOSO, Tom. op. cit., L. 2.059.

${ }^{740}$ CORRÊA, Hudson. op. cit., L. 1.167.
} 
banda alternativa irlandesa U2 y celebrar el cumpleaños de Adriana, siendo muy distinto de realizar actividades administrativas en el Palacio de gobierno.

La idea fue agradar a su mujer y no propiamente cuidar del interés público, con lo cual Cabral aprovechó las vacaciones para darle una sorpresa. El Gobernador sabía que a su mujer Adriana le encantaban las joyas de la tienda Van Cleef \& Arpels, considerada una de las joyerías más famosas y caras del mundo en su momento, así que decidió regalarle una de las piezas de la tienda, un anillo de oro blanco con brillantes, el cual costó la impresionante cifra de doscientos veinte mil (220.000) euros ${ }^{741}$.

En definitiva, algunos minutos antes que comenzara la cena de cumpleaños, Cabral y Cavendish fueron hasta la tienda a recoger el regalo. Para sorpresa de Fernando, apenas recibió la factura, el Gobernador le pidió al compadre y amigo que la pagara con su tarjeta de crédito. Aunque se tratase de un esposo apasionado, Sergio Cabral no utilizó fondos propios para comprarle un regalo de cumpleaños a su mujer. Prefirió transferir esta responsabilidad al amigo y empresario, fiándose de que él no le negaría la solicitud.

En realidad, no se trató apenas de una mera cuestión de amistad. Con la medida buscó impedir que las autoridades brasileñas identificaran la compraventa e iniciaran una investigación por esta causa, además, a cambio del favor, Cabral le prometió a Cavendish que Delta Construcciones firmaría contratos con el Estado de Rio de Janeiro ${ }^{742}$.

Así las cosas, el favor de aquel momento tendría su posterior precio. Para la tranquilidad del compadre y del propio Gobernador, el regalo para Adriana Anselmo no lo pagaría Delta Construcciones, sino la Administración Pública a través de contratos de obras públicas. Esta es la razón por la que Delta Construcciones fue incorporada al consorcio para la reforma del estadio de Maracaná, es más, aunque era la más pequeña de las tres constructoras, Delta tendría derecho a treinta (30) por ciento del valor del contrato, colocándose entre los veintiún (21) por ciento de Andrade Gutierrez y los cuarenta y nueve (49) por ciento de Odebrecht ${ }^{743}$.

Pese a las protestas de Benedicto Junior y Rogerio Nora, el Gobernador se mantuvo irreductible. El anillo de oro blanco con brillantes que Cavendish compró le dio derecho suficiente para incorporarse al consorcio responsable de las obras del principal estadio de

\footnotetext{
${ }^{741}$ CARDOSO. Tom. op. cit., L. 2.070.

${ }^{742}$ BRASIL. Tribunal Regional Federal (2 Região). Processo n. 0017513-212014.4.02.5101. Disponible en: http://www.jfrj.jus.br/ Acceso en: 12 oct. 2019.

${ }^{743}$ Ibidem, p. 5.448-5.452.
} 
fútbol brasileño ${ }^{744}$. Para que esto sucediera sería importante orientar la licitación desde el principio, incorporando a los pliegos cláusulas que restringieran la participación de entidades ajenas al esquema. Se trató de cláusulas de naturaleza técnica que fueron redactadas directamente por los ingenieros de Odebrecht, y enviadas al Secretario Estatal de Obras con el objeto de colocarlas en los pliegos.

En otras palabras, aunque estaban firmados por un funcionario de la Administración Pública, los pliegos relativos a la reforma de Maracaná fueron elaborados, en realidad, por empleados de una de las compañías que participó de la licitación ${ }^{745}$.

En consecuencia, fue establecido como requisito de la licitación la previa participación en obras de construcción de estadios de fútbol con más de treinta mil (30.000) lugares. Aunque Odebrecht y OAS tenían esta experiencia ${ }^{746}$ ambas participaron de la construcción del Estadio Joao Avelange para los Juegos Panamericanos Rio $2007^{747}$.

Como Odebrecht y OAS no estaban juntas esta vez, los directivos de ambas compañías coincidieron en que OAS presentaría un valor superior al ofrecido por Odebrecht y consecuentemente quedaría fuera de la disputa. Existiría lo que las constructoras llamaban propuesta de cobertura, cuando una determinada compañía se presenta a la licitación únicamente para aparentar que hubo una disputa ${ }^{748} \mathrm{y}$ de hecho, así lo hicieron. En la propuesta de OAS se estableció que los costes en la ejecución de las obras llegarían a ciento cincuenta y cinco millones ochocientos mil (155.800.000) euros, mientras que Odebrecht propuso realizar las obras al precio de ciento cincuenta y cuatro millones doscientos mil (154.200.000) euros, lo que dio al consorcio la victoria en el torneo $^{749}$.

Los costes finales de las obras llegaron a doscientos sesenta y dos millones quinientos mil (262.500.000) euros, pese a los valores originalmente presentados, con una

\footnotetext{
${ }^{744}$ CORRÊA, Hudson. op. cit., L. 1241.

${ }^{745}$ BRASIL. op. cit.

${ }^{746}$ Ibidem, p. 5.455-5.456, p. 5.459-5.460.

${ }^{747}$ CORRÊA, Hudson. op. cit., L. 1.253.

${ }^{748}$ BRASIL. Tribunal Regional Federal (2 Região). Processo n. 0017513-21.2014.4.02.5101, p. 5.4555.456. Disponible em: http://www.jfrj.jus.br. Acceso en: 06 nov. 2019.

${ }^{749}$ REFORMA do Maracanã teve aditivos suspeitos e gastos em duplicidade, diz TCE-RJ. Disponible em: https://g1.globo.com/rio-de-janeiro/noticia/reforma-do-maracana-teve-aditivos-suspeitos-e-gastos-emduplicidade-diz-tce-rj.ghtml Acceso en: 12 oct. 2019.
} 
sobrefacturación equivalente a cuarenta y seis millones cien mil (46.100.000) euros, según lo evaluado por el Tribunal de Cuentas del Estado de Rio de Janeiro ${ }^{750}$. En definitiva, durante los primeros cuatro años de la gestión de Sergio Cabral, entre 2007 y 2010, Delta Construcciones perfeccionó

En el Estado de Rio de Janeiro los contratos eran equivalentes a doscientos ochenta y cuatro millones cuatrocientos mil (284.400.000) euros, con la particularidad de que una porción de estos acuerdos aproximadamente cuarenta y seis millones ochocientos mil (46.800.000) euros, fueron perfeccionados directamente sin previa licitación.

\subsubsection{Las Soluciones de ingeniería que limitaron la participación de entidades en cuanto a las obras de urbanización de favelas en Rio de Janeiro}

Las irregularidades en las obras de urbanización de favelas ocurrieron de la misma forma que las malas prácticas identificadas en la licitación para la reforma del estadio de Maracaná. Al principio, los funcionarios y directivos de las compañías se reunieron en secreto para establecer las estrategias destinadas a preparar las licitaciones. En seguida, formaron grupos de trabajo con el objetivo de estudiar las cláusulas que deberían estar en los pliegos y luego trataron de incorporarlas para asegurar la victoria de las constructoras que formaban parte del esquema. ${ }^{751}$

En efecto, antes que las licitaciones se iniciaran, los funcionarios de la Administración Pública del Estado y empresarios se reunieron al menos cuatro veces en el Palacio de gobierno para establecer la forma como pasarían las licitaciones. Durante los encuentros, Wilson Carlos (por entonces secretario de gestión de Sergio Cabral) reveló a Alberto Quintaes (director comercial de Andrade Gutierrez), que las licitaciones para la urbanización de la favela de Rocinha y de los conjuntos de favelas de Manguinhos y del Alemán serían ganadas por tres consorcios diferentes, liderados por las constructoras Queiroz Galváo, Andrade Gutierrez y Norberto Odebrecht.

La elección de cada una de las constructoras no fue una casualidad, según Wilson Carlos. Las compañías le donaron recursos a Sergio Cabral durante la disputa electoral contra la juez Denise Frossard, lo que contribuyó a su victoria. A cambio, el Gobernador

\footnotetext{
${ }^{750}$ Ibidem.

${ }^{751}$ BARBASSA, Juliana. op. cit., p. 48.
} 
regaló a las constructoras los contratos relativos a las obras de urbanización de cada una de estas favelas ${ }^{752}$.

Las obras abarcaron la construcción de cinco mil (5.000) viviendas populares, ocho (8) escuelas públicas, Centros de Cuidados Médicos, un (1) teleférico, un (1) ascensor en plano inclinado y un (1) puente elevado para ferrocarriles. Tras conocer las reglas, el 11 de junio de 2007, los representantes de Queiroz Galváo, Andrade Gutierrez, OAS, Carioca Ingeniería y Odebrecht se reunieron en secreto para dividir el objeto de cada licitación. Aunque no participó en el encuentro, Delta Construcciones también se incorporaría a uno de los consorcios por las estrechas relaciones que su principal directivo, Fernando Cavendish, siempre tuvo con el Gobernador Sergio Cabral ${ }^{753}$.

De acuerdo con Alberto Quintaes, durante estos encuentros, las compañías incorporaron exigencias de naturaleza técnica a los proyectos básicos y a los pliegos de las licitaciones, exactamente para dificultar que entidades independientes pudieran conquistar el derecho a ejecutar las obras. En otras palabras, se trataban de obras y soluciones de ingeniería que apenas ellas podrían ofrecer ${ }^{754}$. Todas las reuniones contaban con la asistencia del secretario de obras del Estado de Rio de Janeiro, Hudson Braga, quien interfirió directamente con la elaboración de los pliegos ${ }^{755}$.

Entre las exigencias destacaron las construcciones de un (1) teleférico, un (1) ascensor en plano inclinado y un (1) puente elevado para ferrocarriles, asignados a las favelas del Alemán, Rocinha y de Manguinhos respectivamente ${ }^{756}$.

Asimismo, durante las reuniones las compañías coincidieron en las propuestas que cada una presentaría en las licitaciones, aparentando, que hubo una verdadera disputa entre los interesados, es decir, todo fue un enorme teatro que buscó ocultar las malas prácticas de funcionarios inescrupulosos en la Administración Pública y de las propias constructoras.

\footnotetext{
752 BRASIL. Tribunal Regional Federal (2 Região). Processo n. 0017513-21.2014.4.02.5101, p. 5.4635.464. Disponible en: http://www.jfrj.jus.br. Acceso en: 06 nov. 2019.

${ }^{753}$ Ibidem, p. 5.464.

${ }^{754}$ Ibidem, p. 3.717.

${ }^{755}$ Ibidem, p. 5.483-5.485.

${ }^{756}$ Ibidem, p. 3.725.
} 
Desde esta perspectiva, incluso las audiencias públicas realizadas por la Administración no cumplieron con su papel. Cuando los encuentros fueron realizados en septiembre de 2007, todos sabían quienes ganarían cada licitación y como pasarían la disputa entre ellas ${ }^{757}$.

Con base a estos acuerdos, las licitaciones fueron ganadas, respectivamente, por los siguientes consorcios ${ }^{758}$ :

a) Favela de Rocinha: ganada por el Consorcio Nuevos Tiempos, formado por las constructoras Carioca Ingeniería y Queiroz Galváo, con inversiones de treinta y ocho millones cuatrocientos mil (38.400.000) euros;

b) Favela de Manguinhos: ganada por el Consorcio Manguinhos, formado por las constructoras CAMTER, EIT y Andrade Gutierrez, con inversiones públicas de cincuenta millones setecientos mil (50.700.000) euros;

c) Favela del Alemán: ganada por el Consorcio Rio Mejor, formado por las constructoras Norberto Odebrecht, OAS y Delta Construcciones, con inversiones de ciento siete millones ochocientos mil (107.800.000) euros.

Con respecto a la construcción del teleférico, conviene señalar que a duras penas la compañía francesa POMAGALSKI S.A disponía de los equipos necesarios para su instalación. Los directivos de Odebrecht trataron de firmar con la entidad un contrato exclusivo de compraventa de ese equipamiento para Brasil, con lo cual trataron de evitar que compañías independientes lograran también ganar la disputa.

Para que todo sucediera como si hubiese una competencia entre los licitantes, Odebrecht también adoptó las providencias debidas para que los consorcios participantes del esquema lograran presentar los mismos documentos que la compañía francesa. Todos los consorcios estaban, en teoría, en condiciones de ejecutar el proyecto, ya que podrían obtener de la compañía francesa los equipos necesarios.

En otras palabras, existiría una competencia entre los tres consorcios en la licitación para las obras de la favela del Alemán, aunque internamente todos sabían quienes vencerían la disputa ${ }^{759}$. Las inversiones públicas llegaron a doscientos sesenta y dos

\footnotetext{
${ }^{757}$ Ibidem, p. 3.727 y p. 5.466 .

758 Ibidem, p. 3.732 y p. 5.465 .

${ }^{759}$ Ibidem, p. 5.46y.
} 
millones quinientos mil (262.500.000) euros ${ }^{760}$, con lo cual se confirmó que los mega eventos deportivos atraen grandes inversiones para la ciudad responsable de su organización. También se confirmó la tendencia que tales mega eventos constituyen un ambiente favorable para cometer malas prácticas administrativas en los contratos perfeccionados con motivo de su preparación.

\subsubsection{Las exigencias técnicas que restringieron la participación de entidades en cuanto a las obras de construcción del BRT Transcarioca}

Las malas prácticas del Gobernador Sergio Cabral y su banda no agotaron el universo de irregularidades asociadas a la realización de los Juegos Olímpicos Rio 2016. Con base en los acuerdos de lenidad perfeccionados por altos directivos y funcionarios de la constructora Carioca Christiani Nielsen Engenharia, ${ }^{761}$ fue posible verificar que los ilícitos cometidos en la gestión estatal, rápidamente, llegaron al Municipio de Rio de Janeiro donde se concentraron en la Secretaría de Obras del referido ente político, en aquel entonces dirigida por Alexandre Pinto da Silva.

Igual que su homologo estatal, Alexandre identificó en las obras de infraestructura y recuperación ambiental a cargo del municipio una oportunidad para lograr excelentes ventajas económicas indebidas, aunque tuviese que compartir parte de las ganancias con otros funcionarios o particulares directamente involucrados con las malas prácticas.

Como en el ámbito estatal, las malas prácticas presentaron rasgos comunes, todas las irregularidades comenzaron a partir de reuniones secretas entre altos funcionarios de la Administración Pública y particulares, evolucionando para un régimen de licitaciones preparadas y pagos de ventajas indebidas, a menudo calculadas a partir de un porcentaje sobre el monto del contrato.

Con base en esta estructura, las irregularidades perpetradas en el Municipio de Rio de Janeiro, más bien se concentraron en las licitaciones y contratos destinados a la construcción de la línea de autobús de tránsito rápido en Rio de Janeiro, que conecta Barra da Tijuca con el Aeropuerto Internacional de Galeáo, mejor conocida como el BRT

760 THUSWOHL, M. Começam Obras em Três Favelas do Rio. Carta Maior. Disponible en: http://cartamaior.com.br/?/Editoria/Politica/Comecam-obras-do-PAC-em-tre $\quad$ s-favelas-do-Rio- deJaneiro/4/13767 Acceso en: 24 sep. 2019.

${ }^{761}$ BRASIL. Tribunal Regional Federal (2 Região). Processos n. 0506972-95.2016.4.02.5101; 050755143.2016.4.02.5101; 0029142-84.2017.4.02.5101. Disponible en: http://www.jfrj.jus.br . Acceso en: 09 out 2019. 
Transcarioca y la recuperación ambiental de la cuenca hidrográfica de Jacarepaguá, dos obras directamente asociadas al legado olímpico de los juegos.

En efecto, las obras de construcción del BRT Transcarioca estuvieron directamente asociadas al tema de la movilidad urbana en Rio de Janeiro y buscaron solucionar los graves problemas del sistema de transporte de la ciudad, considerada la segunda más poblada de Brasil. Adoptado en doscientas (200) ciudades alrededor del planeta, el Bus Rapid Transit utiliza carriles exclusivos para autobuses durante todo el trayecto ${ }^{762}$, con lo cual se buscó facilitar el desplazamiento de los vecinos entre las regiones más distantes de la ciudad.

En Rio, el sistema conecta al aeropuerto internacional con el barrio de la Barra de la Tijuca, donde estuvieron las principales instalaciones olímpicas, extendiéndose a lo largo de treinta y nueve (39) km. Su construcción contempló veintisiete (27) barrios de la capital, beneficiando a trescientos veinte mil (320.000) viajeros diariamente, convirtiéndose en una de las principales obras de ingeniería asociadas al mega evento.

Su magnitud se nota, fundamentalmente, a partir de las intervenciones realizadas con motivo de su edificación. Las obras del BRT Transcarioca demandaron la construcción de diez (10) viaductos, nueve (9) puentes, tres (3) túneles, cuarenta y siete (47) estaciones y cinco (5) terminales de pasajeros a lo largo de todo el trayecto ${ }^{763}$. Las obras costaron cien millones doscientos noventa y un mil treinta (100.291.030) euros y fueron financiadas con recursos del Banco Nacional de Desenvolvimiento Económico y Social (BNDES) ${ }^{764}$ tratándose de recursos públicos.

Asimismo, en lo jurídico, la gran dimensión del proyecto hizo ejecutar las obras por etapas, también llamadas lotes, con la realización de licitaciones diferentes para cada tramo de la construcción. Como en el caso de las obras del arco vial metropolitano, el fraccionamiento del objeto estaba de conformidad con la legislación brasileña ${ }^{765}$, la jurisprudencia del Tribunal de Cuentas de la Unión ${ }^{766}$ y la jurisprudencia del Tribunal

\footnotetext{
762 WRI BRASIL. Disponible en: http://wricidades.org/BRT . Acceso en : 10 out 2019.

${ }^{763}$ Disponible en: http://www.rio.rj.gov.br/web/guest/exibiconteudo?id=4756186 Acceso en: 10 out 2019. ${ }^{764}$ BNDES. Disponible en: http://www.bndes.gov.br/wps/portal/site/home . Acceso en: 10 out 2019.

765 Art. 23, $\S 1^{\circ}$. Cf. BRASIL. Lei n. 8.666/1993, op.cit.

${ }^{766}$ BRASIL. Tribunal de Contas da União. Acórdão n. 1.521/2003-TCU-Plenário e Decisão n. 186/1999TCU-Plenário, Decisão n. 811/2002-TCU-Plenário. Disponible em: https://portal.tcu.gov.br/inicio/. Acceso en: 10 out 2019.
} 
Superior de Justicia ${ }^{767}$, con lo cual aparentemente se trataba de una conducta conforme a las buenas prácticas.

Ahora bien, en base a e este fraccionamiento, el trecho correspondiente al carril número 5, lote 2, responsable de conectar el barrio de la Penha al aeropuerto internacional, fue construido por el Consorcio Transcarioca Rio, formado por las constructoras Carioca Christiani Nielsen Engenharia, OAS S.A y Contern, ganadoras de la licitación realizada por el Municipio de Rio de Janeiro (Concurrencia núm. CO-42/2010) ${ }^{768}$.

Las obras fueron financiadas con recursos públicos gestionados por el BNDES ${ }^{769}$. A pesar de su origen, no todo lo invertidos en la obra fue utilizados para la construcción. Parte de las inversiones se destinaron al pago de ventajas indebidas a funcionarios de la Secretaría de Obras del Municipio de Rio de Janeiro y Ministerio de las Ciudades, más allá de particulares que se aprovecharon de su posición para aumentar sus ganancias a causa del mega evento.

Uno de los beneficiados fue el empresario Laudo Aparecido Dalla Costa Ziani, un Pernambucano que vivió en Rio de Janeiro en 2011, quien disfrutó, en su momento, de gran prestigio junto a funcionarios y altos directivos del Ministerio de las Ciudades.

Laudo estuvo casado con la hija del Diputado Federal Pedro Correa durante los años que antecedieron la realización de los Juegos Olímpicos Rio $2016^{770}$. Durante este período, Pedro Correa y su partido formaban parte de la base de apoyo del gobierno, que como consecuencia, controlaban uno de los más importantes Ministerios brasileños: el Ministerio de las Ciudades. Este órgano tuvo un papel fundamental en la preparación de las Olimpíadas Rio 2016, responsabilizándose de aprobar las principales obras de movilidad urbana asociadas al mega evento.

\footnotetext{
${ }^{767}$ BRASIL. Superior Tribunal de Justiça (2 Turma). Processo RMS n. 6.597/MS. Rel. Min. Antonio de Padoa Ribeiro. jul. 16.12.1996. Disponible en: www.stj.jus.br. Acceso en: 10 out 2019.

${ }^{768}$ BRASIL. Tribunal Regional Federal (2 Região). Processo n. 0174071-16.2017.4.02.5101. Disponible

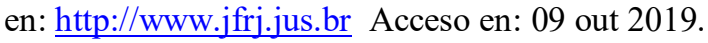

769 BNDES. BNDES e prefeitura do Rio de Janeiro assinam contrato do BRT Transcarioca. Disponible en: https://www.bndes.gov.br/wps/portal/site/home/imprensa/noticias/conteudo/20110110_brt_contrato Acceso en: 10 oct. 2019.

${ }^{770}$ GENRO do ex-deputado federal Pedro Corrêa é preso em nova fase da Lava Jato em Pernambuco. Disponible en: https://g1.globo.com/pernambuco/noticia/genro-do-ex-deputado-federal-pedro-correa-epreso-em-nova-fase-da-lava-jato-em-pernambuco.ghtml Acceso en: 10 oct. 2019.
} 
Con base al poder político de su suegro, Laudo también disfrutaba de gran prestigio en cuanto a los altos directivos del órgano. Su fama y poder para influenciar en las decisiones del Ministerio eran conocidos en todo el sector de la construcción civil, tanto que a menudo empresarios y constructoras buscaban su apoyo para aprobar proyectos de obras públicas en el mencionado órgano. Uno de estos empresarios fue el carioca Antonio Cid Campelo Rodrigues, alto directivo de la constructora OAS, quien procuró a Laudo en el 2011, con objeto de influenciar las decisiones del Secretario Nacional de Movilidad Urbana $^{771}$.

Antonio participó de algunas reuniones sociales en la casa de Laudo Ziani en las que el secretario estuvo presente, por lo que conocía la naturaleza de las relaciones entre ambos. En base a estas relaciones, la constructora tenía la ambición de que el ministerio incluyese la construcción del BRT Transcarioca entre las obras de infraestructura asociadas a la Copa del Mundo de Fútbol FIFA 2014 y a los Juegos Olímpicos Rio 2016, lo que posibilitaría la realización de inversiones federales en el emprendimiento ${ }^{772}$.

En efecto, con motivo de la Copa del Mundo de Fútbol FIFA 2014 y de las Olimpíadas Rio 2016, había muchas obras de infraestructura y movilidad urbana por realizar en todo el Brasil, aunque no todas fuesen contempladas con recursos federales para su ejecución. Para que ello pasara, sería fundamental que el Secretario Nacional de Movilidad Urbana se manifestase favorablemente al proyecto, con lo cual la referida obra sería financiada con recursos del BNDES ${ }^{773}$.

En otras palabras, sin la manifestación favorable del secretario, las obras para la construcción del BRT Transcarioca no llegarían a calificarse como fundamentales para la movilidad urbana y por consiguiente, no recibirían inversiones del BNDES para su ejecución. Sin el visto bueno del secretario muy probablemente esta construcción ni siquiera llegaría a realizarse, porque no existirían recursos suficientes para su financiación ${ }^{774}$.

\footnotetext{
${ }^{771}$ BRASIL. Tribunal Regional Federal (2 Região). Processo n. 0174071-16.2017.4.02.5101, p. 795-803. Disponible en: http://www.jfrj.jus.br. Acceso en: 12 oct. 2019.

${ }^{772}$ Ibidem.

${ }^{773}$ BNDES. op. cit.

${ }^{774}$ BRASIL. op.cit., p. $795-803$ y p. 6.139.
} 
Considerando esta realidad, la labor de Laudo Ziani tenía gran valor para la constructora. Los directivos de OAS esperaban que los fuertes lazos familiares entre Laudo y Pedro Correa fuesen lo suficientemente poderosos para convencer al Secretario Nacional de Movilidad Urbana de incluir la construcción del BRT Transcarioca entre las obras financiadas con recursos del banco.

Consciente del papel que jugaba en situaciones de esta naturaleza, al recibir la solicitud, Laudo Ziani viajó a Brasilia para reunirse con el Secretario Nacional de Movilidad Urbana ${ }^{775}$. Por la relevancia de los asuntos tratados, sería razonable esperar que las partes documentasen lo sucedido a través de un acta u otro documento, que permitiera el control social de los actos oficiales ${ }^{776}$.

Así como sucedió en otras esferas de gobierno, aquí tampoco se produjo ningún acta o documento que indicara el contenido de los debates entre Laudo Ziani y el secretario. Lo único que se supo fue que, con base en lo discutido durante la visita, el secretario incluyo la construcción del BRT Transcarioca entre las obras de movilidad urbana asociadas a los Juegos Olímpicos Rio 2016. Consecuentemente, fueron asegurados los recursos del BNDES para su ejecución ${ }^{777}$.

Laudo viajó de vuelta a Rio de Janeiro, y allí se reunió con Antonio Cid para comunicarle que cumplió con éxito la tarea a su cargo. Las obras para la construcción del BRT Transcarioca serían financiadas con recursos federales. Lo único que faltaba, era que la constructora cumpliese con su parte en el pacto y pagarle un uno (1) por ciento del monto del contrato a título de comisión ${ }^{778}$.

Apenas se conoció la demanda, Antonio Cid llevó la solicitud a los directivos de OAS, para que evaluaran la propuesta considerando los beneficios que tendrían al obtener un futuro contrato, todos coincidieron con pagarle a Laudo Ziani lo solicitado por este ${ }^{779}$. Las declaraciones de Antonio Cid fueron corroboradas por Reginaldo Assunção, director de OAS en Rio de Janeiro. El empresario señaló el papel relevante que Laudo Ziani jugó

\footnotetext{
${ }^{775}$ Ibidem, p. 6.144-6.146.

${ }^{776}$ BRASIL. Tribunal Regional Federal (2 Região). Processo n. 0004639-62.2018.4.02.5101. Disponible en: http://www.jfrj.jus.br Acceso en: 12 oct. 2019.

${ }^{777}$ Ibidem.

${ }^{778}$ Ibidem.

${ }^{779}$ Ibidem.
} 
para que la construcción del BRT Transcarioca fuese incluida entre las obras de movilidad urbana de la Copa del Mundo de Fútbol FIFA 2014 y las Olimpíadas Rio $2016^{780}$.

Antonio y Reginaldo también señalaron que al contrario de los directivos de Andrade Gutierrez en cuanto a las obras gestionadas por el Estado de Rio de Janeiro, no se iba a realizar pago por adelantado. La comisión únicamente se entregaría tras la ganar la compañía el derecho a ejecutar las obras objeto del pacto ${ }^{781}$. Para que ello sucediera, los funcionarios de OAS buscaron al Secretario Municipal de Obras de Rio de Janeiro, Alexandre Pinto da Silva, con la finalidad que adoptara providencias para que la compañía lograra el derecho a ejecutar el proyecto de construcción del BRT Transcarioca $^{782}$. Apenas se conocía la solicitud, ocurría lo mismo en una reunión en la que no se produjo ningún acta o documento, y Alexandre trató de presentar su demanda a las compañías.

En este sentido, no solo Laudo Ziani cobró comisiones del consorcio Transcarioca Rio. Funcionarios y altos directivos de la Secretaría de Obras del Municipio de Rio de Janeiro también cobraron el pago de una ventaja de uno (1) por ciento sobre el monto del contrato, destacando al propio Secretario Municipal de Obras, Alexandre Pinto da Silva ${ }^{783}$.

En efecto, pese a que estuviese legalmente obligado a velar por la transparencia ${ }^{784}$ y la ética ${ }^{785}$ en la gestión de los intereses públicos asociados a la ejecución de tales emprendimientos, Alexandre se aprovechó del cargo para obtener ventajas económicas indebidas. Por tanto, se reunió con altos directivos de la constructora Carioca Christiani Nielsen Ingeniería y presentó los motivos que justificaban el cobro de la comisión.

\footnotetext{
${ }^{780}$ BRASIL. Tribunal Regional Federal (2 Região). Processo n. 0174071-16.2017.4.02.5101, p. 6143. Disponible en: http://www.jfrj.jus.br. Acceso en: 12 oct. 2019.

${ }^{781}$ BRASIL. Tribunal Regional Federal (2 Região). Processo n. 0004639-62.2018.4.02.5101. Disponible en: http://www.jfrj.jus.br Acceso en: 12 oct. 2019.

${ }^{782}$ Ibidem

${ }^{783}$ BRASIL. Tribunal Regional Federal (2 Região). Processos n. 0506972-95.2016.4.02.5101, 050755143.2016.4.02.5101 y 0029142-84.2017.4.02.5101. Disponible en: http://www.jfrj.jus.br/ Acceso en: 12 oct. 2019.

${ }^{784}$ Art. $1^{\text {o }}$, parágrafo único. Cf. BRASIL. Lei n. 12.527/2011, op.cit.

${ }^{785}$ BRASIL. Lei n. 8.429/1992, de 2 de junho de 1992. Dispõe sobre as sanções aplicáveis aos agentes públicos nos casos de enriquecimento ilícito no exercício de mandato, cargo, emprego ou função na administração pública direta, indireta ou fundacional e dá outras providências. Disponible en:http://www.planalto.gov.br/ccivil 03/LEIS/L8429.htm Acceso en: 27 jun 2019.
} 
Según el secretario, al acordar el pago de la ventaja, la constructora directamente a través del consorcio ganaría la licitación, logrando el derecho a ejecutar las obras de construcción del BRT Transcarioca. Asimismo, a raíz del pacto, los ingenieros de la Secretaría de Obras tampoco serían rigurosos en cuanto a identificar posibles errores en la ejecución del proyecto aprobado por el municipio. Con base a esta menor fiscalización, la compañía podría utilizar materiales de calidad inferior en las obras, lo que al final, acabaría con reducir los costes y aumentar las ganancias en la ejecución del emprendimiento.

En otras palabras, la omisión de las autoridades posibilitaría que la constructora recuperase los montos cancelados a título de comisión con la disminución de la calidad de los materiales empleados en las obras, por lo cual todos ganarían en el pacto.

De todo esto, llama la atención dos aspectos importantes en la propuesta. Inicialmente Alexandre Pinto utilizó las prerrogativas de su cargo para subvertir las reglas que gobiernan la contratación pública en Brasil. Según la Ley núm. 8.666, de 21 de junio de 1993, de Licitaciones y Contratos Administrativos, las partes deben cumplir fielmente las cláusulas del contrato, con observación estricta al principio pacta sunt servanda.

Una vez perfeccionado el contrato con la Administración Pública, la empresa Carioca Christiani Nielsen Ingeniería, necesariamente, debería emplear en las obras los materiales acordados en el proyecto aprobado por el municipio, bajo el riesgo de que tal conducta pudiera caracterizar el incumplimiento del contrato ${ }^{786}$.

Con el objetivo de asegurar que el contratista cumpliera con su obligación, o sea, que empleara los materiales relacionados en el proyecto, la ley también establece que la Administración Pública designará un representante para acompañar y fiscalizar las

\footnotetext{
${ }^{786}$ Art. 66. Cf. BRASIL. Lei n. 8.666/1993, de 21 de junho de 1993. Regulamenta o art. 37, inciso XXI, da Constituição Federal, institui normas para licitações e contratos da Administração Pública e dá outras providências. Disponible en: http://www.planalto.gov.br/ccivil 03/leis/18666cons.htm Acceso en: 27 jun. de 2019.
} 
bras $^{787}$, quien deberá identificar las irregularidades ${ }^{788}$, registrarlas en libro propio $^{789} \mathrm{y}$ determinar que el contratista las corrija en tiempo oportuno ${ }^{790}$.

Al contrario de lo manifestado por el Secretario Municipal de Obras, el registro de las irregularidades no caracterizaba un acto discrecional de los responsables de la fiscalización, sino un acto vinculado a la Administración Pública, con lo cual no podría dejar de practicarse basado en pactos espurios, perfeccionados entre el jefe de la secretaría y directivos de la entidad contratada por el Estado.

A tal efecto, el registro fiel y oportuno de las faltas condiciona la actuación de la Administración Pública en esta materia, particularmente al pago de los dispendios asociados con la ejecución objeto del contrato, o sea, la construcción del BRT Transcarioca.

Con base en tales registros, la Administración Pública y los ciudadanos podrán verificar la compatibilidad entre lo establecido en el proyecto básico y lo verdaderamente ejecutado, bien sea en lo relativo a la cualidad, o en lo relativo a la cantidad $^{791}$. En cualquier caso, permaneciendo los vicios o defectos, a la Administración Pública se le reconoce la prerrogativa de recusar, total o parcialmente, la obra o servicio contratado, ${ }^{792}$ aplicándosele al infractor la sanción correspondiente. ${ }^{793}$ Finalmente, en base a la jurisprudencia del Tribunal de Cuentas de la Unión, optando la Administración por recusar el objeto del contrato, deberá adoptar las medidas necesarias para cancelar todos los pagos a favor del contratista infractor. ${ }^{794}$

\footnotetext{
${ }^{787}$ Art. 67. Ibidem.

788 BRASIL. Tribunal de Contas da União. Acórdão n. 265/2010-TCU-Plenário. Disponible en: https://portal.tcu.gov.br/inicio/ Acceso en: 25 out 2019.
}

789 BRASIL. Tribunal de Contas da União. Acórdão n. 1731/2009-TCU-Plenário. Disponible en: https://portal.tcu.gov.br/inicio/ Acceso en: 25 out 2019.

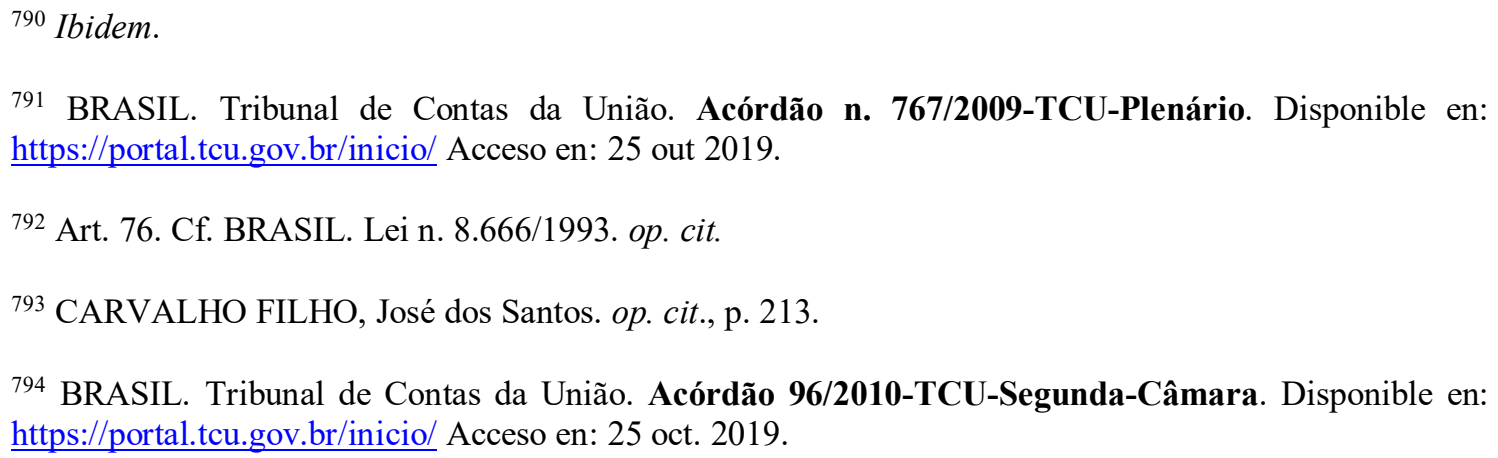
https://portal.tcu.gov.br/inicio/ Acceso en: 25 out 2019.

792 Art. 76. Cf. BRASIL. Lei n. 8.666/1993. op. cit.

${ }^{793}$ CARVALHO FILHO, José dos Santos. op. cit., p. 213.

794 BRASIL. Tribunal de Contas da União. Acórdão 96/2010-TCU-Segunda-Câmara. Disponible en: https://portal.tcu.gov.br/inicio/ Acceso en: 25 oct. 2019. 
Aunque existiera todo este régimen legal y jurisprudencial alrededor del trabajo de los fiscales en las obras, el secretario Alexandre Pinto decidió apartarse de ellos y crear sus propias reglas para la contratación de Carioca Christiani Nielsen Ingeniería. Al aceptar la propuesta, se reconocería el "derecho" de emplear materiales de calidad inferior de lo previsto en las obras y los fiscales del Municipio no registrarían las faltas, así como tampoco aplicarían sanciones a causa de ello.

Otro aspecto que llama la atención en la propuesta hace referencia al razonamiento utilizado por el secretario con la finalidad de convencer a los directivos de Carioca Christiani Nielsen Ingeniería en cuanto a los beneficios de la corrupción. Según Alexandre Pinto, aunque pagara los montos correspondientes a su comisión, la compañía podría recuperarlos rápidamente con la utilización de materiales de calidad inferior de lo previsto en el proyecto de las obras.

Con base en este discurso, la corrupción es presentada como un negocio en que todos ganan, tanto el corrupto como el corrompido, con lo cual no habría motivo para remordimientos en cuanto a su cometimiento. La corrupción permitiría a la empresa superar los obstáculos creados por la burocracia administrativa y facilitaría el desarrollo de su actividad económica y fomentaría la creación de empleos y la recaudación de tributos, beneficiando a todos ${ }^{795}$.

Aun cuanto los beneficios que produciría para todos los involucrados, Alexandre Pinto no logró explicar los motivos por los cuales había existido una reunión entre el jefe de la Secretaría Municipal de Obras y los empresarios sucedió a escondidas. Según Roberto José Teixeira Goncalves, directivo general de la constructora Carioca Ingeniería ${ }^{796}$, la reunión no ocurrió en la sede de la Secretaría de Obras del Municipio, exactamente para que las partes pudieran tratar estos temas con mayor libertad. El encuentro sucedió en un restaurante en la región central de Rio de Janeiro y tampoco fue registrado a través de cualquier acta o documento.

En otras palabras, a pesar de las consecuencias de los acuerdos que habían sido perfeccionados, los ciudadanos no fueron informados de su existencia, ni de los

\footnotetext{
${ }^{795}$ LEFF, N. Economic Development trough Bureaucratic Corruption. VV.AA. Political Corruption. New Jersey,1989, p. 389 y ss. In ALFARO, Luis Humberto Contreras. Corrupción y principio de oportunidad: alternativas en materia de prevención y castigo a la respuesta penal tradicional. Salamanca, Ratio Legis, 2005, p. 141.

${ }^{796}$ BRASIL. Tribunal Regional Federal (2 Região). Processo n. 0507551-43.2016.4.02.5101. Disponible en: http://www.jfrj.jus.br . Acceso en: 10 out 2019.
} 
compromisos realizados entre ellos, exactamente porque esto implicaba revelar un conjunto de malas prácticas cometidas en el seno de la Secretaría de Obras del Municipio y que deberían haber permanecido en secreto.

Considerando los beneficios que tendrían al obtener un futuro contrato, todos coincidieron con pagarle a Alexandre Pinto lo requerido. En cambio, el secretario trató de incluir en los pliegos exigencias de naturaleza técnica que inviabilizaban la participación de entidades ajenas al grupo formado por las grandes constructoras brasileñas.

Tras algunas reuniones entre funcionarios de la Secretaría e ingenieros de OAS, Eduardo Fagundes, ingeniero que actuaba como funcionario en las obras del municipio, presentó la versión final de los pliegos que gobernarían las licitaciones. Todos contenían exigencias técnicas que únicamente las grandes constructoras brasileñas podrían cumplir $^{797}$, tales como la construcción de un puente estriada con sección horizontal y vertical en curva ${ }^{798}$.

Es cierto que algunas constructoras medianas se presentaron a la licitación para realizar parte de las obras del BRT Transcarioca, sin embargo, las exigencias técnicas fijadas en secreto en los pliegos impidieron la fase de habilitación y, en consecuencia, todas acabaron siendo eliminadas de la disputa ${ }^{799}$.

Con la victoria asegurada, el consorcio Transcarioca Rio pudo finalmente ejecutar las obras destinadas a la construcción del tramo correspondiente al trecho número 5 , lote 2, del BRT Transcarioca, que conectó el barrio de Penha al aeropuerto Internacional. Las inversiones públicas llegaron a cien millones doscientos noventa y un mil treinta (100.291.030) euros, lo que demostraba el empeño de los involucrados en frustrar el carácter competitivo de la licitación y adquirir el derecho de contratar con la Administración Pública.

\footnotetext{
${ }^{797}$ BRASIL. Tribunal Regional Federal (2 Região). Processo n. 0004639-62.2018.4.02.5101. Disponible en: http://www.jfri.jus.br. Acceso en: 12 oct. 2019.

${ }^{798}$ BRASIL. Tribunal Regional Federal (2 Região). Processo n. 0174071-16.2017.4.02.5101, p. 795-803. Disponible en: http://www.jfrj.jus.br. Acceso en: 12 oct. 2019.

${ }^{799}$ Ibidem.
} 


\subsubsection{Las cláusulas técnicas que limitaron el número de licitadores en cuanto a las obras} de recuperación ambiental de la cuenca hidrográfica de Jacarepaguá

Otra de las obras asociadas al legado de los juegos fue la recuperación de la cuenca hidrográfica de Jacarepaguá, resultando directamente de los compromisos que Brasil perfeccionó con el COI por motivo de las olimpíadas.

A partir de los años noventa (90's), para coincidir el discurso olímpico con los grandes problemas mundiales, el COI estableció que las ciudades interesadas en acoger una edición de los juegos se obligaban a fomentar la responsabilidad ambiental. Por consiguiente, debían asociar la realización de las olimpíadas a la recuperación de áreas ambientalmente degradadas, realizando obras de saneamiento básico, destinadas a la rehabilitación de Rios, lagos, lagunas, cuencas hidrográficas y bahías ${ }^{800}$.

Atendiendo a estas exigencias, los Juegos de Sídney 2000 propusieron un nuevo concepto para las olimpíadas. El mega evento ya no atendería únicamente la regeneración urbana de la ciudad, o sea, la construcción de grandes monumentos para las presentes y futuras generaciones, tampoco la ejecución de grandes obras de infraestructura, ocupándose en fomentar el desarrollo sustentable de la ciudad, con la recuperación de áreas ambientalmente destruidas ${ }^{801}$.

En este sentido, la propuesta presentada por los australianos al COI, en 1993, señaló que los Juegos Olímpicos 2000, quedarían en la historia como los “Juegos Verdes". Así las cosas, con base en el proyecto olímpico, tendrían una perfecta armonía entre la realización del mega evento y el medio ambiente, con una total integración entre las instalaciones olímpicas y la naturaleza ${ }^{802}$. Como consecuencia, todos los equipamientos olímpicos fueron ubicados en un parque a las afueras de la ciudad, donde se exaltó la naturaleza, con la creación de jardines y espacios verdes por todas partes. El parque se localizó en una región cercana a la bahía de Homebush, un área totalmente recuperada tras las grandes inversiones realizadas por el Gobierno Australiano.

En 1930, la bahía de Homebush era una región completamente destruida, con algas marinas por todas partes, lo que resultó de su contaminación a causa de residuos de todo

\footnotetext{
${ }^{800}$ CARTA OLÍMPICA 1991, p. 11. Disponible en: https://www.olympic.org/olympic-studiescentre/collections/official-publications/olympic-charters. Acceso en: 16 de jul 2018.

${ }^{801}$ GOLDBLATT, David. op. cit., p. 364.

${ }^{802}$ GOLD, John R.; GOLD, Margaret M. op. cit., p. 53-54.
} 
tipo. Con motivo de los juegos, las autoridades trataron de recuperar e incorporar a la ciudad como resultado de las nuevas exigencias fijadas por el COI en esta materia ${ }^{803}$.

Estas exigencias también estuvieron presentes en los Juegos Olímpicos de Rio 2016. Por los acuerdos realizados con el COI, la ciudad debía utilizar al mega evento para recuperar regiones degradadas ambientalmente, como la cuenca hidrográfica de Jacarepaguá, formada por ocho (8) Rios y un (1) canal, totalmente contaminado por la basura y residuos orgánicos de todo tipo. Por lo general, los expertos consideraban que la cuenca estaba biológicamente muerta, porque muchos de los Rios que la formaban no tenían oxigeno que posibilitara la existencia de vida animal o vegetal dentro de ellos ${ }^{804}$.

Para resolver este problema, el Municipio de Rio de Janeiro se comprometió con el COI para edificar cinco unidades de tratamiento de alcantarilla en la región, lo que impuso la necesidad de contratar grandes compañías de ingeniería para que realizaran la tarea ${ }^{805}$.

Así como pasó en el caso del BRT Transcarioca, la magnitud del proyecto hizo que las autoridades realizaran varias licitaciones para la construcción de las unidades posibilitando la participación de consorcios privados para la ejecución de las obras ${ }^{806}$.

Todo indicaba que las autoridades actuaban según el interés público, ya que la división del objeto y la participación de consorcios privados incentivaba la presencia de un mayor número de interesados, lo que al final, acababa beneficiando a la propia Administración Pública.

Por otro lado, la decisión también estaba de conformidad con la legislación brasileña ${ }^{807}$, la jurisprudencia del Tribunal de Cuentas de la Unión ${ }^{808}$ y la jurisprudencia

803 CASHMAN, R. The Sydney Olympic Park model: its evolution and realization. In: HAY, A.; CASHMAN, R. (ed.). Connecting Mega Events Cities: A Publication for the 9th World Congress of Metropolis. Sydney: Sydney Olympic Park Authority, 2008, p. 28.

${ }^{804}$ BERTHONE, R. Programa de Recuperação de Bacia de Jacarepaguá avança de forma lenta. O Globo. Disponible en: https:/oglobo.globo.com/rio/bairros/programa-de-recuperacao-de-bacia-de-jacarepaguaavanca-de-forma-lenta-1-19812922 Acceso en: 10 oct. 2019.

${ }^{805}$ BRASIL, Tribunal Regional Federal (2 Região). Processos n. 0506972-95.2016.4.02.5101; 050755143.2016.4.02.5101; 0029142-84.2017.4.02.5101. Disponible en http://www.jfrj.jus.br . Acceso en: 10 out 2019.

${ }^{806}$ Ibidem.

${ }^{807}$ Art. 23, § $1^{\text {o }}$. Cf. BRASIL. Lei n. 8.666/1993. op. cit.

${ }^{808}$ BRASIL. Tribunal de Contas da União. Acórdão n. 1.521/2003-TCU-Plenário e Decisão n. 186/1999TCU-Plenário, Decisão n. 811/2002-TCU-Plenário. Disponible en: https://portal.tcu.gov.br/inicio/. Acceso em: 10 out. 2019. 
del Superior Tribunal de Justicia ${ }^{809}$, con lo cual, en apariencia, se trataba de una conducta conforme al derecho.

En base a estas premisas, fueron realizados diferentes contratos perfeccionados para cada emprendimiento, también llamados lotes o tramos. En este sentido, la licitación correspondiente a los lotes 1-B y 1-C fue ganada por el Consorcio Rios de Jacarepaguá, formado por las constructoras Carioca Christiani Nielsen Engenharia y Andrade Gutierrez, quienes ejecutaron las obras con recursos de la Caixa Económica Federal, una institución bancaria brasileña que realizó grandes inversiones públicas con motivo de la preparación de la Copa del Mundo de Fútbol FIFA2014 y de las Olimpíadas Rio 2016.

Desde esta perspectiva, los recursos para la recuperación de la cuenca de Jacarepaguá (lotes 1-B y 1-C) fueron transferidos para el Municipio de Rio de Janeiro a través del contrato de financiamiento núm. 0293.552-59. Asimismo, el total de las inversiones llegó a cincuenta y dos millones doscientos setenta y un mil quinientos treinta y dos euros con sesenta y un céntimos $(52.271 .532,61 €)^{810}$, lo que bastaba para demostrar la importancia que el tema de la recuperación ambiental había adquirido durante el período de preparación de los juegos.

Además, la magnitud de los recursos transferidos demostró a las autoridades locales la total responsabilidad en cuanto a la utilización de los fondos públicos, ya que sería imprescindible realizar licitaciones transparentes y competitivas, con el objetivo de seleccionar la propuesta que mejor atendiese a los intereses de la Administración Pública.

De igual manera sucedió en otras oportunidades, la licitación referente a los lotes 1-B y 1-C, también fue orientada para que apenas las constructoras Carioca Christiani Nielsen Engenharia y Andrade Gutierrez lograsen el derecho a contratar con la Administración Pública. Los responsables de las irregularidades, en este caso, fueron el Secretario de Obras del Municipio de Rio de Janeiro, Alexandre Pinto da Silva y el ingeniero municipal Carlos Frederico Peixoto Pires.

Para que tuviesen la garantía de que el Consorcio Rios de Jacarepaguá conquistase el derecho a contratar con el municipio, Alexandre y Carlos llegaron a reunirse con los

\footnotetext{
${ }^{809}$ BRASIL. Superior Tribunal de Justiça (2 Turma). Processo RMS n. 6.597/MS, Rel. Min. Antonio de Padua Ribeiro. jul. 16 de dezembro de1996. Brasília, DF: Superior Tribunal de Justiça [1996]. Disponible em http://www.stj.jus.br/sites/portalp/Inicio Acceso en: 12 oct. 2019.

${ }^{810}$ BRASIL, Tribunal Regional Federal (2 Região). Processos n. 0506972-95.2016.4.02.5101; 050755143.2016.4.02.5101; 0029142-84.2017.4.02.5101. Disponible en: http:/www.jfrj.jus.br, Acceso en: 10 out 2019.
} 
directivos de ambas constructoras. El encuentro, que tampoco produjo acta o documento, sirvió para que los interesados tuviesen influencia en la elaboración de las cláusulas del pliego correspondiente a los lotes 1-B y 1-C de la licitación ${ }^{811}$.

Las compañías incluyeron en los pliegos requisitos de calificación técnica específicos que inviabilizaron la participación de pequeñas y medianas constructoras. Según Cristiano Pimentel Cavalcanti Vieira, asistente comercial de Andrade Gutiérre, los ingenieros de Carioca Christiani Nielsen Engenharia y Andrade Gutierrez incluyeron en el pliego cláusulas que demandaron de los interesados experiencia previa en materias tales como $^{812}$ :

a) La canalización del Rio o canal en área urbana, realizada con revestimiento vertical, hecho de piezas de hormigón prefabricado por una extensión de, como mínimo dos (2) km, en un único contrato; y

b) Que ya hubiese realizado excavación mecánica en área subacuática cubierta con detritos, localizados en el lecho del Rio o canal objeto de las obras.

En base a estas exigencias, los funcionarios de la Secretaría de Obras y los ingenieros de ambas sociedades acabaron dificultando la participación de pequeñas y medianas empresas en la disputa y, por consiguiente, la licitación fue orientada para la victoria de las sociedades Carioca Christiani Nielsen Engenharia y Andrade Gutierrez. ${ }^{813}$

A cambio de lo sucedido, el secretario de obras y los funcionarios directamente involucrados en la trama, Carlos Frederico Peixoto Pires, Antonio Carlos Bezerra y Alexandre Luiz Aragáo, solicitaron a las compañías el pago de una comisión de un uno (1) por ciento sobre el monto del contrato ${ }^{814}$. En base al pacto, cada funcionario cobraría

\footnotetext{
${ }^{811}$ BRASIL. Tribunal Regional Federal (2 Região). Processo n. 0174071-16.2017.4.02.5101, p. 1.2481.252. Disponible en: http://www.jfrj.jus.br. Acceso en: 12 oct. 2019.

${ }^{812}$ Ibidem.

${ }^{813}$ BRASIL, Tribunal Regional Federal (2 Região). Processos n. 0506972-95.2016.4.02.5101; 050755143.2016.4.02.5101; 0029142-84.2017.4.02.5101. Disponible en: http://www.jfrj.jus.br, Acceso en: 10 out 2019.

${ }^{814}$ BRASIL. Tribunal Regional Federal (2 Região). Processo n. 0174071-16.2017.4.02.5101, p. 764-769 e p. 790-791. Disponible en: http://www.jfrj.jus.br. Acceso en: 12 oct. 2019.
} 
la cifra de quinientos veintidós mil setecientos quince euros con treinta y dos céntimos $(522.715,32 €)^{815}$.

Asimismo, al cobrar la comisión por la ventaja, los fiscales tampoco declararían las irregularidades identificadas, pese a lo previsto en la ley y en la jurisprudencia del Tribunal de Cuentas de la Unión. Repitiendo, una vez más, las malas prácticas cometidas durante las obras de construcción del BRT Transcarioca.

En este caso, los fiscales fueron más allá y afirmaron que determinadas estructuras estaban concluidas, aunque en realidad, no lo estuviesen. La falsedad de la declaración, en este caso, se destinó a permitir que las constructoras cobraran del municipio el valor correspondiente al fragmento de obra ejecutado y por consiguiente, pagar a los funcionarios la comisión relativa al referido trecho ${ }^{816}$.Al recibir la retribución, las constructoras pagaban la comisión al secretario y a los fiscales, de acuerdo con lo pactado.

Pese a la importancia de las intervenciones, los recursos invertidos no fueron totalmente aplicados a lo estipulado inicialmente. A raíz de acuerdos espurios perfeccionados entre altos funcionarios de la Administración Municipal y empresarios, parte de los fondos públicos acabaron ingresando al patrimonio de particulares, repitiéndose en este caso las irregularidades cometidas en el ámbito estatal.

Como en el caso de las obras del BRT Transcarioca, Alexandre Pinto da Silva solía recibir la ventaja siempre en efectivo y en lugares públicos, como panaderías y gasolineras para no levantar sospechas en torno a los actos practicados. Los funcionarios, a su vez, cobraban las comisiones en las propias obras, directamente en la sala de los fiscales o dentro de sus coches particulares, siempre al final de la jornada. Así, nadie podría testificar las malas prácticas que realizaban ${ }^{817}$.

En el primer caso, los empleados de las constructoras Carioca Christiani Nielsen Engenharia y Andrade Gutierrez, quienes tenían las llaves de la sala de los fiscales, entraban en ella al final del día y colocaban el dinero de la comisión en un cajón o en un

\footnotetext{
${ }^{815}$ BRASIL, Tribunal Regional Federal (2 Região). Processos n. 0506972-95.2016.4.02.5101; 050755143.2016.4.02.5101; 0029142-84.2017.4.02.5101. Disponible en: http://www.jfrj.jus.br, Acceso en: 10 out 2019.

${ }^{816}$ Ibidem.

${ }^{817}$ Ibidem.
} 
armario, para que posteriormente los funcionarios recogieran el dinero ${ }^{818}$ mientras que en el segundo caso, los propios fiscales solían dejar sus coches abiertos en el aparcamiento cercano a las obras para que al final del día, los empleados de las compañías abandonaran en su interior la comisión correspondiente a cada uno de ellos ${ }^{819}$.

Así lo confirmó el fiscal Alzamir de Freitas Araujo tras realizar acuerdo de colaboración con la Justicia Federal de Rio de Janeiro ${ }^{820}$. Alzamir también reveló que, excepcionalmente, los pagos se realizaban en las afueras de las obras, en un bar y en una sala especialmente alquilada para reuniones llamada Unioffice Espacios Corporativos, ubicada en la región central de Rio de Janeiro ${ }^{821}$.

Con base en estos acuerdos sigilosos, el secretario de obras Alexandre Pinto da Silva cobró ciento nueve mil cuatrocientos diez (109.410) euros, una quinta (1/5) parte de lo acordado inicialmente. A su vez, los funcionarios responsables de fiscalizar las obras cobraron, conjuntamente, ciento setenta y cinco mil cincuenta (175.050) euros, una (1/7) séptima parte de lo establecido previamente.

La interrupción del pago resultó, en ambos casos, de las investigaciones de la operación "Lava Jato", donde se realizaron muchos acuerdos de lenidad con las grandes constructoras brasileñas, responsables de las obras de recuperación de la cuenca hidrográfica de Jacarepaguá, o sea, la Carioca Christiani Nielsen Engenharia y Andrade Gutierrez $^{822}$.

A pesar de suspender el pago, llama la atención, en ambos casos, el hecho de que, así como en otras oportunidades, las reuniones entre el secretario de obras y los empleados de las constructoras no tenían registros en la Administración, tampoco se produjo ningún acta o informe. En el caso de los fiscales, a su vez, además de no existir registro de los

\footnotetext{
${ }^{818}$ BRASIL. Tribunal Regional Federal (2 Região). Processo n. 0174071-16.2017.4.02.5101, p. 790-791. Disponible en: http://www.jfrj.jus.br. Acceso en: 12 oct. 2019.

${ }^{819}$ BRASIL, Tribunal Regional Federal (2 Região). Processos n. 0506972-95.2016.4.02.5101; 050755143.2016.4.02.5101; 0029142-84.2017.4.02.5101. Disponible en: http://www.jfrj.jus.br. Acceso en: 10 out 2019.

${ }^{820}$ BRASIL. Tribunal Regional Federal (2 Região). Processos n. 0068534-94.2018.4.02.5101 e 006854441.2018.4.02.5101. Disponible en: http://www.jfri.jus.br. Acceso en: 12 oct. 2019.

${ }^{821}$ Ibidem.

${ }^{822}$ BRASIL. Tribunal Regional Federal (2 Região). Processo n. 0174071-16.2017.4.02.5101. Disponible en: http://www.jfrj.jus.br. Acceso en: 09 out 2019.
} 
encuentros, se nota que tampoco existió control formal de las personas que entraban en la sala, aunque se tratase de un bien público.

Desde la perspectiva de la transparencia gubernamental, se verifica que las obras para la recuperación de la cuenca de Jacarepaguá revelaron violaciones al control ciudadano, permitiendo el cometimiento de actos de corrupción.

\subsection{Los contratos ficticios como instrumentos a servicio de la oscuridad y la corrupción asociada a los juegos olímpicos Rio 2016}

El contrato siempre ha ocupado una posición de destaque en la sociedad, ya que se trata del principal instrumento para la circulación de bienes y derechos. ${ }^{823} \mathrm{Su}$ presencia se nota en innumerables transacciones alrededor del planeta. ${ }^{824}$ Cualquier individuo, independientemente de su origen, instrucción o clase social, celebra contratos para la satisfacción de su interés, desde pequeñas compras en el comercio del barrio donde vive hasta la constitución de sociedades mercantiles destinadas a grandes inversiones internacionales. Así, el mundo moderno se ha convertido en el mundo del contrato. ${ }^{825}$

Además de su importancia para las relaciones civiles y mercantiles en general, el contrato también ha revelado su valor en el ámbito de los mega eventos deportivos internacionales., ya que se consideran responsables de grandes transformaciones en el espacio urbano de las ciudades anfitrionas, siempre que viabilizan la ejecución de significantes obras de infraestructura y recuperación ambiental. ${ }^{826}$

Pese a su relevancia, el contrato no siempre fue utilizado con fines lícitos a lo largo de la preparación de estos torneos, a menudo utilizándose al lado de figuras del derecho civil para facilitar la comisión de irregularidades asociadas al fenómeno de la corrupción. Una de estas figuras es la simulación, la cual es frecuentemente utilizada para ocultar ciertos negocios jurídicos del conocimiento de terceros, quienes son perjudicados debido a estos acuerdos de voluntad.

\footnotetext{
${ }^{823}$ GALGANO, Francesco. Trattato di Diritto Civile. 3. ed. Milanofiori: Wolters Kluwer, 2015, p. 234. v. II.

${ }^{824}$ LÔBO, Paulo. Direito Civil: Contratos. 5. ed. São Paulo: Saraiva, 2019, L. 276. v. 3

${ }^{825}$ PEREIRA, Caio Mário da Silva. Instituições de Direito Civil. 22. ed. Rio de Janeiro: Forense, 2018, L. 610 .

${ }^{826}$ SÁNCHEZ, Renata Latuf de Oliveira; ESSEX, Stephen. op. cit., p. 97.
} 
En la doctrina, la simulación sucede cuando las partes de un negocio jurídico emiten una declaración deliberadamente discordante con la voluntad interna a modo de crear la apariencia de un negocio que no existe en realidad o es diferente del verdaderamente realizado, ${ }^{827}$ con objetivo de perjudicar a terceros. La simulación es, por tanto, un instrumento al servicio de la apariencia, de la mentira, de la falsedad y del engaño ${ }^{828} \mathrm{y}$, a veces, de la corrupción. Sus requisitos son en primer lugar, la divergencia entre la intensión de las partes y la voluntad efectivamente declarada, luego el acuerdo simulatorio entre las partes y, finalmente, el objetivo de perjudicar a terceros. ${ }^{829}$

En Brasil, los negocios jurídicos simulados se consideran nulos, ${ }^{830}$ según lo prevé la Ley ${ }^{831}$ y ya lo decidió el Tribunal Superior de Justicia. ${ }^{832}$ Como consecuencia, no pueden ser convalidados con el paso del tiempo, así como tampoco pueden ser confirmados por las partes, porque la simulación compromete la causa y la propia función social del negocio.

En otras palabras, prevalece el entendimiento de que no puede considerarse valido un acto que las partes no quieren realizar. En este sentido, la Ley brasileña siguió la misma orientación fijada por el derecho portugués y alemán sobre el asunto ${ }^{833}$ y que también se observa en el derecho español con base a la interpretación del artículo 1.276 del Código Civil, el cual enuncia las consecuencias jurídicas de los negocios perfeccionados con falsedad de la causa. ${ }^{834}$

La solución es diferente cuando uno está delante de las figuras de la simulación absoluta y de la simulación relativa. En el primer caso, la simulación absoluta, las partes

\footnotetext{
${ }^{827}$ DE LA FUENTE, María Linacero. Derecho Civil I. Introducción al Derecho Civil, Derecho de la Persona, Derecho Subjetivo, Negocio Jurídico. Valencia: Tirante Lo Blanch, 2013, L. 13.334.

${ }^{828}$ LÔBO, Paulo. op. cit., L. 6675.

${ }^{829}$ Ibidem, L. 6675.

830 Ibidem, L. 6.707.

831 Art. 167. Cf. BRASIL. Lei 10406, de 10 de janeiro de 2002. Institui o Código Civil. Disponible em: http://www.planalto.gov.br/ccivil_03/leis/2002/110406.htm. Acceso en: 30 nov. 2019.

${ }^{832}$ BRASIL. Superior Tribunal de Justiça (3 Turma). REsp. n. 243.767/MS, Rel. Min. Eduardo Ribeiro, jul. 21 de fevereiro de 2000. Data de publicação: 12/06/2000. Brasília, DF: Superior Tribunal de Justiça [2000], p. 110. Disponible em: www.stj.jus.br. Acceso en: 30 nov. 2019.

${ }^{833}$ LÔBO, Paulo. op. cit., L. 6685.

${ }^{834}$ DE LA FUENTE, María Linacero. op. cit., L. 13.438.
} 
cierran un negocio jurídico, aunque en realidad no lo quieran. Se conforman con que el negocio parezca verdadero, aunque se destine a otra finalidad. El ejemplo de simulación absoluta es la compraventa de un inmueble a una persona que aparenta ser el verdadero adquiriente del bien, pero que en realidad no lo es, actuando más bien como intermediario a beneficio de tercero. Así, nada más adquirir el inmueble, celebra un contrato de compraventa con otra persona, como, por ejemplo, un heredero necesario, con lo cual buscan violar la regla que, en Brasil, prohíbe la compraventa de ascendientes a descendientes sin el previo consentimiento de los demás descendientes. ${ }^{835}$

Tratándose de simulación relativa, las partes concluyen un negocio jurídico, si bien ambicionan a otros fines y contenido diferente de lo efectivamente acordado. En este caso, el negocio aparente o formal esconde a otro negocio subyacente o real verdaderamente querido por las partes. En cuanto declarada la nulidad del negocio simulado o aparente, subsiste el negocio real, salvo que viole la ley o perjudique a terceros. ${ }^{836}$

Finalmente, la simulación puede ser subjetiva u objetiva. Se dice subjetiva cuando se destina a transferir derechos a personas diferentes de quienes efectivamente lo han transferido, como los testaferros, los hombres de paja y los naranjas, figuras comunes en los actos de corrupción. ${ }^{837} \mathrm{~A}$ su vez, la simulación es objetiva cuando la declaración de voluntad manifestada no es real y el negocio jurídico perfeccionado se destina a encubrir la verdadera intención de las partes. Ejemplo de simulación objetiva sucede cuando las partes concluyen un contrato de alquiler, aunque en realidad ambicionan cerrar un contrato de préstamo. ${ }^{838}$

En Brasil, la simulación puede ser declarada de oficio por el juez o alegada por cualquier interesado, así como por el Ministerio Público. ${ }^{839}$ Incluso puede ser invocada por los propios simuladores, aunque no puede ser alegada por quien simuló contra el tercero de buena fe. ${ }^{840}$ Para que tal cosa suceda, es importante que los terceros

\footnotetext{
${ }^{835}$ Art. 496. Cf. BRASIL. Lei 10406, de 10 de janeiro de 2002. op.cit.

${ }^{836}$ LÔBO, Paulo. op. cit., L. 6.707.

${ }^{837}$ Ibidem, L. 6.717.

${ }^{838}$ Ibidem, L. 6.727.

${ }^{839}$ Art. 168. Cf. BRASIL. Lei 10406, de 10 de janeiro de 2002. op.cit.

${ }^{840}$ Art. 167. Cf. Ibidem.
} 
perjudicados tengan conocimiento del negocio jurídico, lo que únicamente es posible, tratándose de medidas de prevención de la corrupción, por medio de la transparencia de los contratos perfeccionados por los sujetos obligados a este deber.

Con motivo de los Juegos Olímpicos Rio 2016, muchas compañías utilizaron la simulación como instrumento para viabilizar la perfección de contratos ficticios con otras sociedades no directamente involucradas con la preparación del mega evento. Con arreglo a estos negocios, lograron justificar determinadas operaciones contables en el ámbito de la propia entidad y pudieron transferir recursos de una a otra persona, como consecuencia de la previa comisión de actos de corrupción. La simulación sirvió, en este caso, como instrumento para la mentira, la falsedad y el engaño.

En todos los casos, las irregularidades fueron posibles debido a una de las principales debilidades del régimen brasileño de transparencia que no considera a los contratistas de la Administración Pública como sujetos obligados a ese deber. Esta omisión legislativa es responsable de crear espacios de oscuridad que permiten a estas personas moverse libremente en el tráfico jurídico, lo que acaba con posibilitar que cierren contratos ficticios apenas con objetivo de viabilizar la comisión de actos de corrupción.

\subsubsection{Los contratos ficticios concernientes a las obras para la construcción del arco vial metropolitano}

Las obras para la construcción del arco vial metropolitano, una carretera de ciento cuarenta y cinco (145) km de largo, constituyo el objeto de las reivindicaciones de los vecinos de Rio de Janeiro desde mediados de los años 1970. La carretera, también conocida como Estrada Raphael de Almeida Magallanes o BR-493, una vez construida, conectó las regiones sur y sudeste a las regiones norte y noreste del Estado, posibilitando el desplazamiento de camiones de un sitio a otro, sin que tuviesen que moverse a través del Municipio de Rio de Janeiro ${ }^{841}$. Se trataba, por tanto, de una importante obra de vialidad urbana asociada a la realización de los juegos olímpicos, responsable de grandes transformaciones en la ciudad a causa del mega evento ${ }^{842}$. En este caso, una vez que todas

\footnotetext{
${ }^{841}$ BRASIL. Ministério Público Federal. Denuncia Operação Calicute. Procuradoria da República no estado do Rio de Janeiro. Disponible em : http://www.mpf.mp.br/rj/sala-de-imprensa/docs/prrj/Denuncia_ALEX\%20SARDINHA_Redigido.pdf/ Acceso en: 23 sept. 2019.

${ }^{842}$ MARICATO, Ermínia. op. cit., p. 36.
} 
las constructoras ocuparon su sitio, los miembros de la banda criminal comandada por el Gobernador Sergio Cabral trataron de poner en marcha las malas prácticas administrativas que habían planificado.

Así, los consorcios responsables de las obras, al cobrar los montos correspondientes a la ejecución de los proyectos, deberían entregarle al Gobernador un cinco (5) por ciento de todo lo recibido, exactamente lo acordado entre todos los interesados. En realidad, estos acuerdos espurios comenzaron mucho antes que Rio fuera elegida ciudad olímpica. Nada más tomar posesión como Gobernador, Cabral y sus comparsas se reunieron con los directivos de estas entidades, ofreciéndoles ventajas en las licitaciones relativas a los preparativos de Rio para la Copa del Mundo de Fútbol FIFA 2014 y las Olimpíadas de 2016, desde que en este último caso, la elección se confirmara por decisión del COI.

Una de estas reuniones tuvo lugar con el presidente de Andrade Gutierrez, Rogerio Nora de Sá y el director comercial de la compañía Alberto Quintaes, aún en 2007, dos años antes que Rio fuese elegida ciudad olímpica. Durante el encuentro, Cabral y su Secretario de Gestión, Wilson Carlos, le solicitaron a Rogerio Nora de Sá el pago de una comisión mensual de setenta y seis mil quinientos noventa (76.590) euros. A cambio de ese pago, Andrade Gutierrez realizaría grandes contratos de ingeniería con el Estado.

Al contrario de lo esperado, la reunión no ocurrió en el Palacio Guanabara, sede del Gobierno de Rio de Janeiro, tampoco fue en el despacho oficial del Gobernador para informar a los ciudadanos de aquellos encuentros en los que participaba la principal autoridad del Estado. Con base en una cultura de secreto y oscuridad ${ }^{843}$, el encuentro tuvo lugar en la casa del Gobernador en el barrio de Leblon y únicamente fue registrado en los ordenadores personales de Sergio Cabral y su mujer Adriana Anselmo. Así, lo reveló el propio Rogerio Nora al declarar ante la Justicia Federal de Rio de Janeiro ${ }^{844}$, y lo ha confirmado en el Informe Análisis de Material núm. 13/2017, elaborado por la Policía Federal tras examinar los archivos guardados en ambos ordenadores ${ }^{845}$.

La propuesta asustó al empresario. Se trataba de un pedido inédito, incluso para un país acostumbrado a tantos casos de corrupción. Pese a que estuvo treinta años en la compañía, Rogerio Nora no había conocido nunca a un político que cobrase sobornos por

\footnotetext{
${ }^{843}$ CANETTI, Elías. Masa y Poder. Madrid: Alianza, 1994, p. 288.

${ }^{844}$ CORRÊA, Hudson. op. cit., L. 999.

${ }^{845}$ BRASIL. Tribunal Regional Federal (2 Região). Processo n. 0509503-57.2016.4.02.5101, p. 8.215. Disponible en: http://www.jfri.jus.br . Acceso en: 12 oct. 2019.
} 
adelantado y que también estableciera las reglas para la compensación de estas ventajas a futuro ${ }^{846}$. El empresario sabía que esas eran las reglas, y si la compañía quería realizar contratos con la Administración Pública, entonces tendría que someterse a las exigencias del Gobernador.

Días después, Rogerio Nora, acompañado de su director comercial Alberto Quintaes, también en secreto, volvió a reunirse con Sergio Cabral y Wilson Carlos. Ahora, el encuentro tuvo lugar en la sede del gobierno, aunque no hubo ningún registro de los debates entre Sergio Cabral y los directivos de la compañía. En otras palabras, no existió en su momento, un acta que documentara los actos practicados por la máxima autoridad del Estado.

Sin los controles propios de la transparencia, Sergio Cabral pudo explicarles a los empresarios como serían las relaciones entre la Administración Pública y las compañías, desde entonces todos los montos pagados por adelantado serían descontados en el futuro de las comisiones que la banda criminal recibiría de la constructora. Existiría, en este caso, una compensación entre los valores cobrados por adelantado y aquellos que la empresa debía entregar a la banda. La compensación, en todos los casos, siempre respetaría el límite del cinco (5) por ciento del valor del contrato, precio que Cabral y sus socios cobraban por entregar a la entidad grandes contratos de ingeniería ${ }^{847}$.

En esa oportunidad, Sergio Cabral les explicó a Rogerio Nora y Alberto Quintaes que a partir de aquel momento, todas las cuestiones relativas al pago de las comisiones serían tratadas directamente con Wilson Carlos. Como principal autoridad política del Estado de Rio de Janeiro, el Gobernador quedaría al margen de estas discusiones, exactamente para no despertar la curiosidad de los ciudadanos.

Considerando la autorización del Gobernador, en el segundo semestre de 2008, Wilson Carlos se reunió sigilosamente con Alberto Quintaes y demandó del director comercial el pago de una comisión adicional de uno (1) por ciento sobre el valor de futuros contratos perfeccionados con la Administración. La comisión, también llamada "tasa de oxígeno", se destinaba a Udson Braga, secretario de obras públicas del Estado de Rio de Janeiro, responsable de las principales contrataciones del ente público en esta materia ${ }^{848}$.

\footnotetext{
${ }^{846}$ CORRÊA, Hudson. op. cit., L. 999.

${ }^{847}$ BRASIL. Tribunal Regional Federal (2 Região). Processo n. 0509503-57.2016.4.02.5101, p. 8.215. Disponible en: http://www.jfrj.jus.br . Acceso en: 12 oct. 2019.

${ }^{848}$ Ibidem.
} 
Una vez aceptadas las reglas fijadas por el Gobernador, Rogerio Nora tenía un enorme problema que resolver. La compañía entregaría al jefe del poder ejecutivo estatal setenta y seis mil quinientos noventa (76.590) euros al mes, aunque no tuviese ningún contrato perfeccionado con la Administración Pública que pudiera soportar este pago ${ }^{849}$.

Con treinta años en el mercado de la construcción civil, Rogerio Nora sabía que, por lo general, las ventajas que se pagaban a políticos siempre tenían como base un contrato previo entre la compañía y la Administración Pública. Así, los recursos que siempre financiaron la corrupción resultaban directamente de los montos cobrados a causa de los contratos y, consecuentemente, la entidad no tenía que utilizar recursos propios con este objetivo. ${ }^{850}$

Al utilizar fondos propios de la compañía para financiar las malas prácticas del Gobernador, Rogerio Nora aún tenía que enfrentarse con los órganos internos de control de Andrade Gutiérrez. En otras palabras, había que encontrar una manera de justificar para dichos órganos los pagos realizados, sin que tuviese que explicarles su verdadero motivo $^{851}$.

En la búsqueda de una solución para el problema, Rogerio Nora trató de reunirse con Clóvis Primo, director general de obras de Andrade Gutiérrez, quien tenía gran experiencia en cuestiones de esta naturaleza y ciertamente, podría ofrecerle la respuesta que tanto necesitaba en aquel momento. Rogerio Nora no estaba equivocado. Clóvis de hecho conocía tres maneras a menudo utilizadas por directivos de entidades del sector privado para retirar dinero de las arcas empresariales sin que los órganos de control interno sospecharan de la operación ${ }^{852}$ :

a) Realizar pagos a otras compañías de modo que ellas entregaran la ventaja a su destinatario final, aprovechándose, en este caso, de los contratos ya existentes;

b) Realizar contratos ficticios con determinadas entidades proveedoras de bienes o servicios, que no entregarían el producto o actividad a la compañía, limitándose a emitir una factura fría que justificara el pago;

\footnotetext{
${ }^{849}$ CORRÊA, Hudson. op. cit., L. 1000.

${ }^{850} \mathrm{Ibidem}$.

${ }^{851}$ Ibidem.

${ }^{852}$ Ibidem.
} 
c) Realizar donaciones a favor de partidos políticos a modo de que ellos entregaran la ventaja a su destinatario final.

Ante las alternativas presentadas, Rogerio Nora eligió la segunda. A su juicio, la compañía no debería contaminar los contratos firmados con otras empresas para viabilizar el pago de la ventaja al Gobernador, tampoco debería realizar donaciones a partidos políticos en aquel momento. En consecuencia, Andrade Gutierrez acordó contratos ficticios de prestación de servicios con las sociedades Legend Ingenieros Associados Ltda., SP Terraplen Ltda., JSM Ingeniería e Terraplanagem Ltda. y Alpha Taxi Aéreo $\operatorname{Ltda}^{853}$.

Estas sociedades eran comandadas por Adir Assad y Samir Assad, una dupla de empresarios con larga experiencia en este tipo de negocios. Los hermanos Assad administraban unas cuantas empresas que desarrollaban, en teoría, actividades en diferentes sectores de la economía, desde la construcción civil hasta la aviación ${ }^{854}$, pese a su actividad principal las entidades también perfeccionaban contratos ficticios con grandes y pequeñas compañías a modo de justificar el retiro de fondos ${ }^{855}$.

Los Assad solían emitir facturas frías para las empresas interesadas a cambio de una comisión del veinte (20) por ciento del valor del contrato. Nada más documentar la operación, restituían el ochenta (80) por ciento del dinero a la compañía, que podría utilizarlo a su conveniencia ${ }^{856}$.

En lo jurídico, los aludidos negocios se trataron de típico ejemplo de simulación objetiva, siempre que las partes no ambicionaron al negocio simulado en sí mismo, ${ }^{857}$ sino buscaron otra finalidad ajena al objeto del pactado.

Con la ayuda de los hermanos Assad, Andrade Gutierrez pudo justificar la retirada de fondos de las arcas de la compañía y entregarlos al Gobernador como parte del pacto que habían perfeccionado en secreto. Internamente, los recursos eran administrados por Alberto Quintaes, quien registraba todos los pagos en una tabla con la finalidad de

\footnotetext{
${ }^{853} \mathrm{Ibidem}$, L. 1016.

${ }^{854}$ BRASIL. Tribunal Regional Federal (2 Região). Processo n. 0502834-85.2016.4.02.5101. Disponible em: http://www.jfrj.jus.br. Acceso en: 12 oct. 2019.

${ }^{855}$ Ibidem.

${ }^{856}$ CORRÊA, Hudson. op. cit., L. 1000.

${ }^{857}$ DE LA FUENTE, María Linacero. op. cit., L. 13.332.
} 
controlar las operaciones. Según estos registros, el primer pago a favor de Sergio Cabral se realizó en mayo de 2007 y alcanzó setenta y seis mil quinientos noventa (76.590) euros $^{858}$.

Con arreglo a estos pagos, Andrade Gutierrez en el 2007, pudo incorporarse al consorcio formado por las constructoras Norberto Odebrecht y Delta Constructores para la reforma del Maracaná ${ }^{859}$, de cara a los mega eventos que sucederían en la ciudad de Rio de Janeiro.

Asimismo, en abril de 2008, el Gobierno del Estado de Rio de Janeiro perfeccionó junto al consorcio formado por las constructoras Norberto Odebrecht y Andrade Gutierrez el contrato para la edificación del primer trecho del arco vial metropolitano contrato núm. 007/2008. La contratación le dio a Rogerio Nora la oportunidad para que recuperara la comisión pagada al Gobernador desde que se reunieron para tratar este asunto.

De hecho, no hubo motivos para quejarse. Las inversiones públicas llegaron a cuarenta y seis millones novecientos cuarenta y cuatro mil quinientos ochenta y cinco euros con veintiséis centavos $(46.944 .585,26 €)^{860}$, siendo una de las principales obras de infraestructura asociadas a los Juegos Olímpicos Rio 2016.

A raíz de los pactos firmados en 2007, Andrade Gutierrez aún tendría que entregarle al Gobernador cinco (5) por ciento del valor del contrato y otro uno (1) por ciento a Hudson Braga a título de "tasa de oxígeno", al Gobernador le tocaban dos millones trescientos cuarenta y siete mil doscientos veintinueve euros con veintiséis centavos (2.347.229,26€), mientras que a Hudson Braga le correspondían cuatrocientos sesenta y nueve mil cuatrocientos cuarenta y cinco euros con ochenta y cinco centavos $(469.445,85$ $€)$.

Ahora bien, de acuerdo con Rogerio Nora y Clóvis Primo, quienes se manifestaron en colaboración premial ante la Justicia Federal de Rio de Janeiro, los montos cancelados a Sergio Cabral y su banda, entre 2008 y 2013, llegaron a treinta y ocho millones

\footnotetext{
${ }^{858}$ BRASIL. Tribunal Regional Federal (2 Região). Processo n. 0502834-85.2016.4.025101. Disponible en: http://www.jfrj.jus.br. Acceso en: 12 oct. 2019.

${ }^{859}$ CORRÊA, Hudson.. op. cit., L. 1022.

860 Los valores invertidos para la construcción del Arco Metropolitano resultaron de un convenio perfeccionado entre el Estado de Rio de Janeiro y la Unión (Convenio n. TT-262/2007-00, Proceso n. 50600.010339/2007), el cual previó inversiones federales de 203.212.510,28 de euros.
} 
seiscientos setenta y ocho mil trescientos noventa y dos euros con treinta y cuatro centavos $(38.678 .392,34 €)^{861}$.

El modelo de reuniones sigilosas y contratos ficticios con terceros no sucedió únicamente con Andrade Gutierrez. A finales de 2006, al ganar las elecciones para Gobernador, Sergio Cabral recibió en su apartamento a los empresarios Ricardo Pernambuco y Pernambuco Junior, padre e hijo, respectivamente, quienes representaban a la constructora Carioca Christiani Nielsen Engenharia S.A. Durante la visita, los empresarios felicitaron a Sergio Cabral por la victoria y manifestaron su interés en realizar contratos con la Administración Pública, mientras que el político estuviese al frente de la gestión del Estado de Rio de Janeiro ${ }^{862}$.

Al final del encuentro, Cabral les explicó a los empresarios que él no trataba estos temas directamente, porque no quería vincular su imagen a las grandes constructoras brasileñas, a menudo involucradas en escándalos de corrupción. Todos los asuntos relativos a la contratación pública serían tratados con su Secretario de Gestión, Wilson Carlos, quien facilitaría las condiciones para hacerlo.

En febrero de 2007, en el Palacio de gobierno, los directivos de Carioca Engenharia se reunieron con Wilson Carlos. Terminado el encuentro, lograron el derecho de ejecutar las obras de urbanización de la favela de Rossinha en el Municipio de Rio de Janeiro, en consorcio con la constructora Queiroz Galváo. Las inversiones públicas llegaron, en este caso, a treinta y ocho millones cuatrocientos mil (38.400.000) euros ${ }^{863}$.

Al año siguiente, en 2008, Wilson Carlos trató de reunirse una vez más con los directivos de Carioca Engenharia. En esta oportunidad, ofreció parte de las obras del arco vial metropolitano a cambio de una comisión mensual que sería pagada al Gobernador antes que se firmara el contrato. Los montos pagados por adelantado serían descontados en el futuro, de tal manera que la constructora no tendría perjuicios en lo pactado $^{864}$.

\footnotetext{
${ }^{861}$ Las revelaciones constan de la colaboración premiada de Alberto Quintaes. Cf. BRASIL. Tribunal Regional Federal (2 Região). Processo n. 0509503-57.2016.4.02.5101. Disponible en: http://jfrj.jus.br Acceso en: 12 oct. 2019.

${ }^{862}$ CORRÊA, Hudson.. op. cit., L. 1093.

${ }^{863}$ Ibidem, L. 1093.

${ }^{864}$ BRASIL. Tribunal Regional Federal (2 Região). Processo n. 0504113-722017.4.02.5101. Disponible en: http://www.jfrj.jus.br . Acceso en: 12 oct. 2019.
} 
Al conocer las exigencias, los directivos de Carioca Ingeniería acordaron un monto mensual de cuarenta y tres mil setecientos (43.700) euros, cantidad de dinero que podrían invertir en el negocio. Igual que los directivos de Andrade Gutierrez, también ellos tuvieron que realizar contratos ficticios con los hermanos Assad al objeto de justificar el retiro de fondos de las arcas empresariales. ${ }^{865} \mathrm{Para}$ cumplir su parte en el acuerdo, Carioca Engenharia logró el derecho a ejecutar las obras del arco vial metropolitano, aunque lo hiciera, una vez más, en consorcio con Queiroz Galváo.

En definitiva, a raíz de los acuerdos perfeccionados, las entidades ganadoras de las licitaciones fueron, respectivamente, las siguientes ${ }^{866}$ :

a) Trecho $1^{\circ}$ : ganado por el Consorcio Arco Metropolitano, formado por las constructoras Norberto Odebrecht y Andrade Gutierrez;

b) Trecho $2^{\mathrm{o}}$ : ganado por el Consorcio Carioca-Queiroz, formado por las constructoras Carioca Christiani Nielsen Engenharia y Queiroz Galváo;

c) Trecho $3^{\text {o}}$ : ganado por el Consorcio Arco do Rio, formado por las constructoras OAS y Camargo Correa; y

d) Trecho $4^{\mathrm{o}}$ : ganado por el Consorcio Arco Metropolitano Rio, formado por las constructoras Delta Construcciones y Oriente Construcciones.

Llama la atención, en ambos casos, la manera como Sergio Cabral negoció con los directivos de Andrade Gutierrez y Carioca Engenharia. Ni el Gobernador, ni sus secretarios registraban las reuniones en sus agendas oficiales. Luego de terminada la reunión, no se hizo una acta o documento que informara de los debates sucedidos y de las decisiones tomadas.

También se observa que, con en base lo pactado, ambas compañías trataron de realizar contratos ficticios con los hermanos Assad a modo de justificar el retiro de fondos de las arcas empresariales. Enseguida, parte de los recursos fueron restituidos a las constructoras y entregados a Carlos Miranda, operador financiero de Sergio Cabral.

\footnotetext{
${ }^{865}$ Ibidem.

${ }^{866}$ BRASIL. Ministério Público Federal. Denuncia Operação Calicute. Procuradoria da República no Estado do Rio de Janeiro. Disponible em : http://www.mpf.mp.br/rj/sala-de-imprensa/docs/prrij/Denuncia_ALEX\%20SARDINHA_Redigido.pdf/ Acceso en: 23 sept. 2019.
} 


\subsubsection{Los contratos ficticios referentes a las obras de construcción del BRT} Transcarioca

Así como ya había pasado en el caso de las obras para la construcción del arco vial metropolitano, el pago de la comisión debida a Laudo Ziani a causa de su labor junto al Ministerio de las Ciudades se realizó a través de contratos ficticios perfeccionados entre las compañías OAS y Carioca Engenharia y terceros, tales como la conclusión de contratos de prestación de servicios, la suscripción de capital en sociedades mercantiles y la compraventa de bienes de todo tipo.

En este sentido, Laudo Ziani pactó con Antonio Cid (OAS) y Rodolfo Mantuano (Carioca Engenharia) que los montos adeudados a él no se le entregarían directamente, sino a través de un despacho de abogados especializado en cuestiones ambientales. Se trataba del despacho Sampaio Volk Abogados, administrado por la abogada Vanuza Vidal Sampaio, quien se hizo cargo de entregarle a Laudo el dinero ${ }^{867}$.

Con la finalidad de cumplir con lo pactado, el Consorcio Transcarioca Rio perfeccionó un contrato de prestación de servicios con el despacho (contrato de prestación de servicios núm. TRANS-093/2012) ${ }^{868}$, aunque todas las compañías que formaban parte de este contrato tenían profesionales especializados en esta materia, tales como ingenieros, biólogos y abogados.

Así como los contratos perfeccionados por Andrade Gutierrez con motivo de las obras del arco vial metropolitano, el contrato firmado entre el Consorcio Transcarioca Rio y el despacho de abogados constituyó un negocio jurídico simulado. Las partes no querían el negocio simulado, es decir, la prestación de consultoría en materia ambiental, sino un instrumento jurídico que permitiera la transferencia de los recursos para Laudo Ziani. Desde el principio, el contrato de prestación de servicio contenía en sí mismo la idea de ocultar o engañar ${ }^{869}$ y se destinó a justificar la transferencia de los recursos de las compañías para su verdadero destinatario ${ }^{870}$.

\footnotetext{
${ }^{867}$ BRASIL. Tribunal Regional Federal (2 Região). Processo n. 0174071-16.2017.4.02.5101, p. 795-803, p. 6.140 y p. 6.144-6.146. Disponible en: http://www.jfrj.jus.br. Acceso en: 12 oct. 2019.

${ }^{868}$ Ibidem.

${ }^{869}$ DE LA FUENTE, María Linacero. op. cit., L. 13.332.

${ }^{870}$ Op. cit. p. 6.143.
} 
Pese a que se trató de un "fraude", aun así, el contrato de prestación de servicios cumplió con su papel. Según reveló la medida cautelar de quiebra de sigilo bancario decretada por la Justicia Federal de Rio de Janeiro, entre 2012 y 2013, el Consorcio Transcarioca Rio pago al despacho Vanuza Sampaio abogados asociados la cifra de un millón cuatrocientos veinte mil trescientos tres euros con cuarenta y tres céntimos $(1.420 .303,43 €),{ }^{871}$ monto superior a las ganancias obtenidas por aludido despacho en los años anteriores a la conclusión del contrato.

En otras palabras, el análisis de los datos obtenidos con base a la medida cautelar reveló que los ingresos normales y corrientes del despacho de abogados en los años anteriores al contrato de prestación de servicios en materia ambiental procedieron, básicamente, de clientes tales como gasolineras, concesionarios de vehículos y una lotería. Por lo general, cada una de estas entidades incorporó a las arcas de aludido despacho, mensualmente, cifras equivalentes a doscientos diecinueve euros con treinta céntimos $(219,30 €)$, mil y noventa y seis euros con cuarenta y nueve céntimos $(1.096,49 €)$ y seis mil quinientos setenta y ocho euros con noventa y cinco céntimos $(6.578,95 €)$, respectivamente. ${ }^{872}$

Se trató, por tanto, de un despacho de abogados pequeño que no tenía grandes contratos de prestación de servicios, hasta que lograra hacerlo con el Consorcio Transcarioca Rio, formado por dos de las principales constructoras brasileñas, quienes, además, tenían capacidad financiera para contratar grandes despachos de abogados brasileños especializados en cuestiones ambientales.

Los datos obtenidos con base a la medida cautelar revelaron otro aspecto relevante en cuanto al contrato de prestación de servicios. Como se nota, el monto cobrado es superior al porcentaje pactado, en tanto que Laudo debió cobrar un millón dos mil novecientos diez euros con treinta céntimos (1.002.910,30€), sin embargo, el valor excedente se destinaba a pagar los tributos relativos a la prestación de la consultoría ambiental y remunerar al despacho Vanuza Sampaio por el servicio prestado.

\footnotetext{
${ }^{871}$ BRASIL, Tribunal Regional Federal (2 Região). Processo n. 0509600-57.2016.4.02.5101. Disponible en: http://www.jfrj.jus.br . Acceso en: 09 out 2019.

${ }^{872}$ BRASIL. Tribunal Regional Federal (2 Região). Processo n. 0174071-16.2017.4.02.5101. Disponible en: http://www.jfrj.jus.br Acceso en: 30 nov. 2019.
} 
Jurídicamente, se buscó dar apariencia de licitud al negocio, ${ }^{873}$ exactamente como sucede en los casos de simulación.

El contrato perfeccionado entre el Consorcio Transcarioca Rio y el despacho de abogados evidenció otra de las debilidades del sistema de transparencia brasileño. Por lo general, ni la Ley de Licitaciones y Contratos Administrativos, ni la Ley de Transparencia y Acceso a la Información, se preocuparon en amparar otros contratos perfeccionados por las entidades que mantenían vínculos de esta naturaleza con la Administración Pública, aunque muchos de estos contratos pudieron ser utilizados para la desviación de fondos públicos.

En los casos de las obras de construcción del arco vial metropolitano y en el caso del BRT Transcarioca, las entidades contratadas por la Administración Pública utilizaron estas estratagemas para blanquear los recursos sacados de las arcas públicas.

Con base en esta premisa, al recibir los dineros del consorcio, Vanuza Sampaio trató de adoptar estrategias para transferir los montos de las comisiones a Laudo Ziani, porque sabía que no estaban sometidas a los controles de la transparencia gubernamental. Por lo general, lo hizo de cinco maneras diferentes, con objeto de dificultar la labor de las autoridades responsables de la prevención del blanqueo de capitales en Brasil:

a) Pago de dispendios personales de Laudo Ziani;

b) Transferencias realizadas a su nombre o en favor de personas indicadas por él;

c) Entrega en efectivo directamente a Laudo Ziani o a personas indicadas por él;

d) Ingresos realizados a las cuentas personales de Laudo Ziani o de la sociedad Rocha Firme Ltda. y

e) Suscripción de capital a favor de la Sociedad Rocha Firme Ltda.

Entre las operaciones realizadas, llama la atención la última de ellas, la suscripción de capital a favor de la Sociedad Rocha Firme Ltda. En este caso, las autoridades de prevención y control de blanqueo de capitales verificaron que al objeto de transferir recursos del despacho de abogados para Laudo Ziani, en febrero de 2013, Vanuza Sampaio se incorporó al cuadro de socios de la sociedad Rocha Firme Ltda.

Por consiguiente, realizó una suscripción de acciones por un monto de seiscientos ochenta y cuatro mil trescientos cincuenta y cuatro euros con cuarenta y nueve céntimos

${ }^{873}$ BRASIL. Tribunal Regional Federal (2 Região). Processo n. 0506972-95.2016.4.02.5101; 050755143.2016.4.02.5101; y 0029142-84.2017.4.02.5101. Disponible em: http://www.jfrj.jus.br. Acceso en: 30 nov. 2019. 
$(684.354,49 €)$. Sin embargo, apenas cinco meses tras la suscripción, o sea, en julio de 2013, dejó la sociedad y traspasó esas acciones a Laudo Ziani, aunque no cobró ningún valor por ellas ${ }^{874}$.

Para justificar la transferencia, el 2 de septiembre de 2013, Laudo y Vanuza perfeccionaron un contrato de compraventa de las acciones. Según lo pactado, Laudo pagaría a la abogada la cantidad de ciento noventa y seis mil novecientos cuarenta (196.940) euros, en doce mensualidades continuas, iniciando a partir de septiembre de 2013, fecha en que se verificó el efectivo retiro de Vanuza de la sociedad ${ }^{875}$.

Transcurrido cuatro años, en septiembre de 2017, Vanuza no cobró ningún dinero a título de pago por las acciones, con lo cual puso de manifiesto que el contrato de compraventa constituyó otro negocio simulado entre las partes, según lo reveló Laudo Ziani a la Justicia Federal de Rio de Janeiro ${ }^{876}$.

Al contrario de Laudo Ziani, el secretario Alexandre Pinto da Silva no perfeccionó ningún contrato ficticio para cobrar los dineros relativos a la ventaja indebida, pagada por el consorcio responsable de la construcción del BRT Transcarioca. Según lo pactado, la compañía entregaría al secretario el uno (1) por ciento del valor del contrato, siempre en efectivo y en lugares públicos, tales como gasolineras, panaderías y centros comerciales. Esta forma particular de cobrar la ventaja lo revelaron Luciana Salles Parente ${ }^{877}$ y Marcos Antonio dos Santos Bonfim ${ }^{878}$, directiva operacional e ingeniero comercial de Carioca Engenharia, respectivamente ${ }^{879}$.

Al recibir la comisión, Alexandre tampoco la ingresaba en sus cuentas porque sabía que estaba sometido a controles, debido al cargo de Secretario Municipal de Obras que ejercía para aquel momento. Con objeto de mantener estos dineros a salvo del control de

\footnotetext{
${ }^{874}$ BRASIL, Tribunal Regional Federal (2 Região). Processo n. 0174071-16.2017.4.02.5101. Disponible en: http://www.jfrj.jus.br . Acceso en: 09 out 2019.

${ }^{875}$ BRASIL. Tribunal Regional Federal (2 Região). Processo n. 0174071-16.2017.4.02.5101, p. 1.1461.151. Disponible en: http://www.jfrj.jus.br. Acceso en: 12 oct. 2019.

${ }^{876}$ Ibidem, p. 6.144-6.146.

${ }^{877}$ Ibidem.

${ }^{878}$ Ibidem, p. $770-779$.

${ }^{879}$ BRASIL. Tribunal Regional Federal (2 Região). Processo n. 0507551-43.2016.4.02.5101. Disponible en: http://www.jfrj.jus.br . Acceso en: 10 out 2019.
} 
terceros, intentaba ingresarlos en las cuentas de su mujer, su madre y sus dos hijos, realizando todo tipo de operaciones de compraventa de bienes y derechos.

Uno de estos ingresos fue identificado por la autoridad responsable de la prevención del blanqueo de capitales de Brasil, quien constató la existencia de una entrada en la cuenta de la madre de Alexandre, Sonia Regina Pinto da Silva, justo en el período en que Luciana Salles Parente les había entregado una comisión relativa a las obras de construcción del BRT Transcarioca ${ }^{880}$.

Además de utilizar cuentas de terceros, Alexandre también solía esconder el producto de la corrupción a través de la compraventa de piedras preciosas, artículos de lujo y obras de arte. Con base en una medida cautelar de búsqueda y aprensión, fueron encontrados en su residencia ciento cincuenta y siete (157) joyas, treinta y ocho (38) relojes de lujo y siete (7) cuadros de alto valor, los cuales no fueron declarados al Ministerio de Hacienda en su momento ${ }^{881}$.

Los malos ejemplos de Alexandre Pinto rápidamente contaminaron a otros funcionarios de la Secretaría de Obras. Igual que al jefe de la unidad, los ingenieros responsables de fiscalizar la construcción del BRT Transcarioca, también realizaron pactos secretos con Carioca Christiani Nielsen Engenharia y OAS. En base a tales acuerdos, las compañías pagaron a los ingenieros Eduardo Fagundes de Carvalho, Ricardo da Cruz Falcao y Alzamir de Freitas Araujo un uno (1) por ciento del valor del contrato para cada funcionario ${ }^{882}$.

En este sentido, a raíz de los acuerdos pactados, los directivos de OAS pagaron a los funcionarios del municipio la cifra de un millón ciento ochenta mil quinientos noventa y nueve euros con cincuenta y seis céntimos $(1.180 .599,56 €)$ hasta agosto de $2014^{883}$.

Según lo acordado, los fiscales no identificaban las irregularidades detectadas en la ejecución de las obras, aunque la ley ${ }^{884}$ y la jurisprudencia del Tribunal de Cuentas de la

\footnotetext{
${ }^{880}$ BRASIL. Tribunal Regional Federal (2 Região). Processo n. 0509600-57.2016.4.02.5101. Disponible en: http://www.jfrj.jus.br . Acceso nen 10 out 2019.

881 BRASIL. Tribunal Regional Federal (2 Região). Processos n. 0174071-16.2017.4.02.5101; 0044.000213-9/2017. Disponible en: http://www.jfrj.jus.br Acceso en: 10 out 2019.

${ }^{882}$ Ibidem, p. 6.172-6.176.

${ }^{883}$ BRASIL. Tribunal Regional Federal (2 Região). Processo n. 0174071-16.2017.4.02.5101, p. 2.966. Disponible en: http://www.jfrj.jus.br. Acceso en: 12 oct. 2019.

${ }^{884}$ Art. 67. Cf. BRASIL. Lei n. 8.666/1993. op.cit.
} 
Unión $^{885}$ determinaran que así lo hicieran. Además, consideraban como acabada determinadas fases de la construcción, aunque no estuviesen concluidas, lo que les posibilitaba a las compañías cobrar la retribución correspondiente y en seguida pagarles a los fiscales la ventaja indebida ${ }^{886}$.

En todos los casos, el secreto de las actuaciones constituyó, una vez más, el rasgo común de las malas prácticas de los funcionarios, quienes se aprovecharon de las debilidades del sistema de transparencia brasileño para consumarlas.

A tales efectos, la Ley núm. 12.527, de 18 de noviembre de 2011, de Transparencia y Acceso a la Información no impone la obligatoriedad de la divulgación de las agendas de trabajo de los funcionarios que acompañan la ejecución de obras públicas, aunque este es un ambiente favorable a las malas prácticas administrativas. Conscientes de estas debilidades, los ingenieros Eduardo Fagundes, Ricardo Falcao y Alzamir Araujo lograron reunirse con empleados de las compañías responsables de las obras y cobrar la comisión pactada, sin existir registro de estos encuentros.

\subsection{3. los contratos ficticios perfeccionados por el Gobernador Sergio Cabral y su mujer para esconder el producto de la corrupción}

Así como los funcionarios de la Secretaría Municipal de Obras Públicas, el Gobernador Sergio Cabral y sus socios también buscaron adoptar estrategias eficientes para esconder tanto de las autoridades como de los ciudadanos los montos desviados de la Administración Pública a causa de los acuerdos perfeccionados por los contratistas. La premisa fundamental, en todos los casos, fue que el dinero no debería moverse a través del sistema bancario brasileño, con lo cual las autoridades no podrían identificar tales operaciones.

Para respetar estas reglas, por lo general, la entrega de la comisión que pagaba Andrade Gutierrez fue en efectivo y directamente a un funcionario designado por los comparsas de Sergio Cabral. La entrega la hacía el director comercial de Andrade

\footnotetext{
885 BRASIL. Tribunal de Contas da União. Acórdão n. 265/2010-TCU-Plenário. Disponible en: https://portal.tcu.gov.br/inicio/ Acceso en: 25 out 2019.

${ }^{886}$ BRASIL. Tribunal Regional Federal (2 Região). Processos n. 0068534-94.2018.4.02.5101; 006854441.2018.4.02.5101. Disponible en: http://www.jfrj.jus.br. Acceso en: 12 oct. 2019.
} 
Gutierrez, Alberto Quintaes, directamente a Carlos Miranda, operador financiero de la organización $^{887}$. En este sentido, la entrega se realizaba de tres maneras ${ }^{888}$ :

a) Directamente a la sede de Andrade Gutierrez en el barrio de Botafogo en Rio de Janeiro;

b) En un despacho que Sergio Cabral tenía en la avenida Ataufo de Paiva, núm. 1251, sala 204, en el barrio de Leblon ${ }^{889}$;

c) En un despacho ubicado en la calle Jardín Botánico, núm. 675, y posteriormente, en un despacho en la avenida Jardín Botánico, núm. $674^{890}$ ambos situados en el barrio de Jardín Botánico ${ }^{891}$.

Siguiendo las instrucciones del Gobernador, Carlos Miranda trataba de utilizar parte de los montos para pagar dispendios personales de Sergio Cabral y su exmujer Susana Neves, con quien tuvo tres hijos. Los gastos variaban entre veintiséis mil doscientos (26.200) euros a treinta y dos mil ochocientos (32.800) euros al mes, según lo reveló Sonia Baptista, una empleada de confianza de Sergio Cabral y quien fue responsable de administrar los dispendios relativos a la familia del Gobernador ${ }^{892}$.

Así, pese a que los principios de responsabilidad y máxima divulgación recomendaran que los Estados Nacionales incorporaran en su ordenamiento jurídico reglas que favorecieran el control ciudadano de los ingresos cobrados por las altas autoridades, dentro o fuera del cargo, mandato o función pública, en 2007 y 2008, la ley brasileña no demandaba de estas personas la divulgación de la aludida información.

Aprovechándose de la omisión, Sergio Cabral destinó parte de las comisiones cobradas a los contratistas para soportar el pago de dispendios personales de todo tipo. Al

\footnotetext{
${ }^{887}$ BRASIL. Tribunal Regional Federal (2 Região). Processo n. 0504466-152017.4.02.5101. Disponible em: http://jfrj.jus.br . Acceso en: 12 oct. 2019.

${ }^{888}$ BRASIL. Tribunal Regional Federal (2 Região). Processo n. 0509503-57.2016.4.02.5101. Disponible en: http://jfrj.jus.br Acceso en: 12 oct. 2019.

889 Por ahí funcionaba la sociedad GRALC consultoría empresarial Ltda., (actual LRG agropecuaria Ltda.), registrada en nombre de Carlos Miranda y Sonia Baptista, exasesora de Sergio Cabral mientras que fue Senador.

${ }^{890}$ Ahí estaba la nueva sede administrativa de la sociedad LRG agropecuaria Ltda.

${ }^{891}$ Posteriormente, la sociedad LRG agropecuaria Ltda. Transfirió su sede administrativa para el Municipio de Paraíba do Sul.

${ }^{892}$ BRASIL. Tribunal Regional Federal (2 Região). Processo n. 0509503-572016.4.02.5101. Disponible em: http://www.jfrj.jus.br . Acceso en: 12 oct. 2019.
} 
final de cada mes, Sonia Baptista preparaba un listado con los gastos de la familia y lo entregaba a Carlos Miranda para que realizara los pagos correspondientes. La ventaja indebida se destinaba, al pago de impuestos, salarios de empleados, escuela de los hijos del Gobernador, además de otros gastos domésticos ${ }^{893}$.

Otra parte de los recursos se destinaba a viabilizar la carrera política de Sergio Cabral. Considerando que, en el año 2010, se presentaría una vez más como candidato a Gobernador, el político solicitó a Rogerio Nora y a Clóvis Primo de Andrade Gutierrez que depositaran parte de los montos en la cuenta del Directorio Nacional de su partido. Los recursos ilícitos serían considerados, desde entonces, donaciones de campaña a favor del candidato ${ }^{894}$.

Siguiendo las instrucciones de Sergio Cabral, en octubre de 2010, Rogerio Nora y Clóvis Primo ingresaron en la cuenta núm. 1515-6, Agencia 3404-8, del Banco de Brasil, perteneciente al Partido del Movimiento Democrático Brasileño, cuatrocientos treinta y siete mil seiscientos treinta y seis euros con setenta y seis céntimos $(437.636,76 €)$, lo que origino el recibo electoral núm. 15.000.000151, considerado lo suficientemente bueno para blanquear el dinero ${ }^{895}$.

Otra estrategia adoptada para esconder el origen ilícito de los recursos fue utilizarlos para adquirir joyas en las principales tiendas especializadas en compraventa de tales activos en Rio de Janeiro. Se destacan, en este caso, las joyerías Antonio Bernardo (Arany Adornos LTDA) ${ }^{896}$ y H Stern (HSJ Comercial SA) ${ }^{897}$. Así, tanto el Gobernador Sergio Cabral como su mujer, la abogada Adriana Anselmo, se compraron un millón cuatrocientos treinta y cinco mil novecientos cuarenta y cinco euros con treinta céntimos $(1.435 .945,30 €)$ en joyas de altísimo valor de mercado, más bien con objeto de ocultar el origen ilícito de las comisiones pagadas por Andrade Gutierrez.

\footnotetext{
${ }^{893}$ Ibidem.

${ }^{894}$ Las revelaciones constan de la colaboración premiada de Alberto Quintaes. BRASIL. Tribunal Regional Federal (2 Região). Processo n. 0509503-57.2016.4.02.5101. Disponible en: http://jfrj.jus.br Acceso en: 12 oct. 2019.

${ }^{895}$ Idem, Ibidem.

896 las joyas fueron compradas en la tienda de Antonio Bernardo ubicada en la calle Marqués de São Vicente, n. 52, LJ. 330, Shopping da Gávea, Gávea, Rio de Janeiro.

${ }^{897}$ Las joyas fueron compradas en la tienda de H Stern ubicada en la calle García D' Avila, n. 113, $8^{\circ}$ andar, Ipanema, Rio de Janeiro.
} 
En todos los casos, Cabral y Adriana se compraron las piezas con cheques de terceros, para que no hubiese ningún vínculo entre el político o su mujer y las adquisiciones. Asimismo, la tienda responsable no emitía factura relativa a la transacción, con lo cual la identidad de ambos siempre se mantuvo en secreto. Sergio Cabral, incluso, fue identificado en la tienda bajo el nombre de "Ramos Filho", mientras que Adriana Anselmo era llamada "Lurdinha".

Se trata de una típica hipótesis de simulación subjetiva, pues se destinó a transferir derechos a una persona diferente de la que figuró en el contrato. Si bien "Ramos Filho" es una persona ficticia, lo cierto es que el Gobernador lo utiliza como se fuese una persona verdadera, un hombre de paja que se coloca al frente del negocio jurídico para viabilizar la compraventa de las joyas y evitar que los ciudadanos y las autoridades puedan identificarlo. Esta circunstancia se puso de manifiesto a partir de la manera como solía pasar el pago de estas joyas por sus verdaderos adquirientes. Antes que los cheques fueran pagados, uno de los miembros de la banda acudía a la tienda y los sustituían por su valor en efectivo, lo que dificultaba, aún más, la identificación de la compraventa y de sus responsables. La metodología utilizada fue revelada por María Lucia Guerra, directora de la joyería Antonio Bernardo, quien al declarar en juicio, clarificó que muchas veces acudió a la casa del Gobernador Sergio Cabral y al Palacio de gobierno para enseñarle algunas joyas que formaban parte del acervo de la tienda.

Lo que llama la atención de esta conducta fue la manera en la que el Gobernador Sergio Cabral se condujo al control ciudadano de sus actos al frente de la Administración Pública. Aunque realizadas en la sede del gobierno, estas reuniones no fueron debidamente registradas en la agenda del Gobernador, con lo cual no se pudo demostrar, por ejemplo, su periodicidad y los temas tratados en cada encuentro, lo que sería importante para saber si algo raro pasaba en el seno de la Administración.

Sin los controles propios de los regímenes democráticos, Cabral tenía amplia libertad en adoptar todas las medidas necesarias para esconder los recursos cobrados a título de comisión. En efecto, apenas se manifestaba su interés por alguna pieza, Cabral ordenaba a miembros de la banda criminal que emitieran cheques para adquirir la joya. Con frecuencia estos cheques pertenecían a Carlos Miranda y a Pedro Ramos, quienes posteriormente asistían a la tienda con el objetivo de sustituir los cheques por su valor en efectivo.

Entre 2000 y 2016, bajo el nombre de "Ramos Filho", Sergio Cabral se compró ciento catorce (114) piezas de la joyería Antonio Bernardo, lo que permitió ocultar a las 
autoridades la suma de ochocientos cuarenta y nueve mil ciento noventa y cinco euros con diecinueve céntimos $(849.195,19 €)$. Ochenta (80) por ciento de estas compraventas ocurrieron durante el período en el que Sergio Cabral actuó como Gobernador del Estado de Rio de Janeiro, lo que implicó una ocultación igual a seiscientos sesenta y ocho mil trescientos noventa y tres euros con ochenta y siete céntimos $(668.393,87 €)$. El 16 de mayo de 2016, se realizó la última compraventa que tuvo como objeto un collar evaluado en cuatro mil quinientos noventa y cinco euros con diecinueve céntimos $(4.595,19 €)^{898}$.

Finalmente, todo lo que no se destinaba a los dispendios personales del Gobernador, no era considerado donaciones de campaña y no utilizado para la compraventa de joyas, se entregaba a los hermanos Renato y Marcelo Chebar. Al recibir el dinero, Renato y Marcelo se encargaban de enviarlo a cuentas ubicadas en paraísos fiscales fuera de Brasil, para que estuviese a salvo de los controles de las autoridades ${ }^{899}$.

Una de estas cuentas fue la de Matlock Capital Group, ubicada en las Islas Vírgenes británicas, perteneciente a Arthur Soares, hombre de confianza de Sergio Cabral. Se trata de la misma cuenta de donde partieron los recursos a Papa Massata Diack y que al final acabaron con financiar la elección de Rio como ciudad anfitriona de las Olimpíadas de 2016, una vez que fueron utilizados para sobornar a directivos africanos del COI.

Con pequeñas variaciones de uno a otro caso, las irregularidades practicadas por el Gobernador Sergio Cabral al frente de la Administración Pública, siempre tuvieron un rasgo en común, todas se iniciaron a partir de reuniones secretas entre el político o sus secretarios y altos directivos de las grandes constructoras brasileñas, con lo cual no se pudo comprobar la finalidad de esos encuentros.

Esta debilidad del sistema de transparencia brasileño también se notó en otras esferas de gobierno, como el Municipio de Rio de Janeiro, permitiendo acuerdos ilegítimos entre funcionarios públicos y empresarios.

\footnotetext{
${ }^{898}$ BRASIL. Tribunal Regional Federal (2 Região). Processo n. 0510038-83.2016.4.02.5101. Disponible en: http://jfrj.jus.br . Acceso en: 12 oct. 2019.

${ }^{899}$ CORRÊA, Hudson. op. cit., L. 1093.
} 


\subsection{Oscuridad y sigilo en la construcción de equipamientos olímpicos.}

Más allá de reuniones secretas y licitaciones sesgadas, las Olimpíadas de Rio 2016, también revelaron otra forma de violación a la transparencia, relativa, en este caso, a la ejecución de los proyectos de arquitectura destinados a la construcción de equipamientos olímpicos. Se destacan al respecto la edificación del Parque Olímpico de Barra de Tijuca y el Complejo Olímpico de Deodoro ${ }^{900}$, que abarcaron importantes estructuras para el torneo, tales como el estadio de tiro, la arena de hipismo, el velódromo, el parque acuático, el estadio de tenis y el estadio de balonmano.

En definitiva, al terminar los Juegos Panamericanos de 2007, Brasil decidió presentar la candidatura de Rio de Janeiro como ciudad olímpica para los Juegos de 2016. Por consiguiente, aun en 2007, el gobierno federal transfirió recursos suficientes a la ciudad para la construcción de instalaciones deportivas, mirando a los futuros compromisos que serían firmados con el COI.

Asimismo, el Parlamento brasileño aprobó la Ley núm. 11.578, de 26 de noviembre de $2007^{901}$, con lo cual se autorizó a que el gobierno federal transfiriese al Municipio de Rio de Janeiro recursos para la financiación de las obras necesarias a la preparación del mega evento. Por consiguiente, apegándose a la referida ley, la Unión y el municipio perfeccionaron acuerdos de naturaleza financiera que, en definitiva, viabilizaron la entrega de los recursos a la futura ciudad olímpica. Al recibir los recursos, Rio de Janeiro realizó las licitaciones destinadas a la construcción de las instalaciones olímpicas.

Una vez concluidas las obras y con base en los acuerdos perfeccionados con el COI, el municipio entregó al Comité Organizador de los Juegos (CO-Río 2016), a través de una permisión de uso, la gestión de las instalaciones, lo que pasó a lo largo de todo el período de realización de los juegos, o sea, entre el 05 de agosto de 2016 y el 18 de septiembre de 2016. Con la culminación del mega evento, la gestión de las instalaciones

\footnotetext{
${ }^{900}$ BRASIL. Tribunal Regional Federal (2 Região). Processo n. 5025453-73.2019.4.02.5101. Disponible en: http://www.jfrj.jus.br . Acceso en: 12 oct. 2019.

901 BRASIL. Lei 11.578, de 26 de novembro de 2007. Dispõe sobre a transferência obrigatória de recursos financeiros para a execução pelos Estados, Distrito Federal e Municípios de ações do Programa de Aceleração do Crescimento - PAC, e sobre a forma de operacionalização do Programa de Subsídio à Habitação de Interesse Social - PSH nos exercícios de 2007 e 2008. Disponible em: http://www.planalto.gov.br/ccivil_03/_Ato2007-2010/2007/Lei/L11578.htm Acceso en: 18 de sep. de 2019.
} 
regresó al municipio, que buscó socios que pudieran realizar asociaciones públicoprivadas para la administración y uso comercial de las arenas.

Pese al esfuerzo, las autoridades municipales no lograron encontrar socios que se interesaran en asumir la gestión de las instalaciones ${ }^{902}$. Por consiguiente, ante esta dificultad, el 23 de diciembre de 2016, firmó un acuerdo con la Unión para esta materia, transfiriendo al ente central, la administración de los equipamientos olímpicos ${ }^{903}$.

Según el instrumento perfeccionado entre las partes, a partir del 23 de diciembre de 2016, por un período de veinticinco (25) años, la Unión se responsabilizó de la gestión de las arenas Carioca 1 y 2, lo que abarcó la administración de estructuras, tales como el velódromo y el estadio de tenis, obligándose a darles utilidad para que no se convirtieran en elefantes blancos, luego de finalizar el mega evento.

La idea fue evitar que pasara en Rio de Janeiro los mismos problemas sucedidos en otras ediciones de los Juegos, tales como Londres $1908^{904}$ y Atenas $2004^{905}$, cuando equipamientos olímpicos acabaron convirtiéndose en catedrales en el desierto. De acuerdo con el instrumento de cesión, el municipio debería facilitar a la Unión, desde ocho días posteriores a firmar el acuerdo, es decir, hasta el 31 de diciembre de 2016, todos los documentos técnicos relativos a la construcción de las referidas instalaciones. Se destacan entre tales documentos los proyectos básicos y ejecutivos, los "As Built", manuales de operación y otros escritos correspondientes.

Más allá de tratarse de un compromiso previsto en el instrumento de cesión, la entrega de estos documentos también tiene relevancia en lo concerniente a la transparencia gubernamental. En este sentido, el “As Built", por ejemplo, es el documento que según el lenguaje técnico de arquitectura, indica la manera como los proyectos

\footnotetext{
${ }^{902} \mathrm{La}$ dificultad del Municipio de Rio de Janeiro para encontrar socios privados que administraran las instalaciones olímpicas fue reconocida a través del Memorando n. 70/2018/AESP SEI. Cf. BRASIL. Tribunal Regional Federal (2 Região). Proceso n. 5025453-73.2019.4.02.5101. Disponible en: http://www.jfrj.jus.br. Acceso en: 12 oct. 2019.
${ }^{903} \mathrm{La}$ transferencia de la gestión de las instalaciones olímpicas se perfecciono a través del Término de Cesión n. 139/2016-SPA, firmado entre la Unión (Ministerio de Deportes) y el Municipio de Rio de Janeiro. Cf. BRASIL. Tribunal Regional Federal (2 Região). Processo n. 5025453-73.2019.4.02.5101. Disponible en: http://www.jfrj.jus.br . Acceso en: 12 oct. 2019.

${ }^{904}$ MANGAN, J.A. Prologue: guarantees of global goodwill: post-Olympic legacies - too many limping white elephants, International Journal of the History of Sport, 25(14), 2008, p. 1869-83.

${ }^{905}$ GOLDBLATT, David. op. cit., p. 388.
} 
diseñados para cada instalación fueron ejecutados por las entidades responsables de las obras.

En base a dicho documento, sería posible identificar si los materiales empleados en la construcción de los equipamientos corresponden a lo previsto en el proyecto básico de la licitación o, en sentido diverso, si utilizaron materiales de calidad inferior para reducir los costes de la sociedad responsable de las obras. En Brasil el "As Built" trata, según la jurisprudencia del Tribunal de Cuentas de la Unión, de un documento obligatorio a todos los contratos de obras perfeccionados con la Administración Pública ${ }^{906}$.

Sin embargo, pese a los compromisos acordados, el Municipio de Rio de Janeiro no le entregó a la unión los documentos referidos, tampoco divulgó esta información para conocimiento de los vecinos, lo que resultó ser muy probable, que los escritos estaban a cargo de la Secretaría Municipal de Obras, órgano comandado por el secretario Alexandre Pinto da Silva, uno de los principales responsables de las irregularidades cometidas durante las obras de preparación de la ciudad para los juegos.

A pesar de la omisión en cuanto a la entrega de los documentos, entre el de febrero de 2017 y el 10 de febrero de 2017, los técnicos de la Unión, toda vez que el ente central administraba las instalaciones, visitaron los equipamientos olímpicos e identificaron un mil quinientas (1.500) irregularidades en la construcción de las aludidas estructuras.

Mediante un análisis preliminar, se pudo verificar que las constructoras responsables de las obras, a lo mejor a causa de una ineficiente actuación de los fiscales del municipio, utilizaron material de inferior calidad a lo previsto en el proyecto básico de las licitaciones, circunstancia que tampoco fue informada a los vecinos por el municipio, aunque a la fecha ya estuviese en vigor la Ley de Transparencia y Acceso a la Información de Brasil.

A modo de obligar al municipio en dar publicidad a todos los documentos relativos a la construcción de las instalaciones olímpicas, lo que resulta de la aplicación del principio de máxima divulgación. El 28 de febrero de 2018, el Tribunal de Cuentas de la Unión dictó la resolución núm. 393/2018-TCU-Plenário ${ }^{907}$. La Corte se refirió, expresamente, a la necesidad de facilitar al ente central toda la documentación pertinente,

\footnotetext{
906 BRASIL. Tribunal de Contas da União. Processo TC 034.628/2012-6. Acórdão n. 853/2013TCUPlenário. Disponible en: https://portal.tcu.gov.br/inicio/ . Acceso en: 12 oct. 2019.

907 BRASIL. Tribunal de Contas da União. Disponible em: https://contas.tcu.gov.br/sagas/SvlVisualizarRelVotoAcRtf?codFiltro=SAGAS-SESSAOENCERRADA\&seOcultaPagina $=$ S\&item0 $=606985$ Acceso en: 16 out 2019.
} 
como los proyectos básicos y ejecutivos, el "As Built" y los manuales de operación de cada instalación ${ }^{908}$.

Asimismo, el Tribunal de Cuentas y el Ministerio de Deportes publicaron el Aviso núm. 83/2018, de fecha 13 de septiembre de 2018, por medio del cual llamaron al Municipio de Rio de Janeiro para que perfeccionara un acuerdo en la entrega de los referidos documentos. La idea fue establecer plazos y condiciones para que el ente local facilitara los escritos, evitando que se presentaran acciones judiciales en este sentido.

A pesar de todas las tentativas, el ente local no acudió al llamado del ministerio, tampoco cumplió con los dictámenes del Tribunal de Cuentas. En consecuencia, impidió el control social en la ejecución de las obras de construcción pertenecientes a las instalaciones olímpicas ${ }^{909}$.

\subsection{Conclusión}

Innegablemente, los mega eventos deportivos internacionales cumplen con un importante papel en cuanto a la transformación y valorización de las ciudades anfitrionas, lo que acompaña los Juegos Olímpicos desde mediados del siglo XX, coincidiendo con la entrada de la televisión en el torneo. A partir de este momento, los Juegos ganaron en complejidad, trataron de acoger a un mayor número de atletas, aficionados, periodistas y patrocinadores, aparte de demandar de los gobiernos mayores inversiones para su realización.

Con motivo de los Juegos se construirían arenas, estadios, gimnasios, alojamientos, así como se ejecutarían grandes obras de infraestructura en la ciudad anfitriona, como aeropuertos, carreteras, nuevas líneas de metro y la creación de carriles exclusivos para autobuses. También serían una oportunidad para la regeneración de áreas degradadas y la recuperación ambiental de ciertas regiones. ${ }^{910}$ Además, se supone que con la realización de los Juegos Olímpicos la ciudad anfitriona puede fomentar el turismo y atraer grandes

\footnotetext{
908 BRASIL. Tribunal de Contas da União. Disponible em: https://portal.tcu.gov.br/imprensa/noticias/tcu-determina-providencias-em-complexos-olimpicos-da-barrada-tijuca-e-deodoro.htm Acceso en: 16 out 2019.

909 La omisión del Municipio en esta materia fue reconocida a través de la Nota Técnica n. 02/2019/DEX/DIN/AGLO/DEX/PR-AGLO/AGLO. Cf. BRASIL. Tribunal Regional Federal (2 Região). Processo n. 0174071-16.2017.4.02.5101. Disponible en: http://www.jfrj.jus.br . Acceso en: 09 out 2019.
}

${ }^{910}$ SÁNCHEZ, Renata Latuf de Oliveira; ESSEX, Stephen. op. cit. p. 97-99. 
inversiones internacionales, incorporándose al clube de las principales metrópolis del planeta.

Estas ideas quedaron más evidentes a partir de los Juegos de Roma (1960). La capital italiana aprovechó las Olimpíadas para modernizar toda la red de suministro de agua y alcantarillas en la ciudad, construir un nuevo aeropuerto, perfeccionar el sistema de transporte y mejorar el alumbramiento de calles y avenidas.

Treinta años después, en 1992, Barcelona también utilizó el mega evento para transformar la estructura y valorizar la imagen de la ciudad internacionalmente. Las Olimpíadas de Barcelona lograron asociar la realización del torneo con una agenda cultural vista nunca, con destaque para la valorización de elementos de la historia y el arte de España. ${ }^{911}$

Los logros de Barcelona contribuyeron directamente para consolidar el discurso olímpico en el sentido de que, hoy por hoy, los Juegos se consideran un evento que va más allá de lo meramente deportivo. Su influencia se nota en varios sectores, tales como el cultural, el urbanístico, el medio ambiental y el marketing, donde contribuyen para la valorización de la imagen de la ciudad internacionalmente.

Asimismo, se firmó el discurso que los Juegos Olímpicos suelen dejar para la ciudad anfitriona un legado, lo cual es constituido a partir de todas las transformaciones que ha generado en el ambiente urbano con motivo de su realización. Estas alteraciones son responsables de una mejor calidad de vida para los vecinos, con lo cual se justifica el interese de los gobiernos en acoger al mega evento. ${ }^{912}$

Cuando Rio de Janeiro fue elegida como ciudad anfitriona de los Juegos Olímpicos de 2016, había una expectativa de que todas estas promesas se cumplirían. Más allá de la gran fiesta del deporte, los Juegos serían responsables de grandes transformaciones en sectores importantes de la ciudad, como lo social, lo ambiental y lo concerniente a la movilidad urbana. Aparte de valorar la imagen de Rio internacionalmente, las Olimpíadas también servirían para demostrar al mundo las calidades de Brasil como un lugar favorable a la realización de grandes inversiones. ${ }^{913}$

\footnotetext{
911 Ibidem, p. 98.

912 Ibidem, p. 98.

${ }^{913}$ Ibidem, p. 100-101.
} 
Pese a este discurso a menudo repetido por políticos, empresarios y autoridades deportivas, lo cierto es que los Juegos Olímpicos Rio 2016 no cumplieron con estos objetivos. Los análisis realizados a lo largo de este capítulo demostraron que las primeras Olimpíadas brasileñas constituyeron un ambiente favorable a la comisión de actos de corrupción, aunque existieran instrumentos legales que permitiesen a la sociedad acompañar los actos practicados con motivo de la preparación del mega evento.

Para asegurar que la información de los actos y decisiones de la Administración Pública llegara a la ciudadanía, la ley brasileña n.12.527, de 18 de noviembre de 2011, de Transparencia y Acceso a la Información, dio a la Contraloría General de la Unión el protagonismo referente a la defensa del patrimonio público y el incremento de la transparencia. En este sentido, la contraloría debe realizar actividades para favorecer el control interno, la auditoría pública, la corrección, la prevención y el combate de la corrupción.

Pese a estas atribuciones, ni la Contraloría General de la Unión, ni los órganos de control interno tanto del Estado como del Municipio de Rio de Janeiro lograron prevenir las malas prácticas asociadas a la preparación de los Juegos Olímpicos Rio 2016. No quiere decir esto que las irregularidades quedaron sin la debida respuesta de las instituciones brasileñas. Tal respuesta fue dada por el derecho penal, más no el derecho administrativo ni la transparencia gubernamental.

Teniendo en cuenta la naturaleza de los actos practicados, cada uno de los responsables, en mayor o menor extensión, sufrieron las consecuencias de sus actos, pero siempre desde la perspectiva del derecho penal. Así, el jefe de la organización criminal, el Gobernador Sergio Cabral, en septiembre de 2017, fue condenado a cuarenta y cinco (45) años de prisión, mientras que su mujer, la abogada Adriana Anselmo, recibió una condena de dieciocho (18) años y tres (3) meses de prisión ${ }^{914}$.

En efecto, la Justicia Penal no dejó de trabajar ni un momento con el objeto de responsabilizar a la principal autoridad del Estado de Rio de Janeiro a causa de los ilícitos cometidos, tanto fue así que un año posterior a recibir su primera condena, la Justicia Federal brasileña dictó ocho (8) sentencias más en contra del Gobernador. La primera de

\footnotetext{
${ }^{914}$ BRASIL. Tribunal Regional Federal (2 Região). Processo n. 0509503-57.2016.4.02.5101. Disponible en: http://www.jfrj.jus.br. Acceso en: 06 nov. 2019.
} 
las condenaciones la impuso la Justicia Federal de Paraná ${ }^{915}$, mientras que las demás las dictó la Justicia Federal de Rio de Janeiro ${ }^{916}$.

Sumadas, las sanciones llegaron a ciento ochenta y tres (183) años y seis (6) meses de prisión. La mayor de las condenaciones, correspondiente a cuarenta y siete (47) años y cuatro (4) meses de prisión, resultó justamente de la ventaja indebida que el Gobernador demandó de Carioca Ingeniería para que la compañía fuese beneficiada en futuras licitaciones de responsabilidad con la Administración Pública Estatal ${ }^{917}$.

En este mismo período, a raíz de los ilícitos cometidos, Wilson Carlos también fue condenado a ochenta y siete (87) años, y ocho (8) meses de prisión, así como al Gobernador, la primera sentencia dictada por la Justicia Federal de Paraná ${ }^{918}$ y las demás las firmó la Justicia Federal de Rio de Janeiro ${ }^{919}$. A su vez, Carlos Miranda recibió una pena total de setenta y ocho (78) años y cuatro (4) meses de prisión, lo que igual resultó de las sentencias dictadas por la Justicia Federal de Paraná ${ }^{920}$ y Rio de Janeiro ${ }^{921}$, respectivamente.

915 BRASIL. Tribunal Regional Federal (4 Região). Processo n. 5063271-36.2016.4.04.7000/PR. Disponible en: http://www.jfpr.jus.br. Acceso en: 06 nov. 2019.

916 BRASIL. Tribunal Regional Federal (2 Região). Processos n. 0509503-57.2016.4.02.5101; 050185322.2017.4.02.5101; $\quad$ 0015979-37.2017.4.02.5101; $\quad$ 0135964-97.2017.4.02.5101; $\quad$ 050163409.2017.4.02.5101; 0504113-72.2017.4.02.5101; 0017513-21.2014.4.02.5101. Disponible en: http://www.jfrj.jus.br. Acceso en: 06 nov. 2019.

917 BRASIL. Tribunal Regional Federal (2 Região). Processo n. 0504113-72.2017.4.02.5101. Disponible en: http://www.jfrj.jus.br. Acceso en: 06 nov. 2019.

918 BRASIL. Tribunal Regional Federal (4 Região). Processo n. 5063271-36.2016.4.04.7000/PR. Disponible en: http://www.jfpr.jus.br. Acceso en: 06 nov. 2019.

919 BRASIL. Tribunal Regional Federal (2 Região). Processo n. 0509503-57.2016.4.02.5101; 050163409.2017.4.02.5101; 0504113-72.2017.4.02.5101; 0017513-21.2014.4.02.5101. Disponible en: http://www.jfrj.jus.br. Acceso en: 06 nov. 2019.

920 BRASIL. Tribunal Regional Federal (4 Região). Processo n. 5063271-36.2016.4.04.7000/PR. Disponible en: http://www.jfpr.jus.br. Acceso en: 06 nov. 2019.

921 BRASIL. Tribunal Regional Federal (2 Região). Processos n. 0509503-57.2016.4.02.5101; 050185322.2017.4.02.5101; $\quad$ 0015979-37.2017.4.02.5101; $\quad 0135964-97.2017 .4 .02 .5101 ; \quad 0501634-$ 09.2017.4.02.5101. Disponible en: http://www.jfrj.jus.br. Acceso en: 06 nov. 2019. 
La abogada Adriana Anselmo, esposa de Sergio Cabral, también recibió una dura respuesta penal a causa de los ilícitos practicados. En total, las penas aplicadas a ella llegaron a cuarenta y un (41) años y cinco (5) meses de prisión ${ }^{922}$.

Finalmente, los hermanos Renato y Marcelo Chebar, operadores financieros del Gobernador, recibieron una condenación de diecisiete (17) años y tres (3) meses de prisión $^{923}$. Sin embargo, a raíz de su colaboración, al revelar los hechos y la restitución de cien (100) millones de dólares que el Gobernador tenía en paraísos fiscales, ambos fueron beneficiados con la disminución de la pena, cumpliendo solamente cinco (5) años de sanción a través de prisión domiciliaría y servicios comunitarios. Asimismo, fueron condenados a una multa de un millón treinta mil (1.030.000) euros y restituir a las arcas públicas doscientos veintiocho mil ochocientos (228.800) euros.

Las condenaciones aplicadas en el ámbito de la Administración Pública Estatal también llegaron a los funcionarios y particulares que actuaban junto a la Secretaría de Obras del Municipio de Rio de Janeiro. En este sentido, el secretario Alexandre Pinto da Silva fue condenado a veintidós (22) años y once (11) meses de prisión, considerado responsable de los crímenes de corrupción y pertenencia a organización criminosa ${ }^{924}$.

A su vez, en el mismo proceso, Laudo Ziani fue condenado a nueve (9) años y cinco (5) meses, por ser considerado responsable de los delitos de tráfico de influencia y blanqueo de capitales.

Por otro lado, los fiscales que actuaban junto a las obras de construcción del BRT Transcarioca y de recuperación ambiental de la cuenca de Jacarepaguá recibieron sentencias más duras. Así, Eduardo Fagundes y Ricardo Falcao, también en el mismo proceso, fueron condenados a dieciséis (16) años y tres (3) meses de prisión, por ser considerados responsables de los crímenes de corrupción y pertenencia a organización criminosa. En base a las mismas infracciones penales, el fiscal Carlos Frederico Peixoto Pires recibió una condena de trece (13) años, ocho (8) meses y trece (13) días de prisión y multa por quinientos diecisiete (517) días.

\footnotetext{
922 BRASIL. Tribunal Regional Federal (2 Região). Processos n. 0509503-57.2016.4.02.5101; 001597937.2017.4.02.5101; 0135964-97.2017.4.02.5101; 0501634-09.2017.4.02.5101. Disponible em: http://www.jfri.jus.br. Acceso en: 06 nov. 2019.

${ }^{923}$ BRASIL. Tribunal Regional Federal (2 Região). Processo n. 0015979-37.2017.4.02.5101. Disponible en: http://www.jfrj.jus.br. Acceso en: 06 nov. 2019.

${ }^{924}$ BRASIL. Tribunal Regional Federal (2 Região). Processo n. 0174071-16.2017.4.02.5101. Disponible em: http://www.jfrj.jus.br. Acceso en: 06 nov. 2019.
} 
En el caso de Antonio Cid, directivo de OAS, recibió una pena de veintiún (21) años y nueve (9) meses de prisión y ochocientos un (801) días de multa, por ser considerado responsable de los crímenes de corrupción, blanqueo de capitales y pertenencia a organización criminosa, sin embargo, la sanción no se aplicó, toda vez que el directivo perfeccionó un acuerdo de cooperación con el Ministerio Público Federal.

Finalmente, la abogada Vanuza Vidal Sampaio recibió una condena de seis (6) años y nueve (9) meses de prisión, además de multa por ciento ochenta (180) días, debido al crimen de blanqueo de capitales Aunque recibieron estas sanciones en el ámbito del derecho penal, desde la perspectiva de la transparencia, lo cierto es que los órganos responsables de prevenir estas malas prácticas no lograron cohibirlas.

Es cierto que la Contraloría General de la Unión de Brasil logró identificar algunas de las malas prácticas relativas a las obras de urbanización de las favelas de Rocinha, Manguinhos y Alemán, cuando se analizó toda la contratación pública perfeccionada entre el Estado de Rio de Janeiro y los consorcios responsables de la ejecución de cada proyecto $^{925}$.

En este sentido, las obras relativas a la urbanización de la favela de Rocinha registraron una sobrefacturación equivalente a dos millones seiscientos setenta y nueve mil ochocientos ochenta y nueve euros con ochenta y nueve céntimos $(2.679 .889,89 €)^{926}$.

A su vez, las obras de urbanización de la favela de Manguinhos registraron una sobrefacturación igual a nueve millones ochenta y ocho mil seiscientos cincuenta y cuatro euros con veintidós céntimos $(9.088 .654,22 €),{ }^{927}$ mientras que las obras relativas a la favela del Alemán registraron una sobrefacturación correspondiente a treinta millones quinientos cuarenta y tres mil seiscientos treinta y ocho euros con dos céntimos $(30.543 .638,02 €)^{928}$.

Considerando la magnitud de las malas prácticas, estas fueron apenas reveladas tras su cometimiento, al ser analizados los procesos de contratación realizados por el Estado de Rio de Janeiro. Desde esta perspectiva, la labor de la Contraloría, a pesar de su

\footnotetext{
${ }^{925}$ BRASIL. Tribunal Regional Federal (2 Região). Processo n. 0017513-21.2014.4.02.5101, p. 5.4705.478. Disponible en: http://www.jfrj.jus.br. Acceso en: 06 nov. 2019.

${ }^{926}$ BRASIL. Tribunal Regional Federal (2 Região). Processo n. 0017513-21.2014.4.02.5101, p. 5.4705.472. Disponible en: http://www.jfrj.jus.br. Acceso en: 06 nov. 2019.

${ }^{927}$ Ibidem, p. 5.472-5.475.

${ }^{928}$ Ibidem, p. 5.475-5.478.
} 
relevancia, únicamente produjo resultados en cuanto a la identificación y represión de las irregularidades, evidenciando su debilidad en lo relativo a la prevención de la corrupción.

El análisis de la página web de la Controlaría General de la Unión reveló que el órgano publicó los costes de la preparación de los Juegos Olímpicos Rio 2016, indicando los lugares que recibirían las principales instalaciones olímpicas y divulgó las obras fundamentales de infraestructura asociadas al mega evento ${ }^{929}$. Lo mismo pasó con las páginas web del Ministerio de Deportes y con el Ministerio de las Ciudades.

Gran parte de estas informaciones, a pesar de su divulgación en las páginas web de la Contraloría, fueron producidas por los órganos, entidades estatales y municipales responsables de la preparación de las Olimpíadas, con lo cual hubo en realidad, una mera repetición de informaciones existentes en otras esferas de gobierno ${ }^{930}$.

Consecuentemente, no existió un control efectivo sobre las agendas de trabajo de los altos directivos de la Administración Pública, ni en las exigencias de naturaleza técnica establecidas en los pliegos relativos a las principales obras de preparación de los juegos, tampoco hubo un acompañamiento de los informes elaborados por los fiscales responsables de verificar la ejecución de cada emprendimiento.

La falta de estas informaciones, pese a todos los datos divulgados, no posibilitó el efectivo control de los actos practicados en cuanto a la preparación de las olimpíadas, además de que permitió la creación de espacios de oscuridad que sirvieron para el cometimiento de malas prácticas administrativas por parte de autoridades, funcionarios y particulares. Estas omisiones explican el motivo por el cual la Contraloría General de la Unión no logró aplicar sanciones a los responsables de estas irregularidades, fallando en su labor preventiva de la corrupción.

A raíz de todo lo dicho, consideramos importante proponer alteraciones en la Ley de Transparencia y Acceso a la Información de Brasil a modo de perfeccionarla para la prevención de la corrupción asociada a los mega eventos deportivos internacionales y, principalmente, a la contratación pública. Se trata de una labor que, además de señalar los

${ }^{929}$ BRASIL. Controladoria Geral da União. CGU prepara portais sobre a Copa 2014 e as Olimpíadas 2016. Disponible em: https://www.cgu.gov.br/noticias/2010/03/cgu-prepara-portais-sobre-a-copa-2014-ea-olimpiadas-2016. Acceso en: 06 nov. 2019.

930 BRASIL. Controladoria Geral da União. CGU dá transparência aos investimentos federais nas Olimpíadas Rio 2016. Disponible em: https://www.cgu.gov.br/noticias/2015/08/cgu-da-transparenciaaos-investimentos-federais-nas-olimpiadas-rio-2016. Acceso en: 06 nov. 2019. 
cambios que consideramos necesarios, se destina a ofrecer los fundamentos teóricos de las reformas, compatibilizándolas con la mejor doctrina sobre las estrategias de prevención de la corrupción. 


\section{CAPÍtULO III - RUMBO A LA CONSTRUCCIÓN DE UNA CULTURA DE TRANSPARENCIA EN LA ADMINISTRACIÓN PÚBLICA}

\section{CONSIDERACIONES GENERALES}

Los estudios desarrollados con motivo de esta investigación demostraron que la corrupción es un fenómeno que suele desarrollarse en la oscuridad, distante del control ciudadano, comúnmente manifestado a través de relaciones de poder paralelas e invisibles que actúan al margen del Estado democrático de derecho, ${ }^{931}$ entendido en la concepción que le dieron los doctrinadores franceses y estadounidenses a partir de finales del siglo XVIII. ${ }^{932}$

De acuerdo con estas concepciones, el poder soberano sobre los destinos de una nación pertenece al pueblo, quien puede ejercerlo directa o indirectamente, dependiendo de las normas en vigor en dado momento.

En este sentido, el Estado democrático se caracteriza por la existencia de reglas primarias y fundamentales que establecen quien está autorizado a tomar las decisiones colectivas y bajo qué procedimientos debe hacerlo. Las normas enmarcan, por tanto, los límites de la actuación de la Administración Pública con base al principio de legalidad, con lo cual no es jurídicamente posible que sean desarrolladas relaciones de poder que no estén disciplinadas con fundamento en las reglas aprobadas por el Parlamento y que reflejan la voluntad del pueblo soberano.

A pesar de esta concepción en vigor en los Estados democráticos modernos, lo cierto es que la corrupción no comparte de las mismas ideas y crea sus propias reglas, muchas veces aprovechándose de las debilidades existentes en el orden jurídico formal, para a partir de ahí, crear una Administración Pública invisible, ${ }^{933}$ que no puede ser controlada por los ciudadanos.

\footnotetext{
${ }^{931}$ BOBBIO. Norberto. La democracia y el poder invisible. Op. Cit., p. 41-43.

932 COMPARATO, Fábio Konder. Ética, Direito, Moral e Religião no mundo moderno. São Paulo: Companhia das letras, 2006, p. 644.

${ }^{933}$ BOBBIO, Norberto. El Futuro de la Democracia. op. cit., p. 30.
} 
A modo de prevenir que esta Administración paralela llegue a formarse, los Estados modernos tratan de adoptar políticas de transparencia y rendición de cuentas de los órganos y entidades del sector público, permitiendo que los ciudadanos puedan acompañar los actos y decisiones de la Administración y manifestarse a su respecto. Así, la visibilidad del poder constituye un eje vertebral de los regímenes democráticos modernos, con lo estamos ante la afirmación de que no se puede hablar de democracia sin transparencia. ${ }^{934}$

Esta transparencia da la posibilidad a los ciudadanos de que se manifiesten de forma crítica en cuanto a las decisiones tomadas en el seno de la Administración Púbica al objeto de conformarlas con sus verdaderas finalidades, o sea, la satisfacción del interes público y no la atención a las comodidades de un restringido número de personas.

Sin embargo, para que la transparencia cumpla con su objetivo, es importante que las normas que establecen su régimen jurídico posibiliten una efectiva rendición de cuentas de los gobernantes frente a los gobernados, lo que depende de la eliminación de espacios de oscuridad que a veces suele identificarse en las normativas que tratan de este asunto. Erradicar estos agujeros, además de dar viabilidad a la claridad de los actos oficiales, favorece al diálogo entre la Administración y la sociedad, ${ }^{935}$ lo que contribuye a la prevención de la corrupción, principalmente cuando asociada a los mega eventos deportivos internacionales.

La eliminación de estas debilidades depende, en el caso brasileño, de alteraciones en la Ley de Transparencia y Acceso a la Información, a modo de incorporarle materias tales como la divulgación de las agendas de los altos directivos de la Administración Pública, la ampliación de los sujetos obligados al deber de transparencia activa y el aumento de los asuntos sometidos a la publicidad oficial.

Asimismo, consideramos importante atender a la claridad de la información concerniente a las contrataciones públicas, en especial cuando son relativas a la elaboración de los pliegos, siempre que ellos pueden ser utilizados para encaminar las

\footnotetext{
${ }^{934}$ PRESGRAVE, Ana Beatriz F. Rebello, COSTA, Daniel. e CAVALCANTI, Francisco Ivo Dantas. O Poder Invisível e a Democracia Representativa na Visão de Norberto Bobbio. Revista Interface. Natal/RN, v. 10, n. 1, 2013, p. 103-121.

${ }^{935}$ HERRERA, ob. Cit., p. 168.
} 
licitaciones para determinadas personas, más bien a través de exigencias técnicas aparentemente neutras, pero que en realidad persiguen un cierto objetivo que no es compatible con el Estado Democrático de Derecho.

En este sentido, opinamos que las Leyes de Transparencia, como pasa con la Ley de Brasil, aparte de exaltar la claridad, la exactitud y la precisión de la información, también deben adoptar instrumentos que efectivamente favorezcan el uso de un lenguaje sencillo en estos asuntos, a pesar de su naturaleza técnica. La sencillez de la información permite a los ciudadanos entender el verdadero significado del mensaje divulgado por la Administración Pública y, consecuentemente, posibilita que ellos opinen críticamente al respecto. $^{936}$

Dicho de otra manera, las políticas de transparencia apenas producen resultados positivos cuando ofrecen a los ciudadanos las informaciones que precisan de la forma como lo necesitan, ${ }^{937}$ con claridad y sencillez para que todos puedan entenderla, independientemente de su formación profesional.

Considerando la importancia que el tema de la contratación pública ha adquirido en los últimos años, entendemos relevante incorporar a los contratistas de la Administración Pública entre los sujetos obligados al deber de transparencia, de tal manera que las entidades del sector privado actúen al lado de la Administración Pública en la lucha contra la corrupción.

Defendemos, además, una valorización de la labor de las mesas o comisiones de contratación, asegurándose su independencia e imparcialidad para analizar las cuestiones de naturaleza técnica concernientes a la licitación.

Finalmente, consideramos que la Ley de Transparencia y Acceso a la Información de Brasil debería prever las llamadas providencias administrativas cautelares, tendentes a asegurar la publicidad de los actos de la Administración en el supuesto de que uno esté

\footnotetext{
${ }^{936}$ CERRILLO I MARTíNEZ, Agustí. "Las compras abiertas y la prevención de la corrupción". Disponible en : https://revistasonline.inap.es/index.php/GAPP/article/view/10314/10875 Acceso en: 13 dic. 2019.

937 WEIL, David., FUNG, Archon., GRAHAM, Mary. "Targeting Transparency". Policy Forum Science and Regulation, vol. 340, 2013, p. 1410-1411. Disponible en https://science.sciencemag.org/content/340/6139/1410.full.pdf+html Acceso en 22 nov. 2019.
} 
dificultando su publicidad, medida que podría ser adoptada por las Contralorías, teniendo en cuenta su papel institucional en cuanto a la defensa de la transparencia gubernamental.

A lo largo de este capítulo, por tanto, tratamos de proponer las alteraciones que consideramos relevantes para mejorar el régimen de transparencia activa en Brasil, teniendo en cuenta las debilidades identificadas con motivo de la preparación de los Juegos Olímpicos Rio (2016). Más allá de ofrecer los medios para eliminar los espacios de oscuridad existentes, buscamos presentar los fundamentos teóricos que justifican los cambios sugeridos, apeándonos, para tanto, en las experiencias exitosas de otros países e instituciones internacionales que se enfrentaron a la corrupción y la falta de rendición de cuentas en la gestión pública.

\subsection{La publicidad de las agendas de los altos directivos y funcionarios de la administración pública}

La transparencia gubernamental se ha convertido en los últimos años en uno de los ejes de los Estados Democráticos de Derecho, ${ }^{938}$ toda vez que favorece el seguimiento de los actos y decisiones de la Administración Pública ${ }^{939}$ y permite la rendición de cuentas de los altos directivos y funcionarios quienes se consideran responsables de colocarla en funcionamiento. ${ }^{940}$

Debido a la transparencia, todos los que ocupan cargos públicos deben obrar de la forma más abierta posible en cualquier de sus acciones, ${ }^{941}$ justificando con regularidad y claridad el contenido de cada una de sus decisiones para el verdadero titular del poder

\footnotetext{
${ }^{938}$ PIÑAR MAÑAS, José Luis. Transparencia y Protección de Datos: las claves de un equilibrio necesario. In: GARCÍA MACHO, R. Derecho administrativo de la información y administración transparente. Madrid: Marcial Pons, 2010, p. 81 y ss.

${ }^{939}$ HERRERA, op. Cit., p. 180.

940 ARANDA ÁlVAREZ, Elviro. Una Reflexión sobre Transparencia y Buen Gobierno. Revista "Cuadernos Manuel Giménez Abad", ISSN-E 2254-445, n. ${ }^{\circ}$ 5, Salamanca, (2013, p. 214-229. Disponible en: https://dialnet.unirioja.es/servlet/articulo?codigo $=4347898$ Acceso en 25 nov. 2019.

${ }^{941}$ NEVADO-BATALLA MORENO, Pedro T. Cumplimento de la Legalidad en la Nueva Gestión Pública: propuestas y realidad en la lucha contra la corrupción. In: La Corrupción en un Mundo Globalizado: análisis interdisciplinar. Salamanca: Ratio Legis, 2004, p. 105.
} 
soberano, el pueblo, ${ }^{942}$ salvo que subsistan razones excepcionales que autorizan el secreto, lo que apenas es posible en las hipótesis previamente establecidas en Ley. ${ }^{943}$

En comparación, mientras que en los estados autoritarios la regla es el secreto y la oscuridad, lo que favorece al no control de las acciones administrativas, en un régimen democrático la premisa básica es la publicidad de los actos y decisiones oficiales, lo que permite el acompañamiento ciudadano de todas sus actuaciones. ${ }^{944}$

Esta idea se firmó a partir de mediados del siglo XX, cuando la transparencia logró asociarse a la expansión de la democracia y buscó satisfacer a las nuevas exigencias de los ciudadanos en cuanto a una mayor participación en los actos y decisiones oficiales.

En definitiva, el incumplimiento de las promesas constitucionalmente asumidas hizo que los ciudadanos exigieran de las instituciones públicas cambios que lograran restablecer los vínculos entre las decisiones estatales y la sociedad con objeto de satisfacer sus demandas. ${ }^{945}$ Los gestores ya no pueden decidir de espaldas para la sociedad como en el pasado, sino que están obligados a escucharla y rendirle cuenta de cada acto o decisión al frente de la Administración Pública, ${ }^{946}$ con lo cual los ciudadanos pueden opinar al respecto y proponer al gestor alternativas para enfrentarse con los problemas concernientes al ejercicio de la actividad política y administrativa. ${ }^{947}$ Entre tantos e importantes desafíos se destaca la prevención de arbitrariedades, abusos y la corrupción, ${ }^{948}$ en especial de los altos cargos de la Administración Pública

\footnotetext{
${ }^{942}$ HERRERA, op. Cit., p. 180.

${ }^{943}$ NEVADO-BATALLA MORENO, Pedro T. op. Cit., p. 105.

944 FERNÁNDEZ RAMOS, Severiano., El derecho de acceso a los documentos administrativos. Op. Cit., p. 311.

945 GIDDENS, Anthony. Un mundo desbocado: Los efectos de la globalización en nuestras vidas, Madrid: Taurus, 1999, p. 35.

946 MORLINO, Leonardo., Calidad democrática entre líderes y partidos. Florencia: Instituto Italiano di Scienze Humane, 2008, p 32.

${ }^{947}$ HERRERA, Manuel Palomares. Op. Cit., p. 28.

948 LOZANO MIRALLES, Jorge. "Auditoria pública", In: Revista de los Órganos Autónomos de Control Externo, núm. 3, 1995, p. 84-85.
} 
Considerada una de las principales enfermedades institucionales de nuestros días, la corrupción distorsiona los objetivos del Estado democrático de derecho, promueve el logro de ventajas patrimoniales indebidas a expensas de las arcas públicas, incentiva el ejercicio nocivo de las competencias administrativas, fomenta el tráfico de influencia en las varias esferas de la Administración Pública y conlleva al favorecimiento de pocos en detrimento de los intereses de la sociedad. ${ }^{949}$

Con objeto de prevenir estas malas prácticas, la transparencia se propone a ofrecer medios para el control ciudadano de los actos y decisiones de los altos cargos de la Administración Pública. Una eficiente manera de controlar estas conductas es por medio de la divulgación de las agendas de estas personas, en especial cuando desarrollan sus actividades en áreas como la contratación pública.

Como ya lo hemos tratado de demostrar a lo largo de esta investigación, los Juegos Olímpicos, independientemente del lugar en donde se organicen, constituyen un ambiente favorable a las malas prácticas administrativas, más bien en lo relativo a las obras públicas ejecutadas con motivo de su realización. Desde Ámsterdam (1928) hasta Rio de Janeiro (2016), las Olimpíadas han registrado innumerables casos de corrupción, siempre con la participación de altos directivos de la Administración Pública y particulares directamente involucrados con la preparación del torneo.

En este sentido, a modo de prevenir estas irregularidades, consideramos importante acompañar desde cerca todos los actos y decisiones de las autoridades y funcionarios directamente implicados en estas actividades, lo que se logra, entre otras medidas, a través de la divulgación de las agendas profesionales de tales personas.

Pese a la relevancia de este tema, la Ley n. 12.527, de 18 de noviembre de 2011, de Transparencia y Acceso a la Información de Brasil, no considera obligatoria la divulgación de las agendas profesionales de los altos directivos del Estado y funcionarios potencialmente expuestos a la corrupción, lo que ha facilitado la comisión de malas prácticas asociadas a los preparativos de los Juegos Olímpicos Rio 2016.

949 PAZZAGLINI FILHO, Marino. ELIAS ROSA, Marcio Fernando. FAZZIO JÚNIOR, Waldo. Improbidade Administrativa: Aspectos Jurídicos da Defesa do Patrimônio Público. 2a ed., São Paulo: Atlas, 1997, p. 37-38. 
La divulgación de estas agendas, en el caso de existir, permitiría a los ciudadanos, por un lado, tomar conocimiento de las reuniones de que participaron los altos directivos del Estado ${ }^{950}$ y las influencias a las que estuvieron sometidos ${ }^{951}$ a lo largo del periodo de preparación del torneo, lo que viabilizaría el control permanente de esas personas por medio de herramientas autónomas e independientes ${ }^{952}$, además de favorecer la prevención de acuerdos fraudulentos con fondos públicos. ${ }^{953}$

En comparación, en España, la importancia de las agendas de los altos cargos de la Administración Pública fue expresamente reconocida por el Consejo de Transparencia y Buen Gobierno, a través de la recomendación n. 1/2017. Dicha recomendación deja claro que la información referida a la actividad de quienes gestionan y organizan, así como también son responsables de la toma de decisiones, debe ser publicada para conocimiento de los ciudadanos, permitiéndoles un mejor conocimiento de la actividad pública en sí misma, además de facilitar "el escrutinio ciudadano y el ejercicio del control democrático".

Teniendo en cuenta el contenido de esta recomendación, el 14 de noviembre de 2019, la Junta de Castilla y León, a partir de una propuesta del Consejero de Transparencia, Ordenación del Territorio y Acción Exterior, y tras previa deliberación favorable del Consejo de Gobierno, firmó el Acuerdo n. 185/2019, de 14 de noviembre, sobre la publicidad de las agendas de trabajo de los altos cargos de la Administración de la referida Comunidad y sus entidades adscritas. ${ }^{954}$

Según el referido acuerdo, las agendas deben facilitar, por ejemplo, información relativas a "reuniones, eventos o encuentros, tanto presenciales como en otros formatos electrónicos o a distancia", destacando las realizadas "con personas físicas o

\footnotetext{
${ }^{950}$ SANCHEZ MORÓN, Miguel. La corrupción y los problemas del control de las Administraciones Públicas. In: LAPORTA, Francisco Javier; ÁLVAREZ MEDINA, Silvina. La Corrupción Política. Madrid: Alianza, 1997, p. 190.

${ }^{951}$ ALFARO, Luis Humberto Contreras. Op. Cit., p. 135-137.

${ }^{952}$ MICHENER, Greg. Op. cit., p. 44.

${ }^{953}$ GUICHOT, Emilio. Op. Cit., L. 4.495.

954 Boletín Oficial de Castilla y León- BOCYL N. 224, de 20 nov.2019. Disponible en: http://bocyl.jcyl.es/boletines/2019/11/20/pdf/BOCYL-D-20112019-5.pdf Acceso en 18 dic. 2019
} 
representantes de personas jurídicas ajenas a la administración autonómica sobre asuntos relacionados con su actividad". Es irrelevante que la reunión, evento o encuentro "se celebren en instalaciones y dependencias de los órganos" de la Administración Pública o fuera de ellos. ${ }^{955}$ En cualquier caso, la reunión, evento o encuentro deberá constar de la agenda de los titulares de altos cargos a modo de permitir el control ciudadano de estas acciones.

Pese a que la Ley de Transparencia y Acceso a la Información de Brasil no tiene un dispositivo con estas características, consideramos que esta debilidad puede ser superada a partir de la aplicación de los criterios de la frecuencia de la solicitud o de la relevancia de la información, dependiendo de las demandas de los ciudadanos sobre este asunto. En efecto, pese a la falta de previsión, a menudo los órganos y entidades del sector público de Brasil divulgan la agenda de sus altos directivos en internet, aunque con base en reglas fijadas por las propias instituciones y no a partir de un modelo uniforme para todo el territorio.

La pluralidad de regímenes entorno a ese asunto genera, como mínimo, dificultades de dos tipos. En principio, la infinidad de reglas acaba creando diferentes niveles de transparencia en la Administración, más amplios o restringidos, según el modelo adoptado en cada órgano o entidad. Por otro lado, no se nota cualquier coordinación entre los normativos que tratan el asunto, tampoco se identifica un contenido mínimo que debe figurar en torno al régimen de divulgación de las agendas profesionales de esas personas.

Con base a esta dificultad, la pregunta que se pone de manifiesto, en primer lugar, es saber sí las Leyes de Transparencia y Acceso a la Información deben establecer un contenido mínimo de las agendas de los altos directivos y demás funcionarios potencialmente expuestos, o si deberá, genéricamente, referirse a la necesidad de divulgación de las agendas públicas de estas personas, transfiriendo para el reglamento de cada administración pública la tarea de establecer su contenido.

955 Boletín Oficial de Castilla y León- BOCYL N. 224, de 20 nov.2019. Disponible en: http://bocyl.jcyl.es/boletines/2019/11/20/pdf/BOCYL-D-20112019-5.pdf Acceso en 18 dic. 2019 
Los resultados obtenidos con motivo de esta investigación recomiendan que las leyes de transparencia deberán adoptar una regulación sustantiva, concreta y específica que establezca un contenido mínimo de las agendas de los altos directivos y demás funcionarios potencialmente expuestos a actos de corrupción. En otras palabras, la Ley de Transparencia no debe limitarse a establecer la obligatoriedad de divulgación de las agendas de los altos directivos y funcionarios especialmente expuestos. También debe avanzar en estos asuntos y fijar un contenido mínimo de las materias que serán transparentadas para los ciudadanos. La iniciativa busca retirar de las autoridades locales amplia discrecionalidad para elegir los asuntos objeto de divulgación en cada caso, lo que puede conllevar a la formación de islas de oscuridad en las Administraciones Públicas locales.

Los estudios internacionales realizados en esta materia han revelado que la falta de transparencia es más frecuente en las administraciones públicas locales que en las administraciones públicas centrales, toda vez que los instrumentos de control no siempre existen o, cuando existen, no son fuertes lo suficiente como para oponerse al poder de las elites políticas locales. En estas comunidades, las aristocracias políticas suelen formarse a partir de factores económicos y sociales propios de la región que no permiten el surgimiento de otros líderes ajenos a este grupo, con lo cual actúan libremente para alcanzar sus objetivos.

Sin opositores fuertes, estos políticos acaban privatizando la propia administración pública y utilizarla para la satisfacción de sus propios intereses. ${ }^{956}$ Esta circunstancia suele agravarse el hecho de que, en estas comunidades, con frecuencia los Parlamentos locales no tienen la independencia política necesaria para enfrentarse al jefe del poder ejecutivo y demandarle la divulgación de su agenda oficial de reuniones, las actas relativas a cada encuentro y otros actos necesarios a una perfecta rendición de cuentas.

Esta dificultad se ha puesto de manifiesto con motivo de los Juegos Olímpicos Rio 2016. Durante todo el periodo de preparación del mega evento, ni el Parlamento del Estado, ni el Parlamento del Municipio de Rio de Janeiro lograron establecer reglas que

\footnotetext{
${ }^{956}$ HUNT, Michael. CHAPMAN, Richard. Freedom of Information: local government. In VAUGHAN, Robert G. Freedom of Information: local government and accountability. 2 ed., New York, Routledge, 2017, L. 374.
} 
impusieran a los altos directivos y funcionarios de las Administraciones Públicas el deber de transparentar sus agendas oficiales.

Debido a esta debilidad institucional, los Juegos Olímpicos de Rio, así como otras ediciones del mega evento, fueron dominados por una cultura de secreto y opacidad propia de los arcana imperii, ${ }^{957}$ donde las decisiones verdaderamente importantes estaban restringidas a un grupo de políticos y funcionarios, no sometiéndose a ningún tipo de control social, lo que, además, viola al principio de responsabilidad.

La falta de una regla que imponga la transparencia de las agendas y estableciera un contenido mínimo de los asuntos divulgados ha permitido que los altos directivos brasileños, en secreto, se reunieran con miembros del COI y coincidieran en cuanto al pago de soborno para que Rio conquistara el derecho de acoger la edición de los Juegos Olímpicos de 2016. Asimismo, la falta de reglas dio la posibilidad de que muchos de los encuentros tuviesen lugar en cuartos de hoteles fuera del territorio brasileño, sin el registro de los asuntos tratados en cada caso, lo que es totalmente incompatible con los Estados verdaderamente democráticos.

Con base a estos acuerdos, la información divulgada en las páginas web de todas las Administraciones Públicas brasileñas el 02 de octubre de 2009, en el sentido de que Rio ha "conquistado" el derecho de acoger una edición de los Juegos Olímpicos no ha reflejado la verdad. La ciudad brasileña no ha logrado tan importante victoria por méritos propios, sino debido al soborno de miembros africanos del COI. Desde esta perspectiva, por tanto, la información facilitada a los ciudadanos ha violado al principio de buena fe, en tanto que no ha retratado con fidelidad lo que ha pasado en el seno de la Administración Pública.

Con base a aludido principio, como ya lo hemos dicho anteriormente, les es vedado a las autoridades y a los funcionarios públicos omitir informaciones con el pretexto de proteger la Administración Pública o satisfacer los intereses personales o de terceros, salvo que la ley lo establezca expresamente. ${ }^{958}$

\footnotetext{
957 Bobbio, 1986, p. 23.

958 Ver al respecto el apartado 1.6.3.
} 
Estas distorsiones entre los actos y decisiones oficiales revelados a los ciudadanos y los momentos previos a su manifestación autorizan un cambio en la actual Ley de Transparencia y Acceso a la Información de Brasil a modo de incorporar a sus dispositivos la obligatoriedad de publicación de las agendas de los altos directivos y funcionarios potencialmente expuestos de las administraciones públicas. Se trata, en este caso, de una norma de mínimos, con lo cual todas las administraciones públicas deberán observarlas en el normal desarrollo de sus actividades.

Las agendas deberán informar, por ejemplo, los actos públicos, solemnidades, conmemoraciones, viajes y reuniones de que participe la autoridad o funcionario potencialmente expuesto, así como comidas y cenas a que acuda con motivo de su trabajo. En otras palabras, la agenda deberá informar la relación de actividades desarrolladas por la autoridad o funcionario, lo que incluye reuniones celebradas dentro o fuera de espacios públicos, eventos oficiales en que se participe y cualesquiera otras que se relacionen con el desempeño de la función pública.

Tratándose de reuniones con personas ajenas a la administración, también deberán ser publicados informes que posibilite a los ciudadanos enterarse al respecto de lo sucedido en cada encuentro, de las personas que participaron y el día y lugar de su realización, además de la forma como sucedió el desplazamiento de las autoridades y funcionarios en cada caso.

Las exigencias se justifican debido a las irregularidades que fueron cometidas en diferentes ediciones de los Juegos Olímpicos, teniendo en cuenta el pago de ventajas indirectas a autoridades y funcionarios personalmente implicados en el proceso de elección de la ciudad anfitriona.

Las investigaciones realizadas con motivo de los Juegos Olímpicos de South Lake City (2002) revelaron que, veinte años antes, miembros del COI solían recibir, directa o indirectamente, alguna ventaja económica para apoyar determinadas candidaturas, además de que los pagos se encubrían como gastos de hospedaje, donaciones de carácter filantrópico y comodidades en viajes internacionales ${ }^{959}$.

\footnotetext{
${ }^{959}$ Goldblatt, David. Op. cit., p. 374-375.
} 
Asimismo, recordamos que Atlanta (1996), gastó siete millones trescientos mil (7.300.000) dólares en hospedaje, con lo cual se sospechó que los recursos fueron utilizados para sobornar a miembros del COI y asegurar la elección de la ciudad como sede de las olimpíadas del centenario.

Estas malas prácticas también pasaron en Nagoya (1998), donde se gastaron veintitrés (23.000.000\$) millones de dólares en hospedaje y ofreció comodidades atípicas a miembros del COI por su visita a la ciudad, como el traslado del presidente del COI y toda su comitiva desde el aeropuerto de Tokio hasta Nagoya en un tren exclusivo, ventaja que jamás disfrutó ninguna de las ediciones anteriores. ${ }^{960}$

En Rio, a su vez, parte de los gastos pagos a título de comisión, todos pactados en reuniones sigilosas, se utilizaron para costear gastos personales de Sergio Cabral y su exmujer Susana Neves, cuyos gastos mensuales variaban entre veintiséis mil doscientos (26.200) euros a treinta y dos mil ochocientos (32.800) euros al mes ${ }^{961}$.

Independientemente del lugar en donde tienen lugar, estas irregularidades ponen de manifiesto la necesidad de divulgar las agendas profesionales de los altos directivos y funcionarios potencialmente expuestos de la Administración Pública al objeto de compatibilizar sus actuaciones con os principios democráticos y de responsabilidad, los cuales demandan una permanente rendición de cuentas de los gestores públicos.

Con base a estas informaciones, la sociedad puede identificar la labor de las grandes compañías en lo relativo a la contratación pública, en especial la asociada a los mega eventos deportivos internacionales, identificando la frecuencia con que tales entidades se reúnen con los altos directivos y funcionarios, además de facilitar el confronto entre cada uno de estos encuentros y las decisiones administrativas subsecuentes.

Tiene especial relevancia, en este caso, la publicidad de las actas elaboradas con motivo de cada encuentro. La transparencia de estos escritos facilita que los ciudadanos sean informados en cuanto a los elementos, propuestas e ideas que las compañías

\footnotetext{
${ }^{960}$ Ibidem, p. 372.

${ }^{961}$ BRASIL. Tribunal Regional Federal da 2a Região, processo n. 0509503-572016.4.02.5101. Disponible em: http://www.jfrj.jus.br, Acceso em 12 oct. 2019.
} 
presentaron durante las reuniones y cuales fueron tomados en cuenta en las decisiones de la Administración Pública.

El control de las agendas busca, por tanto, acompañar las acciones de los grupos de presión que actúan junto a la Administración Pública. Se entiende como grupo de presión a "todo grupo de interés que, para imponer sus pretensiones, crea una relación de fuerzas al margen del poder formal con miras a obtener una decisión favorable a su interés". 962

En Brasil, si bien no existe una regla general que impone la divulgación de las agendas profesionales de los altos directivos y funcionarios potencialmente expuestos de todos los órganos y entidades públicas, así como de las instituciones privadas que reciben fondos públicos, al menos en el ámbito federal, el tema está reglamentado en la Ley n. 12.813, de 16 de mayo de 2013, de Conflictos de Interés en el ejercicio de cargo o empleo en el poder ejecutivo federal e impedimentos posteriores a su ejercicio. ${ }^{963}$ Asimismo, el Decreto n. $4.334,{ }^{964}$ de 12 de agosto de 2002, con arreglo al principio de responsabilidad, disciplina las audiencias concedidas a particulares por agentes públicos en ejercicio en la Administración Pública federal.

En efecto, tenido en cuenta que Ministros de Estado, Presidentes de Autarquías y Fundaciones Públicas pueden enfrentarse con situaciones de conflicto de interés o que podrán acceder a informaciones privilegiadas que interesan a algunos sectores de la sociedad, la aludida Ley n. ${ }^{\circ}$ 12.813/2013 les obliga a divulgar, a diario y por internet, su agenda profesional, para que pueda ser conocida de los ciudadanos.

\footnotetext{
962 FAYT, Carlos Santiago. Teoría de la política en el siglo XXI, La política, el poder y el Estado. La democratización de la democracia. Buenos Aires: La Ley, 2002, p. 137.

963 BRASIL. Lei n. 12.813, de 16 de maio de 2013. Dispõe sobre o conflito de interesses no exercício de cargo ou emprego do Poder Executivo federal e impedimentos posteriores ao exercício do cargo ou emprego; e revoga dispositivos da Lei n. 9.986, de 18 de julho de 2000, e das Medidas Provisórias n.s 2.216-37, de 31 de agosto de 2001, e 2.225-45, de 4 de setembro de 2001. Disponible en http://www.planalto.gov.br/ccivil 03/_ato2011-2014/2013/lei/112813.htm Acceso em: 9 nov 2019.
}

\footnotetext{
964 Decreto n. 4.334, de 12 de agosto de 2002. Dispõe sobre as audiências concedidas a particulares por agentes públicos em exercício na Administração Pública Federal direta, nas autarquias e fundações públicas federais. Disponible en: http://www.planalto.gov.br/Ccivil_03/decreto/2002/D4334.htm Acceso en: 9 nov 2019.
} 
Asimismo, el Decreto n. 4.334/2002 impone a los agentes públicos federales el deber de registrar las audiencias realizadas con particulares, con expresa indicación del nombre del interesado, la fecha y el horario de la reunión, el asunto objeto del encuentro, aparte de los nombres de otros asistentes a la cita.

Pese a la relevancia de estas normas en cuanto a la transparencia gubernamental, lo cierto es que ambas apenas se aplican a los funcionarios del poder ejecutivo federal, con lo cual no se someten a tales exigencias las autoridades y funcionarios de Estados y Municipios que no tienen una regla de esta naturaleza, como pasó en el caso de los Juegos Olímpicos Rio 2016.

Con motivo de las Olimpíadas, ni el poder ejecutivo estatal, ni el municipal tenían una regla que obligara al Gobernador, al alcalde y a sus secretarios publicar las atas de las reuniones pasadas con altos directivos de las grandes constructoras brasileñas, tampoco un informe mensual que diese noticia de estos encuentros. La falta de divulgación contribuyó a la creación de un ambiente de secreto y oscuridad que viabilizó la comisión de todo tipo de irregularidades asociadas a las obras de infraestructura concernientes al mega evento.

A modo de subsanar esta debilidad, consideramos importante realizar cambios em la Ley n. 12.527/2011, de Transparencia y Acceso a la Información de Brasil, con objeto de incorporarle un dispositivo que considere obligatoria la divulgación de las agendas profesionales de los altos directivos y funcionarios potencialmente expuestos a actos de corrupción de todas las Administraciones Públicas.

Buscamos con estas medidas incentivar que estas personas encaminen sus acciones hacia un comportamiento íntegro al frente de la Administración Pública, entendida la integridad como el uso correcto que uno hace de los poderes recibidos. ${ }^{965}$

\footnotetext{
965 RODRÍGUEZ ARANA, Jaime. Ética Institucional: Mercado "Versus" Función Pública, Madrid, Dykinson y Escuela Gallega de Administración Pública, 1996; CRISMANI, Andrea, La Tutela Giuridica degli Interessi Finanziari della Colletività. Aspetti e considerazioni generali con riferimento al diritto comunitario. Milán, Giuffrè, 2000, p. 269 y ss.
} 
Consideramos que la integridad es responsable de establecer la necesaria conexión entre las acciones de los gestores públicos y la buena gestión de los fondos bajo su autoridad ${ }^{966}$.

Recientemente, desde el 2016, el banco mundial estableció que toda entidad o Estado que pretendiese contratar con la institución deberá demostrar que, en el ámbito del derecho interno, existen normas que posibilitan el acompañamiento de la gestión pública (transparencia), así como la conducta de los gestores públicos (integridad) concerniente a la administración de los fondos públicos. ${ }^{967}$ A partir de estas exigencias, los responsables de la gestión pública deberán cumplir con estándares éticos al frente de la administración, sometiendo todas sus acciones al permanente control y evaluación de los ciudadanos a través de la publicidad de sus agendas profesionales.

Tal cosa sucede debido a que, en los estados verdaderamente democráticos, los gobernantes fundamentan su autoridad no solo a partir de la victoria en las elecciones, como pasó con el Gobernador Sergio Cabral. ${ }^{968}$ También justifican su poder a través de una permanente rendición de cuentas de sus actos y decisiones, ${ }^{969}$ lo que es fundamental al dialogo entre administradores y administrados.

En otras palabras, con base a las nuevas concepciones de la democracia, un Estado es considerado democrático no debido a que respeta derechos y libertades, sino que facilita información para los ciudadanos en cuanto a sus acciones, sometiéndose al permanente control social de cada uno de sus actos y decisiones. ${ }^{970}$

966 BRYTTING, Tomas. MINUGUE, Richard. y MORINO, Veronica. The Anatomy of Fraude and Corruption: Organizational Causes and Remedies. Farhnan (Reino Unido): Gower Applied Research, 2011, p. 153.

967 BANCO MUNDIAL. Bank Policy: Procurement in IPF and Other Operational Procurement Matters. 28 de junio de 2016. En vigor desde 1 de julio de 2016, p. 5. Disponible en : https://policies.worldbank.org/sites/ppf3/PPFDocuments/Forms/DispPage.aspx?docid=4004\&ver=current Acceso en : 16 dic 2019

968 CABRAL é eleito no Rio de Janeiro com maioria absoluta dos votos. Disponible en http://g1.globo.com/Noticias/Eleicoes/0,,AA1330709-6302-775,00.html Acceso en: 16 oct. 2019.

${ }^{969}$ FERNÁNDEZ RAMOS, Severiano. El derecho de acceso a los documentos administrativos. Op. Cit., p. 318.

970 TORRES DEL MORAL, Antonio., Estado de Derecho y Democracia de Partidos, $3^{\mathrm{a}}$ ed., Madrid: Universidad Complutense de Madrid, 2010, p. 87. 
Con arreglo a estas premisas, la pregunta que se pone de manifiesto ahora mismo es sí las leyes de Transparencias deben contentarse tan solo con publicar las agendas profesionales de los altos directivos y funcionarios potencialmente expuestos a la corrupción $\mathrm{o}$, alternativamente, si deben avanzar aún más y también imponer la divulgación de las agendas privadas de estas personas. O, mejor dicho, ¿en qué categoría jurídica hemos de clasificar la información constante de la agenda personal de los altos directivos y funcionarios potencialmente expuestos para fines de transparencia gubernamental?

Ya hemos dicho en otra ocasión y volvemos a repetir ${ }^{971}$ que las informaciones se encuentran en manos de los órganos y entidades públicas se clasifican, doctrinariamente, en informaciones de interés colectivo en sentido amplio e informaciones de interés colectivo en sentido estricto. ${ }^{972}$ Las primeras atañen a informaciones de carácter general y deben ser publicadas para conocimiento de los ciudadanos, mientras que las segundas conciernen a cuestiones particulares, consideradas irrelevantes para el conocimiento público, como los datos bancarios o la dirección de un funcionario público. ${ }^{973}$

Aparte de informaciones de interés colectivo, los órganos y entidades públicas también resguardan informaciones de carácter privado que apenas interesan a una cierta persona en particular, como las relativas al prontuario médico. ${ }^{974}$ Se reconoce en estos casos, que cada persona es titular de informaciones de carácter secreto o íntimo que deben estar a salvo del conocimiento de todos, siempre que su no revelación es necesaria para garantizar el normal desenvolvimiento y tranquilidad del individuo. ${ }^{975}$

Considerando cada una de estas categorías jurídicas, podemos decir que las informaciones concernientes a la agenda privada de los altos directivos y funcionarios potencialmente expuestos se califican como información de interés colectivo en sentido amplio. Por tanto, deben ser divulgadas para conocimiento de los ciudadanos, más bien

\footnotetext{
${ }^{971}$ Ver al respecto el apartado 1.6.1.

972 POLÍZIO JÚNIOR, Wladimir. Op. Cit., p. 12.

973 Ibidem, p. 12.

${ }^{974}$ Ibidem, p. 12.

${ }^{975}$ Ibidem, p. 180-181.
} 
porque muchas de las malas prácticas administrativas suelen pactarse fuera de las reparticiones públicas, aprovechándose exactamente de la falta de control de los actos privados de estas personas.

Es cierto que a menudo se utiliza un discurso a favor de la defensa de la privacidad y de la intimidad de estas personas para escapar al control social de actos directamente relacionados con el ejercicio de la función pública.

En este sentido, calificar la agenda privada de estos individuos como información de interés particular implica reconocer que, al menos en principio, las actividades realizadas a ese título se consideran ajenas a cualquier forma de control público. ${ }^{976} \mathrm{Se}$ crea un espacio donde la autoridad o funcionario puede esconderse para, desde ahí, practicar los actos que no quiere revelar a la sociedad.

Ejemplo de estas irregularidades tuvo lugar en los Juegos Olímpicos Rio 2016, cuando el Gobernador Sergio Cabral utilizó muchos encuentros privados con directivos de grandes constructoras para dar viabilidad a la comisión de actos de corrupción. Se destaca entre tantos encuentros el pasado en Paris, el 2011, con motivo de conmemorarle el cumpleaños a Adriana Anselmo, esposa de Sergio Cabral. Durante la conmemoración, Cabral le solicitó al presidente de Delta Construções que le comprara una joya a Adriana a cambio de participar del consorcio responsable de la obra de reforma del estadio de Maracanã.

El encuentro, exactamente por tratarse de un evento privado, no tuvo cualquier registro en la agenda oficial del Gobernador, con lo cual los brasileños no pudieron confrontar, por ejemplo, la asistencia del presidente de Delta Construções a la fiesta de cumpleaños con la posterior decisión estatal que le concedió a la compañía el derecho de participar de la obra de reforma de Maracanã.

La posibilidad de que pactos de esta naturaleza puedan perfeccionarse en el ámbito de relaciones particulares justifica la decisión política de incorporar la agenda privada de los altos directivos y funcionarios potencialmente expuestos entre las materias objeto de la transparencia gubernamental.

\footnotetext{
${ }^{976}$ ESCALANTE, Fernando. Op. Cit., p. 16.
} 
Tales directivos y funcionarios están constantemente sometidos al asedio de dirigentes de compañías interesadas en cerrar contratos con la Administración, quienes pueden, deliberadamente, acercarse a estas personas en privado y sin que nadie pueda controlar sus actuaciones, teniendo en cuenta las debilidades de la Ley de Transparencia.

Asimismo, entendemos que la divulgación de su agenda particular no viola la privacidad, sino que se califica más bien como información de interés colectivo en sentido amplio, teniendo en cuenta los cargos que ocupan en la Administración Pública. Consecuentemente, se someten al principio de publicidad de una manera diferente de las demás personas, exigiéndose una mayor rendición de cuentas de sus actos, bien sean públicos, bien sean privados, siempre que estos últimos pueden interferir con las propias decisiones administrativas. ${ }^{977}$

En otras palabras, teniendo en cuenta la naturaleza de las actividades de estas personas, el término "privado" no significa, necesariamente, "secreto" a tal punto de eliminar por completo el control ciudadano. Como señala Fernando Escalante ${ }^{978}$ :

"Por otra parte, ninguna decisión, ningún espacio es absolutamente privado en el sentido de estar por completo, en todo momento, bajo todo punto de vista fuera del alcance de la autoridad. Lo que hace la ley es restringir y delimitar las circunstancias en que está justificada la intervención. Por ejemplo, lo que cada uno decide hacer en su domicilio es asunto privado, la forma en que cada uno decida organizar su vida familiar es asunto privado, a menos que haya violencia: en ese caso, para proteger a las víctimas de maltrato, la autoridad tiene el derecho y la obligación de intervenir. Por ejemplo, lo que cada uno haga con su dinero es asunto privado, ahorrar o gastar o invertir en lo que sea es un asunto privado, a menos que se trate de un funcionario público: en ese caso, para prevenir el tráfico de influencias o el uso indebido de los recursos, es necesaria la vigilancia pública. Lo mismo sucede en todos los ámbitos: en la conducta de las empresas, en el contenido de los contratos o las prácticas religiosas, en la

\footnotetext{
977 BRASIL. Superior Tribunal de Justiça (4 ${ }^{\text {a }}$ Turma). Processo RESP n.801.109/DF, Rel. Min. Raul Araújo. jul. 12 de junho de 2012. Brasília, DF: Superior Tribunal de Justiça [2012]. Disponible em http://www.sti.jus.br/sites/portalp/Inicio Acceso en: 12 oct. 2019.
}

${ }^{978}$ ESCALANTE, Fernando. “El Derecho a la Privacidad”. Op. Cit. P. 6-7. 
expresión de ideas, hay siempre una suspensión condicionada de la interferencia pública y no una prohibición absoluta".

Si bien los ordenamientos jurídicos reconocen a la privacidad la naturaleza de derecho fundamental, no le confiere carácter absoluto frente a cualquier otro derecho de igual envergadura. Admite restricciones cuando ello es necesario a la protección de otros interes igualmente relevantes, como la protección de la vida, la integridad física o la represión de ilícitos. Así, por ejemplo, sí hay violencia, todos coinciden con que puede romperse la privacidad del domicilio para proteger la vida o la integridad física de la persona. Asimismo, si hay sospechas de actividades ilícitas, se justifica el romper el secreto bancario para acompañar las operaciones financieras de la persona en determinado periodo. ${ }^{979}$

Como se recoge, los límites de lo privado no resultan de la naturaleza de las cosas, no son permanentes y universales, tampoco suelen establecerse de una vez para siempre en los ordenamientos jurídicos. Con frecuencia cambian de tiempos en tiempos, o de uno lugar a otro, conforme con las ideas y los criterios en vigor en una determinada sociedad. ${ }^{980}$

Tratando específicamente de cuestiones relativas al conflicto entre el derecho a la privacidad y el derecho a la comunicación, la suprema corte de los Estados Unidos ya decidió que, en principio, el derecho de comunicación e información prevalece sobre los derechos de personalidad, cuando se refiere a sujetos o asuntos públicos. Se tiene en cuenta, en este caso, el papel que el derecho de informarse juega en las sociedades democráticas, en tanto que favorece el control social de los poderes públicos y fomenta el debate al respecto de los actos practicados, lo que acaba beneficiando a toda la sociedad. ${ }^{981}$

\footnotetext{
${ }^{979}$ Ibidem, P. 6-7.

${ }^{980}$ Ibidem, p. 23.

${ }^{981}$ FARIAS, Edilson Pereira de. Coleção de Direitos à Honra, à Intimidade, à Vida Privada e à Imagem versos a Liberdade de Expressão e Informação, $3^{\mathrm{a}}$ ed., Porto Alegre: Sérgio Antônio Fabris, 2008, p. 155157.
} 
En este sentido, una vez que la prevención de la corrupción es una preocupación de todos los estados, sobre todo en lo relativo a la preparación de los mega eventos deportivos, consideramos razonable defender alteraciones en la ley para también incluir la agenda privada de los altos directivos del estado como tema objeto de la transparencia gubernamental, permitiendo su divulgación para conocimiento de los ciudadanos.

\subsection{La transparencia de las exigencias técnicas y demás informes concernientes a la contratación pública}

La contratación pública siempre constituyó elemento fundamental a la realización de los Juegos Olímpicos, una vez que viabilizó la construcción de los equipamientos directamente asociados al mega evento, lo que resultó de los compromisos perfeccionados entre las diferentes esferas de gobierno y el COI desde el año 1949.982

Asimismo, los contratos administrativos permitieron la ejecución de grandes obras de infraestructura en cada una de las ciudades anfitrionas, lo que se incrementó enormemente a partir de mediados del siglo XX, cuando se consagró el modelo de gestión neoliberal que los expertos califican como emprendedor o empresarial y que es responsable de un cambio en la manera como se administra la ciudad ${ }^{983}$.

Conforme con este modelo, la ciudad ya no es gestionada con arreglo a criterios meramente administrativos y sociales, sino bajo un régimen empresarial, debido a que las autoridades deberán incentivar la realización de grandes obras que promuevan la actividad económica en los centros urbanos ${ }^{984}$.

\footnotetext{
982 OLYMPIC CHARTER 1949. Disponible en: https://www.olympic.org/olympic-studiescentre/collections/official-publications/olympic-chartersAcceso en 22 jul del 2018, p. 7.

${ }^{983}$ HARVEY, David. Op. Cit., p. 164.

${ }^{984}$ Mascarenhas, Gilmar. $\quad$ Op. $\quad$ Cit., $\quad$ p. $54 . \quad$ Disponible en: https://www.redalyc.org/pdf/1154/115437784005.pdf
}

acceso en 13 de mayo de 2018 
Con motivo de los Juegos, fueron realizadas grandes obras en las ciudades anfitrionas a partir de los años sesenta (60), tales como la construcción de aeropuertos, la expansión del sistema de transporte, la regeneración de áreas social y económicamente degradadas y la recuperación de regiones ambientalmente destruidas.

Todas estas transformaciones demandaron grandes inversiones públicas de los gobiernos directamente implicados en la preparación de los Juegos, las cuales no siempre llegaron a su destino, como pasó en Roma (1960), ${ }^{985}$ Tokio (1964), ${ }^{986}$ México (1968) ${ }^{987}$ y Montreal (1976). ${ }^{988}$

Así como en todas estas ediciones, la contratación pública concerniente a los Juegos Olímpicos Rio (2016) también constituyó un ambiente favorable a las malas prácticas administrativas debido a la acción de políticos, funcionarios y empresarios deshonestos. Pese a todos los problemas sucedidos, las irregularidades en cuanto a la contratación pública no constituyen un hecho aislado y exclusivo de los mega eventos deportivos internacionales.

El Informe Anticorrupción publicado por la Comisión, el Consejo y el Parlamento de la Unión Europea en 2014, ${ }^{989}$ puso de manifiesto que los contratos perfeccionados por la Administración Pública constituyen un ambiente favorable a estas irregularidades, las cuales suelen manifestarse de diferentes maneras. De acuerdo con el Tribunal de Cuentas

\footnotetext{
${ }^{985}$ GOLDBLATT, David. op.cit., P. 243.

${ }^{986}$ Ibidem, p. 254-255.

${ }^{987}$ Ibidem.

${ }^{988}$ GOLD, John R. GOLD, Margaret M. op. cit., p. 44-45.

${ }^{989}$ Disponible en: https://eur-lex.europa.eu/LexUriServ/LexUriServ.do?uri=COM:2011:0308:FIN:PT:PDF acceso en 30 nov. 2019.
} 
de la Unión Europea, ${ }^{990}$ entre las causas que contribuyen para que esto suceda sobresalen las relativas $\mathrm{a}^{991}$ :
a) división artificial de servicios;
b) realización de licitaciones de menor envergadura para eludir los límites legalmente establecidos para determinadas materias;
c) adjudicación directa e injustificada de contratos;
d) utilización de procedimientos de licitación inadecuados;
e) falta de publicación y transparencia de los pliegos;
f) especificación de criterios de selección y adjudicación ilícitos;
g) existencia de deficiencias procedimentales graves; y
h) falta de documentación, modificación o ampliación del ámbito de los contratos sin adoptar el procedimiento de contratación correcto.

A su vez, según el Businesses Attitudes Towards Corruption in the United States, el cual mide la percepción de corrupcion desde la perspectiva de los licitadores, las principales causas de irregularidades en la contratación pública son las concernientes a ${ }^{992}$ :
a) especificaciones técnicas preparadas para determinadas compañías;
b) conflictos de intereses en cuanto a la evaluación de las ofertas;
c) prácticas colusorias;
d) criterios de selección vagos;
e) abuso del procedimiento negociado; y
f) abuso de las situaciones de emergencia para justificar procedimientos no competitivos

Entre tantas situaciones, se destaca, en el caso de los juegos olímpicos Rio 2016, el establecimiento de especificaciones técnicas preparadas para favorecer a determinadas compañías, una circunstancia que lo revelaron claramente los propios directivos de las

\footnotetext{
${ }^{990}$ Tribunal de Cuentas Europeo. Informe especial: la necesidad de intensificar los esfuerzos para resolver los problemas de contratación pública que afectan al gasto de la Unión Europea en el ámbito de la cohesión. Tribunal de Cuentas Europeo. Luxemburgo, 2015. Disponible en: https://www.eca.europa.eu/Lists/ECADocuments/SR15 10/SR PROCUREMENT ES.pdf acceso en 11 nov 2019.

${ }^{991}$ MIRANZO DÍAZ, Javier. Op. Cit., L. 355.

${ }_{992}$ Ibidem, L. 356.
} 
principales constructoras brasileñas. Con frecuencia los representantes de estas instituciones se reunieron con altos funcionarios de las Secretarias de Obras del Estado y del Municipio de Rio de janeiro y trataron de incorporar a los pliegos exigencias técnicas que buscaron eliminar la participación de entidades independientes a modo de conquistar el derecho de perfeccionar contrato con la Administración Pública.

Se trata de una conducta que distorsiona la competencia y vulnera al principio de igualdad, teniendo en cuenta los intereses de los demás operadores económicos que actúan en este mercado. ${ }^{993}$

Las relaciones entre la transparencia gubernamental y el principio de igualdad ya lo señalaron el tribunal de justicia de la Unión Europea cuando declaró que el verdadero reconocimiento de la isonomía depende, necesariamente, de la divulgación de los actos y decisiones oficiales para la sociedad. Cuando esto no sucede, señala el Tribunal, el propio reconocimiento del principio de igualdad es infecundo. Consecuentemente, consideramos importante ver las rutinas administrativas para compatibilizarlas con aludido principio 994 y cohibir una de las malas prácticas más comunes en cuanto a la contratación pública ${ }^{995}$ asociada a la preparación de las Olimpíadas, justamente por su carácter técnico.

El banco mundial, a modo de ofrecer herramientas que permitan la identificación de dichas irregularidades, recomienda a los órganos responsables de la prevención y la lucha contra la corrupción que atenten para la existencia de especificaciones innecesarias o inapropiadas, de descripciones o informaciones vagas, así como la exclusión de un gran número de licitadores a causa de la exigencia técnica establecida. ${ }^{996}$ Si esto pasa, advierte

\footnotetext{
993 LAFFONT, Jean-Jacques. y N'GESSAN, Tchetche. "Competition and corruption in an agency relationshipp". Journal of Development Ethics, vol. 60, 1999, Orebro University School of Business, Nake, Suecia, p. 271-295. Disponible en: https://econpapers.repec.org/RePEc:eee:deveco:v:60:y:1999:i:2:p:271-295 Acceso en 20 nov 2019.
}

${ }^{994}$ CERRILLO I Martínez, Agustí. Los conflictos de intereses y los pactos de integridad: la prevención de la corrupción en los contratos públicos. In VILLORIA MENTIETA, Manuel. GIMENO FELIÓ, José María. TEJEDOR BIELSA, Julio César. JIMÉNEZ ASENSIO, Rafael. La corrupción en España. Ámbitos, causas y remedios jurídicos. Barcelona, Atelier, p. 103.

${ }^{995}$ MIRANZO DÍAZ, Javier. Op. Cit., L. 458.

${ }^{996}$ Banco Mundial. Fraud and Corruption . In: Most Common Red Flags of Fraud and Corruption in Procurement. p. 12. Disponible en: 
el Banco, habrá gran posibilidad de que las exigencias se destinen a frustrar el carácter competitivo de las licitaciones y busquen favorecer a una o más compañías.

Pese a estas recomendaciones, lo cierto es que, tratándose de grandes obras de ingeniería, no siempre es fácil para los ciudadanos entiendan si determinadas exigencias fijadas en los pliegos son verdaderamente necesarias o apropiadas para la realización del proyecto o si, al contrario, se destinan únicamente a excluir la participación de otros interesados.

En otras palabras, para que uno pueda tener un juicio crítico en cuanto a la naturaleza de la exigencia, es importante, primero, que entienda su contenido y pueda evaluar las consecuencias que resultan de su incorporación a los pliegos. Para que ello suceda, con base al principio de máxima divulgación, toda información relativa a la contratación pública deberá adoptar un lenguaje claro y directo que permita su comprensión por los ciudadanos, independientemente de su formación profesional. ${ }^{997}$

Así, con arreglo a la transparencia gubernamental, no basta con que la Administración Pública divulgue la información para conocimiento de los licitadores, sino que lo haga de forma clara, precisa e inequívoca, de tal manera que pueda ser entendible por todos los interesados, bien sean ingenieros, abogados, médicos, profesores o empresarios. ${ }^{998}$

En otras palabras, la información facilitada no puede representar una complejidad tal que apenas unos pocos sectores de la sociedad sean capaces de entenderla y manifestarse críticamente al respecto. ${ }^{999}$

Una transparencia gubernamental verdaderamente eficiente utiliza elementos de la teoría de la comunicación que van más allá del mundo jurídico para que cumpla con su objetivo. Tales elementos ponen en evidencia aspectos subjetivos, objetivos, materiales y

http://siteresources.worldbank.org/INTDOII/Resources/Red flags reader_friendly.pdf Acceso en 11 nov 2019.

${ }^{997}$ PESCHARD, Jacqueline. Op. Cit., L. 1111.

${ }^{998}$ MIRANZO DÍAZ, Javier. Op. Cit., L. 3536.

${ }^{999}$ CERRILLO I MARTÍNEZ, Agustí. "Public transparency as a tool to prevent corruption". In CERRILLO I MARTÍNEZ, Agustí. y PONCE SOLÉ, Juli. Preventing Corruption and Promoting Good Governancy and Public Integrity. Bruselas: Brulyant, 2017, p. 1-24. 
significativos asociados al proceso de comunicación entre personas, los cuales se consideran imprescindibles para transmitir el mensaje con claridad y precisión a su destinatario.

En 1948, tratando de cada uno de estos aspectos o elementos, el estadunidense Claude Elwood Shannon creó un modelo matemático que reflejara con fidelidad ese proceso de cambio de información, conocido como Mathematical Theory of Communication. De acuerdo con sus estudios, cualquier proceso de comunicación, independiente del periodo histórico, presenta siempre, como mínimo, cuatro variables: ${ }^{1000}$
a) Un emitente o fuente de la información;
b) Un o más destinatarios del mensaje;
c) Un contenido $u$ objeto de la noticia; y
d) Un código o señal por medio del cual el mensaje será divulgado.

Entre todos los elementos, merece ser destacado lo relativo al código o lenguaje utilizado para transmitir el mensaje. Genéricamente, un código es un sistema arbitrario de señales cuyo significado debe ser conocido de ambas partes de una relación por sí ambos tienen ambición de transmitir una información. Puede ser verbal (como el habla), gestual (como un saludo), visual (como una fotografía), sonoro (como la sirena de una ambulancia) o escrito (como una carta o un documento). ${ }^{1001}$

Independientemente de la manera como se manifiesta, lo importante es que, tanto el emitente, como el destinatario de la información, conozcan el código o lenguaje utilizado para transmitirla, púes, sí ello no sucede, la comunicación es infrugífera ${ }^{1002}$, lo que puede tener consecuencias significativas en cuanto a la prevención de la corrupción. Sí uno no entiende el código o lenguaje que contiene la información, y no es capaz de descifrar o interpretar el mensaje que pretende transmitir, seguramente no podrá manifestarse al respecto, tampoco ejercer cualquier control en cuanto a posibles irregularidades practicadas.

\footnotetext{
${ }^{1000}$ Verdi, Gianluca. il significato della comunicazione nella storia. Roma: Amazon, 2019, L. 91.

${ }^{1001}$ Verdi, Gianluca. Op. cit., L. 103.

1002 Ibidem, L. 469.
} 
Para que ello no suceda, como forma de dar efectividad al principio de máxima divulgación, consideramos que la Administración Pública, nada más publicar los pliegos relativos a una licitación de obras públicas, debe explicarles a los ciudadanos, en lenguaje sencillo, los términos técnicos empleados en determinadas cláusulas, lo que implica valorar la calidad de la información por encima de la cantidad de datos colocados a disposición de la sociedad. ${ }^{1003}$

La medida se destina no solo eliminar espacios de oscuridad en lo relativo a la contratación pública de cara a los mega eventos deportivos, sino que también busca permitir a los ciudadanos establecer un juicio crítico en cuanto a la naturaleza de la exigencia demandada de los licitadores por sí ambicionan perfeccionar contrato con el sector público. Sí la sociedad es capaz de entender las exigencias fijadas por la Administración para cierta licitación, sí es capaz de interpretar el mensaje que ella busca transmitir, en consecuencia, podrá opinar al respecto y proponer alternativas que favorezcan una mayor competitividad entre los interesados, lo que, además, acaba beneficiando al propio sector público.

En cuanto se adopten estas medidas, consideramos que será más difícil para los corruptos establecer requisitos técnicos que conlleven al favoritismo de unos licitadores frente a otros, siempre que la exacta comprensión de las cláusulas de los pliegos de la posibilidad de establecer un diálogo claro entre la Administración Pública y la sociedad.

Aparte de clarificar el contenido de las cláusulas, también con base al principio de máxima divulgación, consideramos oportuno que la Administración Pública proceda a la divulgación de un listado con los nombres de los licitadores que no lograron perfeccionar el contrato con el sector público en cada caso. La medida se destina a permitir el control ciudadano en cuanto a futuras subcontrataciones concernientes al mismo objeto, lo que puede indicar la existencia de rotaciones entre empresas a modo de dividir el mercado de obras, servicios o suministro para el sector público. ${ }^{1004}$

1003 JIMÉNEZ ASENSIO, Rafael. Como prevenir la corrupción: integridad y transparencia, Madrid, Caranta, 2017, p. 108-109.

${ }^{1004}$ Banco Mundial. Fraud and Corruption . In: Most Common Red Flags of Fraud and Corruption in Procurement. p. 14-15. Disponible en: http://siteresources.worldbank.org/INTDOII/Resources/Red_flags_reader_friendly.pdfAcceso en 11 nov 2019. 
Una vez que conozcan estas informaciones, los ciudadanos también podrán atentar para un posible acuerdo entre las compañías en cuanto a los vencedores de las licitaciones, ya sea directamente, o a través de herramientas especialmente dibujadas para tanto, como las aplicaciones de inteligencia artificial. ${ }^{1005}$

En definitiva, las aplicaciones de inteligencia artificial constituyen una realidad en las Administraciones Públicas del siglo XXI, en tanto que buscan contestar con celeridad a las demandas de los ciudadanos, lo que es consecuencia de un mundo que requiere de respuestas inmediatas a sus solicitudes. ${ }^{1006}$

Se trata de una iniciativa semejante a la que adoptó la Unión Europea juntamente con Transparencia Internacional en cuanto a los contratos perfeccionados por entidades privadas con la Administración Pública de Hungría. ${ }^{1007}$

Se destaca, en este caso, la labor de "arachne", una aplicación destinada a la investigación de datos, comúnmente utilizada por la Comisión Europea para detectar proyectos que ofrecen mayor riesgo en cuanto a la comisión de actos de corrupción. Técnicamente, la herramienta recoge, enriquece y coloca a la disposición de las Administraciones Públicas datos que apuntan para posibles situaciones de fraude, conflictos de interese y manipulaciones del contrato.

Para tanto, tiene en cuenta informaciones relativas al mercado de compras, obras y servicios, a las compañías que actúan en cada uno de ellos, los comportamientos que adoptaron en licitaciones anteriores y eventuales lazos con funcionarios o altos directivos de la Administración Pública. Asimismo, la aplicación considera las informaciones constantes de una base de datos que reúne a las empresas condenadas por acto de

\footnotetext{
${ }^{1005}$ PONCE SOLÉ, J. "La Prevención de Riesgos de Mala Administración y Corrupción, La Inteligencia Artificial y Derecho a una Buena Administración." Revista Internacional Transparencia e Integridad, núm. 6, 2018, p. 10 . Disponible en: https://revistainternacionaltransparencia.org/wpcontent/uploads/2018/04/juli_ponce.pdf

${ }^{1006}$ NEVADO-BATALLA MORENO, Pedro T.op. cit. p. 88.

1007 CAPDEFERRO VILLAGRASA, Oscar. Las Herramientas Inteligentes Anticorrupción: entre la aventura tecnológica y el orden jurídico", Revista General de Derecho Administrativo, núm. 50, 2019. Disponible en: httpS://dialnet.unirioja.es/ejemplar/510997 Acceso en 11 nov 2019.
} 
corrupción, el motivo de cada condenación, aparte de noticias que divulgan casos de corrupción concerniente a la contratación pública. ${ }^{1008}$

La herramienta utiliza una base de datos que reúne a más de treinta y cinco mil (35.000) noticias relacionadas con el tema de la corrupción, de tal manera que cualquiera que tenga acceso a la aplicación puede verificar sí un determinado contratista ya estuvo involucrado en casos de esta naturaleza. ${ }^{1009}$

Como se puede prever, hoy por hoy, todas las normas internacionales, comunitarias y nacionales que tratan del tema de la contratación pública demandan de los altos directivos, funcionarios y licitadores un comportamiento ético a lo largo de todo el procedimiento de contratación. ${ }^{1010}$ No se trata de una exigencia en abstracto, sino de un comportamiento que deberá reflejarse en las rutinas administrativas de cada una de estas personas, quienes deberán dotar de transparencia sus actos para conocimiento de los ciudadanos.

Desde esta perspectiva, consideramos justo exigir que los fiscales responsables de acompañar las obras públicas deberán divulgar, periódicamente, los informes que producen con motivo de su trabajo, con lo cual permiten a la sociedad verificar sí los escritos constantes de este documento corresponden a la realidad de los hechos. Buscamos con la medida prevenir comportamientos deshonestos de funcionarios que atestan la conclusión de determinado fragmento de una obra pública en desconformidad con lo que verdaderamente ha pasado, únicamente para asegurar que la compañía realice el cobro de su remuneración y, en seguida, efectúe el pago de la ventaja indebida.

Consideramos que estos escritos deberán informar, asimismo, sobre los materiales empleados en la ejecución de las obras, confrontándolos con las especificaciones constantes de los proyectos aprobados por la Administración antes que comenzara la licitación, exactamente para verificar sí la compañía responsable de su ejecución ha utilizado materiales de calidad inferior durante la ejecución de la tarea a su cargo. La utilización de materiales en estas condiciones puede indicar que el contratista busca

\footnotetext{
${ }^{1008}$ MIRANZO DÍAS, Javier. Op. Cit., L. 2484.

${ }^{1009}$ Ibidem, L. 2495.

${ }^{1010}$ MIRANZO DÍAS, Javier. Op. Cit., L. 1103.
} 
compensar con estos materiales los costes que resultaron del pago de ventajas indebidas a funcionarios o altos directivos de la Administración.

Una vez que estas informaciones sean publicadas por los órganos y entidades del sector público, esperamos que, tanto las compañías, como los funcionarios, aparten su comportamiento de estas malas prácticas, con lo cual la transparencia gubernamental logra cumplir con su papel como estrategia de prevención de la corrupción.

Finalmente, con respecto al tema de la contratación pública, conviene señalar que no toda información en manos de la Administración Pública deberá ser divulgada para conocimiento de los ciudadanos. Tratándose de información que no interesa para aclarar sospechas de actos de corrupción, o de información cuya publicidad no resulta de mandamiento legal expreso, es lícito que los órganos y entidades del sector público dejen de divulgarla, más bien cuando su publicación pudiere colocar en riesgo la competitividad del mercado. ${ }^{1011}$

Dicho de otra manera, antes de decidir sí determinada información deberá ser publicada o no, la Administración debe tener en cuenta los intereses en conflicto, realizando la ponderación entre los principios de buena administración e integridad, por un lado, y el principio de competitividad, por otro. Sí una información es relevante para garantizar la probidad de la contratación, entonces la información debe ser divulgada. Contrariamente, sí ello no pasa y hay riesgos fundados de que la transparencia puede afectar la competitividad, entonces prevalece el sigilo. ${ }^{1012}$

\subsection{La publicidad de los contratos firmados entre los contratistas del sector público y terceros ajenos a la administración}

Otra debilidad identificada con motivo de esta investigación se refiere al control de los actos practicados por los contratistas de la Administración Pública con terceros, durante la ejecución del contrato, y que se destinan a viabilizar el pago de ventajas

\footnotetext{
${ }^{1011}$ Ibidem, L. 3659.

1012 MORANDINI, Federico. "Acceso a la Información Pública en las contrataciones públicas". In RODRIGUEZ ARANA, Jaime. Contrataciones en el marco de los derechos sociales fundamentales, Madrid, INAP, 2017, p. 272-273.
} 
indebidas asociadas con la victoria en cierta licitación. Nos referimos, en este caso, a los contratos ficticios perfeccionados por algunas compañías con otras entidades, con el objetivo de justificar la retirada de fondos de las arcas del contratista del sector público para, posteriormente, entregarlo a un alto directivo o funcionario del órgano o entidad responsable de la licitación.

El contrato ficticio constituye, en este caso, un instrumento al servicio de las malas prácticas administrativas $\mathrm{y}$, por tanto, consideramos importante buscar una alternativa para, desde la perspectiva de la transparencia gubernamental, acompañar estos movimientos de las compañías que perfeccionan algún negocio jurídico con la Administración Pública. Para tanto, entendemos que es importante superar determinados paradigmas en cuanto a la definición de los sujetos obligados al deber de transparencia gubernamental para, a partir de un nuevo modelo, imponer a estos contratistas del sector público los mismos deberes que, hoy por hoy, se imponen únicamente a los órganos y entidades de la Administración Pública.

Desde que fue concebida por primera vez en la ordenanza sueca de 1766, la transparencia gubernamental únicamente se destinó a controlar los actos practicados en el seno de los órganos y entidades de la Administración Pública. Sin embargo, con el paso del tiempo, este modelo tradicional fue siendo progresivamente ampliado para contemplar otras entidades no estatales que también desarrollan actividades de interese público, como los concesionarios y permisionarios de servicios públicos y las entidades que actúan, fundamentalmente, en el universo de las actividades de interés social.

En definitiva, la insuficiente respuesta de la Administración Pública a las demandas de la sociedad hizo que, a partir del siglo $\mathrm{XX}$, se multiplicaran el número de personas que actuaban al lado del estado para desarrollar determinadas actividades. Se destacan, en este caso, además de los concesionarios y permisionarios de servicios públicos, las instituciones religiosas, las entidades de economía solidaria (como cooperativas y mutuales), las instituciones de bien público (como asociaciones y fundaciones) y las organizaciones no gubernamentales. ${ }^{1013}$

La existencia de estas instituciones no significa, necesariamente, que el Estado camina hacia su extinción, sino que, ahora mismo, ya no actúa solo para la consecución

${ }^{1013}$ DROMI, Roberto. Modernización del Control Público, Madrid: editorial Hispania Libros, 2014, p. 63. 
de determinadas actividades, una vez que cuenta con la participación de agentes privados a su lado para la satisfacción de las necesidades de la sociedad. ${ }^{1014}$

Una vez que se haya implementado este nuevo modelo de gestión, es posible afirmar que todas estas entidades fueron incorporadas al orden constitucional material en lo relativo al desarrollo de estas actividades, ${ }^{1015}$ sometiéndose al control de sus actuaciones por medio de la transparencia gubernamental, teniendo en cuenta la naturaleza de los recursos que utilizan para la consecución de sus objetivos.

Aunque jurídicamente cada una de estas instituciones es una persona de derecho privado, las actividades que desarrollan son de carácter público. Interesa, por tanto, para fines de control ciudadano de los actos realizados, la naturaleza de la actividad y no tanto la personalidad del sujeto que la ejecuta.

Tomando como ejemplo las actividades encargadas a los concesionarios de servicios públicos, todos coinciden que los contratistas suceden a la Administración en la gestión de las respectivas actividades, con o cual se consideran responsables de su ejecución. ${ }^{1016}$ Por tanto, reciben poderes que les permitan cumplir con estas tareas, lo que refuerza la idea de que se trata de una actividad de carácter público. ${ }^{1017}$

Por tanto, pese a la concesión, la Administración Pública concedente mantiene la prerrogativa de regular la prestación del servicio, fiscalizar su ejecución, controlar las irregularidades y decidir cuanto la aplicación de sanciones. Asimismo, se reserva la prerrogativa de reasumir la prestación del servicio en determinadas hipótesis fijadas en ley ${ }^{1018}$, lo que, repetimos, evidencia la naturaleza pública de la actividad objeto de la concesión.

\footnotetext{
${ }^{1014}$ DOISTÚA, Roberto San Salvador del Valle. Políticas de Ocio. Cultura, Turismo, Deporte y Recreación, Bilbao: Universidad de Deusto, 2000, p. 29-30.

${ }^{1015}$ DROMI, Roberto. Op. Cit., p. 63.

1016 DROMI, Roberto. Derecho Administrativo, 10 ${ }^{\mathrm{a}}$ ed., Buenos Aires - Madrid: Ciudad Argentina, 2004, p. 833.

${ }^{1017}$ DROMI, Roberto. Derecho Administrativo. Op. Cit., p. 833.

${ }^{1018}$ DROMI, Roberto. Modernización del Control Público. Op. Cit., p. 63-64.
} 
Considerando este entendimiento, las leyes de Transparencia de Argentina ${ }^{1019}$ y Ecuador ${ }^{1020}$ incluyen entre los sujetos obligados al deber de transparencia los concesionarios y permisionarios de servicios públicos, teniendo en cuenta justamente la naturaleza de las tareas que a ellos se encomiendan

En comparación a lo anterior, la ley española n. 19/2013 prevé que todas las personas físicas y jurídicas que prestan servicios públicos o ejercen potestades administrativas están obligadas a informar al Estado o a las entidades a que estén vinculadas, todo lo que sea necesario para que éstas puedan cumplir con el deber de transparencia. Esta obligación también se impone a los adjudicatarios de contratos del sector público ${ }^{1021}$, teniendo en cuenta la naturaleza pública de los recursos invertidos en estos pactos.

Ahora bien, aunque se trate de un país históricamente marcado por incontables escándalos de corrupción, Brasil no ha incorporado a su ley de transparencia y acceso a la Información la obligatoriedad de que los concesionarios de servicios públicos y demás contratistas de la administración se sometan a la misma transparencia de los órganos y entidades del sector público. Se trata de una omisión indeseable que genera espacios de oscuridad en cuanto a las acciones de estas personas, lo que favorece a la comisión de actos de corrupción.

Las debilidades de este régimen se pusieron de manifiesto con motivo de los Juegos Olímpicos Rio (2016). Sin controles preventivos eficaces, las principales constructoras brasileñas actuaron con libertad para la comisión de irregularidades de todos tipos, con frecuencia escondidas por detrás de contratos ficticios de prestación de servicios.

1019 ARGENTINA. Ley n. 27.275/2016, Art. $7^{\circ}$, "i". Disponible en: http://servicios.infoleg.gob.ar/infolegInternet/anexos/265000-269999/265949/nor ma.htm Acceso en 18 nov 2019.

${ }^{1020}$ ECUADOR. Ley Orgánica de Transparencia y Acceso a la Información Pública (LOTAIP), n. ${ }^{\circ}$ 24/2004, Art. $\quad 3^{\circ}$. Disponible $\quad$ en: https:/www.educacionsuperior.gob.ec/wpcontent/uploads/downloads/2014/09/LOTAIP.pdf Acesso em: 18 nov 2019.

1021 ESPAÑA. Ley n. ${ }^{\circ}$ 19, de 9 de diciembre de 2013, de Transparencia y Buen Gobierno, Art. $4^{\circ}$. Disponible en: https://www.boe.es/boe/dias/2013/12/10/pdfs/BOE-A-2013-12887.pdf Acceso: 18 nov 2019. 
La simulación, figura que recibe el rechazo de varios ordenamientos jurídicos como el brasileño, fue utilizada ampliamente para la comisión de estas malas prácticas, viabilizando la realización de negocios jurídicos aparentemente verdaderos, pero que en realidad se destinaron a esconder la real intención de las partes, o sea, el pago de ventajas indebidas a altos directivos, funcionarios o terceros que contribuyeron para que las entidades perfeccionaran contratos con la Administración Pública. La simulación constituyó, por tanto, un instrumento al servicio de la apariencia, de la mentira, de la falsedad y del engaño ${ }^{1022}$

Doctrinariamente, sus requisitos son en primer lugar, la divergencia entre la intensión de las partes y la voluntad efectivamente declarada, luego el acuerdo simulatorio entre ellas $\mathrm{y}$, finalmente, el objetivo de perjudicar a terceros, ${ }^{1023} \mathrm{o}$ sea, los propios ciudadanos, quienes sufren con las consecuencias de la desviación de fondos públicos.

En Brasil, los negocios jurídicos simulados se consideran nulos, ${ }^{1024}$ según lo prevé la Ley, ${ }^{1025}$ con lo cual puede ser declarada de oficio por el juez o alegada por cualquier interesado, así como por el Ministerio Público. ${ }^{1026}$ Resulta evidente, por tanto, que los terceros perjudicados pueden requerir de la nulidad del negocio jurídico simulado a modo de cohibir que sea utilizado al servicio del engaño, de la mentira o de la corrupción.

Para que tal cosa suceda, es fundamental que los terceros tengan conocimiento de su existencia, lo que depende, tratándose de estrategias de prevención de la corrupción, de la transparencia de los contratos perfeccionados por los contratistas de la Administración Pública y otras entidades, como prestadoras de servicios, proveedoras de suministros y empresas de consultoría.

Considerando los fundamentos teóricos antes presentados, creemos importante avanzar aún más en los límites de la ley para, en el caso brasileño, también incorporar

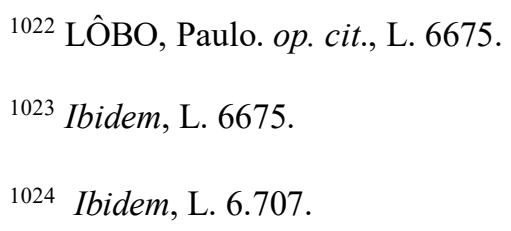
http://www.planalto.gov.br/ccivil 03/leis/2002/110406.htm Acceso en 30 nov. 2019.

${ }^{1026}$ BRASIL. Código Civil, Art. $168 . \quad$ Disponible em: http://www.planalto.gov.br/ccivil_03/leis/2002/110406.htm Acceso en 30 nov. 2019. 
como sujetos obligados al deber de transparencia activa los contratistas de la administración pública, como los concesionarios de servicios públicos y las compañías responsables de la ejecución de obras públicas. Entendemos que el deber de informar resulta, en este caso, de la naturaleza de las actividades desarrolladas (como sucede con los concesionarios y permisionarios), de la naturaleza de los recursos invertidos (como pasa en el caso de las obras públicas) y de la posibilidad de que estas personas acaben con utilizar los pactos celebrados con otras instituciones para viabilizar la comisión de actos de corrupción, aprovechándose, en este caso, de figuras como la simulación.

En efecto, de acuerdo con el orden jurídico brasileño, las empresas privadas no están obligadas, en principio, a divulgar sus actos y decisiones para conocimiento de la sociedad, cuando no se relacionan con la Administración. Sin embargo, cuando optan por establecer algún tipo de vínculo con el sector público, es justo esperar que acaben con hacerlo, toda vez que el interés público en cuanto al control de la actividad desarrollada $\mathrm{o}$ al uso correcto de los fondos públicos prevalece sobre el interés particular. ${ }^{1027}$

Este último aspecto, incluso, justifica que los contratistas de la Administración se obliguen con publicar no solo los actos concernientes al objeto del contrato perfeccionado con el sector público, como también otros acuerdos de voluntad firmados con terceros, dado que ellos pueden ser utilizados como instrumento al servicio de la corrupción. Entran en esta categoría, como ya lo hemos dicho, los contratos perfeccionados con prestadores de servicios, proveedores de suministros y empresas de consultoría.

Sin embargo, en cualquier caso, consideramos que la compañía no se obliga con divulgar todos los detalles del acuerdo de voluntades perfeccionado con estas instituciones, sobre todo cuando esto pueda interferir con el desarrollo de sus actividades principales. La transparencia gubernamental encuentra límites, por ejemplo, en el secreto comercial e industrial, ${ }^{1028}$ una vez que su revelación puede acarrear graves daños para la compañía y comprometer el normal desarrollo de sus actividades.

Sí esto no pasa, sí la noticia en cuanto a la existencia de estos pactos no comprometen el desarrollo de la actividad principal de la compañía en tanto que no se

\footnotetext{
${ }^{1027}$ POLIZIO JUNIOR, Vladimir. Op. Cit., p. 272.

${ }^{1028}$ Ibidem, L. 1173
} 
refiere al secreto comercial e industrial, entendemos que los contratistas del sector público deberán publicar, como mínimo, información relativa al nombre de las entidades con quien mantiene vínculo civil o comercial, tales como instituciones filantrópicas, entidades prestadoras de servicios, proveedores de suministros e instituciones dedicadas a actividades de consultoría.

El conocimiento de estas informaciones permite a los ciudadanos, como mínimo, atentar para posibles irregularidades que puedan implementarse a través de estos contratos, los cuales, como ya lo hemos dicho, pueden ser utilizados como instrumento al servicio de la simulación y, finalmente, de la propia corrupción.

En este sentido, recordamos que el contrato perfeccionado entre el despacho de abogados Vanuza Sampaio y la constructora OAS con motivo de las obras de construcción del BRT transcarioca tuvo como objeto la prestación de servicios de consultoría jurídica en materia ambiental, si bien la compañía ya tuviese abogados con esta especialización en sus cuadros. Asimismo, contaba con ingenieros, biólogos y técnicos ambientales que conocían el tema objeto de la consultoría y su relación con la actividad principal de la constructora, con lo cual podrían ofrecer los esclarecimientos necesarios a subsanar cualquier duda de la entidad.

Legalmente, el contrato constituyó todo un negocio jurídico simulado, como lo han revelado los directivos de OAS, destinándose únicamente a alcanzar un objetivo en específico, la entrega de dinero a una persona quien actuó junto al Ministerio de Ciudades para obtener los recursos necesarios a la financiación de las obras, lo que es totalmente distinto de la prestación de consultoría jurídica en cuestiones ambientales.

Ahora bien, sí estas informaciones estuviesen disponibles durante todo el periodo de vigencia del contrato entre la compañía y la Administración Pública, los ciudadanos podrían confrontar su objeto con el organigrama de la sociedad y rápidamente verificar que el contratista ya contaba con abogados y otros profesionales especializados en cuestiones medio ambientales entre sus empleados a la fecha de la conclusión de aludido pacto.

En este sentido, cualquier análisis crítico de estas informaciones, desde que disponibles y claramente divulgadas, posibilitaría que los ciudadanos comprendiesen que esta consultoría jurídica, al menos en principio, sería innecesaria y podría destinarse a 
otros objetivos, lo que basta con demostrar la importancia de que los contratistas de la Administración Pública también sean incorporados al abanico de sujetos obligados al deber de transparencia gubernamental.

Dicho de otro modo, si bien la prevención de la corrupción tradicionalmente estuvo concentrada sobre la actuación de los órganos y entidades del sector público, tampoco es un error reconocer que el sector privado juega un papel relevante en esta materia, toda vez que, sin su participación, muchas de estas malas prácticas no llegarían siquiera a concretarse. ${ }^{1029}$

Desde esta perspectiva, consideramos legítimo que los contratistas de la administración divulguen sus actos para conocimiento de la sociedad, bien sean los directamente relacionados con el objeto del contrato, o los negocios jurídicos celebrados con terceros, con lo cual permitirán que los ciudadanos verifiquen si, también ellos, se portan con rectitud e integridad en el desarrollo de sus actividades.

Consideramos importante, además, que las compañías faciliten a la Administración Pública y a la sociedad sus políticas internas de transparencia y los mecanismos de prevención de la corrupción, como forma de demostrar que también ellas se preocupan con erradicar estas malas prácticas.

Asimismo, entendemos que las entidades del sector privado deben ofrecer canales de comunicación eficientes con la Administración Pública y la sociedad, por medios de los cuales unos y otros podrán solicitarles aclaraciones por sí consideran que cierta información no es lo suficiente clara como para evidenciar la rectitud e integridad de la compañía en determinado caso concreto. Se toma en cuenta, en este caso, la implementación efectiva de la política de transparencia sobre los resultados concretos de las actividades de la compañía y no sobre la apariencia formal de estas medidas.

Opinamos que la exigencia en cuanto a la transparencia de los actos y decisiones de los contratistas del sector público atiende a los nuevos objetivos de la contratación pública en el siglo XXI, los cuales fueron inaugurados con la CNUCC. Con arreglo a los

\footnotetext{
${ }^{1029}$ IBARRA PALAFOX, Francisco. "Corrupción y poderes privados". In: SALAZAR, Pedro., IBARRA PALAFOX, Francisco. FLORES, imer B. ?Cómo combatir la corrupción?, Universidad Nacional Autónoma de México, 2017, p. 187 y ss. Disponible en: https://archivos.juridicas.unam.mx/www/bjv/libros/9/4315/27.pdf Acceso en 30 nov. 2019.
} 
principios que gobiernan aludida Convención, la licitación y el contrato administrativo ya no se restringen únicamente a seleccionar la propuesta más ventajosa para la Administración, tampoco a satisfacer a las necesidades del sector público.

Ambos institutos, licitaciones y contratos, también se destinan a crear un ambiente éticamente responsable alrededor de la Administración, con lo cual todas las entidades que actúan como proveedoras de bienes y servicios para el sector público deben adoptar políticas de transparencia destinadas a prevenir actos de corrupción.

En este sentido, opinamos que los aludidos contratistas, así como los órganos y entidades de la Administración, deben divulgar las agendas profesionales de sus altos directivos, principalmente cuando estos encuentros pasen con autoridades y altos funcionarios del Estado. Buscamos con esa medida establecer un control recíproco de estas reuniones, transfiriendo a las compañías parcela de la responsabilidad en cuanto al control y la prevención de la corrupción en la Administración Pública.

Esta transferencia de responsabilidad no llega a ser una novedad en cuanto a las estrategias de prevención y combate a la corrupción. En estados unidos, desde los años noventa (90), tras la aprobación del United Federal States Sentencing Guidelines, se demanda de las compañías la adopción de programas de integridad que permitan identificar riesgos de malas prácticas (risk-assesment) cometidas por sus empleados. ${ }^{1030}$ El cumplimiento de estos programas constituye, además, una condición para que la sociedad pueda contratar con la Administración Pública.

A través de medidas de esta naturaleza se tiene la ambición de que el sector privado actúe de lado de la Administración Pública en la lucha contra la corrupción, derribando la idea tradicional de que el enfrentamiento de estas malas prácticas ataña únicamente a los órganos y entidades del sector público.

Considerando estas mismas premisas, el hecho de que las instituciones privadas también deben incorporarse a la lucha contra la corrupción, principalmente a través de la adopción de políticas de transparencia relacionadas con la contratación pública, buscamos

\footnotetext{
1030 PEIRONE, F. Competing Anti-Corruption Strategies for Ensuring Integrity in Public Contracts: U.S. and EU systems compared Procurement Law Journal, n. ${ }^{\circ}$ 1, 23, 2017, p. 28. Disponible en: Peirone, F. (2017). Competing Anti-Corruption Strategies for ensuring Integrity in Public Contracts: U.S. and EU systems compared. Procurement Law Journal, p. 23-39. Acceso en 12 dic. 2019.
} 
ofrecer los fundamentos teóricos que justifican la incorporación de estas personas como sujetos obligados a este deber en el orden jurídico brasileño, además de considerar importante para subsanar una de las debilidades identificadas con motivo de la preparación de los Juegos Olímpicos Rio (2016).

Hasta que esto no ocurra, es decir, que la alteración legislativa no se produzca, entendemos como jurídicamente posible que la Administración Pública trate de incorporar en los pliegos y contratos del sector público cláusulas de integridad que demandan de las compañías interesadas en pactar con el Estado o cualquier de las entidades por él controladas el compromiso de publicar todos sus actos y decisiones, más allá de adoptar políticas internas que incentiven las buenas prácticas administrativas. En todo caso, la divulgación tendrá que respetar los límites fijados en la Ley de Transparencia y Acceso a la Información, en tanto que no consideramos razonable demandar de las entidades privadas un compromiso con la transparencia mayor de lo que se requiere del sector público.

\subsection{La valorización de la labor de las mesas (o comisiones) responsables de contratación pública}

Hemos dicho al principio de esta investigación ${ }^{1031}$ que, doctrinariamente, algunos especialistas suelen identificar tres modelos de autoridades responsables de controlar los actos y decisiones de los órganos y entidades públicas en materia de transparencia gubernamental: ${ }^{1032}$

d) El modelo judicial;

e) El modelo de comisiones especializadas;

f) El modelo de ombudsman.

También hemos dicho que, independientemente del modelo adoptado en cada Estado, lo importante es que se reconozca a aludido órgano, la independencia política necesaria para desarrollar su actividad. ${ }^{1033}$

\footnotetext{
${ }^{1031}$ Ver al respecto el apartado 1.8.

1032 Neuman, Laura. op.cit. p. 25.

${ }^{1033}$ Ibidem, p. 1-5.
} 
Esta despolitización e independencia que se requiere de los órganos responsables de la defensa de la transparencia también debe extenderse a otros órganos directamente involucrados con la contratación pública, como son las mesas o comisiones de contratación. Así, las aludidas mesas deben constituir órganos de naturaleza técnica, formados exclusivamente por funcionarios públicos con estabilidad profesional, con independencia suficiente para manifestarse al respecto de las contrataciones públicas y denunciar irregularidades en los procesos de contratación, como la incorporación de exigencias técnicas indebidas en los pliegos concernientes a la contratación de obras públicas a modo de encaminarlas hacia determinados licitadores.

Así, ni políticos, ni el personal eventual podrán formar parte de estos órganos, así como tampoco emitir informes que valoren la participación o las propuestas de los licitadores, ${ }^{1034} \mathrm{o}$ interferir con la elaboración de los pliegos. ${ }^{1035}$

Los estudios realizados en torno a estos asuntos han revelado que la presencia de políticos o personal eventual al frente de los procedimientos de contratación pública no siempre produce resultados positivos desde la perspectiva de las estrategias anticorrupción, con frecuencia verificándose la conclusión de acuerdos sigilosos y espurios al margen de las reglas previamente establecidas, ${ }^{1036}$ como pasó en los Juegos Olímpicos Rio (2016).

Asimismo, las investigaciones comandadas por Transparencia Internacional ${ }^{1037}$ han revelado que no es rara la vez existe una correlación entre la adjudicación de contratos del sector público y compañías cercanas a determinados grupos políticos, ${ }^{1038}$ lo que

\footnotetext{
${ }^{1034}$ MIRANZO DÍAZ, Javier. Op. Cit., L. 1922

1035 Ibidem, L. 1934.

1036 SANMARTÍN MORA, María Asunción, "La profesionalización de la Contratación Pública en el Ámbito de la Unión Europea." In: GIMENO FELIÓ, José María Observatorio. de Contratos Públicos, 2011, Navarra, Civitas 2012, p. 407-429.

1037 Transparencia Internacional. "Conclusiones de la Jornada sobre Transparencia integral en la contratación pública". Observatorio de Contratación Pública, 3 de julio de 2017. Disponible en https://www.scoop.it/topic/transparencia-by-rafa-camacho?page=4\&tag=Jornadas Acceso en 12 nov 2019.
}

${ }^{1038}$ MIRANZO DÍAZ, Javier. Op. Cit. L. 1911. 
coloca en evidencia la necesidad de dirigir la contratación hasta un punto en donde ya no se verifiquen interferencias de naturaleza política en los aludidos procedimientos. ${ }^{1039}$

Consideramos que esta despolitización de la contratación, así como la independencia de los órganos responsables de la defensa de la transparencia, puede contribuir para prevenir la corrupción a menudo asociada a estos negocios jurídicos, en especial cuando uno está delante de los mega eventos deportivos.

Sin embargo, para que tal cosa suceda, es fundamental que los sectores de la Administración Pública cuenten con personal cualificado en materia de transparencia y contratación pública, con lo cual podrán identificar las maniobras de funcionarios y particulares deshonestos pudiendo incorporar en los contratos exigencias que restrinjan de forma indebida el carácter competitivo de las licitaciones.

En efecto, a partir de los años setenta, principalmente con base al modelo de la llamada Nueva Gestión Pública, se creó un discurso en el sentido de que todo el personal del sector público es incompetente para desarrollar determinadas tareas, en especial cuando relacionada a cuestiones de naturaleza técnica, como son las exigencias de ingeniería necesarias al desarrollo de proyectos para la realización de grandes obras de infraestructura semejantes a las ejecutadas para la recuperación de la cuenca hidrográfica de Jacarepaguá con motivo de los Juegos Olímpicos Rio (2016).

Al contrario, todavía con el referido discurso, el personal del sector privado constituye ejemplos de profesionales cualificados en cuestiones de esta naturaleza, con lo cual las exigencias que buscan incorporar a los pliegos no pueden ser cuestionadas por la Administración Pública, dada la falta de conocimientos técnicos de sus empleados para tanto.

Con base a este discurso de superioridad de los conocimientos privados sobre el público, muchas compañías trataron de influenciar con la elaboración de los contratos

${ }^{1039}$ MARALET, Elisenda. El Nuevo Reto de la Contratación Pública para Afianzar la Integridad y el Control: reforzar el profesionalismo y la transparencia. Revista Digital de Derecho Administrativo, núm. 15, 2016, p. 40. ISSN-E 2145-2946. Disponible en: http://dx.doi.org/10.18601/21452946.n15.04 Acceso en 12 nov. 2019. 
referentes a ciertas contrataciones públicas, exactamente para que la licitación fuese encaminada a la satisfacción de sus propios intereses.

Casi cincuenta años tras la inauguración del modelo de la nueva gestión pública, es posible verificar que el discurso de superioridad de los conocimientos privados sobre el público no refleja la realidad. En los últimos años, se nota como el personal de la Administración Pública busca cada vez más adquirir mayor cualificación profesional y adquirir conocimientos en todas las áreas, principalmente en el sector de la contratación pública, con lo cual no es un despropósito entregar a estos servidores la tarea de comandar los procedimientos de contratación.

La transferencia de responsabilidad no significa que los políticos perdieran totalmente su poder en cuanto a la gestión de los intereses públicos. Como representantes del pueblo, mantienen la prerrogativa de decidir sí la Administración Púbica debe contratar o llevar hacia delante ciertos proyectos. Pero, una vez que tomen la decisión, todo el procedimiento para ello se desarrollará bajo la responsabilidad de un órgano técnico para el cual gobernará sus acciones con transparencia e integridad. ${ }^{1040}$

Además, consideramos que la transparencia de la actuación de estos órganos técnicos resuelve un gran problema identificado en el derecho alemán ${ }^{1041}$ e italiano ${ }^{1042}$ en cuanto a la prevención de la corrupción en la contratación pública. En ambos países, con objetivo de impedir que los miembros de las mesas de contratación sean corrompidos por grandes compañías, que se establezcan lazos o relaciones espurias entre funcionarios y licitadores, se adoptó como regla que los miembros de estas mesas no participan de todas las fases de la contratación, tampoco actúa en contrataciones sucesivas. Se establece una

\footnotetext{
${ }^{1040}$ GIMENO FELIÓ, José María, La Nueva Regulación, de la Contratación Pública. In GIMENO FELIÓ, José María. Estudio Sistemático de la Nueva Ley de Contratos del Sector Público, Cizur Menor, Pamplona, Aranzandi, 2018, p. 130.

${ }^{1041}$ WENSINK, Wim. y MAARTEN DE VERT, Jam. Identifying and Reducing Corruption in Public Procurement in the Eu. Bruselas PwC EU services, 30 de junio 2013, p. 272. Disponible en: https://bit.ly/2b3oLsS Acceso en 12 nov 2019.

1042 RANGONE, Nicoletta. "A behavioral approach to Administrative Corruption Prevention". In: CERRILlO I MARTÍNEZ, Agustí. y PONCE SOLÉ, Juli. Preventing Corruption and Promoting Good Governance and Public Integrity. Bruselas: Brulyant, 2017, p. 69-99. en p. 79.
} 
rotación entre ellos, con lo cual se busca disminuir el poder de los funcionarios públicos en estos asuntos y su capacidad para interferir en todas las etapas del procedimiento. ${ }^{1043}$

Aunque apta a dificultar el surgimiento de conflictos de intereses, medidas de esta naturaleza acaban generando problemas de naturaleza práctica para las Administraciones Públicas debido a que obliga a que el estado tenga un número considerable de funcionarios cualificados para tomar parte al frente del procedimiento de contrataciones, lo que no siempre es posible.

En este sentido, la experiencia ya ha demostrado que las limitaciones presupuestarias y humanas entorno a este asunto son evidentes y ninguna política pública en esta materia podrá ignorar esta realidad a la hora de plantear una solución para el problema. De acuerdo con la Association of Certified Fraud Examiners, alrededor del 50 por ciento de los casos de fraude y corrupción suelen ser revelados a través de delación o accidentalmente. Asimismo, apenas el 14 por ciento resultan de una auditoria llevada a cabo por los órganos de la Administración Pública, ${ }^{1044}$ con lo cual se pone de manifiesto la necesidad de buscar medios alternativos que favorezcan al control y la prevención a bajo coste.

Desde esta perspectiva, la transparencia gubernamental constituye una herramienta eficiente para prevenir la corrupción. De un lado, no obliga a que las administraciones públicas tengan que calificar todo su personal para el tema de la contratación pública; de otro, proporciona la creación de grandes estructuras administrativas que demandarían grandes inversiones para su funcionamiento, lo que no siempre es económicamente viable, además de sufrir con la resistencia de determinados sectores de la sociedad.

En otras palabras, aparte de ser más barata en comparación con el modelo alemán e italiano, la transparencia tiene la virtud de incorporar los ciudadanos en la labor de prevenir la corrupción asociada a los contratos del sector público, toda vez que les permite acompañar y evaluar las actividades desarrolladas en el amito de los órganos encargados de esta materia.

\footnotetext{
${ }^{1043}$ MARALET, Elisenda. Op. Cit. P. 40.

${ }^{1044}$ MIRANZO DÍAZ, Javier. Op. Cit., L. 3429.
} 
A modo de mejorar la labor de estas mesas o comisiones consideramos importante que los contratos del sector público sean reunidos en un único órgano de la Administración Pública, preferentemente en las Contralorías u otros órganos responsables de la transparencia gubernamental, con la creación de un registro central de contratos del sector público.

La creación de aludido registro permite a los ciudadanos verificar sí las mismas instituciones obtienen contratos sucesivos con cierto órgano o entidad adjudicador. ${ }^{1045}$ Con arreglo a los datos registrados, uno puede verificar no solo el nombre de la entidad que firmó el contrato, como también el nombre de los socios o administradores de cada institución.

La experiencia ya ha demostrado que los corruptos suelen crear varias personas jurídicas para participar de licitaciones con la Administración Pública, aunque en su esencia, en su administración, se trate de las mismas personas.

Estas distorsiones ya ocurrieron en Rio de Janeiro antes que la ciudad fuera elegida sede de los Juegos Olímpicos de 2016. Las sociedades comandadas por Arthur Soares de Menezes Filho, aunque se trataran de personas jurídicas distintas, en esencia, se trataban casi que, de la misma persona, en tanto que su cuadro social era casi que totalmente lo mismo, con la particularidad de que el propio Arthur Soares se mantuvo como administrador en todas ellas. ${ }^{1046}$

Claro que la divulgación de los nombres de los responsables de la administración de las entidades puede generar discusiones en cuanto a la protección de datos personales de estos individuos, además de acalorados debates entorno a una posible vulneración a la privacidad. En España, el Tribunal Supremo, mediante la sentencia n. 1007, de 08 de julio de $2019,{ }^{1047}$ ha decidido que la difusión de datos en abierto en materia de contratación pública durante los procedimientos administrativos destinados a este fin depende de previo consentimiento de las personas cuyos datos fueron publicados.

\footnotetext{
1045 Ibidem, L. 471.

${ }^{1046}$ Los recursos obtenidos a través de estos contratos fueron utilizados para la compra de los votos de miembros africanos del COI en 02 de octubre de 2009.

${ }^{1047}$ MIRANZO DÍAS. Javier. Op. Cit., L. 3.607.
} 
Sin embargo, a pesar de estas ponderaciones, consideramos que la transparencia cumple con un papel que va más allá de la mera divulgación de informaciones para el conocimiento de la sociedad. La transparencia sirve a una finalidad superior, es decir, a la concreción del principio de integridad, el cual debe enmarcar la actuación de quienes contratan con la Administración Pública. En base a aludido principio, la persona jurídica no puede ser utilizada para la comisión de cualquier tipo de irregularidad.

Debe pensarse, en este caso, en una licitación de que participan varias empresas cuyos administradores son, con pequeñas variaciones, exactamente los mismos. En este caso, no caben dudas que la estrategia de constituir varias entidades con estas características busca dar apariencia de competitividad a un procedimiento licitatorio que no lo tiene, en tanto que todos los administradores conocen el contenido de las propuestas de sus adversarios.

Consideramos que la divulgación de la información, en este caso, de hecho, sirve para mejorar el procedimiento de contratación y, asimismo, viabiliza la aplicación del principio de integridad.

Finalmente, considerando que la participación ciudadana constituye uno de los principales objetivos de la transparencia gubernamental, opinamos que el órgano responsable de las contrataciones públicas también deberán facilitar a la sociedad en general y a los licitadores en particular canales de denuncia de irregularidades pasadas entre las propias compañías "whistleblowing", con objeto de dividir el mercado de contratos del sector público, establecer especificaciones técnicas preparadas para determinadas compañías y crear propuestas de cobertura entre ellas a modo de aparentar que todo el procedimiento licitatorio transcurrió con observancia a las reglas y principios jurídicos.

En este sentido, el artículo 8.4 de la CNUCC recomienda a cada Estado parte a adoptar medios que faciliten a los funcionarios públicos denunciar a las autoridades la existencia de actos de corrupción. Aunque se es una medida pensada para los órganos y entidades del sector público, entendemos que la iniciativa también puede englobar a los licitadores privados.

La creación de esta herramienta, además de fundamentarse en el principio de integridad, también se justifica a partir del principio de universalidad, en tanto que 
engloba no solo funcionarios de la administración y licitadores, como también otras personas, tales como expertos externos, subcontratistas, y proveedores de productos y servicios de la compañía principal, quienes podrían revelar irregularidades en el ámbito de estas relaciones comerciales. ${ }^{1048}$

Así como también realiza parte de la doctrina sobre el tema, defendemos que estos canales de denuncia no estén restringidos únicamente a los órganos o entidades responsable de la contratación, sino que se establezcan diferentes grados o niveles a que los denunciantes puedan acceder para dar noticia de la irregularidad. ${ }^{1049}$ Habría, por tanto, según este modelo, canales internos y externos de denuncias que se complementan y cuya existencia se basa en un dato de la realidad.

De acuerdo con los estudios realizados en esta materia, por más grave que sea la falta objeto de la denuncia, los denunciantes prefieren comunicarla, primero, a los órganos de control interno de la Administración Pública en donde se ha verificado la infracción. Cuando ya no logren su objetivo, optan con llevarla al conocimiento de órganos externos, con la expectativa de que puedan sancionar estas malas prácticas.

En conclusión, la valorización de las competencias administrativas de las mesas o comisiones de contratación pública y la creación de canales de denuncia internos y externos al órgano o entidad contribuye a prevenir la corrupción y a mejorar la rendición de cuentas de la Administración Pública, en tanto que incorpora a los ciudadanos en la lucha contra estas malas prácticas.

\subsection{El nuevo régimen de sanciones.}

La Ley de Transparencia y Acceso a la Información de Brasil, así como otras Leyes de igual naturaleza, prevé un régimen de sanciones administrativas para el caso de infracciones de sus disposiciones, las cuales deberán ser aplicadas por la autoridad competente, teniendo en cuenta la naturaleza de los actos voluntariamente practicados.

En este sentido, la infracción administrativa resulta del incumplimiento voluntario de una norma administrativa para la cual se establece una sanción leve, media o grave,

\footnotetext{
1048 Ibidem, L. 4365.

1049 Ibidem, L. 4444.
} 
aplicada por una autoridad con competencia para ello y atendiendo a la gravedad de la falta cometida. ${ }^{1050}$

La razón debido a que la Ley considera determinados comportamientos como infracciones administrativas $\mathrm{y}$, además, establece sanciones para el caso de su incumplimiento atiende a una finalidad que va más allá de la propia norma. En cualquier caso, se busca, a partir de este régimen, dar incentivos a los ciudadanos que practiquen determinados actos o dejen de adoptar cierto comportamiento considerado dañino para la convivencia social. ${ }^{1051}$

En consecuencia, el objetivo de cada una de las figuras delictivas y su correspondiente sanción es única y exclusivamente intimidar a potenciales infractores, de modo que no ejecuten cualquiera de las conductas prohibidas, aparte de incentivar a los ciudadanos a actuar de conformidad con determinado mandamiento previsto en Ley. En otras palabras, las sanciones administrativas buscan, por un lado, incentivar a que el infractor no repita el comportamiento ilícito y, por otro, transmitir a los demás individuos el mensaje de que, en un futuro, no deben portarse de esta manera.

Estas consideraciones, aunque evidentes, deben ser repetidas exhaustivamente a modo de incorporarse al espíritu del intérprete y encaminar su labor a la hora de buscar el verdadero objetivo perseguido con la aplicación de cada sanción asociada al incumplimiento de una norma de derecho administrativo. ${ }^{1052}$ En cualquier caso, la aplicación de sanciones no resulta de un acto discrecional de la autoridad. En cuanto identificar la infracción administrativa, la autoridad no tiene libertad como para dejar de aplicar la sanción, viéndose obligada a hacerlo.

La imposición de la sanción obedece a los principios de legalidad, anterioridad, tipicidad, proporcionalidad, debido proceso legal y motivación, ${ }^{1053}$ los cuales encaminan las acciones del Estado en cuanto a la previsión y la aplicación de las sanciones. Los

\footnotetext{
${ }^{1050}$ MELLO, Celso Antônio Bandeira de. Curso de Direito Administrativo, 26 a ed., São Paulo: Malheiros, 2009 , p. 840.

${ }^{1051}$ MELLO, Celso Antônio Bandeira de. Op. Cit., p. 840.

${ }^{1052}$ Ibidem, p. 841.

${ }^{1053}$ Ibidem, p. 843.
} 
principios exigen, por ejemplo, que las normas sancionadoras sean ciertas, previas y claras en cuanto a los comportamientos que busca desestimar. ${ }^{1054}$

Con arreglo a estas enseñanzas, la Ley brasileña considera que la infracción al deber de transparencia conlleva a la aplicación de diferentes sanciones administrativas, tales como advertencia, multa, rescisión del vínculo con el poder público, suspensión temporal de participar en licitación, impedimento de contratar con la administración pública por plazo no superior a años y declaración de falta de idoneidad para licitar o contratar con la Administración Pública, hasta que sea promovida la rehabilitación ante la propia autoridad quien aplicó la penalidad. ${ }^{1055}$

Asimismo, tratándose de funcionarios públicos civiles o militares, la infracción al deber de transparencia puede caracterizar improbidad administrativa o transgresión militar, teniendo en cuenta la gravedad de los actos practicados.

Por tanto, se someten a este régimen de sanciones, por un lado, los funcionarios públicos civiles y militares que violan el deber de transparencia por medio de cualquier de las conductas previstas en Ley, ${ }^{1056}$ así como las personas físicas y las entidades privadas que tengan informaciones debido a algún vínculo con el poder público y que, además, estén obligadas a facilitarlas con base al establecido en la aludida Ley. ${ }^{1057}$

Cuando no lo hacen, pueden someterse desde la aplicación de sanciones leves (como la advertencia) hasta la aplicación de sanciones graves (como la declaración de falta de idoneidad para contratar con la Administración), dependiendo de la gravedad de los actos practicados.

\footnotetext{
${ }^{1054}$ MEDINA OSÓRIO, Fábio. Direito Administrativo Sancionador, São Paulo: Revista dos Tribunais, 2000, p. 211.

${ }^{1055}$ BRASIL. Lei n. 12.527/2011. op. cit. Art. 33.

${ }^{1056}$ BRASIL. Lei n. 12.527/2011. op. cit., Art. 32.

${ }^{1057}$ BRASIL. Lei n 12.527/2011. op. cit., Art. 33.
} 
En este sentido, el abanico de sanciones los suficientemente amplio como para englobar múltiples y variados comportamientos de los infractores, observándose, en cualquier caso, la aplicación de los principios de proporcionalidad y motivación. ${ }^{1058}$

Así, la autoridad sancionadora no solo tiene que señalar el dispositivo legal violado, como también el comportamiento, comisivo u omisivo, que justifica la aplicación de la sanción. Asimismo, siempre que la Ley establezca una gradación de las sanciones en abstracto, la autoridad debe presentar los motivos en concreto debido a que eligió una y no otra penalidad, con lo cual se evitan arbitrariedades. La omisión en cuanto a cualquier de estos elementos conlleva a la nulidad de la sanción impuesta. ${ }^{1059}$

Con base a lo antes referido, resulta evidente que todos los altos directivos y funcionarios que faltaron con el deber de transparencia en cuanto a las licitaciones asociadas a la preparación de los Juegos Olímpicos Rio 2016, además de las sanciones de naturaleza penal a que fueron sometidos, podrían sufrir con la aplicación de las sanciones establecidas en la Ley de Transparencia y Acceso a la Información, como, por ejemplo, la sanción por acto de improbidad administrativa, teniendo en cuenta la naturaleza pública y federal de gran parte de los recursos que financiaron al mega evento.

No ocurre igual en cuanto a las compañías privadas que actuaron al lado de estos altos directivos y funcionarios, una vez que aludidas instituciones no se consideran sujetos obligados al deber de transparencia, ${ }^{1060}$ con lo cual no pueden violarlo.

La aplicación de la sanción, sí existente, quebranta los principios de legalidad y anterioridad, considerados basilares en el Estado Democráticos de Derecho, una vez que representan una garantía de los administrados contra eventual uso indebido del poder por quienes estén al frente de la Administración. ${ }^{1061}$

Esto no significa que tales compañías no podrán someterse a sanciones administrativas dictadas por las autoridades brasileñas, sin embargo, el fundamento de la penalidad, en este caso, resultará de infracciones de otra naturaleza y no de una violación

\footnotetext{
${ }^{1058}$ MELLO, Celso Antônio Bandeira de. op. cit., p. 849-851.

${ }^{1059}$ Ibidem, p. 852.

1060 BRASIL. Lei n. 12.527/2011. op. cit., Art. 1º $^{\circ}$ parágrafo único.

${ }^{1061}$ MELLO, Celso Antônio Bandeira de. op. cit., p. 843-845.
} 
al deber de transparencia. Como ya lo he dicho en otro momento, ${ }^{1062}$ esta debilidad proviene del hecho de que los adjudicatarios de contratos con el sector público no se consideran sujetos obligados al deber de transparencia en el orden jurídico brasileño, con lo cual no se someten al régimen de sanciones tipificado en la Ley.

Así las cosas, opinamos una vez más en el sentido de una alteración de la Ley n. 12.527/2011, de Transparencia y Acceso a la Información de Brasil, a modo de incorporar a los adjudicatarios de contratos con el sector público como sujetos obligados al deber de transparencia activa y pasiva, con lo cual, además, estarán sometidos al régimen de sanciones establecido en la normativa.

Asimismo, al lado de las sanciones administrativas, consideramos que la Ley de Transparencia y Acceso a la Información debería prever las llamadas providencias administrativas cautelares, tendentes a asegurar la publicidad de los actos de la Administración en el supuesto de que uno esté dificultando su publicidad. Doctrinariamente, las providencias administrativas cautelares engloban medidas que la Administración Pública se ve obligada a adoptar inmediatamente a modo de prevenir serios daños al interés público o al buen orden administrativo. ${ }^{1063}$

Al contrario de las sanciones administrativas, las providencias cautelares no buscan intimidar eventuales infractores para que no incurran en conducta u omisión indeseada, sino que se destinan a paralizar comportamientos dañinos a la Administración Pública y a la sociedad. ${ }^{1064}$

Con frecuencia, esta figura se asocia a situaciones tales como la provisoria aprensión de medicinas o alimentos que se presumen impropios al consumo, a la interdicción de un establecimiento que genera polución o la expulsión de un alumno que no se porta correctamente durante las clases. ${ }^{1065}$ Se destinan a detener conductas perjudiciales al buen funcionamiento de la Administración Pública (como sucede en el

\footnotetext{
1062 ver apartado 3.3 .

${ }^{1063}$ LORENZO Susana. Sanciones Administrativas, Montevideo: Julio Cesar Faíra Editor, 1996, p. 5-6.

${ }^{1064}$ LORENZO Susana. op. cit., p. 5-6.

1065 MELLO, Celso Antônio Bandeira de. op. cit., p. 852-853.
} 
caso del alumno) o a detener conductas dañinas a la sociedad (como pasa en el caso del estabelecimiento que genera polución).

Considerando la celeridad de estas providencias desde la perspectiva del derecho administrativo y la importancia que la prevención de la corrupción cobra en la actualidad, opinamos en tal sentido de que las providencias administrativas cautelares sean expresamente incorporadas en la Ley de Transparencia y Acceso a la Información de Brasil, a modo de permitir que la Contraloría General de la Unión, como principal órgano del sistema brasileño de transparencia, pueda suspender la transferencia de recursos federales destinados a la ejecución de obra pública cuya licitación haya pasado sin la observancia de la transparencia gubernamental, lo que tiene especial relevancia en el caso de los mega eventos deportivos internacionales, teniendo en cuenta el gran volumen de recursos invertidos en un corto periodo de tiempo.

Defendemos, en este caso, la adopción de un régimen semejante al planteado por el banco mundial en cuanto a las estrategias de prevención de la corrupción relativa a los recursos facilitados por la entidad para la financiación de programas y políticas públicas. Desde mediados de los años noventa, el banco mundial ha implementado políticas de integridad de carácter internacional, más bien en lo relativo a la contratación pública. ${ }^{1066}$

De acuerdo con la organización, en cuanto se verifique un caso de corrupción en lo relativo a recursos facilitados por la entidad, el banco podrá suspender la financiación inmediatamente, ${ }^{1067}$

independientemente de las garantías ofrecidas por el Estado o las autoridades responsables de la prevención de estas malas prácticas en el ámbito interno.

Asimismo, a modo de fomentar una cultura de transparencia en la sociedad, consideramos importante incorporar en la Ley de Transparencia y Acceso a la Información la obligatoriedad de que las Contralorías Generales publiquen, anualmente, a través de páginas web o cualquier otro medio, la lista de las entidades involucradas en

${ }^{1066}$ MIRANZO DÍAZ, Javier. Op. Cit., L. 1157.

1067 MARTIN, A. Timothy. "The Developmente of International Bribery Law". Natural Resources Environment. Nueva Jersey, American Bar Association, 1999, vol. 14, núm. 2, p. 101. Disponible en: https://www.jstor.org/stable/40924392 Acceso en 12 nov. 2019. 
casos de corrupción, con expresa referencia a los valores destinados, la finalidad del proyecto y los recursos desviados debido a las malas prácticas.

Defendemos, una vez más, la adopción de un modelo semejante al adoptado por el Banco Mundial en esta materia, como forma de incentivar la integridad y la transparencia en la sociedad.

La creación de listas negras ha constituido una práctica común del banco mundial a partir de mediados de los años noventa con el objetivo de excluir a las entidades responsables de estas irregularidades de futuros contratos realizados con la institución. ${ }^{1068}$ Se trata de una medida de nítido carácter pedagógico que busca, en realidad, incentivar a que las empresas se porten conforme al derecho por si quieren seguir contratando con el Banco. ${ }^{1069}$

En base a este modelo, el banco mundial posee un listado de empresas que no podrán contratar con la organización, ni de ella recibir recursos a cualquier título, siempre que estuvieron involucradas en casos de corrupción. Con estas medidas, buscamos perfeccionar el régimen brasileño de transparencia gubernamental a modo de que pueda cumplir con su papel de prevención de la corrupción, en especial cuando asociada a los mega eventos deportivos internacionales.

\section{CONCLUSIÓN}

El objetivo principal de esta investigación ha sido analizar el papel de la transparencia gubernamental como estrategia de prevención de la corrupción comúnmente asociada a la preparación de los grandes eventos deportivos internacionales.

\footnotetext{
${ }^{1068}$ MARTIN, A. op. cit., p. 101.

${ }^{1069}$ SLEVAGGI, Nicola. Las Listas Negras en el Banco Mundial: ?Hacía un sistema global de sanciones? In: Nieto Martín, Adán. y MAROTO CALATAYUD, Manuel. Public Compliance: prevención de la corrupción en Administraciones Públicas y partidos políticos. Ediciones de la Universidad Castilla la Mancha, 2014, p. 121. Disponible en: https://dialnet.unirioja.es/servlet/articulo?codigo=5067561 Acceso en 11 nov 2019
} 
Nos interesó especialmente estudiar estas relaciones en el caso de los Juegos Olímpicos de Rio de Janeiro, debido a los debates que se formaron en la sociedad brasileña desde que la ciudad fue elegida sede de las Olimpiadas de 2016, el 2 de octubre de 2009, en Copenhague, Dinamarca, y que colocaron en lados opuestos los defensores del mega evento y los contrarios a su realización.

Para cumplir con este objetivo, analizamos varios supuestos de corrupción ocurridos en diferentes ediciones de los Juegos, desde la antigüedad hasta nuestros días, destacando las malas prácticas cometidas a lo largo del siglo $\mathrm{XX}$, periodo en que estas irregularidades sobrepasaron las fronteras deportivas para alcanzar actividades de otra naturaleza, como las destinadas a las obras de infraestructura ejecutadas con motivo de preparación del mega evento.

En este sentido, identificamos que la asociación entre obras públicas, contratos administrativos, licitaciones, corrupción y Juegos Olímpicos siempre ha existido, aunque se ha incrementado considerablemente a partir de la segunda mitad del siglo XX, principalmente tras la entrada de la televisión en los Juegos.

A partir de ese periodo, surge la necesidad de mayores inversiones públicas en infraestructura ${ }^{1070}$ con motivo de la celebración del encuentro ${ }^{1071}$ y muchas de estas obras constituyeron un ambiente favorable a las malas prácticas administrativas.

La posibilidad de gastar grandes cantidades de dinero en un corto periodo de tiempo ha llamado la atención de políticos y empresarios alrededor del planeta, corruptos o no, quienes rápidamente trataron de presentar la candidatura de las ciudades ubicadas en su área de influencia, queriendo acoger los Juegos Olímpicos y disfrutar de todos los beneficios que su realización podría proporcionar. ${ }^{1072}$

Asimismo, la realización de grandes eventos de esta naturaleza despierta la preocupación de órganos y entidades dedicados a la lucha contra la corrupción, una vez

\footnotetext{
${ }^{1070}$ OLIVEIRA, Nelma Gusmão de. Op. Cit., p. 53-57.

${ }^{1071}$ RITCHIE, J. R. Brent; Smith, Brian. Op. cit., p. 310.

${ }^{1072 J E N N I N G S, ~ A n d r e w . ~ O p . ~ c i t ., ~ p . ~} 112$.
} 
que, en raras excepciones, los Juegos se han convertido en un ambiente favorable a la desviación de fondos públicos.

En este sentido, la elección de Río fue responsable de una ola de manifestaciones en Brasil, favorables y contrarias a la realización de las Olimpiadas. Había quienes reprodujeron el discurso oficial y dijeron que los Juegos serían responsables de la regeneración urbana de la ciudad, ${ }^{1073}$ de la recuperación de Ríos, lagunas, cuencas hidrográficas, parques y bosques ${ }^{1074} \mathrm{y}$ de la implantación de nuevos sistemas de transporte.

Así las cosas, era evidente la gran preocupación por el enfrentamiento a la corrupción, bien por la trayectoria de los Juegos Olímpicos a lo largo del siglo XX, o por la historia política de Brasil, marcada por varios casos de despilfarro de fondos, desviación de recursos públicos, tráfico de influencia y sobrefacturación de contratos de obras y servicios desde el periodo colonial. ${ }^{1075}$

Esta preocupación tenía sentido, pues dos años antes de que fuera elegida ciudad olímpica, Rio acogió los Juegos Panamericanos de 2007. Así como las Olimpíadas, el evento prometió grandes transformaciones tras su realización ${ }^{1076}$. Debido a los juegos, todos creían que existiría una revolución en la política pública asociada al deporte y se realizarían grandes obras de infraestructura en la ciudad e inversiones en sanidad y educación, que constituiría el legado social del mega evento ${ }^{1077}$.

El torneo no trajo los beneficios que prometió, y al contrario de lo esperado, los juegos fueron responsables de un gran despilfarro de fondos públicos, provocando que los gastos estuvieran muy por encima del presupuesto original.

\footnotetext{
${ }^{1073}$ JONES; STOKES, op. cit, p. 198-211.

1074 BRASIL. Ministerio dos Esportes. Cadernos de legado Rio 2016 reafirmam compromisso olímpico do Brasil. Disponible en: http://www2.esporte.gov.br/snear/rio2016/, Acceso en 06 nov. 2019.

${ }^{1075}$ ROMEIRO, Adriana. Op. Cit. L. 65.

1076 Pan-americano 2007 e Olimpíadas 2016: legados compatíveis, complementares ou divergentes? Disponible em: https://www.efdeportes.com/efd154/pan-americano-2007-e-olimpiadas-2016-legados.htm, Acceso en 12 oct. 2007.

1077 Ibidem.
} 
En comparación, el presupuesto facilitado a la Organización Deportiva Panamericana reveló que los juegos costarían a las arcas públicas doscientos cincuenta millones (250.000.000) de dólares ${ }^{1078}$. Terminado el mega evento, los costes alcanzaron la extraordinaria cifra de dos mil millones (2.000.000.000) de dólares, ocho veces más de lo previsto por las autoridades brasileñas.

Asimismo, los gastos realizados convirtieron al evento en los juegos más caros de la historia hasta la fecha ${ }^{1079}$. En este sentido, los Juegos Panamericanos Rio 2007 costaron a los brasileños más de las cinco ediciones anteriores del torneo. En otras palabras, los gastos con la preparación de los Juegos de Santo Domingo (2003), Winnipeg (1999), Mar del Plata (1995), la Habana (1991) e Indianápolis (1987), sumados, fueron inferiores a los dispendios en el torneo de Rio ${ }^{1080}$.

Más allá de los problemas relativos a los Juegos Panamericanos, también preocupaban otros asuntos a los brasileños de cara a la realización de las Olimpíadas. Un día antes que Rio resultara elegida ciudad olímpica, el Parlamento brasileño aprobó la Ley n. 12.035, de 01 de octubre de 2009, de institución del “Acto Olímpico" 1081 , que trató de ofrecer garantías y estableció reglas especiales para la realización de las Olimpíadas.

Con arreglo a esta ley, el gobierno se comprometió a destinar recursos públicos suficientes para soportar eventual gasto operacional por parte del Comité Organizador de los Juegos (CO-RIO), previa manifestación de los Ministerios de Deporte, Hacienda y Planificación. Las inversiones se destinaban a ofrecer las condiciones económicas para que las olimpíadas sucedieran de manera "satisfactoria y adecuada".

En otras palabras, con el objetivo de cumplir las exigencias fijadas por el COI, se incorporó al ordenamiento jurídico brasileño el compromiso de que el país diera soporte político y financiero al torneo ${ }^{1082}$. En lo jurídico, este soporte se materializó por medio

\footnotetext{
${ }^{1078}$ BOYKOFF, Jules. Op. cit., p. 213.

${ }^{1079}$ BOYKOFF, Jules. Op. Cit., p. 213.

${ }^{1080}$ CARDOSO. Tom.op. cit., L. 1784.

${ }^{1081}$ BRASIL. Lei n. 12.035/2009. Op. Cit.

1082 CARTA OLÍMPICA, 2007,op. Cit.
} 
de una cláusula general: "eventual dispendio operacional de responsabilidad del Comité Organizador del Torneo".

La amplitud de la autorización rápidamente despertó el interés de órganos controladores como el Ministerio Público y el Tribunal de Cuentas ${ }^{1083}$, los cuales temían que la autorización diese posibilidades para el despilfarro de fondos públicos, siempre que no existiera un límite legal para los gastos operacionales del CO-RÍO de cara a la preparación de las Olimpíadas.

Con la finalidad de calmar a los críticos, tres meses después a la sanción de algunas leyes que cambiaron las reglas para la contratación pública asociada a los preparativos para los Juegos Olímpicos, el Parlamento brasileño aprobó la Ley núm. 12.527, de 18 de noviembre de 2011, de Transparencia y Acceso a la Información ${ }^{1084}$. Como cualquier otra normativa de esta naturaleza, la ley brasileña impuso la publicidad de los actos de la Administración Pública como regla y el secreto como excepción, buscando divulgar todos los gastos realizados con motivo de las olimpíadas y prevenir las malas prácticas con frecuencia asociadas a los juegos. Fortalecería, en este caso, los principios de responsabilidad, máxima divulgación, participación, buena fe $\mathrm{y}$ universalidad.

Estos principios orientan la actuación de los órganos y entidades públicas en lo relativo al ejercicio de sus competencias. Sirven de fundamento axiológico a todo el orden jurídico, condicionan la interpretación de las normas y encaminan la actuación del poder público, fijándole una dirección a seguir.

Aunque la transparencia no aparezca expresamente entre los principios que deben regir las Administraciones Públicas, lo cierto es que ella es un principio implícito en los Estados democráticos de derecho y condiciona las acciones de los poderes públicos. Por un lado, inspira la labor del Parlamento en cuanto a la producción de las leyes que disciplinan la forma como pasará la divulgación de la información resguardada en manos de los órganos y entidades públicas. Establecen criterios para la divulgación de la

\footnotetext{
${ }^{1083}$ TCU e MPF cobram acesso a contratos olímpicos e a orçamento do Comitê Rio 2016. Op. Cit.

${ }^{1084}$ BRASIL. Lei n. 12.527/2011. Op. Cit.
} 
información, canales de participación ciudadana en la gestión pública y límites al derecho de acceso, resultado de la ponderación de los intereses en conflicto.

Asimismo, las normas que impone el deber de transparencia no actúan solas. Se conjugan a otras normas jurídicas para que puedan cumplir con su labor de prevenir la corrupción. Se destacan, en este caso, las relativas a la contratación pública, directamente vinculadas a la preparación de los juegos olímpicos y las relativas a la probidad administrativa, que demandan de los administradores públicos transparencia de criterios y procedimientos al frente de la gestión de los intereses públicos.

A pesar de toda reglamentación entorno al control de la contratación pública en la preparación de las Olimpíadas Rio 2016, la Ley núm. 12.527/2011, de Transparencia y Acceso a la Información y la Ley núm. 8.666/1993, de Licitaciones y Contratos Administrativos, no incorporaron entre sus dispositivos herramientas necesarias para enfrentar la corrupción asociada a los juegos.

Entre otros asuntos, las normativas no previeron la divulgación de agendas de los altos directivos de la Administración Pública, las retribuciones que cobraban fuera del cargo público y lo referente a los debates que antecedieron a la elaboración de los pliegos destinados a contratar entidades encargadas de las obras asociadas a su realización.

Tampoco incorporaron a los contratistas de la Administración Pública como sujetos obligados al deber de transparencia activa, lo que ha permitido que muchos empresarios deshonestos utilizaran contratos ficticios para sacar recursos de las compañías que comandaban y pudieran entregarlos a políticos y altos funcionarios de la Administración Pública, de conformidad con lo previamente pactado.

Durante estos encuentros, políticos y empresarios establecieron criterios especiales para la licitación de obras vinculadas a las olimpíadas, fijando el precio de la ventaja indebida y la forma en la que se produjo su pago. Esta omisión legislativa creó espacios de oscuridad, sirviendo de abrigo para personas deshonestas y que a menudo buscaban esconder sus malas prácticas detrás de conductas que, en apariencia, se presentan conforme al derecho.

Las irregularidades comenzaron, en este caso, desde la elección de la ciudad como sede olímpica y se extendieron a las principales obras de infraestructura y de recuperación 
ambiental asociadas a los juegos, con lo cual se puso de manifiesto las fragilidades del régimen de transparencia y acceso a la información en Brasil.

De acuerdo con las investigaciones realizadas por el Ministerio Público francés, diez días antes que Río fuese elegida ciudad anfitriona de los Juegos Olímpicos de 2016, el 23 de septiembre de 2009, la sociedad Matlock Capital Group Limited, con sede en las Islas Vírgenes Británicas, realizó por medio de la cuenta UBSWUS33, una transferencia de dos millones de (2.000.000) dólares para una cuenta del senegalés Papa Massata Diack, hijo de Lamine Diack, por entonces presidente de la Federación Internacional de Atletismo y miembro del COI.

Los recursos se destinaron a la Société Générale en Fontenay Sous Bois, Francia. Cinco días después, el 28 de septiembre de 2009, siguiendo las reglas de prevención del blanqueo de capitales vigentes en Francia, la Société Générale, tras verificar el monto de la transferencia, rechazó el dinero y restituyó a la cuenta de la sociedad Matlock Capital Group Limited en las Islas Vírgenes Británicas el importe de un millón novecientos mil (1.900.000) dólares.

Recibido el dinero, el 29 de septiembre de 2009, con el objetivo de asegurar que los recursos llegaran a Papa Massata Diack lo más breve posible, la sociedad Matlock Capital Group Limited realizó, entonces, desde una cuenta en Miami, dos transferencias a favor de la Société Générale, ubicadas en Rusia y Senegal. La primera transferencia por quinientos mil (500.000) dólares fue realizada a favor de la Société Générale Vostok en Moscú. A su vez, la segunda, de un millón quinientos mil (1.500.000) dólares, fue destinada a la Société Générale Branques Au, en Senegal, para una cuenta con titularidad de la sociedad Pamodzi Consulting, gestionada por Papa Massata Diack.

La magnitud de los ingresos y el hecho de que tan solo tres días después, el 2 de octubre de 2009, sería la elección de la ciudad anfitriona de los juegos olímpicos de 2016, hizo que el Ministerio Público francés solicitara la cooperación internacional al Ministerio de Justicia brasileño y al Ministerio Público brasileño para identificar si autoridades locales estaban involucradas en el soborno de miembros del COI, al ser nombrado Rio de Janeiro como sede de las olimpíadas.

Con tales informaciones, el Ministerio Público brasileño inició su propia investigación a modo de aclarar los hechos. A partir de documentos suministrados por autoridades de Antigua y Barbuda, verificó que la sociedad Matlock Capital Group 
Limited no solo tenía sede administrativa en las Islas Vírgenes Británicas, sino también que su principal socio fue el empresario brasileño Arthur Soares, quien de hecho hizo la transferencia de dos millones (2.000.000) de dólares a favor de Papa Massata Diack.

El pago se destinó a superar dificultades técnicas con las que se enfrentó Rio en el cumplimiento de los requisitos con el objetivo de acoger una edición de las olimpíadas. Un año y medio antes que ocurriera la elección de la ciudad sede de los juegos, en marzo de 2008, el COI divulgó el ranking de las ciudades candidatas a ser anfitrionas de las Olimpíadas de 2016. De acuerdo con la entidad, Tokio ocupó el primer lugar en la clasificación con 8,3 puntos, seguida de Madrid con 8,1 puntos. A su vez, Chicago tuvo 7,0 puntos, mientras que Doha logró 6,9 puntos. Finalmente, Rio de Janeiro ocupó la última posición con 6,4 puntos.

Considerando lo que a menudo ocurría en otras elecciones, la comunidad internacional dio por cierto que la disputa final sería entre Tokio y Madrid, justamente las dos ciudades mejor clasificadas. Asimismo, Rio de Janeiro estuvo virtualmente eliminada de la disputa por que faltó tiempo para subsanar todas las dificultades técnicas.

Con el objetivo de resolver el problema, entre marzo de 2008 y septiembre de 2009, el Gobernador Sergio Cabral de Rio de Janeiro viajó repetidas veces a Paris a reunirse con Carlos Nuzman (presidente del Comité Olímpico brasileño), Leonardo Gryner (director de marketing de la institución), Lamine Diack y Papa Massata Diack. Al finalizar tales encuentros, los asistentes acordaron el pago de dos millones (2.000.000) de dólares a Lamine Diack para que sobornara a miembros africanos del COI. Además, establecieron la forma de realizar la entrega de los beneficios. Los recursos serían transferidos por Arthur Soares a Papa Massata Diack directamente porque Lamine Diack estuvo sometido a mayores controles a raíz de su labor como miembro del COI.

Llama la atención en lo relativo a la transparencia, que las reuniones entre brasileños y senegaleses no fueron debidamente registradas en la agenda de los directivos brasileños, pese a la naturaleza pública de sus actividades. Como principal autoridad del Estado de Rio de Janeiro, el Gobernador Sergio Cabral debió rendir cuentas de sus actos a la sociedad, publicando, como mínimo, la agenda de reuniones con directivos del COI, el contenido de cada encuentro y los acuerdos perfeccionados entre las partes al terminar la cita, lo que naturalmente se espera de un Estado verdaderamente democrático. 
En efecto, la transparencia es un principio elemental de los Estados democráticos de derecho que encamina la actuación de la Administración Pública y sus gestores, quienes deben demostrar a los ciudadanos, permanentemente, la conformidad de sus actos y decisiones con la legalidad, la moralidad y la probidad, compromiso que se extiende a los directivos del Comité Olímpico Brasileño, teniendo en cuenta la naturaleza pública de gran parte de los recursos que siempre financiaron la institución.

Los recursos con los que sobornaron a miembros africanos del COI eran procedentes de ventajas indebidas pagadas al Gobernador Sergio Cabral para que entidades prestadoras de servicios pudieran celebrar contratos con la Administración Pública. El pago de estas ventajas inició en la Secretaria de Sanidad y fue pactado en reuniones secretas de que participaron el Gobernador y algunos de sus secretarios, con la particularidad de que ninguno de los encuentros fue registrado en la agenda oficial de la autoridad.

Las desviaciones ocurridas en la Secretaría de Salud y en los contratos de prestación de servicios contaminaron rápidamente otros órganos de la Administración. En este caso, la principal afectada fue la Secretaría Estatal de Obras Públicas, responsable de los contratos con mayor valor económico en la administración.

El 2007, primer año de mandato del Gobernador Sergio Cabral, el sector de la construcción civil estuvo dominado, básicamente, por cinco grandes compañías (OAS, Odebrecht, Andrade Gutierrez, Camargo Corrêa y Queiroz Galvão), quienes conquistaron los principales contratos con el Estado. Durante este periodo, las aludidas sociedades lograron un treinta y ocho (38) por ciento de las inversiones brasileñas relativas a las cincuenta principales obras públicas de todo el país, lo que ha incrementado aún más en los años siguientes.

E1 2009, año de la elección de Rio como ciudad olímpica, las inversiones públicas a cargo de la Unión, los Estados, los Municipios y demás entidades controladas por cada uno de estos entes políticos llegaron a un sesenta y dos (62) por ciento de los ingresos de Odebrecht, un treinta y cinco (35) por ciento de Camargo Corrêa, un setenta y dos (72) por ciento de Andrade Gutierrez y un cien (100) por ciento de Queiroz Galvão. Asimismo, a lo largo de este periodo, las cuatro hermanas (OAS, Odebrecht, Andrade Gutierrez y Camargo Corrêa) fueron beneficiadas con préstamos baratos junto al Banco Nacional de Desarrollo Económico y Social (BNDES), una importante agencia de fomento en Brasil, 
lo que pone de manifiesto sus cercanas relaciones con la Administración Pública y sus altos directivos. Esta proximidad quedó particularmente evidente en el caso de Rio de Janeiro, donde las compañías controlaron, directamente o a través de subsidiarias, las veinte principales obras públicas en mencionado Estado y Municipio.

Se destacan, en este caso, las obras para la construcción del arco vial metropolitano, la construcción del Bus Rapid Transit System de las Avenidas Transolímpica y Transcarioca, la construcción de un trolebús en la región central y la reurbanización de la región portuaria de la ciudad de Rio de Janeiro, más allá de la edificación de equipamientos olímpicos como el Parque Olímpico de Barra de la Tijuca y la reforma de los estadios João Avelange y Maracanã.

Históricamente, las relaciones entre estas compañías y el Estado comenzaron aún en los años 1970, durante el régimen militar, y se mantuvieron en los años subsecuentes tras la redemocratización del país. A mediados de los años 1980, las constructoras trataron de financiar las campañas políticas de presidentes, Gobernadores, alcaldes y Parlamentarios a modo de garantizar la perfección de contratos con los entes públicos y las instituciones que ellos controlaban.

Asimismo, una vez habían concluido los negocios (o incluso antes que ello pasara), solían pagar comisiones a los altos directivos y funcionarios de la Administración Pública con objeto de mantener sus buenas relaciones con las autoridades y asegurar la conclusión de futuros contratos con el Estado y sus empresas. Las comisiones pagadas a causa de cada negocio fueron muy elevadas en el caso del Estado de Rio de Janeiro, debido al gran volumen de las inversiones públicas realizadas con motivo de los Juegos Olímpicos.

A modo de evitar que otras sociedades lograran el derecho de perfeccionar contratos con la Administración Pública, estas compañías trataron de formar carteles con el objetivo de participar en las licitaciones. En este sentido, se comprometieron en fijar precios, condiciones, ventajas y abstenciones. Asimismo, se dispusieron a dividir el mercado, reunir proyectos de ingeniería bajo una única propuesta, organizarse en consorcios y subcontratar el objeto de la licitación para que todos ganaran con las obras.

Antes que comenzaran las licitaciones, formaron un grupo de trabajo que, en secreto, busco interferir en la elaboración de las condiciones. Las compañías sabían que 
los pliegos constituyen uno de los elementos más importantes de la licitación. Con base en sus elementos, la Administración podía fomentar o restringir la participación de los interesados, por lo que controlar su elaboración significaba, por tanto, controlar la propia licitación.

Con la finalidad de que esto pasara, las constructoras trataron de reunirse para establecer exigencias técnicas que dificultaran la participación de sociedades que no formaban parte del esquema. Incluso antes que las licitaciones iniciaran, todos sabían con antelación quienes vencerían las disputas y qué obras estarían a cargo de cada una de las empresas participantes. El sigilo de esas actuaciones, en este caso, fue fundamental para que los altos directivos del Estado y las constructoras realizaran los acuerdos, y además, pudieran llevar en adelante el modelo de gestión implementado en los contratos del sector de la sanidad.

En el ámbito jurídico, llama la atención la conducta de los responsables de las malas prácticas en cada uno de estos casos. Considerando la magnitud de los proyectos, los implicados trataron de dividir el objeto del contrato en parcelas, realizar varias licitaciones y permitir la formación de consorcios privados para la ejecución de cada obra. Técnicamente, los pliegos estaban realizados conforme a derecho y a las normas de la buena gestión pública. El fraccionamiento del objeto y la participación de consorcios privados fomentaron la presencia de un mayor número de interesados, y asimismo, estaba en armonía con la jurisprudencia del Tribunal de Cuentas de la Unión y del Tribunal Superior de Justicia.

Las restricciones incorporadas a los pliegos contravinieron este hecho. Pese a que en la teoría se defendía que cualquier entidad podía participar de las licitaciones, en realidad, no todas lograron hacerlo, ya que fueron eliminadas de las disputas a causa de las exigencias fijadas en los pliegos. Con base en estas exigencias, las grandes constructoras conquistaron el derecho a realizar las principales obras de infraestructura asociadas a las Olimpíadas Rio 2016. Entre las que se destacan la construcción del arco vial metropolitano, la modernización del estadio de Maracaná y la urbanización de tres grandes conjuntos de favelas ubicadas en la ciudad de Rio de Janeiro.

Las malas prácticas del Gobernador Sergio Cabral y su grupo no agotaron el universo de irregularidades asociadas a la realización de los Juegos Olímpicos Rio 2016. Los ilícitos cometidos en la gestión estatal llegaron rápidamente al Municipio de Rio de 
Janeiro donde se concentraron en la Secretaría de Obras del referido ente político, en aquel entonces dirigida por Alexandre Pinto da Silva. Se repitió en la referida secretaría el gran esquema de fraude a las licitaciones con la inclusión de exigencias técnicas en los pliegos que acabaron con impedir que entidades ajenas al grupo de constructoras anteriormente mencionadas pudiera perfeccionar contrato con la Administración.

A modo de viabilizar el pago de la ventaja indebida asociada a estas obras, muchas compañías utilizaron la simulación como instrumento para dar viabilidad a la perfección de contratos ficticios con otras sociedades no directamente involucradas con la preparación del mega evento. Con arreglo a estos negocios, lograron justificar determinadas operaciones contables en el ámbito de la propia entidad y pudieron transferir recursos de una a otra persona, como consecuencia de la previa comisión de actos de corrupción. La simulación sirvió, en este caso, como instrumento para la mentira, la falsedad y el engaño.

En todos los casos, las irregularidades fueron posibles debido a una de las principales debilidades del régimen brasileño de transparencia que no considera a los contratistas de la Administración Pública como sujetos obligados a ese deber. Esta omisión legislativa es responsable de crear espacios de oscuridad que permiten a estas personas moverse libremente en el tráfico jurídico, lo que acaba con posibilitar que cierren contratos ficticios apenas con objetivo de viabilizar la comisión de actos de corrupción.

Finalmente, para asegurar que la información de los actos y decisiones de la Administración Pública llegara a la ciudadanía, la ley brasileña n.12.527, de 18 de noviembre de 2011, de Transparencia y Acceso a la Información, dio a la Contraloría General de la Unión el protagonismo referente a la defensa del patrimonio público y el incremento de la transparencia. En este sentido, la contraloría debe realizar actividades para favorecer el control interno, la auditoría pública, la corrección, la prevención y el combate de la corrupción.

Pese a estas atribuciones, ni la Contraloría General de la Unión, ni los órganos de control interno tanto del Estado como del Municipio de Rio de Janeiro lograron prevenir las malas prácticas asociadas a la preparación de los Juegos Olímpicos Rio 2016. No quiere decir esto que las irregularidades quedaron sin la debida respuesta de las instituciones brasileñas, pues si fue dada por el derecho penal, pero ni el derecho 
administrativo ni la transparencia gubernamental dieron respuestas, siendo esto resultado de las debilidades de la referida Ley para prevenir la corrupción asociada a la contratación pública, en especial a lo concerniente a los mega eventos deportivos.

En efecto, para que la transparencia cumpla con su objetivo, es importante que las normas que establecen su régimen jurídico posibiliten una efectiva rendición de cuentas de los gobernantes frente a los gobernados, lo que depende de la eliminación de espacios de oscuridad que a veces suele identificarse en las normativas que tratan de este asunto. Erradicar estos agujeros, además de dar viabilidad a la claridad de los actos oficiales, favorece al diálogo entre la Administración y la sociedad, ${ }^{1085}$ lo que contribuye a la prevención de la corrupción, principalmente cuando asociada a los mega eventos deportivos internacionales.

La eliminación de estas debilidades depende, en el caso brasileño, de alteraciones en la Ley de Transparencia y Acceso a la Información, a modo de incorporarle materias que le permitan cumplir con su papel en la sociedad. Considerando todo lo dicho, sugerimos las siguientes alteraciones en la Ley de Transparencia y Acceso a la Información de Brasil:

1) La inclusión de un dispositivo que reconozca como obligatoria la divulgación de las agendas de los altos cargos de la Administración Pública, lo que, en el caso de existir, permitiría a los ciudadanos tomar conocimiento de las reuniones de que participaron los altos directivos del Estado y las influencias a las que estuvieron sometidos antes que decidieran ciertas cuestiones.

2) Asimismo, defendemos que la alteración no debe limitarse a establecer la obligatoriedad de divulgación de las agendas, sino que debe avanzar en estos asuntos y fijar un contenido mínimo de las materias que serán informaciones transparentes, con lo cual buscamos retirar de los altos cargos de algunas unidades políticas locales amplia discrecionalidad para elegir los asuntos objeto de divulgación en cada caso.

3) Las agendas deberán informar sobre los actos públicos, solemnidades, conmemoraciones, comidas, viajes y reuniones en las que participen los altos cargos tanto presenciales como en otros formatos electrónicos o a distancia, destacando sobre todo las

${ }^{1085}$ HERRERA, ob. Cit., p. 168. 
realizadas con personas físicas o representantes de personas jurídicas ajenas a la administración.

4) Teniendo en cuenta la posibilidad de que algunas de estas reuniones sucedan en el ámbito de las relaciones particulares, consideramos oportuno, también, incluir en la Ley la obligatoriedad de divulgación de las agendas privadas de los titulares de altos cargos del Estado, tales como el Presidente de la República, el Presidente de Gobierno, los Presidentes de las Casas Legislativas, los Presidentes de los Tribunales y de las Cortes de Cuentas, los Jefes de los Ministerios Públicos y los Presidentes de las sociedades controladas por el Estado.

5) Asimismo, defendemos la ampliación de los sujetos obligados al deber de transparencia al objeto de incluir entre estas figuras los adjudicatarios de contratos con el sector público, como los concesionarios y permisionarios de servicios públicos y las compañías responsables de la ejecución de obras públicas.

6) Entendemos que el deber de informar resulta, en este caso, de la naturaleza de las actividades desarrolladas (como sucede con los concesionarios y permisionarios) y de la naturaleza de los recursos invertidos (como pasa en el caso de las obras públicas).

Justificamos la medida con base a las ideas que, hoy por hoy, enmarcan la prevención y la lucha contra la corrupción en todo el planeta. Si bien la prevención de la corrupción tradicionalmente estuvo concentrada sobre la actuación de los órganos y entidades del sector público, tampoco es un error reconocer que el sector privado juega un papel relevante en esta materia, toda vez que, sin su participación, muchas de estas malas prácticas no llegarían siquiera a concretarse.

7) Opinamos que la Ley brasileña, aparte de exaltar la claridad, la exactitud y la precisión de la información como una calidad de los mensajes divulgados, debe considerar la posibilidad de que las comunicaciones de naturaleza técnica estén acompañadas de un informe en lenguaje sencillo que permita a los ciudadanos entenderla, importando poco su formación profesional.

8) Aparte de clarificar el contenido de las cláusulas de naturaleza técnica, también con base al principio de máxima divulgación, consideramos oportuno que la Administración Pública proceda a la divulgación de un listado con los nombres de los licitadores que no lograron perfeccionar el contrato con el sector público en cada caso. 
La medida se destina a permitir el control ciudadano en cuanto a futuras subcontrataciones concernientes al mismo objeto, lo que puede indicar la existencia de rotaciones entre empresas a modo de dividir el mercado de obras, servicios o suministro para el sector público.

9) Consideramos oportuno incorporar entre las competencias de las Contralorías Generales la obligatoriedad de que publiquen, anualmente, a través de páginas web o cualquier otro medio, la lista de las entidades involucradas en casos de corrupción, con expresa referencia a los valores destinados, la finalidad del proyecto y los recursos supuestamente desviados debido a las malas prácticas.

Justificamos la medida con base a los resultados positivos que la divulgación de listas negras viene alcanzando en el ámbito internacional, sobre todo debido a la labor de instituciones como Banco Mundial;

10) Finalmente, consideramos que la Ley de Transparencia y Acceso a la Información de Brasil debería prever las llamadas providencias administrativas cautelares, destinadas a asegurar la publicidad de los actos de la Administración en el supuesto de que uno esté dificultando su publicidad. La medida podría figurar entre las competencias de las Contralorías Generales, debido a su papel institucional en cuanto a la defensa de la transparencia gubernamental.

Esperamos con estas propuestas perfeccionar los instrumentos de prevención de la corrupción en Brasil, a modo de evitar que ella continúe a producir serias consecuencias políticas, económicas y sociales en todo el país y no apenas en la ciudad de Rio de Janeiro, la cual elegimos como objeto principal de esta investigación.

Esperamos, además, que, a partir de los cambios propuestos, los brasileños puedan fiarse de sus instituciones públicas, que se vean representados en ellas y no manifiesten la intención de buscar otros núcleos de poder en el tejido social.

Esperamos, también, que a partir de una Ley con estas características ya no existan tantos espacios de oscuridad en el seno de la Administración Pública que favorezcan a la 
desviación de fondos públicos y la disminución de las inversiones públicas en políticas de relevante interés colectivo. ${ }^{1086}$

Esperamos, finalmente, que las alteraciones presentadas sirvan para erradicar los llamados códigos paralelos de conducta que no están reglamentados en el orden jurídico, ${ }^{1087}$ pero que, poco a poco, se diseminan en el tejido social, convirtiéndose en una práctica común entre los ciudadanos.

${ }^{1086}$ RODRÍGUEZ GARCÍA, Nicolás. La Necesaria Flexibilización del Concepto de Soberanía en Pro del Control Judicial de la Corrupción. In: La Corrupción en un Mundo Globalizado: análisis interdisciplinar. Salamanca: Ratio Legis, 2004, p. 246.

${ }^{1087}$ GARCIA, Emerson. op. cit., p. 39. 


\section{FUENTES UTILIZADAS}

\section{Fuentes bibliográficas}

ACKERMAN, John M.; SANDOVAL, Irma. Leyes de acceso a la información en el mundo. In: Cuadernos de Transparencia, 7, IFAI, México, 2005, p. 20-47.

ALASDARI, Roberts. Blacked Out: Government Secrecy in the Information Age. Cambridge: Cambridge University Press, 2006.

ALEXY, Robert. Teoria dos Direitos Fundamentais. Tradução de Virgílio Afonso da Silva. São Paulo: Malheiros, 2008.

ALFARO, Luis Humberto Contreras. Corrupción y principio de oportunidad: alternativas en materia de prevención y castigo a la respuesta penal tradicional. Salamanca: Ratio Legis, 2005.

ALLEN, J. et al. Festival and special event management. Milton/Australia: John Wiley \& Sons Australia, 2002.

ARANDA ÁLVAREZ, Elviro. Una Reflexión sobre Transparencia y Buen Gobierno. In: Revista Cuadernos Manuel Giménez Abad, n. ${ }^{\circ}$ 5, Salamanca, 2013, p. 214-229. ISSNE 2254-445. Disponible en: https://dialnet.unirioja.es/servlet/articulo?codigo $=4347898$ Acceso en: 25 nov. 2019.

ARGANDOÑA, Antonio; BERENDSON, Ricardo Morel. La lucha contra la corrupción. Una perspectiva empresarial. In: Cadernos da Cátedra. IESE Universidad de Navarra, n. 04, julio de 2009. Disponible en: http://bibliotecavirtual.info/2012/03/la-lucha-contrala-corrupcion-una-perspectiva-empresarial/ Acceso en: 6 mar. 2014.

ASIA DEVELOPMENT BANK. Governance: Sound Development Management. Manila: ADB, 1995.

BARBASSA, Juliana. Brazil's Olympic Rollercoaster. In: ZIMBALIST, Andrew. Rio 2016: Olympic Myths, hard realities. Washington D.C.: Brounkings Institution Press, 2017, p. 37-57. 
BELISARIO, Adriano. As quatro irmãs In: Pública, 30 de jun. 2014. Disponible en: http://apublica.org/2014/06/as-quatro-irmas/.

BENALCÁZAR GUERRÓN, Juan Carlos. Participación ciudadana y control de la $\begin{array}{lllll}\text { corrupción. } & 2011, \quad \text { p. } & \text { Disponible }\end{array}$ http://derecho.posgrado.unam.mx/congresos/congreibero/ponencias/juancarlosbenalcaza r.pdf Acceso en: 17 jun. 2019.

BENEDICT, Burton. The Anthropology of World's Fairs: San Francisco's Panama Pacific International Exposition of 1915. Berkeley/CA: Lowie Museum of Anthropology, Shcolarpr editor, 1983.

BERNAL BLAY, Miguel Ángel. Los efectos de los programas de compliance en la contratación pública. In: GIMENO FELIÓ, José María. Observatorio de Contratos Públicos. Las nuevas directivas de contratación pública, Cizur Menor, Navarra, Arazandi, 2015.

BESNIER, Niko; BROWNELL Susan; CARTER, Thomas F. Antropología del deporte: Emociones, poder y negocios en el mundo contemporáneo. Traducción de Teresa Arijón . Buenos Aires: Siglo Veintiuno Editores, 2018.

BETIM, Felipe. La rutina de la violencia en rio perfora la burbuja olímpica. El País. 2016 . Disponible en: https://elpais.com/internacional/2016/08/08/actualidad/1470685327_182344.html Acceso en: 25 jun. 2019.

BIBLIA. Disponible en: https://biblia.com/books/lbla95/Jn1.1 . Acceso en: 6 mar. 2014. BICALHO, Alécia Paolucci Nogueira; MOTTA, Carlos Pinto Coelho. RDC Comentários ao Regime Diferenciado de Contratações: LEI N. 12.462/2011; DECRETO n. 7.581/2011. 2. ed. Belo Horizonte: Fórum: 2014.

BILLINGS, Stephen; HOLLADAY, Scott. Should Cities Go For The Gold? The LongTerm Impacts of Hosting The Olympics. In: Economic Inquiry, v. 50, n.3, 2011, p. 119. Disponible en:https://onlinelibrary.wiley.com/doi/10.1111/j.14657295.2011.00373.x Acceso en: 26 nov. 2019. 
BLANTON, Thomas S. The Global Openness Movement in 2006: 240 Years after the First Freedom of Information Law, Access to Government Information Now Seen as A Human Right. In: MUSTONEN, Juhan (ed.). The worls's First Freedon of information act: Anders Chydenius Legacy Today. Kokkola: Anders Chydenius Foundation, 2006, p. 80-97.

BNDES. BNDES e Prefeitura do Rio de Janeiro assinam contrato do BRT Transcarioca. Disponible en: https://www.bndes.gov.br/wps/portal/site/home/imprensa/noticias/conteudo/20110110 brt contrato Acceso en: 10 oct. 2019.

BOBBIO, Norberto. La democracia y el poder invisible. In: El futuro de la democracia. México: Fondo de Cultura Económica, 1986.

BOK, Sissela. Secrets on the Ethics of Concealment and Revelation. Nueva York: Vintage Books, 2011.

BONOLI, Paolo Bertucci. Análisis de la Correlación entre Corrupción y Deporte desde la Perspectiva Transdisciplinar. In: Revista Encuentros Multidisciplinares, v. 13, n. 39, 2011, p. 47-56. Disponible en: https://dialnet.unirioja.es/servlet/articulo?codigo=3778571. Acceso en: 02 jul. 2019.

BOSIO, Roberto. Roma 2024. Un Affare per Pochi. Roma: Amazon, 2016.

BOYKOFF, Jules. Power Games: A Political History of the Olympics. New York: Verso Editor, 2016.

BREWSTER, Claire; BREWSTER, Keith. Representing the Nation: Sport and Spectacle in Post-revolutionary Mexico. Newcastle: Routledge, 2013.

BROUDEHOUX, Anne-Marie. Mega-events and Urban Image Construction. Oxford: Routledge, 2017.

BUARQUE DE HOLLANDA, Bernardo Borges; MEDEIROS, Jimmy; Fonseca, Vivian. Políticas Públicas Esportivas no Brasil do Século XXI: da Candidatura Olímpica à Construção de um "Legado" para os Jogos Olímpicos Rio 2016. In: MARQUES, José 
Carlos; ROCCO JÚNIOR, Ary José. Leituras e Reflexões sobre os Jogos Olímpicos Rio-2016, São Paulo, Cultura Acadêmica: 2018, p. 37-66.

BUSTOS GISBERT, Rafael. Corrupción de los gobernantes, responsabilidad política y control parlamentario. In: Revista de Direito da UNED (RDUNED). Teoría y realidad constitucional, $\quad$ n. $\quad 19,2007 . \quad$ Disponible en: http://revistas.uned.es/index.php/TRC/article/view/6754 Acceso en: 8 mayo 2014.

CABRAL é eleito no Rio de Janeiro com maioria absoluta dos votos. O Globo. Disponible en: http://g1.globo.com/Noticias/Eleicoes/0,AA1330709-6302-775,00.html Acceso en: 16 oct. 2019.

CABRAL inaugura em Campo Grande a $18^{\text {a }}$ UPA do Rio. Jusbrasil. Disponible em: https://gov-rj.jusbrasil.com.br/noticias/148145/cabral-inaugura-em-campo-grande-a-18upa-do-rio Acceso en: 12 oct. 2019.

CALDAMI, Miguel Ángel Ciurio. Aspectos Filosóficos Etimológicos de la Buena Fe, En Tratado de la Buena Fe en Derecho, T.1. Buenos Aires: Buenos Aires Editorial, 2005 .

CANETTI, Elías. Masa y Poder. Madrid: Alianza, 1994.

CANOTILHO, José Joaquim Gomes; MOREIRA, Vital. Constituição da República portuguesa anotada. São Paulo: Revista dos Tribunais, 2007. v.1.

CAPDEFERRO VILLAGRASA, Oscar. Las Herramientas Inteligentes Anticorrupción: entre la aventura tecnológica y el orden jurídico", Revista General de Derecho Administrativo, núm. $50,2019 . \quad$ Disponible en: httpS://dialnet.unirioja.es/ejemplar/510997 Acceso en 11 nov 2019.

CAPELO, Rodrigo. Os bilhões de Dólares das Olimpíadas e das Copas. Revista Época. Disponible en: https://epoca.globo.com/vida/esporte/noticia/2016/06/os-bilhoes-dedolares-das-olimpiadas-e-das-copas.html, Acceso en: 12 oct. 2019.

CARDOSO, Tom. Se Não Fosse o Cabral: A máfia que destruiu o Rio e assalta o país. São Paulo: Tordesilhas, 2018. 
CARVAlHO FILHO, José dos Santos. Manual de Direito Administrativo. 33. ed. São Paulo, Atlas: 2019.

CASHMAN, R. (ed.) Connecting Mega Events Cities: A Publication for the $9^{\text {th }}$ World Congress of Metropolis. Sydney: Sydney Olympic Park Authority, 2008.

CERRILLO I MARTÍNEZ, Agustí. "Las compras abiertas y la prevención de la corrupción".

Disponible

en:

https://revistasonline.inap.es/index.php/GAPP/article/view/10314/10875 Acceso en:13 dic. 2019.

CHADE, Jamil Strictly Confidential: Access to Information and the Media in Rio. In: ZIMBALIST, Andrew. Rio 2016: Olympic Myths, hard realities, Washington D.C.: Brounkings Institution Press, 2017, p. 121-152.

CHÁIREZ, Cristian Jafet Montenegro. Progreso y Fortalecimiento de Derechos Fundamentales de Nueva Generación en el Estado de Durango: Transparencia y Protección de Datos Personales. In: Revista Científica De La Universidad Autónoma De Sinaloa. 2018. Disponible en: Kindle: www.amazon.es . Acceso en: 8 mayo 2014.

CHAPPLET, Jean-Loup. KUBLER-MABBOTT, Brenda. The International Olympic Committee and the Olympic System. The Governance of World Sport Global institutions. New York: Routledge Editor, 2008.

CIERVA, Yago de la (et al.). Mega eventos de la Iglesia Católica: Derrotero Para Organizadores y Comunicadores. Méjico/DF: Variopinto Comunicación Insurgentes, 2018.

COLOMBIA. Ley no. 1712. Ley de Transparencia y del derecho de acceso a la información de $06 \quad 2014 . \quad$ mar. http://www.anticorrupcion.gov.co/SiteAssets/Paginas/Publicaciones/ley-1712.pdf Acceso en: 8 jun. 2019

COMEÇAM Obras em Três Favelas do Rio. Carta Maior. Disponible en: http://cartamaior.com.br/?/Editoria/Politica/Comecam-obras-do-PAC-em-tre s-favelasdo-Rio- de- Janeiro/4/13767 . Acceso en: 24 sep. 2019. 
COMPARATO, Fábio Konder. Ética, Direito, Moral e Religião no mundo moderno. São Paulo: Companhia das letras, 2006.

. Controladoria Geral da União. CGU dá transparência aos investimentos federais nas Olimpíadas Rio 2016. Disponible em: https://www.cgu.gov.br/noticias/2015/08/cgu-da-transparencia-aos-investimentosfederais-nas-olimpiadas-rio-2016. Acceso en: 06 nov. 2019.

Controladoria Geral da União. CGU prepara portais sobre a Copa 2014 e as

Olimpíadas 2016. Disponible em: https://www.cgu.gov.br/noticias/2010/03/cguprepara-portais-sobre-a-copa-2014-e-a-olimpiadas-2016. Acceso en: 06 nov. 2019.

CORRÊA, Hudson. Sergio Cabral: o homem que queria ser rei. Rio de Janeiro: Primeira Pessoa, 2018.

CORRÊAS, Douglas. Prefeitura do Rio interdita Engenhão por problemas estruturais na cobertura.

EBC.

Disponible

em: http://www.ebc.com.br/noticias/brasil/2013/03/prefeitura-do-rio-interdita-engenhaopor-problemas-estruturais-na-cobertura Acceso en: 12 oct. 2017.

.Corrupción y principio de oportunidad: alternativas en materia de prevención y castigo a la respuesta penal tradicional. Salamanca: Ratio Legis, 2005, p. 141.

COSTA ANDRADE, Manuel da. Liberdade de Imprensa e Inviolabilidade Pessoal: Uma Perspectiva Jurídico-Criminal. Coimbra: Coimbra Editora, 1996.

COSTA JUNIOR, Paulo José Da. Comentários ao Código Penal. Parte Especial. São Paulo: Saraiva, 1988. v. 2.

COSTA, Lamartine Pereira da.; MIRAGAYA, Ana. Estado da Arte do Conhecimento sobre Legados de Megaeventos Esportivos no Exterior e no Brasil. In: COSTA, L. P. et al. (ed.). Legados de megaeventos esportivos. Brasília: Ministério do Esporte, 2008, p. $1-12$.

CTPL. Consejo de Transparencia Chile. ¿Qué es la transparencia activa? Disponible en:

http://www.chiletransparente.cl/wp- 
content/files_mf/1347391972manualfuncionariosleytransparencia.pdfAcceso en: 4 mayo 2019

DALARI, Dalmo de Abreu. Elementos de Teoria Geral do Estado. 27. ed. Sao Paulo: Saraiva, 2007.

DAVIS, J. Access to and Transmission of Information: Position of Media. In: DECKMYN, Veerle; THOMSON, Ian (ed.). Openness and Transparency in the European Union. Maastricht: European Institute of Public Administration, 1997, p. 121126.

DE LA FUENTE, Carlos et al. Las TIC en el Gobierno Abierto: Transparencia, Participación y Colaboración. Electrónica, Madrid: Fundación Telefónica y editorial Planeta, 2013, p. 3.

DE LA FUENTE, María Linacero. Derecho Civil I, Introducción al Derecho Civil, Derecho de la Persona, Derecho Subjetivo, Negocio Jurídico. Valencia: Tirante Lo Blanch, 2013,

DI PIETRO, Maria Sylvia Zanella. Direito Administrativo. 24. ed. São Paulo: Atlas, 2011 .

DIAS, Joelson; Campos, Sarah. Lineamentos Sobre a Lei de Acesso à Informação. In: VALIM, Rafael., MALHEIROS, Antônio Carlos.; BACARIA, Josephina. (coord.). In: Acesso à Informação Pública. Belo Horizonte: Fórum Editora, 2015, p. 47-89.

DIEGO, Manuel Sánchez De. El principio de transparencia y el derecho de acceso a la información pública. A vueltas con el Estado. [S.l: s.n.]. Ponencia presentada en el XII Congreso de Constitucionalistas de España "Participación, representación y Democracia", celebrado en la vieja Universidad de Salamanca el 3 y 4 de abril de 2014, p. 1-36. Disponible en: http://sanchezdediego.blogspot.com.es/ . Acceso en: 4 mayo 2019.

DOISTÚA, Roberto San Salvador del Valle. Políticas de Ocio. Cultura, Turismo, Deporte y Recreación, Bilbao: Universidad de Deusto, 2000, p. 29-30.

DONHA, E. L.; BONIN, A. P. C.; MOSKI, D. Pan-americano 2007 e Olimpíadas 2016: legados compatíveis, complementares ou divergentes? EFDeportes.com. Disponible em: 
https://www.efdeportes.com/efd154/pan-americano-2007-e-olimpiadas-2016legados.htm, Acceso en: 12 oct. 2007.

DORA, Octavio Tavares. Megaeventos Esportivos: Temas Polêmicos. Porto Alegre, v. 17 , n. $03, \quad$ p. 11-35, jul/set de 2011. Disponible em: http://www.pgedf.ufpr.br/Otavio\%20Tavares\%20DORA\%202.pdf Acceso en: 28/09/2018.

DROMI, Roberto. Derecho Administrativo, $10^{\mathrm{a}}$ ed., Buenos Aires - Madrid: Ciudad Argentina, 2004, p. 833.

DROMI, Roberto. Modernización del Control Público, Madrid: editorial Hispania Libros, 2014.

DWORKIN, Ronald. O direito da liberdade: a leitura moral da Constituição norteamericana. São Paulo: Martins Fontes, 2006.

EDICIONES, La Vanguardia. Historia de la corrupción. Disponible en: https://www.lavanguardia.com/estilos-de-vida/20120803/54331562523/historia-de-lacorrupcion.html Acceso en: 8 mar. 2019

ELIAS, Norbert; DUNNING, Eric. Deporte y Ocio en el Proceso de la Civilización. Traducción de Purificación Jiménez. México/DF: Fondo de Cultura Económica, 2015. Ebook.

ESCALANTE GONZALBO, Fernando. El Derecho a la privacidad, $6^{\text {a }}$ ed., México: Cuadernos de transparencia. 2008.

ESCALANTE, Fernando. "El Derecho a la Privacidad". In: Cuadernos De Transparencia. 2, IFAI, México: 2008. p. 8-15.

ESTADO Comete Genocídio com Descaso na Saúde. Estadão. Disponible en: https://brasil.estadao.com.br/noticias/geral,estado-comete-genocidio-com-descaso-nasaude-diz-cabral,20070103p14605, Acceso en: 16 oct. 2019.

ESTAVILLO, María Elena; MARTINEZ, Leonardo; ESCOBAR, Rebeca. Evaluación del Impacto Económico de la Ley Federal de Transparencia y Acceso a la FAZZIO 
JÚNIOR, Waldo. Atos de Improbidade Administrativa: Doutrina, Legislação e Jurisprudência. 2. ed. São Paulo: Atlas, 2008.

FERNÁNDEZ CONTRERAS, R. A. The route of friendship: a testimony to Mexico City's aesthetic modernity. Voices of Mexico, 82, 2008, p. 34-43.

FERNÁNDEZ RAMOS, Severiano. El derecho de acceso a los documentos administrativos. Madrid: Marcial Pons, 1997.

FERNÁNDEZ RAMOS, Severiano. La Transparencia Pública: Pasado, Presente y Futuro. In: Revista Aragonesa de Administración Pública, ISSN 2341-2135, n. ${ }^{\circ}$ 51, Zaragoza, 2018, p. 213-243.

FERNÁNDEZ RAMOS, Severiano; PÉREZ MONGUIÓ, José Maria. Transparencia, Acceso a la Información Pública y Buen Gobierno- Ley 19/2013 de 9 de diciembre. Navarra: Thomson Reuters Arazandi, 2014.

FERREIRA, João Sette Whitaker. Um Teatro Milionário. In: BOITEMPO Editorial y Carta Maior. Brasil em Jogo: o que fica da Copa e das Olimpíadas? São Paulo: Boitempo Editorial, 2014, p. 9-29.

FIORAVANTI, Maurizio. Los Derechos Fundamentales. Apuntes de la Historia de las Constituciones. Madrid: Trotta, 1996.

FLORES GIMÉNEZ, Fernando. "La Participación Democrática: Partidos Políticos, Sistemas Electorales y Participación Ciudadana”. In: FLORES GIMÉNEZ, Fernando. La Participación Política en Ecuador. (coord.). Tribunal Constitucional de la República del Ecuador. Instituto de Derecho Público Comparado de la Universidad Carlos III de Madrid, Comisión Europea, Quito, Corporación Editora Nacional, 2004, p. 21.

FUGUERAS, Ramón Alberch. Archivos: entender el pasado y construir el futuro. Barcelona: Editorial UOC, 2014.

FURTADO, Lucas Rocha. As Raízes da Corrupção no Brasil: Estudo de Casos e Lições para o Futuro. Belo Horizonte: Fórum, 2015.

FURTADO, Lucas Rocha. Curso de Direito Administrativo. 4. ed. Belo Horizonte: Editora Fórum, 2013. 
GALGANO, Francesco. Trattato di Diritto Civile. 3. ed. Milanofiori: Wolters Kluwer, 2015. v. 2.

GARCIA, Emerson. A Cultura da Sociedade Enquanto Fator de Contenção ou de Estímulo à Corrupção. In: AZAMBUJA, Edson; BALLAN JUNIOR, Octahydes; e OLIVEIRA E SILVA, Vinicius de. (org.). Combate à Corrupção na Visão do Ministério Público. Belo Horizonte: JH Mizuno, 2018, p. 36-66.

GASPARINI, Diógenes. Direito administrativo. 15. ed. São Paulo: Saraiva, 2011.

GENRO do ex-deputado federal Pedro Corrêa é preso em nova fase da Lava Jato em Pernambuco. O Globo. Disponible en: https://g1.globo.com/pernambuco/noticia/genrodo-ex-deputado-federal-pedro-correa-e-preso-em-nova-fase-da-lava-jato-empernambuco.ghtml Acceso en: 10 oct. 2019.

GIL VILLA, Fernando. La Cultura de la Corrupción. Madrid: Maia Ediciones, 2008.

GIMENO FELIÓ, José María, La Nueva Regulación, de la Contratación Pública. In GIMENO FELIÓ, José María. Estudio Sistemático de la Nueva Ley de Contratos del Sector Público, Cizur Menor, Pamplona, Aranzandi, 2018, p. 130.

GIMENO FELIÓ, José María. "Reglas para la prevención de la corrupción en la contratación pública". In: Observatorio de Contratación Pública, V Seminario de contratación pública, Formigal (Huesca), septiembre de 2014, p. 37-38. Disponible en: https://contratodeobras.com/2014/09/bibliografia-documentacion-del-v-seminario-decontratos-publicos-formigal-2014/, Acceso en: 28 nov 2019.

GOLD, John R. Gold, Margaret M. Olympic Cities: City Agendas, Planning and the World's Games, 1896-2020. Routledge, Oxford: 2016,

GOLDBLATT, David. The Games: A Global History of The Olympics. London: Pan Macmillan, 2016.

GONÇALVES, Carlos Roberto. Direito Civil Esquematizado. São Paulo: Saraiva, 2011. 
GROHMANN, K. Hamburg beats Berlin to become Germany's 2024 Games bid. Disponible en: $\quad$ http://www.reuters.com/article/us-olympics-2024-germanyidUSKBN0MC23E20150316 Acceso en: 23 ago 2019.

GUICHOT, Emilio et al. Transparencia, Acceso a la Información Pública y Buen Gobierno. Madrid: Tecnos, 2014.

GUICHOT, Emilio. Derecho de acceso a la información: experiencias regionales y estatales en Europa y América. Derecho Comparado de la Información, n. 19, 2012. Disponible en: http://dialnet.unirioja.es/servlet/articulo?codigo=4279291 Acceso en: 9 jun. 2014.

HARVEY, David. A produção capitalista do espaço. 2. ed. São Paulo: Annablume, 2005.

HAWTHORNE, F.H.; PRICE, R. The Soulless Stadium: A Memoir of London's White City, 3-2 Books, Upminster: 2001, p. 7.

HAYES, Graeme; HORNE, John. Sustainable Development: Shock and Awe? London 2012 and civil Society. Sociology, 45(5), 2011, p. 749-764.

HEALD, David. Varieties of Transparency. In: HOOD, Christopher Hood; HEALD, David (ed.). Transparency: The Key to Better Governance? Oxford: Oxford University Press, 2006.

HEATHER. L. Reid, Afterword: "Olympic Philosophy between East and West", In: BROWNELL, Susan (comp.). From Athens to Beijing. West Meets East In the Olympic Games. Sport, the Body and Humanism in Ancient Greece and China, Nueva York, Greekworks, 2013. v. 1.

HERRERA, Manuel Palomares. Transparencia y acceso a la información en el sector público. Madrid: Wolters Kluwer, 2018.

HOLT, Richard; MASON, Tony. Sport in Britain, 1945-2000. Oxford: Blackwell 2000. HORNBUCKLE, A. R. Helsinki. 1952: the Games of the 15th Olympiad, in FINDLING, J.E; PELLE, K.D. (ed.). Historical Dictionary of the Modern Olympic Movement. Westport, CN: Greenwood Press, 1996, p. 109-118. 
HORNE, J; MANZENREITER, W. An introduction to the sociology of sports megaevents. In: HORNE, J; MANZENREITER, W. (ed.). Sports Mega-Events: Social Scientific Analyses of a Global Phenomenon. Special Issue: The Sociological Review Monograph Series, Issue Supplement s2, December 2006. v. 54.

HORNE, John; WHANNEL, Garry. Understanding the Olympics. 2. ed, New York: Routledge, 2016.

HUANG, Hai-Yan et. al. Social exchange process in collectivistic countries: an examination of sporting events in China. In: European Sport Management Quarterly, v. 16, n. 2, 2016.

HUNGRIA, Nélson. Comentários ao Código penal. Dec.-lei n. 2.848, de 7 de dezembro de 1940. Rio de Janeiro: Forense, 1958. v. 9

IBARRA PALAFOX, Francisco. "Corrupción y poderes privados". In: SALAZAR, Pedro., IBARRA PALAFOX, Francisco. FLORES, imer B. ?Cómo combatir la corrupción?, Universidad Nacional Autónoma de México, 2017, p. 187 y ss. Disponible en: https://archivos.juridicas.unam.mx/www/bjv/libros/9/4315/27.pdf Acceso en 30 nov. 2019.

JENNINGS, Andrew. A Máfia dos Esportes e o Capitalismo Global. In: Boitempo Editorial y Carta Maior. Brasil em Jogo: o que fica da Copa e das Olimpíadas? São Paulo: Boitempo Editorial, 2014, p. 101-114.

JONES, Magie; STOKES, Terry. The Commonwealth Games and urban regeneration: an investigation into training initiatives and partnerships and their effects on disadvantaged groups in East Manchester. In: Managing Leisure, v. 8, n. 4, 2003.

JUSTEN FILHO, Marçal. Comentários à Lei de Licitações e Contratos Administrativos. Rio de Janeiro: AIDE: 1993.

KANT, Immanuel. Sobre La Paz Perpetua. Madrid: AKAl, 2012.

KAPLANIDOU, Kiki; KARADAKIS, Kostas. Understanding the legacies of a host Olympic city: the case of the 2010 Vancouver Olympic Games. In: SPORT MARKETING QUARTERLY, v. 19, p. 110-117, 2010. 
KILLANIN, Lord. My Olympic Years. London: Martin Secker and Warburg, 1983.

LAFER, Celso. A Reconstrução dos Direitos Humanos: um diálogo com o pensamento de Hannah Arendt. São Paulo: Companhia das Letras, 2006.

LEFF, N. Economic Development trough Bureaucratic Corruption. VV.AA. Political Corruption. New Jersey,1989, p. 389 y ss. In ALFARO, Luis Humberto Contreras.

LÔBO, Paulo. Direito Civil: Contratos. 5. ed., São Paulo: Saraiva, 2019. v. 3.

LOPES SILVA, Lucilia; TORRES, Alcidio. O Combate contra a corrupção e pela promoção da ética em Portugal e no Brasil. Portugal: Chiado/Bookess, 2013.

LOPES, José Mouraz. O espectro da corrupção. Coimbra: Almedina, 2011.

LOPES, Marilia.CABRAL inaugura $14^{\mathrm{a}}$ UPP do RJ no Engenho Novo. Estadão.

Disponible em: https://www.estadao.com.br/noticias/geral,sergio-cabral-inaugura-14upp-do-rj-no-engenho-novo,673355, Acceso en: 12 oct. 2019.

LOPEZ GUERRA, Luís (org.). Derecho constitucional. 9. ed. Valencia: Tirant lo Blanch, 2013.

LORENZO Susana. Sanciones Administrativas, Montevideo: Julio Cesar Faíra Editor, 1996, p. 5-6.

LULA é o cara diz Obama em reunião do G-20 em Londres. O Globo. Disponible em: http://g1.globo.com/Noticias/Economia_Negocios/0,MUL1070378-9356,00-

$\underline{\mathrm{LULA}+\mathrm{E}+\mathrm{O}+\mathrm{CARA}+\mathrm{DIZ}+\mathrm{OBAMA}+\mathrm{DURANTE}+\mathrm{REUNIAO}+\mathrm{DO}+\mathrm{G}+\mathrm{EM}+\mathrm{LONDRE}}$

S.html, Acceso en: 24 jun. 2019.

MANGAN, J.A. Prologue guarantees of global goodwill: post-Olympic legacies - too many limping white elephants, International Journal of the History of Sport, 25(14), 2008. p. 1869-83.

MARALET, Elisenda. El Nuevo Reto de la Contratación Pública para Afianzar la Integridad y el Control: reforzar el profesionalismo y la transparencia. Revista Digital de Derecho Administrativo, núm. 15, 2016, p. 21-60. ISSN-E 2145-2946. Disponible en: http://dx.doi.org/10.18601/21452946.n15.04 Acceso en 12 nov. 2019. 
MARICATO, Ermínia. A Copa do Mundo no Brasil: tsunami de capitais aprofunda a desigualdade urbana. In: Boitempo Editorial y Carta Maior. Brasil em Jogo: o que fica da Copa e das Olimpíadas? São Paulo: Boitempo Editorial, 2014.

MARTIN, A. Timothy. "The Developmente of International Bribery Law". Natural Resources Environment. Nueva Jersey, American Bar Association, 1999, vol. 14, núm. 2, p. 101. Disponible en: https://www.jstor.org/stable/40924392 Acceso en 12 nov. 2019.

MARTINS, Humberto. Lei da Transparência e sua Aplicação na Administração Pública: Valores, Direito e Tecnologia em Evolução. Superior Tribunal de Justiça (STJ), $\mathrm{s} / \mathrm{d}$. Disponible em: http://www.stj.jus.br/internet_docs/ministros/Discursos/0001182/LEI\%20DA\%20TRA NSPAR $\%$ C3 $\% 8$ ANCIA $\% 20 \mathrm{E} \% 20$ SUA $\% 20$ APLICA $\% \mathrm{C} 3 \% 87 \% \mathrm{C} 3 \% 83 \mathrm{O} \% 20 \mathrm{NA} \% 20$ ADMINISTRA $\% \mathrm{C} 3 \% 87 \% \mathrm{C3} \% 83 \mathrm{O} \% 20 \mathrm{P} \% \mathrm{C} 3 \% 9 \mathrm{ABLICA} \% 20$ VALORES, $\% 20 \mathrm{DIREI}$ TO\%20E\%20TECNOLOGIA\%20EM\%20EVOLU\%C3\%87\%C3\%830.pdf Acceso em: 10 en. 2019.

MARTINS, Ricardo Marcondes. Restrições ao Acesso à Informação. In: VALIM, Rafael; MALHEIROS, Antônio Carlos; BACARIA, Josephina. Acesso à Informação Pública. Belo Horizonte: Fórum Editora, 2015. p. 111-134.

MASCARENHAS, Gilmar. Cidade mercadoria, cidade-vitrine, cidade turística: a espetacularização do urbano nos megaeventos esportivos. Caderno Virtual de Turismo, v. $14, \quad$ n. 1, nov. 2014, p. 52-53. Disponible en: http://www.redalyc.org/articulo.oa?id=115437784005 Acceso en: 13 mayo 2018.

MAZZEI, Leandro Carlos. E para o Esporte Brasileiro, Existe Luz no Fim do Túnel? Reflexões pós Jogos Olímpicos do Rio de Janeiro 2016. In: MARQUES, José Carlos; ROCCO JÚNIOR, Ary José. Leituras e Reflexões sobre os Jogos Olímpicos Rio-2016. São Paulo: Cultura Acadêmica, 2018.

MEDEIROS, Carolina. Trégua Olímpica: Da Antiguidade Aos Dias de Hoje. Revista Pré-Univesp, n. 61, UNIVERSO, dezembro 2016, janeiro 2017, p. 1-14. Disponible en http://pre.univesp.br/tregua-olimpica\#.WzO27haHvYU Acceso en: 10 en. 2019

MEDINA OSÓRIO, Fábio. Direito Administrativo Sancionador, São Paulo: Revista dos Tribunais, 2000, p. 211. 
MELlo, Celso Antônio Bandeira de. Curso de Direito Administrativo. 21.ed. São Paulo: Malheiros Editores, 2006.

MELLO, Celso Antônio Bandeira de. Curso de Direito Administrativo, 26 a ed., São Paulo: Malheiros, 2009.

MENDEL, Toby. Right to Transparency Index, Rating Data Analysis Series: Overview of Results and Trends. Centre for Law and Democracy Access Info Europe. 2013, p. 1-16. Disponible en: http://www.law-democracy.org/live/wpcontent/uploads/2013/09/Report-1.13.09.Overview-of-RTI-Rating.pdf $\quad$ Acceso en: 26. nov. 2019

MENDES, Gilmar Ferreira. MÁRTIRES COELHO, Inocêncio. GONET BRANCO, Paulo Gustavo. Curso de Direito Constitucional. 4. ed. São Paulo: Saraiva, 2009.

MERINO, Mauricio. El Desafío de la Transparencia. Una Revisión de las Normas de Acceso a la Información Pública en las Entidades Federativas de México. In: ELIZONDO, Carlos et al. Democracia y Transparencia. IEDF, México, 2005.

MICHENER, Greg. FOIA: Laws around the World. In: JOURNAL OF DEMOCRACY, 2011, p. 145-159.

MINISTÉRIO PÚBLICO. Ministério Público Federal denuncia Operação Calicute Disponible em $\quad: \quad$ http://www.mpf.mp.br/rj/sala-de-imprensa/docs/prrj/Denuncia_ALEX\%20SARDINHA_Redigido.pdf/ Acceso em: 23 sept. 2019. - Ministério dos Esportes. Cadernos de legado Rio 2016 reafirmam compromisso olímpico do Brasil. Brasília, DF: Ministério dos Esportes. Disponible en: http://www2.esporte.gov.br/snear/rio2016/. Acceso en: 06 nov. 2019.

. Ministério Público Federal. Denuncia Operação Calicute. Procuradoria da República no Estado do Rio de Janeiro. Disponible em : http://www.mpf.mp.br/rj/salade-imprensa/docs/pr-rj/Denuncia_ALEX\%20SARDINHA_Redigido.pdf/ Acceso en: 23 sept. 2019.

MIRANZO DÍAZ, Javier. La Prevención de la Corrupción en la Contratación Pública. Madrid: Wolterskluver, 2019. 
MONTERO CARO, María Dolores. La regulación del acceso a la información en la unión europea. Universidad de Córdoba, 2018, p. 1-12. Disponible en: www.europarl.europa.eu Acceso en: 30 nov. 2019.

MORAES, Alexandre de. Direito Constitucional. 35. ed. São Paulo: Atlas 2019.

MORANDINI, Federico. "Acceso a la Información Pública en las contrataciones públicas". In RODRIGUEZ ARANA, Jaime. Contrataciones en el marco de los derechos sociales fundamentales, Madrid, INAP, 2017, p. 272-273.

MOTTA, Fabricio. Notas Sobre Publicidade e Transparência na Lei de Responsabilidade Fiscal. Revista Eletrônica de Direito do Estado, Salvador, Bahia, n. 14, p. 2-3, abriljunho de 2008.

NETTO, Vladimir; PARREIRA, Marcelo. Em Acordo de Leniência Empreiteira Revela Cartel Para Fraudar Obras no Rio. O Globo, nov. 30, 2016. Disponible em: http://g1.globo.com/economia/noticia/2016/11/em-acordo-de-leniencia-empreiteirarevela-cartel-para-fraudar-obras-no-rio.html Acceso en: 30 nov. 2019.

NEUMAN, Laura. Enforcement Models content and Context. Banco Mundial, 2009. Disponible em: http://siteresources.worldbank.org/EXTGOVACC/Resources/LNEumanATI.pdf. Acceso em: 8 jun. 2019.

NEVADO-BATALLA MORENO, Pedro T. Cumplimento de la Legalidad en la Nueva Gestión Pública: propuestas y realidad en la lucha contra la corrupción. In: La Corrupción en un Mundo Globalizado: análisis interdisciplinar. Salamanca: Ratio Legis, 2004, p. 87107.

NIEBOHR, Joel de Menezes, Licitações e Contratos Administrativos, $3^{\mathrm{a}}$ ed., Belo Horizonte, Fórum, 2013, p. 57.

OAS. Organización de los Estados Americanos: Democracia para la paz, la seguridad y el desarrollo. Disponible en: http://www.oas.org/es/sla/ddi/acceso_informacion_ley_modelo_. Acesso em 10 enero 2019. 
ODONNELL, Guillermo. Horizontal Accountability: The Legal institutionalization of mistrust. In: MAINWARING, Scott; WELNA, Christopher (coords.). Democratic Accountability in Latin America. Oxford: Oxford University Press, 2003, p. 34-54.

ODONNELL, Guillermo. Horizontal Accountability: The Legal institutionalization of mistrust. In: MAINWARING, Scott; WELNA, Christopher (coord.). Democratic Accountability in Latin America. Oxford: Oxford University Press, 2003.

OEA - Organización de los Estados Americanos: Democracia para la paz, la seguridad $\mathbf{y}$ el desarrollo. Disponible en: http://www.oas.org/es/sla/ddi/acceso_informacion_ley_modelo.asp Acesso em: 8 jun. 2014c.

OEA. Organización de los Estados Americanos: Democracia para la paz, la $\begin{array}{lllll}\text { seguridad } & \mathbf{y} & \text { el desarrollo. } & \text { Disponible }\end{array}$ http://www.oas.org/es/sla/ddi/acceso informacion ley modelo.asp, Acceso en: 8 jun. 2019.

OLIVEIRA, Edmundo. Crimes de corrupção. Rio de Janeiro: Forense, 1991.

OLIVEIRA, Nelma Gusmão de. Jogo Espetáculo, Jogo Negócio. In Boitempo Editorial y Carta Maior. Brasil em Jogo: o que fica da Copa e das Olimpíadas? São Paulo: Boitempo Editorial, 2014, p. 56.

OLIVEIRA, Nelma Gusmão de. O Poder dos Jogos e os Jogos de Poder: os interesses em campo na produção de uma cidade para o espetáculo esportivo. Tese apresentada ao Curso de Doutorado do Programa de Pós-Graduação em Planejamento Urbano e Regional da Universidade Federal do Rio de Janeiro - UFRJ. Rio de Janeiro: 2012.

OLYMPIC CHARTER 2007, p. 73-74. Disponible en: http://www.olympic.org/olympicstudies-center-collections-official-publications-olympic-charters. Acceso en: 25 jul. 2018 .

OTÁVIO, Chico; BIASETTO, Daniel. Rei Arthur confirma compra de votos para escolha do Rio nos Jogos Olímpicos de 2016. O Globo. Disponible em: https://oglobo.globo.com/brasil/rei-arthur-confirma-compra-de-votos-para-escolha-dorio-nos-jogos-olimpicos-de-2016-1- 


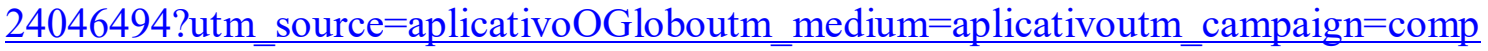
artilhar, Acceso en: 31 out 2019.

PAU I VALL, Francesc. La transparencia desde el Parlamento. XXI Jornadas de la Asociación Española de Letrados de Parlamentos. Madrid: Tecnos, 2015.

PAYNE, Michael. A Virada Olímpica: Como os Jogos Olímpicos Tornaram-se a Marca Mais Valorizada no Mundo. Rio de Janeiro: Casa da Palavra, 2006.

PAZZAGLINI FILHO, Marino. ELIAS ROSA, Marcio Fernando. FAZZIO JÚNIOR, Waldo. Improbidade Administrativa: Aspectos Jurídicos da Defesa do Patrimônio Público. $2^{a}$ ed., São Paulo: Atlas, 1997, p. 37-38.

PAZZI Jr, M. Rio é escolhido como cidade-sede de Olimpíada de 2016. Estadão. Disponible en: https://esportes.estadao.com.br/noticias/geral,rio-e-escolhido-comocidade-sede-da-olimpiada-de-2016,444804 Acceso en: 24 jun. 2019.

PEIRONE, F. Competing Anti-Corruption Strategies for Ensuring Integrity in Public Contracts: U.S. and EU systems compared Procurement Law Journal, n. ${ }^{\circ}$ 1, 23, 2017, p. 23-39. Disponible en: Peirone, F. (2017). Competing Anti-Corruption Strategies for ensuring Integrity in: Public Contracts: U.S. and EU systems compared. Procurement Law Journal, 23-39. Acceso en 12 dic. 2019.

PEREIRA, Caio Mário da Silva. Instituições de Direito Civil. 22. ed. Rio de Janeiro: Forense, 2018.

PÉREZ GUEVARA, Martín. Bases Normativas del Control Jurisdiccional de los Poderes Públicos en Venezuela. Instituto de Derecho Público, Facultad de Ciencias Jurídicas y Políticas, Universidad Central de Venezuela. Caracas: Imprenta Universitaria, 1979.

PÉREZ, Iván Mera. Los Juegos Olímpicos de la Era Antigua en Grecia, La Carrera de Filípedes en el año 490 a.C. y la Batalla de Maratón. Charleston, South Carolina/Estados Unidos: José Millariega Editor, 2014.

PÉREZ, Jesús González. El Principio General de Buena Fe en el Derecho Administrativo. 3. ed. Madrid: Civitas, 1999. 
PESCHARD, Jacqueline. Transparencia: Promesas y Desafíos (Grandes Problemas). Ciudad de México: El Colegio de México, 2018.

PIÑAR MAÑAS, José Luis. Transparencia y Protección de Datos: las claves de un equilibrio necesario. In: GARCÍA MACHO, R. Derecho administrativo de la información y administración transparente. Madrid: Marcial Pons, 2010.

PISANI, Silvia. Brasil ya es la octava economía mundial. La Nación. Disponible en : https://www.lanacion.com.ar/el-mundo/brasil-ya-es-la-octava-economia-mundialnid1312483 Acceso en: 24 jun 2019.

POLÍZIO JÚNIOR, Wladimir. Lei de Acesso à Informação, Manual Teórico e Prático. Curitiba: Juruá, 2015.

POMED SÁNCHEZ, Luis Alberto. El derecho de acceso de los ciudadanos a los archivos y registros administrativos. Madrid: Ministério de Administraciones Públicas, 1989.

PORTUGAL. Decreto Lei No. 47344. Código Civil, 25 nov. 1966. Disponible en: https://diario.vlex.pt/vid/decreto-lei-novembro-33046705 Acceso en: 13 des 2019

PRESGRAVE, Ana Beatriz F. Rebello, COSTA, Daniel. e CAVALCANTI, Francisco Ivo Dantas. O Poder Invisível e a Democracia Representativa na Visão de Norberto Bobbio. Revista Interface. Natal/RN, v. 10, n. 1, 2013, p. 103-121.

PREUSS, Holger; SOLBERG, Harry. Attracting Major Sporting Events: The Role of Local Residents. In: EUROPEAN SPORT MANAGEMENT QUARTERLY, v. 06, n. 04, 2006.

PRIMEROS Juegos Olímpicos Modernos: de Grecia a Rio. El País. Disponible en: https://elpais.com/deportes/2016/04/06/actualidad/1459929798_239239.html Acceso en: 24 jun. 2019.

PROGRAMA de Recuperação de Bacia de Jacarepaguá avança de forma lenta. O Globo. Disponible en: https://oglobo.globo.com/rio/bairros/programa-de-recuperacao-de-baciade-jacarepagua-avanca-de-forma-lenta-1-19812922 Acceso en: 10 oct. 2019. 
PRONI, Marcelo Weishaupt. A Reinvenção dos Jogos Olímpicos: um projeto de marketing. Revista Esporte e Sociedade da Universidade Estadual de Campinas, Ano 3, n. 9, julho a outubro de 2008. Disponible em: http://www.cev.org.br/biblioteca/areinvencao-dos-jogos-olimpicos-um-projeto-marketing. Acesso em 10 jul 2018.

PUFF, Jefferson. TCU e MPF cobram acesso a contratos olímpicos e a orçamento do Comitê Rio 2016. BBC News. Disponible em: https://www.bbc.com/portuguese/noticias/2015/09/150904_rio_legado questionado_jp, Acceso en: 28 jun. 2019.

RANGONE, Nicoletta. "A behavioral approach to Administrative Corruption Prevention". In: CERRILLO I MARTÍNEZ, Agustí. y PONCE SOLÉ, Juli. Preventing Corruption and Promoting Good Governance and Public Integrity. Bruselas: Brulyant, 2017, p. 69-99. en p. 79.

REFORMA do Maracanã teve aditivos suspeitos e gastos em duplicidade, diz TCE-RJ.

O Globo. Disponible em: https:/g1.globo.com/rio-de-janeiro/noticia/reforma-domaracana-teve-aditivos-suspeitos-e-gastos-em-duplicidade-diz-tce-rj.ghtml Acceso en: 12 oct. 2019.

. Relatoría Especial para la Libertad de Expresión de la Comisión Interamericana de Derechos Humanos, Marco jurídico interamericano sobre el derecho a la libertad de expresión. OEA, CIDH, 2009. (OEA, 2009: 17).

RENSON, Roland. The Games Reborn: The VIIth Olympiad. London: Pandora, 1996.

RIBEIRO, Tiago; CORREIA, Abel; BISCAIA, Rui; FIGUEIREDO, Carlos. Perspectiva Social e Organizacional dos Jogos Olímpicos: Estado da Arte. In: MARQUES, José Carlos; ROCCO JR., Ary José (coord.). Leituras e Reflexões sobre os Jogos Olímpicos Rio-2016. São Paulo: Cultura Acadêmica, 2018. p. 19-36.

RICHARDS, Greg; PALMER, Robert. Why cities need to be eventful. Eventful Cities: Cultural Management and Urban Revitalization. London: Routledge, 2012.

RIGOLIN, Ivan. Manual Prático das Licitações, São Paulo, Saraiva: 1991. 
RIO 2016 - festa na Praia de Copacabana - Escolha do Rio como cidade sede dos jogos olímpicos 2016. Disponible em: https://www.youtube.com/watch?v=Y4fbFl6gc0M. Acceso en: 24 jun. 2016.

RÍOS, Luis Fernández. Psicología de la corrupción y de los corruptos. Santiago de Compostela: Grupo Editorial Universitario, 1999.

RITCHIE, J. R. Brent; SMITH, Brian. The impact of a mega-event on host region awareness: A longitudinal study. In: JOURNAL OF TRAVEL RESEARCH, v. 30, n.1, 1991.

RIVERA, José Antonio Aguilar. Transparencia y Democracia: claves para un concierto, Cuadernos de Transparencia, IFAI, México, 2008.

ROCHA, Carmen Lúcia Antunes. Princípios constitucionais da administração pública. Belo Horizonte: Del Rey, 1994.

RODRÍGUEZ ARANA, Jaime. Los principios generales del derecho global de la contratación pública. In: RODRÍGUEZ ARANA, Jaime. Contrataciones públicas en el ámbito de los derechos sociales fundamentales. Madrid: INAP, 2017.

RODRÍGUEZ GARCÍA, Nicolás. La Necesaria Flexibilización del Concepto de Soberanía en Pro del Control Judicial de la Corrupcion. In: La Corrupción en un Mundo Globalizado: análisis interdisciplinar. Salamanca: Ratio Legis, 2004, p. 241-275.

ROMEIRO, Adriana. Corrupção e Poder no Brasil: uma história, séculos XVI a XVIII. Belo Horizonte: Autentica Editora, 2017.

ROSANVALlON, Pierre. La Contra democracia: la política em la era de la desconfianza. Buenos Aires: Manantial, 2008.

ROSE-ACKERMAN, Susan. Economía política de las raíces de la corrupción: investigación y políticas públicas. In: SANDOVAL, Irma Eréndira (org.). Corrupción y transparencia: debatiendo las fronteras entre estado, mercado y sociedad. México: Siglo XXI Editores, 2009, p. 23-43.

RÚBEO, Kátia. Jogos Olímpicos da Era Moderna: uma proposta de periodização. Artigo publicado na Revista Brasileira de Educação Física e Esporte, São Paulo, v. 24, n.1, 
janeiro-março de 2010, p. 55-68. Disponible en: http://www.revistas.usp.br/rbefe/article/view/16747 Acceso en: 13 dic 2019.

RUBINO, Leonardo. Informazione, Acceso e Trasparenza a 800 anni dalla Magna Carta (dall'habeas corpus all'habeas data). Roma: Leonardo Rubino Editore, 2016.

RUFATO, Pedro Evandro de Vicente. A Tutela Preventiva da Corrupção e dos Atos de Improbidade. In: AZAMBUJA, Edson; BALLAN JUNIOR, Octahydes; e OLIVEIRA E SILVA, Vinicius de. (org.). Combate à Corrupção na Visão do Ministério Público. Belo Horizonte: J. H. Mizuno, 2018. p. 239-287.

RUIZ, Rebecca; BELSON, Ken. El trafico de rio empeora a niveles olímpicos. New York Times. 2016. Disponible en: https://www.nytimes.com/es/2016/08/19/nadie-puedeescapar-a-la-congestion-vehicular-en-rio-de-janeiro-durante-las-olimpiadas/Acceso en: 25 jun. 2019.

SALGADO, Max. A reforma protestante. Reforma, Tratado e o pacto cristão. [S.1.]: Rubidelfon, [S.d.].

SÁNCHEZ, Renata Latuf de Oliveira; ESSEX, Stephen. Architecture and Urban Design: The Shaping of Rio 2016 Olympic Legacies. In: ZIMBALIST, Andrew. Rio 2016: Olympic Myths, hard realities, Washington D.C.: Brounkings Institution Press, 2017, p. 97-120.

SANDERS, Barry A. The Los Angeles Olympic Games. Charleston, South Carolina Library of Congress: Arcadia Publishing, 2013.

SANDOVAL, Irma E. (coord.). Corrupción y Transparencia: debatiendo las fronteras entre Estado, mercado y sociedad. México: Siglo XXI Editores, 2009.

SANMARTÍN MORA, María Asunción, "La profesionalización de la Contratación Pública en el Ámbito de la Unión Europea." In: GIMENO FELIÓ, José María Observatorio. de Contratos Públicos, 2011, Navarra, Civitas 2012.

SANTANDREU, Alba. Brasil inicia Ano Olímpico Cercado Por Crises. Exame. Disponible em: https://exame.abril.com.br/brasil/brasil-inicia-ano-olimpico-cercadopor-crises/Acceso en: 24 jun. 2019. 
SCHUMPETER, Joseph A. Capitalismo, Socialismo y Democracia. Nueva York: Harber, 1947.

SCOFIELD JR, Gilberto QUATRO empreiteiras concentram R\$ 138 bilhões em obras no país. O Globo, 7 may. 2011. Disponible en: https://oglobo.globo.com/economia/quatro-empreiteiras-concentram-138-bilhoes-emobras-no-pais-2773130 Acceso en: 11 des 2019

SHAUDSON, Michael. Origins of Freedom of Information Act in United States. In: BOWLES, Nigel. HAMILTON, James y LEVY, David (ed). Transparency in Politics and Media. Accountability and Open Government. Londres: Ib Tauris-Reuters Institute of the Study of Journalism, 2014.

SILVESTRI, Lilián Pájaro. El Contenido del Principio de Buena Fe: Análisis de la Relación Contractual del Tercer Adquirente en Pública Subasta Judicial. Ibáñez, Barranquilla: Universidad del Norte, 2013.

SLEVAGGI, Nicola. Las Listas Negras en el Banco Mundial: ?Hacía un sistema global de sanciones? In: Nieto Martín, Adán. y MAROTO CALATAYUD, Manuel. Public Compliance: prevención de la corrupción en Administraciones Públicas y partidos políticos. Ediciones de la Universidad Castilla la Mancha, 2014, p. 115-127. 121. Disponible en: https://dialnet.unirioja.es/servlet/articulo?codigo=5067561 Acceso en 11 nov 2019

SOUZA, Cláudio Pereira de.; SARMENTO, Daniel. Direito Constitucional: Teoria, História e Métodos de Trabalho, 2. ed. Belo Horizonte: Editora Fórum, 2014.

Stato, Governo, Società: Per una teoria generale de la politica. Torino: Giulio Einaudi editore s. p. a., 1985.

STIGLITZ, Joseph E. On Liberty, the Right to Know and Public Discourse: The Role of Transparency in Public Life. Banco Mundial. Oxford: Oxford Amnesty Lecture, 1999.

Teoria do ordenamento jurídico. Brasília: Polis-UNB, 1991. 
THE NATIONAL ARCHIVES HISTORY OFFICE preserves and promotes the history of the National Archives. Disponible en: https://www.archives.gov/about/history. Acceso en: 15 en. 2019.

Transparencia integral en la contratación pública". Observatorio de Contratación Pública, 3 de julio de 2017. Disponible en: https://bit.ly/2OkoMkS Acceso en 12 nov 2019.

UE. Tratado de funcionamiento de la unión europea. 13 diciembre 2007. Disponible en: http://www.boe.es/doue/2010/083/Z00047-00199.pdf. Acceso en: 8 mayo 2014.

VAINER, Carlos. A Cidade do pensamento único: desmanchando consensos. Os Liberais também fazem planejamento. Petrópolis: Vozes, 2000.

VAINER, Carlos. Como serão nossas cidades após a Copa e as Olimpíadas? In: Boitempo Editorial y Carta Maior. Brasil em Jogo: o que fica da Copa e das Olimpíadas? São Paulo: Boitempo Editorial, 2014, p. 148-162.

VEIGA, Alexandre Brandao Da. Acceso à Informação da Administração Pública pelos Particulares. Coimbra: Almedina, 2007.

VERRILli, Antonio; SOLENNE, Diego. Diritto Costituzionale. Santarcangelo di Romagna: Maggioli Editore, 2013.

VIANA, Ruth Araújo. Poder Discricionário e Atos de Corrupção: uma análise de casos concretos. In: AZAMBUJA, Edson; BALLAN JUNIOR, Octahydes; e OLIVEIRA E SILVA, Vinicius de. (org.). Combate à Corrupção na Visão do Ministério Público. Belo Horizonte: JH Mizuno, 2018, p. 68-127.

VILLA, Marco Antônio. Mensalão: O julgamento do maior caso de corrupção da história política brasileira. São Paulo: Leya, 2012.

WEIL, David., FUNG, Archon., GRAHAM, Mary. Targeting Transparency. Policy Forum Science and Regulation, vol. 340, 2013, p. 1410-1411. Disponible en: https://science.sciencemag.org/content/340/6139/1410.full Acceso en: 22 nov. 2019.

WENDL, Karel. The route of friendship: a cultural/artistic event of the Games of the XIX Olympiad in Mexico City, 1968. Olympika, 7, 1998, p. 113-134. 
WENSINK, Wim. y MAARTEN DE VERT, Jam. Identifying and Reducing Corruption in Public Procurement in the Eu. Bruselas PwC EU services, 30 de junio 2013, p. 272. Disponible en: https://bit.ly/2b3oLsS Acceso en 12 nov 2019.

ZAMORA, Miguel Agudo et al. Manual de Derecho Constitucional. 2. ed. Madrid: Tecnos, 2013.

ZANCANER, Weida. Lineamentos Sobre a Lei de Acesso à Informação. In: VALIM, Rafael.; MALHEIROS, Antônio Carlos.; BACARIA, Josephina. (coord.). Acesso à Informação Pública. Belo Horizonte: Fórum Editora, 2015, p. 25-34.

ZAVALA, Juan Roberto. Breves apuntes sobre la historia de la corrupción. In: REVISTA CONOCIMIENTO 123. UANL - Universidad Autónoma de Nuevo León. Nuevo León. México, 2012 Disponible http://issuu.com/revistaconocimiento/docs/123/7. Acceso en: 8 mar. 2014.

ZEPEDA, Jesús Rodríguez. Estado y Transparencia: Un Paseo por la Filosofía Política, Cuadernos de Transparencia 4, IFAI, Ciudad de México: 2006.

\section{Fuentes Jurisprudenciales}

Convención Americana Sobre Derechos Humanos (Pacto de San José). Nov, 1969. Disponible en: $\quad$ http://www.oas.org/dil/esp/tratados B32_Convencion_Americana_sobre_Derechos_Humanos.htm. Acceso en: 13 dic 2019.

Convención de las Naciones Unidas contra la corrupción de 9 dez. 2003. Disponible en: http://europa.eu/legislation_summaries/fight_against_fraud/fight_against_corruption/133 300 es.htm Acceso en: 16 mar. 2019.

Convención Interamericana Contra La Corrupción (B-58) : Disponible en: http://www.oas.org/juridico/spanish/tratados/b-58.html . Acceso en: 13 dic. 2019. 
Convenio del Consejo de Europa sobre el Acceso a los Documentos Públicos.

Disponible en:

Medida Provisória n. 488, de 12 de maio de 2010. Autoriza a criação da Empresa Brasileira de Legado Esportivo S.A. Brasil 2016 e dá outras providências. Disponible em: http://www.planalto.gov.br/ccivil_03/_Ato20072010/2010/Mpv/488.htm Acceso en: 27 jun. 2019.

Medida Provisória n. 489, de 12 de maio de 2010. Autoriza a União a integrar, na forma de consórcio público de regime especial, a Autoridade Pública Olímpica - APO, e dá outras providências. Disponible em: http://www.planalto.gov.br/ccivil_03/_Ato2007-2010/2010/Mpv/489.htm Acceso en: 27 jun. 2019.

. Sentencia n. 161/1988, de 20 de septiembre de 1988. Disponible en: http:/hj.tribunalconstitucional.es/cs-CZ/Resolucion/Show/1102 Acceso en: 03 mayo 2019.

. Sentencia n. 46/2017, de 22 de junio de 2017, del Juzgado Central de lo Contencioso-Administrativo núm. 2 de Madrid, dictada en el PO 38/2016. Disponible en: https://eur-lex.europa.eu. Accesso en: 09 enero, 2019.

Sentencia n. 85/2016, de 14 de junio de 2016, del Juzgado Central de lo Contencioso-Administrativo núm. 5 de Madrid, dictada en el PO 43/2015. Disponible en: https://eur-lex.europa.eu, Accesso en: 09 enero, 2019.

Superior Tribunal de Justiça (2 Turma). Processo RMS n. 6.597/MS, Rel. Min. Antonio de Pádua Ribeiro. jul. 16 de dezembro de1996. Brasília, DF: Superior Tribunal de Justiça [1996]. Disponible em http://www.stj.jus.br/sites/portalp/Inicio Acceso en: 12 oct. 2019.

. Superior Tribunal de Justiça (3 Turma). REsp. n. 243.767/MS, Rel. Min. Eduardo Ribeiro, jul. 21 de fevereiro de 2000. Data de publicação: 12/06/2000. Brasília, DF: Superior Tribunal de Justiça [2000], p. 110. Disponible em: www.stj.jus.br. Acceso en: 30 nov. 2019. 
Supremo Tribunal Federal. Ação Penal n. 470. Brasília, DF: Superior Tribunal

de Justiça [2013]. Disponible em: http://www.stf.jus.br/portal/cms/verNoticiaDetalhe.asp?idConteudo=236494, Acceso en: 12 oct. 2019.

. Tribunal de Contas da União. Acórdão n. 3162/2016-PI. Brasília, DF: Tribunal de Contas da União [2016].Disponible en: https://www.lexml.gov.br/urn/urn:lex:br:tribunal.contas.uniao;plenario:acordao:201612-07;3162. Acceso en: 18 sep. 2019.

. Tribunal de Contas da União. Processo TC 034.628/2012-6, Acórdão n. 853/2013-TCU-Plenário. Brasília, DF: Tribunal de Contas da União [2013].Disponible en: https://portal.tcu.gov.br/inicio/, Acceso en: 12 oct. 2019.

. Tribunal de Contas da União. Acórdão 96/2010-TCU-Segunda-Câmara. Brasília, DF: Tribunal de Contas da União [2010].Disponible en: https://portal.tcu.gov.br/inicio/ Acceso en: 25 oct. 2019.

. Tribunal de Contas da União. Acórdão n. 1.064/2005-Plenário. Brasília, DF: Tribunal de Contas da União [2005]. Disponible em: www.tcu.gov.br Acceso em: 17 oct. 2019.

. Tribunal de Contas da União. Acórdão n. 1.521/2003-TCU-Plenário e Decisão n. 186/1999-TCU-Plenário, Decisão n. 811/2002-TCU-Plenário. Brasília, DF: Tribunal de Contas da União [2003;1999;2002]. Disponible en: https://portal.tcu.gov.br/inicio/index.htm Acceso en: 11 dic 2019

. Tribunal de Contas da União. Acórdão n. 1731/2009-TCU-Plenário. Brasília, DF: Tribunal de Contas da União [2009].Disponible en: https://portal.tcu.gov.br/inicio/ Acceso en: 25 out 2019.

. Tribunal de Contas da União. Acórdão n. 265/2010-TCU-Plenário. Brasília, DF: Tribunal de Contas da União [2010].Disponible en: https://portal.tcu.gov.br/inicio/ Acceso en: 25 out 2019. 
. Tribunal de Contas da União. Acórdão n. 265/2010-TCU-Plenário. Brasília, DF: Tribunal de Contas da União [2010].Disponible en: https://portal.tcu.gov.br/inicio/ .br. Acceso en: 25 out 2019.

. Tribunal de Contas da União. Acórdão n. 767/2009-TCU-Plenário. Brasília, DF: Tribunal de Contas da União [2009].Disponible en: https://portal.tcu.gov.br/inicio/ Acceso en: 25 out 2019.

Tribunal de Contas da União. Acórdão n. 819/2005-Plenário. Brasília, DF: Tribunal de Contas da União [2005]. Disponible en: www.tcu.gov.br Acceso em: 17 oct. 2019.

. Tribunal de Contas da União. Ata n. 35 de 24 de agosto de 2011. Brasília, DF:

Tribunal de Contas da União [2011]. Disponible em: http://www.tcu.gov.br/Consultas/Juris/Docs/CONSES/TCU_ATA_0_N_2011_35.pdf Acceso en: 12 out. 2019.

. Tribunal de Contas da União. Decisão n. 347/1994-Plenário. Brasília, DF: Tribunal de Contas da União [1994].Disponible em: www.tcu.gov.br Acceso em: 17 oct. 2019.

. Tribunal Regional Federal (2 Região). Processo n. 0004639-62.2018.4.02.5101. Disponible en: http://www.jfrj.jus.br .Acceso en: 12 oct. 2019.

Tribunal Regional Federal (2 Região). Processo n. 0015979-37.2017.4.02.5101. Disponible en: http://www.jfrj.jus.br Acceso en: 12 oct. 2019. Tribunal Regional Federal (2 Região). Processo n. 0017513-21.2014.4.02.5101. Disponible em: http://www.jfrj.jus.br . Acceso em 06 nov. 2019. . Tribunal Regional Federal (2 Região). Processo n. 0029142-84.2017.4.02.5101. Disponible en: http://www.jfrj.jus.br . Acceso en: 09 oct. 2019. . Tribunal Regional Federal (2 Região). Processo n. 0044.000213-9/2017. Disponible en: http://www.jfrj.jus.br . Acceso en: 10 oct. 2019. . Tribunal Regional Federal (2 Região). Processo n. 0068534-94.2018.4.02.5101 Disponible en: http://www.jfrj.jus.br . Acceso en: 12 oct. 2019. 
Tribunal Regional Federal (2 Região). Processo n. 0068544-41.2018.4.02.5101.

Disponible en: http://www.jfrj.jus.br . Acceso en: 12 oct. 2019.

. Tribunal Regional Federal (2 Região). Processo n. 0135964-97.2017.4.02.5101.

Disponible en: http://www.jfrj.jus.br Acceso en: 12 oct. 2019.

. Tribunal Regional Federal (2 Região). Processo n. 0174071-16.2017.4.02.5101.

Disponible en: http://www.jfrj.jus.br .Acceso en: 09 oct. 2019.

Tribunal Regional Federal (2 Região). Processo n. 0196181-09.2017.4.02.5101

Disponible en: https://www.jfrj.jus.br Acceso en: 12 oct. 2019.

. Tribunal Regional Federal (2 Região). Processo n. 0501634-09.2017.4.02.5101.

Disponible en: http://www.jfrj.jus.br Acceso en: 12 oct. 2019.

. Tribunal Regional Federal (2 Região). Processo n. 0501853-22.2017.4.02.5101.

Disponible en: http://www.jfrj.jus.br . Acceso en: 12 oct. 2019.

Tribunal Regional Federal (2 Região). Processo n. 0502834-85.2016.4.02.5101.

Disponible em: http://www.jfrj.jus.br . Acceso em 12 oct. 2019.

. Tribunal Regional Federal (2 Região). Processo n. 0504113-722017.4.02.5101.

Disponible en: http://www.jfrj.jus.br .Acceso en: 12 oct. 2019.

. Tribunal Regional Federal (2 Região). Processo n. 0504466-15.2017.4.02.5101.

Disponible en: http://jfrj.jus.br . Acceso en: 12 oct. 2019.

. Tribunal Regional Federal (2 Região). Processo n. 0506972-95.2016.4.02.5101.

Disponible en: http://www.jfrj.jus.br . Acceso en: 09 oct. 2019.

. Tribunal Regional Federal (2 Região). Processo n. 0507524-26.2017.4.02.5101.

Disponible em: http://www.jfrj.jus.br Acceso em 12 oct. 2019.

. Tribunal Regional Federal (2 Região). Processo n. 0507551-43.2016.4.02.5101.

Disponible en: http://www.jfrj.jus.br . Acceso en: 09 oct. 2019.

Tribunal Regional Federal (2 Região). Processo n. 0509503-57.2016.4.02.5101.

Disponible en: http://jfrj.jus.br Acceso en: 12 oct. 2019. 
. Tribunal Regional Federal (2 Região). Processo n. 0509600-57.2016.4.02.5101.

Disponible en: http://www.jfrj.jus.br .Acceso en: 09 oct. 2019.

. Tribunal Regional Federal (2 Região). Processo n. 0510038-83.2016.4.02.5101.

Disponible en: http:// www .jfrj.jus.br . Acceso en: 12 oct. 2019.

. Tribunal Regional Federal (2 Região). Processo n. 5025453-73.2019.4.02.5101.

Disponible en: http://www.jfrj.jus.br . Acceso en: 12 oct. 2019.

Tribunal Regional Federal (2 Região). Processo n.0501024-41.2017.4.02.5101.

Disponible en: http://www.jfrj.jus.br Acceso en: 12 oct. 2019.

. Tribunal Regional Federal (4 Região). Processo n. 5063271-

36.2016.4.04.7000/PR. Disponible en: http://www.jfpr.jus.br .Acceso en: 06 nov. 2019.

CASE OF TÁRSASÁG A SZABADSÁGJOGOKÉRT v. HUNGARY. 37374/05. , 14

jul. $2009 . \quad$ Disponible en:

http://hudoc.echr.coe.int/sites/eng/pages/search.aspx\#\{\%22dmdocnumber\%22:[\%22849 278\%22],\%22itemid\%22:[\%22001-92171\%22]\} Acceso en: 5 mayo 2014.

CASE OF YOUTH INITIATIVE FOR HUMAN RIGHTS v. SERBIA. 25 jun. 2013. Disponible

en:

http://hudoc.echr.coe.int/sites/eng/Pages/search.aspx\#\{\%22fulltext\%22:[\%22Youth\%20 Initiative $\% 20$ for $\% 20$ Human $\% 20$ Rights $\% 20 \mathrm{v} . \% 20$ Serbia $\% 22], \% 22$ sort $\% 22:[\% 22$ appno year $\% 20$ Descending,appnocode $\% 20$ Descending $\% 22$ ], $\% 22$ documentcollectionid $2 \% 22:$ [ \%22GRANDCHAMBER\%22,\%22CHAMBER \%22],\%22itemid\%22:[\%22001-

120955\%22]\} Acceso en: 5 mayo 2014.

CGU - CONTROLADORIA-GERAL DA UNIÃO. Disponible en: http://www.cgu.gov.br Acceso en: 17 mar. 2019.

COE. Group of States against corruption (GRECO) Website. Disponible en: http://www.coe.int/t/dghl/monitoring/greco/default en.asp Acceso en: 16 mar. 2014.

CONSEJO DE EUROPA. Convenio del Consejo de Europa sobre el Acceso a los Documentos Públicos, 2009. Disponible en: http://www.oas.org/es/sla/ddi/docs/acceso_informacion_desarrollos_convenio_consejo europeo.pdfAcceso en: 8 jun. 2019 
CONSELHO DE ARQUITETURA E URBANISMO DE SÃO PAULO. Autor da Lei de Licitações: "RDC propicia a corrupção e a injustiça". Disponible em: https://www.causp.gov.br/autor-da-lei-de-licitacoes-rdc-propicia-a-corrupcao-e-ainjustica/, Acceso en: 26 jun. 2019.

CORTE INTERAMERICANA DE DERECHOS HUMANOS, 2006. Disponible em: http://www.corteidh.or.cr. Acceso en: 26 nov. 2019.

EU. Convención de las Naciones Unidas contra la corrupción. Decisión del Consejo $2008 / 801 / \mathrm{CE}$, de 25 de septiembre de 2008, sobre la celebración, en nombre de la Comunidad Europea, de la Convención de las Naciones Unidas contra la opción (DO L 287 de 29.10.2008). Disponible en: https://eur-lex.europa.eu/legalcontent/ES/TXT/?uri=LEGISSUM\%3A133300 Acceso en: 16 mar. 2019.

http://www.oas.org/es/sla/ddi/docs/acceso_informacion_desarrollos_convenio_consejo europeo.pdf Acesso em: 8 jun. 2019

Información Pública Gubernamental. IFAI, México, 2006.

OCDE. Convenio de lucha contra la corrupción de agentes públicos extranjeros en las transacciones comerciales. Disponible en: https://www.oecd.org/daf/antibribery/ConvCombatBribery_Spanish.pdf Acceso en: 13 dic. 2019.

\section{Fuentes Normativas}

[Constituição (1988) Constituição da república Federativa do Brasil de 1988. Brasília, DF: Presidência da República. Disponible en: http://www.planalto.gov.br/ccivil_03/Constituicao/Constituicao.htm, Acceso en: 08 oct. 2019.

. Decreto n. 7.724, de 16 maio de 2014. Regulamenta a lei de acesso à informação. Disponible en: http://www.planalto.gov.br/ccivil 03/ato20112014/2012/Decreto/D7724.htm Acceso en: 8 jun. 2014. 
Decreto-Lei 4.657, de 4 de setembro de 1942. Lei de Introdução às normas do

Direito brasileiro. Disponible en: http://www.planalto.gov.br/ccivil_03/decretolei/Del4657compilado.htm Acceso en: 6 mayo 2014.

Instrumento de Ratificación del Convenio penal sobre la corrupción BOLETÍN OFICIAL DEL ESTADO. De 28 de julio de 2010. Disponible en: https://www.boe.es/boe/dias/2011/03/07/pdfs/BOE-A-2011-4192.pdf Acceso en:16 mar. 2019.

_. La Constitución española de 1978. Disponible en: https://boe.es/legislacion/documentos/ConstitucionCASTELLANO.pdf Acceso en: 13 dic 2019.

Lei 10406, de 10 de janeiro de 2002. Institui o Código Civil. Disponible em: http://www.planalto.gov.br/ccivil 03/leis/2002/110406.htm. Acceso en: 30 nov. 2019.

Lei n. 10.264/2001, de 16 de julho de 2001. Acrescenta inciso e parágrafos ao art. 56 da Lei no 9.615, de 24 de março de 1998, que institui normas gerais sobre desporto. Disponible en: http:/www.planalto.gov.br/ccivil 03/LEIS/LEIS_2001/L10264.htm Acceso en: 18 de sep. de 2019.

Lei n. 12.035/2009, de $1^{\circ}$ de outubro de 2009. Institui o Ato Olímpico, no âmbito da administração pública federal, com a finalidade de assegurar garantias à candidatura da cidade do Rio de Janeiro a sede dos Jogos Olímpicos e Paraolímpicos de 2016 e de estabelecer regras especiais para a sua realização, condicionada a aplicação desta Lei à confirmação da escolha da referida cidade pelo Comitê Olímpico Internacional. Disponible en: http://www.planalto.gov.br/ccivil_03/_Ato20072011/2009/Lei/L12035.htm, Acceso en: 12 out 2019.

Lei n. 12.439/2010, de 15 de dezembro de 2010. Altera as Leis $\mathrm{n}^{\text {os }}$ 8.666, de 21 de junho de 1993, 8.958, de 20 de dezembro de 1994, e 10.973, de 2 de dezembro de 2004; e revoga o $\S 1^{\circ}$ do art. $2^{\circ}$ da Lei $n^{\circ} 11.273$, de 6 de fevereiro de 2006. Disponible en: http://www.planalto.gov.br/ccivil 03/Ato2007-2010/2010/Lei/L12349.htm, Acceso en: 08 oct. 2019. 
Lei n. 12.462/2011, de 4 de agosto de 2011. Institui o Regime Diferenciado de Contratações Públicas - RDC; altera a Lei n ${ }^{\circ} 10.683$, de 28 de maio de 2003, que dispõe sobre a organização da Presidência da República e dos Ministérios, a legislação da Agência Nacional de Aviação Civil (Anac) e a legislação da Empresa Brasileira de Infraestrutura Aeroportuária (Infraero); cria a Secretaria de Aviação Civil, cargos de Ministro de Estado, cargos em comissão e cargos de Controlador de Tráfego Aéreo; autoriza a contratação de controladores de tráfego aéreo temporários; altera as Leis $\mathrm{n}^{\circ} \mathrm{s}$ 11.182, de 27 de setembro de 2005, 5.862, de 12 de dezembro de 1972, 8.399, de 7 de janeiro de 1992, 11.526, de 4 de outubro de 2007, 11.458, de 19 de março de 2007, e 12.350, de 20 de dezembro de 2010, e a Medida Provisória $\mathrm{n}^{\circ}$ 2.185-35, de 24 de agosto de 2001; e revoga dispositivos da Lei $\mathrm{n}^{\circ}$ 9.649, de 27 de maio de 1998. Disponible en: http://www.planalto.gov.br/ccivil_03/_Ato2011-2014/2011/Lei/L12462.htm Acceso en: 30 nov. 2019.

Lei n. 12.527, de 18 de novembro de 2011. Regula o acesso a informações previsto no inciso XXXIII do art. 5o, no inciso II do $\S 30$ do art. 37 e no $\S 20$ do art. 216 da Constituição Federal; altera a Lei no 8.112, de 11 de dezembro de 1990; revoga a Lei no 11.111, de 5 de maio de 2005, e dispositivos da Lei no 8.159, de 8 de janeiro de 1991; e dá outras providências. Disponible en: http://www.planalto.gov.br/ccivil_03/_ato20112014/2011/lei/112527.htm Acceso en: 8 mayo 2014.

Lei n. 8.429/1992, de 2 de junho de 1992. Dispõe sobre as sanções aplicáveis aos agentes públicos nos casos de enriquecimento ilícito no exercício de mandato, cargo, emprego ou função na administração pública direta, indireta ou fundacional e dá outras providências. Disponible en: : http://www.planalto.gov.br/ccivil 03/LEIS/L8429.htm Acceso en: 27 jun 2019.

Lei n. 8.666/1993, de 21 de junho de 1993. Regulamenta o art. 37, inciso XXI, da Constituição Federal, institui normas para licitações e contratos da Administração Pública e dá outras providências. Disponible en: http://www.planalto.gov.br/ccivil 03/leis/18666cons.htm Acceso en: 27 jun. de 2019.

Lei n. 9.504/1997, de 30 de setembro de 1997. Estabelece normas para as eleições. Disponible em: http://www.planalto.gov.br/ccivil_03/leis/19504.htm , Acceso en: 12 oct. 2019. 
Lei n. 9.615/1998, de 24 de março de 1998. Institui normas gerais sobre desporto e dá outras providências. Disponible en: https://www2.camara.leg.br/legin/fed/lei/1998/lei-9615-24-marco-1998-351240publicacaooriginal-1-pl.html, Acceso en: 18 sep. 2019.

Ley $2 / 2015$, de 2 de abril, de Transparencia, Buen Gobierno y Participación Ciudadana de la Comunitat Valenciana. Disponible en: : https://www.boe.es/buscar/pdf/2015/BOE-A-2015-4547-consolidado.pdf Acceso en: 30 nov. 2019.

Ley n. 19/2013. Ley de transparencia, acceso a la información pública y buen gobierno. Disponible en: https://www.boe.es/buscar/pdf/2013/BOE-A-201312887-consolidado.pdf . Acceso en: 6 mayo 2019.

Ley no 20.285, de 11 de agosto de 2008. Acceso a la información pública. Disponible en: http://www.leychile.cl/Navegar?idNorma=276363\&idVersion=2008-0820 Acesso em: 06 mayo 2014.

. Ley Orgánica de Transparencia y Acceso a la Información Pública (LOTAIP), n. ${ }^{\circ}$ 24/2004, Art. $3^{\circ}$. Disponible en: https://www.educacionsuperior.gob.ec/wpcontent/uploads/downloads/2014/09/LOTAIP.pdf Acesso em: 18 nov 2019.

ARGENTINA. Decreto no 1172/2003. Acceso a la información publica. Disponible en: http://servicios.infoleg.gob.ar/infolegInternet/anexos/90000-94999/90763/norma.htm. Acesso em: 5 jun. 2014.

Boletín Oficial de Castilla y León- BOCYL Num. 224, de 20 nov.2019. Disponible en: http://bocyl.jcyl.es/boletines/2019/11/20/pdf/BOCYL-D-20112019-5.pdf Acceso en 18 dic. 2019

CHILE. Constitución política de la república de Chile de 1980. Disponible en: https://www.camara.cl/camara/media/docs/constitucion_politica.pdf Acceso en: 11 mayo 2014.

ECUADOR. Constitución del Ecuador de 2008. Disponible en: https://www.asambleanacional.gob.ec/documentos/constitucion_de_bolsillo.pdf Acceso en: 11 mayo 2019. 
ESPAÑA. Real Decreto de 24 de julio de 1889 por el que se publica el Código Civil, 25 jul. 1889. Disponible en: https://www.boe.es/buscar/act.php?id=BOE-A-1889-4763 Acceso en: 6 mayo 2019

Ley n. 27.275/2016, Art. $7^{\circ}$, "i". Disponible en: http://servicios.infoleg.gob.ar/infolegInternet/anexos/265000-269999/265949/nor ma.htm Acceso en 18 nov 2019.

NACIONES UNIDAS. La Declaración Universal de Derechos Humanos. Disponible en: http://www.un.org/es/documents/udhr Acceso en: 15 jan 2019. 